UNIVERSIDADE DE SÃO PAULO

FACULDADE DE ECONOMIA, ADMINISTRAÇÃO E CONTABILIDADE DEPARTAMENTO DE ADMINISTRAÇÃO

PROGRAMA DE PÓS-GRADUAÇÃo EM ADMINISTRAÇÃo

Ricardo Toshio Yugue

Fatores Contribuintes para o Desempenho em Projetos de Desenvolvimento de Produtos: O Caso dos Medicamentos Genéricos

SÃO PAULO

2020 
Prof. Dr. Vahan Agopyan

Reitor da Universidade de São Paulo

Prof. Dr. Fábio Frezatti

Diretor da Faculdade de Economia, Administração e Contabilidade

Prof. Dr. Moacir de Miranda Oliveira Junior

Chefe do Departamento de Administração

Prof. Dr. Eduardo Kazuo Kayo

Coordenador do Programa de Pós-Graduação em Administração 


\section{Fatores Contribuintes para o Desempenho em Projetos de Desenvolvimento de Produtos: O Caso dos Medicamentos Genéricos}

Tese apresentada ao Programa de Pós-Graduação em Administração do Departamento de Administração da Faculdade de Economia, Administração e Contabilidade da Universidade de São Paulo, como requisito parcial para a obtenção do título de Doutor em Ciências.

Orientador: Prof. Dr. Roberto Sbragia

\section{Versão Corrigida}

(versão original disponível na Faculdade de Economia, Administração e Contabilidade)

São Paulo 
Ficha Catalográfica

Elaborada pela Seção de Processamento Técnico do SBD/FEA com dados inseridos pelo autor

Yugue, Ricardo Toshio.

Fatores Contribuintes para o Desempenho em Projetos de

Desenvolvimento de Produtos: O Caso dos Medicamentos Genéricos /

Ricardo Toshio Yugue. - São Paulo, 2020.

$374 \mathrm{p}$.

Tese (Doutorado) - Universidade de São Paulo, 2020.

Orientador: Roberto Sbragia.

1. Desenvolvimento de Produtos. 2. Medicamento Genérico. 3.

Desempenho de Projetos. 4. Desenvolvimento de Medicamentos. 5.

Indústria Farmacêutica . I. Universidade de São Paulo. Faculdade de

Economia, Administração e Contabilidade. II. Título. 
Aos meus pais, Rosa e Mário (saudades), pelo exemplo, amor e sacrifício.

À Valéria e à Beatriz. 



\section{Agradecimentos}

Ao Prof. Dr. Roberto Sbragia, por me acolher em seu grupo de orientandos e pelo suporte e apoio nesta caminhada.

Ao Prof. Dr. Antonio Cesar Amaru Maximiano, pelo exemplo, gentileza e doação. Obrigado pela amizade, já de longa data, e pelo carinho.

Aos professores doutores Adriana Marotti de Mello e Roque Rabechini Junior, pelos valiosos comentários e sugestões por ocasião do exame de qualificação. Os professores doutores Marcos Antonio Gaspar e Renato Telles pelas análises e contribuições por ocasião do consórcio doutoral do XXI SEMEAD - Seminários em Administração FEA- USP de 2018.

Aos professores Drs. Abraham Sin Oih Yu, Ana Akemi Ikeda, Andres Rodrigues Veloso, Antonio Geraldo da Rocha Vidal, Diogenes de Souza Bido, Felipe Rebello Lourenço, Fernando Carvalho de Almeida, Humberto Gomes Ferraz, Jose Afonso Mazzon, Leonardo Augusto de Vasconcelos Gomes, Marisa Pereira Eboli, Moacir de Miranda Oliveira Júnior, Paulo Tromboni de Souza Nascimento e Sérgio Luiz de Oliveira Assis pelos ensinamentos, orientações e incentivo.

Aos amigos Prof. Dr. Cleonir Tumelero e Prof. Dr. Eduardo Mangini e à minha esposa Valéria dos Santos Cozzolino Yugue pelos conselhos e inestimáveis contribuições para esta tese.

A todos de minha família: Valeria, Beatriz, Eduardo, Alexandre, Sayuri, Patrícia, Caio e Enzo Angela e Mario Cozzolino (in memorian); e às famílias Yugue, Matsuda, Haranaka, Hayashi, Hoshida, Ito, Reis e Terada. Aos amigos, entre tantos, aqui representados por: Adriana Schulz, Adriano Bronzatto, Alessandra Zago Dahmer, Ana Caroline Nonato, Ana Maria Monteiro, Antoine Mallia, Arlito Silva, Beatriz Chamie, Brunet França, Carlos Eduardo Trevisan, Carlos Morais, Cecilia Ognibene, Celso Rosin, Charles Sampaio, Clauci Turri, Conceição Condesso, Eliane Ringer, Eusébio Salas, Evandro Andaku, Fernando Lima, Frederico Bellini Coelho, Gildasio Lima, Gisele França, Gleidivania Silva, Helbert dos Santos, Heloisa Oliveira, Henry Suzuki, João Carlos Boyadjian José Gleilton Silva, Joseph Young, Juliana Dalla Pria, Juliana Rodrigues, Katia Simone da Silveira, Lamartine Soares, Leonardo Miya, Marcos Medina Leite, Marcos Ognibene, Marilena Gonçalves, Mario Takaoka, Mércia Bezerra, Monica Soares, Neusa Ramos, Nica Gonçalves, Norberto Pierdona (in memorian), Neto Galizi, Norma Hayashi, Patrícia Maia Boldrin, Paulo José da Silva, Poliana Nogueira, Regina Lima, Roberto Matsubayashi, Sergio do Nascimento, Shinichiro Tamura, Silveraldo Mendes, Solange Rocco, Sonia Paulino e Virginia Vaamonde, que sempre demonstraram interesse pelo que faço, por entenderem as minhas ausências eventuais, e por sempre me apoiarem.

Aos colegas nesta caminhada aqui representados por Almir Kimura Jr, Ana Carolina Shinoda, Heloiza Hirano, Fábio Affonso Antonio, Gabriel Rocha Venturim, Andre Nardy, Alejandra Flechas, Kelly Sacramento, Viviane Menezes, Natalia Eiro, Natan Marques, Rachel Chang e Sergio Zacarias, 
entre tantos que conheci e com quem convivi neste tempo de doutorado. Um especial agradecimento ao colega Rafael Morais Pereira, pelo suporte ao tratamento dos dados da pesquisa e, sobretudo, pela atenção, amizade e zelo.

À Faculdade de Economia, Administração e Contabilidade da Universidade de São Paulo, como instituição de excelência e principalmente como professores, funcionários e colegas que me acolheram, me formaram desce a graduação, me deram amigos e me acompanharam até este momento. Um especial agradecimento para Adriana Molina, Carlos de Assunção, Cintia Yamamoto e Marcia Delatorre da Silva. 
"Tudo vale a pena

se a alma não é pequena." Fernando Pessoa 



\section{RESUMO}

Yugue, R. T. (2020). Fatores contribuintes para o desempenho em projetos de desenvolvimento de produtos: o caso dos medicamentos genéricos. (Tese de Doutorado). Faculdade de Economia, Administração e Contabilidade, Universidade de São Paulo, São Paulo.

Os investimentos em novos medicamentos podem ser significativos e, consequentemente, é de grande relevância o desempenho dos seus projetos de desenvolvimento. $\mathrm{O}$ desenvolvimento de medicamentos genéricos representa parte significativa dos investimentos em novos produtos feitos pelos laboratórios farmacêuticos estabelecidos no Brasil. Porém, análises recentes com dados da Agência Nacional de Vigilância Sanitária (Anvisa) mostram que parcela relevante das solicitações de registros de medicamentos genéricos são negados. Estes resultados deram origem a questões sobre as razões para tão elevada taxa de insucesso e cujas respostas não foram encontradas na literatura. Assim, este estudo buscou identificar quais seriam os fatores que contribuem para o desempenho dos projetos de desenvolvimento dos medicamentos genéricos na indústria farmacêutica instalada no Brasil. Na fase qualitativa, foram identificadas as categorias de dados e proposto um modelo teórico para representar as relações entre o desempenho dos projetos de desenvolvimento de medicamentos genéricos (PDMG) e seus fatores contribuintes, relações estas que definiram as hipóteses da pesquisa. Na fase quantitativa, foram analisados o modelo estrutural definido a partir dos dados da primeira fase do estudo, juntamente com seus constructos e indicadores. Os dados coletados por meio de um questionário eletrônico foram analisados utilizando método modelagem de equações estruturais com estimação por mínimos quadrados parciais (PLS-SEM). Os resultados permitiram identificar e validar 5 indicadores para o desempenho dos PDMG para o constructo Desempenho e 44 indicadores de fatores contribuintes para os constructos Gerencial, Estrutural e Técnico. A análise do modelo estrutural indicou haver relação entre as dificuldades gerenciais (constructo gerencial) e o desempenho fora do planejado (constructo desempenho) dos PDMG. No entanto, a relação entre as dificuldades técnicas e o desempenho fora do planejado da mesma forma que a relação entre as dificuldades estruturais e o desempenho fora do planejado, não foi confirmada. O modelo estrutural também testou o efeito indireto das dificuldades técnicas e das dificuldades estruturais sobre o desempenho fora do planejado dos PDMG por meio da mediação das dificuldades gerenciais. Ambos os efeitos indiretos foram confirmados. Assim, o estudo concluiu que o desempenho fora do planejado dos PDMG são influenciados diretamente pelas dificuldades no gerenciamento dos PDMG. Também concluiu que mesmo fatores que teoricamente estariam fora do controle dos projetos, como os estruturais e os requisitos técnicos, podem ser influenciados pela gestão. O estudo também identificou os fatores com as maiores contribuições para o desempenho fora do planejado como deficiências relacionadas à: gestão dos projetos, gestão do portfólio de projetos e integração com outros participantes dos PDMG. Além disso, apontou a possibilidade das dificuldades nos PDMG terem origem em características e decisões organizacionais, tais como sua cultura, estrutura organizacional e definições estratégicas da empresa.

Palavras-Chave: Desenvolvimento de produtos. Medicamento genérico. Desempenho do projeto. Desenvolvimento de drogas. Fatores influenciadores. 


\begin{abstract}
Investments in new drugs can be significantly high and, consequently, the performance of their development projects is of great relevance. The development of generic drugs represents a significant portion of investments in new products made by pharmaceutical laboratories established in Brazil. However, recent analyzes with data from the Brazilian Health Regulatory Agency (Anvisa) show that a relevant portion of requests for generic drug approval are denied. These results gave rise to questions about the reasons for such a high failure rate and whose answers were not found in the literature. Thus, this study aimed to identify the factors that contribute to the performance of development projects for generic drugs in the pharmaceutical industry installed in Brazil. In the qualitative phase, the categories of data were identified and a theoretical model was proposed to represent the relationships among the performance of generic drug development projects (GDDP) and their contributing factors, which defined the research hypotheses. In the quantitative phase, the structural model defined from the data of the first phase of the study was analyzed together with its constructs and indicators. The data collected through an electronic questionnaire were analyzed using partial least squares structural equation modeling (PLS-SEM). The results allowed to identify and validate 5 indicators for the performance of the GDDP for the Performance construct and 44 indicators of contributing factors for the Managerial, Structural and Technical constructs. The analysis of the structural model indicated that there is a relationship between managerial difficulties (Managerial construct) and low performance (performance construct) of the GDDP. However, the relationship between technical difficulties and low performance and the relationship between structural difficulties and low performance could not be confirmed. The structural model also tested the indirect effect of technical difficulties and structural difficulties on low performance of the GDDP through the mediation of managerial difficulties. Both indirect effects have been confirmed. Thus, the study concluded that the low performance of the GDDP is directly influenced by the difficulties in managing the GDDP. It also concluded that even factors that theoretically would be out of project control, such as structural and technical requirements for the drug products, can be influenced by management. The study also identified the factors with the greatest contributions to low performance, such as: deficiencies in project management, project portfolio management and integration with other GDDP members. In addition, it pointed out the possibility that the difficulties in the GDDP are influenced by organizational specific characteristics and decisions, such as its culture, organizational structure and companies' strategic decisions.
\end{abstract}

Keywords: Product development. Generic drug. Project performance. Drug development. Influencing factors. 


\section{SUMÁRIO}

1. INTRODUÇÃ

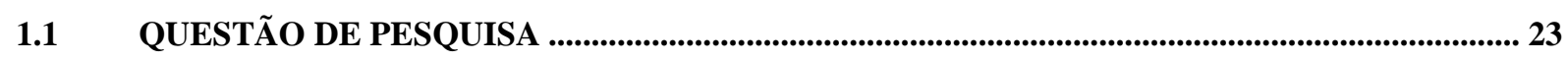

1.2 OBJETIVOS DO ESTUDO ....................................................................................................... 23

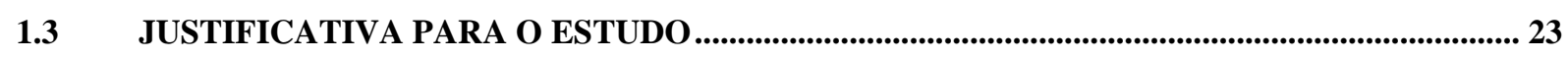

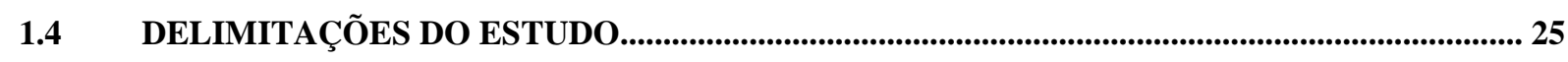

1.5 ESTRUTURA DO ESTUDO …….............................................................................................. 27

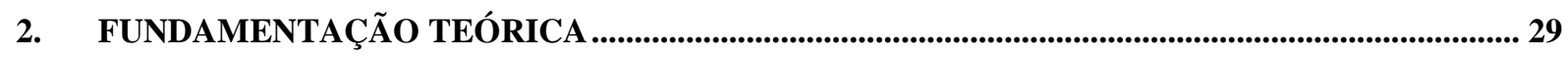

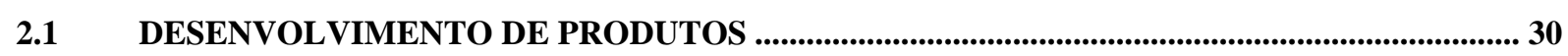

2.1.1 Processo de desenvolvimento de produtos ................................................................................................... 37

2.1.2 Abordagens para o desenvolvimento de produtos ................................................................................. 45

2.1.2.1 Desenvolvimento sequencial............................................................................................................ 45

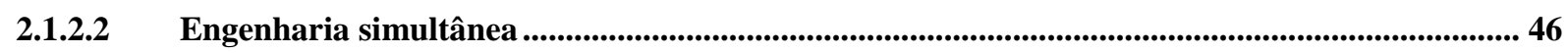

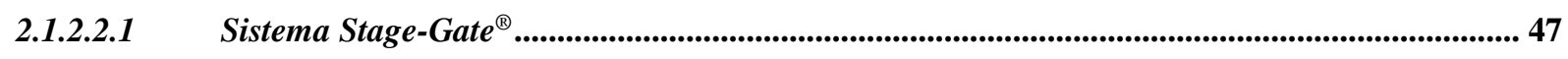

2.1.2.2.2 Desenvolvimento enxuto de produtos ................................................................................... 48

2.1.2.3 Desenvolvimento integrado do produto ………................................................................................ 49

2.1.2.4 - Desenvolvimento ágil de produtos....................................................................................................... 49

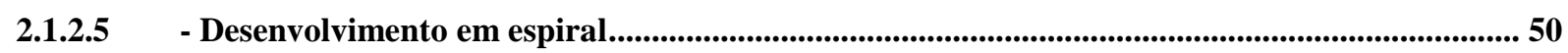

2.1.3 Desenvolvimento de produtos na indústria farmacêutica .................................................................. 53

2.1.3.1 "Quality by Design" - QbD ou qualidade por meio do delineamento ............................................ 55

2.1.4 Desenvolvimento de medicamentos no Brasil.............................................................................. 60

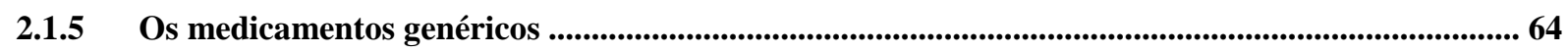

2.1.6 Desenvolvimento de medicamentos genéricos ............................................................................ 67

2.2 DESEMPENHO DE PROJETOS DE DESENVOLVIMENTO DE PRODUTOS .......................... 74

2.2.1 Dimensões do sucesso do desenvolvimento de produtos ........................................................................... 77

2.2.2 Desempenho dos projetos de desenvolvimento de medicamentos ....................................................... 82

2.3 FATORES CONTRIBUINTES PARA O DESEMPENHO DOS PROJETOS DE

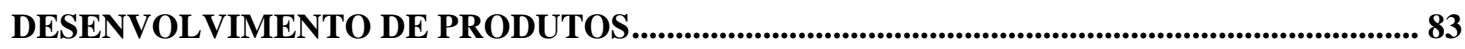

2.3.1 Estratégia e portfólio de projetos de desenvolvimento de produtos ....................................................... 95

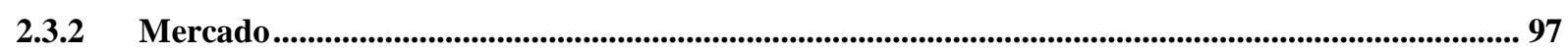

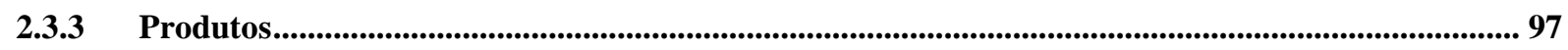

2.3.4 Clima e cultura organizacional........................................................................................................... 98

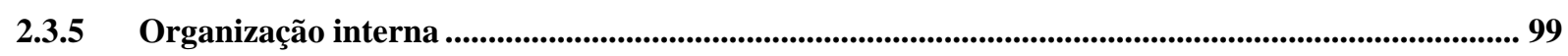

2.3.6 Alta administração........................................................................................................................ 99

2.3.7 Planejamento do projeto de desenvolvimento de produto ................................................................ 100

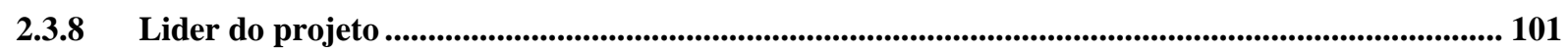

2.3.9 Equipe do projeto de desenvolvimento do produto ............................................................................... 102

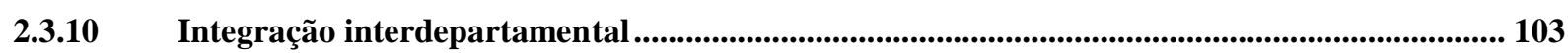


2.3.11 Relacionamento com fornecedores .................................................................................................. 103

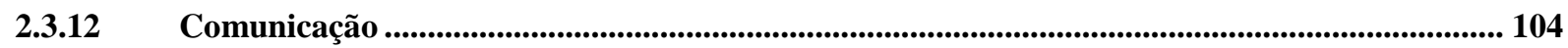

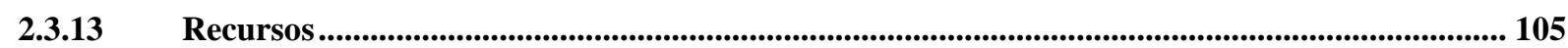

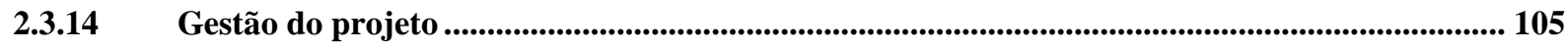

2.4 FATORES CONTRIBUINTES PARA O DESEMPENHO DOS PDMG .................................... 106

2.5 MODELO CONCEITUAL PARA A RELAÇÃO ENTRE O DESEMPENHO E SEUS FATORES

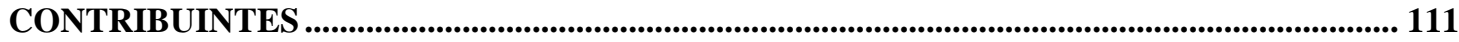

2.6 CONSOLIDAÇÃO DA FUNDAMENTAÇÃO TEÓRICA E PROPOSIÇÃO DO MODELO CONCEITUAL E DAS HIPÓTESES DA PESQUISA.

2.6.1 Influência direta dos fatores gerenciais sobre o desempenho dos projetos de desenvolvimento de medicamentos genéricos (Hipótese H1)

2.6.2 Influência direta dos fatores estruturais sobre o desempenho dos projetos de desenvolvimento de medicamentos genéricos (Hipótese H2) ......................................................................................120

2.6.3 Influência direta dos fatores técnicos sobre o desempenho dos projetos de desenvolvimento de medicamentos genéricos (Hipótese H3) ......................................................................................121

2.6.4 Influências de fatores estruturais e técnicos sobre o desempenho são mediadas pela gestão dos projetos de desenvolvimento de medicamentos genéricos (Hipóteses H4 e H5) ............................. 121

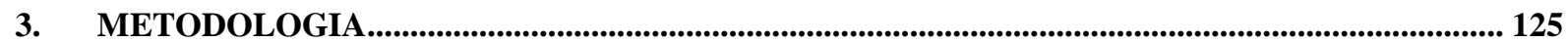

3.1 NATUREZA E CARACTERÍSTICAS GERAIS DA PESQUISA ................................................... 125

3.2 PRIMEIRA FASE DA PESQUISA - QUALITATIVA ...................................................................... 126

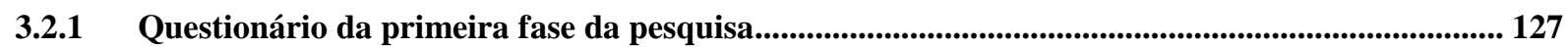

3.2.2 Amostra e coleta dos dados da pesquisa qualitativa .......................................................................... 129

3.2.3 Método de análise dos dados da fase qualitativa.................................................................................... 130

3.2.3.1 Separação das unidades de significado nos temas originais .................................................... 131

3.2.3.2 Análise do conteúdo e classificação nos temas reconfigurados ...................................................... 132

3.2.3.3 Delimitação e tratamento de equivalências e duplicidades............................................................... 135

3.2.3.4 Classificação das unidades de significado nos indicadores de desempenho ................................. 136

3.2.3.5 Classificação das unidades de significado em categorias de fatores contribuintes..................... 137

3.2.3.6 Classificação das unidades de significado em subcategorias ........................................................... 138

3.2.4 Proposição do modelo teórico e de suas dimensões e constructos..................................................... 138

3.3 SEGUNDA FASE DA PESQUISA - QUANTITATIVA ................................................................. 141

3.3.1 Adequação do modelo teórico para o modelo de caminhos...................................................................... 141

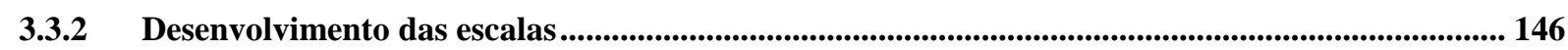

3.3.2.1 Constructo Desempenho ............................................................................................................ 147

3.3.2.2 Dimensão Gerencial .............................................................................................................. 147

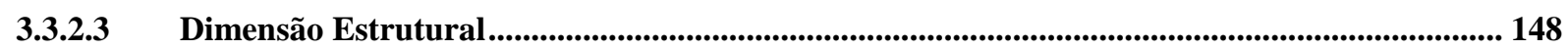

3.3.2.4 Dimensão Técnico ....................................................................................................................... 148

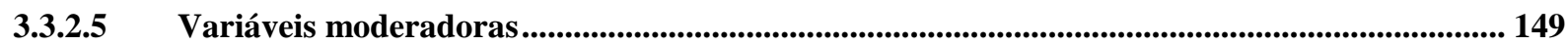

3.3.3 Desenvolvimento do questionário para coleta de dados ................................................................. 150

3.3.3.1 Validade do conteúdo................................................................................................................. 155

3.3.3.2 Versão final do questionário ........................................................................................... 161

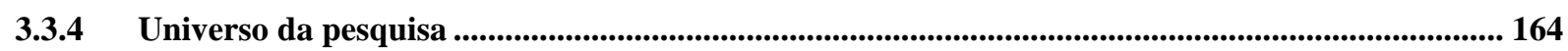


3.3.5 Critério de elegibilidade e amostragem .............................................................................................. 166

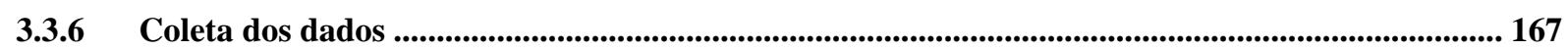

3.3.7 Tratamento e validação dos dados brutos ................................................................................. 167

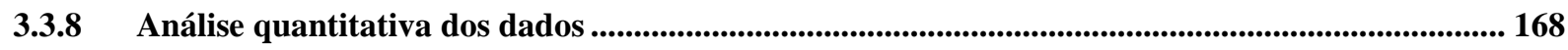

3.3.8.1 Análise dos dados sócio-demográficos...................................................................................... 169

3.3.8.2 Análises dos dados dos projetos de desenvolvimento de medicamentos genéricos.................... 169

3.3.8.3 Análise do modelo de equações estruturais.............................................................................169

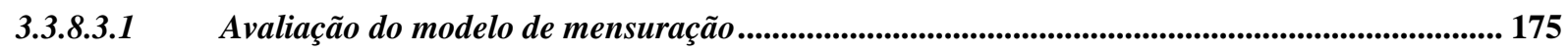

3.3.8.3.1.1 Confiabilidade dos indicadores ou de carga fatorial ........................................................... 178

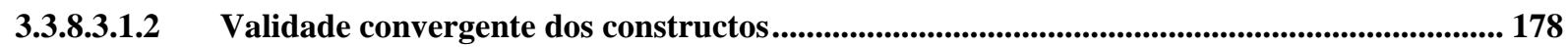

3.3.8.3.1.3 Validade discriminante dos constructos ......................................................................................... 179

3.3.8.3.2 Avaliação do modelo estrutural ................................................................................................ 181

3.3.8.3.2.1 Coeficiente de determinação $\left(R^{2}\right)$ de Pearson ...................................................................... 181

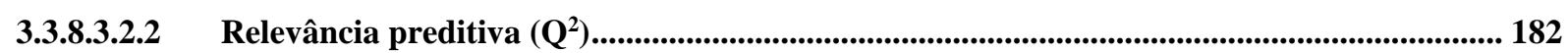

3.3.8.3.2.3 Tamanho do efeito $\left(f^{2}\right)$ ou Indicador de Cohen.................................................................. 182

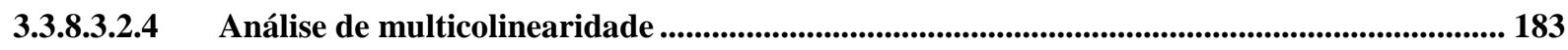

3.3.8.3.2.5 Coeficientes de caminho do modelo estrutural .............................................................................. 183

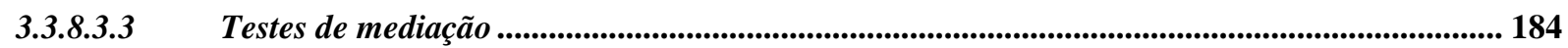

3.3.8.3.4 Verificação das hipóteses de pesquisa ...................................................................... 185

3.3.9 Resumo dos procedimentos metodológicos e das limitações ................................................................ 185

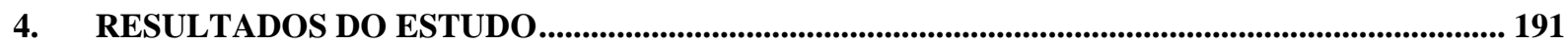

4.1 RESULTADOS DA FASE DE PESQUISA QUALITATIVA

4.1.1 Características da amostra da pesquisa qualitativa ....................................................................... 191

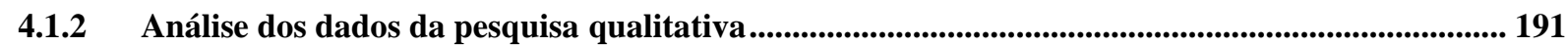

4.1.2.1 Categorização das unidades de significado ........................................................................... 192

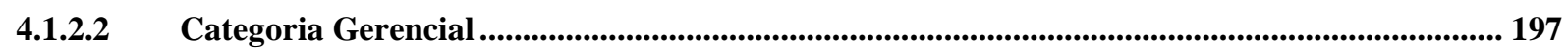

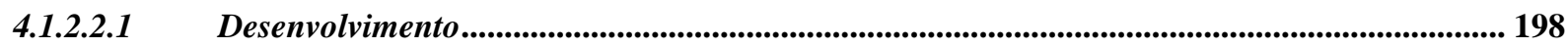

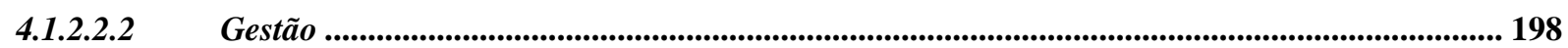

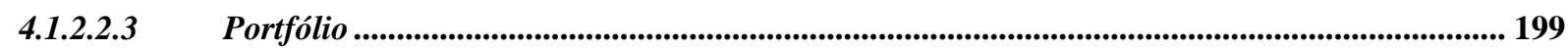

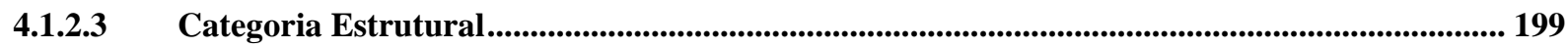

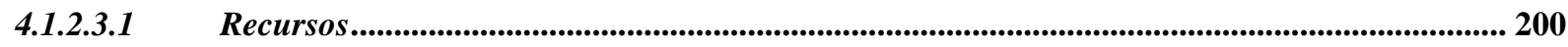

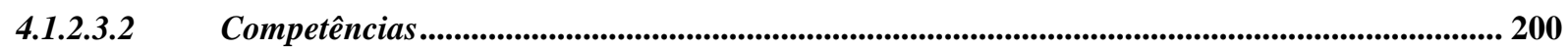

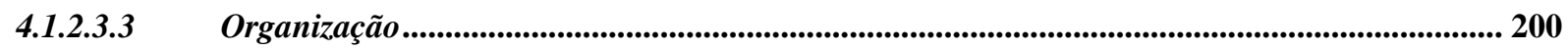

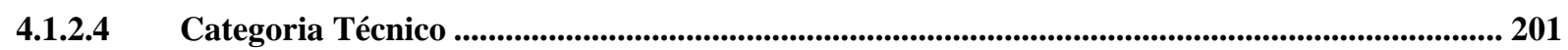

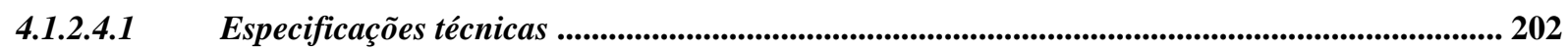

4.1.2.4.2 Requisitos do projeto ….......................................................................................................... 202

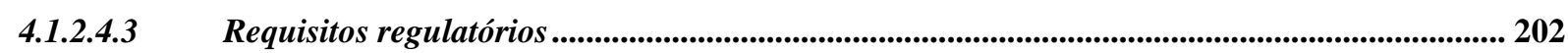

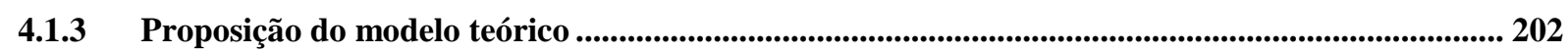

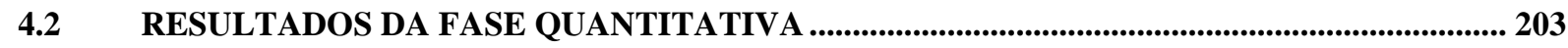

4.2.1 Resultados da análise da validade do conteúdo do questionário .................................................... 204 
4.2.2 Resultados da análise descritiva dos dados............................................................................... 207

4.2.2.1 Descrição do perfil dos respondentes e dos laboratórios em que atuavam .................................. 207

4.2.2.2 Características dos projetos de desenvolvimento de medicamentos genéricos ........................... 212

4.2.2.3 Análise univariada dos indicadores dos constructos do modelo estrutural .............................. 217

4.2.2.3.1 Análise dos indicadores do constructo Desempenho ..........................................................217

4.2.2.3.2 Análise dos indicadores do constructo Desenvolvimento ........................................................218

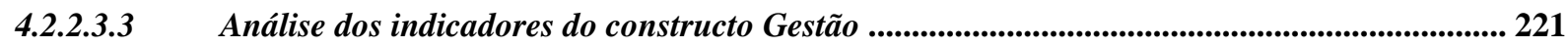

4.2.2.3.4 Análise dos indicadores do constructo Portfólio ....................................................................... 223

4.2.2.3.5 Análise dos indicadores do constructo Especificações Técnicas .................................................. 225

4.2.2.3.6 Análise dos indicadores do constructo Requisitos do Projeto .................................................... 227

4.2.2.3.7 Análise dos indicadores do constructo Requisitos Regulatórios ................................................. 228

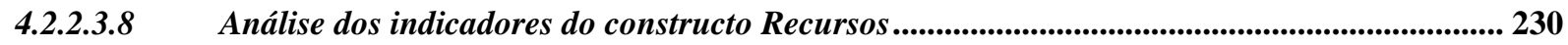

4.2.2.3.9 Análise dos indicadores do constructo Competências ...................................................................... 232

4.2.2.3.10 Análise dos indicadores do constructo Organização ................................................................. 233

4.2.2.4 Análise do conjunto de fatores contribuintes para resultados fora dos planejados .................. 235

4.2.3 Análises das relações entre os fatores contribuintes e o desempenho dos PDMG........................ 235

4.2.3.1 Análise do modelo de mensuração ................................................................................................... 237

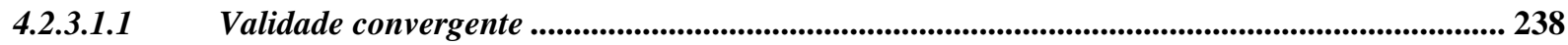

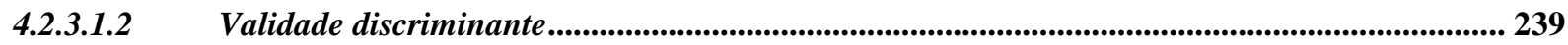

4.2.3.1.3 Confiabilidade dos indicadores ................................................................................................. 247

4.2.3.1.4 Constructo Desempenho …..........................................................................................................248

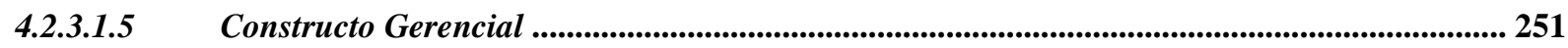

4.2.3.1.6 Constructo Desenvolvimento ….......................................................................................... 251

4.2.3.1.7 Constructo Gestão .................................................................................................................... 256

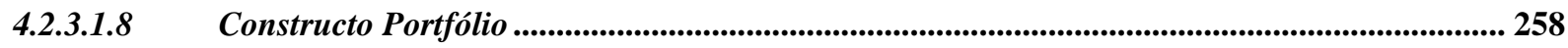

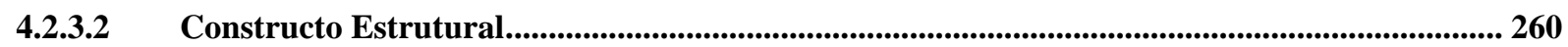

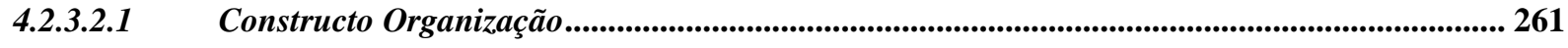

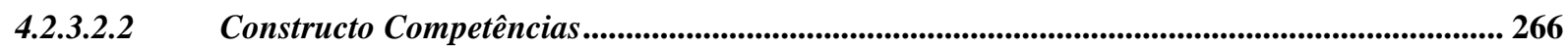

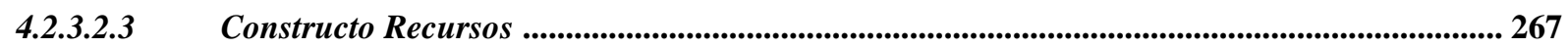

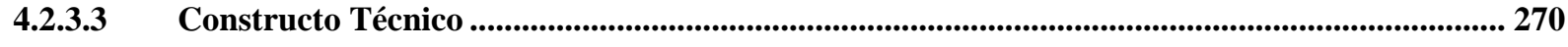

4.2.3.3.1 Constructo Especificações Técnicas ...................................................................................................... 271

4.2.3.3.2 Constructo Requisitos Regulatórios ....................................................................................... 273

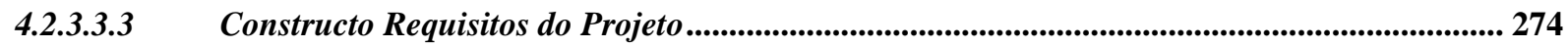

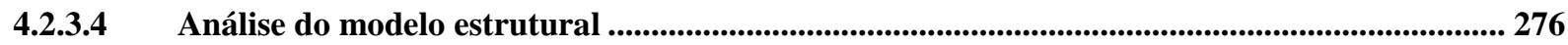

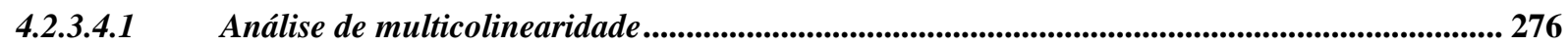

4.2.3.4.2 Coeficiente de determinação de Pearson $\left(R^{2}\right)$........................................................................... 277

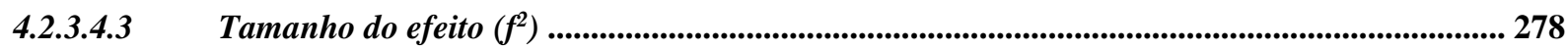

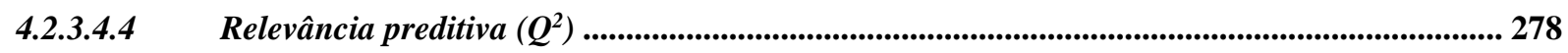

4.2.3.4.5 Coeficientes de caminho entre constructos exógenos e endógenos .......................................... 278

4.2.3.4.6 Relação entre o constructo Gerencial e o constructo Desempenho............................................. 281 
4.2.3.4.8 Relação constructo Técnico e constructo Desempenho ............................................................... 283

4.2.3.5 Análise das relações de mediação ................................................................................................... 283

4.2.3.5.1 Mediação gerencial da relação entre estrutural e desempenho (hipótese H4).......................... 284

4.2.3.5.2 Mediação gerencial da relação entre técnico e desempenho (hipótese H5) .............................. 287

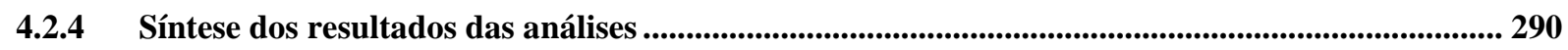

5. CONCLUSÕES E CONSIDERAÇÕES FINAIS ...................................................................... 295

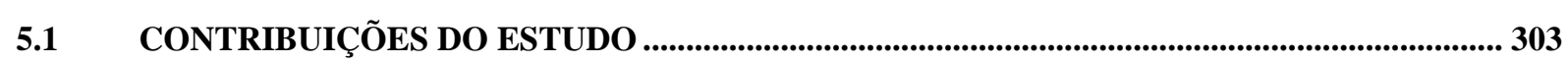

5.2 LIMITAÇÕES DO MÉTODO DE PESQUISA ..................................................................... 306

5.3 OPORTUNIDADES PARA ESTUDOS NO FUTURO ................................................................ 307

6. REFERÊNCIAS BIBLIOGRÁFICAS............................................................................................. 309

ANEXO I - Mercado Farmacêutico Brasileiro - Medicamentos Genéricos 2017 ........................................... 327

ANEXO II - Contagem de medicamentos genéricos registrados por laboratório farmacêutico. ................ 329

APÊNDICE I - Pesquisa do referencial teórico ................................................................................. 331

APÊNDICE II - Resultados das pesquisa do referencial teórico................................................................. 334

APÊNDICE III - Levantamento da literatura sobre o desenvolvimento de medicamentos no Brasil ....... 336

APÊNDICE IV - Questionário (etapa qualitativa) ............................................................................. 339

APÊNDICE V - Unidades de significado (impactos/resultados dos problemas nos projetos) ..................... 342

APÊNDICE VI - Unidades de significado (causas/origens dos problemas nos projetos) .............................. 343

APÊNDICE VII - Questionário para Validação do Conteúdo ....................................................................... 344

APÊNDICE VIII - Resultados para o grau de relevância das variáveis para a avaliação do desempenho dos projetos de desenvolvimento de medicamentos genéricos. $(n=19)$.............................................. 350

APÊNDICE IX - Resultados para o grau de relevância das situações relacionadas ao desempenho fora do planejado para os projetos de desenvolvimento de medicamentos genéricos. ................................... 351

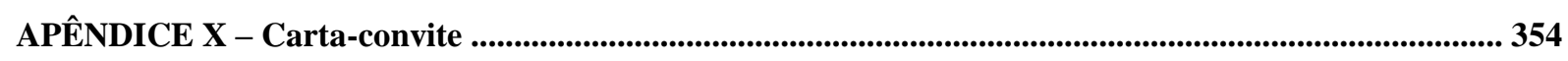

APÊNDICE XI - Questionário aplicado na etapa quantitativa ................................................................... 355

APÊNDICE XII - Indicadores que compõem os constructos definidos no modelo de caminhos proposto e seus códigos de identificação

APÊNDICE XIII - Médias e desvios padrões dos constructos e de seus indicadores .................................... 366

APÊNDICE XIV - Matriz de cargas cruzadas ("cross loadings") ................................................................... 369

APÊNDICE XV - Confiabilidade e validade dos constructos.................................................................. 371

APÊNDICE XVI - Validade discriminate (critério de Fornell-Larcker) .................................................... 372

APÊNDICE XVII - Validade discriminate (critério de Fornell-Larcker) .................................................... 373

APÊNDICE XVIII - Confiabilidade e validade do constructo ................................................................. 374 



\section{LISTA DE ABREVIATURAS E SIGLAS}

Anvisa: Agência Nacional de Vigilância Sanitária

API: "Active pharmaceutical ingredient” (IFA: Ingrediente farmacêutico ativo)

AVE: “Average Variance Extracted" (raiz quadrada do valor da média da variância extraída)

PMBOK: Project Management Body of Knowledge (Guia do conhecimento em gerenciamento de projetos)

BNDES: Banco Nacional de Desenvolvimento Econômico e Social

CAAE: Certificado de apresentação para apreciação ética

CC: Confiabilidade Composta ("Composite Reliability" - CR)

CEP: Controle estatístico de processo

CMA: "Critical material atributes" (atributos críticos de materiais)

CMED: Câmara de Regulação do Mercado de Medicamentos

CMMI: "Capability Maturity Model Integration"

CPP: "Critical process parameter" (parâmetro crítico de Processo)

CQA: "Critical quality attributes" (atributos críticos de qualidade)

Deinfar: Laboratório de Inovação e Desenvolvimento Farmacotécnico

DoE: "Design of Experiments" (delineamento de experimentos)

DP: Desenvolvimento de produtos

DS: "Design Space" (espaço de delineamento)

$\mathrm{f}^{2}$ : Tamanho do efeito ou indicador de Cohen

FDA: Food and Drug Administration (Administração Federal de Alimentos e Medicamentos dos Estados Unidos)

FMEA: "Failure Mode and Effect Analysis" (Análise de Modo de Falha e Efeito)

ICH: International Conference on Harmonisation (Conselho Internacional sobre Harmonização de Requisitos Técnicos em Produtos Farmacêuticos para Uso Humano)

IFA: Ingrediente farmacêutico ativo

IN: Instrução normativa (Anvisa)

ISPE: International Society for Pharmaceutical Engineering

IVC: Índice de validade de conteúdo

GDDP: "Generic drug development projects" (projetos de desenvolvimento de medicamentos genéricos)

GP: Gerente de projeto

MEE: Modelagem de equações estruturais

PAT: "Process Analytical Technology" (tecnologia analítica de processo)

PDCA: "Plan-Do-Check-Act" (na língua portuguesa, planeje, faça, verifique e aja)

PDMG: Projetos de desenvolvimento de medicamentos genéricos 
PDP: Projetos de desenvolvimento de produtos

P\&D: Pesquisa e desenvolvimento

PD\&I: Pesquisa, desenvolvimento e inovação

PLS-SEM: Partial least squares structural equation modeling (modelagem de equações estruturais com estimação por mínimos quadrados parciais)

PME: Pequenas e médias empresas

PMI: Project Management Institute

PROFARMA: Programa de Apoio ao Desenvolvimento da Cadeia Produtiva Farmacêutica

ProGenéricos: Associação Brasileira das Indústrias de Medicamentos Genéricos

$\mathrm{Q}^{2}$ : Relevância preditiva

QTPP: “Quality Target Product Profile” (Perfil de qualidade alvo do produto)

QbD: "Quality by Design" (qualidade por meio do delineamento)

$\mathrm{R}^{2}$ : Coeficiente de determinação $\left(\mathrm{R}^{2}\right)$ de Pearson

RDC: Resolução da Diretoria Colegiada (Anvisa)

Sindusfarma: Sindicato da Indústria de Produtos Farmacêuticos

VAF: "Variance accounted for" (variância explicada por)

VD: Variável dependente

VI: Variável independente

VIF = "Variance inflaction factor" (fator de inflação da variância)

VL: Variável latente 


\section{LISTA DE TABELAS}

Tabela 1 - Resumo das publicações com revisões de literatura sobre DP .......................................... 32

Tabela 2 - Temas de pesquisa sobre o desenvolvimento de produtos e publicações relacionadas ........ 33

Tabela 3 - Síntese das características dos modelos de desenvolvimento sequencial, de engenharia simultânea e de desenvolvimento integrado. ..................................................................... 52

Tabela 4 - Características das abordagens de desenvolvimento de produtos ....................................... 53

Tabela 5 - Conceitos, componentes, ferramentas e técnicas da abordagem de "Quality by Design"... 57

Tabela 6 - Abordagem mínima e aprimorada de qualidade por meio do delineamento ........................ 59

Tabela 7 - Componentes dos projetos de desenvolvimento de medicamentos em laboratórios

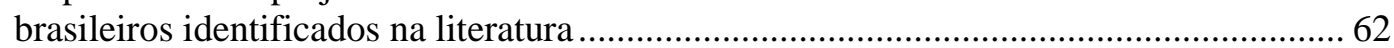

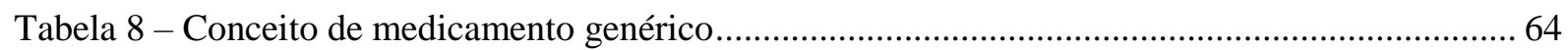

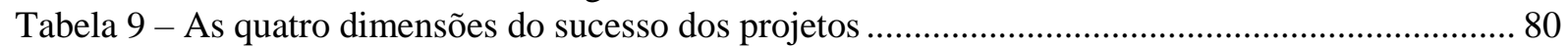

Tabela 10 - Dimensões e indicadores do desempenho do DP encontrados na literatura. ...................... 81

Tabela 11 - Comparação entre características de projetos problemáticos e efetivos .............................. 84

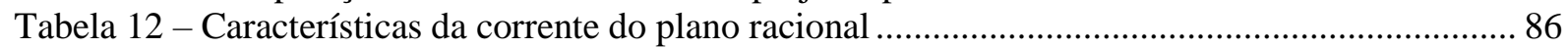

Tabela 13 - Características da corrente da rede de comunicação .......................................................... 87

Tabela 14 - Características da corrente da solução disciplinada de problemas ..................................... 88

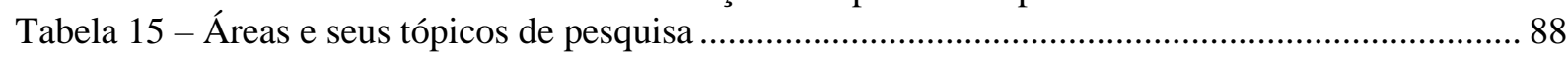

Tabela 16 - Dimensões e fatores contribuintes ou influenciadores do desempenho do DP ................. 92

Tabela 17 - Componentes das categorias de fatores contribuintes para o sucesso do DP ................... 94

Tabela 18 - Critérios para o gerenciamento de portfólio na indústria farmacêutica............................ 108

Tabela 19 - Razões para recusa da Anvisa para o registro de medicamentos genéricos e similares. . 109

Tabela 20 - Requisitos sanitários para registro relacionados aos medicamentos genéricos ................ 110

Tabela 21 - Constructos relacionados ao DP estudados por Cooper e Kleinschmidt .......................... 112

Tabela 22 - Dimensões e itens componentes da escala de mensuração da efetividade das atividades de

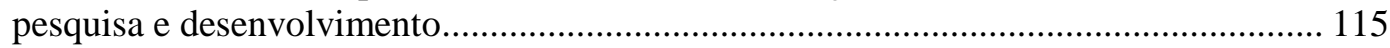

Tabela 23 - Dimensões e fatores contribuintes ou influenciadores do desempenho do DP ................ 119

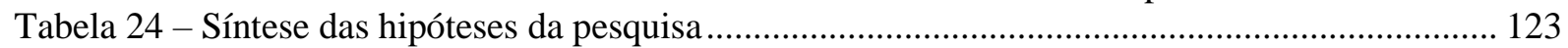

Tabela 25 - Estrutura do questionário (fase qualitativa) .................................................................... 129

Tabela 26 - Equivalência entre os termos das fases qualitativa e quantitativa e suas definições e operacionalizações .................................................................................................... 142

Tabela 27 - Indicadores do constructo Desempenho relacionados aos projetos de desenvolvimento de medicamentos genéricos .......................................................................................... 147

Tabela 28 - Indicadores (fatores contribuintes) dos constructos da dimensão Gerencial ................... 147

Tabela 29 - Indicadores (fatores contribuintes) dos constructos da dimensão Estrutural .................... 148

Tabela 30 - Indicadores (fatores contribuintes) dos constructos da dimensão Técnico....................... 149

Tabela 31 - Indicadores componentes do constructo "Desempenho" para o desenvolvimento de medicamentos genéricos e assertivas para sua mensuração..

Tabela 32 - Indicadores, constructos para mensuração dos fatores contribuintes para o desempenho nos projetos de desenvolvimento de genéricos e as assertivas formuladas para sua mensuração

Tabela 33 - Estrutura do questionário utilizado para validação do conteúdo ....................................... 160

Tabela 34 - Estrutura do questionário (fase quantitativa) ................................................................. 161

Tabela 35 - Matriz de amarração teórica com a relação entre a questão de pesquisa, as hipóteses, as perguntas e as técnicas estatísticas empregadas.............................................................. 162

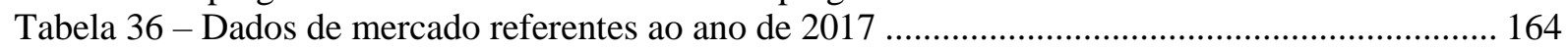

Tabela 37 - Dados para o cálculo do tamanho mínimo da amostra ...................................................... 165

Tabela 38 - Cálculo estimativo para amostragem utilizando o G*Power......................................... 165

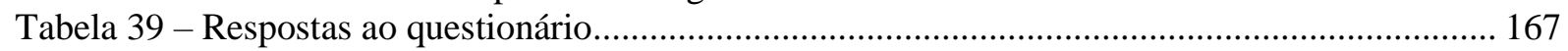

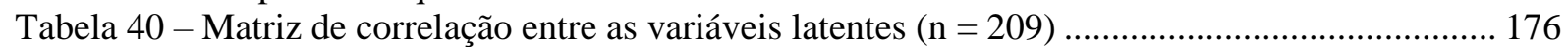

Tabela 41 - Matriz de cargas fatoriais e cargas cruzadas ("crossloads") $(n=209) \ldots \ldots \ldots \ldots \ldots \ldots \ldots \ldots \ldots . . . . . . . . . . .176$

Tabela 42 - Possíveis resultados da análise da validade discriminante e ações sugeridas................... 180

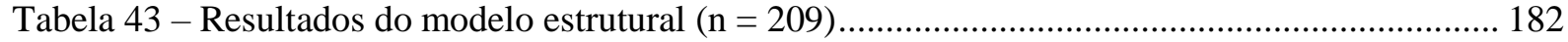


Tabela 44 - Mediação, efeitos diretos e indiretos

Tabela 45 - Matriz de amarração teórica envolvendo a relação entre a questão central da pesquisa, os objetivos específicos, as hipóteses e os métodos de coleta e análise dos dados. ............ 187

Tabela 46 - Técnicas de tratamento dos dados da pesquisa................................................... 188

Tabela 47 - Resumo das limitações, confiabilidade e validade dos métodos de pesquisa................ 189

Tabela 48 - Distribuição das unidades de significado entre as respostas recebidas ......................... 192

Tabela 49 - Distribuição das unidades de significado após análise inicial de conteúdo.................... 192

Tabela 50 - Unidades de significado relacionadas ao tema dos indicadores de desempenho de projetos de desenvolvimento de medicamentos.

Tabela 51 - Unidades de significado relacionadas ao tema dos fatores contribuintes para o desempenho de projetos de desenvolvimento de medicamentos genéricos

Tabela 52 - Unidades de significado relacionadas à categoria Gerencial divididas nas subcategorias.

Tabela 53 - Unidades de significado relacionadas à categoria Estrutural subdivididos nos subtemas.

Tabela 54 - Unidades de significado relacionadas à categoria Técnico subdivididos nas subcategorias.

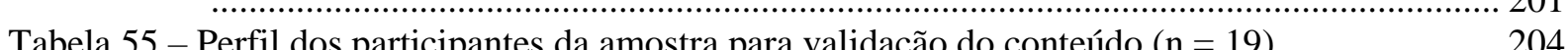

Tabela 56 - Indicadores excluídos do estudo após validação do conteúdo. $(n=19)$....................... 206

Tabela 57 - Validade discriminante pelo critério de Fornell e Larcker $(1981)(\mathrm{n}=209)$.................. 240

Tabela 58 - Cargas fatoriais e de cargas cruzadas do modelo final $(\mathrm{n}=209)$................................ 241

Tabela 59 - Relação de indicadores excluídos para ajuste do modelo de mensuração ..................... 242

Tabela 60 - Confiabilidade do modelo de mensuração: Alfa de Cronbach e Confiabilidade Composta

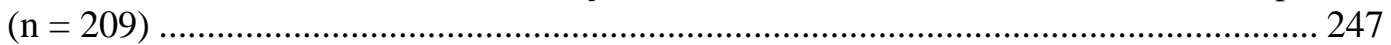

Tabela 61 - Valores do VIF (fator de inflação da variância) $(n=209)$.......................................... 276

Tabela 62 - Coeficiente de determinação $\left(\mathrm{R}^{2}\right)$, tamanho do efeito $\left(\mathrm{f}^{2}\right)$ e relevância preditiva $\left(\mathrm{Q}^{2}\right)(\mathrm{n}=$ 209)

Tabela 63 - Síntese dos resultados da análise do modelo estrutural $(n=209)$................................ 279

Tabela 64 - Análise de mediação Estrutural -> Gerencial -> Desempenho (hipótese H4) $(\mathrm{n}=209)$.. 284

Tabela 65 - Análise de mediação Técnico -> Gerencial -> Desempenho (hipótese H5) $(\mathrm{n}=209)$..... 287

Tabela 66 - Síntese dos resultados das hipóteses propostas $(n=209)$......................................... 292

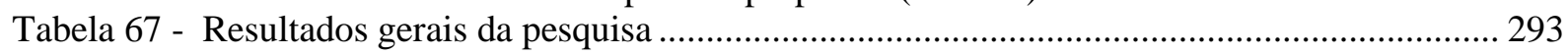

Tabela 68 - Indicadores que mais contribuíram para os seus constructos ................................... 298

Tabela 69 - Resultados das análises das relações hipotetizadas no modelo conceitual proposto ....... 301

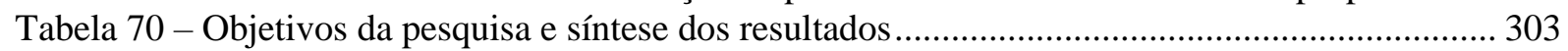




\section{LISTA DE FIGURAS}

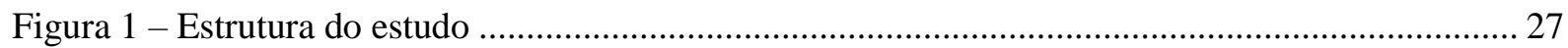

Figura 2 - Estrutura da fundamentação teórica ............................................................................... 29

Figura 3 - Classificação de projetos de desenvolvimento com base nas mudanças em produtos e em

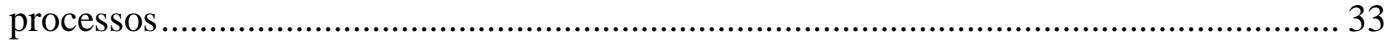

Figura 4 - Tipologia de estratégias de projetos de DP na relação empresa "versus" mercado ............. 35

Figura 5 - Modelo geral do processo de desenvolvimento de produtos .............................................. 39

Figura 6 - Modelo de referência genérico para processos de engenharia, fabricação e implantação.... 43

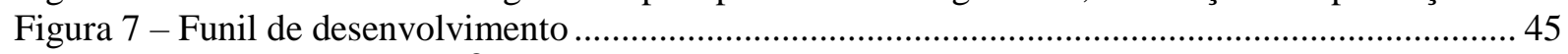

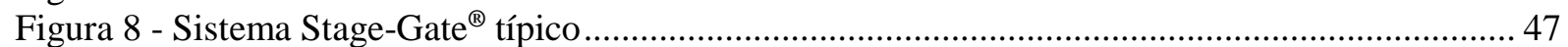

Figura 9 - Desenvolvimento em espiral com iterações "Build-Test-Feedback-Revise" ...................... 50

Figura 10 - Macro-etapas, fases e pacotes de trabalho da área de pesquisa e desenvolvimento. ......... 54

Figura 11 - Fases e atividades de um projeto de desenvolvimento de um novo medicamento ............ 55

Figura 12 - Sequência de processos pela abordagem do "Quality by Design"..................................... 56

Figura 13 - Sequência de pacotes de trabalho para o desenvolvimento de um medicamento genérico.

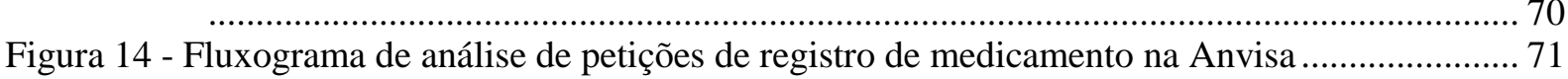

Figura 15 - Processo da Anvisa para o registro de um novo medicamento ............................................. 72

Figura 16 - Etapas para desenvolvimento de formulações genéricas usando o "Quality by Design" .. 73

Figura 17 - Desenvolvimento de um medicamento genérico usando Seis Sigma .................................. 74

Figura 18 - Estruturação das influências de projetos............................................................................ 90

Figura 19 - Fatores que afetam o sucesso de projetos de desenvolvimento de produtos ....................... 113

Figura 20 - Relações entre as dimensões da escala de mensuração da efetividade das atividades de

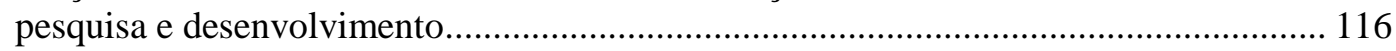

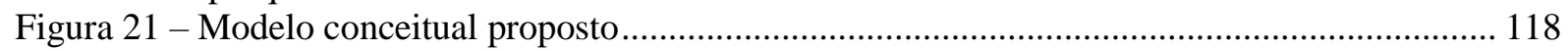

Figura 22 - Modelo geral de mediação …………........................................................................ 122

Figura 23 - Procedimento para identificação dos indicadores de desempenho e fatores contribuintes

Figura 24 - Relação entre os fatores contribuintes e o desempenho dos projetos de desenvolvimento de

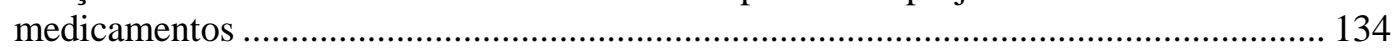

Figura 25 - Modelo teórico para as relações entre o desempenho dos projetos de desenvolvimento de medicamentos genéricos e seus fatores contribuintes................................................. 140

Figura 26 - Modelos de relacionamento entre constructos e suas medidas ....................................... 144

Figura 27 - Símbolos empregados no modelo de caminhos .................................................................. 145

Figura 28 - Modelo de caminhos para o desempenho de projetos de desenvolvimento de medicamentos genéricos e seus fatores contribuintes................................................. 145

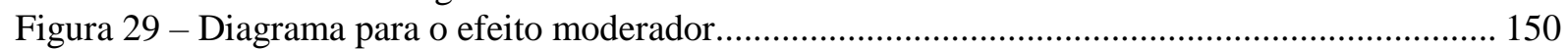

Figura 30 - Esquema de avaliação do modelo de equações estruturais ............................................. 174

Figura 31 - Modelo conceitual e as hipóteses de pesquisa ................................................................. 203

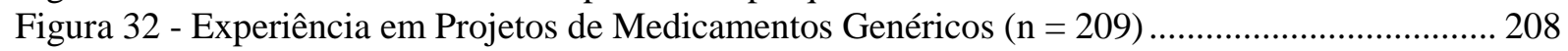

Figura 33 - Participação recente ou atual em projetos de medicamentos genéricos $(\mathrm{n}=209) \ldots \ldots \ldots . . . . .208$

Figura 34 - Função nos Projetos de Desenvolvimento de Medicamentos Genéricos ( $n=209) \ldots \ldots . . . . .209$

Figura 35 - Área ou departamento predominante nos Projetos de Desenvolvimento de Medicamentos

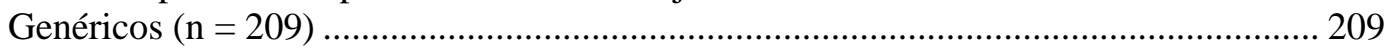

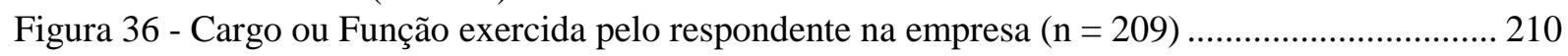

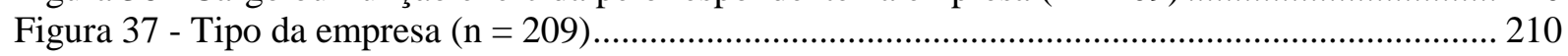

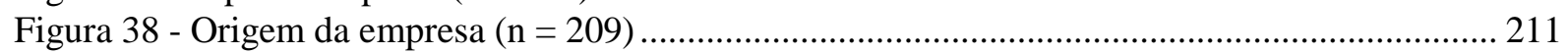

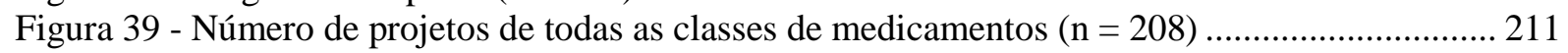

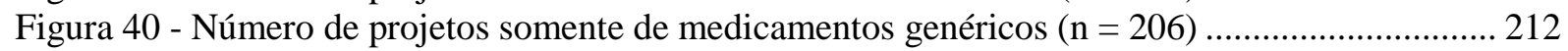

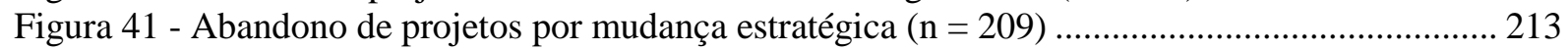

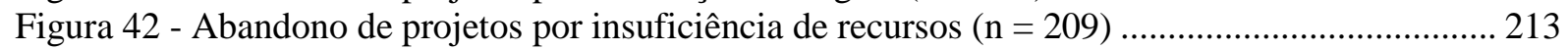

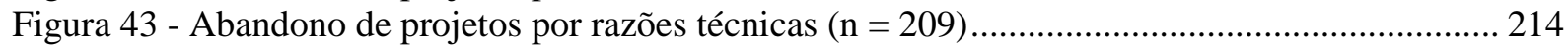

Figura 44 - Conclusão de projetos com desempenho fora do planejado $(\mathrm{n}=209)$........................... 215 
Figura 45 - Conclusão de projetos com desempenho dentro do planejado $(\mathrm{n}=209)$......................... 216

Figura 46 - Descrição dos indicadores do constructo Desempenho $(\mathrm{n}=209)$..................................... 217

Figura 47 - Descrição dos indicadores do constructo Desenvolvimento $(\mathrm{n}=209)$............................... 219

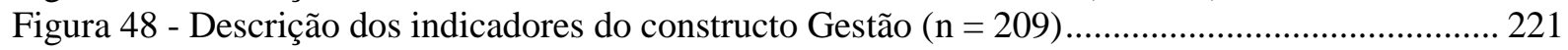

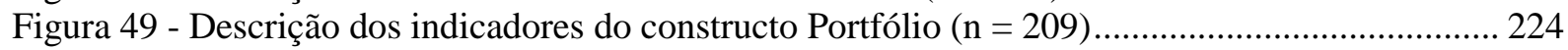

Figura 50 - Descrição dos indicadores do constructo Especificações Técnicas $(n=209) \ldots \ldots \ldots \ldots \ldots \ldots . . . . .226$

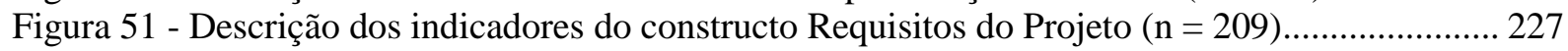

Figura 52 - Descrição dos indicadores do constructo Requisitos Regulatórios $(\mathrm{n}=209) \ldots \ldots \ldots \ldots \ldots \ldots . . . . .229$

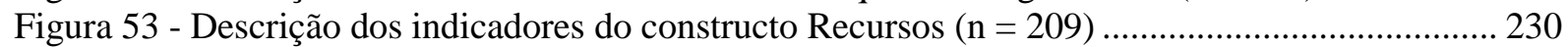

Figura 54 - Descrição dos indicadores do constructo Competências $(n=209)$................................... 232

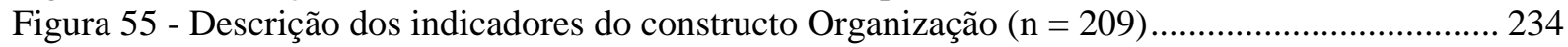

Figura 56 - Reapresentação do esquema de análise do modelo de equações estruturais ...................... 236

Figura 57 - Modelo estrutural (versão inicial sem ajustes) ............................................................... 237

Figura 58 - Constructo Desempenho e seus indicadores reflexivos $(\mathrm{n}=209)$................................... 248

Figura 59 - Constructo Gerencial e seus constructos exógenos Gestão, Desenvolvimento e Portfólio

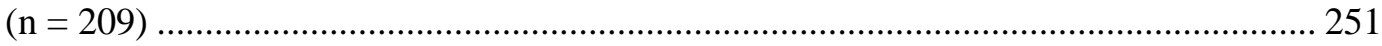

Figura 60 - Constructo Estrutural e seus constructos exógenos Organização, Recursos e

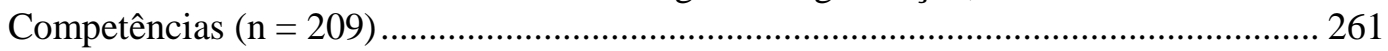

Figura 61 - Constructo Técnico e seus constructos exógenos Requisitos do Projeto, Especificações

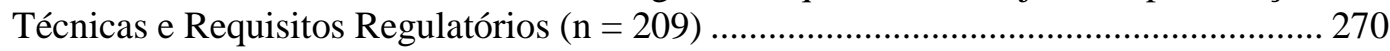

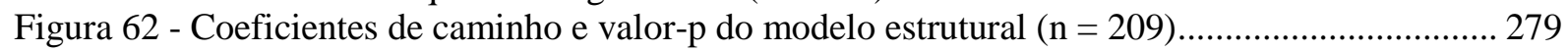

Figura 63 - Modelo estrutural com os constructos Desempenho, Gerencial, Estrutural e Técnico $(\mathrm{n}=209)$

Figura 64 - Coeficientes de caminho e valores-p da análise de mediação Estrutural -> Gerencial ->

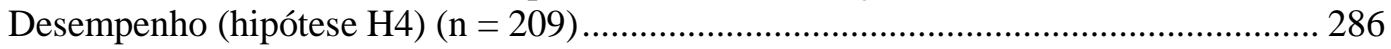

Figura 65 - Coeficientes de caminho e valor p da análise de mediação Técnico -> Gerencial -> Desempenho (hipótese H5) $(\mathrm{n}=209)$ 


\section{INTRODUÇÃO}

Já na década de 1990, Wheelwright e Clark (1992) afirmam que em um ambiente global, intenso e dinâmico, o desenvolvimento de novos produtos e processos é um importante e crescente ponto de foco de competição entre as empresas, sendo geradores de vantagem competitiva a eficiência e a rapidez em colocar no mercado produtos mais adequados às necessidades e expectativas do consumidor.

O desenvolvimento de novos medicamentos é um dos processos fundamentais para a indústria farmacêutica, sendo considerado o condutor operacional da gestão de portfólio dos produtos oferecidos pela empresa ao mercado (Moreira, 2008). É crítico para muitas organizações por envolver decisões complexas e que consideram ao mesmo tempo: objetivos e prioridades da organização; benefícios financeiros; benefícios intangíveis; disponibilidade de recursos; e nível de riscos. Segundo Loveday (1985), de longa data a indústria farmacêutica já é muito dependente do desenvolvimento de novos medicamentos para o seu crescimento e sustentabilidade no longo prazo.

Por atuarem em setor fortemente regulado, os laboratórios farmacêuticos possuem requisitos ${ }^{1}$ específicos que devem ser atendidos para o lançamento de novos produtos (Braum, 2014; Loch \& Kavadias, 2008). Blau, Pekny, Varma e Bunch (2004) destacam como desafios para o desenvolvimento de novos fármacos (medicamentos inovadores) a reduzida probabilidade de sucesso técnico, os altos custos de desenvolvimento, as incertezas de mercado, a escassez de novas ideias e limitações dadas pela escassez de recursos financeiros.

De acordo com Moreira e Cheng (2010), naquela época, as atividades de pesquisa farmacêutica no Brasil consistiam basicamente do desenvolvimento de formulações de medicamentos cujas patentes já expiraram. De uma forma geral, esses medicamentos pertenciam a duas classes: os medicamentos similares e os medicamentos genéricos. Yugue, Yoshida, Vidal e Tavares (2010) observaram no mesmo período que os laboratórios farmacêuticos produtores de medicamentos genéricos estavam mais voltados a aspectos de demanda de mercado e viabilidade técnica para disponibilizar medicamentos a custos competitivos, pouco investindo no desenvolvimento de medicamentos inovadores. Ainda segundo os pesquisadores, a aprovação pela Agência Nacional de Vigilância Sanitária (Anvisa) era um ponto-crítico no caminho para o lançamento de um novo produto, uma vez que é fonte de riscos importantes para o sucesso do projeto, pois a reprovação e mesmo as ações de correção podiam representar elevados custos à organização e a perda de competitividade. Para

\footnotetext{
1 O termo "requisito" é definido pelo PMI (2017:131) como "uma condição ou capacidade que deve estar presente em um produto, serviço ou resultado para cumprir um acordo ou outra especificação imposta formalmente".
} 
Basavaraj e Betageri (2014), o receio do fracasso e o rigoroso processo de revisão regulatória acabam por pressionar as empresas farmacêuticas para o desenvolvimento de medicamentos já existentes e de genéricos melhorados.

Por outro lado, em publicação mais recente, Taylor (2016) destaca que os laboratórios farmacêuticos que produzem medicamentos genéricos são empresas de baixo custo, de baixa margem e, por outro lado, de baixo risco, uma vez que os produtos que fabricam e distribuem já possuem comprovado valor comercial. Uma das justificativas está no fato dos genéricos não necessitarem incorrer em custos de pesquisa e desenvolvimento de novos fármacos, embora ainda haja a necessidade do desenvolvimento da formulação e dos processos com os objetivos de aprovação para comercialização e de uma produção mais eficiente e de menor custo. Ainda para o pesquisador, embora a produção de medicamentos genéricos seja altamente regulamentada, os custos de fabricação e de marketing são muito baixos, uma vez que os produtos já são bem estabelecidos no mercado e a demanda é bem compreendida, podendo ser considerado um mercado de "commodities", onde a diferenciação competitiva é baseada no custo dos produtos e a rentabilidade é determinada pela participação de mercado. Para Dylst, Vulto, Godman e Simoens (2013), no entanto, a pressão contínua para redução dos preços é um dos fatores que poderiam comprometer a sustentabilidade da indústria produtora de medicamentos genéricos no longo prazo.

Muitos pedidos de registro de medicamentos genéricos são indeferidos pelas autoridades sanitárias em razão de deficiências técnicas, documentais e processuais (Do Carmo, 2017; Do Carmo, Piras, et al., 2017; Aloka Srinivasan, Iser, \& Gill, 2010; Worku, Gordon, Stahl, \& Rago, 2012). Os desafios no desenvolvimento de novos medicamentos genéricos dificultam a obtenção do máximo valor do medicamento para o paciente que seria a sua rápida disponibilização e a baixo custo (Pete Harpum, 2010). Indeferimentos também ocorrem no Brasil, como abordado por Do Carmo (2017) e Do Carmo, Piras, Rocha e Gratieri (2017). Os estudos indicam que cerca de metade dos pedidos de registro de medicamentos genéricos submetidos à aprovação da Anvisa são reprovados. Há também estudos (Braum, 2014; Moreira, 2008; Moreira \& Cheng, 2010; Yugue et al., 2010) que apontam para oportunidades de melhoria em processos de seleção e gestão de projetos de desenvolvimento de novos medicamentos dos laboratórios farmacêuticos instalados no Brasil.

Para a agência norte-americana de controle de alimentos e medicamentos, o Food and Drug Administration - FDA (2007), o desenvolvimento dos medicamentos com bases sólidas de dados científicos aceleraria a aprovação dos medicamentos genéricos. Mais importante, ele propiciaria a ampliação da gama de produtos disponíveis, a manutenção de altos padrões de qualidade, segurança e eficácia, além da construção da confiança dos profissionais de saúde, pacientes e do público. Dificuldades no desenvolvimento dos novos medicamentos genéricos seriam barreiras ao acesso a estes benefícios. 


\subsection{QUESTÃO DE PESQUISA}

Considerando a taxa de indeferimento dos pedidos de registro dos medicamentos genéricos no Brasil e a lacuna encontrada na literatura sobre o desempenho dos projetos de desenvolvimento destes medicamentos, a questão definida para esta pesquisa foi: quais são os fatores que contribuem para o desempenho dos projetos de desenvolvimento de medicamentos genéricos?

\subsection{OBJETIVOS DO ESTUDO}

Para responder à questão de pesquisa e organizar o seu desenvolvimento, foram estabelecidos objetivos específicos, os quais são listados a seguir:

a. Identificar os indicadores de desempenho dos projetos de desenvolvimento de medicamentos genéricos;

b. Identificar os fatores que contribuem para o desempenho dos projetos de desenvolvimento de medicamentos genéricos;

c. Propor de um modelo teórico multidimensional que integre o desempenho dos projetos de desenvolvimento de medicamentos genéricos e seus fatores contribuintes;

d. Analisar empiricamente as relações entre os fatores contribuintes e o desempenho dos projetos de desenvolvimento dos medicamentos genéricos.

\subsection{JUSTIFICATIVA PARA O ESTUDO}

Em levantamento realizado nas bases de dados Scopus ${ }^{\circledR}$ e Google Acadêmico ${ }^{\circledR}$ em dezembro de 2018 e complementado em novembro de 2019, não foram encontrados estudos publicados que tratassem especificamente do desempenho dos projetos de desenvolvimento de medicamentos a partir de fármacos cujas patentes já expiraram, como é o caso dos medicamentos genéricos. O esquema de pesquisa nas bases de dados e resultados estão disponíveis nos Apêndices I e II desta tese.

A razão da raridade dos estudos sobre a eficiência dos projetos de desenvolvimento de medicamentos genéricos (PDMG) pode estar relacionada à dificuldade de conseguir dados da indústria farmacêutica, pois é plausível supor que os laboratórios não teriam interesse em apresentar seus indicadores e eventuais problemas e ineficiências, mesmo com o compromisso de confidencialidade dos dados. Contribui para esta situação a possibilidade de tais ocorrências possuírem potencial para expor eventuais pontos fracos das empresas, em especial no desenvolvimento dos medicamentos.

A ausência de publicações sobre os PDMG pode também ter como uma das razões a percepção de que se trata de um tipo de projeto pouco complexo, bastante conhecido pela indústria farmacêutica e de menor valor a agregar dos pontos de vista acadêmico e gerencial. As poucas publicações relacionadas aos medicamentos genéricos, ou têm foco no desenvolvimento de produtos (DP) 
específicos, ou em processos genéricos de desenvolvimento. São exemplos as publicações de Harpum (2010); Srinivasan e Iser (2010); Srinivasan e colaboradores (2010); e Srinivasan, Iser e Gill ( 2011). Ou ainda estudos baseados em dados das agências reguladoras, basicamente sobre deficiências nos processos de autorização para a comercialização dos medicamentos. São exemplos as publicações de Worku e colaboradores (2012); Huang e colaboradores (2013); Do Carmo (2017); e Do Carmo, Piras e colaboradores (2017).

Com relação à mensuração dos resultados dos projetos de desenvolvimento de medicamentos, mesmo de uma forma geral e para novas drogas, o único estudo encontrado com constructos e escalas validados para foi o realizado por Mendigorri, Valderrama e Cornejo (2016). Desta forma, verificou-se que há uma lacuna na literatura com relação a estudos sobre o desempenho de PDMG.

Em 2017, segundo dados da Anvisa (2018d), esta classe de medicamentos já correspondia a 34,6\% das vendas em unidades no mercado farmacêutico brasileiro. Este dado demonstra a relevância do tema deste estudo, considerando ainda a importância dos medicamentos genéricos para a ampliação do alcance das pessoas aos medicamentos e pelo fato de que ineficiências nos seus projetos de desenvolvimento, além de retardar o acesso aos medicamentos, também pode resultar em custos maiores para a sua produção e, consequentemente, do ponto de vista do laboratório farmacêutico desenvolvedor, na diminuição de sua competitividade e lucratividade (Dylst et al., 2013; D. Taylor, 2016). Além disso, os seguintes fatos também foram considerados para justificar esta pesquisa:

- Os estudos encontrados na literatura (Do Carmo, 2017; Do Carmo, Cunha-Filho, Gelfuso, \& Gratieri, 2017; Huang et al., 2013; Worku et al., 2012) indicam que os PDMG possuem oportunidades de melhoria, portanto, há espaço para contribuições teóricas e gerenciais;

- Os dados das pesquisas publicadas têm por referência os medicamentos que chegaram à fase de seu registro ou de autorização para comercialização (Do Carmo, 2017; Do Carmo, CunhaFilho, et al., 2017; Huang et al., 2013; Worku et al., 2012). Assim, não consideram os projetos de desenvolvimento que não chegaram a esta fase e nem outros aspectos do desenvolvimento dos medicamentos além dos intrínsecos ao medicamento e à documentação, como, por exemplo, os fatores ligados ao processo e à infraestrutura de desenvolvimento;

- Para possibilitar análises com qualidade e/ou aprofundadas, as ocorrências de falhas e problemas durante o desenvolvimento de um novo medicamento devem ter registros completos e detalhados. Mesmo que fosse permitido o acesso a essas informações, seria necessário que fossem disponibilizadas integralmente e com descrições detalhadas;

- Os dados disponíveis na literatura não permitem identificar diretamente quais os componentes dos PDMG demandam mais atenção dos profissionais que neles trabalham;

- De acordo com Kalluri e Kodali (2014), a possibilidade de desenvolvimento de novas práticas para a melhoria das taxas de sucesso é um dos motivadores da pesquisa em DP. 
Estas constatações indicam, sobretudo, limitações importantes das possíveis fontes de dados. Por outro lado, são também razões para o foco deste estudo estar em dados fornecidos pelos profissionais que atuam no desenvolvimento dos medicamentos genéricos e não em dados obtidos diretamente dos laboratórios farmacêuticos, ou seja, a pesquisa é baseada na percepção dos profissionais sobre o desempenho dos projetos em que atuaram e sobre os seus fatores contribuintes.

Kalluri e Kodali (2014) observaram a partir dos resultados dos métodos de pesquisa de DP que a abordagem metodológica da pesquisa de DP era fortemente concentrada em pesquisas quantitativas, amostras grandes e extensas análises estatísticas. Os resultados são conclusões gerais sem implicações gerenciais que levariam a dificuldades de implementação. Também concluíram que as pesquisas sobre o desempenho do DP se concentravam mais na identificação e validação dos vários fatores de sucesso no nível do produto e do projeto, sem, no entanto, distinguir entre os diferentes níveis de fatores, ou seja, como os fatores são inter-relacionados e como influenciam o sucesso do DP.

Barczak, Griffin e Kahn (2009) relataram que, embora as empresas tenham implementado uma série de novos métodos e técnicas para melhorar a maneira como os novos produtos são desenvolvidos, muito pouco progresso foi alcançado nas taxas de sucesso. Assim, os pesquisadores destacaram a importância de também estudar e relatar os fatores de falha no nível do produto ou projeto no DP.

Os dados apresentados por Do Carmo (2017) e Do Carmo, Nogueira e colaboradores (2017) indicaram que cerca de metade dos pedidos de registro de medicamentos genéricos submetidos à Anvisa são indeferidos. Esta constatação deu origem a questão desta pesquisa, ou seja: quais são os fatores que contribuem para o desempenho dos projetos de desenvolvimento de medicamentos genéricos?

\subsection{DELIMITAÇÕES DO ESTUDO}

O conceito de desenvolvimento de novos medicamentos adotado por este estudo não inclui a pesquisa de novos fármacos ou moléculas, que é próprio do desenvolvimento dos medicamentos chamados inovadores, de referência ou "de marca". Assim, o objeto de pesquisa está relacionado ao desenvolvimento farmacotécnico ou da formulação de um novo medicamento que tem princípio(s)ativo(s) ou fármaco(s) já registrados e cujas patentes já expiraram. Mais especificamente, o estudo aborda o desenvolvimento dos medicamentos classificados como genéricos.

Embora também se utilizem de princípio(s)-ativo(s) ou fármaco(s) já registrados e cujas patentes já expiraram, não foram incluídos no escopo deste estudo os projetos de desenvolvimento de medicamentos classificados como similares e os que são considerados inovações a partir de medicamentos genéricos. Ainda que os similares somente se diferenciem dos genéricos basicamente 
por serem identificados pelo nome comercial e não pelo nome do(s) princípio(s) ativo(s), esta classe de medicamentos necessita de modelo de negócio diferente dos genéricos (R. T. Yugue, Maximiano, Sbragia, \& Nascimento, 2018) e esta característica pode influenciar as estratégias adotadas pelas empresas para seu desenvolvimento.

Outra delimitação importante diz respeito às fases do ciclo de vida dos projetos de desenvolvimento de um medicamento. O estudo é limitado às fases após a seleção dos projetos a serem desenvolvidos, ou seja, após da decisão de portfólio de projetos e, assim, após o momento em que é dado início ao PDMG proposto, caracterizado, segundo o PMI (2017), pela alocação de recursos e indicação do gerente do projeto. Do outro lado, não são tratadas neste estudo as fases posteriores ao desenvolvimento, ou seja, as fases que compreendem a produção industrial, o lançamento, a distribuição e a comercialização do novo medicamento. De acordo com Shenhar, Levy e Dvir (1997), os gerentes de projetos podem influenciar o resultado do projeto durante a execução do projeto, porém eles não possuem influência exclusiva em atividades como marketing, distribuição ou serviços de campo. Portanto, o escopo desta pesquisa limitou-se às fases que mais comumente compõem os PDMG e que se encerram com a entrega da formulação e do processo de fabricação do medicamento.

Também não são tratados os fatores ligados a requisitos e/ou necessidades dos consumidores ou de mercado, embora sejam componentes de avaliação dos resultados de projetos de desenvolvimento de novos produtos de uma forma geral. Isso porque o desenvolvimento dos medicamentos genéricos parte do medicamento de referência, cujas necessidades de mercado e requisitos dos consumidores já são conhecidos. Sendo assim, o foco principal dos PDMG está no atendimento aos requisitos estritamente técnicos, considerando que obrigatoriamente devem apresentar exatamente as mesmas características de seus medicamentos de referência.

O estudo dá atenção principal à área de pesquisa e desenvolvimento e, de maneira complementar, às áreas de assuntos regulatórios, qualidade e produção. Assim, por ter como foco principal o desenvolvimento técnico dos produtos, componentes destas áreas complementares são considerados quando têm influência sobre os PDMG.

Sendo um estudo aplicado a pessoas e a população alvo da pesquisa (profissionais da indústria farmacêutica) muito sensível a questões éticas e de confidencialidade, a pesquisa foi registrada na Plataforma Brasil sob o número CAAE 94791118.7.0000.0067 e analisada e aprovada pelo Comitê de Ética em Pesquisa da Faculdade de Ciências Farmacêuticas da Universidade de São Paulo: Av. Prof. Lineu Prestes, 580, Bloco 13 A, Butantã, São Paulo, CEP 05508-000, Telefones (11) 3091-3622 e (11) 3091-3677, e-mail: cepfcf@usp.br. 


\subsection{ESTRUTURA DO ESTUDO}

Para melhor entendimento de sua estrutura e facilitar o acompanhamento de seu relato, a Figura 1 a seguir apresenta os principais capítulos e componentes deste estudo.

Figura 1 - Estrutura do estudo

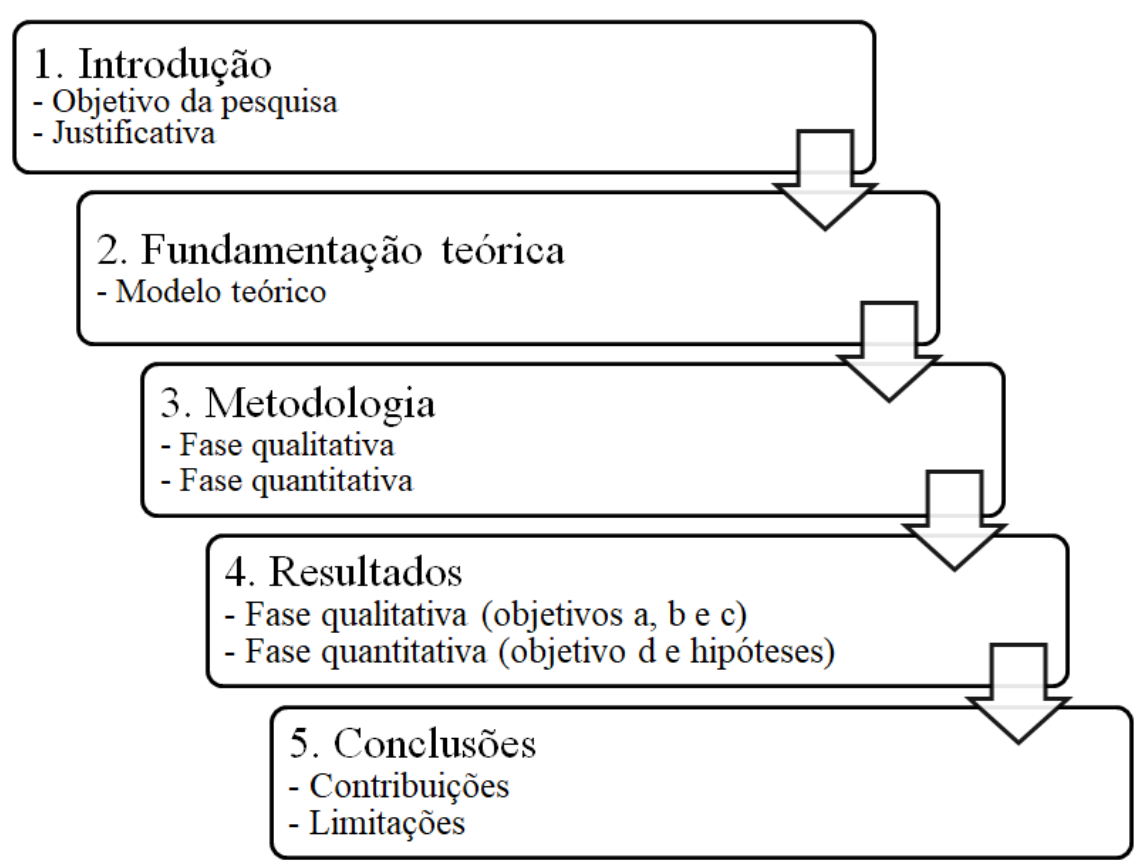

Fonte: dados da pesquisa

O capítulo 1 contextualiza o estudo ao apresentar as principais justificativas para a sua realização e que levaram à questão de pesquisa e que também definiram os seus objetivos. Também delimita o escopo ao definir os limites e restrições considerados.

A fundamentação com os principais conceitos e abordagens aos temas que dão sustentação teórica ao estudo é apresentada no capítulo 2. O levantamento na literatura buscou identificar as teorias e o seu estado atual para os temas do desenvolvimento de produtos, desenvolvimento de medicamentos genéricos, indicadores de desempenho de projetos de desenvolvimento de produtos e fatores contribuintes para o desempenho de projetos de desenvolvimento de produtos.

O capítulo 3 descreve os procedimentos metodológicos realizados para a coleta e análise dos dados em suas fases qualitativa e quantitativa. Para facilitar o entendimento de como o estudo foi desenvolvido, são apresentados neste capítulo os resultados intermediários que foram usados na construção, por exemplo, do modelo estrutural proposto e do questionário da pesquisa quantitativa.

A apresentação e a discussão dos principais resultados do estudo são realizadas no capitulo 4, iniciando pelos resultados mais relevantes da pesquisa qualitativa, os quais responderam aos três primeiros objetivos do estudo. O capítulo é finalizado com a discussão dos resultados das análises do 
modelo de mensuração e do modelo estrutural proposto e que respondem ao quarto objetivo e às hipóteses do estudo.

O capítulo 5 apresenta as principais conclusões do estudo a partir dos resultados mais relevantes e das hipóteses e objetivos estabelecidos. O capítulo é encerrado com as possíveis contribuições do estudo, as limitações que devem ser consideradas e as propostas e recomendações para novos estudos. 


\section{FUNDAMENTAÇÃO TEÓRICA}

A estrutura da fundamentação teórica segue a orientação da abordagem geral para o específico. Para facilitar o acompanhamento do desenvolvimento da fundamentação teórica deste estudo, a estrutura deste capítulo é apresentada esquematicamente na Figura 2.

Figura 2 - Estrutura da fundamentação teórica

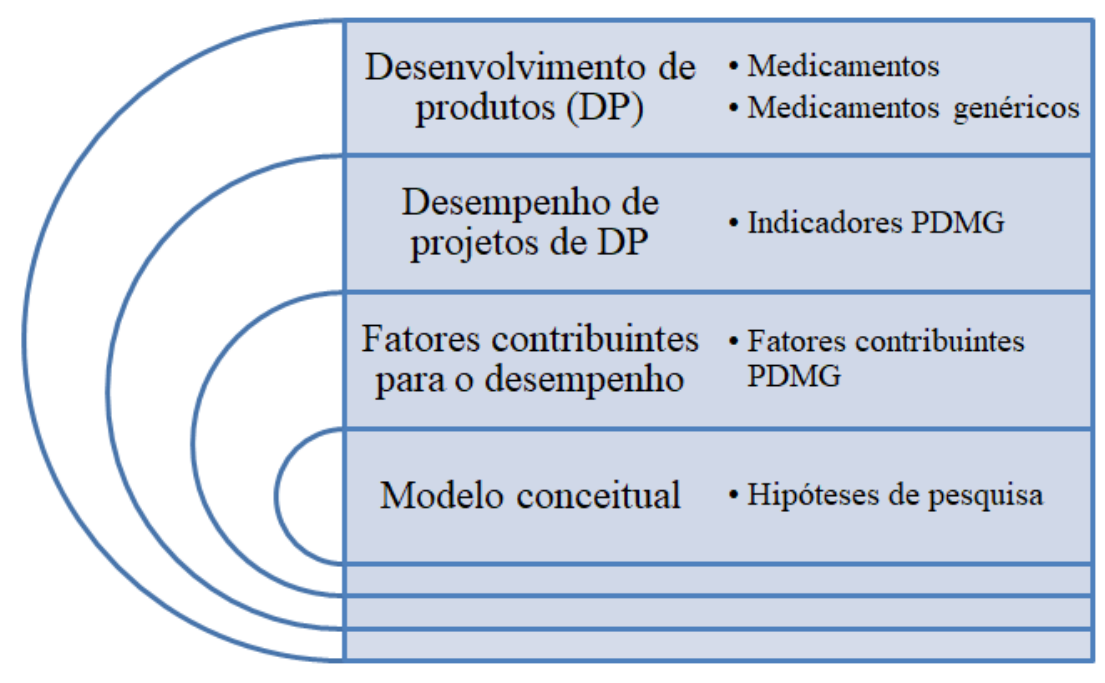

Fonte: dados da pesquisa

A relato da fundamentação teórica tem início com o tópico sobre o desenvolvimento de produtos (DP), os principais conceitos a ele relacionados, o processo de DP, os modelos e as principais abordagens. Dentro do tópico são apresentadas as características específicas do desenvolvimento dos medicamentos genéricos. O tópico seguinte trata do desempenho dos projetos de DP, dos seus conceitos, dos indicadores e as especificidades relacionadas ao desempenho dos PDMG. Fechando a fundamentação teórica, é desenvolvido o tópico que trata dos fatores influenciadores para o desempenho dos projetos de DP em geral e dos PDMG em específico. A fundamentação teórica é por fim utilizada como base para a proposição do modelo conceitual para representar os indicadores de desempenhos, seus fatores contribuintes e as relações hipotetizadas entre eles.

No levantamento da literatura, verificou-se nas publicações sobre o desenvolvimento de produtos a predominância do enfoque em produtos inovadores. Assim, quando foi possível identificar o direcionamento ou tendência para produtos inovadores, neste referencial teórico procurou-se considerar apenas os aspectos avaliados como válidos também para os não inovadores. 


\subsection{DESENVOLVIMENTO DE PRODUTOS}

Já no início da década de 1990, Wheelwright e Clark (1992) afirmaram que em um ambiente global, intenso e dinâmico, o desenvolvimento de novos produtos e seus processos eram importantes e crescentes pontos de foco de competição entre as empresas. Para eles, quanto mais eficientes e rápidas fossem as empresas em colocar no mercado produtos mais adequados às necessidades e expectativas do consumidor, maiores seriam suas vantagens competitivas. Griffin e Page (1996), por sua vez, destacaram o investimento no DP como a chave para uma empresa manter uma posição competitiva no mercado com base em sua capacidade de repetidamente comercializar novos produtos de sucesso.

O DP é tratado na literatura sob a ótica de seu processo geral de desenvolvimento, ou seja, é analisado como um componente das operações de uma organização. Rozenfeld e colaboradores (2006) definem o processo de DP como:

Conjunto de atividades por meio das quais busca-se, a partir das necessidades do mercado e das possibilidades e restrições tecnológicas, considerando as estratégias competitivas e de produto da empresa, se chegar às especificações de projeto de um produto e de seu processo de produção, para que a manufatura seja capaz de produzi-lo e de acompanhá-lo após seu lançamento. (p. 33)

O PD também é tratado na literatura sob a ótica de seus projetos, já que existem peculiaridades em cada produto desenvolvido que determinam diferentes abordagens e o uso de técnicas e métodos particulares. No entanto, o conceito de projeto de DP muitas vezes se confunde com o de processo de DP. O processo de DP de uma empresa define um padrão de como desenvolver os seus produtos e que pode ser aplicado aos projetos, ou seja, define uma linguagem comum e indica quais práticas e ferramentas serão aplicadas em todos os projetos de DP, ao mesmo tempo em que permite que as particularidades de cada projeto e de cada equipe de DP sejam atendidas (Rozenfeld et al., 2006). Desta forma, a abordagem do DP como processo em geral envolve temas como: políticas, estratégias, modelos, padrões e gestão do portfólio de projetos.

Os projetos são meios de organizar atividades que normalmente não são abordadas dentro das operações rotineiras da organização (Shenhar et al., 1997). Em geral, eles são desenvolvidos com o objetivo de cumprir requisitos legais ou sociais; atender a requisitos ou necessidades das partes interessadas ou "stakeholders"; criar, melhorar ou corrigir produtos, serviços ou processos; e implementar ou alterar estratégias de negócios ou de tecnologia (PMI, 2017). Assim, os projetos de DP tem como resultado produtos singulares, conceitos, serviços e/ou competências organizacionais (Cleland, 1999; Maximiano, 2002).

$\mathrm{Na}$ literatura, as formas diferentes de organizar e gerenciar o DP, seja como processos ou como projetos, recebem diferentes denominações. Alguns autores as chamam de métodos, outros de sistemas 
e outros ainda de abordagens. Nesta revisão, quando adequado, as denominações originais serão mantidas, não havendo, portanto, uma padronização do termo, uma vez que elas podem trazer em si significados e conotações diferentes.

O processo de DP situa-se na interface entre a empresa e o seu mercado e possui basicamente os seguintes objetivos:

- transformar uma oportunidade de mercado e uma série de premissas sobre a tecnologia do produto em um produto disponível para venda (Griffin \& Page, 1996; Kalluri \& Kodali, 2014; Krishnan \& Ulrich, 2001; Rozenfeld et al., 2006);

- criar produtos mais competitivos e em menos tempo para atender à constante evolução do mercado, da tecnologia e dos requisitos do ambiente institucional (S. Brown \& Eisenhardt, 1995; Cooper \& Kleinschmidt, 1987a; Griffin \& Page, 1996; Guo, 2008; Kalluri \& Kodali, 2014; Rozenfeld et al., 2006);

- estabelecer uma forma dos profissionais diversificarem, adaptarem e até reinventarem suas empresas para atender à evolução tecnológica e mudança do mercado, principalmente naqueles mais competitivos ou em ritmo acelerado (S. Brown \& Eisenhardt, 1995);

- promover a criação de propriedade intelectual na forma de patentes, direitos autorais, desenhos industriais e marcas registradas que podem significar barreiras à entrada de competidores em seus mercados (Pandey, Patwardhan, \& Rao, 2019);

- gerar receitas advindas dos novos produtos por meio da exploração de oportunidades de mercado para aumento das vendas e lucros e destacadamente como uma determinante chave para as competências das empresas e que pode influenciar seus planos estratégicos ( $\mathrm{S}$. Brown \& Eisenhardt, 1995; Cooper \& Kleinschmidt, 1987a; Griffin \& Page, 1996; Guo, 2008; Kalluri \& Kodali, 2014; Pandey et al., 2019; Rozenfeld et al., 2006);

- garantir que novos produtos e seus processos considerem a sustentabilidade (Figueiredo \& Loiola, 2012; Samaan, Salgado, Silva, \& Mello, 2012).

Apesar das diferentes razões para o DP, Rozenfeld e colaboradores (2006) destacam a necessidade de identificar a premissa de criação de valor que garantiria, no mercado, a satisfação dos clientes e o tempo adequado para aproveitar ao máximo a oportunidade que se apresenta, ou seja, as empresas produziriam valor de mercado ao entregar o que e quando as pessoas desejam comprar.

Na literatura, há um significativo número de publicações sobre o tema do PD. Assim, são de especial valor as contribuições das revisões da literatura para uma visão da evolução do tema, de sua teoria, a identificação de estudos mais relevantes e para a proposição de novos estudos e hipóteses (Conforto, Amaral, \& Silva, 2011). Algumas das revisões da literatura publicadas até o início do ano de 2019 estão relacionadas na Tabela 1 a seguir. 
Tabela 1 - Resumo das publicações com revisões de literatura sobre DP

\begin{tabular}{|c|c|c|c|}
\hline Autores & Título da publicação & Método & Dimensões analisadas \\
\hline $\begin{array}{l}\text { Montoya- } \\
\text { Weiss e } \\
\text { Calantone } \\
\text { (1994) }\end{array}$ & $\begin{array}{l}\text { "Determinants of New } \\
\text { Product Performance: } \\
\text { A Review and Meta- } \\
\text { Analysis." }\end{array}$ & Meta-análise & $\begin{array}{l}\text { Relacionamento entre múltiplas variáveis } \\
\text { exploratórias determinantes do desempenho } \\
\text { de novos produtos (variáveis independentes - } \\
\text { VI) e o desempenho e a funcionalidade dos } \\
\text { novos produtos (variável dependente - VD) }\end{array}$ \\
\hline $\begin{array}{l}\text { Brown e } \\
\text { Eisenhardt } \\
\quad(1995)\end{array}$ & $\begin{array}{l}\text { "Product Development: } \\
\text { Past Research, Present } \\
\text { Findings, and Future } \\
\text { Directions" }\end{array}$ & $\begin{array}{l}\text { Revisão } \\
\text { sistemática da } \\
\quad \text { literatura }\end{array}$ & $\begin{array}{l}\text { Papel estratégico do DP; papéis das } \\
\text { comunicações na internet e da disciplina na } \\
\text { solução de problemas. }\end{array}$ \\
\hline $\begin{array}{c}\text { Griffin e } \\
\text { Hauser (1996) }\end{array}$ & $\begin{array}{l}\text { "Integrating R \& D and } \\
\text { marketing: A review and } \\
\text { analysis of the literature" }\end{array}$ & $\begin{array}{c}\text { Revisão da } \\
\text { literatura }\end{array}$ & $\begin{array}{c}\text { Métodos para integração funcional entre } \\
\text { marketing e P\&D, incluindo realocação e } \\
\text { instalações físicas, movimentação de pessoal, } \\
\text { sistemas sociais informais, estruturas } \\
\text { organizacionais, incentivos e recompensas e } \\
\text { processos formais de gerenciamento } \\
\text { integrativo. }\end{array}$ \\
\hline $\begin{array}{c}\text { Henard e } \\
\text { Szymanski } \\
(2001)\end{array}$ & $\begin{array}{l}\text { "Why Some New Products } \\
\text { Are More Successful Than } \\
\text { Others" }\end{array}$ & Meta-análise & Antecedentes do desempenho de DP. \\
\hline $\begin{array}{l}\text { Krishnan e } \\
\text { Ulrich (2001) }\end{array}$ & $\begin{array}{l}\text { "Product Development } \\
\text { Decisions: A Review of } \\
\text { the Literature" }\end{array}$ & $\begin{array}{l}\text { Revisão } \\
\text { sistemática da } \\
\text { literatura e } \\
\text { "survey" }\end{array}$ & $\begin{array}{c}\text { Alinhamento temático entre os domínios } \\
\text { acadêmicos (marketing, organizações, design } \\
\text { de engenharia e gerenciamento de operações) } \\
\text { com foco em decisões de DP. }\end{array}$ \\
\hline $\begin{array}{l}\text { Page e Schirr } \\
\quad(2008)\end{array}$ & $\begin{array}{l}\text { "Growth and Development } \\
\text { of a Body of Knowledge: } \\
16 \text { Years of New Product } \\
\text { Development Research, } \\
\text { 1989-2004" }\end{array}$ & $\begin{array}{l}\text { Análise de } \\
\text { conteúdo e de } \\
\text { cluster / } 1989 \\
\quad \text { a } 2004\end{array}$ & $\begin{array}{l}\text { Classificação dos domínios do conhecimento } \\
\text { e identificação das correntes de pesquisa mais } \\
\text { comuns. }\end{array}$ \\
\hline $\begin{array}{l}\text { Benito- } \\
\text { Osorio, } \\
\text { Guerras- } \\
\text { Martín, e } \\
\text { Zuñiga- } \\
\text { Vicente } \\
(2012)\end{array}$ & $\begin{array}{l}\text { "Four decades of research } \\
\text { on product diversification: } \\
\text { a literature review." }\end{array}$ & $\begin{array}{l}\text { Revisão } \\
\text { sistemática da } \\
\text { literatura }\end{array}$ & $\begin{array}{l}\text { Diversificação e desempenho de produtos; } \\
\text { impacto do ambiente do país de origem e do } \\
\text { tempo sobre o desempenho; utilidade dos } \\
\text { vários modelos para análise do impacto da } \\
\text { diversificação de produtos sobre o } \\
\text { desempenho. }\end{array}$ \\
\hline $\begin{array}{c}\text { Kalluri e } \\
\text { Kodali (2014) }\end{array}$ & $\begin{array}{c}\text { "Analysis of new product } \\
\text { development research: } \\
\text { 1998-2009." }\end{array}$ & $\begin{array}{c}\text { Revisão } \\
\text { sistemática da } \\
\text { literatura } \\
\end{array}$ & $\begin{array}{l}\text { Contexto organizacional, nível de inovação, } \\
\text { "frameworks", desempenho, design e } \\
\text { elementos de boas práticas de DP. }\end{array}$ \\
\hline $\begin{array}{l}\text { Pandey e } \\
\text { colaboradores } \\
\quad(2019)\end{array}$ & $\begin{array}{l}\text { "Four decades of new } \\
\text { product development } \\
\text { research: an integrative } \\
\text { review" }\end{array}$ & $\begin{array}{l}\text { Revisão } \\
\text { sistemática da } \\
\text { literatura }\end{array}$ & $\begin{array}{l}\text { Principalmente tendências e características } \\
\text { comuns das publicações, em especial suas } \\
\text { perspectivas (consumidor, organização e } \\
\text { estratégia) e as dimensões a elas associadas. }\end{array}$ \\
\hline
\end{tabular}

Fonte: dados da pesquisa baseados em Pandey e colaboradores (2019)

O DP tem sido uma área crescente de pesquisa interdisciplinar desde a década de 1970 (Page \& Schirr, 2008; Pandey et al., 2019). Pandey e colaboradores (2019) selecionaram publicações entre 1976 e 2017 . Os pesquisadores verificaram que aproximadamente $62 \%$ dos artigos (236 de 381) sobre DP foram publicados entre 2005 e 2017. Assim, concluíram que a pesquisa sobre o DP evoluiu significativamente e, em especial, nas duas últimas décadas.

Com o objetivo de identificar características comuns das pesquisas e características da evolução teórica do desenvolvimento de novos produtos, Griffin e Hauser (1996) e Pandey e colaboradores 
(2019) identificaram algumas das linhas de pesquisas e exemplos de publicações relacionadas a elas, as quais são retratadas na Tabela 2 a seguir.

Tabela 2 - Temas de pesquisa sobre o desenvolvimento de produtos e publicações relacionadas

\begin{tabular}{|c|c|}
\hline Tema da pesquisa & Autores \\
\hline $\begin{array}{c}\text { Desempenho do DP e } \\
\text { fatores influenciadores }\end{array}$ & $\begin{array}{c}\text { Chen, Damanpour, \& Reilly, 2010; Ernst, 2002; Henard \& Szymanski, 2001; } \\
\text { Montoya-Weiss \& Calantone, 1994; Pattikawa, Verwaal, \& Commandeur, } \\
\text { 2006; Poolton \& Barclay, 1998; Rubenstein, Chakrabarti, O'Keefe, Souder, \& } \\
\text { Young, 1976 }\end{array}$ \\
\hline $\begin{array}{c}\text { Interdisciplinaridade no } \\
\text { DP }\end{array}$ & $\begin{array}{c}\text { S. L. Brown \& Eisenhardt, 1995; Griffin \& Hauser, 1996; Moenaert \& Souder, } \\
1990\end{array}$ \\
\hline Decisões de DP & Garcia \& Calantone, 2002; Krishnan \& Ulrich, 2001 \\
\hline
\end{tabular}

Fontes: Griffin e Hauser (1996) e Pandey e colaboradores (2019)

Formas de caracterização e de classificação do DP são ferramentas que ajudam no planejamento estratégico do portfólio da empresa com vistas a assegurar os recursos necessários para gerenciar e executar os vários projetos, conseguir eficiência nas atividades realizadas e obter um padrão adequado de inovação dos produtos (Rozenfeld et al., 2006). Uma forma de classificação muito referenciada é baseada no grau de mudanças que o projeto representa em relação a projetos anteriores, ou seja, em relação aos produtos e em relação aos processos. A Figura 3 traz a classificação de projetos de desenvolvimento elaborada por Wheelwright e Clark (1992).

Figura 3 - Classificação de projetos de desenvolvimento com base nas mudanças em produtos e em processos

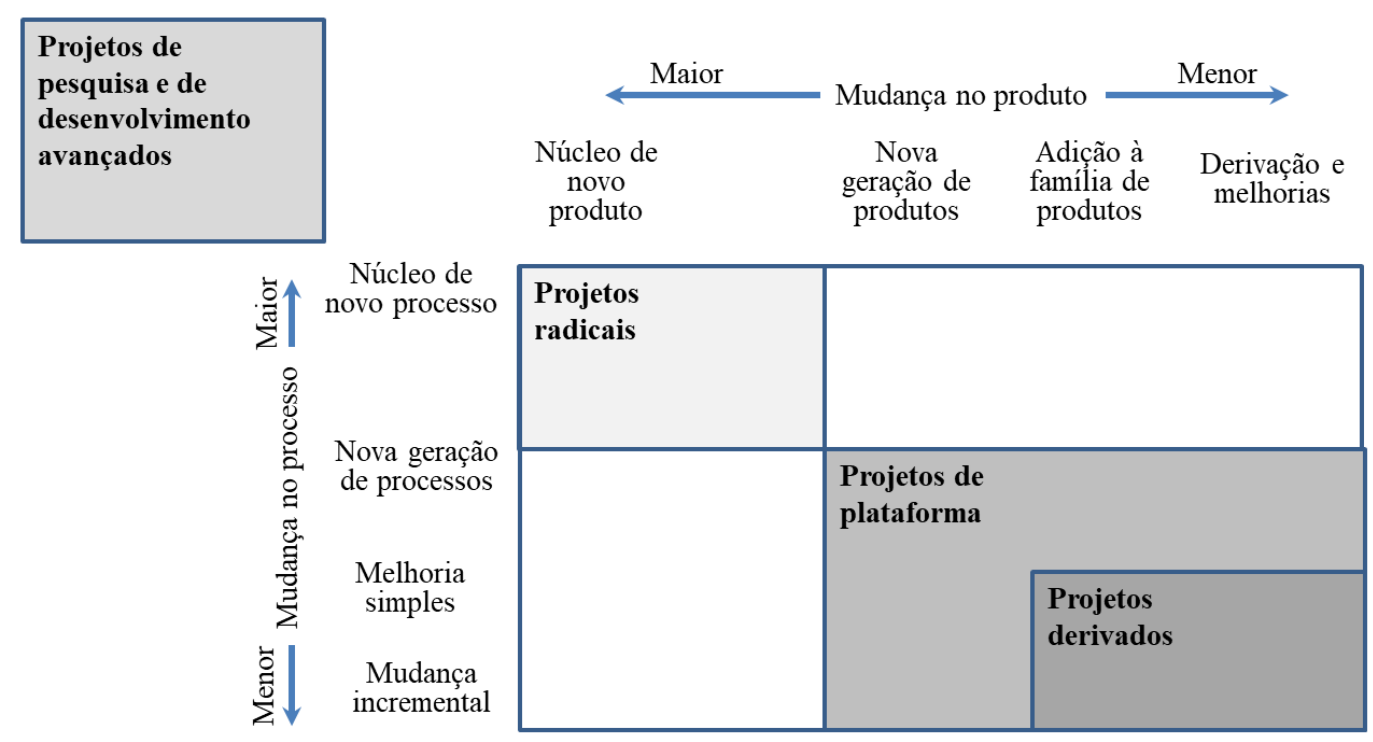

Fonte: reproduzido e traduzido de Wheelwright e Clark (1992, p. 4).

As classes de projetos consideradas na matriz elaborada por Wheelwright e Clark (1992) são:

- Projetos de pesquisa avançada: objetivam a criação de conhecimento para futuros projetos normalmente com fins comerciais, mas não no curto prazo;

- Projetos radicais ("breakthrough"): envolvem modificações significativas no produto ou no processo existente. Podem criar uma nova categoria ou família de produtos com a 
incorporação de novas tecnologias e materiais que normalmente requerem um processo de manufatura também inovador;

- Projetos de plataforma ou de próxima geração: envolvem alterações significativas no produto e/ou no processo, mas sem significar a introdução de novas tecnologias ou materiais. Podem representar: um novo sistema de soluções para o cliente em uma próxima geração de um produto ou de uma família de produtos já existentes; uma estrutura básica do produto que seria comum entre os diversos modelos que compõem uma família de produtos; ou ainda funcionar como plataforma, ou seja, um projeto que irá dar suporte a toda uma geração de produto (ou de processo) com ligações com as gerações anteriores e posteriores do produto;

- Projetos incrementais ou derivados: são considerados nesta classe os projetos que criam produtos e processos que são derivados, híbridos ou com pequenas modificações em relação aos projetos já existentes e, por esta razão, em geral, requerem menos recursos. Alguns exemplos são: versões de redução de custo de um produto e projetos com inovações incrementais nos produtos e processos.

Rozenfeld e colaboradores (2006) consideram que o Brasil teria uma classe diferenciada para os seus processos de DP, ou seja, os projetos que chamariam de "follow-source" (na língua portuguesa, seguir a fonte). Nesta classe estão os projetos que não requerem desenvolvimentos e/ou alterações significativos, mas apenas adequações do produto que chegam da matriz ou de outras unidades do grupo. Essas adequações seriam adaptações à realidade local e a validação do processo e de equipamentos e ferramentas.

Outra forma de classificação de projetos de DP é baseada no escopo da nova tecnologia ou de mudanças na plataforma e de quão rápido a empresa transfere a plataforma de um projeto para outro. Assim, a combinação entre escopo e rapidez de transferência definiriam a classificação do projeto em quatro tipos (Rozenfeld et al., 2006):

- Novo projeto: desenvolvimento de nova plataforma tecnológica;

- Transferência de tecnologia simultânea: um novo projeto utiliza a plataforma de um projetobase ainda em desenvolvimento;

- Transferência de tecnologia sequencial: um novo projeto utiliza a plataforma de um projetobase concluído e já em fase de produção;

- Modificação de projeto: não há transferência de tecnologia ou de plataforma de um projeto para outro. O projeto consiste em modificações em projeto existente, mas sem que haja mudança na plataforma.

Os projetos de novos produtos podem ser classificados também considerando se são novos para a empresa e/ou novos para o mercado. Os projetos novos para a empresa são aqueles nos quais os produtos já existem no mercado, mas que ainda não fazem parte do portfólio da empresa. 
Por fim, baseados na tipologia de projetos de DP proposta por Booz, Allen e Hamilton (1982), Griffin e Page (1996) estudaram as possíveis estratégias caracterizadas pela combinação entre a novidade no mercado e a novidade do produto para a empresa. A Figura 4 dispõe a matriz que representa esta combinação cujos cruzamentos dão origem a seis categorias de estratégias:

- Novo no mercado ou no mundo - novos produtos que criam um mercado totalmente novo;

- Novo na empresa - novos produtos que, pela primeira vez, permitem que uma empresa entre em um mercado estabelecido;

- Adições a linhas de produtos existentes - novos produtos que complementam as linhas de produtos estabelecidas de uma empresa;

- Melhorias / Revisões de produtos existentes - Novos produtos que oferecem melhor desempenho ou maior valor percebido e substituem os produtos existentes;

- Reposicionamentos - Produtos existentes voltados para novos mercados ou segmentos de mercado;

- Reduções de custo - Novos produtos com desempenho semelhante, mas a um custo menor.

Figura 4 - Tipologia de estratégias de projetos de DP na relação empresa "versus" mercado

Novidade para o mercado

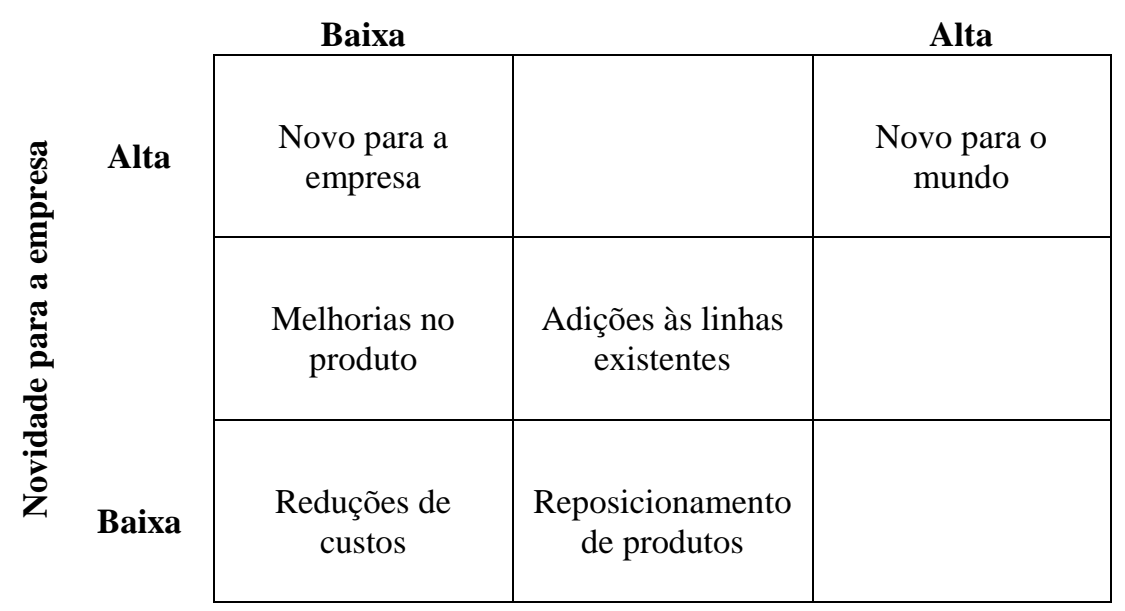

Fonte: Griffin e Page (1996, p. 489).

De acordo com Griffin e Page (1996), esta tipologia forneceria uma abordagem intermediária entre o conjunto de variáveis estratégicas proposto por Cooper (1985), o qual consideravam complexo, e o conjunto de categorias definidas por Clark e Wheelwright (1993), que também não utilizaram por julgarem excessivamente focada em tecnologia. No entanto, incorporam os fatores mais significativos das três dimensões de sucesso investigadas por Cooper (1985), ou seja, o desempenho geral, a taxa de sucesso e o impacto. 
Complementarmente, com intuito de relacionar as estratégias utilizadas pelas empresas com o foco dado ao desenvolvimento de produtos, Griffin e Page (1996) adotaram a tipologia desenvolvida por Miles, Snow, Meyer e Coleman (1978) que divide as empresas em quatro categorias:

- Prospectores: buscam ser os "primeiros" em novos produtos, mercados e tecnologias, mesmo à custa da lucratividade de curto prazo. Procuram desenvolver produtos mais inovadores e respondem rapidamente a sinais precoces de oportunidades;

- Analistas: são mais imitativos do que inovadores. Raramente são os primeiros a comercializar novos produtos. Monitoram com cuidado as ações dos principais concorrentes em busca de oportunidades para lançar rapidamente no mercado produtos mais competitivos;

- Defensores: tentam localizar e manter um nicho seguro em uma área de serviço ou produto relativamente estável. Eles protegem seu domínio por meio da oferta de maior qualidade, serviço superior e/ou preços mais baixos. Também investem em extensões de linha que forneçam penetração adicional no mercado;

- Reagentes: respondem apenas quando sofrem fortes pressões ambientais. Adotam com frequência estratégias inconsistentes ao longo do tempo com o desenvolvimento do produto variando em resposta às demandas do mercado.

Em outra publicação no mesmo ano, Griffin e Hauser (1996) escrevem que as incertezas do projeto são afetadas pelas características do mercado (clientes e concorrentes) e da tecnologia (técnicos e de recursos). Em relação ao mercado, a incerteza seria mais baixa (a certeza é mais alta) para um projeto de DP cujo objetivo é atender a um conjunto de necessidades dos clientes atuais e que já são conhecidos pela empresa. O nível de incerteza se elevaria quando o conjunto de necessidades é expandido para um novo conjunto de clientes. O nível mais elevado de incerteza seria atingido quando o DP busca o atendimento de um novo conjunto de necessidades para um novo conjunto de clientes.

Já em relação à tecnologia, a incerteza seria mais baixa em um projeto de DP que busca apenas o desempenho do produto, mantendo-se as mesmas tecnologias de processo. As incertezas aumentariam quando há a incorporação de tecnologias não usadas anteriormente nos produtos, mas que já são conhecidas pela empresa. As incertezas aumentariam mais quando há a incorporação de tecnologias não utilizadas pela empresa, mas que outras empresas já a empregam. Por fim, o nível mais elevado de incerteza tecnológica ocorreria quando a empresa deve desenvolver tecnologias completamente novas (Griffin \& Hauser, 1996).

Estas análises como a de Griffin e Hauser (1996), Griffin e Page (1996), Rozenfeld e colaboradores (2006) e Wheelwright e Clark (1992) são formas para caracterização do DP que facilitam a compreensão de sua natureza e a identificação de estratégias para seu desenvolvimento, uma vez que, conforme comentam Rozenfeld e colaboradores (2006), a gestão do processo de DP é considerada complexa em razão: da natureza dinâmica desse processo; da grande interação com as 
demais atividades e funções da empresa e com a cadeia de suprimentos; e da quantidade e diversidade das informações de natureza econômica e tecnológica envolvidas no processo. Salgado e Dekkers (2018) consideram que em geral o DP deve ser considerado em um contexto mais amplo que cubra a estratégia corporativa de desenvolvimento e marketing de produtos, incluindo modelos de negócios, estratégia competitiva, recursos humanos e desempenho de processos. Rozenfeld e colaboradores (2006), por sua vez, acreditam que as frequentes mudanças nos requisitos dos clientes, nas tecnologias disponíveis e nas regulamentações que se aplicam aos produtos também resultam em complexidade. Outros fatores estariam relacionados à própria natureza dinâmica do processo iterativo de DP.

Sobre o Brasil, Rozenfeld e colaboradores (2006) consideram que as atividades de DP se concentram em adaptações e melhorias de produtos existentes (exemplos: automóveis, equipamentos eletrônicos e produtos farmacêuticos), sendo que os produtos inovadores tenderiam a ser concebidos e projetados nos países desenvolvidos, onde estão localizados os centros de desenvolvimento das corporações multinacionais.

Rozenfeld e colaboradores (2006) também ressaltam, no entanto, que mesmo que a tecnologia e a concepção de um novo produto venha do exterior, ainda assim existem muitas atividades de desenvolvimento que estão inseridas no escopo do desenvolvimento de produtos e que fazem parte das responsabilidades das filiais locais. Entre elas eles citam: o projeto detalhado, o projeto ou planejamento do processo, os testes necessários, o projeto de fábrica e o lançamento, entre outros.

\subsubsection{Processo de desenvolvimento de produtos}

A natureza do processo de DP é relativamente diferente dos demais processos de uma empresa, o que condiciona seus modelos e práticas de gestão, além do perfil e das capacitações requeridas dos profissionais que nele atuam. O DP é constituído por um fluxo de atividades e de informações que tem por objetivo produzir um novo bem ou serviço. Esta visão permite compreender as ligações entre as áreas da empresa e desta com o mercado, os fornecedores, as fontes de informação tecnológica e os órgãos de regulamentação do produto. O processo de DP também envolve a integração de todas as atividades internas à empresa e destas com as cadeias de suprimentos e de distribuição. O processo de DP deve realizar a tradução das necessidades do mercado, das oportunidades tecnológicas e das estratégias da empresa em informações para todo o ciclo de vida do produto, que é composto pela produção, distribuição, uso, manutenção e descarte do produto (Rozenfeld et al., 2006).

Assim, o desenvolvimento de produto envolve atividades a serem executadas por profissionais de diferentes áreas da empresa e com diferentes perspectivas, tais como: Marketing, Pesquisa \& Desenvolvimento, Engenharia do Produto, Suprimentos, Manufatura e Distribuição. Esta característica faz com que seja necessário que as atividades e as decisões do processo de DP sejam realizadas em conjunto e de forma integrada (Rozenfeld et al., 2006). 
As descrições do processo de DP mais frequentemente encontrados na literatura muito se assemelham à forma como o PMI (2004) descreve as fases do desenvolvimento de um projeto e que se utiliza do conceito dos macroprocessos do ciclo PDCA ("Plan, Do, Check and Act", em português, planeje, faça, verifique e aja), ou seja, iniciação, planejamento, execução, monitoramento e controle e encerramento. Rozenfeld e colaboradores (2006), por exemplo, descrevem o DP por meio de uma sequência formada pelos processos Projetar-Construir-Testar-Otimizar e que se relacionam iterativamente. Assim, tal como os projeto em geral (PMI, 2017), o processo de DP, de acordo com Rozenfeld e colaboradores (2006), possui as seguintes características:

- elevado grau de incertezas e riscos das atividades e resultados;

- decisões importantes devem ser tomadas no início do processo, quando as incertezas são ainda maiores;

- dificuldade de mudar as decisões iniciais;

- as atividades básicas seguem um ciclo iterativo do tipo: Projetar (gerar alternativas)Construir-Testar-Otimizar;

- muito baseado em informações cujo volume de entrada, de informações processadas e repassadas é relativamente alto, variado e complexo;

- as informações e atividades provêm de diversas fontes e áreas da empresa e da cadeia de suprimentos;

- multiplicidade de requisitos a serem atendidos pelo processo, considerando todas as fases do ciclo de vida do produto e seus clientes.

Rozenfeld e colaboradores (2006) destacam que processos mais coesos, nos quais o planejamento, a execução e o acompanhamento do produto pós-venda estão integrados como em um ciclo, permitem que seja gerenciada e garantida a retroalimentação rápida e contínua dos dados e das informações sobre o desempenho do produto e sobre os requisitos dos clientes, da sociedade e dos órgãos de regulamentação. De uma forma geral, o desenvolvimento de produtos deve considerar:

- o planejamento e gerenciamento do portfólio de produtos (produtos já no mercado, sendo lançados e em fase de descontinuidade);

- o planejamento e gerenciamento do portfólio de projetos (em fase de planejamento, em andamento e concluídos);

- a especificação de todos os recursos e procedimentos de manufatura (máquinas, equipamentos, ferramentas e eventual construção de novas unidades de produção);

- as informações e serviços associados ao seu uso e manutenção (garantia da qualidade de todos os itens e informações);

- a integração do processo com as funções e outros processos empresariais envolvidos na realização de atividades ou suprimento de informações para o DP; 
- o planejamento estratégico do produto com orientações sobre as estratégias tecnológicas (tecnologia do produto, fontes para aquisição da tecnologia e "timing" para introdução das inovações tecnológicas) e as estratégias de produto (linhas de produto, segmentos de mercado, canais de distribuição, características competitivas dos produtos, etc.).

O processo de DP pode ser representado e ter como referência um modelo no qual são indicados: atividades e seus responsáveis, resultados ou entregas esperadas, recursos necessários, ferramentas de suporte e as informações necessárias e ou geradas pelo processo. Além de estruturar e padronizar os processos de DP, os modelos de referência podem: estabelecer uma base comum para o gerenciamento do desenvolvimento, facilitar o entendimento e a comunicação entre as pessoas; e facilitar a integração de métodos, técnicas e sistemas de apoio (Hinckeldeyn, Dekkers, \& Kreutzfeldt, 2010; Rozenfeld et al., 2006).

Representando uma visão mais frequente na literatura, o modelo apresentado na Figura 5 foi elaborado por Rozenfeld e colaboradores (2006) e é voltado principalmente para empresas de manufatura de bens de consumo duráveis e de capital, sendo dividido em macrofases, as quais são subdivididas em fases e atividades. As macrofases deste modelo são: pré-desenvolvimento, desenvolvimento e pós-desenvolvimento.

Figura 5 - Modelo geral do processo de desenvolvimento de produtos

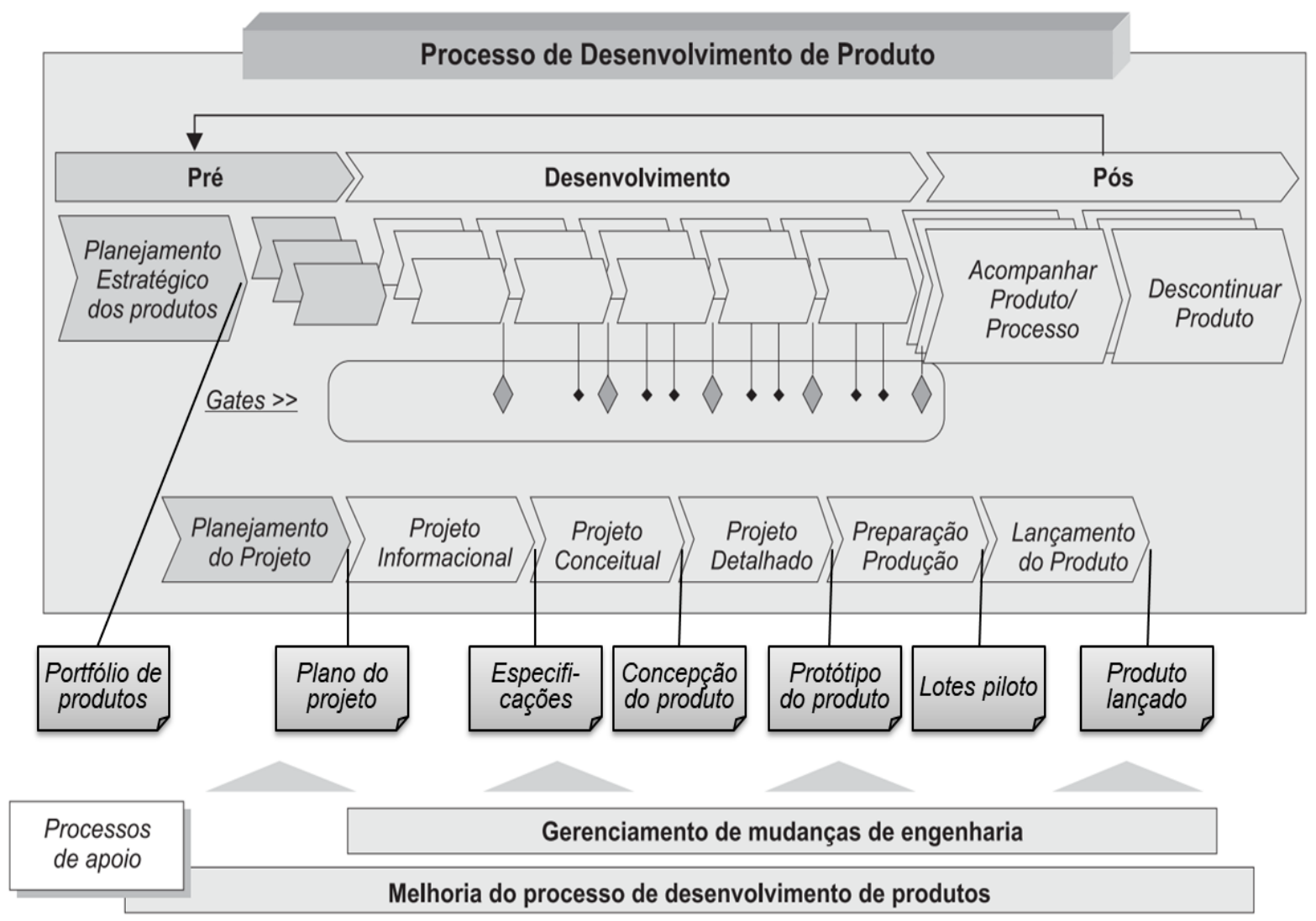

Fonte: adaptado de Rozenfeld e colaboradores (2006, pp. 44 e 47). 
O que determina uma fase é a produção de um conjunto de resultados ou entregas (“deliverables” na língua inglesa). Estas entregas são avaliadas e, se consideradas satisfatórias e aprovadas, o processo de DP progride para uma nova fase. A avaliação dos resultados de uma fase serve também como um marco ("milestone" na língua inglesa) no qual a situação do projeto é confrontada com o planejado. A definição de uma fase está relacionada com o conceito de "gate" (portão na língua portuguesa), quando há uma avaliação do andamento do projeto e a decisão de prosseguimento ou suspensão e/ou abandono do projeto. Este conceito será tratado com mais detalhes na seção sobre as abordagens de gerenciamento do DP.

A macrofase de pré-desenvolvimento do modelo de Rozenfeld e colaboradores (2006) é composto pelas fases de planejamento estratégico dos produtos e de planejamento do projeto. A primeira fase teria como objetivo garantir a melhor decisão sobre o portfólio de produtos e projetos, respeitando a estratégia da empresa e as restrições e tendências mercadológicas e tecnológicas.

A correta definição e priorização dos projetos possibilita que a empresa canalize seus esforços de desenvolvimento nos produtos com maior potencial para atingir os resultados esperados, mas com riscos aceitáveis de perdas. Assim, os principais resultados do planejamento estratégico dos produtos seriam: a descrição preliminar de cada um dos produtos que serão desenvolvidos e as datas de início de desenvolvimento e de lançamento. A organização também deverá destacar um profissional para analisar e começar o planejamento específico. Neste momento é que o PMI (2017), por exemplo, considera ter sido iniciado o projeto.

A fase seguinte de planejamento do projeto teria como objetivo principal o detalhamento do escopo do produto e o planejamento macro do projeto, o qual pode ser composto pelos seguintes conjuntos de informações também produzidos nesta fase: escopo do projeto, atividades e durações, prazos, orçamento, plano de recursos necessários para realizar o projeto, especificação dos critérios e procedimentos para avaliação da qualidade, normas que precisam ser atendidas, plano de riscos, plano de comunicação, plano de engajamento das partes interessadas e indicadores de desempenho para o projeto e suas entregas (PMI, 2017; Rozenfeld et al., 2006). O plano de desenvolvimento do produto seria então submetido à análise para decisão sobre o prosseguimento do projeto para a próxima fase (Rozenfeld et al., 2006).

A macrofase seguinte, denominada desenvolvimento do produto ou projeto do produto, está no centro do modelo de referência de DP e tem por foco as definições tecnológicas do produto, de suas características e da forma de sua produção. Para Rozenfeld e colaboradores (2006), ela deve entregar informações técnicas detalhadas para a produção e comercialização dos produtos. Em suas fases componentes, esta macrofase pode: produzir protótipos e aprovar, definir e prover os recursos a serem 
utilizados para a sua produção, comercialização e suporte técnico; produzir e aprovar lotes-piloto dos produtos; lançar o produto no mercado; e prover treinamentos tanto internos quanto para terceiros que participem da cadeia de suprimentos e da comercialização dos produtos.

A macrofase de desenvolvimento é composta pelas seguintes fases descritas a seguir (Rozenfeld et al., 2006):

- Entendimento do plano do projeto (elaborado na fase anterior) - envolve a identificação das partes envolvidas em todo o ciclo de vida do produto e o levantamento das necessidades e requisitos;

- Projeto informacional - a partir do plano do projeto, há a definição das especificações do produto para estabelecimentos das estruturas funcionais do produto que atenderão os requisitos identificados. O projeto informacional também pode incluir a definição de alternativas de solução construtiva e tecnológica que serão selecionadas com base no atendimento às especificações técnicas;

- Projeto conceitual - soluções de projeto são geradas e estudadas detalhadamente até que seja estruturada uma solução capaz de atender às especificações concebidas na fase anterior. Há então o detalhamento das informações técnicas que inclui a definição dos sistemas, subsistemas e componentes do produto. As soluções de projeto são resumidas em um conjunto de documentos denominado concepção do produto, o qual é utilizado na avaliação de sua viabilidade econômico-financeira. Wheelwright e Clark (1992) incluem nesta fase o desenvolvimento do desenho (“design”) conceitual e a descrição do mercado-alvo;

- Projeto detalhado - envolve o processo de projetar-construir-testar-otimizar o produto em ciclos de cálculos e desenhos detalhados e otimizações para a definição das especificações finais. Pode incluir um projeto de recursos (dispositivos e ferramentas) e até a homologação de protótipos do produto. Também inclui o processo de organização das informações, produção de materiais e elaboração de sistemas de apoio, além do planejamento do lançamento do produto no mercado. Em algumas organizações também é elaborado o plano de fim de vida com as condições para a descontinuidade e a reciclagem dos produtos. Wheelwright e Clark (1992) descrevem esta fase como ciclo desenho-construção-teste.

- Preparação para produção - nesta fase os processos de manufatura são definidos e descritos na forma de procedimentos, fluxos de atividades, especificações das máquinas e das ferramentas e métodos de produção. Para avaliação dos procedimentos e especificações, podem ser manufaturados lotes piloto do produto. A aprovação dos lotes piloto e eventual certificação significa que a empresa é capaz de fabricar os produtos com as mesmas características do protótipo e de acordo com os requisitos e especificações requeridos. Também pode haver a homologação da produção. 
Terminada a macrofase de desenvolvimento e lançamento do produto, a responsabilidade por ele é transferida para a área de produção, pois inicia-se a sua produção e comercialização por meio de outros processos de negócio da empresa, assim como de outras áreas. Neste momento ocorre a dissolução da equipe do projeto, o que para os pesquisadores seria uma perda da oportunidade de aprendizado e de compartilhamento dos conhecimentos adquiridos com o desenvolvimento.

O acompanhamento sistemático e a documentação referente às melhorias de produto ocorridas durante o seu ciclo de vida são considerados atividades centrais do pós-desenvolvimento. Assim, neste ponto, não cessariam as responsabilidades da área de desenvolvimento ou engenharia, uma vez que pode haver a necessidade de mudanças para aprimorar ou reparar defeitos nos produtos. Complementarmente, também pode haver participação em serviços de assistência técnica e de atendimento ao cliente, além de demandas para eventual descontinuação ou retirada do produto do mercado. Em alguns setores, o pós-desenvolvimento pode ser uma obrigação legal (Rozenfeld et al., 2006), como no caso dos medicamentos (Anvisa, 2019f).

Dekkers, Chang e Kreutzfeldt (2013) realizaram uma revisão sistemática da literatura sobre a interface entre o design e engenharia de produtos e a produção. O termo "design e engenharia de produtos" é usado pelos autores também, onde apropriado, como sinônimo de desenvolvimento de novos produtos. Eles criticam os estudos realizados até então em razão deles terem como foco a eficácia do desenvolvimento de novos produtos, deixando em segundo plano a sua eficiência. Além disso, consideraram também que poucos trabalhos abordaram a interação entre o conjunto design do produto, gerenciamento da engenharia e o gerenciamento da produção. Os trabalhos encontrados em sua revisão da literatura, em geral tratavam de questões específicas ou de casos específicos ${ }^{2}$.

Para os pesquisadores, os gerentes responsáveis pelo desenvolvimento e engenharia de novos produtos precisam ter uma visão mais ampla do processo de DP, o qual necessita estar vinculado aos processos de engenharia e manufatura. Assim, para fundamentar a pesquisa que realizaram, Dekkers e colaboradores (2013) combinaram as abordagens da teoria de sistemas e adaptaram a estrutura de Hinckeldeyn e colaboradores (2010) para desenvolver o modelo genérico representado na Figura 6.

2 Dekkers, Chang e Kreutzfeldt (2013, pp. 318-320) apresentam um quadro com dados das principais referências encontradas 
Figura 6 - Modelo de referência genérico para processos de engenharia, fabricação e implantação.

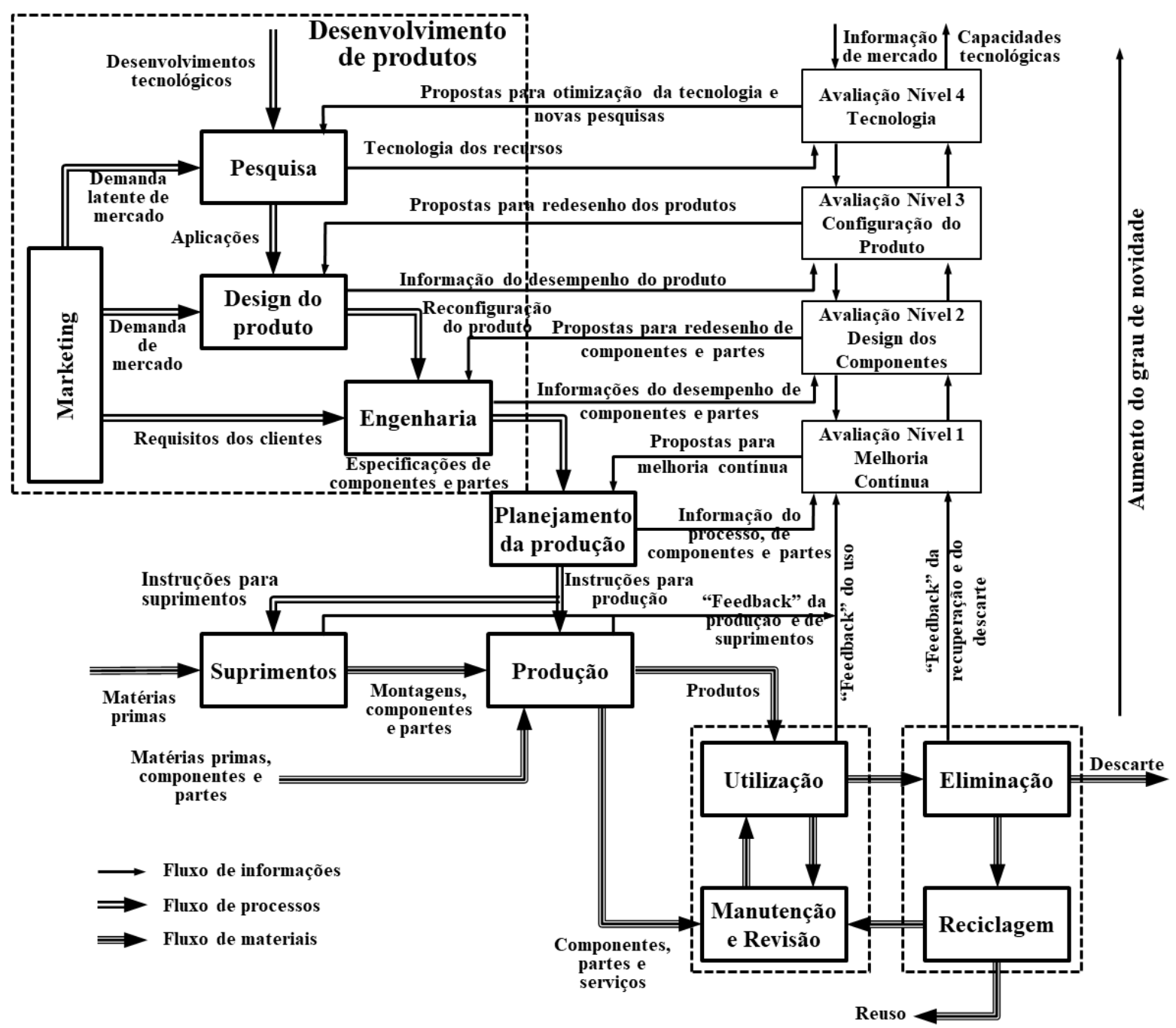

Fonte: adaptado de Dekkers e colaboradores (2013, p. 321) e Hinckeldeyn e colaboradores (2010, p. 2).

O modelo adotado por Dekkers e colaboradores (2013) consiste em: (i) processo primário de engenharia, incluindo desde as atividades de pesquisa até as de engenharia de produção, (ii) processo primário de fornecimento, produção, manufatura e o uso do produto (implantação, serviço e descarte) e (iii) "feedback" do processo principal para as atividades de engenharia.

Em uma visão sistemática da transformação da demanda do mercado e dos requisitos do cliente em instruções e especificações de produtos, processos ou sistemas, o modelo de referência para o processo primário de engenharia representado na Figura 6 pode ser dividido em diferentes estágios ou processos: marketing (compreensão dos requisitos dos clientes e da demanda de mercado); pesquisa (P\&D e inovação); "design" de produto e de processos ("design" do produto); processos de engenharia (engenharia); fornecimento de matérias-primas, componentes e partes (suprimentos); processo de 
produção e suporte (produção); e implantação / aplicação, serviço e disponibilização ou descarte (utilização, manutenção e revisão e reciclagem e eliminação). A manufatura de um produto ou serviço começaria com o fornecimento de materiais, progredindo para o ciclo de vida do produto, incluindo o serviço, e finalmente terminaria com o descarte. Basicamente, pode-se entender que as atividades de engenharia (processos de pesquisa, "design" do produto e engenharia) do modelo da Figura 6 equivalem às atividades de DP.

Paralelamente a esses processos, também estão representadas na Figura 6 as atividades de análise de dados e resultados dos processos e retroalimentação ("feedback") com identificação de oportunidades de melhorias e/ou de inovações. Estas atividades foram agrupadas em níveis de acordo com os processos de desenvolvimento aos quais se relacionam, ou seja:

- Avaliação Nível 1 - Melhoria Contínua que analisa os dados e propõem melhorias ao processo de planejamento da produção;

- Avaliação Nível 2 - Design dos Componentes que analisa os dados e propõem melhorias ao processo de Engenharia;

- Avaliação Nível 3 - Configuração do Produto que analisa os dados e propõem melhorias ao processo de Design do Produto;

- Avaliação Nível 4 - Tecnologia que por sua vez analisa os dados e propõe melhorias ao processo de Pesquisa.

Portanto, os processos de engenharia não apenas transformam os requisitos do cliente em informações para o processo primário de produção e desenvolvimento, mas também incorporam o "feedback" interno nos produtos e processos existentes. Hinckeldeyn e colaboradores (2010) verificaram que os níveis mais altos de processo (pesquisa) e avaliação (Nível 4 - Tecnologia) correspondem a um maior grau de inovação.

Ainda de acordo com a Figura 6, uma característica do relacionamento entre os processos de marketing, pesquisa, "design” de produto, engenharia, planejamento da produção e produção é que ele se dá por meio da troca de informações. O fluxo de informações também é característica das relações entre estes processos e seus respectivos conjuntos de atividades de análise (níveis). Diferentemente, o relacionamento entre os processos de produção (suprimentos, produção, utilização, manutenção e revisão e reciclagem e eliminação) tem por característica o fluxo de materiais.

Em termos de componentes ou fases e de seu sequenciamento, os modelos adotados por Dekkers e colaboradores (2013) e Hinckeldeyn e colaboradores (2010) (Figura 6) em comparação com o de Rozenfeld e colaboradores (2006) (Figura 5) podem ser considerados equivalentes. Embora o modelo da Figura 5 não detalhe os fluxos de informações entre as atividades, eles estão presentes nas descrições das fases que o compõem. O modelo de Dekkers e colaboradores (2013, p. 321) e Hinckeldeyn e colaboradores $(2010$, p. 2) dá destaque às decisões que são tomadas ao longo do 
processo e ao que denominam de avaliações em vários níveis. Rozenfeld e colaboradores (2006) tratam estas decisões como "gates" entre as fases do processo e que vão decidindo sobre a continuidade dos projetos. O conceito do chamado funil de desenvolvimento (Figura 7) apresentado por Wheelwright e Clark (1992) seria um exemplo do efeito das decisões sobre o portfólio ao longo do ciclo de vida dos projetos. Pela boca do funil entram as várias oportunidades ou propostas para desenvolvimento de novos produtos que, após processos de análises que incluem fatores técnicos e relacionados ao negócio, vão sendo selecionadas até que na ponta de saída são concluídos e lançados somente os produtos considerados de valor para a empresa.

Figura 7 - Funil de desenvolvimento

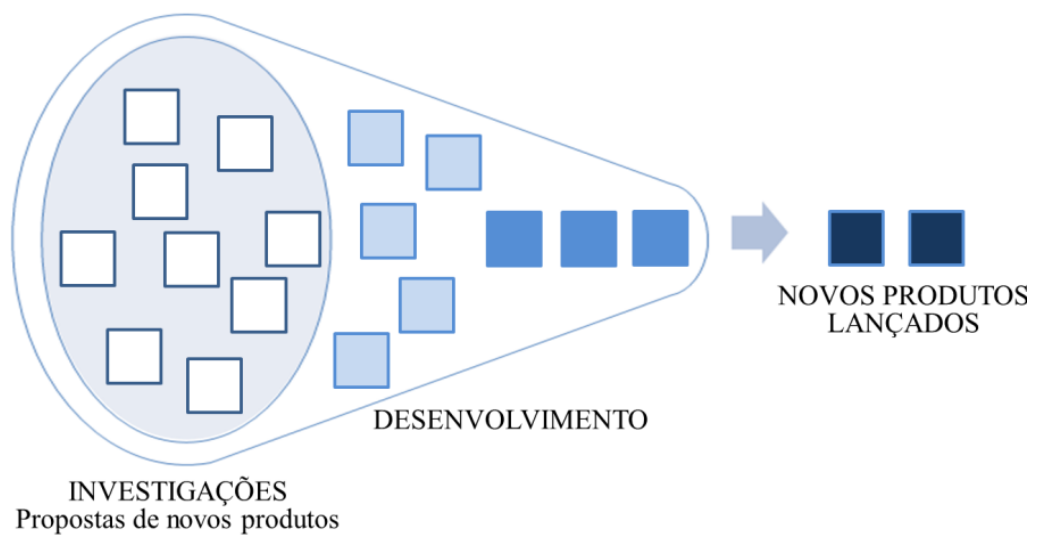

Fonte: adaptado de Wheelwright e Clark (1992, p. 112).

Um fator não considerado no modelo de Rozenfeld e colaboradores (2006) foi o grau de novidade do produto e/ou de seu processo de produção. No modelo de Dekkers e colaboradores (2013, p. 321) e Hinckeldeyn e colaboradores (2010, p. 2) foi considerada a novidade nos processos a montante como um fator que influenciaria a seleção das técnicas nos processos a jusante.

\subsubsection{Abordagens para o desenvolvimento de produtos}

A evolução da visão sobre o modo de gerenciamento do processo de DP caminhou com a evolução do modo de gestão geral das organizações. Basicamente, as várias abordagens para o DP possuem como objetivos o aumento de qualidade do produto com base nos requisitos e necessidades dos clientes; a diminuição do ciclo de desenvolvimento; e a redução dos custos. São três as abordagens de referência de DP: Desenvolvimento Sequencial, Engenharia Simultânea e Desenvolvimento Integrado do Produto (Rozenfeld et al., 2006). Em cada uma das abordagens de referência podem ser encontrados na literatura abordagens mais específicas, além de métodos, técnicas e ferramentas que complementam e/ou auxiliam as suas aplicações, como é apresentado a seguir.

\subsubsection{Desenvolvimento sequencial}

A abordagem do desenvolvimento de produtos denominado Engenharia Tradicional ou Desenvolvimento de Produtos Sequencial foi estabelecida com base: nos princípios da administração 
científica; na divisão de tarefas; na busca pela otimização e por recursos especializados; e na estruturação funcional das organizações. Nesta abordagem, as informações sobre o produto são definidas em uma ordem lógica de uma área funcional para outra e, assim, o projeto é desenvolvido entre os departamentos que possuem funções e responsabilidades específicas, com interação limitada entre eles. Há certa informalidade das atividades e procedimentos. O gerenciamento é baseado na experiência das pessoas e é diferente entre as áreas funcionais em razão de culturas e padrões de trabalho próprios (Rozenfeld et al., 2006).

Rozenfeld e colaboradores (2006) apontam como deficiências da abordagem de desenvolvimento sequencial de produtos: a dificuldade de compreensão mútua entre as áreas e de coordenação do projeto; os conflitos entre áreas funcionais para a resolução de problemas; a elevada turbulência; e a falta de contribuições efetivas. Ainda de acordo com os pesquisadores, foi neste mesmo movimento que se desenvolveram as metodologias de projeto e que tinham como proposta a racionalização das etapas, das atividades e o seu sequenciamento. Com elas se desenvolveu também o papel do gerente de projeto (GP) que tinha como objetivo cuidar do DP como um todo e ser um facilitador nas relações do projeto com as áreas. No entanto, o poder e influência dos esses profissionais ainda eram limitados e menores que os gerentes funcionais que podiam tomar a decisão final e que muitas vezes priorizavam as demandas de suas áreas.

Em relação ao ambiente do DP, Rozenfeld e colaboradores (2006) comentam que na década de 1990, as barreiras culturais envolvendo valores, procedimentos e padrões de cada uma das áreas dificultavam a integração, resultando na fragmentação do conhecimento e de informações sobre o andamento dos projetos. Os participantes dos projetos eram especializados e tinham acesso somente à atividade sob sua responsabilidade, em alguns casos sem noção das relações entre a sua parte e a dos demais participantes e sem uma visão compartilhada do ciclo de vida do produto. Outra característica da abordagem de desenvolvimento sequencial de produtos é a auto-suficiência dos departamentos de engenharia com os projetos sendo realizados quase inteiramente por profissionais da mesma empresa.

\subsubsection{Engenharia simultânea}

Na abordagem denominada engenharia simultânea, a estrutura organizacional passou a ser composta por equipes multifuncionais de projeto, muitas vezes liderados por um gerente de projeto chamado "peso pesado" por receber poderes superiores aos dos gerentes funcionais. Tem como uma de suas iniciativas a busca pelo aumento no grau de paralelismo entre as atividades de DP para evitar os tempos de espera para as análises e aprovações, já que considera que este tempo não agrega valor ao produto (Rozenfeld et al., 2006). O paralelismo em projetos é caracterizado pela realização simultânea de tarefas ou atividades que deveriam ser realizadas sequencialmente, uma vez que a atividade seguinte dependeria do término e/ou aprovação de sua atividade predecessora (PMI, 2017). 


\subsection{Sistema Stage-Gate ${ }^{\circledR}$}

Um sistema desenvolvido no mesmo período da engenharia simultânea foi o denominado sistema ou método Stage-Gate ${ }^{\circledR}$ (fase-portão em tradução livre para a língua portuguesa) desenvolvido por Robert G. Cooper (1990) como solução para a crescente pressão para redução do tempo do ciclo de DP e, ao mesmo tempo, melhorar a taxa de sucesso. O sistema Stage-Gate ${ }^{\circledR}$ é um modelo conceitual e operacional para mover um novo produto da ideia até o seu lançamento. Seu desenvolvedor cita como benefícios: trabalho em equipe aprimorado; menos reciclagem e retrabalho; melhores taxas de sucesso; detecção precoce de falhas; um melhor lançamento; e tempos de ciclo ainda mais curtos.

Conceitualmente, o sistema Stage-Gate ${ }^{\circledR}$ considera o desenvolvimento de novos produtos como um processo que pode ser administrado pela aplicação de métodos de gerenciamento. Analogamente ao processo de produção, o desenvolvimento de produtos é composto por fases ("stages") e entre estes há pontos de verificação da qualidade (“checkpoints" ou "gates"). Em cada um destes pontos há conjuntos de entregas ("deliverables") ou critérios de qualidade ou aceitação previamente definidos e que os resultados das fases devem atender antes de poderem passar para a próxima fase, onde há mais um conjunto de atividades a serem realizadas (Cooper, 1990). Um sistema Stage-Gate ${ }^{\circledR}$ típico é apresentado pela Figura 8 a seguir. Nela pode-se visualizar que a entrada para cada estágio é um "gate" que controla o processo.

Figura 8 - Sistema Stage-Gate ${ }^{\circledR}$ típico

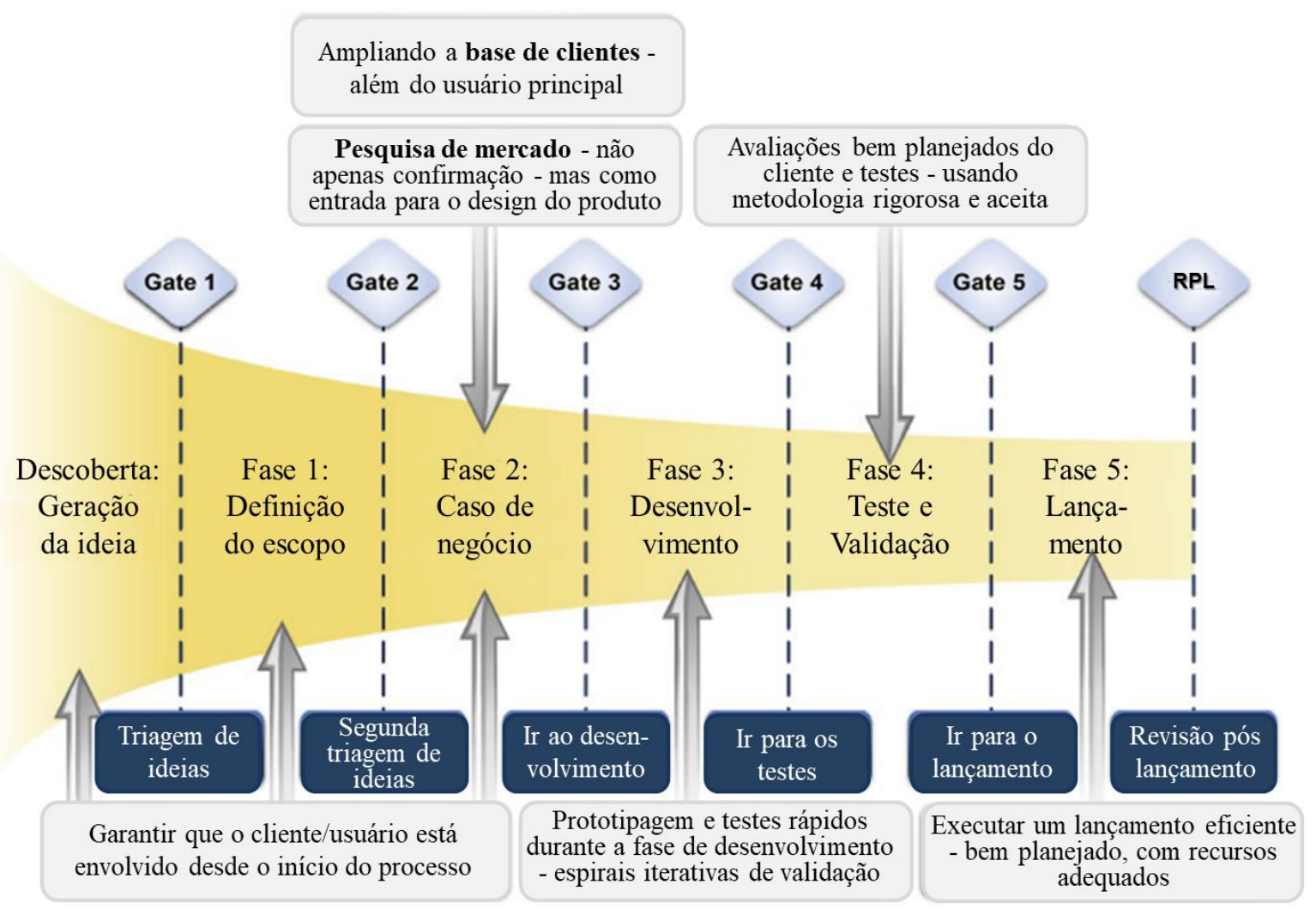

Fonte: reproduzido de Cooper (2019, p. 38). Tradução livre para a língua portuguesa. 
Cada "gate" é composto por um conjunto de entradas, um conjunto de critérios de saída e uma saída, também chamada de entrega ou produto. As entradas são as entregas que o responsável pelo projeto deve levar ao "gate" para avaliação em relação aos requisitos e critérios de aprovação ou aceitação da conclusão da fase. Uma lista de verificação com os critérios e um modelo de pontuação (escalas de classificação ponderada) pode ser usada para ajudar a focar a discussão e decidir sobre o encaminhamento do projeto. Se aprovado, tem-se a autorização para passagem e/ou início da fase seguinte. Assim, como resultado desta avaliação nos "gates", que normalmente é realizada por gestores em posição mais elevada, as possíveis decisões seriam: avançar/ terminar / aguardar / refazer ("go" / "kill" / "hold" / "recycle" na língua inglesa). A decisão pode envolver a aprovação de um plano de ação para o próximo estágio. É importante ressaltar que nem todos os projetos passam por todas as etapas do modelo. A aprovação para o projeto prosseguir inclui também o comprometimento dos recursos necessários (Cooper, 1990, 2019).

A perspectiva de negócio deve ser considerada nas avaliações do projeto para garantir que ele esteja sempre alinhado às estratégias da empresa, isso desde a definição do portfólio de produtos e projetos que seriam desenvolvidos. Esta perspectiva deve ser mantida em todos os "gates". Assim, o sistema de Stage-Gate ${ }^{\circledR}$, além de considerar conjuntamente os aspectos técnicos do produto, de gerenciamento do projeto e da situação do mercado, deve também avaliar o projeto de DP em relação aos demais produtos e projetos da empresa (Cooper, 1990; Rozenfeld et al., 2006).

O sistema mostrado na Figura 8 é um modelo genérico e bastante próximo do modelo geral do processo de desenvolvimento de produtos apresentado na Figura 5. É possível também compará-lo ao funil de desenvolvimento (Figura 7) proposto por Wheelwright e Clark (1992), uma vez que parte de uma ideia de novo produto que vai sendo avaliado no decorrer das fases do seu desenvolvimento e, eventualmente, abandonado caso não seja aprovado em um dos "gates".

Apesar das etapas na Figura 8 e atividades contidas nelas parecerem ser executadas sequencialmente, o processamento paralelo é uma característica importante do sistema Stage-Gate ${ }^{\circledR}$ (Cooper, 1990). Este paralelismo é usado por Rozenfeld e colaboradores (2006) para justificar a sua classificação entre os sistemas pertencentes à abordagem da engenharia simultânea. Outra característica do sistema Stage-Gate ${ }^{\circledR}$ destacada por (Cooper, 1990) é a de que cada fase é geralmente mais caro que a anterior, ao mesmo tempo em que as informações se tornam cada vez melhores e, portanto, as incertezas são reduzidas da mesma forma que os riscos. Estas características são próprias do ciclo de vida dos projetos em geral (PMI, 2013).

\subsection{Desenvolvimento enxuto de produtos}

Uma abordagem que tem sido frequente na literatura é a do chamado desenvolvimento enxuto (ou "lean" na língua inglesa) de produtos e que também é classificada no grupo da engenharia simultânea. Para Salgado e Dekkers (2018), esta abordagem incorpora ao DP os princípios do 
pensamento enxuto tais como a eliminação de resíduos e a busca de valor para os clientes. No entanto, os pesquisadores verificaram que nos estudos publicados até então, além dos princípios do pensamento enxuto, a abordagem do desenvolvimento enxuto estaria baseada em outras abordagens e modelos anteriores e em outros conceitos. Assim, concluiram que o conceito de desenvolvimento enxuto de produtos não seria nem único e nem novo. Concluem ainda que o pensamento enxuto aplicado ao DP não beneficiaria o desempenho geral em comparação a outras abordagens, mas comporia uma abordagem integral à racionalização do DP e contribuiria para o aprendizado organizacional, para redução ou eliminação de desperdícios e para a agregação de valor no processo de DP.

\subsubsection{Desenvolvimento integrado do produto}

Os projetos de DP tem tomado outras dimensões em razão das demandas de mercado e da evolução rápida das tecnologias. Portfólios mais complexos e extensos de projetos (multiprojetos) são mais comuns, podendo envolver o consórcio entre empresas e cujos produtos e a manufatura em unidades diferentes (multiplantas). As tecnologias de comunicação vêm permitindo que o DP, a produção e o suprimento aconteçam em redes de empresas. Por outro lado, aumentam os desafios de integração, comunicação e compatibilidade das decisões, já que os projetos estão mais complexos pelo número maior, mais diversificado e disperso de participantes (Rozenfeld et al., 2006).

Os modelos de DP tem tido que acompanhar estas mudanças para melhor responder a estes desafios, o que implica não só em novas abordagens, mas também em combinações entre as já existentes. Para Rozenfeld e colaboradores (2006), a era do desenvolvimento integrado do produto foi composta a partir das abordagens da engenharia simultânea, funil de desenvolvimento e Stage-Gate ${ }^{\circledR}$, que se desenvolveram quase simultaneamente, influenciaram umas às outras e compartilharam várias características.

\subsubsection{4 - Desenvolvimento ágil de produtos}

Os métodos ágeis foram introduzidos pelo chamado Manifesto Ágil ou "Agile” (Beck, et al., 2001) e inicialmente tinham por foco o desenvolvimento de softwares. De acordo com (Cooper, 2019), o desenvolvimento ágil é composto por um grupo de métodos baseados no desenvolvimento iterativo e incremental em que requisitos e soluções evoluem por meio da colaboração entre equipes multifuncionais e auto-organizadas. Os métodos ágeis promovem o planejamento adaptativo, desenvolvimento evolutivo e a entrega ao utilizarem uma abordagem iterativa com prazo determinado e incentivarem uma resposta rápida e flexível à mudança.

Em uma de suas versões do chamado Scrum, um projeto de desenvolvimento de software é executado em uma série de iterações chamadas "sprints" que desenvolvem e entregam produtos de trabalho em prazos muito curtos (uma etapa de desenvolvimento necessita em geral de 2 a 4 semanas) e que podem ser demonstrados às partes interessadas (etapa de teste). Cada iteração ou "sprint" 
desenvolve partes ou módulos do produto, não necessariamente adicionando funcionalidades suficientes para garantir um lançamento parcial no mercado, embora o objetivo possa ser esse. Assim, vários "sprints" podem ser necessários para liberar um produto ou novos recursos. Em seu modelo, os "sprints" tem início com uma reunião de planejamento. Durante os "sprints" são realizadas reuniões da equipe do projeto (também chamados de "scrums" diários). Os "sprints" terminam com uma demonstração do produto (para gestão e clientes) e uma retrospectiva do "sprint" (Cooper, 2019).

O desenvolvimento ágil pode ser aplicado ao desenvolvimento de produtos físicos, necessitando, porém, de alguns ajustes, uma vez que o projeto pode não ser tão divisível (as entregas podem tomar mais tempo para serem desenvolvidas). Assim, cada "sprint" não construiria uma parte ou módulo do produto em funcionamento, mas uma versão do produto entre um "produto virtual" e um "protótipo pronto para teste", ou seja, algo tangível que possa ser demonstrado ao cliente que deseja obter "feedback". Cooper (2019) destaca como vantagens desta abordagem: a velocidade ( "sprints" com prazos curtos e sem o relaxamento da linha do tempo); equipes dedicadas (os membros da equipe geralmente são dedicados a um único projeto); comunicação dentro da equipe (via "scrums" diários); e "feedback" constante do cliente (revisões e validações).

\subsubsection{5 - Desenvolvimento em espiral}

Cooper (2019) destaca o uso da abordagem do desenvolvimento espiral ou iterativo para projetos dinâmicos cujas informações são fluidas e variáveis. Por meio dele, são realizadas etapas iterativas pelas quais versões sucessivas do produto são apresentadas ao cliente ou usuário para buscar "feedback" e validação em um processo "Build-Test-Feedback-Revise" (na língua portuguesa, desenvolver-testar-avaliar-revisar) conforme mostrado pelas setas em espiral na Figura 9.

Figura 9 - Desenvolvimento em espiral com iterações "Build-Test-Feedback-Revise"

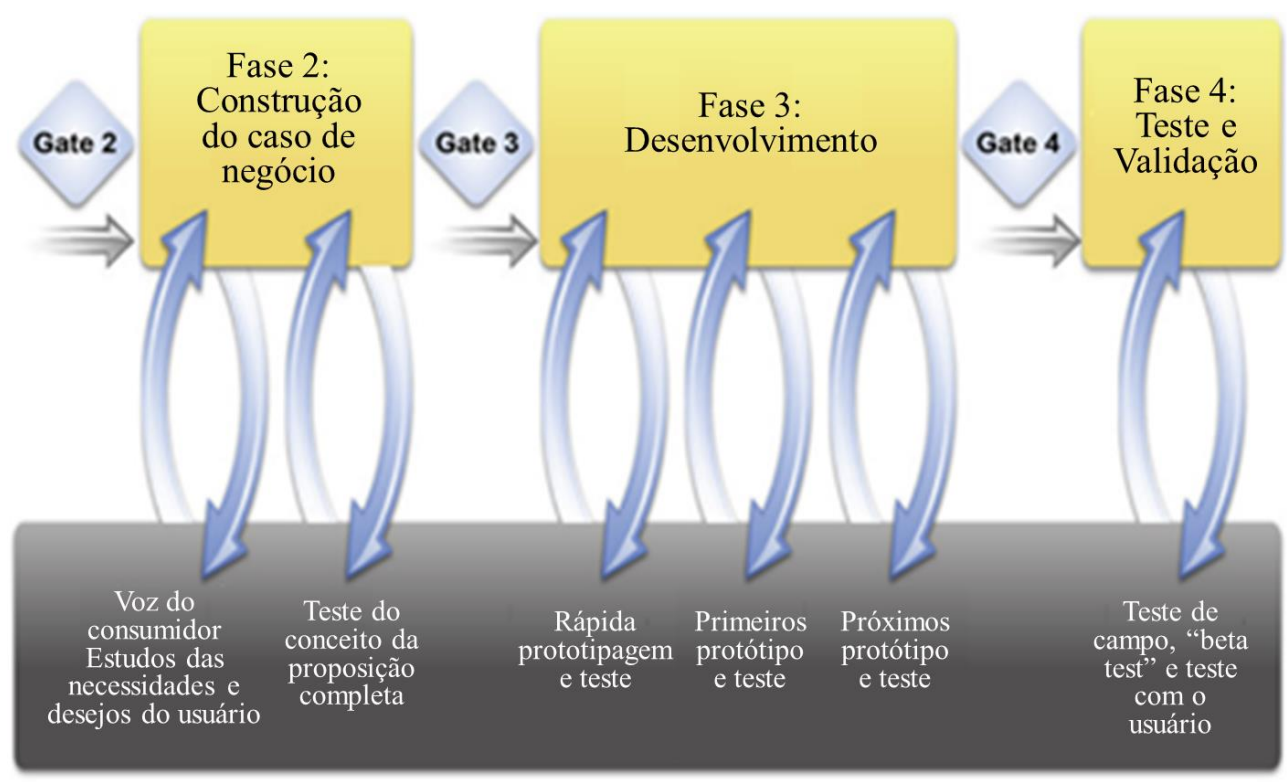

O consumidor ou usuário

Fonte: reproduzido de Cooper (2017, p. 77; 2019, p. 40). Tradução livre para a língua portuguesa. 
De acordo com Cooper (2019), cada iteração no desenvolvimento em espiral é composta pelas seguintes atividades:

- compilar (criar e apresentar ao cliente uma representação do produto. Podem ser gráficos gerados por computador, uma simulação, um protótipo, um modelo de trabalho, uma versão de testes e/ou o produto mínimo viável);

- testar (apresentar cada versão do produto para o cliente);

- avaliar (obter "feedback" do cliente ou usuário sobre essa versão do produto, o que gostaram ou não e o valor que percebem);

- revisar (se necessário, redefinir a proposta de valor, os benefícios procurados e o design do produto); e passar para a próxima iteração.

As vantagens desta abordagem estariam na promoção da experimentação, na identificação rápida de falhas e na redução das incertezas técnicas e de mercado. Os modelos e abordagens podem ser combinados formando sistemas híbridos. Por exemplo, um modelo pode ser composto tendo como base o Sistema Stage-Gate ${ }^{\circledR}$ ao qual são incorporados componentes do método enxuto e de desenvolvimento em espiral em cada uma de suas fases.

Outras abordagens encontradas na literatura para o DP são: plataformas de produtos (Meyer \& Utterback, 1992; Shamsuzzoha \& Kekale, 2010); modelos em cascata (Bassler, Oehmen, Seering, \& Ben-Daya, 2011; Bullinger, Fähnrich, \& Meiren, 2003); “Capability Maturity Model Integration” CMMI (integração de modelos de maturidade de capabilidade em tradução livre para a língua portuguesa) (Chrissis, Konrad, \& Shrum, 2011) e gestão do ciclo de vida de produtos (Hicks e McGovern, 2009).

Um aspecto importante sobre classificações e agrupamentos de modelos, métodos, técnicas, ferramentas e mesmo princípios de DP foi mencionado por Salgado e Dekkers (2018). Como muitos estudos ajustam ou complementam os modelos com um ou mais de seus elementos, ao alterar seus escopos acabam por dificultar a classificação do modelo estudado ou proposto e a sua comparação com outros modelos de DP. Assim, segundo os pesquisadores, o conteúdo instável e as diferentes interpretações do escopo não permitiriam a adequada avaliação sistemática de seus princípios.

As Tabelas 3 e 4 apresentam um síntese de algumas das abordagens e modelos mais frequentemente encontrados na literatura. 
Tabela 3 - Síntese das características dos modelos de desenvolvimento sequencial, de engenharia simultânea e de desenvolvimento integrado.

\begin{tabular}{|c|c|c|c|c|c|c|c|c|c|}
\hline \multirow{2}{*}{$\begin{array}{c}\text { Era da } \\
\text { gestão do } \\
\text { DP } \\
\\
\text { Exemplos } \\
\text { de } \\
\text { modelos }\end{array}$} & \multicolumn{3}{|c|}{$\begin{array}{l}\text { Desenvolvimento sequencial de } \\
\text { produtos }\end{array}$} & \multicolumn{3}{|c|}{ Engenharia simultânea } & \multicolumn{3}{|c|}{$\begin{array}{l}\text { Desenvolvimento integrado de } \\
\text { produtos }\end{array}$} \\
\hline & $\begin{array}{l}\text { Tradicio- } \\
\text { nal ou se- } \\
\text { quencial }\end{array}$ & $\begin{array}{l}\text { Metodo- } \\
\text { logia de } \\
\text { projeto }\end{array}$ & $\begin{array}{c}\text { Engenharia } \\
\text { simultânea }\end{array}$ & $\begin{array}{l}\text { "Stage- } \\
\text { gates" }\end{array}$ & $\begin{array}{l}\text { Modelo } \\
\text { de funil }\end{array}$ & "Lean" & $\begin{array}{l}\text { "Six } \\
\text { Sigma" }\end{array}$ & $\begin{array}{l}\text { Modelos } \\
\text { de matu- } \\
\text { ridade }\end{array}$ & $\begin{array}{l}\text { Ciclo de } \\
\text { vida dos } \\
\text { produtos }\end{array}$ \\
\hline $\begin{array}{l}\text { Exemplos } \\
\text { de } \\
\text { Referên- } \\
\text { cias }\end{array}$ & $\begin{array}{c}\text { (Krishnan, } \\
\text { Eppinger, } \\
\text { \& Whitney, } \\
\text { 1997; } \\
\text { Nonaka e } \\
\text { Takeuchi } \\
\text { (1986) }\end{array}$ & $\begin{array}{c}\text { (PMI } \\
\text { Standards } \\
\text { Commi- } \\
\text { ttee, } \\
1996)\end{array}$ & $\begin{array}{l}\text { (Koufteros, } \\
\text { Vonderemb } \\
\text { se, \& Doll, } \\
\text { 2001) }\end{array}$ & $\begin{array}{l}\text { (Cooper, } \\
1990)\end{array}$ & $\begin{array}{c}\text { (Steven C. } \\
\text { Wheel- } \\
\text { wright \& } \\
\text { Clark, } \\
\text { 1992) }\end{array}$ & $\begin{array}{c}\text { (Womack } \\
\text { \& Jones, } \\
1996)\end{array}$ & $\begin{array}{l}\text { (Bañuelas } \\
\text { \& Antony, } \\
\text { 2003) }\end{array}$ & $\begin{array}{l}\text { (Dooley, } \\
\text { Subra, \& } \\
\text { Anderson, } \\
\text { 2001) }\end{array}$ & $\begin{array}{c}\text { (Hicks \& } \\
\text { McGo- } \\
\text { vern, } \\
\text { 2009) }\end{array}$ \\
\hline $\begin{array}{l}\text { Principais } \\
\text { contribui- } \\
\text { ções }\end{array}$ & $\begin{array}{l}\text { Técnicas } \\
\text { focadas nos } \\
\text { produtos }\end{array}$ & $\begin{array}{l}\text { Sistema- } \\
\text { tização } \\
\text { das } \\
\text { ativida- } \\
\text { des }\end{array}$ & $\begin{array}{c}\text { Equipes } \\
\text { multidis- } \\
\text { ciplinares } \\
\text { Colocali- } \\
\text { zação } \\
\text { Medologias } \\
\text { de DP } \\
\text { integradas }\end{array}$ & $\begin{array}{c}\text { Procedi- } \\
\text { mento } \\
\text { para } \\
\text { transição } \\
\text { de fases } \\
\text { Relacio- } \\
\text { namento } \\
\text { entre } \\
\text { fases e } \\
\text { gestão do } \\
\text { portfólio }\end{array}$ & $\begin{array}{c}\text { Gestão de } \\
\text { portfólio } \\
\text { Integração } \\
\text { entre pré e } \\
\text { pós- } \\
\text { desenvol- } \\
\text { vimento }\end{array}$ & $\begin{array}{l}\text { Valoriza- } \\
\text { ção do } \\
\text { "front- } \\
\text { end" } \\
\text { Padroni- } \\
\text { zação e } \\
\text { simplifi- } \\
\text { cação de } \\
\text { ativida- } \\
\text { des } \\
\text { rotineiras }\end{array}$ & $\begin{array}{l}\text { Tratamento } \\
\text { estatístico } \\
\text { do } \\
\text { relaciona- } \\
\text { mento entre } \\
\text { requisitos e } \\
\text { especifica- } \\
\text { ções e entre } \\
\text { processo de } \\
\text { desenvol- } \\
\text { vimento da } \\
\text { tecnologia e } \\
\text { de produtos }\end{array}$ & $\begin{array}{c}\text { Níveis de } \\
\text { maturida- } \\
\text { de } \\
\text { indica- } \\
\text { dores de } \\
\text { evolução } \\
\text { do } \\
\text { processo } \\
\text { de } \\
\text { negócio }\end{array}$ & $\begin{array}{c}\text { Gerenci- } \\
\text { amento } \\
\text { integrado } \\
\mathrm{e} \\
\text { computa- } \\
\text { dorizado } \\
\text { de } \\
\text { projetos e } \\
\text { das etapas } \\
\text { do ciclo } \\
\text { de vida } \\
\text { dos } \\
\text { produtos }\end{array}$ \\
\hline $\begin{array}{c}\text { Foco } \\
\text { principal } \\
\text { do modelo }\end{array}$ & $\begin{array}{l}\text { Divisão de } \\
\text { tarefas } \\
\text { Especia- } \\
\text { lização } \\
\text { ênfase nas } \\
\text { áreas } \\
\text { funcio-nais }\end{array}$ & $\begin{array}{c}\text { Divisão } \\
\text { de tarefas } \\
\text { Especia- } \\
\text { lização } \\
\text { ênfase } \\
\text { nas áreas } \\
\text { funcio- } \\
\text { nais }\end{array}$ & $\begin{array}{c}\text { Equipes } \\
\text { multidici- } \\
\text { plinares } \\
\text { Co-locali- } \\
\text { zação } \\
\text { parale- } \\
\text { lismo entre } \\
\text { atividades }\end{array}$ & $\begin{array}{l}\text { Processo } \\
\text { de } \\
\text { negócio } \\
\text { Avalia- } \\
\text { ção da } \\
\text { transição } \\
\text { de fases }\end{array}$ & $\begin{array}{c}\text { Processo } \\
\text { de } \\
\text { negócio } \\
\text { Integração } \\
\text { DP e } \\
\text { estratégia } \\
\text { de } \\
\text { negócio e } \\
\text { tecnoló- } \\
\text { gica }\end{array}$ & $\begin{array}{c}\text { Trabalho } \\
\text { em } \\
\text { equipe } \\
\text { Simplifi- } \\
\text { cação e } \\
\text { padroni- } \\
\text { zação } \\
\text { Ênfase } \\
\text { nas fases } \\
\text { iniciais } \\
\text { Busca de } \\
\text { novas } \\
\text { soluções }\end{array}$ & $\begin{array}{l}\text { Otimização } \\
\text { utilizando } \\
\text { ferramentas } \\
\text { estatísticas }\end{array}$ & $\begin{array}{c}\text { Melhoria } \\
\text { incremen- } \\
\text { tal e } \\
\text { radical } \\
\text { Avaliação } \\
\text { do nível } \\
\text { de maturi- } \\
\text { dade }\end{array}$ & $\begin{array}{c}\text { Integração } \\
\text { das etapas } \\
\text { do ciclo } \\
\text { de vida } \\
\text { dos } \\
\text { produtos }\end{array}$ \\
\hline
\end{tabular}

Fontes: Rozenfeld e colaboradores (2006, pp. 23-24) e Salgado e Dekkers (2018). 
Tabela 4 - Características das abordagens de desenvolvimento de produtos

\begin{tabular}{|c|c|c|c|c|c|c|c|c|c|}
\hline \multirow[b]{2}{*}{$\begin{array}{c}\text { Era de evolução da gestão } \\
\text { do DP } \\
\text { Abordagem do processo de } \\
\text { DP }\end{array}$} & \multicolumn{3}{|c|}{$\begin{array}{c}\text { Desenvolvimento sequencial } \\
\text { de produtos }\end{array}$} & \multicolumn{3}{|c|}{ Engenharia simultânea } & \multicolumn{3}{|c|}{$\begin{array}{c}\text { Desenvolvimento integrado } \\
\text { de produtos }\end{array}$} \\
\hline & $\begin{array}{l}\text { Tradi- } \\
\text { cional } \\
\text { ou } \\
\text { sequen- } \\
\quad \text { cial }\end{array}$ & $\begin{array}{l}\text { Meto- } \\
\text { dologia } \\
\text { de } \\
\text { projeto }\end{array}$ & $\begin{array}{l}\text { Enge- } \\
\text { nharia } \\
\text { simul- } \\
\text { tânea }\end{array}$ & $\begin{array}{l}\text { "Stage- } \\
\text { gates" }\end{array}$ & $\begin{array}{l}\text { Modelo } \\
\text { de funil }\end{array}$ & "Lean" & $\begin{array}{l}\text { Design } \\
\text { for Six } \\
\text { Sigma }\end{array}$ & $\begin{array}{l}\text { Mode- } \\
\text { los de } \\
\text { maturi- } \\
\text { dade }\end{array}$ & $\begin{array}{c}\text { Ciclo de } \\
\text { vida dos } \\
\text { pro- } \\
\text { dutos }\end{array}$ \\
\hline \multicolumn{10}{|l|}{ Gestão interprojetos } \\
\hline \multicolumn{10}{|l|}{ Gestão do ciclo de vida } \\
\hline \multicolumn{10}{|l|}{$\begin{array}{l}\text { Melhoria contínua do PDF - } \\
\text { Níveis de maturidade }\end{array}$} \\
\hline \multicolumn{10}{|l|}{$\begin{array}{l}\text { Processo sistemático para } \\
\text { avaliaçãa da tecnologia e } \\
\text { otimização do produto }\end{array}$} \\
\hline \multicolumn{10}{|l|}{$\begin{array}{l}\text { Liderança por meio do } \\
\text { conhecimento }\end{array}$} \\
\hline \multicolumn{10}{|l|}{$\begin{array}{l}\text { Incentivo á busca de } \\
\text { soluções inovadoras }\end{array}$} \\
\hline \multicolumn{10}{|l|}{$\begin{array}{l}\text { Integração com a estratégia } \\
\text { de negócios e tecnológica }\end{array}$} \\
\hline \multicolumn{10}{|l|}{$\begin{array}{l}\text { Processo de aprovação } \\
\text { sistemático de fases }\end{array}$} \\
\hline \multicolumn{10}{|l|}{$\begin{array}{l}\text { Adoção da abordagem por } \\
\text { processos de negócio }\end{array}$} \\
\hline \multicolumn{10}{|l|}{$\begin{array}{l}\text { Paralelismo para integração } \\
\text { entre as áreas e menor tempo }\end{array}$} \\
\hline \multicolumn{10}{|l|}{$\begin{array}{l}\text { Integração de técnicas, } \\
\text { métodos e princípios }\end{array}$} \\
\hline \multicolumn{10}{|l|}{$\begin{array}{l}\text { Integração com parceiros e } \\
\text { fornecedores }\end{array}$} \\
\hline \multicolumn{10}{|l|}{ Co-localização } \\
\hline \multicolumn{10}{|l|}{$\begin{array}{l}\text { Adoção de gerentes de } \\
\text { projetos peso pesado }\end{array}$} \\
\hline \multicolumn{10}{|l|}{$\begin{array}{l}\text { Adoção de times } \\
\text { multidisciplinares }\end{array}$} \\
\hline \multicolumn{10}{|l|}{$\begin{array}{l}\text { Uso de métodos sistemáticos } \\
\text { de projeto }\end{array}$} \\
\hline Uso de estruturas funcionais & & & & & & & & & \\
\hline
\end{tabular}

Fontes: Rozenfeld e colaboradores (2006, pp. 23-24) e Salgado e Dekkers (2018).

\subsubsection{Desenvolvimento de produtos na indústria farmacêutica}

De acordo com Harpum (2010), o gerenciamento de projetos na área das ciências da vida só se estabeleceu como uma abordagem confiável para gerenciar o trabalho de desenvolvimento de produtos após o início dos anos 1980, apesar das grandes vantagens que essa abordagem já havia trazido para outras indústrias desde o final dos anos 1950.

De acordo com Kennedy (2008), da década de 1980 até meados da década de 2000, a função de gerenciamento de projetos teve atuação em três áreas: suporte a projetos individuais, apoio ao gerenciamento de portfólio e melhoria do processo de desenvolvimento de novos medicamentos. Podem ser encontradas na literatura muitas referências sobre a pesquisa e desenvolvimento com foco em novos fármacos tais como: Dimasi, Feldman, Seckler e Wilson (2009); Drews (2000); Henderson e Cockburn (1996); e Jorgensen (2004). Ou ainda abordando aspectos técnicos do desenvolvimento das formulações de medicamentos ou formas farmacêuticas específicas como, por exemplo: T. M. Allen e Cullis (2004); Aulton e Taylor (2016); Hillery e Park (2017); Jain (2008); e Tiwari e colaboradores 
(2012). No entanto, mesmo na atualidade, poucas referências são encontradas com abordagem gerencial para o desenvolvimento de formulações, como já havia observado De Paula (2004b).

De acordo com Trassato (2017), o termo projeto não possui conceituação complementar ou específica para o segmento farmacêutico. A principal norma para a produção de medicamentos no Brasil e citada por ela, a resolução RDC 17/2010 (Anvisa, 2010b), foi substituída em agosto de 2019 pela RDC 301/2019, porém sem mudanças significativas em relação à abordagem dada aos projetos. Basicamente, a norma faz menção a projeto como sinônimo de esquema, planta ou desenho de instalações, equipamentos e processos operacionais e não como um processo ou conjunto de atividades a serem desenvolvidas ou executadas. No entanto, para o desenvolvimento de novos medicamentos, a Instrução Normativa - IN no 47 de 21 de agosto de 2019 (Anvisa, 2019b) faz referência à abordagem denominada "Quality by Design" - QbD (em português qualidade por "design" (Anvisa, 2019f) ou qualidade por meio do delineamento (R. T. Yugue, Sbragia, \& Maximiano, 2018).

De Paula (2004), em sua tese de doutorado, elaborou uma proposta de modelo de referência para o processo de desenvolvimento de produtos farmacêuticos (Figura 10) combinando os preceitos da engenharia simultânea, desenvolvimento integrado e o sistema de "gates" de Cooper (1990).

Figura 10 - Macro-etapas, fases e pacotes de trabalho da área de pesquisa e desenvolvimento.

\begin{tabular}{|c|c|c|c|c|c|c|}
\hline $\begin{array}{l}\text { Identificação } \\
\text { e seleção da } \\
\text { oportuni- } \\
\text { dade de } \\
\text { negócio }\end{array}$ & $\begin{array}{l}\text { Geração e } \\
\text { seleção de } \\
\text { conceito }\end{array}$ & $\begin{array}{c}\text { Detalhamen- } \\
\text { to e seleção } \\
\text { do conceito } \\
\text { detalhado }\end{array}$ & $\begin{array}{l}\text { Desenvolvi- } \\
\text { mento e } \\
\text { análise de } \\
\text { produto e } \\
\text { processo }\end{array}$ & $\begin{array}{l}\text { Execução da } \\
\text { produção e } \\
\text { do plano de } \\
\text { marketing }\end{array}$ & $\begin{array}{l}\text { Conclusão } \\
\text { do PDP e } \\
\text { registro do } \\
\text { produto na } \\
\text { Anvisa }\end{array}$ & $\begin{array}{c}\text { Lançamento } \\
\text { do produto e } \\
\text { avaliação } \\
\text { pós-vendas }\end{array}$ \\
\hline
\end{tabular}

Legenda: + = atividade com responsabilidade compartilhada $/$ AA = Alta administração $/$ AR $=$ Assuntos regulatórios $/ \mathrm{FC}=$ Financeiro e compras $/ \mathrm{GQ}=$ Garantia da qualidade $/ \mathrm{MV}=$ Marketing e vendas $/ \mathrm{PR}=$ Produção. Fonte: reproduzido de: De Paula (2004). 
Um exemplo de estruturação do projeto de desenvolvimento de um novo medicamento com escopo delimitado para a formulação e organizado em fases e seus pacotes de trabalho foi elaborado por V. Yugue (2014) e é apresentado na Figura 11. Cada fase está basicamente relacionada a um requisito regulatório, que frequentemente está atrelado à realização de testes e comprovações cientificamente fundamentadas.

Figura 11 - Fases e atividades de um projeto de desenvolvimento de um novo medicamento

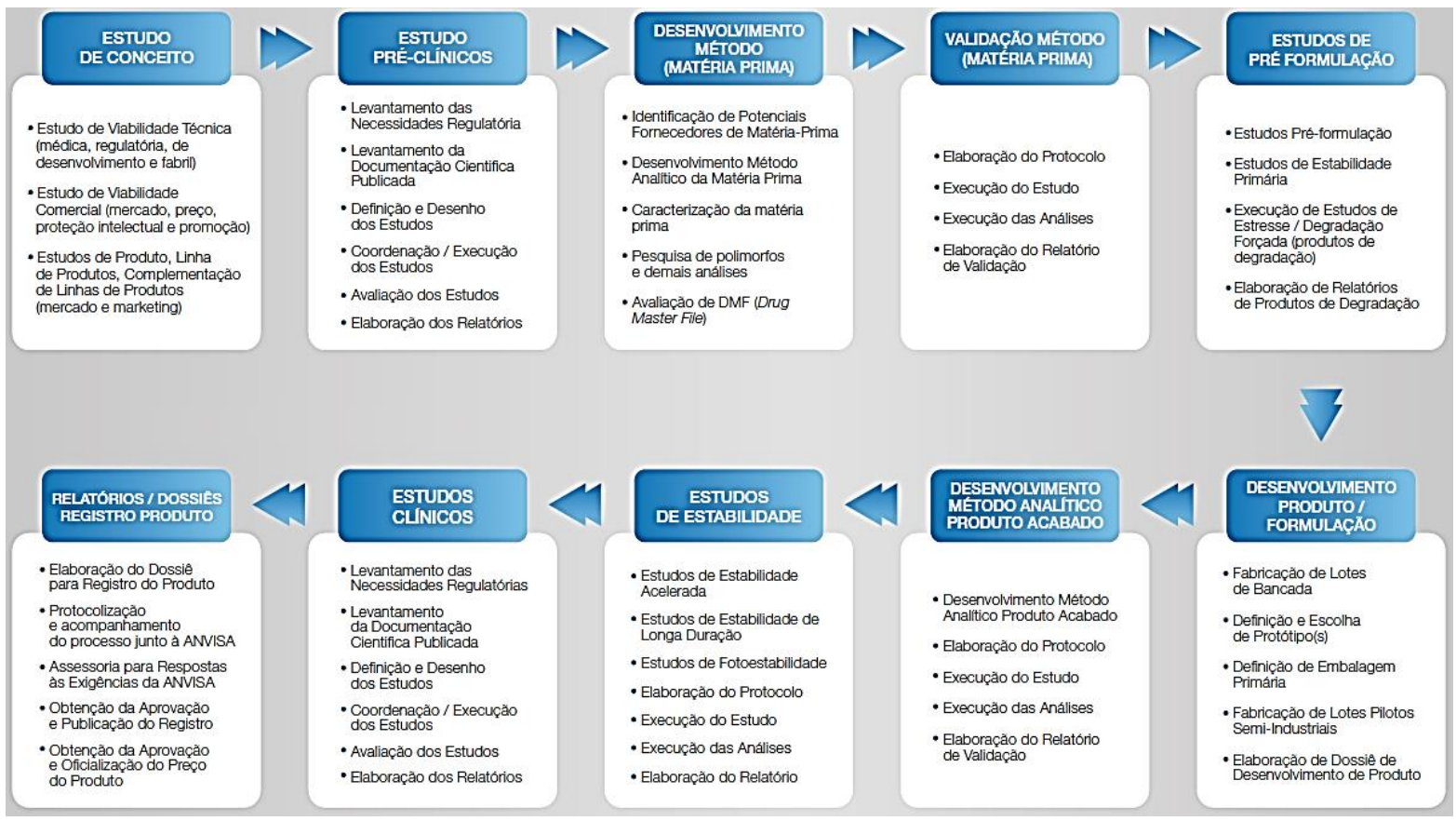

Fonte: reproduzido de V. Yugue (2014).

O modelo proposto por De Paula (2004) e o de V. Yugue (2014) apresentam diferenças basicamente em razão das delimitações dos modelos. Enquanto De Paula (2004) considera desde o processo de seleção dos novos projetos até a avaliação pós-venda, V. Yugue (2014) foca o seu modelo apenas aos processos do projeto de desenvolvimento relacionados à formulação do novo medicamento. Estes processos são denominados por De Paula (2004) como fase tecnológica, a qual, considerando as delimitações estabelecidas, é o objeto específico do presente estudo.

\subsubsection{1 "Quality by Design" - QbD ou qualidade por meio do delineamento}

Kanfer, Walker, Löbenberg e Bou-Chacra (2014) consideram que a introdução do conceito de QbD marcou uma mudança fundamental no processo de desenvolvimento de medicamentos. Tradicionalmente, o desenvolvimento de novos medicamentos vinha sendo realizado parcial ou totalmente a partir de conhecimentos empíricos e/ou com o uso de abordagens estatísticas, como o delineamento de experimentos (na língua inglesa "Design of Experiments" - DoE) e de testes após o desenvolvimento para comprovação da qualidade. No entanto, para o FDA (2004), o ideal é prever os efeitos sobre a qualidade e desempenho de mudanças e até mesmo de falhas na produção do 
medicamento para que seja garantida uma produção confiável e de alta qualidade dos medicamentos sem a necessidade de ampla supervisão regulatória. Para tanto, segundo Kanfer e colaboradores (2014), os laboratórios farmacêuticos necessitariam ter a capacidade de analisar ou entender os motivos das falhas de fabricação tendo dados que suportem especificações e justifiquem os limites de controle. Este direcionamento deu forças ao uso da abordagem do QbD no desenvolvimento e fabricação de produtos farmacêuticos.

O QbD é definido pela Anvisa (2019b, p. 96) como "uma abordagem sistemática que se inicia com objetivos pré-definidos e enfatiza o conhecimento/entendimento dos produtos, dos processos e dos controles em processos". Com base nele, de acordo com Kanfer e colaboradores (2014), o desenvolvimento e fabricação de produtos farmacêuticos são totalmente baseados em dados científicos e no gerenciamento de risco da qualidade. As metas e especificações são definidas antes de qualquer experimento, ou antes mesmo do trabalho de formulação, sendo necessária uma ampla base de conhecimento para a definição de uma estratégia de desenvolvimento. Outros conceitos como o perfil de qualidade do produto alvo ("Quality Target Product Profile" - QTPP), os atributos críticos de qualidade ("Critical Quality Atribute" - CQA), os parâmetros críticos de processo ("Critical Process Parameters" - CPPs), o espaço de desenho ou delineamento ("Design Space" - DS), o planejamento ou delineamento de experimentos ("Design of Experiments" - DOE) e a gestão de riscos compõem ou complementam a abordagem do QbD.

A abordagem do QbD é aplicada em um projeto de desenvolvimento de um medicamento por meio de uma sequência de processos cujo fluxo básico é apresentado na Figura 12. Os processos componentes do fluxo são detalhados na Tabela 5 .

Figura 12 - Sequência de processos pela abordagem do "Quality by Design"

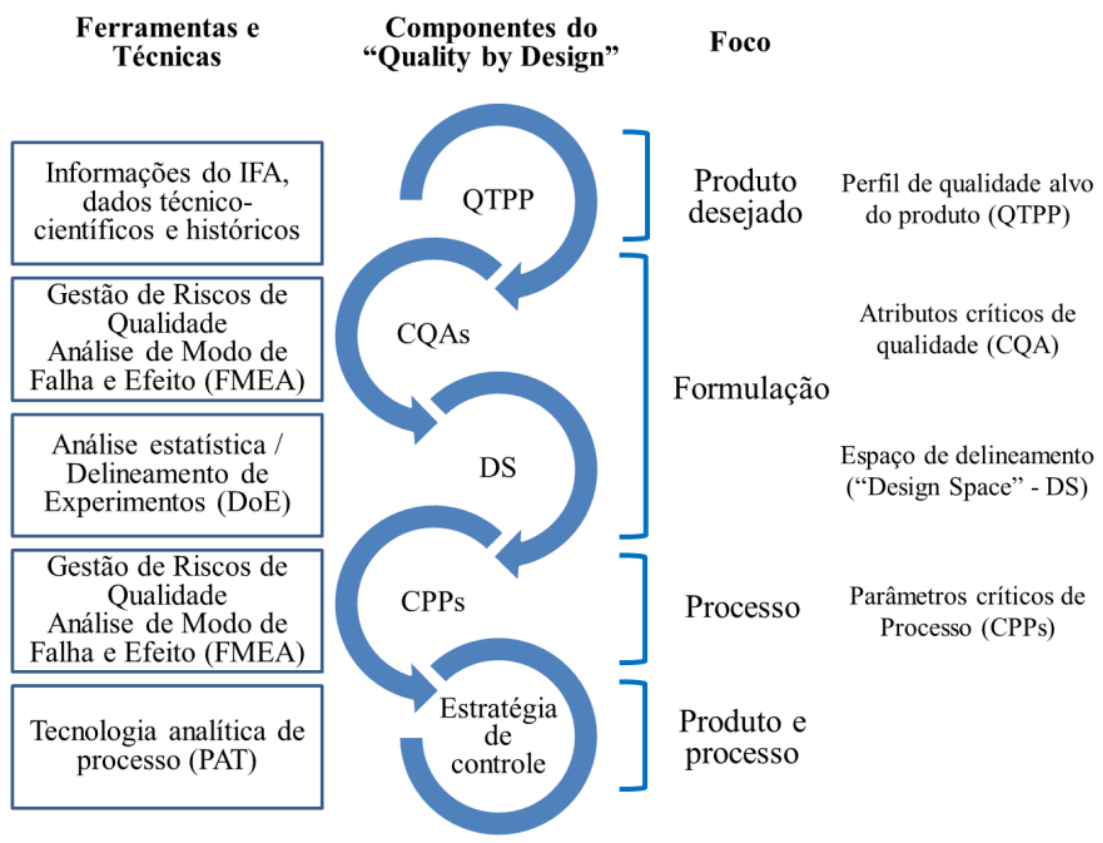

Fonte: elaborado com base em Kader (2016) e Kanfer e colaboradores (2014) 
Tabela 5 - Conceitos, componentes, ferramentas e técnicas da abordagem de "Quality by Design"

\begin{tabular}{|c|c|}
\hline $\begin{array}{l}\text { Perfi } \\
\text { qualidade } \\
\text { produto }\end{array}$ & $\begin{array}{l}\text { É a visão do produto final composta pelas características básicas relacionadas ao } \\
\text { ingrediente farmacêutico ativo (IFA), forma farmacêutica, via de administração, tipo de } \\
\text { recipiente, farmacocinética desejada e atributos críticos de qualidade (CQA). Na } \\
\text { elaboração do QTPP, as características de qualidade prospectivas e dinâmicas de um } \\
\text { medicamento são definidas para garantir que a qualidade, segurança e eficácia desejadas } \\
\text { possam ser alcançadas. São consideradas informações do IFA e de referencial proveniente } \\
\text { da literatura e de experiências com produtos e processos já desenvolvidos. }\end{array}$ \\
\hline $\begin{array}{r}\text { Atribut } \\
\text { de } \mathrm{q} \\
(\mathrm{C}\end{array}$ & $\begin{array}{l}\text { Incluem características que precisam ser controladas (direta ou indiretamente) para } \\
\text { garantir que a qualidade e o desempenho do produto sejam alcançados. Também incluem } \\
\text { os atributos críticos de materiais (CMA) que afetam o desempenho dos medicamentos. }\end{array}$ \\
\hline $\begin{array}{r}\text { Gerenciam } \\
\text { de riscos } \\
\text { qualidad }\end{array}$ & $\begin{array}{l}\text { Seu objetivo é identificar riscos, controlar processos, testar a variabilidade e estabelecer } \\
\text { uma estratégia de controle. É usado para avaliar sistematicamente os riscos à qualidade do } \\
\text { medicamento associados a todos os processos e controles e minimizá-los ao longo do } \\
\text { ciclo de vida do produto. O uso de ferramentas para a análise de riscos como o FMEA } \\
\text { (Análise de Modo de Falha e Efeito ou "Failure Mode and Effect Analysis") auxilia na } \\
\text { seleção dos parâmetros importantes para avaliação do processo. }\end{array}$ \\
\hline $\begin{array}{r}\text { Parấ } \\
\text { Crít } \\
\text { Proces }\end{array}$ & $\begin{array}{l}\text { Incluem características do processo de fabricação que precisam ser controladas para } \\
\text { garantir que a qualidade e o desempenho do produto sejam alcançados (necessidades do } \\
\text { paciente e requisitos de desempenho definidos pelo CQA). A variabilidade inerente ao } \\
\text { processo de fabricação não deve comprometer a qualidade dos produtos se o processo for } \\
\text { estabelecido e mantido dentro dos limites definidos por meio dos estudos. Mesmo que o } \\
\text { parâmetro seja adequadamente controlado, ele não deixa de ser crítico para o processo. }\end{array}$ \\
\hline $\begin{array}{r}\text { Espaç } \\
\text { delineam } \\
\text { de des } \\
\text { ("Design } \\
\text { - D }\end{array}$ & $\begin{array}{l}\text { Trata-se de uma combinação multidimensional da interação de variáveis relacionadas à } \\
\text { formulação do medicamento e de parâmetros de processo que demonstraram fornecer } \\
\text { garantia da qualidade e entendimento do processo (base do conhecimento sobre o impacto } \\
\text { da variabilidade no desempenho do medicamento). O DS possibilita a aceitação pela } \\
\text { autoridade sanitária de certa flexibilização de um processo de fabricação com base em } \\
\text { estudos sobre os riscos, evitando ou reduzindo a necessidade de processos após o registro } \\
\text { do medicamento. A definição das fronteiras do DS usa como requisitos: o controle do } \\
\text { CPP, o conhecimento dos efeitos no desempenho do produto e a análise estatística dos } \\
\text { dados. O conhecimento que pode ser obtido por meio da aplicação do DoE, por exemplo, } \\
\text { pode ser usado para definir uma estratégia de controle e distinguir os parâmetros entre } \\
\text { críticos e não críticos. O DS deve ser confirmado por abordagens experimentais após o } \\
\text { desenvolvimento do medicamento e pode fazer parte do seu pedido de registro. }\end{array}$ \\
\hline $\begin{array}{r}\text { Delin } \\
\text { de expe } \\
\text { (" } D \\
\text { Exper } \\
\mathrm{I}\end{array}$ & $\begin{array}{l}\text { Trata-se de uma ferramenta para determinar a influência de várias variáveis e suas } \\
\text { interações nos processos de produção. Possibilita a identificação de possíveis } \\
\text { relacionamentos entre os fatores que afetam um processo (variável independente) e suas } \\
\text { consequências sobre o processo (variável dependente). }\end{array}$ \\
\hline $\begin{array}{r}\text { Estra } \\
\text { co }\end{array}$ & $\begin{array}{l}\text { Trata do controle dos atributos de qualidade ao longo do processo de fabricação em tempo } \\
\text { real, levando a uma possível redução ou até a eliminação dos testes de qualidade que são } \\
\text { realizados nos produtos finais nos lotes produzidos para fins de sua liberação para } \\
\text { distribuição e comercialização. Os controles de material de entrada, controles de processo } \\
\text { ou dados de monitoramento de processo e testes de produto acabado (se apropriado) são } \\
\text { combinados para estabelecer e garantir a qualidade do produto. A estratégia de controle } \\
\text { pode considerar o uso de tecnologia analítica de processo (PAT). }\end{array}$ \\
\hline $\begin{array}{l}\text { Tecnologi } \\
\text { analítica c } \\
\text { processo } \\
\text { ('Proces } \\
\text { Analytica } \\
\text { Technology } \\
\text { PAT) }\end{array}$ & $\begin{array}{l}\text { Ferramenta de monitoramento do processo em escala industrial que permite o } \\
\text { desenvolvimento de métodos quantitativos para previsão em tempo real de CQA. Inclui o } \\
\text { sistema utilizado para projetar, analisar e controlar a fabricação através de medições } \\
\text { durante o processamento de CQA e atributos críticos com o objetivo de garantir a } \\
\text { qualidade do produto final. Quando associado à avaliação da qualidade e ferramentas } \\
\text { estatísticas, pode auxiliar na detecção e análise de variações nos processos de fabricação e } \\
\text { avaliação de seus efeitos no CQA. Assim, possibilita o controle da variabilidade } \\
\text { considerando os riscos que representam para o processo e para o produto. }\end{array}$ \\
\hline
\end{tabular}

Fontes: Kader (2016), Kanfer e colaboradores (2014) e ICH (2009). 
O International Conference on Harmonisation - ICH (2009) $)^{3}$ sugere que sejam considerados os atributos críticos da formulação em conjunto com as opções disponíveis para o processo de produção, tendo por objetivo a própria seleção do processo de produção e a confirmação da adequação dos componentes e do equipamento utilizado para a produção. Destaca também que os estudos de desenvolvimento do processo devem servir de sustentação para sua validação, eventuais melhorias, verificação e controle.

Ainda de acordo com ICH (2009), os estudos de desenvolvimento farmacêutico podem levar a um melhor conhecimento do desempenho do medicamento por poderem fornecer: uma ampla gama de atributos materiais; opções de processamento e parâmetros do processo; e oportunidades para demonstração de um maior grau de entendimento científico dos atributos materiais, processos de produção e seus controles. Isso facilitaria a criação do espaço de delineamento (DS - "Design Space" na língua inglesa) e produziria oportunidades para o desenvolvimento de abordagens regulatórias mais flexíveis para:

- decisões regulatórias baseadas no gerenciamento dos riscos (monitoramentos e inspeções);

- melhorias com mudanças no processo de produção dentro do espaço de delineamento aprovado, sem novo monitoramento regulatório;

- redução de ajustes após a aprovação pelo órgão regulador;

- controle de qualidade em processo, o que levaria a uma redução dos testes de libertação do produto final.

A Tabela 6 reproduz os potenciais contrastes entre o que na perspectiva do $(\mathrm{ICH}, 2009)$ poderia ser considerada, por um lado, uma abordagem mínima e, por outro lado, uma abordagem aprimorada da qualidade por meio do delineamento. A entidade, no entanto, afirma que o comparativo tem o intuito de auxiliar no entendimento de uma variedade de potenciais abordagens para $o$ desenvolvimento farmacêutico e que não devem ser consideradas como abrangentes. Ainda segundo o $\mathrm{ICH}$, as práticas correntes da indústria farmacêutica variam e normalmente situam-se entre as duas abordagens apresentadas na tabela.

3 ICH - "International Conference on Harmonisation of Technical Requirements for Registration of Pharmaceuticals for Human Use" reúne autoridades reguladoras e associações de indústrias farmacêuticas para discutir aspectos técnicos e científicos para o registro de medicamentos. 
Tabela 6 - Abordagem mínima e aprimorada de qualidade por meio do delineamento

\begin{tabular}{|c|c|c|}
\hline Aspecto & Abordagem Mínima & Abordagens Aprimorada e de QbD \\
\hline $\begin{array}{l}\text { Desenvolvimento } \\
\text { Farmacêutico Geral }\end{array}$ & $\begin{array}{l}\text { - Principalmente empírica } \\
\text { Pesquisa de desenvolvimento, } \\
\text { muitas vezes com condução de } \\
\text { uma variável de cada vez }\end{array}$ & $\begin{array}{l}\text { - Sistemática, relacionando o entendimento } \\
\text { mecanicista dos atributos dos materiais e os } \\
\text { parâmetros de processo com os CQAs (“critical } \\
\text { quality atributes” ou atributos críticos de qualidade) } \\
\text { dos medicamentos } \\
\text { - Experiências multivariadas para entender os produtos } \\
\text { e os processos } \\
\text { - Estabelecimento de espaço de delineamento } \\
\text { - Utilização de ferramentas de PAT (“Process } \\
\text { analytical technology" ou tecnologia analítica de } \\
\text { processos) }\end{array}$ \\
\hline $\begin{array}{l}\text { Processo de } \\
\text { Produção }\end{array}$ & $\begin{array}{l}\text { - Fixo } \\
\text { - Validação baseada basicamente } \\
\text { em lotes iniciais de grande } \\
\text { escala } \\
\text { - Foco na otimização e } \\
\text { reprodutibilidade }\end{array}$ & $\begin{array}{l}\text { - Ajustável dentro do espaço de delineamento } \\
\text { - Abordagem de ciclo de vida para validação e, } \\
\text { idealmente, a verificação contínua do processo } \\
\text { - Foco na estratégia de controle e robustez } \\
\text { - Uso de métodos de controle estatístico de processo } \\
\text { (CEP) }\end{array}$ \\
\hline $\begin{array}{l}\text { Controles de } \\
\text { Processo }\end{array}$ & $\begin{array}{l}\text { - Testes em processo } \\
\text { basicamente para decisões de } \\
\text { "continuar/abandonar" (go/no } \\
\text { go) } \\
\text { - Análise "fora de linha" (off- } \\
\text { line) }\end{array}$ & $\begin{array}{l}\text { - Ferramentas de PAT utilizadas com controles } \\
\text { apropriados de orientações referentes a expectativas } \\
\text { (feedforward) e avaliações das experiências } \\
\text { (feedback) } \\
\text { - Operações de processos rastreadas e propensas a } \\
\text { apoiar os esforços de melhoria contínua após a sua } \\
\text { aprovação }\end{array}$ \\
\hline $\begin{array}{l}\text { Especificações do } \\
\text { Produto }\end{array}$ & $\begin{array}{l}\text { - Meio primário de controle } \\
\text { Baseadas em dados de lotes } \\
\text { disponíveis no momento do } \\
\text { registro }\end{array}$ & $\begin{array}{l}\text { - Parte da estratégia geral de controle de qualidade } \\
\text { Baseadas no desempenho desejado do produto com } \\
\text { dados de suporte relevantes }\end{array}$ \\
\hline $\begin{array}{c}\text { Estratégia de } \\
\text { Controle }\end{array}$ & $\begin{array}{l}\text { Qualidade do medicamento } \\
\text { controlado principalmente por } \\
\text { intermediários (materiais em } \\
\text { processo) e testes no produto } \\
\text { final }\end{array}$ & $\begin{array}{l}\text { - Qualidade do medicamento assegurada pela } \\
\text { estratégia de controle baseada no risco para produto e } \\
\text { processo bem entendidos } \\
\text { - Controles de qualidade deslocados a montante, com a } \\
\text { possibilidade de testes de liberação em tempo real ou } \\
\text { redução de testes no produto final }\end{array}$ \\
\hline $\begin{array}{l}\text { Gestão do Ciclo de } \\
\text { Vida }\end{array}$ & $\begin{array}{l}\text { - Reativa (isto é, resolução de } \\
\text { problemas e ação corretiva) }\end{array}$ & $\begin{array}{l}\text { - Ação preventiva } \\
\text { - Melhoria contínua facilitada }\end{array}$ \\
\hline
\end{tabular}

Fonte: reproduzido de ICH (2009).

Sobre a abordagem mínima apresentada pelo ICH (2009), Davis, Lundsberg e Cook (2008) consideram que na abordagem mínima a qualidade do produto farmacêutico é controlada principalmente por meio de testes nos produtos intermediários e finais e, por outro lado, na abordagem melhorada, ela é assegurada por uma estratégia de controle baseada em risco bem entendido para um produto e processo e controles de qualidade transferidos para etapas anteriores, com a possibilidade de liberação em tempo real ou com testes reduzidos no produto final. Porém, o ICH (2009) alerta que, em 
todos os casos, o produto deve ser projetado para atender às necessidades dos pacientes e o desempenho pretendido para o produto.

Com base no relatório da McKinsey publicado por (Fuhr, Holcomb, \& Rutten, 2009) sobre o QbD, Kader (2016) destacou como benefícios da implementação do QbD as possibilidades de: selecionar as formulações e processos ideais com uma confiança razoável; minimizar as respostas a questionamentos; favorecer a aprovação como resultado da construção do QbD na revisão regulatória do processo de desenvolvimento; reduzir o tempo para a preparação de documentos técnicos; reduzir os custos gerais de desenvolvimento de produtos e processos; e dar condições a melhorias contínuas ao longo do ciclo de vida do produto. A aplicação do QbD também minimizaria os riscos de falhas nos estudos de bioequivalência, de "scale up" (escalonamento na língua portuguesa), de validação e de estabilidade, os quais demandam tempo considerável durante a fase de caracterização do produto e do processo.

\subsubsection{Desenvolvimento de medicamentos no Brasil}

De acordo com dados do Sindicato da Indústria de Produtos Farmacêuticos - Sindusfarma (2019), as vendas de medicamentos no Brasil no ano de 2018 foram da ordem de 17 bilhões de dólares americanos (preço de compra da farmácia) com mais de 4,1 bilhões de unidades vendidas. Desses totais de 2018, os medicamentos genéricos foram responsáveis por 1,4 bilhões de unidades vendidas e que geraram mais de 2,3 bilhões de dólares americanos em vendas. Ainda segundo o relatório, em 2018 atuavam no Brasil 244 laboratórios farmacêuticos com medicamentos registrados, sendo 101 (41\%) laboratórios de capital estrangeiro e 143 (59\%) de capital nacional. Os laboratórios nacionais responderam em 2018 por $48,51 \%$ do mercado em faturamento e $66 \%$ em unidades vendidas (caixas). O mercado farmacêutico brasileiro representa aproximadamente $2 \%$ do mercado mundial, sendo o $7^{\circ}$ em faturamento no ranking das 20 principais economias do mundo. No Anexo I estão dados de faturamento do mercado brasileiro de medicamentos genéricos do ano de 2017 por grupo econômico e por laboratório farmacêutico.

O Brasil teve avanços significativos na pesquisa e desenvolvimento de medicamentos na década de 2000. Calixto e Siqueira Jr. (2008) apontam como algumas das evidências destas mudanças: a aprovação da lei de patentes; a criação da Anvisa; a lei dos medicamentos genéricos; a criação das fundações de apoio à pesquisa e dos fundos setoriais; e o surgimento do Programa de Apoio ao Desenvolvimento da Cadeia Produtiva Farmacêutica (PROFARMA) através do Banco Nacional de Desenvolvimento Econômico e Social (BNDES).

No entanto, Calixto e Siqueira Jr. (2008) comentaram também quais seriam os principais entraves para o desenvolvimento de novos medicamentos no Brasil no período estudado. Os pesquisadores citaram: a pouca visibilidade da legislação regulatória; deficiências nos laboratórios de pesquisa nas universidades e centros de pesquisas nacionais na área de farmacologia pré-clínica; e 
dificuldades para a importação de reagentes e de equipamentos para pesquisa. Como resultado, apontam a baixa competitividade dos laboratórios brasileiros, já que a estes entraves se somam os altos custos e riscos para o desenvolvimento de medicamentos inovadores, a dificuldade de financiamentos das pesquisas, o longo tempo para se chegar a um novo produto e a experiência limitada em projetos de desenvolvimento de produtos inovadores, o que incluiria pesquisadores capacitados.

A literatura sobre o desenvolvimento de novos medicamentos no Brasil é bastante restrita. Levantamento realizado em 2018 na base de dados Scopus ${ }^{\circledR}$ sobre o tema dos projetos de desenvolvimento de medicamentos resultou em apenas 23 publicações de interesse. No entanto, nenhuma destas publicações fez referência ao Brasil. No entanto, o levantamento realizado na base de dados do Google Acadêmico ${ }^{\circledR}$ (atualizado em novembro de 2019) resultou na identificação de 27 registros a partir do ano 2000 (relacionados no Apêndice III) e que foram considerados de interesse para esta pesquisa. Destes, 11 (42\%) são dissertações de mestrado, 6 (23\%) são teses de doutorado e apenas 5 (19\%) são artigos publicados em periódicos, todos brasileiros. Quanto ao método de pesquisa, 12 (46\%) são estudos de casos, 5 (19\%) são estudos multicasos e 5 (15\%) são revisões da literatura.

Especificamente sobre o desenvolvimento de medicamentos genéricos no Brasil, foram encontradas em levantamento no Google Acadêmico as pesquisas realizadas por (em ordem cronológica): De Paula (2004), Pinto (2007), Hajjar Júnior (2010), (Silva, 2015) e Cunha, Rodrigues, Mendonça, Cunha e Araujo (2016).

De acordo com Moreira e Cheng (2010), no Brasil, as atividades de pesquisa farmacêutica consistem basicamente do desenvolvimento de formulações de medicamentos cujas patentes já expiraram. De uma forma geral, esses medicamentos pertencem a duas classes: os medicamentos similares e os medicamentos genéricos (R. Yugue et al., 2010). Esta característica não se alterou significativamente nos últimos anos, uma vez que o Sindusfarma (2019) credita a liderança em vendas por unidades das empresas nacionais à crescente participação dos medicamentos genéricos no mercado brasileiro.

A pesquisa bibliográfica possibilitou a elaboração de uma relação dos componentes (atividades, informações, recursos, etc.) dos projetos de desenvolvimento de medicamentos desenvolvidos no Brasil, os quais são relacionados na Tabela 7. Foram listados os componentes com relação mais direta com as atividades da área de $\mathrm{P} \& \mathrm{D}$, sendo excluídos componentes específicos das outras áreas, principalmente a alta administração, comercial, logística e financeira. 
Tabela 7 - Componentes dos projetos de desenvolvimento de medicamentos em laboratórios brasileiros identificados na literatura

\begin{tabular}{|c|c|c|c|c|}
\hline Componentes & $\begin{array}{c}\text { De Paula } \\
\text { (2004) } \\
\text { Produtos } \\
\text { para saúde }\end{array}$ & $\begin{array}{c}\text { Yugue, } \\
\text { 2014) } \\
\text { Medicame } \\
\text { ntos }\end{array}$ & $\begin{array}{c}\text { (Silva, } \\
2015) \\
\text { Medica- } \\
\text { mento } \\
\text { genérico } \\
\end{array}$ & $\begin{array}{c}\text { (Anvisa, } \\
\text { 2007) RDC } \\
16 / 2007 \\
\text { (regula- } \\
\text { tórios) } \\
\end{array}$ \\
\hline ANTES DO INÍCIO DO PROJETO & $\mathrm{X}$ & & & \\
\hline Estabelecimento dos atributos do produto & $\mathrm{X}$ & & $\mathrm{X}$ & \\
\hline Definição do mercado-alvo & $\mathrm{X}$ & $\mathrm{X}$ & & \\
\hline Identificação dos requisitos legais / regulatórias & $\mathrm{X}$ & $\mathrm{X}$ & & $\mathrm{X}$ \\
\hline Identificação dos requisitos de marketing & $\mathrm{X}$ & $\mathrm{X}$ & & \\
\hline Determinação dos requisitos financeiros & $\mathrm{X}$ & & & \\
\hline Análise de viabilidade técnica & $\mathrm{X}$ & $\mathrm{X}$ & & \\
\hline Identificação de demandas internas & $\mathrm{X}$ & & & \\
\hline Elaboração do plano estratégico de desenvolvimento & $\mathrm{X}$ & $\mathrm{X}$ & & \\
\hline Seleção dos projetos de desenvolvimento & $\mathrm{X}$ & & & \\
\hline Gestão do portfólio de projetos & $\mathrm{X}$ & & & \\
\hline Análise do escopo do projeto & $\mathrm{X}$ & & & \\
\hline Identificação das restrições do projeto & $\mathrm{X}$ & & & \\
\hline Identificação das necessidades de recursos tecnológicos & $\mathrm{X}$ & & & \\
\hline Análise de patentes & $\mathrm{X}$ & & $\mathrm{X}$ & \\
\hline Análise de bases de dados & $\mathrm{X}$ & & & \\
\hline Estabelecimento de convênios com instituições de pesquisa & $\mathrm{X}$ & & & \\
\hline Estabelecimento de grupos de trabalho multifuncionais & $\mathrm{X}$ & & & \\
\hline Análise de viabilidade financeira & $\mathrm{X}$ & & & \\
\hline Determinação do custo-alvo de produção & $\mathrm{X}$ & & & \\
\hline Análise dos riscos do projeto & $\mathrm{X}$ & & & \\
\hline Definição do escopo e configuração do produto & $\mathrm{X}$ & $\mathrm{X}$ & & \\
\hline Análise do medicamento de referência & $\mathrm{X}$ & & & \\
\hline Análise de bula e rótulo & $\mathrm{X}$ & & & $\mathrm{X}$ \\
\hline Revisão da literatura técnica & $\mathrm{X}$ & $\mathrm{X}$ & & $\mathrm{X}$ \\
\hline Análise de processos de produção & $\mathrm{X}$ & & & $\mathrm{X}$ \\
\hline Definição do processo de produção & $\mathrm{X}$ & & & $\mathrm{X}$ \\
\hline Definição dos requisitos de produção & $\mathrm{X}$ & & & $\mathrm{X}$ \\
\hline Definição dos requisitos de garantia de qualidade & $\mathrm{X}$ & & & $\mathrm{X}$ \\
\hline Definição dos requisitos de controle de qualidade & $\mathrm{X}$ & & & $\mathrm{X}$ \\
\hline Definição da tecnologia de produção & $\mathrm{X}$ & & & $\mathrm{X}$ \\
\hline Definição da embalagem & $\mathrm{X}$ & & & $\mathrm{X}$ \\
\hline Análise de viabilidade de mercado & $\mathrm{X}$ & $\mathrm{X}$ & & \\
\hline Definição da equipe do projeto & $\mathrm{X}$ & & & \\
\hline Estabelecimento do cronograma & $\mathrm{X}$ & & & \\
\hline Desenvolvimento do plano de comunicação & $\mathrm{X}$ & & & \\
\hline Estabelecimento da matriz de responsabilidades & $\mathrm{X}$ & $\mathrm{X}$ & & \\
\hline Contratação de terceiros & $\mathrm{X}$ & & & \\
\hline \multicolumn{5}{|l|}{ DESENVOLVIMENTO DO PROJETO } \\
\hline Deformulação do medicamento de referência & & & $\mathrm{X}$ & \\
\hline Aquisição dos insumos & $\mathrm{X}$ & & & $\mathrm{X}$ \\
\hline Seleção / Desenvolvimento de fornecedores & $\mathrm{X}$ & $\mathrm{X}$ & $\mathrm{X}$ & $\mathrm{X}$ \\
\hline Desenvolvimento de embalagens & $\mathrm{X}$ & $\mathrm{X}$ & & $\mathrm{X}$ \\
\hline Desenvolvimento da formulação do produto & $\mathrm{X}$ & & & $\mathrm{X}$ \\
\hline Desenvolvimento do processo de fabricação & $\mathrm{X}$ & & & $\mathrm{X}$ \\
\hline Definição dos equipamentos & & & & $\mathrm{X}$ \\
\hline Definição da infraestrutura (facilidades) & $\mathrm{X}$ & & & $\mathrm{X}$ \\
\hline Obtenção do certificado de boas práticas (BPF) & $\mathrm{X}$ & & & $\mathrm{X}$ \\
\hline
\end{tabular}




\begin{tabular}{|c|c|c|c|c|}
\hline Componentes & $\begin{array}{c}\text { De Paula } \\
\text { (2004) } \\
\text { Produtos } \\
\text { para saúde }\end{array}$ & $\begin{array}{l}\text { Yugue, } \\
\text { 2014) } \\
\text { Medicame } \\
\text { ntos }\end{array}$ & $\begin{array}{c}\text { (Silva, } \\
2015) \\
\text { Medica- } \\
\text { mento } \\
\text { genérico }\end{array}$ & $\begin{array}{c}\text { (Anvisa, } \\
\text { 2007) RDC } \\
\text { 16/2007 } \\
\text { (regula- } \\
\text { tórios) }\end{array}$ \\
\hline Desenvolvimento do método de análise dos insumos & $\mathrm{X}$ & $\mathrm{X}$ & $\mathrm{X}$ & $\mathrm{X}$ \\
\hline Desenvolvimento do método de análise dos produtos finais & $\mathrm{X}$ & $\mathrm{X}$ & $\mathrm{X}$ & $\mathrm{X}$ \\
\hline Realização de estudos de pré-formulação & $\mathrm{X}$ & $\mathrm{X}$ & $\mathrm{X}$ & \\
\hline Pesquisa de polimorfos & & $\mathrm{X}$ & & $\mathrm{X}$ \\
\hline Avaliação do "Drug Master File" - (DMF) ${ }^{4}$ & & $\mathrm{X}$ & & $\mathrm{X}$ \\
\hline Validação dos métodos analíticos & $\mathrm{X}$ & $\mathrm{X}$ & $\mathrm{X}$ & $\mathrm{X}$ \\
\hline Validação da limpeza dos equipamentos & $\mathrm{X}$ & & & \\
\hline Qualificação dos fornecedores & $\mathrm{X}$ & & & \\
\hline Produção do medicamento em lote de bancada & $\mathrm{X}$ & $\mathrm{X}$ & $\mathrm{X}$ & \\
\hline Definição da fórmula padrão ou fórmula mestra & $\mathrm{X}$ & & $\mathrm{X}$ & $\mathrm{X}$ \\
\hline Realização do teste de perfil de dissolução & & & $\mathrm{X}$ & $\mathrm{X}$ \\
\hline Produção do produto em lote piloto & $\mathrm{X}$ & $\mathrm{X}$ & $\mathrm{X}$ & $\mathrm{X}$ \\
\hline Realização de estudos de equivalência farmacêutica & $\mathrm{X}$ & & $\mathrm{X}$ & $\mathrm{X}$ \\
\hline Realização de estudos de estabilidade acelerada & $\mathrm{X}$ & $\mathrm{X}$ & $\mathrm{X}$ & $\mathrm{X}$ \\
\hline Realização de estudos de estabilidade de longo prazo & $\mathrm{X}$ & $\mathrm{X}$ & & $\mathrm{X}$ \\
\hline Realização de estudos de produtos de degradação & & $\mathrm{X}$ & & $\mathrm{X}$ \\
\hline Realização de estudos de produtos de fotoestabilidade & & $\mathrm{X}$ & & $\mathrm{X}$ \\
\hline Realização dos testes de controle de qualidade & & & & $\mathrm{X}$ \\
\hline Transferência para escala industrial ("scale up") & $\mathrm{X}$ & & & \\
\hline Realização da validação do processo & $\mathrm{X}$ & & & \\
\hline Realização de estudos de biodisponibilidade & $\mathrm{X}$ & & & $\mathrm{X}$ \\
\hline Realização de estudos de bioequivalência & & $\mathrm{X}$ & $\mathrm{X}$ & $\mathrm{X}$ \\
\hline $\begin{array}{l}\text { Elaboração do documento mestre de produto / dossiê }{ }^{5} \text { de } \\
\text { desenvolvimento do produto }\end{array}$ & $\mathrm{X}$ & $\mathrm{X}$ & & $\mathrm{X}$ \\
\hline Determinação dos procedimentos de armazenamento & $\mathrm{X}$ & & & \\
\hline Determinação dos procedimentos de transporte & $\mathrm{X}$ & & & \\
\hline Elaboração do dossiê para registro do produto na Anvisa & $\mathrm{X}$ & $\mathrm{X}$ & & $\mathrm{X}$ \\
\hline \multicolumn{5}{|l|}{ APÓS O DESENVOLVIMENTO DO PRODUTO } \\
\hline $\begin{array}{l}\text { Acompanhamento de eventuais reações indesejadas ao } \\
\text { produto }\end{array}$ & $\mathrm{X}$ & & & $\mathrm{X}$ \\
\hline Conclusão do estudo de estabilidade de longo prazo & $\mathrm{X}$ & & & $\mathrm{X}$ \\
\hline $\begin{array}{l}\text { Acompanhamento de eventuais problemas técnicos com o } \\
\text { produto }\end{array}$ & $\mathrm{X}$ & & & $\mathrm{X}$ \\
\hline Atendimento a eventuais exigências da Anvisa & $\mathrm{X}$ & $\mathrm{X}$ & & \\
\hline
\end{tabular}

Fonte: dados da pesquisa.

${ }^{4}$ DMF (Arquivo Mestre da Droga, na sigla em inglês) é um documento base para o registro de insumos farmacêuticos e contém informações técnicas (físicas, químicas, físico-químicas e farmacológicas) da substância, incluindo detalhes de seu processo de fabricação que possam ter influência sobre a suas propriedades.

${ }^{5}$ Dossiê é um conjunto de documentos normalmente elaborado para descrever um produto e/ou processo para fins de comprovação e/ou sustentação de uma solicitação legal para, por exemplo, o registro de um medicamento. 


\subsubsection{Os medicamentos genéricos}

Os medicamentos genéricos foram aprovados em 1999 (Brasil, 1999) com o objetivo de aumentar o acesso da população aos medicamentos, uma vez que seus preços são obrigatoriamente menores do que os dos seus medicamentos de referência. Sua introdução no mercado foi muito importante para a sociedade brasileira em razão do aumento da disponibilidade de medicamentos com qualidade, segurança e eficácia garantidas a um custo menor. A política dos genéricos foi criada no mesmo ano que a Anvisa, estando alinhada à missão da agência no que diz respeito a promover e proteger a saúde da população (Do Carmo, Piras, et al., 2017).

Tendo por referência a Artigo XXIV da Lei no 5.991, de 17/12/1973 (Brasil, 1973), a Anvisa, (2016) define medicamento como um produto farmacêutico, tecnicamente obtido ou elaborado e com finalidade profilática, curativa, paliativa ou para fins de diagnóstico.

O medicamento genérico, mais especificamente, é definido como:

Medicamento que contém o mesmo princípio ativo, na mesma dose e forma farmacêutica, é administrado pela mesma via e com a mesma posologia e indicação terapêutica do medicamento de referência, apresentando eficácia e segurança equivalentes à do medicamento de referência podendo, com este, ser intercambiável (Anvisa, 2018b, p.1).

Embora a definição adotada por este estudo seja a da Anvisa (2018b, p.1), outras definições para "medicamento genérico" encontradas na literatura (Tabela 8) auxiliam na compreensão do conceito.

Tabela 8 - Conceito de medicamento genérico

\begin{tabular}{|c|c|}
\hline Autor & Conceito de medicamento genérico \\
\hline $\begin{array}{l}\text { Shargel e Kanfer } \\
(2005, \text { p. 1) }\end{array}$ & $\begin{array}{l}\text { Um medicamento genérico (...) “é considerado 'essencialmente similar’ ou } \\
\text { bioequivalente a um produto inovador (de marca)." } \\
\text { "Os medicamentos genéricos normalmente são vendidos com descontos substanciais em } \\
\text { relação às suas contrapartes de marcas." }\end{array}$ \\
\hline $\begin{array}{l}\text { Organização } \\
\text { Mundial da Saúde } \\
\text { (WHO, 2016) }\end{array}$ & $\begin{array}{l}\text { "Medicamentos genéricos são aqueles produzidos sem uma licença da empresa } \\
\text { inovadora quando a patente ou outros direitos de exclusividade de mercado do produto } \\
\text { inovador expiraram." }\end{array}$ \\
\hline $\begin{array}{l}\text { Do Carmo, } \\
\text { Nogueira, e } \\
\text { colaboradores } \\
(2017, \text { p. } 121)\end{array}$ & $\begin{array}{l}\text { "Os medicamentos genéricos são intercambiáveis com um medicamento de referência, } \\
\text { com comprovada segurança eficácia e qualidade". } \\
\text { "É produzido geralmente após expiração ou renúncia da proteção patentária do } \\
\text { medicamento de referência." }\end{array}$ \\
\hline
\end{tabular}

Fonte: dados da pesquisa. 
Na definição de medicamento genérico estão presentes outros conceitos necessários para o seu entendimento. $\mathrm{O}$ medicamento de referência, também denominado medicamento de marca, de acordo com a Anvisa (2018c, p.1), é definido como:

Um produto inovador, registrado no órgão federal responsável pela vigilância sanitária e comercializado no País cuja eficácia, segurança e qualidade foram comprovadas cientificamente junto ao órgão federal competente por ocasião do registro, conforme a definição do inciso XXII, artigo $3^{\circ}$, da Lei n. 6.360, de 1976 (com redação dada pela Lei nº 9.787/1999).

A intercambialidade, por sua vez, é definida como a:

Segura substituição do medicamento de referência pelo seu genérico, (...) assegurada por testes de equivalência terapêutica, que incluem comparação in vitro, através dos estudos de equivalência farmacêutica e in vivo, com os estudos de bioequivalência apresentados à Agência Nacional de Vigilância Sanitária. (Anvisa, 2018c, p.1).

A equivalência terapêutica é demonstrada por meio da avaliação da bioequivalência entre um novo medicamento e seu medicamento de referência envolvendo um estudo farmacocinético comparativo padronizado (Worku et al., 2012). Conforme definição do FDA (2007), um medicamento é farmaceuticamente equivalente e bioequivalente ao medicamento de referência se contiver a(s) mesma(s) substância(s) ativa(s) na mesma potência e na mesma forma de dosagem. Medicamentos bioequivalentes não mostram nenhuma diferença significativa na taxa e extensão da absorção do ingrediente ativo no local da ação. A bioequivalência com base na concentração do fármaco no plasma é considerada como o marcador mais comumente utilizado e bem sucedido de segurança e eficácia.

Muitos autores abordam o tema dos medicamentos genéricos conjuntamente com os medicamentos denominados similares em razão das semelhanças entre estas duas categorias de medicamentos. O medicamento similar é conceituado como:

Aquele que contém o mesmo ou os mesmos princípios ativos, apresenta a mesma concentração, forma farmacêutica, via de administração, posologia e indicação terapêutica, e que é equivalente ao medicamento registrado no órgão federal responsável pela vigilância sanitária, podendo diferir somente em características relativas ao tamanho e forma do produto, prazo de validade, embalagem, rotulagem, excipientes e veículos, devendo sempre ser identificado por nome comercial ou marca. (Anvisa, 2018c, p.1).

Prado (2011) aponta que, em geral, a produção de medicamentos genéricos exige menor grau de verticalização por não ser necessária a realização das fases de pesquisa que exigem maior investimento e capacidade tecnológica específica, exceto a realização de testes de bioequivalência e biodisponibilidade. Estas são algumas das razões apontadas pela pesquisadora para esse segmento de mercado ter se tornado atraente aos laboratórios farmacêuticos de pequeno e médio porte. 
Os medicamentos genéricos desempenham um papel importante na saúde pública, pois são bem conhecidos pela comunidade médica, são mais acessíveis e tem qualidade, eficácia e segurança com os mesmos padrões exigidos dos medicamentos de referência (Worku et al., 2012). Para Gota e Patial (2014), os pacientes tendem a valorizar mais as economias com os medicamentos genéricos do que a qualidade "premium" dos medicamentos de marca.

De acordo com Suchak \& Murray (2017), os elevados preços dos medicamentos de marca e o aumento dos custos dos cuidados com a saúde tem contribuído para o aumento da demanda por medicamentos genéricos de baixo custo. Além disso, Genazzani e Pattarino (2008) e a própria Organização Mundial da Saúde - OMS (WHO, 2016) afirmam que os medicamentos genéricos criam competição de mercado, o que também favoreceria a redução de preços e a melhoria da qualidade dos medicamentos. Fatokun, Mohamed Ibrahim e Ahmad Hassali (2013) relatam o caso da Malásia que, segundo os pesquisadores, depende da disponibilidade de medicamentos genéricos para conter o aumento das despesas com medicamentos de seu setor de saúde pública, que é altamente subsidiado, e reduzir o peso para os consumidores que pagam para ter acesso aos serviços privados de saúde. Huang e colaboradores (2013) acreditam que a disponibilização de medicamentos genéricos com qualidade assegurada é um recurso crítico para colocar o conceito de medicamentos essenciais em prática.

As poucas publicações encontradas na literatura e relacionadas aos medicamentos genéricos, ou têm foco no desenvolvimento de produtos específicos, ou em processos genéricos de desenvolvimento. São exemplos as publicações de Kader (2016), Harpum (2010) e Shargel e Kanfer (2005). Outros estudos são baseados em dados das agências reguladores, basicamente sobre deficiências nos processos de autorização para a comercialização dos produtos. São exemplos as publicações de Do Carmo (2017), Do Carmo, Nogueira e colaboradores (2017), Huang e colaboradores (2013), Organização Mundial da Saúde (WHO, 2016), Srinivasan e Iser (2010) e Worku e colaboradores (2012). Esta escassez de estudos foi constatada pelo levantamento bibliográfico realizado, o qual é detalhado nos Apêndices I e II desta tese.

Torres e Souza (2010) realizaram estudo sobre o mercado brasileiro de medicamentos genéricos e verificaram que a principal disputa entre os fabricantes de medicamentos genéricos pela presença nos pontos de dispensação de medicamentos (farmácias comerciais, hospitalares e públicas) estaria em ter o maior número de itens para atender o máximo da demanda pelos medicamentos. No entanto, dada a limitação no número de itens em razão do espaço nos pontos de dispensação, nem todos os produtos e fornecedores conseguem entrar em todos os pontos, estabelecendo-se um dos fatores para competição. Entrar primeiro nestes pontos pode estabelecer uma forma de barreira aos novos entrantes pela maior dificuldade de acesso aos canais de distribuição. Além disso, o estudo indica que em razão da 
impossibilidade de diferenciação entre os medicamentos genéricos, a concorrência se desenvolve com foco em preço e desconto, evidenciando a adoção de uma estratégia de liderança em custo.

Em abordagem gerencial voltada ao desenvolvimento de produtos, Wheelwright e Clark (1992) destacam três fontes de vantagem competitiva que a habilidade para desenvolver produtos pode gerar para as empresas: qualidade do "design", desempenho do produto e participação de mercado e custos. As duas primeiras fontes de vantagem competitiva em produtos em geral não seriam capazes de gerar significativa vantagem competitiva em se tratando de medicamentos genéricos, uma vez que devem ser exatamente iguais ao medicamento de referência (Anvisa, 2018b). No entanto, participação de mercado e custos são fatores de diferenciação dos medicamentos genéricos (D. Taylor, 2016). De acordo com Wheelwright e Clark (1992), as empresas podem decidir por precificar seus produtos com o objetivo de criar valor superior a seus consumidores e assim buscar maior participação de mercado. Quando custos mais baixos são direcionados por crescimento e aumento em volume, aumentos em participação de mercado podem ser traduzidos em melhor posição competitiva em custos.

\subsubsection{Desenvolvimento de medicamentos genéricos}

Embora focada em formas farmacêuticas sólidas (por exemplo, comprimidos e cápsulas), a única referência encontrada na literatura que trata especificamente e de forma abrangente do desenvolvimento dos medicamentos genéricos é o livro de Shargel e Kanfer (2005). Segundo os autores, o desenvolvimento de medicamentos genéricos parte de moléculas (fármacos ou princípios ativos) já conhecidas e devem ser formulados para apresentar a mesma eficácia terapêutica e desempenho clínico do medicamento de referência ou inovador.

Os medicamentos genéricos devem corresponder aos medicamentos originais, o que significa atender a critérios rígidos de aceitação e contornar patentes restritivas (além da patente do ativo farmacêutico). Há restrições ao desenvolvimento do medicamento genérico que vão além de desafios regulatórios e legais e que podem trazer dificuldades importantes. Algumas das possíveis razões para não se conseguir reproduzir as características do medicamento de referência são: as características do IFA (ingrediente farmacêutico ativo ou princípio-ativo), a composição da formulação em relação aos excipientes utilizados e o processo de fabricação empregado desejado (Genazzani \& Pattarino, 2008; Isadore Kanfer et al., 2014; Leon Shargel \& Kanfer, 2005). Por estas razões, o desenvolvimento de um medicamento genérico pode ser desafiador.

Além destes desafios de ordem técnica e regulatória, os laboratórios farmacêuticos se empenham para levar os medicamentos genéricos rapidamente ao mercado, pressionadas por fatores como: vencimento da patente de vários medicamentos em um curto espaço de tempo; aumento da concorrência de novos entrantes; e aumento do número de medicamentos genéricos concorrentes para o mesmo fármaco (Kader, 2016). 
Para Do Carmo (2017), mesmo em se tratando de um medicamento genérico, o seu projeto de desenvolvimento e o processo de submissão de registro exigem cuidadoso planejamento, uma vez que demandam tempo, recursos e o atendimento às normas especificas e às excepcionalidades de cada caso. Kanfer e colaboradores (2014) sugerem que o desenvolvimento da formulação deva começar apenas depois que os seguintes itens forem adequadamente atendidos: patentes relevantes acessadas e investigadas; pesquisa bibliográfica realizada; estratégias regulatórias e de formulação estabelecidas; e os ingredientes farmacêuticos ativos (IFA) encomendados e recebidos.

De acordo com Kanfer e colaboradores (2014), o desenvolvimento de um novo medicamento genérico em geral tem início com a definição de uma estratégia regulatória que direciona a decisão sobre quais os projetos a serem desenvolvidos (portfólio) e que considera o casamento entre a data em que o novo medicamento poderia ser legalmente comercializado (vencimento da patente) e data em que o medicamento desenvolvido poderia ter sua comercialização aprovada ao atender a todos os requisitos regulatórios. Em outras palavras, de um lado considera o objetivo de ser o primeiro a entrar no mercado e, de outro lado, a necessidade de atender aos requisitos legais.

Com relação aos requisitos legais mais especificamente, estes estão relacionados às patentes das matérias-primas e dos processos de fabricação, as quais precisam ser detalhadamente investigadas. Para cada obstáculo devem ser estabelecidas e implementadas estratégias para evitar a possibilidade de infração das patentes (Isadore Kanfer et al., 2014). Atendidos os requisitos relacionados às patentes, o atendimento aos requisitos regulatórios passam a ser os mais críticos. No caso brasileiro, a Anvisa (2017b), por meio da RDC 200/2017, define os requisitos para o registro de um novo medicamento. São solicitadas informações sobre a formulação, processo de produção, IFA, coadjuvantes, embalagem, fornecedores, equipamentos, relatórios e resultados de testes de controle de qualidade, equivalência, bioequivalência, estabilidade, entre outros.

Já do ponto de vista da viabilidade técnica, para o desenvolvimento da formulação do medicamento, Kanfer e colaboradores (2014) sugerem avaliar criticamente o produto e, sempre que possível, a sua composição e as características e especificações de seus componentes, dos equipamentos necessários e do processo de fabricação a ser utilizado. Existem, complementarmente, normas específicas para a maioria desses itens, como, por exemplo, a RDC 301/2019 (Anvisa, 2019f) que trata das boas práticas de fabricação e o guia da (Anvisa, 2019c) que estabelece os critérios para a realização de estudos de estabilidade de insumos farmacêuticos ativos e medicamentos.

No desenvolvimento de um novo medicamento, a aquisição de matéria-prima pode ser um grande desafio, mais especificamente do IFA, que é o componente principal de um medicamento. Primeiro é necessário encontrar os fabricantes e/ou distribuidores (autorizados ou representantes) que tenham os IFAs disponíveis para fornecimento. Segundo, os fornecedores identificados devem 
fornecer informações técnicas sobre os IFAs de acordo com os requisitos regulatórios específicos e suficientes para a avaliação inicial de adequação ao medicamento pretendido. Estas informações incluem instalações, processos de fabricação, rota de síntese da molécula, embalagem e armazenamento. Terceiro, devem ser avaliadas as informações sobre o fornecedor como histórico de contratos de fornecimento anteriores, prontidão, qualidade dos insumos, relações de trabalho e viabilidade comercial (Isadore Kanfer et al., 2014).

Um aspecto importante diz respeito ao elevado grau de integração que deve existir entre o fabricante do IFA e o laboratório farmacêutico em razão da necessidade de compartilhamento de propriedade intelectual e estratégias, além da elevada dependência do medicamento em relação ao IFA selecionada para compor a sua formulação (Isadore Kanfer et al., 2014). Este ponto é de especial criticidade quando considerado que, pela legislação brasileira, as mudanças após o registro de um medicamentos são classificadas de acordo com o seu potencial impacto na qualidade, segurança e eficácia, podendo ter autorização para implementação imediata ou depender de análise e aprovação da (Anvisa, 2017b).

Ainda de acordo com Kanfer e colaboradores (2014), outra importante dificuldade nos projetos de desenvolvimento de medicamentos genéricos (PDMG) ocorre nas mudanças de escala de produção, uma vez que os estudos tem início com lotes de bancada de laboratório para depois serem transferidos para produção industrial. $\mathrm{O}$ aumento do tamanho do lote pode trazer problemas difíceis de detectar em escalas menores e/ou provocar ou gerar comportamentos não esperados das matérias-primas e/ou do processo. Na medida do possível, o tipo de equipamento e de ferramentas usados na fase de desenvolvimento devem ser compatíveis com aqueles usados para a fabricação em escala de produção para que seja reduzida a necessidade de ajustes no momento de realizar a transferência da escala menor para a industrial.

Embora seja composta pela mesma lógica do desenvolvimento de outros medicamentos não inovadores, a Figura 13 representa a sequência de grupos de atividades que, em geral, são realizadas nos PDMG. Pode-se verificar que não há diferenças significativas em relação aos modelos apresentados nas Figuras 10 e 11. 
Figura 13 - Sequência de pacotes de trabalho para o desenvolvimento de um medicamento genérico.

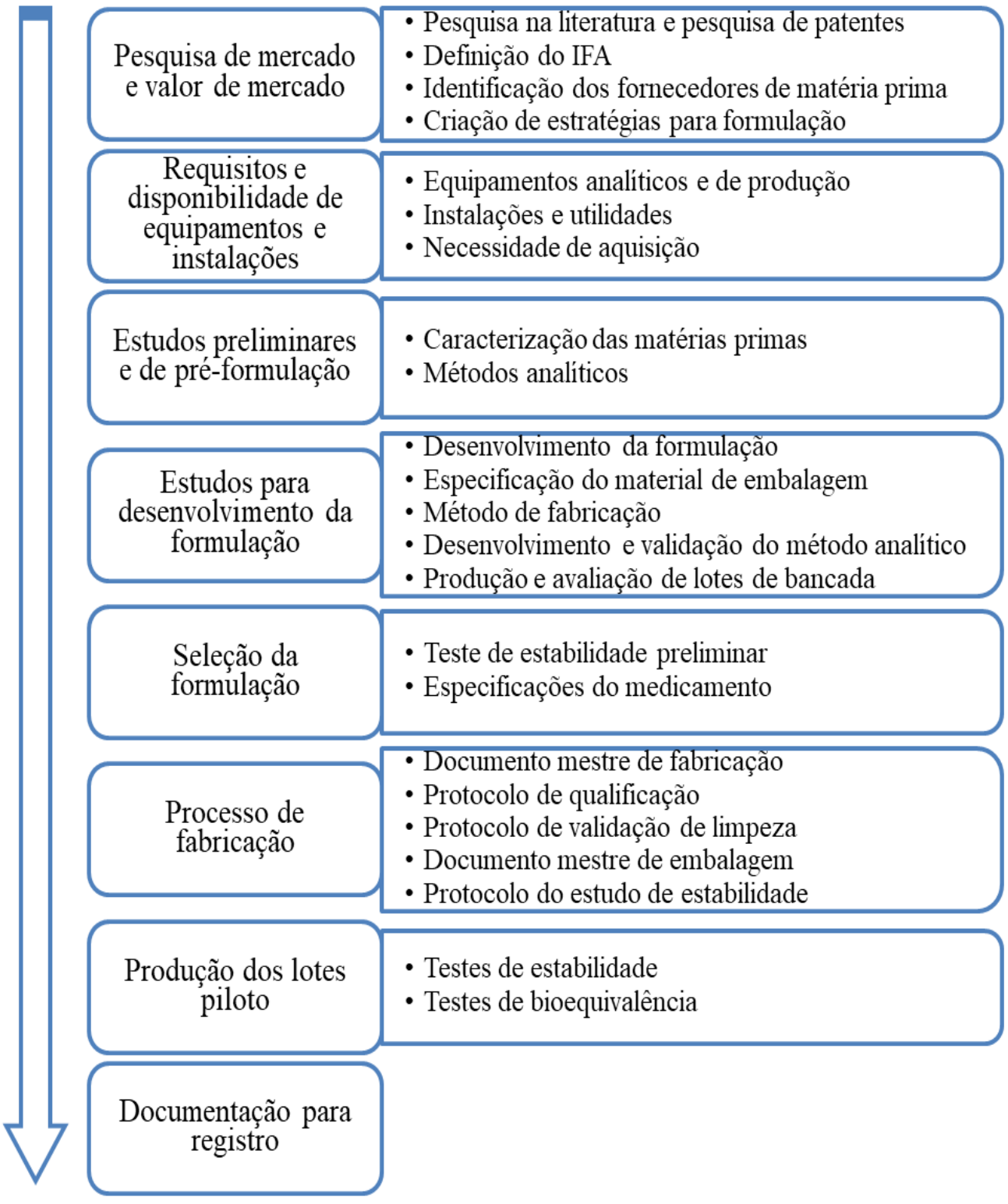

Fonte: adaptado de Kanfer e colaboradores (2014, pp. 76-77).

O registro do medicamento no órgão regulador, a Anvisa no caso brasileiro, é condição obrigatória para que o medicamento possa ser colocado no mercado. Para tanto, o laboratório precisa solicitar o registro àquele órgão e fornecer um conjunto de dados, informações e documentos sobre a empresa, o medicamento, seu processo de fabricação e os resultados dos testes realizados que comprovem a sua segurança, eficácia e, no caso dos medicamentos genéricos, a sua equivalência em relação ao medicamento de referência (Anvisa, 2017b). Esta documentação é chamada de dossiê de registro. Do Carmo (2017) apresenta um fluxograma representando o processo de análise dos pedidos de registro de medicamentos genéricos no Brasil, o qual é representado na Figura 14 a seguir. 
Figura 14 - Fluxograma de análise de petições de registro de medicamento na Anvisa

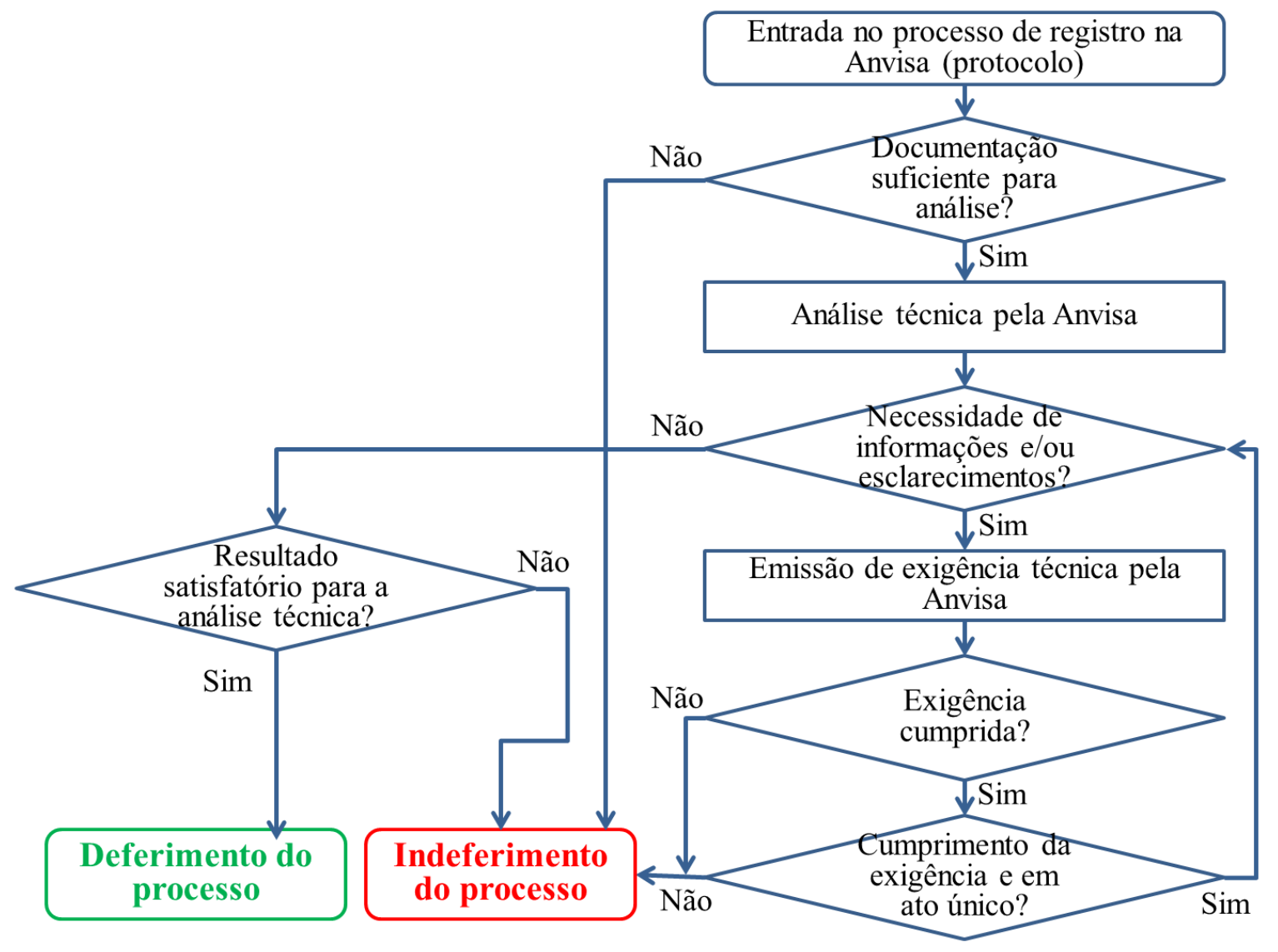

Fonte: adaptado de Do Carmo (2017, p. 19).

Hajjar Júnior (2010) realizou para sua dissertação de mestrado uma pesquisa sobre o processo de desenvolvimento e lançamento usando como base o caso de um novo medicamento genérico. $\mathrm{O}$ projeto estudado teve um custo estimado em cerca de meio milhão de reais e um prazo estimado em 16 meses que tiveram início nas análises de viabilidade e terminaram com a preparação da documentação para o pedido de registro do medicamento. A pesquisa estimou ainda em 9 meses o prazo para análise e aprovação pela Anvisa, totalizando 25 meses do início do projeto à aprovação do registro do novo medicamento genérico.

A (Anvisa, 2019d) apresenta um esquema mais detalhado do processo de registro com as etapas internas divididas em cinco, como pode ser visualizado na Figura 15. 
Figura 15 - Processo da Anvisa para o registro de um novo medicamento

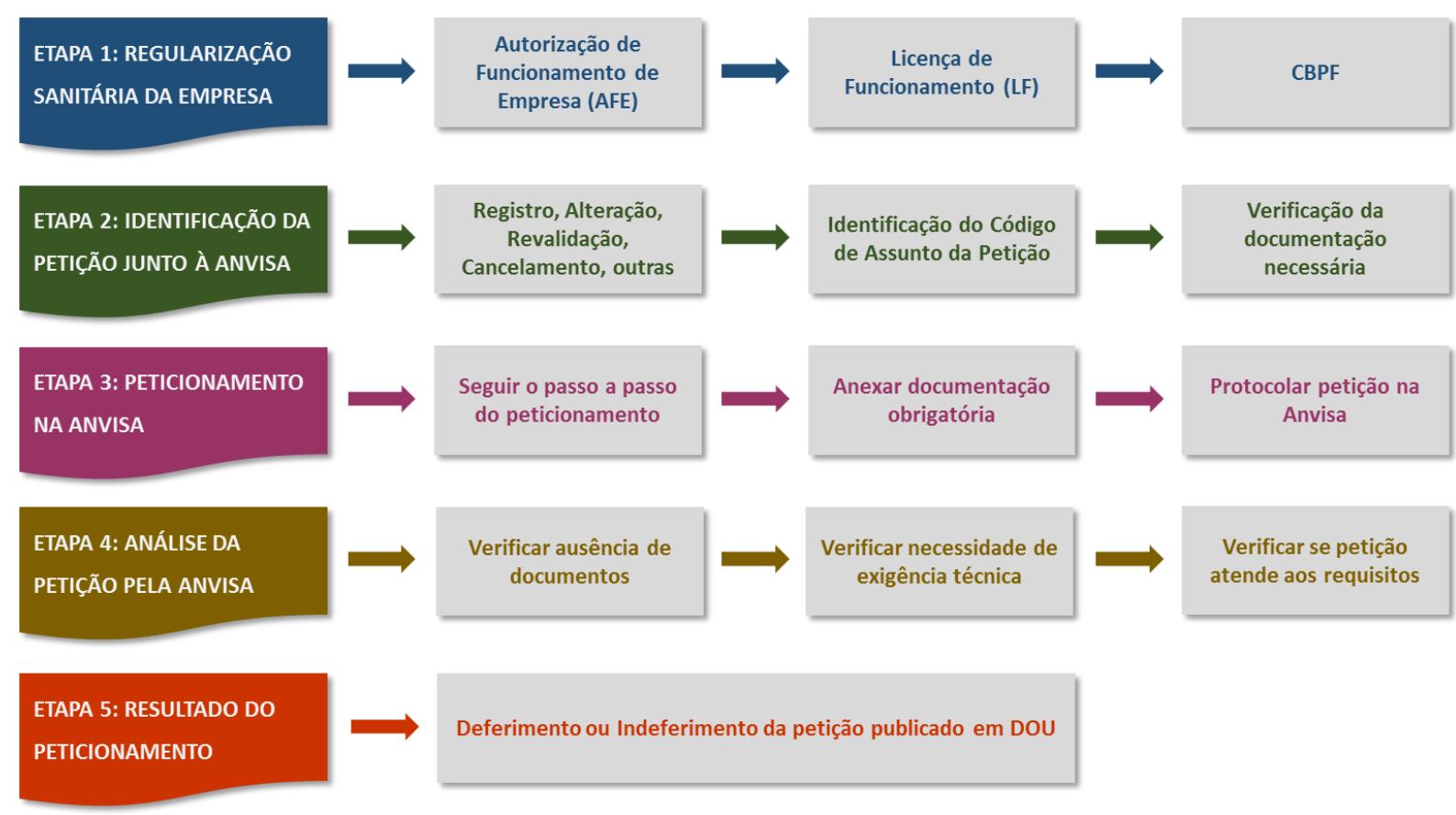

Fonte: reproduzido de Anvisa (2019d).

O FDA (2007) identificou quatro áreas de oportunidades no desenvolvimento mais eficiente de produtos de alta qualidade, com foco especial em medicamentos genéricos, as quais são relacionadas a seguir.

- Melhorar o embasamento científico usando a qualidade por meio do delineamento ("Quality by Design" - QbD) para o desenvolvimento e fabricação de medicamentos;

- Melhorar a eficiência dos métodos atuais de avaliação da bioequivalência de medicamentos como os que usam novas tecnologias complexas de liberação do fármaco;

- Desenvolver métodos para a avaliação da bioequivalência de medicamentos que agem localmente;

- Desenvolver métodos para caracterização de substâncias medicamentosas e de produtos complexos.

Kader (2016) menciona a recomendação dos órgãos reguladores, como o FDA, para que a indústria de medicamentos genéricos adote o QbD para desenvolver as formulações e os processos de fabricação, mas coloca a questão de como o QbD pode ser implementado sem afetar o tempo e o custo do desenvolvimento. Um esquema da abordagem QbD no desenvolvimento de formulações genéricas e processo de fabricação é ilustrado na Figura 16. 
Figura 16 - Etapas para desenvolvimento de formulações genéricas usando o "Quality by Design"

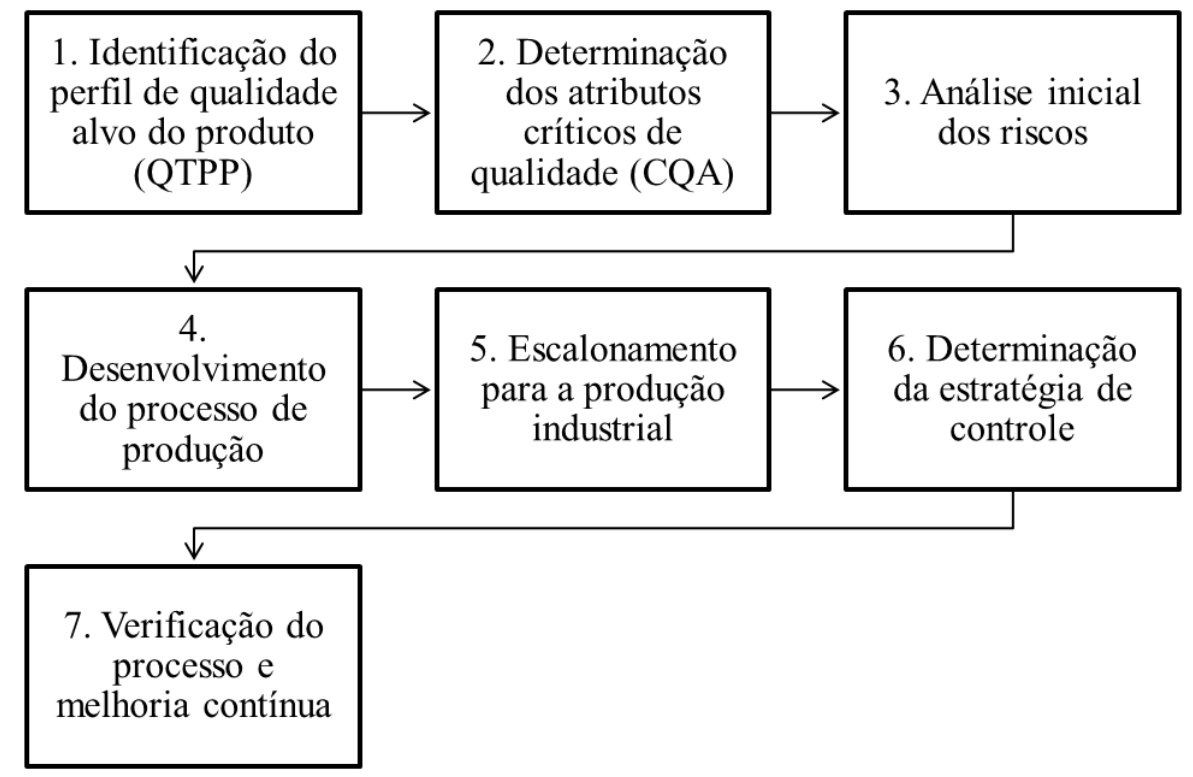

Fonte: adaptado de $\operatorname{Kader}(2016$, p. 37).

Um tópico importante refere-se à igualdade entre os medicamentos de referência e seus genéricos. Genazzani e Pattarino (2008) afirmam que, embora existam salvaguardas nos regulamentos para garantir a segurança do paciente e a eficácia dos medicamentos genéricos, não se deve presumir que todos os genéricos são totalmente idênticos. Os pesquisadores chegam a concluir que os medicamentos genéricos podem diferir significativamente do medicamento de referência e entre si, particularmente em termos de propriedades farmacocinéticas ${ }^{6}$. Esta constatação está intimamente ligada à questão desta pesquisa, uma vez que as normas estritas para o registro dos medicamentos genéricos podem ser determinantes do desempenho de seus projetos de desenvolvimento.

Em abordagem com a aplicação de métodos alternativos de DP, Chaudhuri (2013) sugeriu um processo de desenvolvimento de medicamentos genéricos seguindo a metodologia Seis Sigma. Como justificativa, o pesquisador indicou a padronização, a otimização e a colaboração como geradoras de melhorias no tempo, no custo e na qualidade do desenvolvimento simultaneamente. A Figura 17 apresenta o diagrama proposto pelo pesquisador para o processo de desenvolvimento de um produto farmacêutico genérico.

\footnotetext{
${ }^{6}$ Farmacocinética é o estudo e a caracterização do comportamento no tempo da absorção, da distribuição, do metabolismo e da eliminação de medicamentos do organismo de uma pessoa e é avaliado pela medição sistemática da concentração do medicamento do sangue (perfil plasmático) (Aulton \& Taylor, 2016)
} 
Figura 17 - Desenvolvimento de um medicamento genérico usando Seis Sigma

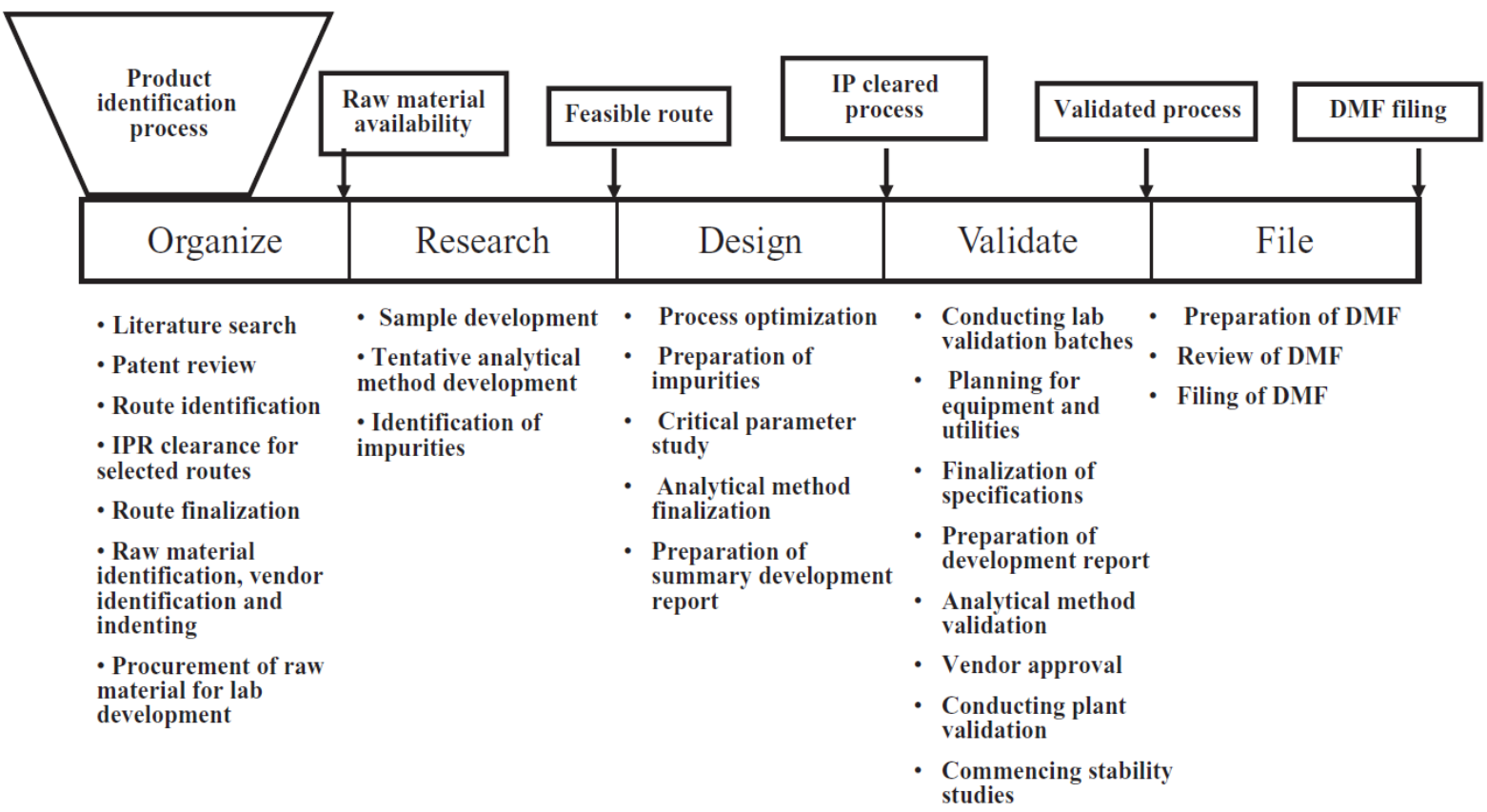

Fonte: reproduzido de Chaudhuri, (2013, p. 233).

Outros pesquisadores que abordam o desenvolvimento de medicamentos genéricos, mas para temas mais específicos são: Anand, Yu, Conner e Davit (2011); Davit e colaboradores (2009); Chang, Raw, Lionberger e Yu (2013); Chongprasert (2016); Jen e Liu (2012); Lionberger (2008); Lee, Chen, Romanelli e Segal (2016); Varu e Khanna (2010); Yousefi, Mehralian, Rasekh e Yousefi (2017); e Yu (2008).

\subsection{DESEMPENHO DE PROJETOS DE DESENVOLVIMENTO DE PRODUTOS}

Em seu estudo no início da década de 1990, Cooper (1990) já observava que na prática que poucos desenvolvimentos de produtos são bem sucedidos. Mais especificamente, encontrou que apenas um projeto de DP em cada quatro se tornava vencedor e que quase $50 \%$ dos recursos que as empresas norte-americanas dedicavam ao desenvolvimento de novos produtos eram gastos em projetos perdedores.

De acordo com Rozenfeld e colaboradores (2006), na década de 2000, estimava-se que em torno de $85 \%$ dos custos do ciclo de vida de um produto seria reflexo da fase de projeto do DP, uma vez que é nela que são determinadas as tecnologias básicas do produto e do processo, os materiais e as especificações. Eles também estimaram que seriam possíveis reduções de mais de $50 \%$ no tempo de lançamento de um produto quando os problemas de projeto são identificados e resolvidos com antecedência, em razão da redução do número de alterações posteriores e da otimização dos tempos de manufatura. 
A importância de medir o desempenho em diferentes estágios do processo de DP é destacada por vários autores na literatura, tais como: Alegre, Lapiedra e Chiva (2006); Driva, Pawar e Menon, (2000) e Montoya-Weiss e Calantone (1994). Estes últimos concluíram que o conteúdo da literatura analisada por eles sobre o DP era bastante diversificado e, em específico, as pesquisas sobre o desempenho de novos produtos não eram suficientemente consistentes para a definição dos fatores considerados em cada estudo. Na mesma época, Griffin e Page (1996) contabilizaram que empresas e acadêmicos já haviam usado mais de 75 medidas distintas de sucesso no desenvolvimento de produtos, com pouco consenso sobre quais seriam as medidas mais úteis e, assim, haveria dificuldade para uma empresa definir se um novo produto era realmente bem-sucedido.

Além disso, embora o objetivo final da maioria das empresas fosse o sucesso financeiro, de acordo com Griffin e Page (1996), projetos diferentes de DP teriam necessidades de resultados diferentes. Assim, um grande problema na determinação do sucesso de produtos individuais teria por origem a multidimensionalidade dos resultados do desenvolvimento de produtos. McNamee e Celona (2008), em publicação sobre decisões, apresentam um caso sobre projetos de pesquisa de novos medicamentos e indicaram a dificuldade em definir exatamente o que significava um desenvolvimento ser tecnicamente bem sucedido e consideraram que pode ser necessário modelar vários níveis de sucesso.

Cooper e Kleinschmidt (1987b) definiram o sucesso como a realização de algo desejado, planejado ou tentado, ou seja, medidas de desempenho "versus" objetivos. Griffin e Hauser (1996), por sua vez, definiram uma medida de resultado primário que denominaram "sucesso" e que operacionalizada usando uma combinação das medidas definidas pelo Product Development \& Management Association - PDMA (em português Associação de Desenvolvimento e Gestão de Produtos), ou seja: medidas relacionadas aos clientes (participação de mercado e satisfação de clientes); medidas financeiras (metas e margens de lucro); medidas de processo (desempenho técnico e tempo para colocação no mercado); medidas no nível da empresa (taxa de sucesso e porcentagem de vendas de novos produtos); e medidas do programa (satisfação da equipe com os resultados). Rozenfeld e colaboradores (2006) consideram que o processo de desenvolvimento de um produto teve sucesso se o produto resultante for aceito no mercado como previsto e se atingiu principalmente os objetivos de faturamento, rentabilidade e aumento da participação no mercado.

Cooper e Kleinschmidt (1987b) analisaram fatores que contribuem para o sucesso dos novos produtos. As principais conclusões do estudo foram:

- O sucesso de novos produtos é um conceito multidimensional com três dimensões independentes e subjacentes do sucesso: desempenho financeiro, janela de oportunidade e participação de mercado; 
- O sucesso de novos produtos é previsível. Existem relações fortes entre os resultados do projeto e a natureza do produto, mercado e sinergia;

- O conjunto de fatores vinculados a cada tipo de sucesso é normalmente diferente entre si. Em outras palavras, além de existirem ao menos três dimensões independentes do desempenho de novos produtos, os fatores correlacionados de sucesso também são diferentes para cada uma das dimensões de desempenho.

Para que o sucesso do DP possa ser verificado, é necessário um sistema de medição de desempenho que pode ser definido como o conjunto de métricas usadas para quantificar a eficiência e a eficácia das ações (Kalluri \& Kodali, 2014; Neely, Gregory, \& Platts, 2005). De uma forma geral, quando a eficácia é avaliada, o foco está no sucesso do produto desenvolvido, ou seja, no atingimento dos resultados de mercado e de retorno sobre o investimento. Já quando a eficiência é avaliada, o foco está no sucesso do projeto de desenvolvimento, ou seja, na entrega do produto dentro ou melhor que o prazo, os custos, o escopo e a qualidade planejados.

A eficácia do processo de DP é obtida quando ele entrega os resultados que atendem às expectativas dos clientes e às estratégias da empresa. Para Wheelwright e Clark (1992), o atendimento das necessidades e requisitos dos consumidores não só leva à vantagem competitiva, mas também a outros resultados como: a abertura de novos mercados, a atração de novos consumidores e a melhoria dos ativos da empresa, incluindo novas competências. Cooper e Kleinschmidt (1987a) advogaram que o desenvolvimento com vantagens reais é o principal objetivo do processo de DP. Maximiano (2002), considera que o conceito de sucesso é subjetivo, pois depende do entendimento do cliente. A eficiência do processo de DP, por sua vez, é entendida como o atingimento dos resultados pretendidos utilizando o mínimo possível de recursos (Rozenfeld et al., 2006).

Em uma discussão sobre a eficiência e a eficácia dos projetos de DP, Shenhar e colaboradores (1997) consideram que as medidas internas de eficiência (orçamento, cronograma e metas técnicas) são parciais e por vezes enganosas ao ignorarem a possibilidade de um projeto ser eficientemente executado, mas não atender às expectativas dos clientes e/ou da organização. Desta forma, a mensuração dos resultados de um projeto somente sobre o processo de implementação não seria suficiente. Esta constatação seria a responsável por pesquisas que levaram à complementação do conceito de sucesso dos projetos. O PMI (2017), por exemplo, apresenta uma ampla relação de medidas mais amplas para o resultado dos projetos. Entre elas está o cumprimento dos termos e condições do contrato para o caso do DP ser realizado para ou por terceiros.

Também sobre a eficácia e a eficiência do DP, Henard e Szymanski (2001) estudaram o desempenho considerando fatores significativos e não significativos, os direcionadores dominantes e a amplitude e a ênfase em modelagem do desempenho. Eles concluíram que haveria mais chances de 
sucesso se mais ênfase fosse dada ao mercado, à estratégia e às características do produto (eficácia) do que às características do processo (eficiência).

Já na década de 1970, era considerável a produção de pesquisas sobre o gerenciamento de projetos de DP. No entanto, Murphy, Baker e Fisher (1974) avaliaram que pouco havia sido feito no sentido de formular uma teoria completa sobre o desempenho dos projetos. Em sua pesquisa mesmo duas décadas depois, Griffin e Page (1996) observaram que ainda havia deficiências nos estudos ao constatarem pouca correlação entre as mensurações que as empresas usavam e as mensurações que os desenvolvedores de produtos gostariam de usar para julgar o desempenho do DP. Algumas das causas seriam a inexistência de sistemas para obter os números necessários e pela falta de uma cultura que apoiasse a mensuração do desempenho dos projetos de DP.

Na mesma época, Shenhar e colaboradores (1997) verificaram que havia várias formas de mensuração para expressar o sucesso ao nível dos projetos, sendo as mais comuns as relacionadas ao atendimento das metas de cronograma, orçamento e desempenho, ou seja, de eficiência dos projetos. Publicações mais recentes, como do PMI (2017), da mesma forma, consideram como medidas gerais para os resultados dos projetos: a qualidade do produto, a qualidade do projeto, o cumprimento de prazos, a conformidade com o orçamento e o grau de satisfação do cliente.

\subsubsection{Dimensões do sucesso do desenvolvimento de produtos}

Embora pesquisas anteriores indicassem que o sucesso do projeto era formado por dimensões independentes, Griffin e Page (1996) entenderam que as empresas frequentemente precisam sacrificar algum nível de sucesso em uma dimensão para obter sucesso em outra. Desta forma, uma empresa necessita medir o sucesso e o fracasso do DP ao longo das diferentes dimensões de desempenho e assim separar as expectativas de sucesso do projeto por dimensão do resultado. As expectativas para cada dimensão de sucesso variariam individualmente de acordo com o projeto e dependendo também da estratégia adotada para cada um dos projetos. A seguir são apresentadas algumas destas dimensões.

Estratégia, portfólio e projeto - Estratégias diferentes produzem diferentes níveis de dependência do desenvolvimento de novos produtos, ou seja, um mesmo conjunto de medidas gerais de sucesso não deve ser adequado para empresas com estratégias diferentes (Griffin \& Page, 1996). Em outras palavras, as expectativas para cada dimensão de sucesso variariam de acordo com o projeto individual, dependendo da estratégia adotada especificamente para ele.

Ao analisar o desempenho do DP é preciso diferenciar os indicadores em relação à sua aplicação ao nível dos projetos e ao nível do portfólio ou do programa. De uma forma geral, Griffin e Page (1996) concluíram que o grau em que uma vantagem competitiva é obtida seria o indicador mais útil do sucesso baseado no desempenho do projeto. No nível do portfolio de projetos de DP, as empresas com estratégias menos inovadoras indicaram achar mais útil concentrarem-se na medição da 
eficiência de seu programa de DP do que em resultados financeiros. Já empresas com estratégias moderadamente inovadoras preferiam as medidas que forneciam informações sobre a eficiência e a eficácia de seus programas.

Considerando que o desenvolvimento de um produto específico ocorre por meio de um projeto, os indicadores de sucesso denominados operacionais (Rozenfeld et al. (2006), parte dos indicadores de qualidade e dos relacionados às partes interessadas são os mesmos da gestão de projetos. Para relacionar o desempenho do portfolio e dos projetos específicos, Griffin e Hauser (1996) afirmam que, embora as empresas desenvolvam novos produtos para obter lucros a longo prazo, muitas vezes é difícil vincular medidas agregadas de lucro a projetos individuais de DP, ou mesmo a programas, havendo então a necessidade de adoção de uma ampla variedade de medidas de sucesso.

O modelo conceitual proposto por Andreassi e Sbragia (2002) também segrega os indicadores dos resultados dos projetos, porém em apenas duas classes, os resultados de pesquisa e desenvolvimento ("out puts") e os resultados empresariais ("outcomes"). Os resultados das atividades de pesquisa e desenvolvimento seriam os projetos finalizados e as patentes para o caso de inovações. Já os resultados empresariais seriam resultantes da ação, por exemplo, das áreas de marketing, produção e engenharia sobre os projetos finalizados. Neste caso, os indicadores dos resultados empresariais seriam compostos pelo lucro, faturamento global, faturamento gerado por novos produtos, participação no mercado e redução de custos como resultado de melhorias em processos. Esta abordagem é muito próxima da que diferencia a eficiência e a eficácia do DP (Kalluri \& Kodali, 2014; Neely et al., 2005).

Área funcional - Montoya-Weiss e Calantone (1994) verificaram que as pesquisas sobre o desempenho do DP proviam de diversas disciplinas, incluindo marketing, comportamento organizacional, engenharia e gestão de operações. As visões de cada disciplina definiriam diferentes conjuntos de indicadores de desempenho.

Específico ou geral - Griffin e Hauser (1996) abordaram as diferenças entre as perspectivas sobre o desempenho para as empresas e para os acadêmicos. As empresas utilizariam mais metas de receita, metas de lucro e medidas de sucesso no tempo de colocação no mercado e satisfação do cliente. Já os pesquisadores acadêmicos teriam preferência por medidas não só no nível da empresa, tais como vendas de novos produtos e taxa de sucesso ou falha, mas também em medidas de processo como o sucesso técnico e a conclusão dentro do orçamento. Estas diferenças surgiriam em parte porque os acadêmicos buscariam as causas do sucesso por possuírem maior necessidade de vincular causa ao resultado e buscar medidas que permitam a comparação entre empresas. As empresas, por outro lado, estariam mais interessadas em avaliar pessoas e projetos com a necessidade de auferir lucro, ou seja, as medidas buscadas são as que permitiriam gerenciar o desempenho. 
Tempo e velocidade - Wheelwright e Clark (1992) indicam 2 grupos de capacidades necessárias: ser rápido e responsivo e desenvolvimento com alta produtividade. Para ter bons resultados, as empresas necessitam responder adequadamente e rapidamente às mudanças nas necessidades dos consumidores e aos movimentos dos concorrentes, ou seja, é preciso ter habilidade para identificar as oportunidades, realizar o necessário esforço de desenvolvimento e levar rapidamente e eficientemente novos produtos e processos ao mercado. Para os pesquisadores, uma vantagem baseada na capacidade de ciclo rápido é composta por habilidades e competências humanas e organizacionais, processos, sistemas e conhecimentos que sejam difíceis de copiar.

Ainda com relação à dimensão temporal, mas com a perspectiva de futuro, Cooper e Kleinschmidt (1987b) apresentaram o conceito de "janela de oportunidade" como forma de definição do sucesso de novos produtos e que considera a abertura de novas oportunidades para novos mercados e/ou novas categorias de produtos para a empresa. Assim, uma janela de oportunidade em novas categorias ocorreria quando o produto abre oportunidades em uma nova categoria de produtos para a empresa e uma janela de oportunidade em novos mercados ocorreria quando o produto abre oportunidades em um novo mercado para a empresa.

De acordo com Cooper (2019), a velocidade do DP oferece a vantagem competitiva de ser a primeira no mercado e que normalmente resulta na realização mais rápida dos lucros. Associada à ideia de janela de oportunidade, também seria uma forma de redução do risco de entrega somente após a situação do mercado ter mudado. $\mathrm{O}$ autor, no entanto, alerta que a velocidade é apenas um objetivo intermediário para o objetivo final que é a lucratividade. Além disso, há que se considerar que os métodos usados para reduzir o tempo de desenvolvimento têm contrapartidas. A velocidade pode dar origem a uma série de falhas rápidas e a ênfase excessiva na velocidade pode influenciar a decisão pelo investimento em muitas modificações e extensões de linha que podem ser feitas rapidamente, em detrimento do desenvolvimento de produtos inovadores e mais lucrativos.

Para Shenhar e colaboradores (1997), ao nível dos projetos, os indicadores mais tradicionais poderiam ser separados em relacionados às restrições de recursos (metas de prazo e orçamento) e relacionados ao atendimento às especificações (satisfação do consumidor), sendo as primeiras mais relacionadas a eficiência e as últimas à eficácia dos projetos. Os autores elaboraram uma estrutura multidimensional para fins de avaliação do sucesso dos projetos considerando os benefícios do projeto no horizonte de tempo. O estudo propõe ser possível que o sucesso de um projeto seja avaliado por meio de ao menos quatro dimensões distintas, ou seja: a eficiência do projeto; o impacto no cliente; o sucesso direto e comercial; e a preparação para o futuro. Essas dimensões seriam hierárquicas e aplicadas diferentemente para projetos distintos e em tempos também diferentes, como apresentado na Tabela 9. 
Tabela 9 - As quatro dimensões do sucesso dos projetos

\begin{tabular}{|c|c|c|c|c|}
\hline Dimensões & $\begin{array}{l}\text { 1 - Eficiência do } \\
\text { projeto } \\
\text { É uma medida de } \\
\text { curto prazo que } \\
\text { expressa a eficiência } \\
\text { na qual o processo } \\
\text { do projeto foi } \\
\text { gerenciado. }\end{array}$ & $\begin{array}{l}2 \text { - Impacto no } \\
\text { cliente } \\
\text { Trata da importância } \\
\text { que as empresas } \\
\text { devem dar aos } \\
\text { requisitos e às reais } \\
\text { necessidades dos } \\
\text { consumidores. }\end{array}$ & $\begin{array}{l}3 \text { - Sucesso direto e } \\
\text { comercial } \\
\text { Trata do impacto } \\
\text { direto do projeto } \\
\text { sobre a organização } \\
\text { (vendas, receitas, } \\
\text { lucros, resultados } \\
\text { dos negócios e } \\
\text { participação de } \\
\text { mercado). }\end{array}$ & $\begin{array}{l}4 \text { - Preparação } \\
\text { para o futuro } \\
\text { Trata da preparação } \\
\text { da infraestrutura } \\
\text { organizacional e } \\
\text { tecnológica para o } \\
\text { futuro (mercados, } \\
\text { inovações, produtos, } \\
\text { ideias, habilidades, } \\
\text { competências e } \\
\text { mudanças). }\end{array}$ \\
\hline $\begin{array}{l}\text { Benefícios do } \\
\text { projeto no } \\
\text { horizonte de } \\
\text { tempo }\end{array}$ & Curto prazo & & & Longo prazo \\
\hline $\begin{array}{l}\text { Itens de } \\
\text { mensuração do } \\
\text { sucesso do } \\
\text { projeto }\end{array}$ & $\begin{array}{l}\text { - Atendimento às } \\
\text { metas de prazos } \\
\text { - Atendimento às } \\
\text { metas } \\
\text { orçamentárias }\end{array}$ & $\begin{array}{l}\text { - Atendimento a } \\
\text { especificações } \\
\text { operacionais } \\
\text { - Atendimento a } \\
\text { especificações } \\
\text { técnicas } \\
\text { - Atendimento a } \\
\text { necessidades dos } \\
\text { consumidores } \\
\text { - Solução de um } \\
\text { problema } \\
\text { operacional } \\
\text { importante } \\
\text { - Uso do "produto" } \\
\text { pelo consumidor } \\
\text { - Satisfação do } \\
\text { consumidor }\end{array}$ & $\begin{array}{l}\text { - Nível de sucesso } \\
\text { comercial } \\
\text { - Geração de } \\
\text { grande } \\
\text { participação de } \\
\text { mercado }\end{array}$ & $\begin{array}{l}\text { - Abertura de um } \\
\text { novo mercado } \\
\text { - Abertura de uma } \\
\text { nova linha de } \\
\text { produto } \\
\text { - Desenvolvimento } \\
\text { de uma nova } \\
\text { tecnologia }\end{array}$ \\
\hline
\end{tabular}

Fonte: Shenhar e colaboradores (1997)

Inovação - Griffin e Page (1996) postulavam que mensurações de sucesso ou fracasso dos projetos de DP devam também considerar as características de inovação dos produtos e processos. Assim, indicadores de crescimento da empresa (recente e futuro) seriam mais apropriadas para estratégias voltadas à inovação. Indicadores de eficácia do desenvolvimento de produtos seriam mais apropriadas para empresas moderadamente inovadoras. Por fim, indicadores de eficiência do desenvolvimento de produtos seriam mais apropriadas para empresas menos inovadoras.

A Tabela 10 a seguir apresenta as dimensões e indicadores do desempenho do DP mais frequentemente encontradas na literatura. Observa-se que os indicadores financeiros incluem também indicadores de mercado e comerciais, tais como: a participação de mercado e a ampliação de linhas de produtos (Cooper \& Kleinschmidt, 1987b; Montoya-Weiss \& Calantone, 1994). Nota-se também que indicadores como prazo para desenvolvimento e orçamento do projeto, dependendo do autor, são classificados em dimensões denominadas de projeto, operacionais, de engenharia e mesmo de processo de desenvolvimento. 
Tabela 10 - Dimensões e indicadores do desempenho do DP encontrados na literatura.

\begin{tabular}{|c|c|c|}
\hline Dimensão & Indicadores & Estudos \\
\hline Estratégica & $\begin{array}{l}\text { vantagem competitiva } \\
\text { oportunidade de nova categoria } \\
\text { oportunidade de novo mercado } \\
\text { atração de novos consumidores } \\
\text { melhoria dos ativos da empresa } \\
\text { novas competências }\end{array}$ & $\begin{array}{l}\text { Cooper, 1984; Cooper \& Kleinschmidt, } \\
\text { 1987a; Griffin \& Hauser, 1996; Montoya- } \\
\text { Weiss \& Calantone, 1994; Rozenfeld et } \\
\text { al., 2006; S. C. Wheelwright \& Clark, } \\
1992\end{array}$ \\
\hline Produto & $\begin{array}{l}\text { satisfação do consumidor } \\
\text { atendimento às especificações } \\
\text { atendimento às necessidades do consumidor } \\
\text { valor intrínseco } \\
\text { benefícios exclusivos para os clientes } \\
\text { alta qualidade } \\
\text { custo atraente } \\
\text { desempenho técnico } \\
\text { menor custo } \\
\text { confiabilidade } \\
\text { recursos inovadores } \\
\text { solução de um problema operacional } \\
\text { uso do "produto" pelo consumidor } \\
\end{array}$ & $\begin{array}{l}\text { Andreassi \& Sbragia, 2002; S. Brown \& } \\
\text { Eisenhardt, 1995; Cooper, 1984; Cooper } \\
\& \text { Kleinschmidt, 1987a; Griffin \& } \\
\text { Hauser, 1996; Montoya-Weiss \& } \\
\text { Calantone, 1994; PMI, 2017; Rozenfeld } \\
\text { et al., 2006; Shenhar et al., 1997; S. C. } \\
\text { Wheelwright \& Clark, 1992; Zirger \& } \\
\text { Maidique, } 1990\end{array}$ \\
\hline $\begin{array}{l}\text { Financeira } \\
\text { comercial }\end{array}$ & $\begin{array}{l}\text { Rentabilidade ou lucratividade } \\
\text { "payback“ou período de retorno } \\
\text { participação de mercado } \\
\text { participação nas vendas } \\
\text { participação nos lucros } \\
\text { vendas } \\
\text { lucros } \\
\text { custos }\end{array}$ & $\begin{array}{l}\text { Andreassi \& Sbragia, 2002; S. Brown \& } \\
\text { Eisenhardt, 1995; Cooper, 1984; Cooper } \\
\& \quad \text { Kleinschmidt, 1987a; Griffin \& } \\
\text { Hauser, 1996; Montoya-Weiss \& } \\
\text { Calantone, 1994; PMI, 2017; Rozenfeld } \\
\text { et al., 2006; Shenhar et al., 1997 }\end{array}$ \\
\hline $\begin{array}{l}\text { Projeto, } \\
\text { engenharia, } \\
\text { operacional ou } \\
\text { de processo de } \\
\text { desenvolvimento }\end{array}$ & $\begin{array}{l}\text { metas de prazos } \\
\text { metas orçamentárias } \\
\text { atendimento a especificações operacionais } \\
\text { atendimento a especificações técnicas } \\
\text { atendimento aos requisitos das partes } \\
\text { interessadas }\end{array}$ & $\begin{array}{l}\text { Andreassi \& Sbragia, 2002; S. Brown \& } \\
\text { Eisenhardt, 1995; Cooper, 1984; Griffin } \\
\& \text { Hauser, 1996; Montoya-Weiss \& } \\
\text { Calantone, 1994; PMI, 2017; Rozenfeld } \\
\text { et al., 2006; Shenhar et al., 1997; S. C. } \\
\text { Wheelwright \& Clark, 1992 }\end{array}$ \\
\hline
\end{tabular}

Fonte: dados da pesquisa.

Para Rozenfeld e colaboradores (2006), em uma visão mais ampla, o que distinguiria as empresas com excelência em desenvolvimento de produtos seria o padrão de coerência e consistência em todo o seu processo de desenvolvimento, incluindo a estratégia, a estrutura organizacional, a sistematização das atividades, as habilidades técnicas, as abordagens para resolução de problemas, os mecanismos de aprendizagem e a cultura dominante na organização. De certa forma, também consideram que a definição dos indicadores de desempenho depende das características dos fatores que os influenciam. 


\subsubsection{Desempenho dos projetos de desenvolvimento de medicamentos}

Percebe-se em publicações do FDA (2007) e da International Conference on Harmonisation ICH (2009) que há mais de dez anos já havia preocupação com o desenvolvimento mais eficiente de medicamentos de alta qualidade. Suas recomendações e direcionamentos apontam para soluções basicamente técnicas. O ICH, por exemplo, apresenta aspectos ligados às substâncias medicamentosas, excipientes, sistemas de fechamento do recipiente e processos de produção que também podem ser considerados para os medicamentos não inovadores. Como são dimensões críticas para a qualidade do medicamento, a entidade fornece orientação sobre o desenvolvimento farmacêutico de medicamentos por meio de um documento específico denominado Guia ICH Q8 (ICH, 2009).

Court e Fowler (2008) afirmam que para o desenvolvimento de medicamentos, assim como para produtos de uma forma geral, as métricas de desempenho podem ser definidas como indicadores de eficiência e produtividade com o intuito de monitorar a entrega e a utilização de recursos. Entre as métricas destacadas pelos autores estão: qualidade (quão bem algo é feito), tempo de ciclo (quanto tempo é necessário para fazer alguma coisa), custo ou recursos necessários (quanto ou quantos) e riscos (qual é o risco de fazer ou não fazer algo).

Segundo Shargel e Kanfer (2005), quando do surgimento dos medicamentos genéricos, o desenvolvimento e a aprovação de um novo produto eram associados a questões de segurança, eficácia e equivalência terapêutica dos medicamentos candidatos em comparação ao medicamento de referência. Depois, o desenvolvimento de medicamentos genéricos passou a basear-se em princípios e processos científicos para garantir que esses produtos farmacêuticos satisfizessem padrões necessários de qualidade, segurança e eficácia antes que obtivessem aprovação e serem colocados no mercado.

De acordo com Powell (2010), o controle de projetos de novos produtos na área das ciências da vida trata essencialmente sobre como gerenciar o tempo de desenvolvimento, o custo de desenvolvimento e os recursos organizacionais da maneira mais eficiente de forma a assegurar a entrega confiável de produtos ao mercado. Em seu limite, ineficiências no desenvolvimento e no processo de registro de um medicamento genérico poderiam levar ao indeferimento do pedido de registro pelo órgão regulador. Do Carmo (2017) considera que o indeferimento é, sobretudo, uma ferramenta de proteção da saúde da população ao impedir que entrem no mercado os medicamentos que não demonstraram qualidade, segurança e eficácia mínimas. Em uma visão ampliada, ainda segundo a pesquisadora, o indeferimento tem consequências para todas as partes:

- laboratório farmacêutico - desperdício de recursos com o desenvolvimento do medicamento e/ou submissão para registro;

- agência reguladora - desperdício de recursos no processo de avaliação do pedido de registro;

- população - não terá acesso a mais uma opção de tratamento. 
Um indicador importante para o desempenho dos projetos de desenvolvimento de medicamentos é a aprovação do registro do medicamento pela autoridade sanitária. Sem esta aprovação, o medicamento não pode ser comercializado e/ou distribuído. $\mathrm{O}$ fato é que muitos pedidos de registro de medicamentos genéricos são indeferidos pelas autoridades sanitárias em razão de deficiências técnicas, documentais e processuais (Do Carmo, Piras, et al., 2017; Aloka Srinivasan \& Iser, 2010; Aloka Srinivasan et al., 2010; Worku et al., 2012).

Gota e Patial (2014) chamam a atenção para os problemas relacionados a medicamentos com baixa qualidade e que comprometem a credibilidade dos medicamentos genéricos e a eficácia dos tratamentos médicos. Indeferimentos também ocorrem no Brasil, como abordado por Do Carmo (2017) e Do Carmo, Piras e colaboradores (2017), cujos estudos indicam que cerca de metade dos pedidos de registro de medicamentos genéricos submetidos à aprovação da Anvisa são reprovados. Estas publicações foram os principais motivadores deste estudo e deram origem à questão de pesquisa que busca as razões para uma taxa de sucesso relativamente baixa.

\subsection{FATORES CONTRIBUINTES PARA O DESEMPENHO DOS PROJETOS DE DESENVOLVIMENTO DE PRODUTOS}

Para Cooper e Kleinschmidt (1987a), não há questão mais fundamental para os gestores do que o entendimento dos fatores que levam ao sucesso ou ao fracasso de um novo produto, uma vez que fornecem parâmetros para a seleção dos projetos de novos produtos e para o processo de gerenciamento dos projetos de DP. Segundo Griffin e Page (1996), desde o final da década de 1960, um grande número de pesquisas foram feitas para estudar os fatores que levam ao sucesso no desenvolvimento de produtos. Montoya-Weiss e Calantone (1994) afirmam que comparações diádicas entre o sucesso e o insucesso de projetos se tornaram populares na busca pela identificação dos principais fatores discriminantes e pelo estabelecimento de estratégias normativas para aumentar a probabilidade de sucesso ou evitar o fracasso.

Em publicação da década de 1970, Rubenstein e colaboradores (1976) já observavam que não haveria um fator único ou um conjunto único de fatores que determinam o sucesso ou o fracasso do projeto. Os projetos de DP seriam bem-sucedidos por inúmeras razões (facilitadores) e falhariam também por outros conjuntos de razões (barreiras). Murphy, Baker e Fisher (1974) também concluíram que o DP é um mecanismo complexo e que contém inúmeras variáveis relacionadas ao sucesso do projeto, não havendo somente uma abordagem simples para garantir a eficácia do projeto.

Os estudos sobre o desempenho do DP podem ser categorizados em três domínios: pesquisa sobre fatores que levam ao sucesso, fatores que levam ao fracasso e fatores que distinguem entre 
sucesso e fracasso (Kalluri \& Kodali, 2014; Montoya-Weiss \& Calantone, 1994). De acordo com o levantamento de Kalluri e Kodali (2014), os estudos de desempenho no DP concentram-se principalmente na identificação das características e fatores que conduzem ao sucesso. Os estudos com foco no insucesso ou fracasso fornecem análises retrospectivas de falhas no passado ou armadilhas e problemas comuns no processo de desenvolvimento e para os quais os gestores poderiam tomar ações para sobrepor ou evitar nos futuros projetos (Cooper \& Kleinschmidt, 1987a; Kalluri \& Kodali, 2014; Montoya-Weiss \& Calantone, 1994).

Como exemplo de estudo que busca distinguir entre fatores que levam ao sucesso e ao fracasso, Wheelwright e Clark (1992) abordaram o tema do desempenho dos projetos de desenvolvimento de produtos comparando características ou fatores que contribuem para os projetos problemáticos e para projetos de desempenho superior. A Tabela 11 a seguir resume algumas destas características.

Tabela 11 - Comparação entre características de projetos problemáticos e efetivos

\begin{tabular}{|c|c|c|}
\hline Dimensão & Projetos problemáticos & Projetos efetivos \\
\hline $\begin{array}{l}\text { Objetivos e } \\
\text { requisitos }\end{array}$ & $\begin{array}{l}\text { Objetivos múltiplos e ambíguos e agendas } \\
\text { funcionais diferentes levando a fases longas de } \\
\text { planejamento, necessidade de consenso e } \\
\text { conflitos em fases mais adiantadas. }\end{array}$ & $\begin{array}{l}\text { Objetivos claros e compartilhamento do } \\
\text { entendimento das intensões do projeto } \\
\text { relacionadas a toda a organização e } \\
\text { resolução dos conflitos logo no início e } \\
\text { nos níveis mais baixos }\end{array}$ \\
\hline Público-alvo & $\begin{array}{l}\text { Foco nos consumidores atuais e confusão acerca } \\
\text { dos futuros consumidores-alvo levando a } \\
\text { mudanças de alvo, surpresas e desapontamentos e } \\
\text { testes de mercado, redefinições tardias e } \\
\text { diferenças entre "design" e mercado. }\end{array}$ & $\begin{array}{l}\text { Antecipação ativa das necessidades dos } \\
\text { consumidores no futuro; oferta contínua } \\
\text { de desenvolvimentos. }\end{array}$ \\
\hline Prazos & $\begin{array}{l}\text { Desenvolvimento com foco estrito em soluções } \\
\text { intrínsecas e reduzida importância dada aos } \\
\text { prazos provocando atrasos e necessidade de } \\
\text { compressão do cronograma. }\end{array}$ & $\begin{array}{l}\text { Manutenção do foco no "tempo-para- } \\
\text { mercado" ao mesmo tempo em que são } \\
\text { solucionados os problemas criativamente } \\
\text { e visão sistêmica do conceito do projeto. }\end{array}$ \\
\hline Produto & $\begin{array}{l}\text { Dependência de mudanças técnicas e evolução da } \\
\text { produção para encontrar e resolver problemas } \\
\text { resultando em protótipos inadequados e não } \\
\text { representativos, muitas mudanças tardias, difícil } \\
\text { fabricação, atropelos na produção e rendimentos } \\
\text { abaixo do planejado. }\end{array}$ & $\begin{array}{l}\text { Testes e validação dos "designs" do } \\
\text { produto e do processo antes do } \\
\text { investimento intensivo ou produção } \\
\text { comercial. }\end{array}$ \\
\hline Pessoas & $\begin{array}{l}\text { Poucos especialistas em funções-chave causando } \\
\text { idas e voltas, esforços ineficientes de } \\
\text { comunicação e direcionamento e uso do tempo } \\
\text { para substituir a integração. }\end{array}$ & $\begin{array}{l}\text { Ampla competência em funções críticas, } \\
\text { responsabilidade das equipes, e solução } \\
\text { integrada de problemas com a } \\
\text { participação de várias funções. }\end{array}$ \\
\hline Liderança & $\begin{array}{l}\text { Direcionamento confuso, nenhum gestor e } \\
\text { responsabilidade limitada levando a falta de } \\
\text { coerência, de visão compartilhada do conceito do } \\
\text { projeto, passagens apressadas e muitos inícios e } \\
\text { términos falsos. }\end{array}$ & $\begin{array}{l}\text { Liderança forte e responsabilidades } \\
\text { disseminadas. }\end{array}$ \\
\hline
\end{tabular}

Fonte: adaptado de Wheelwright e Clark (1992) 
Brown e Eisenhardt (1995) realizaram uma revisão da literatura sobre o desenvolvimento de produtos tendo como especial interesse os estudos empíricos e normativos em que os projetos de desenvolvimento eram as unidades de análise. A revisão foi estruturada tendo por referência três correntes com distintos padrões de citações cumulativas que evoluíram a partir de um ou dois estudos pioneiros. Eles denominaram as três correntes como: plano racional, rede de comunicação e solução disciplinada de problemas. Embora as três correntes sejam corpos de trabalho coerentes, elas também se complementam e se sobrepõem umas às outras.

De acordo com Brown e Eisenhardt (1995), o trabalho mais antigo da corrente de plano racional enfatizou a importância das questões de mercado em detrimento de questões meramente técnicas para o desenvolvimento bem-sucedido de produtos. Eles citam Myers e Marquis (1969), que tendo uma visão multidisciplinar como componente-chave, estudaram o desenvolvimento de produtos e processos de sucesso e concluíram que identificar e entender as necessidades dos consumidores era substancialmente mais importante para o sucesso dos produtos do que a tecnologia.

Os estudos SAPPHO (“Scientific Activity Predictor from Patterns with Heuristic Origins", em português, preditor de atividade científica a partir de padrões com origens heurísticas), em especial o estudos de Rothwell (1972) e Rothwell e colaboradores (1974), foram conduzidos usando pares de sucesso e falha entre empresas do Reino Unido e resultaram na seleção de 41 fatores significativamente relacionados ao desenvolvimento bem-sucedido de produtos (Brown \& Eisenhardt, 1995). Entre esses fatores, tiveram destaque a compreensão das necessidades dos usuários, a atenção ao mercado, o desenvolvimento eficiente e a liderança sênior.

Para a corrente do plano racional, o sucesso dos projetos é avaliado basicamente por indicadores financeiros (lucros, vendas, participação de mercado) e possui como principais chaves para o seu atingimento:

(a) o planejamento cuidadoso de um produto superior para um mercado atraente;

(b) a execução do plano por uma equipe multifuncional competente e bem coordenada; e

(c) o suporte da alta administração.

Brown e Eisenhardt (1995) consideraram que as pesquisas nesta corrente eram fundamentalmente exploratórias e ateóricas e que buscaram descobrir quais variáveis independentes estavam correlacionadas com o sucesso financeiro de um projeto de DP. A Tabela 12 a seguir apresenta as principais publicações classificadas nesta corrente e as medidas de desempenho e fatores influenciadores identificados pelos pesquisadores. 
Tabela 12 - Características da corrente do plano racional

\begin{tabular}{|c|c|c|c|}
\hline \multicolumn{4}{|c|}{ Corrente do Plano Racional } \\
\hline Autores (ano) & $\begin{array}{c}\text { Medida de } \\
\text { desempenho } \\
\text { (variáveis } \\
\text { dependentes) }\end{array}$ & \multicolumn{2}{|r|}{$\begin{array}{l}\text { Fatores influenciadores } \\
\text { (variáveis independentes) }\end{array}$} \\
\hline $\begin{array}{l}\text { Myers e Marquis } \\
\text { (1969) }\end{array}$ & $\begin{array}{l}\text { - Receita do produto } \\
\text { - Redução nos custos } \\
\text { de produção }\end{array}$ & $\begin{array}{l}\text { Mercado } \\
\text { Comunicação }\end{array}$ & $\begin{array}{l}\text { Atração } \\
\text { Multifuncional }\end{array}$ \\
\hline $\begin{array}{c}\text { Rothwell (1972) e } \\
\text { Rothwell e } \\
\text { colaboradores (1974) }\end{array}$ & $\begin{array}{l}\text { - Rentabilidade do } \\
\text { produto } \\
\text { - Participação de } \\
\text { mercado }\end{array}$ & $\begin{array}{l}\text { Mercado } \\
\text { Produto } \\
\text { Alta } \\
\text { administração }\end{array}$ & $\begin{array}{l}\text { Entendimento das necessidades do } \\
\text { consumidor } \\
\text { Atenção ao mercado } \\
\text { Desenvolvimento eficiente } \\
\text { Envolvimento e liderança }\end{array}$ \\
\hline Cooper (1979) & $\begin{array}{l}\text { - Rentabilidade do } \\
\text { produto }\end{array}$ & $\begin{array}{l}\text { Produto } \\
\text { Mercado } \\
\text { Comunicação }\end{array}$ & $\begin{array}{l}\text { Único ou exclusivo aos olhos do } \\
\text { consumidor } \\
\text { Alto crescimento, não competitivo e } \\
\text { consumidores insatisfeitos } \\
\text { Sinergia entre diferentes funções }\end{array}$ \\
\hline $\begin{array}{l}\text { Cooper e } \\
\text { Kleinschmidt } \\
\quad(1987 a)\end{array}$ & $\begin{array}{l}\text { Resultados } \\
\text { financeiros } \\
\text { - Rentabilidade } \\
\text { - Participação de } \\
\quad \text { mercado } \\
\text { - Receita relativa }\end{array}$ & $\begin{array}{l}\text { Produto } \\
\text { Mercado } \\
\text { Comunicação } \\
\text { Alta } \\
\text { administração } \\
\text { Organização do } \\
\text { trabalho }\end{array}$ & $\begin{array}{l}\text { Conceito claro } \\
\text { Melhor em razão do custo, qualidade ou } \\
\text { exclusividade } \\
\text { Atrativo pelo tamanho e pelo potencial } \\
\text { de crescimento } \\
\text { Sinergia entre diferentes funções } \\
\text { Apoiadora } \\
\text { Planejamento do pré-desenvolvimento }\end{array}$ \\
\hline $\begin{array}{l}\text { "Stanford Innovation } \\
\text { Project" } \\
\text { Maidique e Zirger, } \\
\text { (1984, 1985); } \\
\text { Zirger e Maidique, } \\
\quad(1990)\end{array}$ & $\begin{array}{l}\text { - Rentabilidade do } \\
\text { produto }\end{array}$ & $\begin{array}{l}\text { Mercado } \\
\text { Comunicação } \\
\text { Alta } \\
\text { administração }\end{array}$ & $\begin{array}{l}\text { Sinergia com competências } \\
\text { Melhor em razão do custo, qualidade ou } \\
\text { exclusividade } \\
\text { Grande e em crescimento } \\
\text { Elevada comunicação interna em equipes } \\
\text { multifuncionais } \\
\text { Apoiadora }\end{array}$ \\
\hline
\end{tabular}

Fonte: Brown e Eisenhardt (1995)

De acordo com Brown e Eisenhardt (1995), a segunda corrente, denominada rede de comunicação, tem como suas principais referências as publicações de Allen (1971, 1977), que considerava a percepção da equipe do projeto e da gestão da organização e tinha por fundamento a ideia de que a comunicação entre os membros da equipe e com pessoas externas ao projeto estimularia o desempenho. De certa forma, vai além da corrente do plano racional ao complementar a visão ateórica com conceitos do processamento de informações e da dependência de recursos. O principal fator influenciador seria a comunicação (variável independente), em específico das equipes de desenvolvimento. Inclui aspectos políticos e de processamento de informações do desenvolvimento de produtos. 
A Tabela 13 a seguir apresenta as principais publicações classificadas nesta corrente e as medidas de desempenho e fatores influenciadores levantados pelo estudo de Brown e Eisenhardt (1995).

Tabela 13 - Características da corrente da rede de comunicação

\begin{tabular}{|c|c|c|c|}
\hline \multicolumn{4}{|c|}{ Corrente da Rede de Comunicação } \\
\hline Autores (ano) & $\left|\begin{array}{r}\text { Medida de desempenho } \\
\text { (variáveis dependentes) }\end{array}\right|$ & & $\begin{array}{l}\text { Fatores influenciadores } \\
\text { (variáveis independentes) }\end{array}$ \\
\hline $\begin{array}{l}\text { Allen }(1971,1977)^{7} ; \\
\text { Katz e Tushman } \\
\text { (1981) }\end{array}$ & $\begin{array}{l}\text { Desempenho técnico } \\
\text { geral do projeto }\end{array}$ & $\begin{array}{l}\text { Comunicação } \\
\text { Líder do projeto }\end{array}$ & $\begin{array}{c}\text { Monitoramento da tecnologia } \\
\text { Frequente comunicação externa } \\
\text { Planejamento do pré-desenvolvimento } \\
\text { Político }\end{array}$ \\
\hline Katz (1982) & $\begin{array}{c}\text { Desempenho geral da } \\
\text { equipe do projeto }\end{array}$ & Comunicação & $\begin{array}{l}\text { Relação curvilínea com a longevidade do } \\
\text { grupo mediada pela comunicação externa }\end{array}$ \\
\hline Katz e Allen (1985) & Desempenho da equipe & Líder do projeto & $\begin{array}{c}\text { Gerente do projeto como gestor poderoso } \\
\text { de pequeno grupo } \\
\text { Gerente funcional como líder interno e } \\
\text { focado na tecnologia }\end{array}$ \\
\hline Keller (1986) & $\begin{array}{c}\text { Desempenho de } \\
\text { qualidade, orçamento e } \\
\text { cronograma. }\end{array}$ & Comunicação & $\begin{array}{l}\text { Comunicação interna como coesão do } \\
\text { grupo }\end{array}$ \\
\hline $\begin{array}{l}\text { Ancona e Caldwell } \\
\text { (1992); Ancona e } \\
\text { Caldwell (1990, } \\
\text { 1992) }\end{array}$ & $\begin{array}{c}\text { Desempenho de } \\
\text { inovação, cronograma, } \\
\text { eficiência, orçamento e } \\
\text { conflito. }\end{array}$ & Comunicação & $\begin{array}{c}\text { Comunicação externa combinando a } \\
\text { coordenação diplomática e de tarefas } \\
\text { Comunicação interna conforme as metas } \\
\text { definidas } \\
\text { Planos executáveis } \\
\text { Trabalho prioritário } \\
\end{array}$ \\
\hline $\begin{array}{l}\text { (Dougherty, 1990, } \\
\text { 1992a; Dougherty \& } \\
\text { Corse, 1995) }\end{array}$ & $\begin{array}{c}\text { Fracasso } \\
\text { (cancelamento) e } \\
\text { sucesso }\end{array}$ & Comunicação & $\begin{array}{l}\text { Comunicação interativa e iterativa } \\
\text { Experiências concretas } \\
\text { Mudanças de rotinas organizacionais }\end{array}$ \\
\hline
\end{tabular}

Fonte: Brown e Eisenhardt (1995)

A terceira corrente proposta por Brown e Eisenhardt (1995) foi a de Solução Disciplinada de Problemas. Suas principais referências são as publicações de Imai, Nonaka e Takeuchi (1985) e Quinn (1985). Nesta corrente, o sucesso dos projetos de DP eram avaliadas por meio de duas dimensões: operacional, composto pelas variáveis velocidade e produtividade; e efetividade do conceito do produto, composta pela variável integridade do produto. Seus fundamentos iriam além das estratégias de resolução de problemas ao usar a progressão da pesquisa indutiva para a dedutiva com base em estudos globais. A Tabela 14 a seguir apresenta as principais publicações classificadas na corrente da solução disciplinada de problemas e as medidas de desempenho e fatores influenciadores identificados pelo estudo de Brown e Eisenhardt (1995).

\footnotetext{
${ }^{7}$ S. Brown \& Eisenhardt, 1995) relacionam em suas referências Allen, T. J. 1971. Communications, technology transfer, and the role of technical gatekeeper. R\&D Management, 1: 14-21. Porém, o próprio periódico em sua página na internet relaciona apenas o seguinte artigo entre 1970 e 1971: Allen, T. J. 1970. Communication networks in R\&D Laboratories. R\&D Management, 1: 14-21
} 
Tabela 14 - Características da corrente da solução disciplinada de problemas

\begin{tabular}{|c|c|c|c|}
\hline \multicolumn{4}{|c|}{ Corrente da Solução Disciplinada de Problemas } \\
\hline Autores (ano) & $\begin{array}{l}\text { Medida de } \\
\text { desempenho } \\
\text { (variáveis } \\
\text { dependentes) }\end{array}$ & & $\begin{array}{l}\text { Fatores influenciadores } \\
\text { (variáveis independentes) }\end{array}$ \\
\hline $\begin{array}{c}\text { Imai, Nonaka e } \\
\text { Takeuchi (1985); } \\
\text { Nonaka e Takeuchi } \\
\text { (1986) }\end{array}$ & $\begin{array}{l}\text { Velocidade } \\
\text { Flexibilidade }\end{array}$ & $\begin{array}{l}\text { Alta } \\
\text { administração } \\
\text { Comunicação } \\
\text { Organização do } \\
\text { trabalho } \\
\text { Fornecedores } \\
\end{array}$ & $\begin{array}{l}\text { Controle sutil } \\
\text { Elevada comunicação interna da equipe } \\
\text { Aprendizagem multifuncional } \\
\text { Equipes multifuncionais } \\
\text { Fases sobrepostas } \\
\text { Elevado envolvimento }\end{array}$ \\
\hline $\begin{array}{l}\text { Harvard Auto Study } \\
\text { Clark, Chew e } \\
\text { Fujimoto (1987); } \\
\text { Clark e Fujimoto } \\
\text { (1991); Hayes, } \\
\text { Wheelwright e Clark } \\
\text { (1988) }\end{array}$ & $\begin{array}{l}\text { Qualidade } \\
\text { Velocidade } \\
\text { Produtividade }\end{array}$ & $\begin{array}{l}\text { Produto } \\
\text { Comunicação } \\
\text { Organização do } \\
\text { trabalho }\end{array}$ & $\begin{array}{l}\text { Integridade do produto } \\
\text { Elevada comunicação interna da equipe } \\
\text { Equipes multifuncionais } \\
\text { Fases sobrepostas } \\
\text { Planejamento do pré-desenvolvimento } \\
\text { Gerente do projeto "peso-pesado" } \\
\text { Elevado envolvimento }\end{array}$ \\
\hline $\begin{array}{l}\text { MIT Auto Study } \\
\text { Womack, Jones, e } \\
\text { Roos (1992) }\end{array}$ & $\begin{array}{l}\text { Operação } \\
\text { Qualidade } \\
\text { Velocidade } \\
\text { Produtividade } \\
\end{array}$ & $\begin{array}{l}\text { Comunicação } \\
\text { Organização do } \\
\text { trabalho }\end{array}$ & $\begin{array}{l}\text { Elevada comunicação interna da equipe } \\
\text { Equipes multifuncionais } \\
\text { Fases sobrepostas } \\
\text { Planejamento do pré-desenvovimento }\end{array}$ \\
\hline Iansiti (1993) & $\begin{array}{l}\text { Velocidade } \\
\text { Produtividade }\end{array}$ & $\begin{array}{l}\text { Produto } \\
\text { Organização do } \\
\text { trabalho }\end{array}$ & $\begin{array}{l}\text { Integridade do produto } \\
\text { Planejamento do pré-desenvovimento }\end{array}$ \\
\hline $\begin{array}{l}\text { Eisenhardt e Tabrizi } \\
\text { (1995) }\end{array}$ & Velocidade & $\begin{array}{l}\text { Organização do } \\
\text { trabalho }\end{array}$ & $\begin{array}{l}\text { Equipes multifuncionais } \\
\text { Prototipagem e testes iterativos } \\
\text { Limitados planejamento e uso de CAD } \\
\text { Não recompensa por cronograma }\end{array}$ \\
\hline
\end{tabular}

Fonte: Brown e Eisenhardt (1995)

Kalluri e Kodali (2014) realizaram uma revisão sistemática dos artigos publicados entre 1998 e 2009 sobre o DP utilizando quatro palavras-chaves: novo produto, "design" de produto, desenvolvimento de produto e inovação de produto. Como resultado, selecionaram 1.127 artigos e os classificaram adotando a taxonomia desenvolvida por Guo, (2008) e que é composta por seis áreas de pesquisa subdividas em 26 tópicos, os quais estão relacionados na Tabela 15.

Tabela 15 - Áreas e seus tópicos de pesquisa

\footnotetext{
Área um: superestrutura $\mathrm{DP}=\mathbf{3 9 , 8 \%}$ das publicações

- Gerenciamento de tecnologia e propriedade intelectual

- Estratégia

- Gestão do conhecimento e da criatividade

- Planejamento e gerenciamento de portfólio

- Gerenciamento de processos

Área dois: questões organizacionais do $\mathrm{DP}=\mathbf{1 1 , 4 \%}$ das publicações

- Clima de controle, liderança, campeão e organização

- Estrutura organizacional

- Gerenciamento e colaboração departamental e interdepartamental

- Comunicação e transferência de informações

- Gerenciamento geral da organização
} 


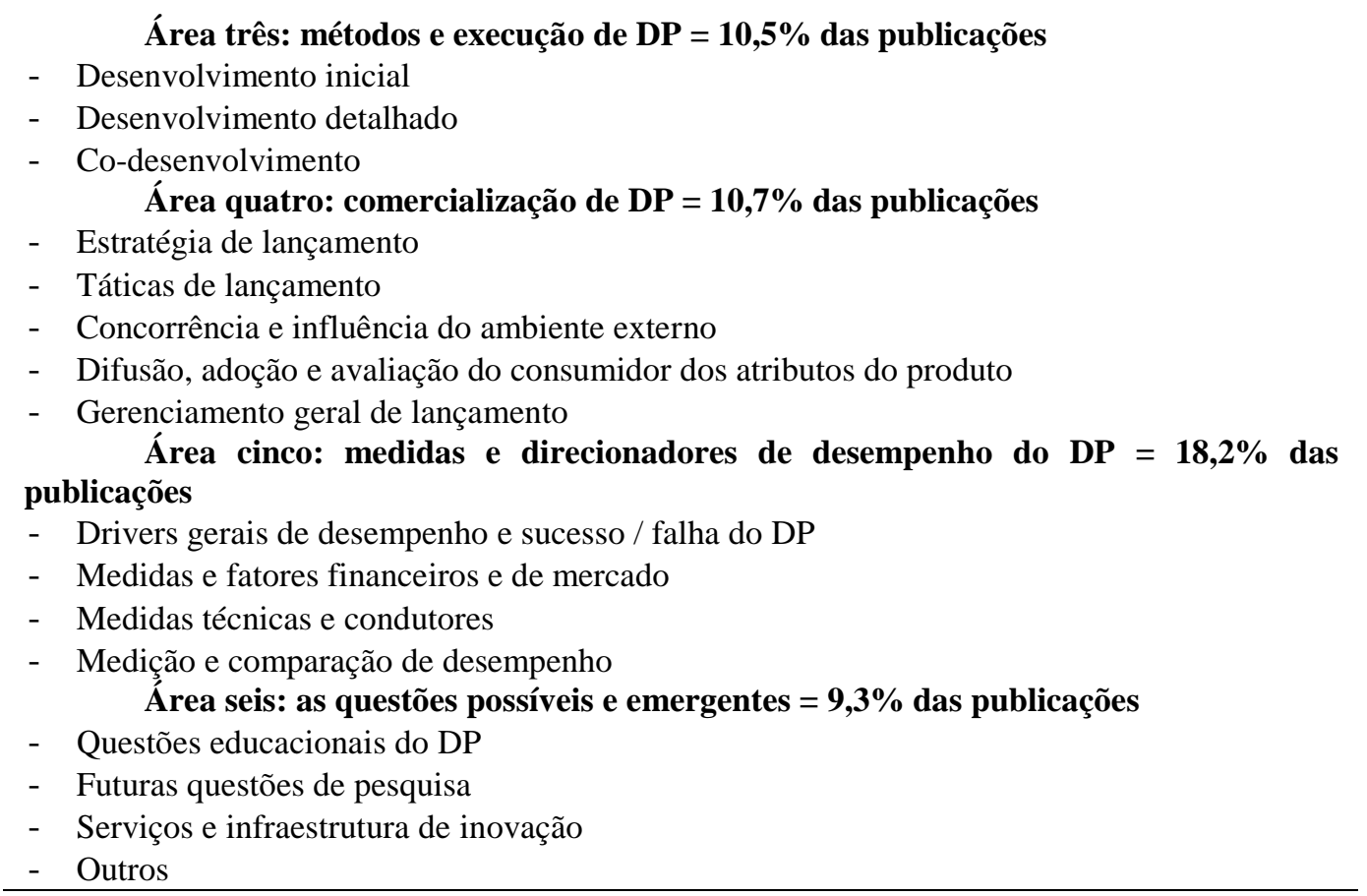

Fonte: Guo (2008, pp. 254-255) e Kalluri e Kodali (2014, p. 533).

Rozenfeld e colaboradores (2006) comentam que, por influência da cultura dominante nos tradicionais laboratórios de pesquisa e desenvolvimento (P\&D) no passado, o êxito das empresas no desenvolvimento de produtos era considerado como significativamente dependente da genialidade dos pesquisadores e dos recursos financeiros alocados aos projetos. Complementarmente, as incertezas, a criatividade e a baixa previsibilidade inerentes a esse processo eram usadas como justificativa para a falta de disciplina, de estrutura e gestão para o processo. Atualmente, consideram que o desempenho do DP depende do modelo e das práticas de gestão adotadas, ou seja, mesmo com incerteza, baixa previsibilidade e a criatividade necessária (no caso de inovações), é preciso gerenciar o processo por meio de planejamento, execução, controle e melhoria das atividades para que sejam alcançados melhores resultados de desempenho e de aprendizagem.

Segundo o PMI (2017), os projetos são desenvolvidos e executados em ambientes que podem influenciá-los positiva ou negativamente. As influências podem ser agrupadas em duas classes:

- fatores ambientais da empresa - tem origem no ambiente externo ao projeto, interno ou externo à empresa. Podem ter impacto no âmbito da organização, do portfólio, do programa ou mesmo somente sobre o projeto.

- ativos de processos organizacionais - são unicamente internos à organização, podendo surgir desta, de um portfólio, de um programa, de outro projeto ou de uma combinação destes. 
A Figura 18 a seguir apresenta as classes de influências definidas pelo PMI (2017) e seus principais componentes, incluindo a estrutura de governança organizacional ${ }^{8}$.

Figura 18 - Estruturação das influências de projetos.

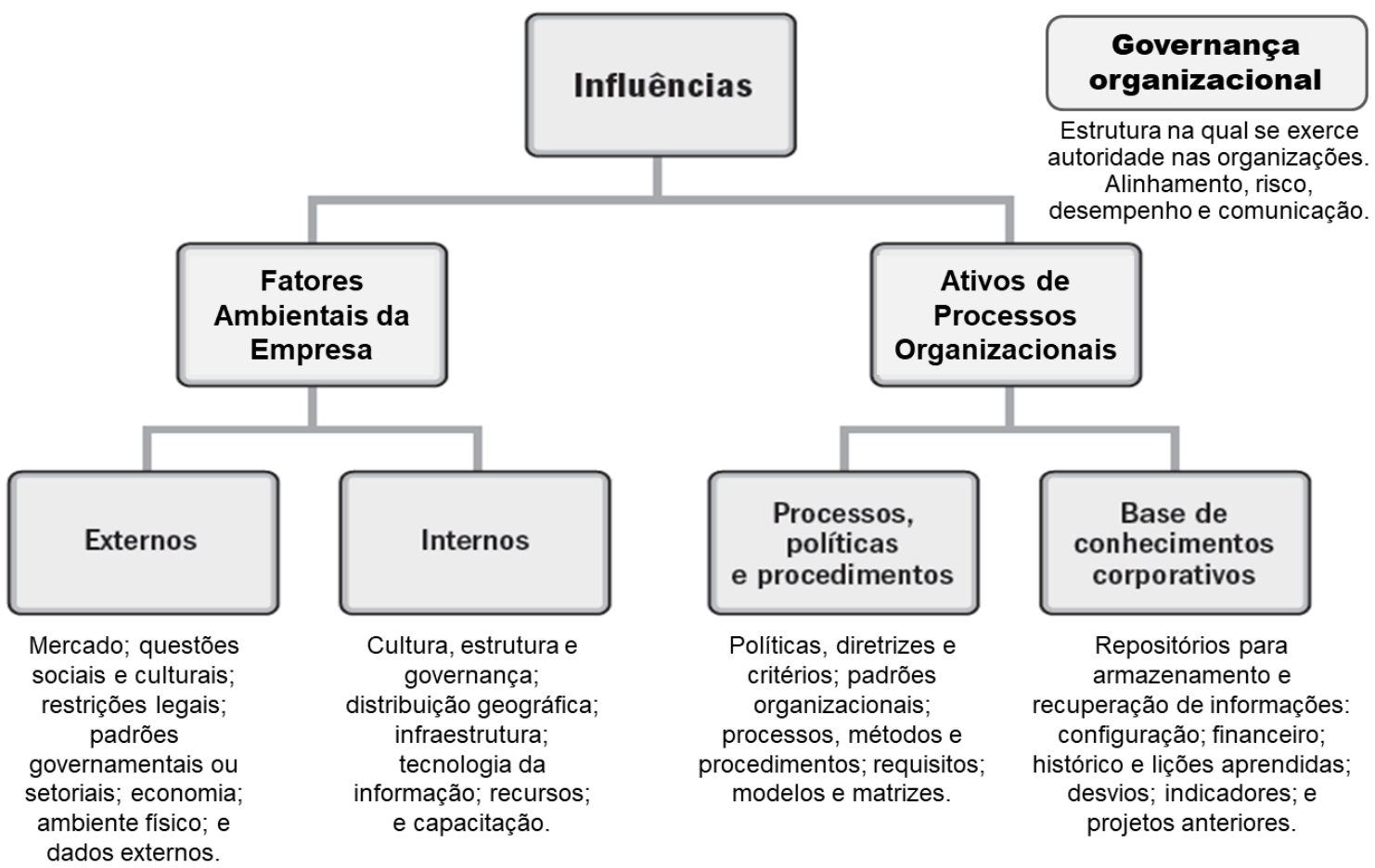

Fonte: PMI (2017, pp. 38-43)

Apesar do grande número de estudos que já foram publicados, continuam sendo estudadas as relações de fatores determinantes, influenciadores ou contribuintes para o desempenho dos projetos de DP. No entanto, levantamentos como os de Montoya-Weiss e Calantone (1994) e de Page e Schirr (2008) indicaram haver deficiências na maioria deles. As principais razões seriam: poucos fatores considerados; estudo insuficiente do contexto e fatores importantes; construtos não confiáveis; medidas de sucesso fora do padrão; e relatos incompletos dos resultados. Levantamentos mais recentes como o de Kalluri e Kodali (2014) também apresentam indicações neste mesmo sentido.

Brown e Eisenhardt (1995) consideraram que alguns dos construtos encontrados na literatura eram difíceis de compreender. Por exemplo, controle sutil, visão do produto e foco no sistema foram considerados conceitos vagos. Mesmo com tentativas de esclarecimento (por exemplo: Clark e

\footnotetext{
${ }^{8}$ Governança organizacional - "diz respeito a arranjos organizacionais ou estruturais em todos os níveis de uma organização projetados para determinar e influenciar o comportamento dos membros da organização." (PMI, 2017)
} 
Fujimoto (1991); e Clark e Wheelwright (1992)), os conceitos de integridade de produto e líder de projeto de alto desempenho também foram considerados nebulosos.

Já no final da década de 1980, Cooper e Kleinschmidt (1987b) identificaram um total de 40 variáveis com potencial influência sobre os resultados e os distribuíram em cinco blocos de variáveis: produto, mercado, compra, sinergia e protocolo. Por meio de uma matriz de correlação preparada com os dados coletados verificaram que muitas dessas variáveis não eram independentes umas das outras, uma vez que foram encontradas correlações significativas entre as medidas de desempenho.

A revisão realizada por Montoya-Weiss e Calantone (1994) já no final da década de 1990 produziu uma lista de determinantes do desempenho do DP partindo dos fatores utilizados por Cooper e Kleinschmidt (1987a) para codificar as variáveis. No total, eles selecionaram dezoito fatores relacionados a quatro categorias: ambiente do mercado, estratégia do novo produto, execução do processo de desenvolvimento e organização. Garcia e Calantone (2002) também realizaram uma revisão da literatura com olhar para as disciplinas de marketing, engenharia e DP e definiram uma tipologia e a terminologia, no caso específica para produtos inovadores.

Com base na codificação resultante da análise dos dados que coletaram, Henard e Szymanski (2001) selecionaram 24 variáveis influenciadoras (denominadas por eles como preditoras ou antecedentes) do desempenho dos novos produtos. Estas variáveis foram organizadas também em 4 categorias com base na estrutura taxonômica de Cooper e Kleinschmidt (1987a) e Montoya-Weiss e Calantone (1994), ou seja, características do produto, estratégia, processo e mercado.

Apesar da indicação na literatura de fatores de diferentes naturezas, Murphy, Baker e Fisher (1974) concluíram que, na maioria dos projetos, os determinantes do sucesso são múltiplos e que muitos deles estão sob o controle daqueles que estão gerenciando o projeto, ou seja, os determinantes do sucesso do projeto seriam fatores que a gestão teria a capacidade potencial de influenciar. O estudo de Cooper e Kleinschmidt (1987a) corrobora de certa forma ao concluir que apesar da superioridade do produto ser o principal fator influenciador do sucesso comercial, a definição do projeto e as atividades precoces e de pré-desenvolvimento eram os passos mais críticos no DP. Assim, o sucesso não seria o resultado específico de influências situacionais ou ambientais. A Tabela 16 organiza as dimensões e indicadores encontrados em algumas das publicações avaliadas, em sua maioria revisões da literatura e que são utilizadas como referência até os dias atuais. 
Tabela 16 - Dimensões e fatores contribuintes ou influenciadores do desempenho do DP

\begin{tabular}{|c|c|c|}
\hline Dimensão & Indicadores & Estudos \\
\hline Estratégica & 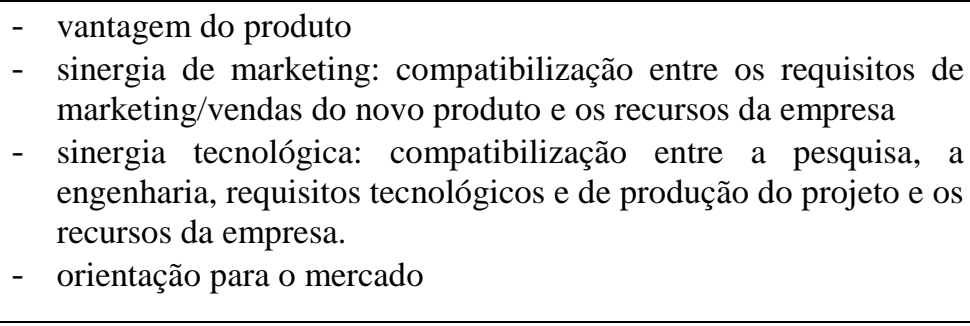 & $\begin{array}{l}\text { S. Brown } \quad \& \\
\text { Eisenhardt, 1995; } \\
\text { Cooper, 2019; Cooper } \\
\& \quad \text { Kleinschmidt, } \\
\text { 1987b; Henard \& } \\
\text { Szymanski, 2001; } \\
\text { Montoya-Weiss \& } \\
\text { Calantone, 1994 }\end{array}$ \\
\hline $\begin{array}{l}\text { Mercado - } \\
\text { atratividade }\end{array}$ & $\begin{array}{ll}\text { - } & \text { características do mercado } \\
\text { - } & \text { tamanho do mercado } \\
\text { - } & \text { crescimento do mercado } \\
\text { - } & \text { competição relativamente fraca } \\
\text { - } & \text { nível de necessidade do cliente } \\
\text { - } & \text { satisfação do cliente com produtos competitivos } \\
\text { - } & \text { grau de mudança das necessidades dos clientes } \\
\text { - } & \text { frequência de lançamentos de novos produtos } \\
\text { - } & \text { nível de sucesso típico para novos produtos } \\
\text { - } & \text { novidade da tarefa de compra (nova tarefa "versus" compra de } \\
& \text { rotina) } \\
\text { - } & \text { comprador pronto para experimentar novos produtos } \\
\text { - } & \text { magnitude da compra (compra grande versus pequena) } \\
\text { - } & \text { importância do produto para o cliente } \\
\text { - } & \text { familiaridade do cliente com produtos da categoria. } \\
\text { - } & \text { frequência de compra }\end{array}$ & $\begin{array}{lr}\text { S. Brown } & \& \\
\text { Eisenhardt, } & 1995 ; \\
\text { Cooper } & \& \\
\text { Kleinschmidt, } & 1987 \mathrm{~b} ; \\
\text { Montoya-Weiss } \& \\
\text { Calantone, } \\
\text { Zirger \& Maidique, } \\
1990\end{array}$ \\
\hline $\begin{array}{l}\text { Marketing - } \\
\text { características } \\
\text { do } \\
\text { consumidor }\end{array}$ & $\begin{array}{l}\text { - entendimento das necessidades dos usuários } \\
\text { - conhecimento do mercado } \\
\text { - competência em marketing } \\
\text { - foco nas etapas preliminares de coleta de informações de } \\
\text { mercado } \\
\text { - grande lançamento } \\
\text { - comprometimento e competência nas atividades de venda e } \\
\text { promoção }\end{array}$ & $\begin{array}{l}\text { Cooper, 1979; Garcia } \\
\& \text { Calantone, 2002; } \\
\text { Montoya-Weiss \& } \\
\text { Calantone, 1994; R. } \\
\text { Rothwell et al., 1974; } \\
\text { Roy Rothwell, } 1972\end{array}$ \\
\hline $\begin{array}{l}\text { Produto } \\
\text { diferencial } \\
\text { competitivo }\end{array}$ & $\begin{array}{ll}\text { - } & \text { benefícios exclusivos aos clientes } \\
\text { - } & \text { benefícios não encontrados em produtos concorrentes } \\
\text { - } & \text { relação custo-benefício favorável } \\
\text { - } & \text { vantagens econômicas para o usuário } \\
\text { - } & \text { alta margem de contribuição para a empresa } \\
\text { - } & \text { uso de tecnologia nova ou avançada } \\
\text { - } & \text { design diferenciado (ergonomia, estética, etc.) } \\
\text { - } & \text { permite que o cliente execute uma tarefa única ou nova } \\
\text { - } & \text { reduz os custos do cliente (custos totais - compra e operação) } \\
\text { - } & \text { preço menor do que produtos concorrentes } \\
\text { - } & \text { inovador - primeiro no mercado } \\
\text { - } & \text { superior aos produtos concorrentes } \\
\text { - } & \text { resolve problema de produto concorrente }\end{array}$ & $\begin{array}{l}\text { S. Brown \& } \\
\text { Eisenhardt, 1995; K. } \\
\text { B. Clark \& Fujimoto, } \\
\text { 1991; Kim B. Clark et } \\
\text { al., 1987; Cooper, } \\
\text { 2019; Cooper \& } \\
\text { Kleinschmidt, 1987b; } \\
\text { Henard \& Szymanski, } \\
\text { 2001 }\end{array}$ \\
\hline
\end{tabular}




\begin{tabular}{|c|c|c|}
\hline Dimensão & Indicadores & Estudos \\
\hline $\begin{array}{l}\text { Organização - } \\
\text { recursos, } \\
\text { competências } \\
\text { e experiência }\end{array}$ & $\begin{array}{ll}\text { - } & \text { suporte/habilidade da alta administração } \\
\text { - } & \text { integração interfuncional } \\
\text { - } & \text { força de vendas da empresa ou distribuidora } \\
\text { - } & \text { P\&D e habilidades e recursos para desenvolvimento de produtos } \\
\text { - } & \text { habilidades e recursos de engenharia } \\
\text { - } & \text { proficiência e recursos tecnológicas } \\
\text { - } & \text { recursos de produção e operações } \\
\text { - } & \text { habilidades e recursos de publicidade e promoção } \\
\text { - } & \text { habilidades e recursos de pesquisa de marketing } \\
\text { - } & \text { habilidades e recursos de atendimento ao cliente } \\
\text { - } & \text { recursos e habilidades de gerenciamento } \\
\text { - } & \text { recursos financeiros } \\
\text { - } & \text { política }\end{array}$ & $\begin{array}{l}\text { S. Brown \& } \\
\text { Eisenhardt, 1995; K. } \\
\text { B. Clark \& Fujimoto, } \\
\text { 1991; Kim B. Clark et } \\
\text { al., 1987; Cooper, } \\
\text { 2019; Cooper \& } \\
\text { Kleinschmidt, 1987b; } \\
\text { Eisenhardt \& Tabrizi, } \\
\text { 1995; Griffin \& } \\
\text { Hauser, 1996; Gupta } \\
\text { \& Wilemon, 1990; } \\
\text { Hayes et al., 1988; } \\
\text { Henard \& Szymanski, } \\
\text { 2001; Imai et al., } \\
\text { 1985; Rozenfeld et al., } \\
\text { 2006; Womack et al., } \\
\text { 1992; Zirger \& } \\
\text { Maidique, 1990 }\end{array}$ \\
\hline $\begin{array}{l}\text { Projeto, } \\
\text { engenharia, } \\
\text { operacional } \\
\text { ou de } \\
\text { processo de } \\
\text { desenvolvime } \\
\text { nto }\end{array}$ & 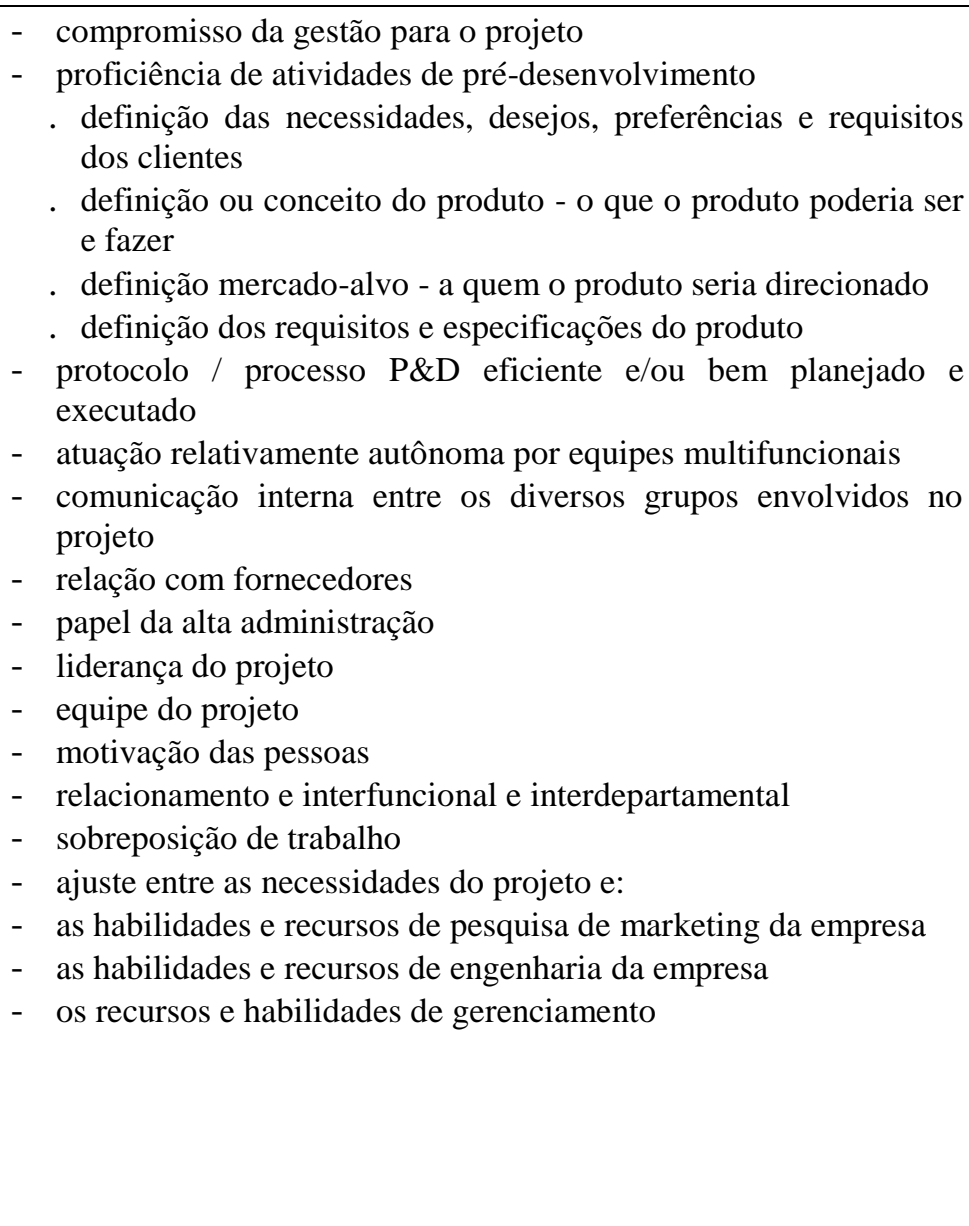 & $\begin{array}{l}\text { Birou \& Fawcett, } \\
\text { 1994; Boer \& During, } \\
\text { 2001; S. Brown \& } \\
\text { Eisenhardt, 1995; K. } \\
\text { B. Clark \& Fujimoto, } \\
\text { 1991; Kim B. Clark et } \\
\text { al., 1987; Kim B. } \\
\text { Clark \& Wheelwright, } \\
\text { 1992; Cooper, 2019; } \\
\text { Cooper \& } \\
\text { Kleinschmidt, 1987b; } \\
\text { Eisenhardt \& Tabrizi, } \\
\text { 1995; Griffin \& } \\
\text { Hauser, 1996; Gupta } \\
\text { \& Wilemon, 1990; } \\
\text { Hayes et al., 1988; } \\
\text { Henard \& Szymanski, } \\
\text { 2001; Henke, } \\
\text { Krachenberg, \& } \\
\text { Lyons, 1993; Imai et } \\
\text { al., 1985; Montoya- } \\
\text { Weiss \& Calantone, } \\
\text { 1994; M. B. Pinto \& } \\
\text { Pinto, 1990; PMI, } \\
\text { 2017; Rozenfeld et al., } \\
\text { 2006; Salgado \& } \\
\text { Dekkers, 2018; } \\
\text { Womack et al., 1992; } \\
\text { Zirger \& Maidique, } \\
\text { 1990 }\end{array}$ \\
\hline
\end{tabular}

Fonte: Dados originais da pesquisa

Em artigo recentemente publicado, Cooper (2019) identificou três categorias de fatores de sucesso utilizados em vários estudos sobre o desempenho do PD na indústria. Os fatores componentes das três categorias são apresentados na Tabela 17 a seguir. 
Tabela 17 - Componentes das categorias de fatores contribuintes para o sucesso do DP

Fatores táticos - projetos de DP. Explicam o sucesso de projetos individuais de novos produtos e capturam as características dos projetos ou dos novos produtos. Incluem certas práticas recomendadas de execução (por exemplo: construção da voz do cliente; realização da tarefa de "front-end' e adotar uma orientação global para o projeto) e também a natureza do próprio produto (por exemplo, proposta de valor).

1. Produto superior único

2. Voz do cliente - orientação para o mercado e focado no cliente

3. Pré-desenvolvimento - trabalho antes do desenvolvimento começar

4. Definição nítida e antecipada do produto

5. Desenvolvimento iterativo ou em espiral - construção, teste, verificação e revisão

6. Orientação global- conceito de plataforma global adaptado localmente

7. Lançamento bem planejado e concebido

Fatores do negócios - organizacionais e estratégicos. Incluem fatores organizacionais e estratégicos (por exemplo, a estratégia de inovação da empresa e como a empresa toma suas decisões de investimento em P\&D); de como se organiza para o DP; clima e cultura; e liderança.

1. Estratégia de inovação e tecnologia de produtos para focar os negócios

2. Foco com gerenciamento sistemático de portfólio

3. Exploração das competências essenciais

4. Busca por mercados atraentes

5. Exploração dos recursos disponíveis

6. Equipes multifuncionais eficazes

7. Clima e cultura adequados

8. Liderança e apoio da alta administração

Fatores de gerenciamento - sistemas, processos e metodologias adequados. Incluem sistemas e métodos que a empresa possui para gerenciar o DP (por exemplo, sistemas de "gates", abordagens de desenvolvimento ágil e métodos de ideação ${ }^{9}$ ).

1. Sistema de gestão por fases (Stage-Gate ${ }^{\circledR}$ )

2. Aceleração do desenvolvimento sem comprometer a qualidade.

3. Métodos ágeis embutidos nos sistemas tradicionais para gerar agilidade

4. Ideação eficaz para alimentar o funil de inovação

5. Qualidade de execução da ideia ao lançamento

Fonte: Cooper (2019)

Em seu estudo publicado na década de 1970, Murphy, Baker e Fisher (1974) fizeram contribuições importantes para as pesquisas sobre o tema do desempenho dos projetos, embora não especificamente para o desenvolvimento de produtos. A análise revelou que as sete variáveis que se mostraram mais fortes como influenciadores do sucesso dos projetos, consideradas em conjunto, explicaram $91 \%$ da variação no fator de sucesso. Em outras palavras, apesar do sucesso ser resultante de múltiplos fatores, um reduzido número deles pode explicar o desempenho dos projetos.

Outra conclusão importante do estudo de Murphy, Baker e Fisher (1974) foi de que todos esses sete fatores influenciadores do sucesso dos projetos poderiam ser gerenciados em algum grau, mesmo em se tratando de fatores relativamente menos controláveis como: o ambiente político-jurídico, a natureza da organização matriz e o comportamento do cliente. Esse resultado aponta para a importância do gerenciamento de projetos como determinante do sucesso.

9 "Ideação" é definida como a geração de ideias sem avaliação, ou seja, durante a ideação, todo pensamento julgador, racional e convergente é deliberadamente adiado em favor do pensamento não julgador, imaginativo e divergente (Basadur \& Finkbeiner, 1985). 
A seguir, são abordados mais detalhadamente os fatores contribuintes para o desempenho do DP mais frequentemente encontrados na literatura.

\subsubsection{Estratégia e portfólio de projetos de desenvolvimento de produtos}

De acordo com Rozenfeld e colaboradores (2006), a estratégia de DP deve criar uma estrutura capaz de reduzir problemas típicos, como a falta de envolvimento da alta administração nas decisões do desenvolvimento de produtos e a falta de sintonia entre o plano de negócios da empresa e os projetos em curso ou a serem iniciados. Assim, estratégia de DP deve traduzir os objetivos do negócio em requisitos detalhados, tais como: tempos para introdução de novos produtos, custos de desenvolvimento e definição de capacidades e de "mix" de produção. Também enfatizam a identificação e o desenvolvimento das capacidades críticas para o DP eficaz.

Os resultados da pesquisa de Henard e Szymanski (2001) indicaram que o alinhamento estratégico e o desempenho do produto estão relacionados, ou seja, a existência de alinhamento do produto, estratégias e processos com o contexto ambiental pode levar ao aumento do desempenho de novos produtos. Cooper (2019), por sua vez, considera que o crescimento corporativo e a lucratividade podem depender de uma estratégia global de negócios casada com a inovação de produtos. Estudo publicado por Yugue, Maximiano, Sbragia e Nascimento (2018) concluiu que mesmo no caso de inovações em medicamentos cujas patentes já expiraram, a atuação global pode ser necessária para que os investimentos em novos produtos possam ser economicamente viáveis.

Neste ponto, vale lembrar que, embora muitas publicações aqui consideradas tenham foco na inovação, há muitos pontos que são aplicáveis também ao desenvolvimento de produtos não inovadores. Além disso, embora o medicamento genérico possa não ser inovador para o mercado, do ponto de vista da empresa que o desenvolve, a sua produção pode envolver a utilização de novas tecnologias e processos que para elas podem ser consideradas inovações. Não se pode também descartar a possibilidade de inovações, principalmente nos processos de fabricação, mesmo havendo a obrigatoriedade de apresentação das mesmas propriedades do medicamento de referência.

Os produtos e os projetos de uma empresa devem ser inter-relacionados e interdependentes para que possa existir o compartilhando de tecnologias, componentes, conceitos e de projetos básicos desde o início (Rozenfeld et al., 2006). Neste sentido, para Cooper e Kleinschmidt (1987b) a eficiência no DP já começa na atuação mais perspicaz dos gestores na seleção de possíveis produtos de sucesso. Uma triagem mais eficaz resultaria em uma alocação mais eficiente dos recursos das empresas. Para Cooper (2019), a seleção de projetos de novos produtos deve considerar a combinação e o equilíbrio de projetos no portfólio de desenvolvimento e garantir o alinhamento estratégico.

Para Cooper e Kleinschmidt (1987b), o desafio inicial da seleção dos produtos a serem desenvolvidos e do gerenciamento de seus projetos de desenvolvimentos levam à necessidade de 
compreensão dos fatores determinantes do sucesso e de falhas. Estes fatores forneceriam os critérios iniciais para a triagem e avaliação das propostas para o DP e os por quês forneceriam indicativos sobre como o desenvolvimento do novo produto deve ser gerenciado, isto é, quais elementos devem ser incorporados ao gerenciamento do projeto para aumentar as chances de sucesso.

Um dos itens avaliados na seleção de projetos de novos medicamentos é a viabilidade técnica. Nesta análise técnica preliminar estaria também incluída a estratégia tecnológica da empresa (R. T. Yugue, Sbragia, et al., 2018). No entanto, apesar de não específicos para medicamentos, os resultados das análises dos dados da pesquisa de Cooper e Kleinschmidt (1987a) apoiaram parcialmente a relação entre a sinergia tecnológica e os resultados do DP. Cooper (2019) explica que sinergia significa ter um forte ajuste entre as necessidades do projeto DP e os recursos, competências e experiência da empresa.

Para Cooper (2019), se não houver familiaridade com o novo produto, os projetos emergentes são mais arriscados e apresentam taxas de falha mais altas devido à falta de experiência, conhecimento, habilidades e recursos. Por outro lado, considera que às vezes é necessário ter iniciativas em desconhecidos e novos mercados, tecnologias, processos de fabricação e áreas onde a alavancagem pode ser limitada, mas que podem ser ajudadas com a adoção de desenvolvimento colaborativo e inovação aberta para a aquisição de recursos, habilidades e conhecimentos necessários e ausentes. Esta colaboração pode envolver recursos de empresas parceiras, clientes, outras empresas desenvolvedoras e até fornecedores.

Cooper (2019) acredita que estratégias de inovação e tecnologia de produtos estão fortemente ligadas ao desempenho positivo e incluem: metas e objetivos de inovação de produtos claramente definidos; o papel da inovação de produtos e suas metas para que as metas gerais de negócios e da empresa sejam alcançadas; as arenas ou áreas de foco estratégico nas quais devem ser concentrados os esforços de DP, ou seja, arenas estratégicas ricas em oportunidades de inovação e que irão fundamentar o crescimento do negócio no futuro; e um roteiro de produto com a visão de como alcançar o objetivo desejado e que forneça marcadores para projetos de DP.

A combinação da necessidade de eliminar projetos ruins com a necessidade de focar os recursos limitados nos melhores projetos pode significar que decisões difíceis devem ser tomadas. Processos de decisões estruturados como o proposto por Sharpe e Keelin (1998) podem ser importantes diferenciais.

Já em relação à gestão do portfólio de projetos em andamento, Cooper (2019) cita o processo de funil já retratado na Figura 7, que sucessivamente elimina projetos ruins por meio da adoção de critérios claros de decisão nos "gates" e que pode incluir um modelo de avaliação por pontuação. 


\subsubsection{Mercado}

As características do mercado incluem fatores como: potencial de mercado, atividade competitiva e a intensidade competição em resposta a introduções de novos produtos (S. Brown \& Eisenhardt, 1995; Henard \& Szymanski, 2001). Cooper (2019) justifica esta importância citando os modelos estratégicos das "cinco forças" de Porter (1985) e o mapa bidimensional da GE-McKinsey (B. Taylor, 1975).

O elevado potencial de mercado é caracterizado por mercados grandes e em crescimento, com grande potencial em longo prazo e onde a compra é importante para o cliente. Brown e Eisenhardt (1995) relacionaram esses fatores ao sucesso financeiro por oferecem a possibilidade de grandes vendas e, no caso de mercados em crescimento, instabilidade competitiva que pode favorecer novos produtos. Já a situação competitiva envolve a intensidade da concorrência de preços, nível das margens, força dos produtos concorrentes, forças de vendas competitivas, sistemas de canais e serviço de suporte (Cooper, 2019; Cooper \& Kleinschmidt, 1987a).

Zirger \& Maidique (1990) incluíram na relação de fatores críticos a entrada antecipada no mercado, ou seja, implicitamente a eficiência e/ou velocidade do desenvolvimento do produto. Cooper (2019) também cita que o fracasso em adotar uma forte orientação para o mercado, a falta de vontade de realizar as avaliações de mercado necessárias e deixar o cliente fora do desenvolvimento do produto prejudicariam os resultados do DP.

\subsubsection{Produtos}

Para Cooper (2019), a entrega de produtos diferenciados com benefícios exclusivos e uma proposta de valor atraente para o cliente inclui:

- atender às necessidades dos usuários, oferecer recursos exclusivos não disponíveis em produtos concorrentes ou resolver um problema que o cliente tem com outros produtos;

- apresentar boa relação custo/benefício para o cliente, reduzir os custos totais do cliente e apresentar excelentes características de preço/desempenho;

- fornecer excelente qualidade do produto em relação aos produtos dos concorrentes; e

- oferecer benefícios ou atributos do produto que sejam altamente visíveis e facilmente percebidos como úteis pelo cliente.

Ao falar sobre o desenvolvimento de produtos, Wheelwright e Clark (1992) destacam como crítica a variável incerteza ao considerarem que os produtos serão lançados, consumidos ou usados em um futuro que pode estar alguns anos distante do início do projeto. Para os pesquisadores, a existência de diferentes pontos-de-vista sobre as ações a serem tomadas, novas circunstâncias, mudanças na validade de premissas básicas e problemas não previstos contribuem para compor a complexidade do 
desenvolvimento de produtos e processos. Esta complexidade inclui os produtos com um grande grau de precisão, produtos com requisitos de desempenho muito altos, produtos cujo processo de fabricação envolve equipamentos sofisticados e/ou um grande número de operações e produtos com elevado número de critérios e atributos estabelecidos de diferentes maneiras pelos consumidores. Como resposta, a empresa necessitaria de pessoas com grande variedade de competências e atuando de maneira integrada para atender às especificações, níveis de custos e funcionalidades desejadas.

Cooper (2019) alerta para o fato de bons produtos novos por si só não se venderem, pois dependem também de um lançamento adequado, que já deve ser tratado desde o início do projeto com um plano de marketing. Yugue, Maximiano, Sbragia e Nascimento (2018), por exemplo, identificaram que para o caso das inovações em medicamentos genéricos, as empresas necessitam um modelo de negócio que inclua a propagando do produto diferenciado. Para Shenhar e colaboradores (1997), os produtos do projeto, além de atender aos consumidores, devem também trazer valor para a organização.

\subsubsection{Clima e cultura organizacional}

O estudo de Murphy, Baker e Fisher (1974) concluiu que as condições ambientais (externas ao projeto) não afetavam necessariamente o sucesso do projeto de forma direta, mas geralmente por meio de influência em outras condições e processos de gerenciamento intervenientes. Mais atual, Cooper (2019) destaca o clima positivo como um dos principais fatores para um melhor desempenho no desenvolvimento de novos produtos, o que incluiria:

- forte apoio da alta administração;

- incentivo a "intrapreneurs" (empreendedores internos) e à aceitação de riscos;

- alta administração disposta a investir em eventual projeto arriscado de interesse;

- sucessos de novos produtos recompensados ou reconhecidos (e falhas não punidas);

- esforços de equipe reconhecidos em vez de individuais;

- alta administração que evita o microgerenciamento dos projetos e contradizer a equipe do projeto;

- reuniões abertas de revisão de projetos com a alta administração (com participação de toda a equipe do projeto);

- geradores de ideias reconhecidos ou recompensados;

- tempo permitido para que as pessoas criativas trabalharem em projetos de livre escolha (projetos paralelos); e 
- empregar "skunk works"10 e permitir alguns projetos não oficiais (projetos realizados fora do sistema).

\subsubsection{Organização interna}

Henard e Szymanski (2001) acrescentaram aos fatores influenciadores do desempenho de DP os princípios de alinhamento organizacional e estratégico. Para Brown e Eisenhardt (1995), a organização interna envolve a execução por equipes multifuncionais competentes e bem coordenadas e que aproveitam as sinergias da empresa e conseguem apoio significativo da alta gerência.

\subsubsection{Alta administração}

A influência do apoio da alta administração sobre o desempenho do DP é considerada fundamental (S. Brown \& Eisenhardt, 1995; Cooper \& Kleinschmidt, 1987a; Gupta \& Wilemon, 1990; Roy Rothwell, 1972; Zirger \& Maidique, 1990)). Ela ocorre por meio da provisão de recursos para a equipe do projeto, incluindo recursos financeiros e políticos, o que facilitaria a atração de membros para a equipe para o projeto e a aprovação do projeto e de financiamento, todos necessários para o desenvolvimento rápido e eficiente de produtos (Cooper \& Kleinschmidt, 1987a; Gupta \& Wilemon, 1990; R. Katz \& Allen, 1985; Zirger \& Maidique, 1990).

Cooper (2019) verificou que nas empresas com melhor desempenho, a alta administração se compromete a longo prazo com o DP como fonte de crescimento ao: estabelecer visão, objetivos e uma estratégia para o DP; disponibilizar os recursos necessários para o desenvolvimento do produto; garantir que eles não sejam desviados para necessidades mais imediatas em tempos de escassez; ter comprometimento com um sistema disciplinado da ideia do produto ao seu lançamento no mercado; ter envolvimento no processo do novo produto, revisando projetos, tomando decisões oportunas e firmes para prosseguimento ou abandono; decidir pelo prosseguimento, assumir compromissos de recursos com as equipes do projeto; capacitar as equipes do projeto; e apoiar os campeões ${ }^{11}$ comprometidos, atuando como mentores, facilitadores, "padrinhos" ou patrocinadores dos líderes e equipes dos projetos. No entanto, Cooper (2019) defende que o principal papel da alta administração seja preparar o cenário para o DP, ser mais um facilitador e muito menos um ator central.

Em seu estudo da década de 1980, Imai, Nonaka e Takeuchi (1985) sugeriram que, em vez de desempenhar apenas um papel de apoio, como sugerido pelos estudos de Cooper e Kleinschmidt, 1987a; Gupta e Wilemon (1990); Zirger e Maidique (1990), os gestores deveriam exercer um

\footnotetext{
${ }^{10}$ Skunkworks - "são basicamente equipes especiais de intra-empreendedores apaixonados, isolados do resto de seus negócios, com recursos e um domínio relativamente livre para inovar e desenvolver." (T. E. Brown, 2004): 132

11 "Project champion" ou campeão do projeto é definido como "alguém que é ao mesmo tempo um recurso organizacional e de vital importância para o sucesso do projeto e da organização”. (J. K. Pinto, 2013):120
} 
"controle sutil", ou seja, comunicando uma visão clara dos objetivos para suas equipes e simultaneamente dando aos seus membros a liberdade de trabalhar de forma autônoma dentro da disciplina dessa visão.

\subsubsection{Planejamento do projeto de desenvolvimento de produto}

Após a decisão para iniciar um projeto com a definição de seus objetivos e a designação do responsável pelo projeto ou o seu gerente, dá-se início ao seu processo de planejamento (PMI, 2017). Brown e Eisenhardt (1995) consideram que, de forma mais abrangente, o desenvolvimento bemsucedido de produtos é o resultado de planejamento e execução racionais. Em estudo do final da década de 1980, Hayes e colaboradores (1988) consideraram o início do processo de desenvolvimento como o momento para a solução de conflitos por meio do alinhamento entre todos os envolvidos para uma clara visão do projeto. Cooper e Kleinschmidt (1987a), na mesma época, concluíram que um projeto bem definido preliminarmente em termos de mercado-alvo, posicionamento de produto, benefícios do produto e requisitos do produto teria forte relação com resultados positivos do DP.

As atividades preliminares ao desenvolvimento envolvem (K. B. Clark \& Fujimoto, 1991; Cooper, 2019; Cooper \& Kleinschmidt, 1987b; Dwyer \& Mellor, 1991; Iansiti, 1993; Womack et al., 1992; Zirger \& Maidique, 1990):

- avaliação preliminar para avaliar o potencial do mercado e os atributos desejados do produto;

- avaliação técnica preliminar do projeto e identificação dos riscos técnicos;

- estudo detalhado de mercado, pesquisa de mercado e pesquisa da voz do cliente (necessidades e requisitos);

- estratégia de posicionamento (incluindo o preço-alvo);

- avaliação técnica detalhada, estabelecimento de prova de conceito, resolução de problemas de propriedade intelectual e avaliação de operações ou de fonte de suprimento;

- recursos, atributos, requisitos e especificações de alto nível do produto;

- análise comercial e financeira para decisão de investimento para desenvolvimento em larga escala;

- identificação dos benefícios a serem entregues ao usuário (incluindo a proposta de valor).

Tendo por referência o conceito de ciclo de vida dos projetos, de acordo com Cooper (1990), as atividades do estágio de pré-desenvolvimento foram as relacionadas a diferenças maiores entre sucesso e fracasso. Para o pesquisador, dois dos piores desperdiçadores de tempo são o desvio (mudança) do escopo do projeto e as especificações instáveis do produto, ou seja, requisitos e especificações do produto que continuam mudando ao longo do projeto. Para Shenhar e colaboradores 
(1997), deficiências nas definições do projeto e na articulação dos requisitos do produto podem gerar insatisfação com o resultado do projeto, mesmo quando todas as especificações foram atendidas.

As vantagens da definição preliminar e adequada do escopo, de acordo com Cooper (2019), são resultados dos seguintes fatos: força mais atenção nas tarefas preliminares; serve como uma ferramenta de comunicação entre as áreas funcionais; e fornece objetivos claros para os membros da equipe de desenvolvimento (técnico).

\subsubsection{Lider do projeto}

Há estudos que indicam a influência de características dos líderes e de sua atuação sobre o desempenho do DP tais como: ligação da equipe com a alta administração da empresa e com os administradores das áreas funcionais; gerenciamento das atividades do projeto; influência sobre a motivação das pessoas e a capacidade de resolver conflitos; isolamento da equipe de problemas exteriores; visão ampla sobre o projeto; e o provimento dos recursos e de bom ambiente de trabalho (Rozenfeld et al., 2006). O líder do projeto poderia afetar tanto o desempenho do processo (velocidade e produtividade do processo de desenvolvimento) quanto a eficácia do produto (S. Brown \& Eisenhardt, 1995; K. B. Clark \& Fujimoto, 1991; R. Katz \& Allen, 1985).

Clark, Chew e Fujimoto (1987) e Clark e Fujimoto (1991) introduziram o conceito de "líder de equipe peso pesado" ("heavyweight project managers"), que seria um poderoso ponto de ligação que coordena as atividades de uma equipe de DP ao mesmo tempo em que trabalha com a alta administração para criar um conceito de produto abrangente. Isso permitiria à alta administração exercer o chamado "controle sutil". Esses líderes de equipe seriam capazes de obter recursos, conquistar respeito e romper alianças funcionais tradicionais enquanto constroem uma forte visão do produto (S. Brown \& Eisenhardt, 1995; K. B. Clark \& Fujimoto, 1991; Kim B. Clark et al., 1987; Kim B. Clark \& Wheelwright, 1992; Hayes et al., 1988; Womack et al., 1992).

O modelo teórico proposto por Brown e Eisenhardt (1995) considera o líder do projeto como figura central no processo de desenvolvimento, embora também considere a equipe interfuncional o coração do desenvolvimento eficiente de produtos. Os pesquisadores destacam algumas características dos líderes dos projetos de DP que podem influenciar o desempenho e que são comentados a seguir.

- Líder do projeto com visão, ou seja, como definem Brown e Eisenhardt (1995, com capacidade cognitiva de mesclar vários fatores para criar uma visão holística efetiva e comunicá-la aos outros;

- Líder do projeto com elevado poder, ou seja, com responsabilidade significativa para a tomada de decisões, autoridade em toda a organização e alto nível hierárquico. Desta forma, eles seriam eficazes na obtenção de recursos para o projeto. 
Cooper (2019) destaca a importância de haver um líder de projeto claramente identificado e que tenha por responsabilidade a condução do projeto desde a ideia até o lançamento, conduzindo o projeto através do processo e não apenas em um ou alguns estágios. No entanto, considera importante que toda a equipe do projeto compartilhe da responsabilidade pelos resultados.

\subsubsection{Equipe do projeto de desenvolvimento do produto}

Brown e Eisenhardt (1995) consideram que a composição, o processo de grupo e a organização do trabalho da equipe do projeto afetam as informações, os recursos e o estilo de solução de problemas da equipe que, por sua vez, influenciam a velocidade e a produtividade do processo. A seguir são relacionadas características das equipes que são consideradas relevantes.

- A interfuncionalidade ou diversidade funcional aumentaria a quantidade e variedade de informações disponíveis para o desenvolvimento dos produtos (Boer \& During, 2001; K. B. Clark \& Fujimoto, 1991; Cooper, 2019; Dougherty, 1992b; Henard \& Szymanski, 2001; Henke et al., 1993; Imai et al., 1985; M. B. Pinto \& Pinto, 1990; Rozenfeld et al., 2006; Salgado \& Dekkers, 2018; Zirger \& Maidique, 1990). No entanto, Henard e Szymanski (2001) indicam que elementos da diversidade funcional não estão diretamente relacionados ao desempenho de novos produtos por si só por haver efeitos moderadores da comunicação multifuncional;

- A atuação dos chamados "gatekeepers", ou seja, indivíduos que frequentemente obtêm informações externas ao grupo e depois compartilham dentro da equipe do projeto afetariam o desempenho do processo aumentando também a quantidade e a variedade de informações disponíveis ao projeto (T. J. Allen, 1971, 1977; Ralph Katz \& Tushman, 1981; Rozenfeld et al., 2006);

- O tempo em que equipe já trabalha junto é também fator que influencia o desempenho do processo Katz (1982);

- Características como coesão, integração e compartilhamento de uma mesma visão e dos objetivos do projeto são relacionados à adequada transformação de informações sobre o mercado e as tecnologias em informações para a realização de todas as fases do ciclo de vida do projeto (Rozenfeld et al., 2006);

- A forte identificação e comprometimento com o projeto influenciariam positivamente os resultados (S. Brown \& Eisenhardt, 1995; Kim B. Clark \& Wheelwright, 1992; Cooper, 2019; Salgado \& Dekkers, 2018).

Um sistema central de informações compartilhadas para os membros da equipe do projeto é também considerado por Cooper (2019) como um importante fator a ser considerado para que os 
membros da equipe trabalhem efetivamente juntos, mesmo sendo de funções, locais e até países diferentes.

\subsubsection{Integração interdepartamental}

Wheelwright e Clark (1992) destacaram que o desenvolvimento de novos produtos é um desafio, pois envolve um conjunto complexo de atividades multidepartamentais ${ }^{12}$. A integração entre as áreas funcionais é caracterizada pela colaboração e troca de informações em todas as fases do desenvolvimento entre os diversos setores e departamentos de uma empresa. É relacionada ao melhor gerenciamento das interfaces dos projetos, à prevenção e à resolução antecipada de problemas e à melhoria das decisões (Boer \& During, 2001; S. Brown \& Eisenhardt, 1995; Kim B. Clark \& Wheelwright, 1992; Cooper \& Kleinschmidt, 1987b; Griffin \& Hauser, 1996; Gupta \& Wilemon, 1990; PMI, 2017; Salgado \& Dekkers, 2018; Zirger \& Maidique, 1990).

Dougherty (1992b) verificou, no entanto, que os diferentes departamentos funcionais eram equivalentes a "mundos do pensamento" também diferentes, cada um com seu próprio "conhecimento" e "sistema de significado". Desta forma, profissionais de diferentes departamentos perceberiam diferentes aspectos e os entenderiam de maneiras diferentes, podendo resultar em barreiras para o desenvolvimento. Com conclusão semelhante, Cooper (2019) afirma que a análise dos resultados de projetos de DP mal sucedidos muito invariavelmente indicará que cada área funcional participante executou apenas a própria parte do projeto, com muito pouca comunicação entre as áreas funcionais (uma mentalidade de feudo) e sem compromisso real dos membros da equipe do projeto.

\subsubsection{Relacionamento com fornecedores}

Os fornecedores contribuem para os resultados do DP ao possibilitarem a melhor utilização dos recursos e a ampliação do conhecimento tecnológico (Birou \& Fawcett, 1994; Boer \& During, 2001; Cooper, 2019; Salgado \& Dekkers, 2018). Em se tratando de integração com a cadeia de suprimentos, o envolvimento dos fornecedores desde as fases iniciais do DP diminuiria o tempo de conclusão ou o tempo para lançamento (“time to market") e aumentaria a produtividade do DP em razão da diminuição da complexidade e da antecipação da solução de problemas no projeto (Rozenfeld et al., 2006).

No mesmo sentido, Clark \& Fujimoto (1991) e Imai, Nonaka e Takeuchi (1985) destacaram o envolvimento extensivo dos fornecedores que, no caso da definição do "design" do produto, poderia contribuir com informações e ideias para a redução de sua complexidade e alertar a equipe do projeto para possíveis problemas a jusante no início, em um momento em que eles são mais fáceis e rápidos

\footnotetext{
12 Equipes interdepartamentais ("cross-functional teams") - grupos de projetos com membros de mais de uma área funcional, como engenharia, manufatura ou marketing (S. Brown \& Eisenhardt, 1995, p.367).
} 
de serem corrigidos. Os fornecedores podem até estar dispostos a compartilhar novas ideias de produtos com os clientes (Wagner, 2012). Entretanto, a parceria representa riscos e cuidados devem ser tomados no compartilhamento de ideias e informações e em relação à propriedade dos resultados do trabalho conjunto. Cooper (2019) alerta para a possibilidade de conflitos e desalinhamentos devido a mal-entendidos, diferenças culturais e até falta de confiança.

Além de poder fornecer componentes ou ingredientes essenciais, o relacionamento com fornecedores e redes de $\mathrm{P} \& \mathrm{D}$ pode também proporcionar o desenvolvimento de habilidade técnica especializada, o que permitia o atendimento a solicitações emergenciais ou incomuns de maneira rápida e eficaz (Cooper, 2019; Gupta \& Wilemon, 1990; Imai et al., 1985).

\subsubsection{Comunicação}

A pesquisa que Griffin e Hauser (1996) realizaram indicou que, para facilitar a tomada de decisões conjunta em um processo ideal de desenvolvimento de produtos, há a necessidade de transferência eficiente das informações entre os participantes. Assim, um dos fatores-chave para o desempenho das equipes é a comunicação interna (K. B. Clark \& Fujimoto, 1991; Kim B. Clark et al., 1987; Hayes et al., 1988; Keller, 1986; Womack et al., 1992). Mais especificamente, Ancona e Caldwell (1992b) concluíram que equipes com uma comunicação onde havia objetivos definidos, planos viáveis e priorização do trabalho tiveram desempenho superior.

O processo de grupo, especialmente a comunicação, quando eficazes, aumentam a informação e são essenciais para processos de desenvolvimento de alto desempenho (Imai et al., 1985; Ralph Katz, 1982; Zirger \& Maidique, 1990). De acordo com o PMI (2017), a fim de realizar as entregas de um projeto conforme planejado, a equipe do projeto precisa ser capaz de manter uma comunicação proativa com as partes interessadas. A seguir são apresentadas algumas características da comunicação eficiente:

- comunicação interna frequente, pois aumenta diretamente a quantidade de informação, na medida em que mais comunicação geralmente produz mais informação (S. Brown \& Eisenhardt, 1995; Dougherty, 1990; Keller, 1986). De maneira mais sutil, também cria a coesão da equipe (Keller, 1986);

- comunicação estruturada, pois evita mal-entendidos e barreiras à troca, aumentando a quantidade de informação transmitida, a velocidade e a produtividade de todo o processo de desenvolvimento (S. Brown \& Eisenhardt, 1995; Dougherty, 1992b);

- comunicação externa frequente, pois abre a equipe do projeto para novas informações (K. B. Clark \& Fujimoto, 1991; Imai et al., 1985; Ralph Katz, 1982);

- comunicação externa orientada por tarefas, pois os membros da equipe obtêm informações de diversos pontos de vista além dos da equipe (Ancona \& Caldwell, 1992b); 
- comunicação externa na forma de atividades políticas, como fazer "lobby" por recursos, engajar-se em gerenciamento de impressão e buscar apoio da alta administração para o projeto (Ancona \& Caldwell, 1992b; S. Brown \& Eisenhardt, 1995);

- comunicação interna e externa conjuntamente, pois aumentam a quantidade e a variedade de informações e os recursos disponíveis para a equipe do projeto (Ancona \& Caldwell, 1992b; K. B. Clark \& Fujimoto, 1991; Imai et al., 1985; R. Katz \& Allen, 1985; Ralph Katz, 1982; Ralph Katz \& Tushman, 1981)

\subsubsection{Recursos}

A limitação de recursos é considerada por Cooper (2019) a causa raiz de grande parte dos fatores que afetam o desenvolvimento de produtos. Restrições impostas pela falta de tempo e o comprometimento financeiro provocam o desenvolvimento inadequado dos projetos de DP, a ênfase excessiva em projetos simples, rápidos e baratos e/ou a realização de número excessivo de projetos para os recursos disponíveis. Em específico para os recursos humanos, Cooper (2019) destaca que estes devem ser focados e dedicados, evitando que os membros da equipe do projeto trabalhem em muitos projetos ou tarefas.

\subsubsection{Gestão do projeto}

Para Cooper e Kleinschmidt (1987b), para a eficiência no DP, os gestores também deveriam se tornar mais eficientes na administração dos processos do projeto, ou seja, deveriam garantir a efetiva realização das atividades que movem um produto da ideia para o lançamento. Griffin e Hauser (1996) afirmam que o uso de um processo formal de gerenciamento do desenvolvimento de produtos que especifique quais tarefas serão concluídas, em que ordem e por quem, pode levar a melhores resultados. A má qualidade de execução geralmente resulta em muito desperdício, podendo haver a necessidade de retroceder para correção e ajustes.

Wheelwright e Clark (1992), já no início da década de 1990, verificaram que os projetos estruturados que levam ao desenvolvimento rápido e efetivo de produtos e processos de produção estavam relacionados à clareza dos objetivos, ao foco no tempo-para-mercado, à integração interna e externa, aos protótipos de alta qualidade e à forte liderança. A publicação recente de Cooper (2019) aponta como áreas suscetíveis a problemas de execução o "front-end" (pré-desenvolvimento). Por outro lado, as tarefas técnicas seriam menos frequentemente responsáveis por problemas na execução. Para melhorar a execução dos projetos de DP, o autor sugere a incorporação da qualidade aos processos do projeto por meio de: equipe de projeto com pessoas capazes e treinadas; membros da equipe dedicados, com tempo disponível para realizar um trabalho de qualidade; orientação e suporte gerencial; processo claro com diretrizes úteis para a equipe do projeto; e verificações de qualidade ou "gates" durante o projeto com resposta à questão "estamos fazendo certo este projeto?". De acordo 
com Rozenfeld e colaboradores (2006), a gestão operacional do DP também ocupa-se do controle das atividades rotineiras de desenvolvimento tais como: o mapeamento dos requisitos dos clientes e do projeto, a realização de avaliações, a construção dos protótipos e as análises de custos e prazos.

Griffin e Hauser (1996) verificaram que os processos formais de DP frequentemente utilizavam uma abordagem em fases ou sequencial, ao que chamaram de processo de revisão de fases em abordagem semelhante ao sistema Stage-Gate ${ }^{\circledR}$ de Cooper (1990). Cooper (2019) relaciona alguns dos fatores relacionados à gestão de projetos que podem contribuir para a melhoria do desempenho do DP:

- Realização de atividades do "front-end" (pré-desenvolvimento);

- Verificação da qualidade de execução em todas as etapas do projeto ("gates");

- Equipes multifuncionais eficazes;

- Processamento paralelo (execução simultânea de tarefas, como engenharia simultânea);

- Desenvolvimento em espiral ou iterativo (iterações de revisão com testes e ajustes).

Abordados os fatores contribuintes ou influenciadores dos projetos de DP de uma forma geral, o referencial teórico passará agora a tratar mais especificamente da literatura que trata dos fatores relacionados ao desempenho dos PDMG.

\subsection{FATORES CONTRIBUINTES PARA O DESEMPENHO DOS PDMG}

Considerando os projetos desenvolvidos dentro da indústria farmacêutica, o International Society for Pharmaceutical Engineering - ISPE (2011) considera o contexto do negócio como componente a ser considerado. O entendimento é o de que os projetos em geral tem origem em casos de negócios ("business cases") aprovados pela organização. Assim, os projetos devem estar relacionados às necessidades e ao contexto do negócio deste o seu início. A instituição também considera importante a relação custo-benefício. A análise dos benefícios envolve o escopo a ser entregue pelo projeto, o qual deve considerar requisitos tecnológicos, regulatórios e de competitividade. Ainda segundo a instituição, completando a tríade do desempenho dos projetos, a análise de custo-benefício também deve considerar o prazo para a entrega.

Outro importante componente a ser considerado diz respeito à legislação ou, mais especificamente, aos requisitos regulatórios. Um medicamento só pode ser colocado no mercado se obtiver aprovação do órgão regulador (Do Carmo, Piras, et al., 2017), a Anvisa no caso brasileiro. Assim, o desenvolvimento de um novo medicamento só pode ser tecnicamente considerado um sucesso se tiver o seu registro aprovado. Portanto, é condicionante para o sucesso do desenvolvimento dos medicamentos genéricos o atendimento aos requisitos legais. 
Quando aplicável, as regras de boas práticas exigidas devem ser integradas aos requisitos do projeto. O ISPE (2011) enfatiza que falhas no atendimento aos requisitos legais podem resultar em elevadas penalidades financeiras e operacionais. Kennedy 2008) dá como exemplo o não cumprimento dos prazos de envio do dossiê de registro dos medicamentos e indica que esta deficiência pode ser resultado de recursos insuficientes, gerenciamento inadequado, falha na priorização e/ou falta de colaboração dos departamentos funcionais.

Huang e colaboradores (2013) estudaram as lacunas técnicas enfrentadas pelos fabricantes chineses de medicamentos genéricos para atender aos requisitos do programa da Organização Mundial da Saúde (OMS) para pré-qualificação de medicamentos. Os pesquisadores encontraram deficiências nas boas práticas de fabricação no que se refere à gestão da qualidade e em procedimentos de validação e qualificação, calibração e manutenção. Outras lacunas técnicas identificadas diziam respeito à gestão de riscos e ao chamado Sistema CAPA ("Correction Action and Preventive Action" Ação Corretiva e Ação Preventiva). Com relação aos dossiês para registros dos medicamentos que analisaram, encontraram três principais falhas técnicas: testes de bioequivalência, informações dos fornecedores dos ingredientes farmacêuticos ativos (IFAs) e testes de estabilidade. Todos são componentes dos projetos de desenvolvimento dos medicamentos.

Worku e colaboradores (2012) também realizaram estudo para determinar o tipo e extensão das deficiências nos dossiês de produtos genéricos submetidos ao Programa de Pré-qualificação de Medicamentos da OMS, porém, especificamente para as áreas terapêuticas do HIV / AIDS, tuberculose, malária e saúde reprodutiva. Eles verificaram a existência de deficiências relacionadas à qualidade, especialmente na especificação da categoria dos IFAs, ao desenvolvimento farmacêutico, ao método de fabricação e às especificações dos produtos farmacêuticos acabados. Eles também verificaram que as deficiências nos dossiês relacionadas aos aspectos de eficácia e segurança apresentaram tendência semelhante à observada para os aspectos de qualidade, sendo as deficiências mais críticas as relacionadas ao delineamento incorreto do projeto, ao uso de um medicamento de referência indevido e à ausência dos estudos requeridos. Os pesquisadores concluíram que havia a necessidade de capacitação contínua dos fabricantes locais de genéricos, o desenvolvimento de monografias farmacopéicas ${ }^{13}$ e promover o desenvolvimento de novos guias ou diretrizes, ou seja, documentos de orientação para o setor regulado. No entanto, Genazzani e Pattarino (2008) afirmam que, embora a legislação sobre genéricos em todo o mundo seja suficiente para garantir que somente

\footnotetext{
${ }^{13}$ Monografia farmacopeica - documento oficial com dados técnicos de caracterização de fármacos, ingredientes e medicamentos; métodos e testes para suas análises; e requisitos e especificações para suas aprovações. É componente de uma farmacopeia, que é uma publicação oficial aceita como referência pelos órgãos regulatórios.
} 
produtos seguros e eficazes sejam lançados no mercado, a homogeneidade de todos os produtos que contenham o mesmo princípio ativo seja difícil de alcançar.

Moreira e Cheng (2010) aprofundaram os conhecimentos sobre os critérios técnicos ligados aos requisitos dos produtos e dos processos de fabricação e propuseram uma lista de verificação contendo os itens a serem avaliados, os quais são apresentados na Tabela 18 a seguir. Embora os critérios relacionados estejam voltados para o gerenciamento de portfólio, o foco está nos componentes dos projetos de desenvolvimento de novos medicamentos que devem ser considerados no processo de seleção de um novo projeto.

Tabela 18 - Critérios para o gerenciamento de portfólio na indústria farmacêutica

\begin{tabular}{|c|c|}
\hline Aspectos & Critério de verificação \\
\hline $\begin{array}{l}\text { Farmacotécnicos } \\
\text { e de controle da } \\
\text { qualidade }\end{array}$ & 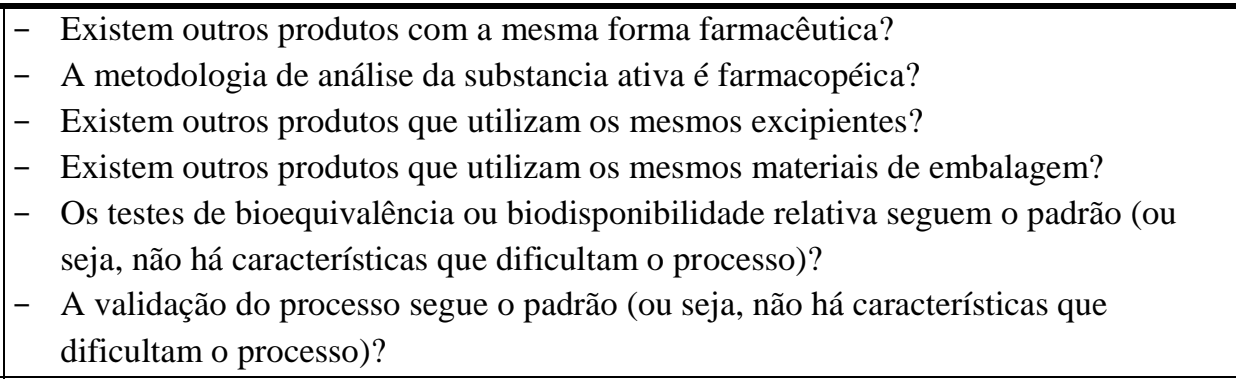 \\
\hline Infraestrutura & $\begin{array}{ll}\text { - } & \text { Existe infraestrutura (equipamento, área, utilidades, etc.) para a produção industrial? } \\
\text { - } & \text { Existe infraestrutura (equipamento, área, utilidades, etc.) para o desenvolvimento? } \\
\text { - } & \text { Existe infraestrutura (equipamento, área, utilidades, etc.) para os estudos de } \\
& \text { estabilidade? } \\
\text { - } & \text { Existe infraestrutura (equipamento, área, utilidades, etc.) para a produção industrial? } \\
\text { - } & \text { Existe infraestrutura (equipamento, área, utilidades, etc.) para o controle da } \\
& \text { qualidade? } \\
\text { - } & \text { A capacidade produtiva atual comporta o novo produto? }\end{array}$ \\
\hline Regulatórios & $\begin{array}{l}\text { - } \text { O dossiê de registro segue o formato padrão (ou seja, não há características que } \\
\text { dificultam o processo)? } \\
\text { - } \quad \text { O novo produto está de acordo com as BPF? } \\
\text { - } \quad \text { O novo produto está de acordo com as normas de segurança? }\end{array}$ \\
\hline
\end{tabular}

Fonte: Moreira e Cheng (2010)

Yugue e colaboradores (2010) realizaram pesquisa sobre a seleção de projetos de desenvolvimento de novos produtos na indústria farmacêutica e identificaram os conhecimentos considerados importantes para as decisões de novos projetos de medicamentos. Os autores destacaram a valorização do conhecimento do mercado de produtos farmacêuticos e da regulamentação dos medicamentos. Por outro lado, os dados também mostraram que são pouco valorizados os conhecimentos ligados às técnicas e ferramentas de tomada de decisão. Entre as técnicas empregadas pelas empresas no processo de tomada de decisão sobre novos produtos, os seguintes apresentaram destaque entre os mais utilizados:

- estudo de viabilidade de aprovação pela ANVISA;

- análise de viabilidade econômico-financeira e/ou projeção de lucros; 
- cronograma do projeto de desenvolvimento do novo produto (tempo estimado de desenvolvimento).

A pesquisa realizada por Do Carmo, Piras e colaboradores (2017) com dados da Anvisa dos anos de 2007 a 2015 teve como um de seus resultados a identificação das principais razões para o recusa da agência para a aprovação de medicamentos genéricos e similares. A Tabela 19 a seguir apresenta a distribuição das principais classes de razões para a não aprovação dos medicamentos.

Tabela 19 - Razões para recusa da Anvisa para o registro de medicamentos genéricos e similares.

\begin{tabular}{lcc}
\hline Razões para recusa & $\mathbf{N}$ & $\mathbf{\%}$ \\
\hline Controle de qualidade do medicamento & 67 & $13,3 \%$ \\
Estudo de estabilidade do medicamento & 62 & $12,4 \%$ \\
Descumprimento dos prazos & 50 & $9,9 \%$ \\
Controle de qualidade do IFA pelo fabricante do medicamento & 41 & $8,2 \%$ \\
Ingrediente Farmacêutico Ativo (IFA) & 41 & $8,2 \%$ \\
Relatório de produção & 29 & $5,8 \%$ \\
Equivalência farmacêutica & 27 & $5,4 \%$ \\
Estudos de estabilidade do IFA & 23 & $4,6 \%$ \\
Dissolução & 23 & $4,6 \%$ \\
Estudos de bioequivalência & 17 & $3,4 \%$ \\
Controle de qualidade de excipientes & 16 & $3,2 \%$ \\
Análises preliminares & 16 & $3,0 \%$ \\
Documentação & 13 & $2,6 \%$ \\
Fotoestabilidade do medicamento & 61 & $12,7 \%$ \\
\hline Total & 501 & $100,0 \%$ \\
\hline
\end{tabular}

Fonte: Do Carmo, Piras e colaboradores (2017)

Do Carmo, Piras e colaboradores (2017) analisaram 501 pedidos para aprovação de registro de medicamentos genéricos e similares e que não foram aprovados pela Anvisa. Desse total, $84 \%$ (420 pedidos) foram por razões técnicas e 16\% (81 pedidos) por razões não técnicas, ou seja, o não cumprimento de prazos, análises preliminares e documentação.

Os pesquisadores também verificaram que em 2015 a Anvisa aprovou os registros de 99 medicamentos genéricos e não aprovou outros 93, ou seja, apenas $48 \%$ do total de 192 pedidos de registro de medicamentos genéricos foram aprovados em 2015. Este dado foi um dos principais motivadores deste estudo, pois considerou-se muito elevada esta taxa de insucesso e que haveria interesse em identificar e buscar entender suas possíveis razões.

De maneira sistematizada, são apresentados na Tabela 20 os itens que têm ligação mais direta com a questão desta pesquisa entre os requisitos da Anvisa estudados por Do Carmo (2017). 
Tabela 20 - Requisitos sanitários para registro relacionados aos medicamentos genéricos

\begin{tabular}{|c|c|}
\hline Itens & Requisitos \\
\hline \multirow[t]{2}{*}{$\begin{array}{l}\text { Documentação } \\
\text { administrativa }\end{array}$} & $\begin{array}{l}\text { Formulários de petição: dados do fabricante do medicamento, classe do } \\
\text { medicamento, apresentações, formulação, cuidados de conservação, embalagem } \\
\text { primária e secundária }\end{array}$ \\
\hline & Modelos de bula e rotulagem \\
\hline \multirow{7}{*}{$\begin{array}{l}\text { Relatório de } \\
\text { produção }\end{array}$} & Fórmula mestre: o lote piloto deve ter o mesmo processo produtivo \\
\hline & Etapas do processo de produção \\
\hline & Equipamentos utilizados na produção \\
\hline & Tamanho de lote \\
\hline & $\begin{array}{l}\text { Cópia dos dossiês de produção: dossiê de um lote e fichas de pesagens e de cálculo } \\
\text { de rendimento das etapas de manipulação, embalagem e final. }\end{array}$ \\
\hline & Relatório sumário de validação de processo \\
\hline & Controle das etapas críticas de processo \\
\hline \multirow{9}{*}{$\begin{array}{l}\text { Ingrediente } \\
\text { Farmacêutico Ativo } \\
\text { (IFA) }\end{array}$} & Informações sobre o fabricante do IFA \\
\hline & Fórmula estrutural \\
\hline & $\begin{array}{l}\text { Rota de síntese: descrição de materiais de partida, intermediários e solventes } \\
\text { utilizados. }\end{array}$ \\
\hline & $\begin{array}{l}\text { Métodos analíticos e especificações adotadas: método analítico não farmacopeico } \\
\text { deve ser validado. }\end{array}$ \\
\hline & $\begin{array}{l}\text { Certificado de análise do IFA: emitido pelo fabricante do medicamento, inclusive } \\
\text { para fabricação dos lotes piloto. }\end{array}$ \\
\hline & Principais impurezas: devem ser monitoradas no controle de qualidade. \\
\hline & $\begin{array}{l}\text { Quiralidade do IFA: impacto na segurança e eficácia do medicamento devem ser } \\
\text { avaliados. }\end{array}$ \\
\hline & $\begin{array}{l}\text { Polimorfismo: pode afetar a solubilidade, dissolução e consequentemente a } \\
\text { biodisponibilidade. }\end{array}$ \\
\hline & $\begin{array}{l}\text { Estudos de estabilidade e fotoestabilidade: devem ser realizados na zona climática } \\
\text { brasileira, zona IVb, } 30 \mathrm{oC} \pm 20 \mathrm{o} ; 75 \% \pm 5 \% \text {. }\end{array}$ \\
\hline \multirow[t]{2}{*}{$\begin{array}{l}\text { Controle de qualidade } \\
\text { dos excipientes }\end{array}$} & $\begin{array}{l}\text { Especificações, métodos analíticos e laudo analítico para os excipientes: deve } \\
\text { incluir referência bibliográfica. }\end{array}$ \\
\hline & $\begin{array}{l}\text { Controle da encefalopatia espongiforme transmissível (EET) para os excipientes de } \\
\text { origem animal }\end{array}$ \\
\hline \multirow{4}{*}{$\begin{array}{l}\text { Desenvolvimento da } \\
\text { Formulação }\end{array}$} & Resumo do desenvolvimento da formulação. \\
\hline & Informações sobre a compatibilidade do IFA com os excipientes. \\
\hline & Justificativa no caso de excesso de ativo. \\
\hline & Dados de excipientes e sistemas conservantes utilizados pela primeira vez. \\
\hline \multirow{3}{*}{$\begin{array}{l}\text { Controle de qualidade } \\
\text { do medicamento }\end{array}$} & Métodos analíticos e especificações adotadas \\
\hline & $\begin{array}{l}\text { Laudos de análise de controle de qualidade dos lotes: métodos devem apresentar } \\
\text { especificidade. }\end{array}$ \\
\hline & $\begin{array}{l}\text { Estudos de degradação forçada: para predizer a rota de degradação do fármaco e a } \\
\text { formação de produtos de degradação durante os estudos de estabilidade e o } \\
\text { processo produtivo. }\end{array}$ \\
\hline $\begin{array}{l}\text { Embalagem primária, } \\
\text { acessórios dosadores }\end{array}$ & $\begin{array}{l}\text { Métodos analíticos e especificações adotadas: embalagem secundária funcional e o } \\
\text { envoltório intermediário }\end{array}$ \\
\hline \multirow[t]{4}{*}{$\begin{array}{l}\text { Estudos de } \\
\text { estabilidade e } \\
\text { fotoestabilidade do } \\
\text { medicamento }\end{array}$} & $\begin{array}{l}\text { Relatório de estudo de estabilidade acelerada e/ou de longa duração de três lotes } \\
\text { piloto: métodos indicativos de estabilidade capazes de detectar mudanças nas } \\
\text { propriedades físicas, químicas ou microbiológicas de uma substância. }\end{array}$ \\
\hline & Estudo de fotoestabilidade: métodos analíticos devem ser validados \\
\hline & Especificações determinadas de acordo com os resultados de análise do produto. \\
\hline & A ausência de estudos de fotoestabilidade deve ser justificada. \\
\hline \multirow[t]{2}{*}{ Importador } & $\begin{array}{l}\text { Especificações e métodos de controle de qualidade adotados pelo importador: } \\
\text { método analítico não farmacopeico deve ser validado. }\end{array}$ \\
\hline & Laudos analíticos de controle de qualidade de três lotes. \\
\hline
\end{tabular}




\begin{tabular}{c|l}
\hline \multicolumn{1}{c}{ Itens } & \multicolumn{1}{c}{ Requisitos } \\
\hline $\begin{array}{c}\text { Equivalência } \\
\text { Terapêutica }\end{array}$ & $\begin{array}{l}\text { Equivalência farmacêutica: comparação entre o biolote (lote do medicamento } \\
\text { submetido a estudos de bioequivalência) e o medicamento referência. }\end{array}$ \\
\cline { 2 - 2 } & $\begin{array}{l}\text { Perfil de dissolução comparativo: comparação entre o biolote e o medicamento } \\
\text { referência para comportamentos in vitro. }\end{array}$ \\
\cline { 2 - 2 } & $\begin{array}{l}\text { Bioequivalência: estudo in vivo que compara a biodisponibilidade do medicamento } \\
\text { genérico ou similar à do medicamento referência. }\end{array}$ \\
\hline \multirow{2}{*}{$\begin{array}{c}\text { Reguatório de } \\
\text { Regurance eficácia }\end{array}$} & Relatório de ensaios não clínicos. \\
\cline { 2 - 2 } & Plano de farmacovigilância. \\
\hline
\end{tabular}

Fonte: extraído de Do Carmo (2017).

Para a aprovação da produção de um novo medicamento, além dos requisitos para os medicamentos em si, também existem requisitos para os seus processos de produção. A instrução normativa - IN no 47/2019 da (Anvisa, 2019b), em sua Subseção III, estabelece a necessidade de validação do processo de fabricação. O objetivo da norma é a garantia de que o processo tem condições de oferecer produtos de qualidade de forma consistente.

Vale destacar que a IN $n^{\circ} 47 / 2019$ da (Anvisa, 2019b) incluiu em seu texto o conceito de qualidade pelo desenho ou por meio do delineamento ("Quality by Design"), que é definido em seu artigo $3^{\circ}$ - item XXI a como:

Uma abordagem sistemática que se inicia com objetivos pré-definidos e enfatiza o conhecimento/entendimento dos produtos, dos processos e dos controles em processos. É baseada/suportada pela ciência e pelo gerenciamento de risco da qualidade.

Em geral, publicações específicas sobre a tecnologia de desenvolvimento de medicamentos genéricos, como o de Shargel e Kanfer (2005), descrevem o processo de desenvolvimento dos medicamentos, mais especificamente sobre as técnicas e métodos para a execução das atividades, não tendo uma abordagem gerencial e sem relacioná-los aos resultados ou desempenho dos projetos.

\subsection{MODELO CONCEITUAL PARA A RELAÇÃO ENTRE O DESEMPENHO E SEUS FATORES CONTRIBUINTES}

Em um dos poucos modelos encontrados na literatura que relacionavam o desempenho do DP e seus fatores contribuintes, Cooper e Kleinschmidt (1987a) apresentaram uma proposta baseada nos modelos e fatores de sucesso definidos em estudos anteriores. O modelo postulava que os resultados do DP (sucesso ou fracasso) são determinados pela interação entre o mercado, a estratégia e execução do projeto do novo produto. Estes últimos seriam o resultado de um processo que ocorre dentro do ambiente da empresa e que é composto por recursos, experiência e competências em marketing, produção e tecnologia. 
Para a análise do modelo conceitual que propuseram, Cooper e Kleinschmidt (1987a) definiram hipóteses sobre as relações entre 10 fatores de sucesso e os resultados dos DP. Os constructos de interesse para este estudo (seis dos dez) são apresentados na Tabela 21.

Tabela 21 - Constructos relacionados ao DP estudados por Cooper e Kleinschmidt

\begin{tabular}{|c|c|c|c|}
\hline Constructo & $\begin{array}{c}\text { Confiabilidade } \\
\text { Coeficiente alfa } \\
(\alpha)\end{array}$ & Itens & $\begin{array}{c}\text { Correlação } \\
\text { total do } \\
\text { item } \\
\end{array}$ \\
\hline $\begin{array}{c}\text { Sinergia } \\
\text { tecnológica }\end{array}$ & 0,84 & $\begin{array}{l}\text { Um bom ajuste entre as necessidades do projeto e: } \\
\text { - as competências e recursos da empresa para a } \\
\text { P\&D e o desenvolvimento de produtos } \\
\text { - as competências e recursos da engenharia da } \\
\text { empresa } \\
\text { - as competências e recursos da produção da } \\
\text { empresa }\end{array}$ & $\begin{array}{l}0,72 \\
0,78 \\
0,61\end{array}$ \\
\hline Protocolo & 0,98 & $\begin{array}{l}\text { Antes do desenvolvimento do produto: } \\
\text { - o mercado alvo foi bem definido } \\
\text { - as necessidade, desejos e preferências dos } \\
\text { consumidores foram bem definidos } \\
\text { - o conceito do produto - o que o produto será e } \\
\text { fará - foi bem definido } \\
\text { - as especificações e requisitos do produto foram } \\
\text { bem definidos }\end{array}$ & $\begin{array}{l}0,92 \\
0,94 \\
0,95 \\
0,94\end{array}$ \\
\hline $\begin{array}{l}\text { Proficiência nas } \\
\text { atividades de pré- } \\
\text { desenvolvimento }\end{array}$ & 0,50 & $\begin{array}{l}\text { Proficiência no: } \\
\text { - "screening" inicial } \\
\text { - avaliação preliminar do mercado } \\
\text { - avaliação técnica preliminar } \\
\text { - estudo do mercado/pesquisa de marketing } \\
\text { detalhada } \\
\text { - análise do negócio ou financeira }\end{array}$ & $\begin{array}{l}0,46 \\
0,46 \\
0,22 \\
0,25 \\
0,37\end{array}$ \\
\hline $\begin{array}{l}\text { Proficiência nas } \\
\text { atividades } \\
\text { tecnológicas }\end{array}$ & 0,54 & $\begin{array}{l}\text { Proficiência no: } \\
\text { - avaliação técnica preliminar } \\
\text { - desenvolvimento do produto } \\
\text { - teste do produto internamente (prototipagem) } \\
\text { - produção de lote de teste/piloto } \\
\text { - início da produção }\end{array}$ & $\begin{array}{l}0,31 \\
0,43 \\
0,36 \\
0,19 \\
0,20 \\
\end{array}$ \\
\hline $\begin{array}{l}\text { Suporte da alta } \\
\text { administração }\end{array}$ & 0,81 & $\begin{array}{l}\text { - comprometimento da alta administração com o } \\
\text { projeto } \\
\text { - envolvimento da alta administração com a gestão } \\
\text { diária do projeto } \\
\text { - orientação/direcionamento comprometimento da } \\
\text { alta administração para o projeto }\end{array}$ & $\begin{array}{l}0,52 \\
0,73 \\
0,76\end{array}$ \\
\hline
\end{tabular}

Fonte: Cooper e Kleinschmidt (1987a, pp. 1776-177)

Entre as hipóteses, cinco referiam-se diretamente a fatores de mercado, ou seja: a. vantagens do produto; b. potencial de mercado; c. competitividade no mercado; d. estratégia de mercado; e e. proficiência em atividades relacionadas ao mercado. Isso indica uma abordagem com foco nos resultados de mercado do DP. Outras quatro hipóteses referiam-se a fatores técnicos, ou seja: f. 
sinergia tecnológica; g. $\operatorname{protocolo}^{14}$; h. proficiência em atividades de pré-desenvolvimento; e i. proficiência em atividades tecnológicas. Por fim, a última hipótese procurou testar a relação entre o suporte da alta administração com os resultados do DP.

Para cada uma das dez hipóteses, Cooper e Kleinschmidt (1987a) desenvolveram constructos ou variáveis latentes. Vale comentar que embora os nomes dos constructos para a mensuração do protocolo e proficiência nas atividades de pré-desenvolvimento fossem constituídos por itens predominantemente técnicos, alguns itens também eram relacionados a questões de mercado. Os constructos foram medidos utilizando assertivas sobre os itens em uma escala de 0 a 10.

Um outro modelo teórico, este proposto por Brown e Eisenhardt (1995) e disposto na Figura 19, teve como referencial a junção das três perspectivas ou correntes de DP propostas pelos pesquisadores.

Figura 19 - Fatores que afetam o sucesso de projetos de desenvolvimento de produtos

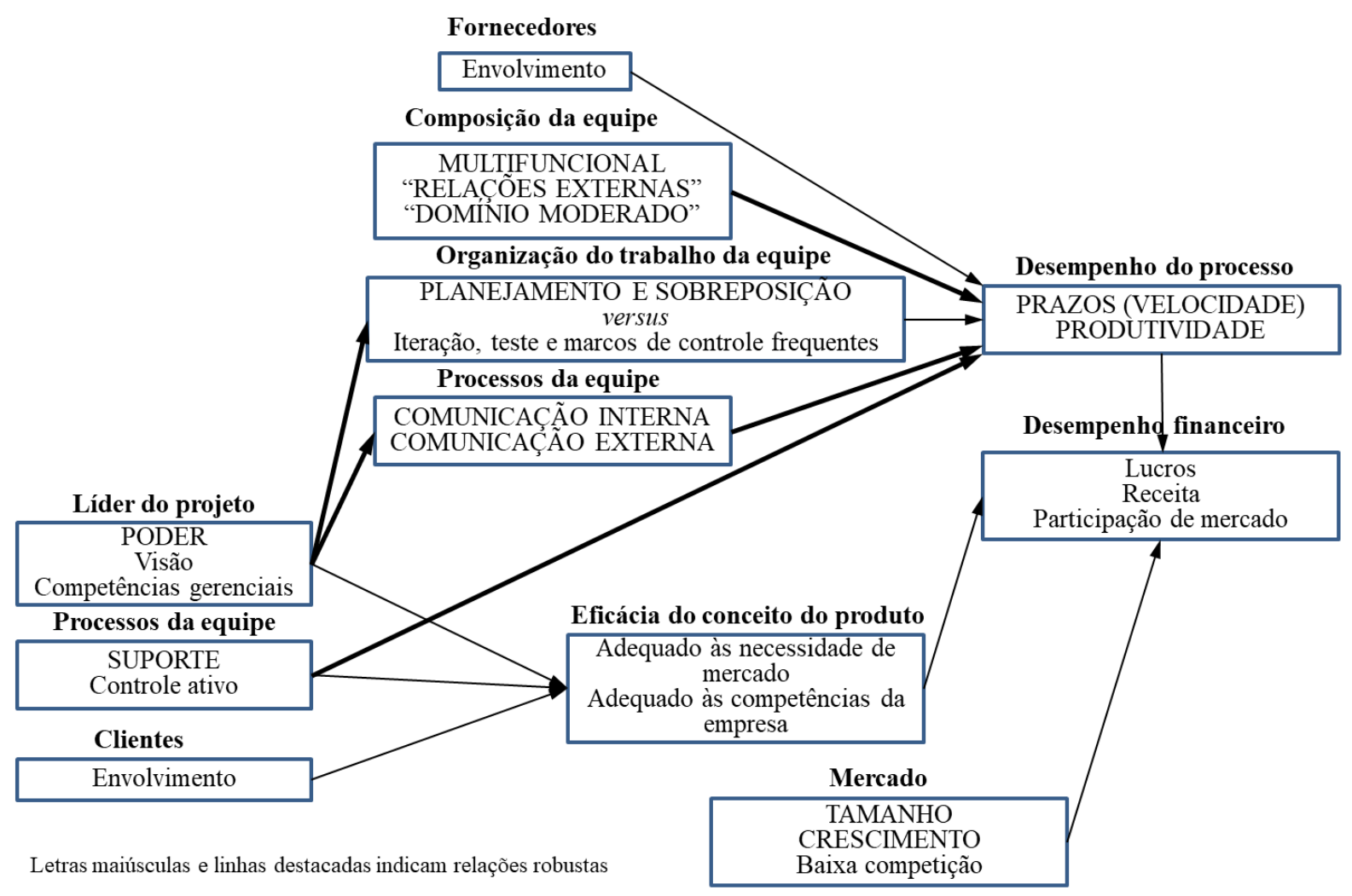

Fonte: reproduzido e traduzido de Brown e Eisenhardt (1995)

Em termos gerais, a perspectiva do plano racional contribuiu com uma visão abrangente do desenvolvimento do produto para prever o sucesso financeiro, o que inclui a equipe, a gerência sênior, o mercado e as características do produto.

${ }^{14}$ Os protocolos de projeto ou definições de produto descrevem os parâmetros gerais que o novo produto deve exibir tais como: segmentos-alvo, funções e recursos do produto, tecnologia de base, preços, canais de comunicação e distribuição e recursos necessários (McNally, Cavusgil, \& Calantone, 2010). 
Já a perspectiva de solução de problemas contribuiu com uma visão mais focada no processo de DP ao incluir conceitos de equipe de projeto e dos fatores de gerenciamento que contribuem para um processo de desenvolvimento de produto mais eficaz. Da perspectiva da rede de comunicação, adotaram aspectos da comunicação interna e externa dos membros da equipe do projeto.

Para a estruturação do modelo que propuseram, Brown e Eisenhardt (1995) consideraram a atuação de vários "players", aqui chamados de partes, e que influenciariam o desempenho do produto. Também definiram as relações entre o desempenho e seus contribuintes ou impulsionadores, os quais são apresentados a seguir.

- o desempenho do processo é impulsionado pela quantidade, variedade e organização de informações de solução de problemas e pelos recursos disponíveis para a equipe;

- a eficácia do produto é impulsionada pela entrada de líderes, gerência sênior e clientes na formação de uma visão clara do produto; e

- o sucesso financeiro do produto é impulsionado tanto pela eficácia do produto quanto pelo desempenho do processo.

O modelo proposto por Brown e Eisenhardt (1995) assume que o sucesso financeiro do DP é função do desempenho e da eficácia do produto combinados com características do mercado. Em relação ao desempenho do processo, as explicações dadas são as seguintes:

- um processo produtivo com custos mais baixos tem por resultado preços mais baixos e, consequentemente, contribui para o maior sucesso do produto;

- um processo mais rápido possibilita a flexibilidade estratégica e menos tempo para o lançamento do produto. Assim, contribuem para produtos financeiramente bem-sucedidos.

Em relação à eficácia do produto, Brown e Eisenhardt (1995) consideraram que:

- benefícios de baixo custo e exclusivos e competências adequadas à empresa criariam produtos financeiramente bem-sucedidos, pois esses produtos seriam teoricamente mais atraentes para os consumidores.

Finalmente, Brown e Eisenhardt (1995) relacionaram um mercado grande, crescente e com baixa concorrência ao sucesso financeiro por oferecem a possibilidade de grandes vendas e, no caso de mercados em crescimento, instabilidade competitiva que pode favorecer os novos produtos. No geral, o argumento é que um forte processo de desenvolvimento de produto, um produto atraente e um mercado favorável devem levar a um produto financeiramente bem-sucedido.

Em específico para o desenvolvimento de medicamentos, Mendigorri e colaboradoras (2016) realizaram a validação empírica de uma escala de mensuração para a efetividade das atividades de 
P\&D em empresas do setor farmacêutico instaladas na Espanha. A Tabela 22 apresenta as descrições das dimensões da escala validada e seus itens componentes.

Tabela 22 - Dimensões e itens componentes da escala de mensuração da efetividade das atividades de pesquisa e desenvolvimento

\begin{tabular}{|c|c|c|c|}
\hline $\begin{array}{c}\text { Constructo } \\
\text { Segunda ordem }\end{array}$ & $\begin{array}{c}\text { Constructo } \\
\text { Primeira ordem }\end{array}$ & $\begin{array}{c}\text { Item } \\
\text { componente }\end{array}$ & Descrição do item \\
\hline \multirow[t]{2}{*}{ ENTRADAS } & Esforço em P\&D & $\begin{array}{l}\text { ERD } \\
\text { SRD } \\
\text { PGR }\end{array}$ & $\begin{array}{l}\text { Despesas em pesquisa e desenvolvimento } \\
\text { Intensidade de gastos em P \& D } \\
\text { Crescimento do pessoal }\end{array}$ \\
\hline & $\begin{array}{l}\text { Competências dos } \\
\text { recursos humanos }\end{array}$ & $\begin{array}{l}\text { APE } \\
\text { EXP }\end{array}$ & $\begin{array}{l}\text { Competências do pessoal de P \& D } \\
\text { Experiência do pessoal de P \& D }\end{array}$ \\
\hline \multirow[t]{3}{*}{ PROCESSOS } & $\begin{array}{l}\text { Planejamento } \\
\text { adequado de } \mathrm{P} \& \mathrm{D}\end{array}$ & $\begin{array}{l}\text { PLN } \\
\text { ADP } \\
\text { AOF } \\
\text { CAP } \\
\text { DOR }\end{array}$ & $\begin{array}{l}\text { Planejamento adequado de P \& D } \\
\text { Desenho adequado de processos de P \& D } \\
\text { Adequação de objetivos e financiamento } \\
\text { de P \& D } \\
\text { Comunicação de atividades a serem } \\
\text { realizadas } \\
\text { Definição de resultados }\end{array}$ \\
\hline & $\begin{array}{l}\text { Relações com } \\
\text { outros } \\
\text { departamentos }\end{array}$ & $\begin{array}{l}\text { IRC } \\
\text { APP } \\
\text { CBD } \\
\end{array}$ & $\begin{array}{l}\text { Informações sobre P \& D para o resto da } \\
\text { empresa } \\
\text { Adaptação do pessoal de produção } \\
\text { Coordenação entre departamentos }\end{array}$ \\
\hline & Relações externas & $\begin{array}{l}\text { ISA } \\
\text { LEG }\end{array}$ & $\begin{array}{l}\text { Influência dos atores sociais } \\
\text { Efeitos da legislação sobre P \& D }\end{array}$ \\
\hline \multirow[t]{2}{*}{ SAÍDAS } & Saídas de P\&D & $\begin{array}{l}\text { PAT } \\
\text { COP } \\
\text { AQP }\end{array}$ & $\begin{array}{l}\text { Patentes } \\
\text { Participação em conferências } \\
\text { Atendimento a parâmetros de qualidade }\end{array}$ \\
\hline & Inovações de P\&D & $\begin{array}{l}\text { PDI } \\
\text { PCI }\end{array}$ & $\begin{array}{l}\text { Inovação em produtos } \\
\text { Inovação em processos }\end{array}$ \\
\hline \multirow[t]{2}{*}{ RESULTADOS } & Resultados de P\&D & $\begin{array}{l}\text { INC } \\
\text { MSH } \\
\text { SAT } \\
\text { PER } \\
\text { CRR } \\
\text { POS } \\
\text { DTR }\end{array}$ & $\begin{array}{l}\text { Receita } \\
\text { Participação de mercado } \\
\text { Satisfação do cliente } \\
\text { Percepção do cliente } \\
\text { Taxa de retenção do cliente } \\
\text { Posicionamento da empresa } \\
\text { Resultados de tecnologia desenvolvida }\end{array}$ \\
\hline & TÉGIA & $\begin{array}{l}\text { MKS } \\
\text { PST } \\
\text { CPS }\end{array}$ & $\begin{array}{l}\text { P \& D como uma variável estratégica } \\
\text { Participação do gerente na estratégia de P } \\
\text { \& D } \\
\text { O gerente conhece os objetivos } \\
\text { estratégicos } \\
\text { Projetos relacionados à estratégia } \\
\text { Controle de projetos relacionados à } \\
\text { estratégia }\end{array}$ \\
\hline
\end{tabular}

Fonte: Mendigorri e colaboradoras (2016)

Foi analisado um conjunto amplo de variáveis propostas na literatura, com o objetivo de estabelecer as relações e a classificação das variáveis. O estudo adotou padrões psicométricos para a análise das fases de dimensionalidade, confiabilidade e validade (convergentes, discriminantes e nomológicas) dos constructos. A Figura 20 apresenta o resumo das relações entre as dimensões da escala de mensuração para a efetividade das atividades de P\&D validada por Mendigorri e colaboradoras (2016). 
Figura 20 - Relações entre as dimensões da escala de mensuração da efetividade das atividades de pesquisa e desenvolvimento

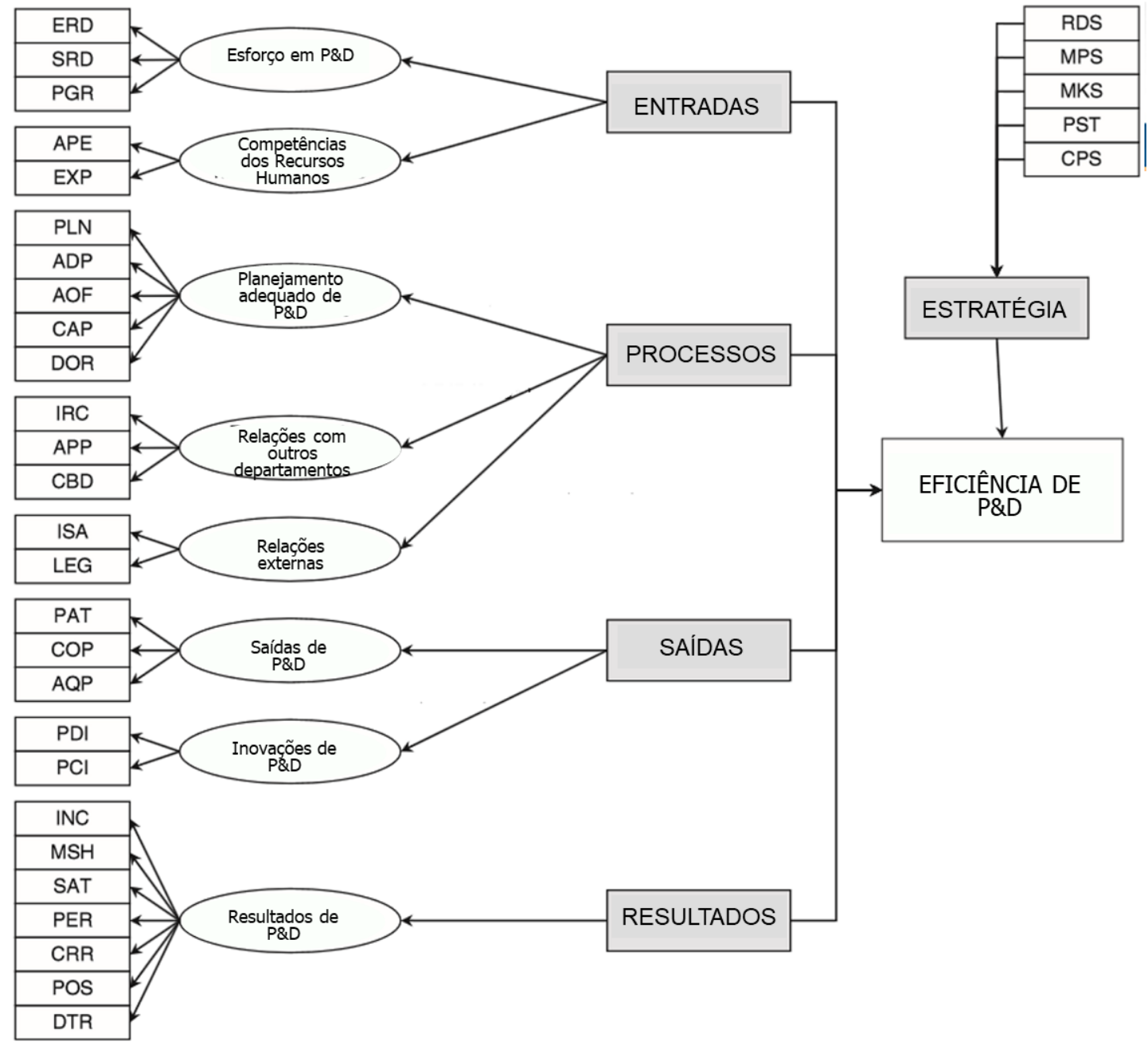

Fonte: extraído de Mendigorri e colaboradoras (2016)

Os critérios da escala de Mendigorri e colaboradoras (2016) apresentaram-se válidos em suas três manifestações temporais (retrospectiva, concorrente e preditiva). De acordo com as pesquisadoras, até a data da pesquisa, a escala de mensuração da efetividade das atividades de P\&D só havia sido validada teoricamente, não tendo sido encontradas na literatura publicações com sua validação empírica.

\subsection{CONSOLIDAÇÃO DA FUNDAMENTAÇÃO TEÓRICA E PROPOSIÇÃO DO MODELO CONCEITUAL E DAS HIPÓTESES DA PESQUISA}

De uma forma geral, o referencial aqui apresentado sobre os temas do desenvolvimento de produtos, desenvolvimento de medicamentos, medicamentos genéricos, indicadores de desempenho e seus fatores contribuintes foi concentrado nos conceitos e modelos básicos e que ainda são reproduzidos e servem de referencial para aplicações sucessoras mais atuais e específicas. Isso basicamente em razão dos projetos de desenvolvimento dos medicamentos genéricos não empregarem abordagens diferentes das classicamente utilizadas e do caráter descritivo desta pesquisa. 
O tema do desempenho dos projetos de DP vem sendo estudado desde a década de 1950. O desempenho dos projetos de DP vem sendo analisado desde o mesmo perído, utilizando como base um conjunto estável de indicadores relacionados ao mercado, aos resultados financeiros e aos de projeto (prazo, custo, escopo e qualidade). Porém, o peso de cada um deles varia dependendo da indústria, das estratégias e do contexto no qual os projetos são desenvolvidos. De uma forma geral, o desempenho dos projetos de desenvolvimento de medicamentos tem um indicador específíco e que é comum para os setores altamente regulados, ou seja, a aprovação pelo órgão regulador, a (Anvisa, 2017b) no caso dos medicamentos comercializados no Brasil. E vem da legislação também os principais requisitos considerados pelos PDMG, mais especificamente da resolução RDC 200/2017 (Anvisa, 2017b).

Esta obrigatoriedade de aprovação dos medicamentos genéricos deu origem ao estudo de Do Carmo (2017) sobre as causas da rejeição dos pedidos de registro desta classe de medicamentos. O resultado dessa pesquisa forneceu a principal justificativa para este estudo e a questão de pesquisa sobre quais seriam os fatores que contribuem para o desempenho dos projetos de desenvolvimento de medicamentos genéricos.

Embora possam ser encontradas referências específicas como o de Shargel e Kanfer (2005), estudos sobre melhorias na eficiência dos projetos como o de Chaudhuri (2013) e pesquisas sobre as dificuldades no desenvolvimento de medicamentos genéricos como a de Genazzani e Pattarino (2008), não foram encontradas publicações que tratassem especificamente do gerenciamento de projetos de desenvolvimento desta classe de medicamentos. Desta forma, considerou-se que há oportunidade para a realização de estudos empíricos sobre este tema. No entanto, em razão de não haverem sido encontrados modelos e/ou constructos específicos e validados para a mensuração do desempenho do desenvolvimento dos medicamentos genéricos é que foi proposto proposto um modelo teórico próprio.

Como é amplamente aceito que o desempenho dos projetos de DP teriam inúmeras razões (facilitadores ou influenciadores) e falhariam também por outros conjuntos de razões (barreiras) (Cooper \& Kleinschmidt, 1987b; Montoya-Weiss \& Calantone, 1994; Murphy et al., 1974; Page \& Schirr, 2008; Rubenstein et al., 1976), o modelo é composto por três conjuntos de fatores (variáveis independentes), aqui denominadas dimensões, ou seja: Gerencial, Estrutural e Técnico. No modelo conceitual também foi proposta uma dimensão dependente denominada Desempenho e que contêm os indicadores para mensuração dos resultados dos PDMG.

As três dimensões de variáveis independentes (Gerencial, Estrutural e Técnico) estão alinhadas concitualmente com a taxonomia proposta por Cooper e Kleinschmidt (1987) e Montoya-Weiss e Calantone (1994) e que era formada por quatro categorias, ou seja, características do Processo, Estratégia e Produto e Mercado. Neste estudo em específico, em razão da delimitação estabelecida, fatores relacionados ao mercado não estão sendo abordados. Assim, restaram as categorias Processo, 
Estratégia e Produto cujas definições estão bem próximas das dimensões Gerencial, Estrutural e Técnico proopostas por este estudo.

O modelo conceitual com as dimensões, as relações propostas e as respectivas hipóteses são ilustradas na Figura 21.

Figura 21 - Modelo conceitual proposto

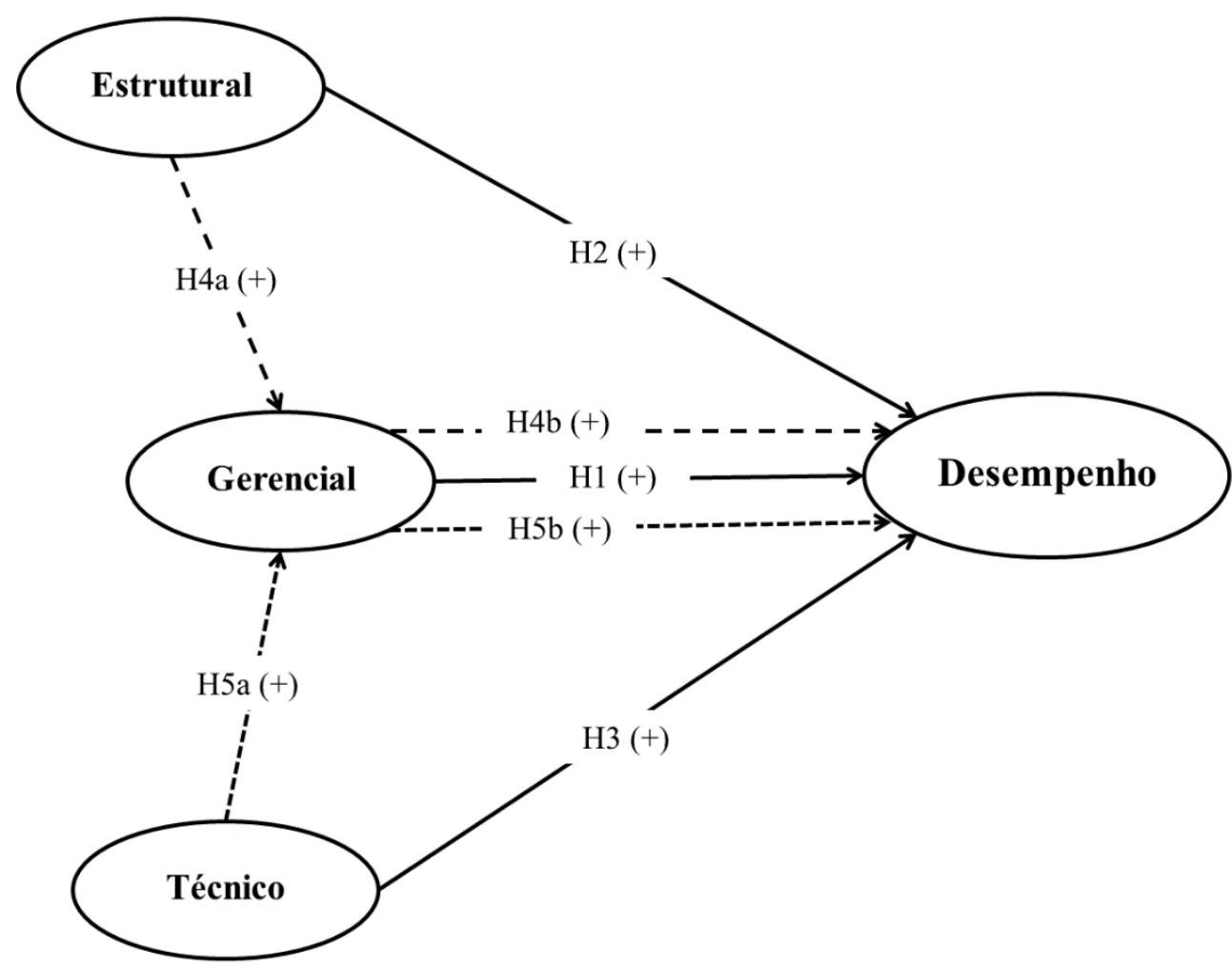

Fonte: dados da pesquisa.

O modelo de influências do projeto do PMI (2017) e que foi apresentado na Figura 18 é a base do referencial teórico adotado para a definição da dimensão Estrutural do modelo conceitual, uma vez que inclui, os fatores ambientais externos e internos da empresa, além dos ativos de processos organizacionais, ou seja, os processos, políticas e procedimentos.

A legislação referente ao registro de medicamentos genéricos (Anvisa, 2017b) forma a base para os fatores técnicos contribuintes para o modelo conceitual proposto (Figura 21). São considerados para os fatores contribuintes gerenciais a abordagem de gerenciamento de projetos do PMI (2017) e os processos de desenvolvimento de medicamentos genéricos, principalmente dos autores: De Paula (2004); Shargel e Kanfer (2005); Silva (2015); e Yugue (2014).

O modelo conceitual proposto, além do referencial básico considerado, foi complementado por outros estudos encontrados na literatura e que foram esquematizados na Tabela 23. 
Tabela 23 - Dimensões e fatores contribuintes ou influenciadores do desempenho do DP

\begin{tabular}{|c|c|c|c|}
\hline $\begin{array}{l}\text { Dimensões } \\
\text { encontradas } \\
\text { na literatura }\end{array}$ & $\begin{array}{l}\text { Dimensões } \\
\text { do modelo } \\
\text { proposto }\end{array}$ & Comentário & Principais referências \\
\hline Estratégica & Estrutural & $\begin{array}{l}\text { A dimensão estrutural } \\
\text { considera fatores como a } \\
\text { gestão do portfólio de } \\
\text { projetos e sinergia } \\
\text { tecnológica }\end{array}$ & $\begin{array}{l}\text { S. Brown \& Eisenhardt, 1995; Cooper \& } \\
\text { Kleinschmidt, 1987b; Henard \& Szymanski, 2001; } \\
\text { Mendigorri et al., 2016; Montoya-Weiss \& } \\
\text { Calantone, 1994; PMI, } 2017\end{array}$ \\
\hline $\begin{array}{l}\text { Mercado - } \\
\text { atratividade }\end{array}$ & $\begin{array}{c}\text { Não } \\
\text { incluída }\end{array}$ & $\begin{array}{l}\text { Em razão da delimitação } \\
\text { do escopo deste estudo que } \\
\text { não inclui as fases pré e } \\
\text { pós desenvolvimento. }\end{array}$ & $\begin{array}{l}\text { S. Brown \& Eisenhardt, 1995; Cooper \& } \\
\text { Kleinschmidt, 1987a; Henard \& Szymanski, 2001; } \\
\text { Zirger \& Maidique, } 1990\end{array}$ \\
\hline $\begin{array}{l}\text { Marketing - } \\
\text { características } \\
\text { do } \\
\text { consumidor }\end{array}$ & $\begin{array}{c}\text { Não } \\
\text { incluída }\end{array}$ & $\begin{array}{l}\text { Em razão da delimitação } \\
\text { do escopo deste estudo que } \\
\text { não inclui as fases pré e } \\
\text { pós desenvolvimento. }\end{array}$ & $\begin{array}{l}\text { S. Brown \& Eisenhardt, 1995; Cooper, 2019; } \\
\text { Griffin \& Hauser, } 1996\end{array}$ \\
\hline $\begin{array}{c}\text { Projeto, } \\
\text { engenharia, } \\
\text { operacional } \\
\text { ou de } \\
\text { processo de } \\
\text { desenvolvi- } \\
\text { mento }\end{array}$ & Gerencial & $\begin{array}{lr}\text { A dimensão } & \text { gerencial } \\
\text { considera fatores } & \text { como o } \\
\text { gerenciamento } & \text { dos } \\
\text { projetos } & \text { de } \\
\text { desenvolvimento, } & \end{array}$ & $\begin{array}{l}\text { Anvisa, 2017b; Birou \& Fawcett, 1994; Boer \& } \\
\text { During, 2001; S. Brown \& Eisenhardt, 1995; K. B. } \\
\text { Clark \& Fujimoto, 1991; Kim B. Clark et al., 1987; } \\
\text { Kim B. Clark \& Wheelwright, 1992; Cooper, 2019; } \\
\text { Cooper \& Kleinschmidt, 1987b; De Paula (2004); } \\
\text { Eisenhardt \& Tabrizi, 1995; Griffin \& Hauser, } \\
\text { 1996; Gupta \& Wilemon, 1990; Hayes et al., 1988; } \\
\text { Henard \& Szymanski, 2001; Henke et al., 1993; } \\
\text { Imai et al., 1985; Mendigorri et al., 2016; } \\
\text { Montoya-Weiss \& Calantone, 1994; M. B. Pinto \& } \\
\text { Pinto, 1990; PMI, 2017; Rozenfeld et al., 2006; } \\
\text { Salgado \& Dekkers, 2018; Leon Shargel \& Kanfer, } \\
\text { 2005; Silva, 2015; Womack et al., 1992; V. dos S. } \\
\text { C. Yugue, 2014; Zirger \& Maidique, 1990 }\end{array}$ \\
\hline $\begin{array}{l}\text { Organização - } \\
\text { recursos, } \\
\text { competências } \\
\text { e experiência }\end{array}$ & Estrutural & $\begin{array}{l}\text { A dimensão estrutural } \\
\text { considera fatores como a } \\
\text { infraestrutura, os recursos } \\
\text { e as competências dos } \\
\text { profissionais. }\end{array}$ & $\begin{array}{l}\text { S. Brown \& Eisenhardt, 1995; K. B. Clark \& } \\
\text { Fujimoto, 1991; Kim B. Clark et al., 1987; Cooper, } \\
\text { 2019; Cooper \& Kleinschmidt, 1987b; Eisenhardt } \\
\text { \& Tabrizi, 1995; Griffin \& Hauser, 1996; Gupta \& } \\
\text { Wilemon, 1990; Hayes et al., 1988; Henard \& } \\
\text { Szymanski, 2001; Imai et al., 1985; Mendigorri et } \\
\text { al., 2016; PMI, 2017; Rozenfeld et al., 2006; } \\
\text { Womack et al., 1992; Zirger \& Maidique, 1990 }\end{array}$ \\
\hline Produto & Técnico & $\begin{array}{l}\text { A dimensão técnica } \\
\text { considera fatores como os } \\
\text { requisitos do produto e sua } \\
\text { produção, os quais são } \\
\text { fundamentalmente técnico- } \\
\text { científicos e determinados } \\
\text { por normas por se tratarem } \\
\text { de medicamentos. }\end{array}$ & $\begin{array}{l}\text { Anvisa, 2007, 2017b; S. Brown \& Eisenhardt, } \\
\text { 1995; K. B. Clark \& Fujimoto, 1991; Kim B. Clark } \\
\text { et al., 1987; Cooper \& Kleinschmidt, 1987b; De } \\
\text { Paula (2004); Do Carmo, 2017; Do Carmo, Piras, } \\
\text { et al., 2017; Henard \& Szymanski, 2001; ISPE, } \\
\text { 2011; Kennedy, 2008b; PMI, 2017; Leon Shargel } \\
\text { \& Kanfer, 2005; Silva, 2015; V. dos S. C. Yugue, } \\
2014\end{array}$ \\
\hline
\end{tabular}

Fonte: dados da pesquisa.

Para responder aos objetivos e às delimitações deste estudo, como pode ser notado na Tabela 23, algumas dimensões não foram incluídas e outras foram resignificadas para facilitar o entendimento e ajuste ao modelo proposto. Assim, tomando-se por referência as quatro dimensões do sucesso definidos por Shenhar e colaboradores (1997), o modelo tratará das dimensões de eficiência do projeto 
e parcialmente da dimensão de impacto no cliente, também em razão da delimitação estabelecida por este estudo. A seguir são descritas as relações hipotetizadas no modelo conceitual proposto.

\subsubsection{Influência direta dos fatores gerenciais sobre o desempenho dos projetos de desenvolvimento de medicamentos genéricos (Hipótese H1)}

Esta é a relação central do estudo, pois não há como dissociar o desenvolvimento de projetos de seu gerenciamento (Murphy et al., 1974). Wheelwright e Clark (1992) identificaram em projetos problemáticos características como; direcionamento confuso, ausência de um gestor, responsabilidade limitada, falta de coerência e a falta de visão compartilhada do projeto, entre outros. O PMI (2017), por sua vez, considera que o gerenciamento de projetos permite que os projetos sejam realizados eficaz e eficientemente, relacionando desta forma o sucesso de um projeto de DP como o seu gerenciamento. Condiderando o exposto, a primeira hipótese proposta para este estudo foi a seguinte:

Hipótese 1 (H1): As dificuldades gerenciais estão associadas positivamente com o desempenho fora do planejado dos projetos de desenvolvimento de medicamentos genéricos.

A descrição da relação como sendo entre dificuldades e desempenho fora do planejado está alinhado com o fato que justificou o estudo e que foi o elevado índice de pedidos de registro de medicamentos genéricos indeferidos pela Anvisa (Do Carmo, 2017), ou seja, projetos que fracassaram. Além disso, os estudos sobre o desempenho do desenvolvimento de novos produtos pode ser realizado sobre os fatores que levam ao fracasso (Kalluri \& Kodali, 2014; Montoya-Weiss \& Calantone, 1994).

\subsubsection{Influência direta dos fatores estruturais sobre o desempenho dos projetos de desenvolvimento de medicamentos genéricos (Hipótese H2)}

Os projetos são desenvolvidos e executados em ambientes que podem influenciá-los positiva ou negativamente. O PMI (2017) classificou estas influências em dois grupos: os fatores ambientais da empresa (por exemplo: mercado, legislação, padrões, ambiente físico, cultura infraestrutura, recursos e capacitação) e ativos de processos organizacionais (por exemplo: políticas, diretrizes, processos, métodos e procedimentos, modelos e indicadores).

Basicamente, os fatores ambientais, os ativos de processos e as estratégias das organizações encontram-se fora do domínio da gestão dos projetos de DP, ou seja, são estabelecidos fora de sua alçada de decisão. No entanto, as referências encontradas sobre PDMG não tratam dos aspectos ambientais e estruturais dos projetos, embora alguns abordem aspectos relacionados ao mercado (Chaudhuri, 2013) e às estratégias corporativas e de portfólio (Hansen \& Tunnah, 2003). Desta forma, considerando que fatores relacionados ao ambiente e à estrutura na qual os PDMG ocorrem podem influenciar seu o desepemnho é que foi estabelecida a segunda hipótese da pesquisa

Hipótese 2 (H2): As dificuldades estruturais da desenvolvedora estão associadas positivamente com o desempenho fora do planejado dos projetos de desenvolvimento de medicamentos genéricos. 


\subsubsection{Influência direta dos fatores técnicos sobre $o$ desempenho dos projetos de desenvolvimento de medicamentos genéricos (Hipótese H3)}

Wheelwright e Clark (1992) identificaran em projetos problemáticos características como a dependência de mudanças técnicas e da produção para encontrar e resolver problemas, os quais poderiam resultar em protótipos inadequados e não representativos, mudanças tardias, difícil fabricação, atropelos na produção e rendimentos abaixo do planejado.

Os medicamentos genéricos, conforme destacado por Shargel e Kanfer (2005), devem ser idênticos ao produto farmacêutico referência em termos de ingrediente (s) ativo(s), potência, forma de dosagem, via de administração, qualidade, segurança, eficácia, características de desempenho e indicação terapêutica. Ou seja, devem atender a requisitos específicos e bastante estritos, o que seria desafio considerável em razão de características particulares dos ingredientes, dos equipamentos e dos processos de produção que são utilizados na produção do medicamento, uma vez que normalmente são diferentes dos empregados pelo fabricante do medicamento de referência. Genazzani e Pattarino (2008) tratam especificamente das dificuldades em desenvolver medicamentos idênticos do ponto-devista tecnológico, chegando a afirmar que não se deve assumir que todos os medicamentos genéricos não exatamente iguais. Desta forma, a terceira hipótese estabelecida foi a seguinte:

Hipótese 3 (H3): As dificuldades técnicas estão associadas positivamente com o desempenho fora do planejado dos projetos de desenvolvimento de medicamentos genéricos.

\subsubsection{Influências de fatores estruturais e técnicos sobre o desempenho são mediadas pela gestão dos projetos de desenvolvimento de medicamentos genéricos (Hipóteses H4 e H5)}

De uma forma geral, supõe-se que nos modelos de caminho os constructos independentes (variáveis latentes) afetam diretamente construções dependentes sem nenhuma influência sistemática de outras variáveis. No entanto, em razão da natureza dos relacionamentos do modelo, há casos em que é necessária a inclusão de uma terceira variável, que pode ser mediadora ou moderadora (Hair Jr., Hult, Ringle, \& Sarstedt, 2017).

De acordo com Hair Jr e colaboradores (2017), a mediação ocorre quando uma terceira variável intervém entre duas outras variáveis relacionadas. A Figura 22 ilustra um efeito direto $p 3$ entre a variável $Y 1$ e a variável $Y 3$ e um efeito indireto da variável $Y 1$ na variável $Y 3$ na forma de uma sequência $Y 1 \rightarrow Y 2 \rightarrow Y 3$. O efeito indireto de $p 1 \cdot p 2$ representa o efeito mediador da variável $Y 2$ na relação entre $Y 1$ e $Y 3$. Hair Jr e colaboradores (2017) consideram que um suporte teórico/conceitual robusto é um requisito essencial para explorar efeitos significativos de mediação. 
Figura 22 - Modelo geral de mediação

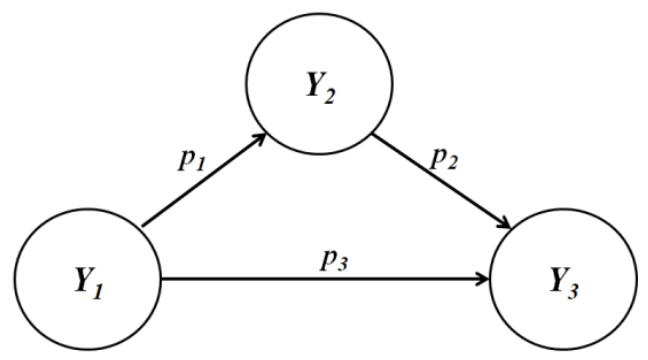

Fonte: reproduzido de Hair Jr e colaboradores (2017, p. 229).

Apesar da indicação na literatura de fatores de diferentes naturezas, Murphy, Baker e Fisher (1974) concluíram que, na maioria dos projetos, os determinantes do sucesso são múltiplos e que muitos deles estão sob o controle daqueles que estão gerenciando o projeto, ou seja, os determinantes do sucesso do projeto seriam fatores que a gerência teria a capacidade potencial de influenciar. $\mathrm{O}$ estudo de Cooper e Kleinschmidt (1987a) corrobora com esta constatação ao concluir que o sucesso seria conquistado e não apenas o resultado específico de influências situacionais ou ambientais.

Entende-se também que, como advoga o PMI (2017, p. 10), por meio das práticas adotadas e organizadas em seu guia denominado PMBOK (Project Management Body of Knowledge - Guia do conhecimento em gerenciamento de projetos), o gerenciamento dos projetos é uma aplicação de conhecimentos, habilidades, ferramentas e técnicas às atividades do projeto que permite que as organizações executem projetos de forma eficaz e eficiente.

Assim, o gerenciamento de projetos teria por função fornecer apoio às organizações para que possam, por exemplo, cumprir os objetivos do negócio, satisfazer as expectativas das partes interessadas, entregar os produtos certos no momento certo, otimizar o uso dos recursos organizacionais e gerenciar as restrições. Desta forma, o gerenciamento de projetos buscaria otimizar a realização dos projetos ao gerenciar os objetivos, requisitos, fatores ambientais, expectativas e restrições para que os produtos do projeto sejam entregues (PMI, 2017).

Para Kanfer e colaboradores (2014), os requisitos regulatórios, as especificações técnicas e os recursos da organização devem ser considerados na definição da estratégia de desenvolvimento a ser adotada, indicando assim haver atuação da gestão sobre estes grupos de fatores. O International Society for Pharmaceutical Engineering - ISPE (2011), por sua vez, considera que as boas práticas de gerenciamento de projetos na indústria farmacêutica estão relacionadas a fatores como: contexto do negócio, contexto regulatório, gestão do valor, tecnologia e inovação, trabalho colaborativo, ciclo de vida da validação, gestão de riscos e a abordagem de Stage-Gate ${ }^{\circledR}$.

Desta forma, especificamente para o caso do desenvolvimento dos medicamentos genéricos, considera-se que possivelmente os fatores gerenciais atuarem como mediadores das relações dos fatores estruturais e dos fatores técnicos com o desempenho dos projetos. Em outras palavras, a relação destes fatores com o desempenho dos PDMG passaria pelas práticas de gerenciamento, o que 
conduz à hipótese de haver efeito mediador da gestão do PDMG. Assim, as duas hipóteses a seguir são fundamentadas por este raciocínio.

Hipótese 4 (H4): A influência das dificuldades estruturais sobre o desempenho fora do planejado dos projetos de desenvolvimento de medicamentos genéricos é mediada pelas dificuldades gerenciais.

Hipótese H4a: As dificuldades estruturais estão associadas positivamente com as dificuldades gerenciais dos projetos de desenvolvimento de medicamentos genéricos.

Hipótese $\mathrm{H} 4 \mathrm{~b}=\mathrm{H} 1$ : As dificuldades gerenciais estão associadas positivamente com o desempenho fora do planejado dos projetos de desenvolvimento de medicamentos genéricos.

Hipótese 5 (H5): A influência das dificuldades técnicas sobre o desempenho fora do planejado dos projetos de desenvolvimento de medicamentos genéricos é mediada pelas dificuldades gerenciais.

Hipótese H5a: As dificuldades técnicas estão associadas positivamente com as dificuldades gerenciais dos projetos de desenvolvimento de medicamentos genéricos.

Hipótese $\mathrm{H} 5 \mathrm{~b}=\mathrm{H} 1$ : As dificuldades gerenciais estão associadas positivamente com o desempenho fora do planejado dos projetos de desenvolvimento de medicamentos genéricos.

A Tabela 24 a seguir apresenta uma síntese das hipóteses que foram estabelecidas para esta pesquisa.

Tabela 24 - Síntese das hipóteses da pesquisa

\begin{tabular}{|c|l|}
\hline & \multicolumn{1}{|c|}{ Hipóteses } \\
\hline H1 & $\begin{array}{l}\text { As dificuldades gerenciais estão associadas positivamente com o desempenho fora do planejado dos } \\
\text { projetos de desenvolvimento de medicamentos genéricos. }\end{array}$ \\
\hline H2 & $\begin{array}{l}\text { As dificuldades estruturais da desenvolvedora estão associadas positivamente com o desempenho } \\
\text { fora do planejado dos projetos de desenvolvimento de medicamentos genéricos. }\end{array}$ \\
\hline H3 & $\begin{array}{l}\text { As dificuldades técnicas estão associadas positivamente com o desempenho fora do planejado dos } \\
\text { projetos de desenvolvimento de medicamentos genéricos. }\end{array}$ \\
\hline H4 & $\begin{array}{l}\text { A influência das dificuldades estruturais sobre o desempenho fora do planejado dos projetos de } \\
\text { desenvolvimento de medicamentos genéricos é mediada pelas dificuldades gerenciais. }\end{array}$ \\
\hline H4a & $\begin{array}{l}\text { As dificuldades estruturais estão associadas positivamente com as dificuldades gerenciais dos } \\
\text { projetos de desenvolvimento de medicamentos genéricos. }\end{array}$ \\
\hline H4b & $\begin{array}{l}\text { As dificuldades gerenciais estão associadas positivamente com o desempenho fora do planejado dos } \\
\text { projetos de desenvolvimento de medicamentos genéricos. }\end{array}$ \\
\hline H5 & $\begin{array}{l}\text { A influência das dificuldades técnicas sobre o desempenho fora do planejado dos projetos de } \\
\text { desenvolvimento de medicamentos genéricos é mediada pelas dificuldades gerenciais. }\end{array}$ \\
\hline H5a & $\begin{array}{l}\text { As dificuldades técnicas estão associadas positivamente com as dificuldades gerenciais dos projetos } \\
\text { de desenvolvimento de medicamentos genéricos. }\end{array}$ \\
\hline H5b & $\begin{array}{l}\text { As dificuldades gerenciais estão associadas positivamente com o desempenho fora do planejado dos } \\
\text { projetos de desenvolvimento de medicamentos genéricos. }\end{array}$ \\
\hline
\end{tabular}

Fonte: dados da pesquisa. 
É importante salientar que nem todas as possíveis hipóteses que poderiam ter sido derivadas do referencial teórico foram propostas e testadas neste estudo. Dito isto, considerando-se o conjunto de indicadores de desempenho e de seus fatores contribuintes ou influenciadores relacionados aos objetivos e ao contexto dos PDMG e observadas as delimitações deste estudo, defende-se a tese de que as dificuldades e deficiências estruturais, técnicas e gerenciais dos laboratórios farmacêuticos instalados no Brasil tem influência direta sobre o desempenho fora do planejao dos projetos de desenvolvimento de medicamentos genéricos. Também defende-se a tese de que as dificuldades e deficiências no gerenciamento exercem efeito mediador entre as dificuldades e deficiências estruturais e técnicas e o desempenho fora do planejado dos projetos desenvolvimento de medicamentos genéricos. 


\section{METODOLOGIA}

Neste capítulo são descritos os procedimentos metodológicos que foram realizados pelo estudo para que seus objetivos fossem atingidos. A primeira seção descreve a natureza e características gerais da pesquisa. Na segunda seção, são descritos os procedimentos realizados na primeira fase do estudo que identificou e classificou os indicadores e fatores relacionados aos PDMG empregando método qualitativo para a coleta e tratamento dos dados empíricos. Nesta fase, tendo como fonte os dados da pesquisa qualitativa e o referencial teórico, foi proposto o modelo conceitual, suas dimensões, constructos, relações e as hipóteses de pesquisa.

$\mathrm{Na}$ terceira seção são descritos os procedimentos realizados na segunda fase do estudo e que empregou método quantitativo. Assim, são detalhados o modelo estrutural e seus constructos e indicadores; a elaboração do instrumento de coleta de dados; a validação de seu contéudo; a amostragem; e os critérios de elegibilidade. Também são descritos os procedimentos realizados para a coleta, tratamento e análise dos dados que empregou o método de equações estruturais com estimação por mínimos quadrados parciais (PLS-SEM). Em sua quarta seção, é apresentado um resumo dos procedimentos e as limitações metodológicas do estudo.

\subsection{NATUREZA E CARACTERÍSTICAS GERAIS DA PESQUISA}

O planejamento para o desenvolvimento deste estudo considerou o paragdima ou concepção em que a estratégia de investigação e os métodos de pesquisa seriam estabelecidos. Em razão da constatação da necessidade de identificação das variáveis relacionadas à questão de pesquisa, sob predominante concepção ou paradigma construtivista (John W. Creswell, 2010), a primeira fase do estudo utilizou método qualitativo, com emprego de questionário eletrônico com perguntas abertas para coleta dos dados e uso da análise de conteúdo como método de análise dos dados coletados. Assim, tratou-se de pesquisa que pode ser classificada como exploratória por seu intuito de identificar temas relevantes relacionados aos projetos de desenvolvimento de medicamentos e suas principais categorias de dados (Sampieri, Collado, \& Lucio, 2013).

A identificação das variáveis, a proposição do modelo teórico e a definição das hipóteses de pesquisa permitiram a realização da segunda fase da pesquisa, desta vez com o objetivo de testar as relações hipotetizadas pelo modelo conceitual proposto. Assim, pode-se caracterizar esta segunda fase como do tipo descritivo-relacional com a aplicação de método quantitativo sob concepção ou 
paradigma pós-positivista, considerando que é defendida como uma filosofia determinista em que os problemas estudados buscam identificar e avaliar as causas que influenciam os resultados (John W. Creswell, 2010). A coleta de dados foi realizada por meio de questionário eletrônico e a análise dos dados utilizou técnicas multivariadas (equações estruturais com estimação por mínimos quadrados parciais).

De forma mais específica para estudos na área do DP, Montoya-Weiss e Calantone (1994) propuseram uma maneira de descrevê-los. Assim, utilizando o modelo que propuseram, esta pesquisa teria as seguintes características:

- Escopo do estudo: projetos de desenvolvimento de medicamentos genéricos

- Nível da coleta de dados: conjunto de projetos desenvolvidos pela empresas

- Perspectiva do desempenho: insucesso

- Perspectiva funcional: infraestrutura, pesquisa e desenvolvimento e gestão

- Tipo de organização: industrial

- Região geográfica: Brasil

- Tipo de inovação: sem inovação

- Indústria: farmacêutica (medicamentos genéricos)

\subsection{PRIMEIRA FASE DA PESQUISA - QUALITATIVA}

A pesquisa empírica teve início com um levantamento dos problemas enfrentados pelos laboratórios farmacêuticos instalados no Brasil em seus projetos de desenvolvimento de novos medicamentos. Do ponto-de-vista do projeto de pesquisa, este levantamento buscou identificar os problemas e necessidades das organizações com relação aos seus projetos de desenvolvimento de novos produtos e que também se constituíssem em oportunidades para pesquisa acadêmica.

Bickman e Rog (2009) consideram que os estudos qualitativos podem ser realizados quando se quer: compreender os processos pelos quais os eventos e ações ocorrem e que conduzem a resultados de interesse; e desenvolver novas teorias fundamentadas ("grounded theories") a partir da identificação de fenômenos e influências ainda não relatadas com o intuito de identificar as variáveis para estudos sucessores.

Creswell (2014) comenta que a pesquisa qualitativa é adequada quando um problema ou questão necessita ser explorado para que possam ser identificadas variáveis que não podem ser medidas facilmente. A realização da pesquisa qualitativa também tem indicação quando se pretende compreender os contextos ou ambientes em que as pessoas abordam o tema em estudo. 
Embora o estudo nesta fase não tenha tido por objetivo o desenvolvimento de uma nova teoria em seu sentido mais estrito, foi parcialmente adotado o método da teoria fundamentada, uma vez que a revisão da literatura preliminar não identificou pesquisas já realizadas com escopo semelhante. Podese considerar que a abordagem para a pesquisa qualitativa realizada teve intenção de procurar identificar componentes de um processo com o objetivo de explicar a prática ou fornecer uma estrutura para o aprofundamento da pesquisa. Assim, conceitos da teoria fundamentada foram utilizados nesta fase da pesquisa pelas seguintes razões ( Creswell, 2014, pp. 80-81):

- é uma possibilidade quando não há entre as teorias já desenvolvidas, uma considerada adequada para explicar ou entender um processo por serem baseadas em outras populações e amostras e/ou serem incompletas por não considerem variáveis potencialmente importantes ou categorias de interesse para a pesquisa. No caso desta pesquisa, o levantamento da literatura não encontrou estudos semelhantes e/ou que pudessem ser adotados sem que houvesse necessidade de adaptação e validação.

- uma teoria ou uma estrutura geral pode ser necessária para explicar como as pessoas percebem o fenômeno. No caso desta pesquisa, a definição das variáveis se fez necessária para que se pudesse verificar a relação entre as variáveis identificadas.

Desta forma, com foco nos projetos de desenvolvimento de novos medicamentos, foi realizada a primeira pesquisa do estudo. Ela questionou profissionais que atuavam em laboratórios farmacêuticos instalados no Brasil sobre os problemas que eles enfrentavam nesses projetos, as suas possíveis causas, os impactos resultantes, as oportunidades de melhoria e suas expectativas para o desenvolvimento dos medicamentos no futuro. Por se tratar de uma pesquisa exploratória com objetivo de imersão inicial, ela envolveu diferentes aspectos para que se pudesse obter dados mais abrangentes sobre os projetos. Em outra perspectiva, o objetivo desta primeira fase também foi desenvolver os itens que, seguindo os preceitos de Hinkin (1998), resultariam em medidas que pudessem avaliar o domínio teórico de interesse.

\subsubsection{Questionário da primeira fase da pesquisa}

Para a coleta dos dados, foi aplicado um questionário eletrônico com perguntas fechadas e abertas. Segundo Selltiz, Jahoda, Deutsch e Cook (1975), os questionários são meios de coleta de dados que podem ser aplicados a um grande número de pessoas ao mesmo tempo. A decisão por este instrumento de coleta de dados é justificada por três razões principais: 
- Por se tratar de uma abordagem inicial e exploratória, não havendo a necessidade de aprofundamento e detalhamento das respostas;

- Maior probabilidade de participação em comparação com outras técnicas como as entrevistas e "focus groups" (grupos focais na língua portuguesa);

- Em pesquisa acadêmica, admite-se o uso de respostas a questionários de pesquisa como fonte de dados para a aplicação de técnicas de tratamento como a análise de conteúdo (Bardin, 2015).

O desenvolvimento do questionário considerou a publicação de Creswell (2014) que recomenda que as perguntas devem ser acerca da compreensão de como os indivíduos experimentam o processo, qual o fenômeno central para o processo, o que influencia ou desencadeia a ocorrência do fenômeno (condições causais), quais estratégias foram empregadas no processo e quais os efeitos (consequências). Assim, seguindo este direcionamento, o questionário foi composto por perguntas acerca dos problemas enfrentados no decorrer dos projetos de desenvolvimento dos novos medicamentos, de suas causas ou origens, dos seus impactos, de sugestões de melhorias e das expectativas para o futuro. Foram pesquisadas características dos projetos de desenvolvimento de novos medicamentos e que foram definidas operacionalmente da seguinte forma:

- problemas nos projetos - desvios que ocorrem nos projetos de desenvolvimento de novos medicamentos e que tem efeitos sobre os resultados.

- causas dos problemas nos projetos - justificativas ou as razões para os desvios que ocorrem nos projetos de desenvolvimento de novos medicamentos. Podem ser erros, restrições e/ou dificuldades.

- impacto dos problemas nos projetos - efeitos dos desvios dos projetos sobre os resultados dos projetos de desenvolvimento de novos medicamentos.

- melhorias - indicações de oportunidades de melhoria das práticas de desenvolvimento de novos medicamentos, incluindo sugestões de estratégias e ações.

- futuro - perspectivas de mudanças que acreditam que ocorrerão no processo de desenvolvimento de novos medicamentos no futuro.

O questionário que foi desenvolvido está no Apêndice III e a estrutura básica do questionário é apresentada na Tabela 25 a seguir. 


\begin{tabular}{|c|c|c|c|}
\hline Variáveis & $\begin{array}{c}\text { Número } \\
\text { questão }\end{array}$ & Forma de verificação & Resultados possíveis \\
\hline $\begin{array}{l}\text { Problemas } \\
\text { (VD/VI) }\end{array}$ & 8 & $\begin{array}{l}\text { Pergunta aberta. } \\
\text { Problemas e/ou erros que enfrenta(ou) no } \\
\text { decorrer dos projetos de desenvolvimento } \\
\text { de novos medicamentos (VD) }\end{array}$ & Relatos de problemas \\
\hline Causas (VI) & 9 & $\begin{array}{l}\text { Pergunta aberta. } \\
\text { Causas/origens dos problemas nos projetos } \\
\text { de desenvolvimento de novos } \\
\text { medicamentos }\end{array}$ & Relatos das causas dos problemas \\
\hline Impactos (VD) & 10 & $\begin{array}{l}\text { Pergunta aberta. } \\
\text { Impactos/resultados dos problemas nos } \\
\text { projetos de desenvolvimento de novos } \\
\text { medicamentos }\end{array}$ & $\begin{array}{l}\text { Relatos dos impactos/resultados } \\
\text { dos problemas }\end{array}$ \\
\hline Melhoria & 11 & $\begin{array}{l}\text { Pergunta aberta. } \\
\text { Estratégias, ações e oportunidades de } \\
\text { melhoria das práticas de desenvolvimento } \\
\text { de novos medicamentos. }\end{array}$ & $\begin{array}{l}\text { Relatos de estratégias, ações e } \\
\text { oportunidades de melhoria }\end{array}$ \\
\hline Mudanças & 12 & $\begin{array}{l}\text { Pergunta aberta. } \\
\text { Mudanças que acredita que ocorrerão no } \\
\text { processo de desenvolvimento de novos } \\
\text { medicamentos no futuro. }\end{array}$ & $\begin{array}{l}\text { Relatos de mudanças que poderão } \\
\text { ocorrer no futuro }\end{array}$ \\
\hline \multirow[t]{7}{*}{$\begin{array}{l}\text { Respondentes } \\
\text { (VI) }\end{array}$} & 1 & Se trabalha na indústria farmacêutica & $\begin{array}{l}\text { Pergunta qualificadora de } \\
\text { múltipla escolha (trabalho, já } \\
\text { trabalhei, não trabalho, } \\
\text { consultoria, etc.) }\end{array}$ \\
\hline & 2 & Área de trabalho & $\begin{array}{l}\text { Pergunta qualificadora de } \\
\text { múltipla escolha (pesquisa e } \\
\text { desenvolvimento, regulatório, } \\
\text { corporativo, etc.) }\end{array}$ \\
\hline & 3 & Cargo ou função & $\begin{array}{l}\text { Pergunta qualificadora de } \\
\text { múltipla escolha (presidência, } \\
\text { diretoria, gerência, coordenação, } \\
\text { etc.) }\end{array}$ \\
\hline & 4 & Tempo de trabalho & $\begin{array}{l}\text { Pergunta de múltipla escolha } \\
\text { (escala ordinal) }\end{array}$ \\
\hline & 5 & Classe de medicamentos & $\begin{array}{l}\text { Pergunta de múltipla escolha } \\
\text { (novos, genéricos, similares, etc.) }\end{array}$ \\
\hline & 13 e 14 & Nome e sobrenome & Perguntas abertas \\
\hline & 15 & Email & Pergunta aberta \\
\hline \multirow{3}{*}{$\begin{array}{l}\text { Características } \\
\text { da organização } \\
\text { (VI) }\end{array}$} & 6 & Origem & $\begin{array}{l}\text { País onde está localizada a matriz } \\
\text { (Brasil ou outro país) }\end{array}$ \\
\hline & 7 & $\begin{array}{l}\text { Quem toma decisões de desenvolvimento } \\
\text { de produtos? }\end{array}$ & $\begin{array}{l}\text { Pergunta de múltipla escolha } \\
\text { (matriz, conselho, comitê, etc.) }\end{array}$ \\
\hline & 16 & Nome da empresa & $\begin{array}{l}\text { Relação de nomes de laboratório } \\
\text { (Anvisa) }\end{array}$ \\
\hline
\end{tabular}

Tabela 25 - Estrutura do questionário (fase qualitativa)

Fonte: dados da pesquisa.

\subsubsection{Amostra e coleta dos dados da pesquisa qualitativa}

Ao abordarem os estudos da experiência, Selltiz e colaboradores (1975) afirmam que as pessoas estão em situação que lhes permitem observar os efeitos de ações e decisões referentes a problemas de seus cotidiano. Assim, considerando os requisitos indicados por Creswell (2014), foram convidados a 
responder à pesquisa os profissionais da indústria farmacêutica com experiência no desenvolvimento de novos medicamentos. $\mathrm{O}$ contato com os participantes foi predominantemente realizado por meio da rede de relacionamento profissional denominada LinkedIn ${ }^{\odot}$. Desta forma, a amostragem adotada foi do tipo não-probabilística e por indivíduos-tipo, uma vez que os participantes deveriam ter certas características necessárias ao atendimento da especificidade e da profundidade de conhecimento da situação problema estabelecida pela pesquisa (Sampieri et al., 2006).

Em junho de 2016, os convites para participar da pesquisa foram enviados aos profissionais por meio de mensagem-convite pelo próprio módulo de mensagens do Linked ${ }^{\odot}{ }^{\odot}$. A mensagem continha um endereço de internet para acesso ao questionário eletrônico que foi desenvolvido e disponibilizado no ambiente do provedor de soluções de pesquisa chamado QuestionPro ${ }^{\odot}$ (www.questionpro.com).

Os dados das respostas dos participantes foram armazenados pela própria plataforma de pesquisa do QuestionPro $^{\odot}$ (www.questionpro.com). A consulta aos dados pôde ser feita por meio do próprio site na internet e também localmente após a baixa (“download”) do arquivo de dados no formato de planilha eletrônica (MS Excel $\left.{ }^{\circledR}\right)$.

\subsubsection{Método de análise dos dados da fase qualitativa}

Para um estudo com enfoque qualitativo, Creswell (2014) e Hinkin (1998) consideram duas abordagens para a análise dos dados: a dedutiva e a indutiva.

- Abordagem indutiva. Também conhecida como "agrupamento" ou "classificação de baixo", muitas vezes parte do envolvimento de pouca teoria. Busca identificar constructos e gerar medidas a partir de respostas individuais. As escalas são desenvolvidas a partir de descrições dos sentimentos de entrevistados sobre suas organizações ou de algum aspecto do comportamento. As respostas são separadas em classes por análise de conteúdo com base em palavras-chave ou temas (Hinkin, 1998).

- Abordagem dedutiva. De acordo com Hinkin (1998), a abordagem dedutiva é muitas vezes chamada de "particionamento lógico" ou "classificação de cima". Nesta abordagem, a base teórica fornece informações suficientes para gerar o conjunto inicial de itens. Sendo assim, requer compreensão do fenômeno a ser investigado e uma revisão completa da literatura para desenvolver a definição teórica do constructo em análise. Segundo Creswell (2014), o pensamento dedutivo é aplicado na construção dos temas na medida em que é verificado contra os dados.

Nesta pesquisa foi adotada uma combinação das duas abordagens na busca pela redução da ocorrência de inconsistências conceituais nos itens definidos com base nos dados empíricos (indução). Considerando as definições de Creswell (2014), pode-se considerar que a primeira análise seguiu a abordagem indutiva, dos dados empíricos individuais para as unidades de significado e os temas. 
A segunda análise desta primeira fase da pesquisa pode ser considerada dedutiva ao buscar reunir as evidências encontradas na literatura para definição das categorias e subcategorias de dados. A esta estrutura teórica foram relacionadas as unidades de significado surgidas da análise dos dados empíricos. A Figura 23 a seguir apresenta esquematicamente o procedimento realizado na primeira fase da pesquisa para identificação dos indicadores de desempenho dos projetos de desenvolvimento de medicamentos e de seus fatores contribuintes.

Figura 23 - Procedimento para identificação dos indicadores de desempenho e fatores contribuintes

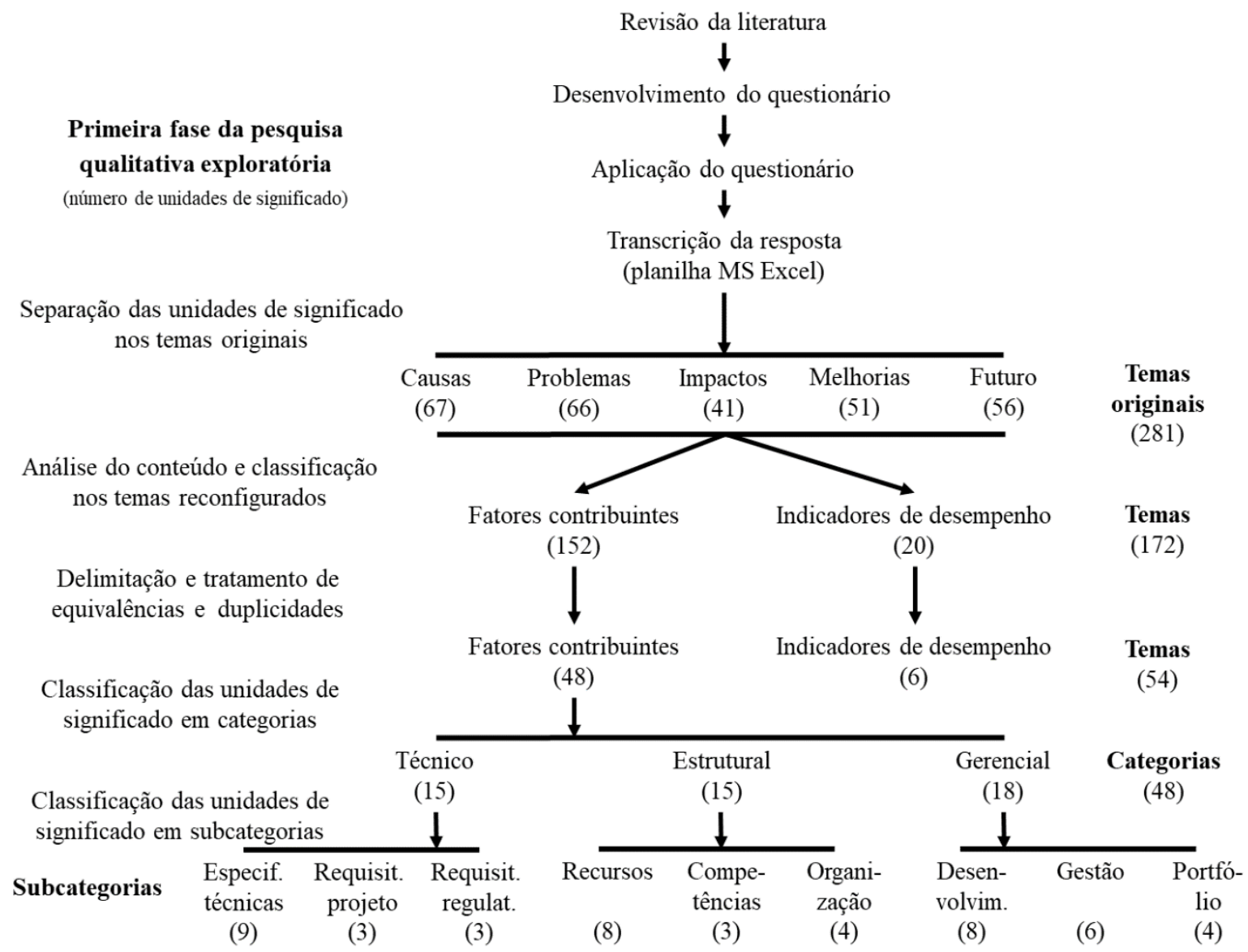

Nota: entre parêntesis o número de unidades de significado. Fonte: dados da pesquisa.

\subsubsection{Separação das unidades de significado nos temas originais}

Os dados foram transferidos da plataforma do QuestionPro $^{\odot}$ em arquivo no formato de planilha eletrônica $\left(\mathrm{MS} \mathrm{Excel}^{\circ}\right.$ ) tendo as perguntas em suas colunas e as respostas de cada respondente em suas linhas. Os dados contidos na planilha foram tratados preliminarmente para apenas conter respostas válidas. A seguir foram segregadas as unidades de significado contidas nas respostas.

As unidades de significado (também denominadas na literatura como elementos de significação, unidades de registro, unidades de codificação e unidades de conteúdo) foram definidas como uma frase ou um fragmento das respostas capaz de representar um pensamento, ideia, situação ou conceito 
único, indivisível e completo. Por exemplo, a frase "estrutura e experiência no processo de seleção de moléculas" foi segregada em "estrutura para a seleção de moléculas" e "experiência no processo de seleção de moléculas" gerando assim duas unidades de significado.

Bardin (2015) define um tema como uma unidade de significado extraído naturalmente do texto analisado, mas seguindo critérios baseados na teoria. Comenta ainda que inicialmente a informação pode ser tratada para que se possa chegar a representações condensadas no que seria uma análise descritiva do conteúdo ainda com um baixo nível de teorização. Selltiz e colaboradores (1975), já na década de 1970, consideravam que se os dados foram obtidos com um instrumento sistemático como um questionário, este já definiria naturalmente uma categorização definida pelas questões.

Assim, nesta fase da pesquisa, os temas definidos inicialmente, aqui chamados de temas originais, foram formados pelas próprias questões, ou seja, problemas, causas, impactos, melhorias e futuro. Este procedimento resultou na identificação inicial das unidades de significado dentro das respostas recebidas, sem diferenciação de peso ou importância entre elas neste momento.

Este procedimento inicial é denominado por Creswell (2014) como codificação aberta, ou seja, a codificação dos dados é realizada com foco no fenômeno central para as suas principais categorias de informação. Também considerou-se em toda a análise do conteúdo das respostas o conceito de unidade de contexto que, segundo Bardin (2015), direciona a compreensão mais apropriada do conteúdo na codificação das unidade de significado extraídas das respostas recebidas.

Nesta pesquisa, a referência ao contexto tem como principal direcionador os projetos de desenvolvimento de novos medicamentos, não tendo havido, neste momento, preocupação com a direção das unidades de significado, ou seja, se favoráveis, desfavoráveis ou neutras, por exemplo.

\subsubsection{Análise do conteúdo e classificação nos temas reconfigurados}

Após esta separação das unidades de significado extraídas das respostas recebidas conforme seus temas originais, foi realizada uma análise inicial do conteúdo de cada unidade de significado. De acordo com Bardin (2015, p. 44), a análise de conteúdo pode ser definida como:

Um conjunto de técnicas de análise das comunicações visando obter por procedimentos sistemáticos e objetivos de descrição do conteúdo das mensagens indicadores (quantitativos ou não) que permitam a inferência de conhecimentos relativos às condições de produção/recepção (variáveis inferidas) dessas mensagens.

Ainda segundo Bardin (2015), mesmo seguindo procedimentos sistemáticos e objetivos de descrição do conteúdo das mensagens, por depender de interpretação, a análise de conteúdo oscilaria entre o rigor da objetividade e a fecundidade da subjetividade.

Uma das possibilidades para início da análise de conteúdo é a análise categorial ou método das categorias. Bardin (2015) define a categorização como uma operação de classificação de elementos de 
um conteúdo por meio de diferenciação e, seguidamente, de reagrupamento por analogia com base em critérios previamente definidos. Desta forma, as categorias, rubricas ou classes são compostas por um grupo de unidades de significado com características comuns entre si com base em critérios que podem ser semânticos (temáticos), sintáticos, léxicos (palavras segundo o seu sentido) e expressivos. As unidades de significado identificadas são classificadas no que o autor chamou de gavetas ou rubricas significativas. Um dos seus principais objetivos é condensar os dados da pesquisa e produzir uma representação simplificada destes.

Assim, as unidades de significado extraídas das respostas recebidas foram analisadas em seu conteúdo, principalmente quanto à sua relação com cada uma das questões colocadas. Isso porque algumas respostas recebidas para uma questão continham elementos mais relacionados à outra questão. Para tal análise, foram utilizadas como referencial as definições operacionais estabelecidas para a elaboração das questões da pesquisa. Um exemplo é a resposta "retrabalho nos desenvolvimentos" que foi dada para a questão sobre causas dos problemas nos projetos de desenvolvimento de novos medicamentos. Entende-se, com base nas definições operacionais, que não se trata de uma causa, mas sim de um possível resultado dos desvios que decorrem nos projetos de desenvolvimento de novos medicamentos.

Durante esta primeira análise de conteúdo, percebeu-se sobreposição entre as definições de problema e causa. Entendeu-se de uma forma mais abrangente que toda causa de um problema é também um problema em si. Esta sobreposição dificultou a segregação das unidades de significado extraídas das respostas recebidas entre estes dois temas. Esta situação não permitiu, adicionalmente, que este procedimento de segregação atendesse ao requisito de exclusividade das categorias de dados, ou seja, uma mesma unidade de significado não poderia ser classificada em duas categorias diferentes (Bardin, 2015). Desta forma, para viabilizar uma categorização adequada, após avaliar as definições dos temas previamente estabelecidas, a decisão foi por ajustar suas operacionalizações. Assim, o tema impacto utilizado no questionário e empregado para a segregação inicial das unidades de significado recebeu uma definição mais específica passando a ser denominado indicador de desempenho (variável dependente), uma vez que o impacto final dos problemas no desenvolvimento dos medicamentos é mensurado pelas variações em seu desempenho. Em outras palavras, entende-se que os impactos dos desvios que decorrem nos projetos de desenvolvimento de novos medicamentos podem ser traduzidos em variações em seus resultados.

Por outro lado, os temas problema e causa utilizados no questionário e empregados para a segregação inicial das unidades de significado foram juntados e receberam uma definição única passando a ser denominados fatores contribuintes (variáveis independentes), ou seja, foram definidos operacionalmente como itens relacionados aos projetos de desenvolvimento de novos medicamentos que podem contribuir para ineficiências e/ou resultados indesejáveis ou aquém dos esperados ou 
planejados. A justificativa para este direcionamento para ineficiências e/ou resultados indesejáveis e não para o sucesso dos projetos está nos seguintes argumentos:

- se uma determinada atividade ou um requisito é necessário para o desenvolvimento de um novo medicamento genérico, é aceitável considerar que falhas na realização da atividade ou no atendimento do requisito darão origem a problemas para o projeto de desenvolvimento do novo medicamento e, portanto, produzirão efeitos sobre o desempenho do projeto;

- se a pesquisa focasse nos fatores para o sucesso, os fatores mandatórios como aqueles determinados pela legislação teriam plena contribuição para os projetos concluídos com sucesso, impossibilitando verificar variações ou diferenças entre os projetos quanto a estes fatores. Por outro lado, ao focar nos fatores contribuintes para o insucesso, é possível diferenciar estes mesmos fatores mandatórios em seus graus de contribuição quando falham.

Consequentemente, houve ajuste no contexto que passou a ter como principal direcionador o desempenho dos projetos de desenvolvimento de novos medicamentos. Além disso, passou a haver direção para a identificação das unidades de significado, ou seja, a contribuição negativa para o desempenho. No entanto, conforme Murphy, Baker e Fisher (1974) é preciso considerar que a ausência de fatores que levam ao insucesso dos projetos não garante automaticamente o seu sucesso.

A Figura 24 a seguir traz a representação da relação estudada.

Figura 24 - Relação entre os fatores contribuintes e o desempenho dos projetos de desenvolvimento de medicamentos

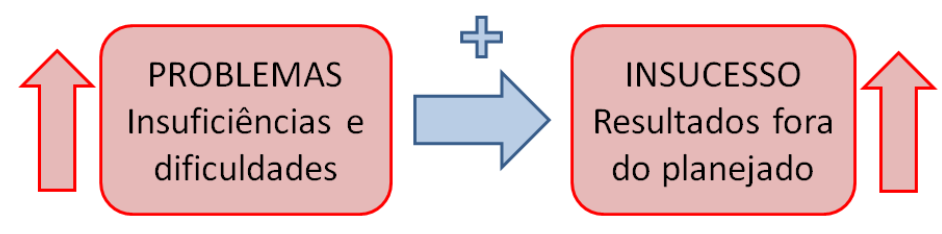

Fonte: Dados da pesquisa

Assim, nesta fase da pesquisa, a análise foi estruturada para produzir uma codificação denominada axial em torno do fenômeno central por condições causais (identificação dos fatores causadores do fenômeno central), condições intervenientes e causais (fatores influenciadores situacionais amplos e específicos) e consequências (Creswell, 2014). As classificações nas categorias e subcategorias buscaram atender aos requisitos indicados por Bardin (2015), ou seja:

- Exclusão mútua - um elemento (unidade de significado) não pode pertencer a mais de uma categoria, ou seja, não pode ter ambiguidades ou aspectos susceptíveis de classificação em duas ou mais categorias;

- Homogeneidade - um único princípio de classificação deve definir a organização das unidades de significado em uma mesma categoria; 
- Pertinência - uma categoria é pertinente quando está ajustada ao material de análise e também ao quadro teórico adotado, fazendo com que o sistema de categorias represente o objetivo, as questões de pesquisa e/ou corresponda às características dos conteúdos analisados;

- Objetividade e a fidelidade - as diferentes partes de um mesmo material devem ser submetidos aos mesmos critérios e classificados da mesma maneira, independentemente do número de análises. A qualidade das definições e da escolha das categorias evitam distorções que surgem quando há subjetividade e variação dos juízos nas avaliações;

- Produtividade - um conjunto de categorias é produtivo se fornece índices de inferências, hipóteses novas e dados com qualidade.

Tendo por referência os temas redefinidos e suas operacionalizações, as unidades de significado foram então analisadas e categorizadas. De acordo com Bardin (2015), "um sistema de categorias é válido se puder ser aplicado com precisão ao conjunto da informação e se for produtivo no plano das inferências". Assim, foram tratados os casos em que duas ou mais unidades de significado são escritas semelhantemente, porém relacionadas a situações ou contextos diferentes. Por exemplo, a unidade "provocar atrasos" pode fazer referência a uma atividade ou ao projeto como um todo. Nestes casos, o procedimento considerou o contexto específico no qual a unidade de significado aparece na resposta recebida. Desta forma, tendo por referência as redefinições dos temas, a análise do conteúdo das unidades de significado resultou na redistribuição das unidades de significado.

\subsubsection{Delimitação e tratamento de equivalências e duplicidades}

Na continuação das análises, o estudo estreitou o seu escopo, passando a ter como objeto apenas os indicadores de desempenho e seus fatores contribuintes. Assim, a redefinição do escopo da pesquisa determinou a exclusão do estudo das classes denominadas melhorias e futuro. Outra decisão tomada com respeito à delimitação do estudo determinou que fizessem parte do escopo apenas as fases dos projetos de desenvolvimento de novos medicamentos entre a iniciação e a aprovação do novo produto pelo órgão regulamentador, ou seja, pela Anvisa no caso brasileiro. Desta forma, foram excluídas do escopo da pesquisa as fases anteriores ao início dos projetos, mais especificamente os processos de análise, seleção e decisão dos projetos a serem desenvolvidos. No outro extremo, também não foram contemplados as fases posteriores à finalização dos projetos com a aceitação dos produtos desenvolvidos, o que inclui a produção industrial, a distribuição, a promoção e a comercialização dos produtos. A principal razão está exatamente no foco da pesquisa estar no desenvolvimento técnico dos medicamentos, alinhado com o conceito apresentado pelo PMI (2017) para o ciclo de vida do projeto.

Uma última decisão nesta fase sobre os limites da pesquisa, que teve reflexos sobre esta nova categorização, foi a definição dos medicamentos genérico como tipo específico de projeto de 
desenvolvimento de novo produto a ser estudado. A principal razão para esta delimitação está baseada nos resultados da pesquisa de Do Carmo, Piras e colaboradores (2017) que indicaram baixa taxa de aprovação dos pedidos de registro dos medicamentos genéricos e que é parte da justificativa deste estudo. Neste ponto, a referência ao contexto foi estreitada passando a considerar mais especificamente como principal elemento os PDMG. Tendo por referências estas decisões tomadas em relação ao escopo da pesquisa e sua operacionalização, foi realizado um procedimento para tratar os casos de unidades de significado idênticos, sinônimos ou próximos em nível semântico. Até este momento, a abordagem da pesquisa foi indutiva.

Como sugere Bardin (2015), as unidades de significado da classe indicadores de desempenho foram então analisadas de maneira criteriosa, recorrendo-se a referenciais quando necessário, sejam teóricos, de senso comum, de experiências pessoais, ou sejam ainda decorrentes de um saber mais elaborado. Creswell (2014) corrobora com esta ideia ao considerar que o referencial teórico é fornecedor de um quadro geral das associações e relações.

As publicações e documentos encontrados na revisão da literatura tratam em sua maioria das características dos processos de desenvolvimento de novos medicamentos, incluindo os requisitos técnicos, legais e eventuais recomendações, como as publicadas pelo FDA (2007). Em uma abordagem que se aproxima à dedutiva, todos foram considerados na composição do referencial teórico que dá sustentação à definição tanto da relação de indicadores de desempenho de PDMG quanto da relação dos fatores que os influenciam.

\subsubsection{Classificação das unidades de significado nos indicadores de desempenho}

Após a análise do referencial teórico e dos resultados da primeira da fase da pesquisa empírica, a conclusão foi a de que seria mais adequada a adoção de indicadores tradicionais de desempenho de projetos, tais como os utilizados pelo PMI (2017), por Wheelwright e Clark (1992) e principalmente pelas duas primeiras dimensões do sucesso dos projetos do modelo proposto por Shenhar e colaboradores (1997), porém ajustados às características específicas dos PDMG. Desta forma, as unidades de significado relacionadas ao tema dos indicadores de desempenho de PDMG tiveram como principal referencial os modelos gerais de avaliação de desempenho de projetos.

Considerando estas definições, as unidades de significado extraídas das respostas recebidas e relacionadas aos indicadores de desempenho foram submetidas ao tratamento das equivalências e duplicidades, observando-se as decisões de delimitação da pesquisa. Os indicadores especificamente relacionados ao processo de desenvolvimento dos novos medicamentos genéricos são apontados por estudos como os realizados por Do Carmo (2017), Srinivasan e Iser (2010), Srinivasan, Iser e Gill (2011) e Worku e colaboradores (2012). Assim, as unidades de significado inicialmente definidas para o tema dos indicadores de desempenho foram condensadas e reclassificadas. 


\subsubsection{Classificação das unidades de significado em categorias de fatores contribuintes}

Seguindo o fluxo de atividades apresentado na Figura 23, as mesmas avaliações e decisões em relação ao escopo da pesquisa e sua operacionalização foram realizadas para o caso das unidades de significado extraídas das respostas recebidas e classificadas sob o tema dos fatores contribuintes para o desempenho. Mais especificamente para os PDMG, os fatores contribuintes para o desempenho foram definidos como situações ou condições de recursos, atividades e/ou decisões necessárias ao desenvolvimento de medicamentos genéricos e entendidos como contribuintes para o surgimento e/ou agravamento de problemas para os projetos.

Também com base no referencial teórico, no resultado da análise do conteúdo das respostas recebidas pela pesquisa qualitativa preliminar e, em especial, no modelo conceitual proposto, foi produzida uma relação inicial de itens ligados aos fatores contribuintes. Neste processo, foram identificadas quais variáveis citadas pela literatura que também foram mencionados pelos participantes da pesquisa qualitativa.

Assim, também tendo por referência as decisões tomadas em relação ao escopo da pesquisa e sua operacionalização, foi realizado um procedimento para tratar os casos de unidades de significado idênticos, sinônimos ou próximos em nível semântico. As unidades de significado da classe fatores contribuintes foram então analisadas de maneira criteriosa, recorrendo-se ao referencial teórico quando necessário, com o objetivo de verificar sobreposições e redundâncias entre as unidades previamente categorizadas, sendo, desta forma, racionalizadas e reestruturadas.

Neste último tratamento, percebeu-se que as unidades de significado eram de diferentes naturezas. Esta constatação foi corroborada pelo fato do referencial utilizado como apoio às análises realizadas até então pertenciam a grupos de distintas de áreas de pesquisa. Bardin (2015) considera que a categorização como parte da análise de conteúdo é um processo de tipo estruturalista e que possui duas etapas: o inventário que isola os elementos, aqui denominados unidades de significado, e a classificação que os separa com o objetivo de obter certa organização aos elementos isolados. Este estudo optou pela classificação progressiva das unidades de significado decorrente da própria análise das unidades de significado extraídas das respostas recebidas e não adotar um sistema de categorias previamente estabelecido ou definido pelo referencial teórico, embora já tivesse sido dedutivamente proposto o modelo conceitual. Isso para permitir que eventuais diferenças entre o modelo conceitual e os resultados da pesquisa empírica pudessem ser analisadas e eventualmente provocar ajustes no modelo inicialmente proposto.

As unidades de significado resultantes desta fase do estudo foram então classificadas considerando a proximidade de seus conteúdo e características comuns entre elas com o objetivo de facilitar a organização dos itens e verificar possíveis sobreposições e redundâncias. As unidades de 
significado em cada uma das classes que surgiram deste procedimento foram avaliadas quanto à adequação de suas classificações às definições estabelecidas no modelo conceitual. Verificou-se então que suas naturezas muito se assemelhavam às dimensões de fatores influenciadores definidas no modelo conceitual. Esta avaliação não só buscou por eventuais diferenças, mas também por semelhanças que acabaram por alinhar as classes surgidas da análise qualitativa com as definições das dimensões do modelo conceitual. Como resultado, foram adotadas as seguintes categorias de fatores influenciados do desempenho dos PDMG:

- Categoria ou dimensão Gerencial: conteúdos relacionados às decisões de gerenciamento dos projetos, ou seja, inclui os processos que visam, sobretudo, identificar, definir e coordenar as atividades e recursos dos projetos de forma integrada;

- Categoria ou dimensão Estrutural: conteúdos relacionados a fatores externos ao projeto, ou seja, à disponibilidade dos recursos, cultura, infraestrutura, competências e estrutura organizacional;

- Categoria ou dimensão Técnico: conteúdos relacionados aos requisitos técnicos para os produtos e os projetos envolvendo a legislação, especificações técnicas, escopo do produto e escopo do projeto.

\subsubsection{Classificação das unidades de significado em subcategorias}

As unidades de significado de cada uma das categorias ou dimensões estabelecidas foram então analisadas mais especificamente no sentido da identificação de subconjuntos a partir também da proximidade de seus conteúdo e características comuns. Cada uma das unidades de significado das três dimensões foi então analisada em um contexto mais restrito e específico, dando origem a 9 subcategorias diferentes de unidades de significado, ou seja:

- Categoria ou dimensão Gerencial: subcategorias Desenvolvimento, Gestão e Portfólio;

- Categoria ou dimensão Estrutural: subcategorias Recursos, Competências e Organização;

- Categoria ou dimensão Técnico: subcategorias Especificações técnicas, Requisitos do projeto e Requisitos regulatórios.

A definição das três categorias e a segregação das unidades de significado entre as 9 subcategorias associadas à categorias foi submetida à avaliação e validação por um especialista com mais de 20 anos de experiência em projetos de desenvolvimento de medicamentos para eventuais correções, ajustes e aprimoramentos.

\subsubsection{Proposição do modelo teórico e de suas dimensões e constructos}

Para Bardin (2015), o interesse da análise de conteúdo não está unicamente na descrição dos dados coletados, mas também no que pode surgir após serem tratados. Neste sentido, Creswell (2014) 
considera que nos procedimentos analíticos predominantemente sistemáticos, o objetivo está no desenvolvimento de uma teoria que explique o processo, ação ou interação sobre um tópico. No entendimento do autor, uma teoria seria uma explicação de alguma coisa ou uma compreensão que o pesquisador desenvolve. Para (Kerlinger, 2007, p. 18), cuja publicação data de 1910, teorias seriam:

Tentativas sistemáticas de "explicar" os vários fenômenos, postulando as relações entre os fenômenos a serem explicados e um certo número de "variáveis explicativas" que também estão relacionadas entre si de modo sistemático.

Denominado "relatório holístico" por Creswell (2014), a identificação dos fatores envolvidos e a construção de um esquema geral para representá-los é uma das possíveis resultantes de uma pesquisa qualitativa se o objetivo for explicar os mecanismos e ou ligações em modelos causais. Quando a análise dos dados é estruturada, uma categoria aberta pode ser selecionada para ser o foco da teoria para depois serem detalhadas categorias adicionais na chamada codificação axial para formar o modelo teórico, o qual é definido pela intersecção das categorias e representado como um diagrama, proposições (hipóteses) ou discussão.

Bardin (2015) também afirma que as análises aplicadas com procedimentos de inventário e de classificação podem resultar em hipóteses. O modelo visual chamado por Creswell (2014) de paradigma de codificação axial é a representação do relacionamento entre as categorias que se estabelecem em torno do fenômeno central. Nele são representados o fenômeno central (categoria a respeito do fenômeno) e as condições identificadas, quais sejam: causais (influenciam o fenômeno), estratégias (ações ou interações resultantes do fenômeno), o contexto e as condições intervenientes (condições restritas e amplas que influenciam as estratégias) e, por fim, as consequências (resultados das estratégias).

Com a elaboração do modelo, também podem ser especificadas proposições ou hipóteses para as relações definidas (Creswell, 2014). Para Bickman e Rog (2009, p. 222), o modelo de um estudo é "o sistema de conceitos, suposições, expectativas, crenças e teorias que apoiam e informam a pesquisa". Na prática, seria uma tentativa de formulação de uma teoria sobre o que esta sendo observado nos dados da pesquisa e por quê. Na visão deles, o "problema de pesquisa" é uma parte do modelo conceitual cuja finalidade não é apenas descritiva, mas também crítica do que já se estudou sobre o fenômeno. Seria construído e não encontrado a partir de partes trazidas de outras referências, mas cuja estrutura, a coerência geral, é desenvolvida e não copiada.

De acordo com Creswell (2010), a revisão da literatura deve indicar quais teorias podem ser utilizadas para explorar as questões que estão sendo estudadas. O referencial teórico fornece componentes ou módulos para a construção do modelo após examinados criticamente. Ainda de acordo com o autor, são quatro as fontes principais para estes módulos: o conhecimento experiencial 
do pesquisador; a teoria e pesquisa já realizadas, estudos piloto e exploratórios; e experimentos mentais. Para Bardin (2015), o aspecto iterativo da análise de conteúdo envolve a teoria, as hipóteses, as interpretações e os métodos de análise.

Para Bickman e Rog (2009), o modelo seria uma simplificação do fenômeno estudado sob a ótica do pesquisador com o objetivo de esclarecer e explicar o seu funcionamento envolvendo o quê, como e por quê está acontecendo. Sua utilidade está em esclarecer o fenômeno, favorecer novas abordagens e ampliar a compreensão sobre ele. Além disso, o modelo teria por função servir de alicerce para os passos seguintes de um projeto de pesquisa ao auxiliar na avaliação dos objetivos, no desenvolvimento e seleção de questões e métodos de pesquisa e na identificação de potenciais ameaças de validade de suas conclusões. Desta forma, nesta etapa foram realizadas análise e inferências para se obter a melhor interpretação do conteúdo das respostas recebidas e das relações entre suas unidades de significado.

Apenas lembrando que a proposição do modelo teórico próprio e dos construtos e de seus componentes, tem por razão não haverem sido encontrados modelos e/ou constructos já existentes, específicos e validados para a mensuração do desempenho dos PDMG. O modelo teórico proposto e complementado com as nove subcategorias de unidades de signficado e as relações entre elas é apresentado na Figura 25 a seguir.

Figura 25 - Modelo teórico para as relações entre o desempenho dos projetos de desenvolvimento de medicamentos genéricos e seus fatores contribuintes.

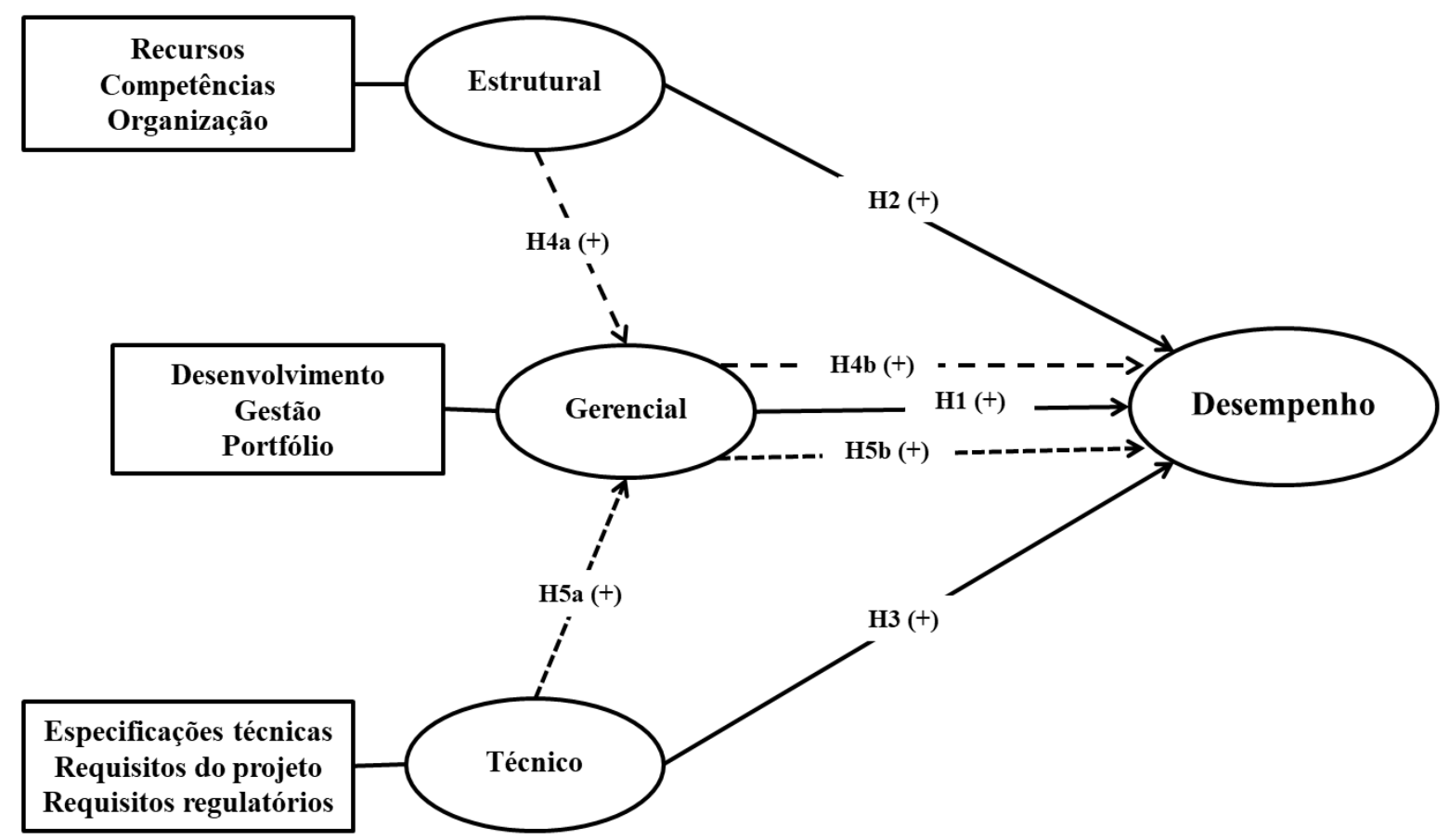

Fonte: dados da pesquisa. 


\subsection{SEGUNDA FASE DA PESQUISA - QUANTITATIVA}

A pesquisa de Page e Schirr (2008) com foco na evolução das pesquisas sobre o tema do desenvolvimento de novos produtos detectou que entre 2001 e 2004 as técnicas analíticas multivariadas foram aplicadas em $77 \%$ dos artigos empírico-quantitativos publicados nos periódicos selecionados por eles, sendo que a modelagem de equações estruturais - MEE foi usada em 19\% dos artigos, contra $8 \%$ no quadriênio anterior.

A escolha da MEE como principal técnica de análise dos dados se justifica por trata-se de método que permite o estudo das diferentes relações entre as múltiplas variáveis simultaneamente. Mais especificamente, foi empregado a modelagem de equações estruturais com estimação por mínimos quadrados parciais - PLS-SEM.

\subsubsection{Adequação do modelo teórico para o modelo de caminhos}

Para que o modelo teórico pudesse ser avaliado utilizando a técnica de MEE, foi necessária a realização de ajustes na própria representação gráfica do modelo e na nomenclatura dada aos seus componentes, uma vez que, embora haja equivalência, a técnica de análise de conteúdo e a técnica de modelagem de equações estruturais tem denominações e jargões que lhes são próprios.

Para este ajuste, é importante também lembrar a questão central da pesquisa, ou seja: quais são os fatores que contribuem para o desempenho dos projetos de desenvolvimento de medicamentos genéricos? Complementarmente, a pesquisa buscou analisar empiricamente as relações entre os fatores contribuintes e o desempenho dos PDMG.

Um conceito importante para esta fase da pesquisa é o de constructo, o qual é definido como um termo conceitual que é usado para descrever um fenômeno teórico de interesse e que possui as seguintes características (Edwards \& Bagozzi, 2000):

- se referem a fenômenos que são reais e existem além da consciência e interpretação do pesquisador e das pessoas que estão sendo estudadas, ou seja, são utilizados para descrever fenômenos reais que são vividos pelas pessoas ou são formulados para representar um fenômeno real em coletivos sociais;

- embora se refiram a fenômenos reais, eles por si só não são reais em um sentido objetivo, mas elementos do discurso científico que servem como substitutos ("surrogates") verbais dos fenômenos de interesse;

- os fenômenos descritos por eles podem ser inobserváveis (por exemplo: atitudes e crenças) ou observáveis (por exemplo: desempenho da tarefa), ou seja, o próprio constructo pode ser 
um termo abstrato que descreve o fenômeno. Desta forma, os estados subjetivos são descritos como atitudes e o comportamento é descrito como desempenho da tarefa.

A Tabela 26 a seguir apresenta a equivalência entre os termos das fases qualitativa e quantitativa e suas definições e operacionalizações a fim de facilitar a passagem dos resultados da primeira fase qualitativa para a esta fase quantitativa.

Tabela 26 - Equivalência entre os termos das fases qualitativa e quantitativa e suas definições e operacionalizações

\begin{tabular}{|c|c|c|c|}
\hline $\begin{array}{l}\text { Primeira fase - } \\
\text { qualitativa }\end{array}$ & $\begin{array}{l}\text { Segunda fase - } \\
\text { quantitativa }\end{array}$ & Definição & Operacionalização \\
\hline Modelo teórico & $\begin{array}{l}\text { Modelo de } \\
\text { caminhos ("path } \\
\text { model") }\end{array}$ & $\begin{array}{l}\text { É composto por dois elementos: a. } \\
\text { modelo estrutural que representa } \\
\text { os constructos (círculos ou elipses) } \\
\text { e os relacionamentos (caminhos) } \\
\text { entre eles; b. modelo de } \\
\text { mensuração dos construtos que } \\
\text { exibem as relações entre os } \\
\text { construtos e as variáveis } \\
\text { indicadoras (retângulos). }\end{array}$ & $\begin{array}{l}\text { Representado graficamente pelo } \\
\text { modelo de caminhos }\end{array}$ \\
\hline $\begin{array}{l}\text { Unidades de } \\
\text { significado }\end{array}$ & $\begin{array}{l}\text { Indicadores das } \\
\text { escalas de } \\
\text { mensuração ou } \\
\text { variáveis } \\
\text { observadas (VO) } \\
\text { ou mensuradas }\end{array}$ & $\begin{array}{l}\text { As variáveis independentes que } \\
\text { compõem os constructos de } \\
\text { primeira ordem. Os indicadores, } \\
\text { também chamados de itens ou } \\
\text { variáveis manifestadas, são as } \\
\text { variáveis "proxy" diretamente } \\
\text { mensuradas que contêm os dados } \\
\text { brutos (Hair Jr. et al., 2017). }\end{array}$ & $\begin{array}{l}\text { As unidades de significado } \\
\text { relacionadas ao desempenho dos } \\
\text { projetos foram denominadas } \\
\text { indicadores de desempenho. } \\
\text { Já as unidades de significado } \\
\text { que segundo o modelo de } \\
\text { caminhos influenciam o } \\
\text { desempenho dos projetos foram } \\
\text { denominadas fatores } \\
\text { contribuintes. } \\
\text { Elas são representadas no } \\
\text { modelo de caminho como } \\
\text { retângulos }\end{array}$ \\
\hline Subcategorias & $\begin{array}{c}\text { Constructos ou } \\
\text { variáveis latentes } \\
\text { (VL) de primeira } \\
\text { ordem ou } \\
\text { exógenos. }\end{array}$ & $\begin{array}{l}\text { Escalas de mensuração, Variáveis } \\
\text { latentes ou constructos de primeira } \\
\text { ordem. São variáveis que não são } \\
\text { medidas diretamente. Trata-se de } \\
\text { modelo de mensuração para as } \\
\text { variáveis latentes exógenas (ou } \\
\text { seja, aqueles construtos que } \\
\text { explicam outros construtos no } \\
\text { modelo). (Hair Jr. et al., 2017) }\end{array}$ & $\begin{array}{l}\text { Exemplos os Constructos: } \\
\text { Especificações técnicas, } \\
\text { Requisitos do projeto, } \\
\text { Requisitos regulatórios, } \\
\text { Desenvolvimento, Gestão, } \\
\text { Portfólio, Recursos, } \\
\text { Competências e Organização, } \\
\text { além da Dimensão } \\
\text { Desempenho*. } \\
\text { Eles são representados no } \\
\text { modelo de caminho como } \\
\text { elipses. }\end{array}$ \\
\hline Categorias & $\begin{array}{l}\text { Dimensões ou } \\
\text { constructos ou } \\
\text { variáveis latentes } \\
\text { (VL) de segunda } \\
\text { ordem ou } \\
\text { endógenos. }\end{array}$ & $\begin{array}{l}\text { Escalas de mensuração, variáveis } \\
\text { latentes ou constructos de segunda } \\
\text { ordem. Tratam-se também de } \\
\text { modelos de mensuração, mas para } \\
\text { as variáveis latentes endógenas (ou } \\
\text { seja, aqueles construtos que estão } \\
\text { sendo explicados no modelo). } \\
\text { (Hair Jr. et al., 2017) }\end{array}$ & $\begin{array}{l}\text { São exemplos as Dimensões: } \\
\text { Gerencial, Estrutural e Técnico. } \\
\text { Elas são representadas no } \\
\text { modelo de caminho como } \\
\text { elipses, porém somente } \\
\text { constructos são ligados a elas. }\end{array}$ \\
\hline
\end{tabular}

Nota: Na coluna com os termos da segunda fase, quando há sinônimos, estão em negrito os termos que foram adotados nesta pesquisa. Fonte: dados da pesquisa. 
Neste ponto, torna-se útil também esclarecer os conceitos de causalidade e da relação entre constructos e medidas. Edwards e Bagozzi (2000) observaram que, embora as discussões sobre medidas usem frequentemente a linguagem causal, raramente incorporam princípios da causalidade da filosofia da ciência. Também mencionam que a literatura indica algum consenso sobre quatro condições para estabelecer a causalidade nas ciências sociais, comportamentais e de gestão, as quais são relacionadas a seguir:

- entidades distintas - a causalidade requer que a causa e o efeito sejam entidades distintas;

- associação - a causalidade requer associação, o que significa que a causa e o efeito covariam. A associação geralmente é vista como probabilística em vez de determinística, o que significa que a causa aumenta a probabilidade do efeito, mas não garante que o efeito ocorrerá;

- precedência temporal - causalidade requer precedência temporal, de modo que a causa deve ocorrer antes do efeito, mesmo que seja quase instantânea;

- eliminação de explicações rivais concorrentes - a causalidade exige a eliminação de explicações rivais para a relação presumida entre a causa e efeito.

Outro esclarecimento importante para a construção do modelo diz respeito à direção causal entre o constructo e a medida. Uma medida é definida por Edwards e Bagozzi (2000) como uma pontuação observada por meio de auto-relato, entrevista, observação ou algum outro meio. Em outras palavras, uma medida é um registro quantificado, ou dado, tomado como um análogo empírico para um constructo.

Complementarmente, Edwards e Bagozzi (2000) identificaram algumas regras para a decomposição de correlações na análise de caminhos e na modelagem de equações estruturais. Essas regras estipulam que a correlação entre duas variáveis pode ser decomposta em quatro componentes:

- efeito direto - uma variável afeta diretamente outra;

- efeito indireto - o efeito de uma variável sobre outra é mediado (transmitido através) por outra ou outras variáveis;

- componente espúrio - é devido a causas comuns ou correlacionadas; e

- componente não analisado - resultante de associações entre variáveis predeterminadas (exógenas).

Ainda segundo Edwards e Bagozzi (2000, p. 161), os efeitos diretos e indiretos podem operar em qualquer direção, dependendo de qual variável é especificada como a causa do outro. A aplicação 
dessas distinções à relação entre um constructo e uma medida produz seis categorias básicas de modelos cujas características básicas são apresentadas na Figura 26.

Figura 26 - Modelos de relacionamento entre constructos e suas medidas

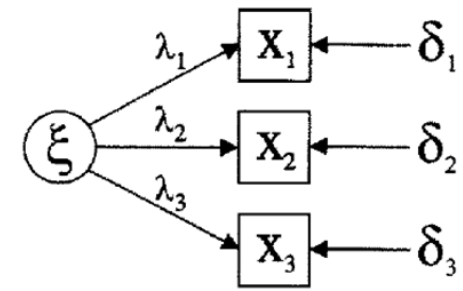

A - Modelo reflexivo direto

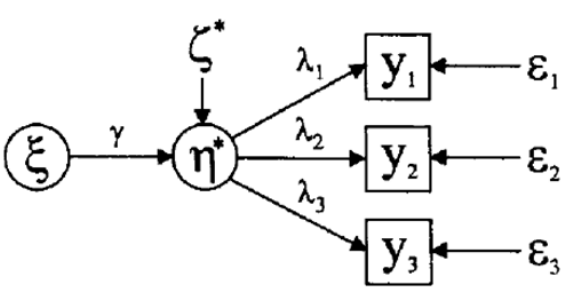

$\mathrm{C}$ - Modelo reflexivo indireto -

Constructo com mediação simples

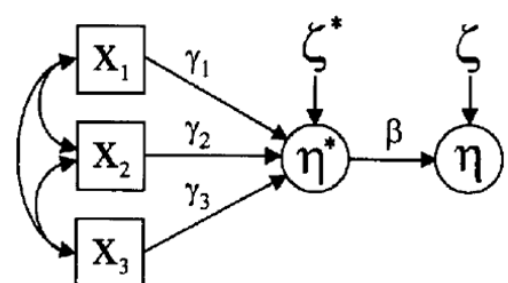

E - Modelo formativo indireto Constructo com mediação simples

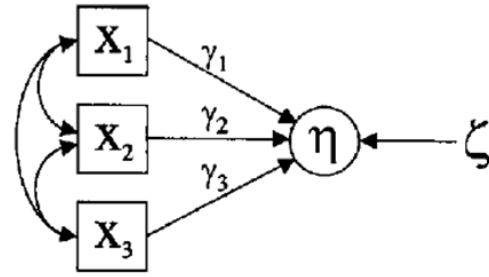

B - Modelo formativo direto

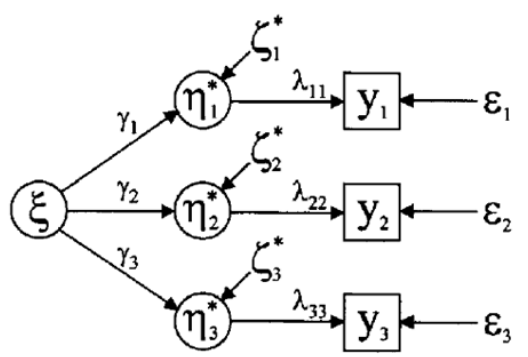

D - Modelo reflexivo indireto Constructo com mediação múltipla

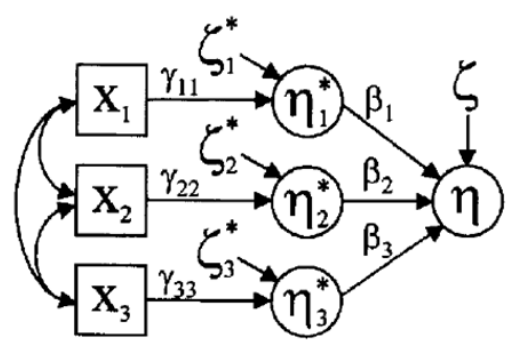

F - Modelo formativo indireto -

Constructo com mediação múltipla

Notas: $\xi=$ constructo; $X_{i}=$ medida; $\delta_{i}=$ erro de medição aleatória; $\lambda_{i}=$ fator de carga que representa a magnitude do efeito do constructo sobre a medida.

$\eta=$ constructo; $\gamma_{i}=$ parâmetro estrutural que representa a magnitude do efeito da medida sobre o constructo. $\zeta=$ termo de ruídos ("disturbance").

$\mathrm{y}_{\mathrm{i}}=$ medidas; $\eta_{j}^{*}=$ variáveis latentes (asterisco para indicar que $\eta_{j}{ }^{*}$ não é o constructo que será medido pelo $\mathrm{y}_{\mathrm{i}} ; \varepsilon_{\mathrm{i}}$ $=$ erros de medição; $\beta_{\mathrm{i}}=$ indica a magnitude do efeito da variável latente sobre o constructo.

Fonte: extraído e traduzido de Edwards e Bagozzi (2000, pp. 160-164).

Com a definição da dimensão Desempenho (contructo ou variável latente dependente), das 9 dimensões de fatores contribuintes dos projetos de desenvolvimento dos medicamentos genéricos (contructos ou variáveis latentes independentes) e das três dimensões (constructos ou varáveis latentes de segunda ordem), foi possível propor o modelo de caminhos e as hipóteses associadas a ele. É importante destacar que, embora a dimensão Desempenho tenha origem em uma das categorias de unidades de significado (fase qualitativa), ela é conceitualmente um constructo de primeira ordem. Os símbolos utilizados para a representação do modelo de caminhos são apresentados na Figura 27. 
Figura 27 - Símbolos empregados no modelo de caminhos

\begin{tabular}{|c|l|}
\hline \multicolumn{1}{|c|}{ Símbolo } & \multicolumn{1}{|c|}{ Definição } \\
\hline & $\begin{array}{l}\text { Constructo ou variável latente (VL) ou ainda dimensão no caso das } \\
\text { variáveis latentes de segunda ordem. }\end{array}$ \\
\hline & $\begin{array}{l}\text { Indicador ou variável observada (VO) ou mensurada } \\
\text { Construçaço entre um indicador (variável observada - VO) e um } \\
\text { reflexivo }\end{array}$ \\
\hline & $\begin{array}{l}\text { Relação causal (independente } \rightarrow \text { dependente) - coeficiente de } \\
\text { caminho entre um constructo variável latente de primeira ordem) e } \\
\text { a uma dimensão (variável latente de segunda ordem) }\end{array}$ \\
\hline
\end{tabular}

Nota: em negrito os termos adotados nesta pesquisa. Fonte: adaptado de Ringle, Da Silva e Bido (2014, p. 59).

Utilizando esta notação, a representação gráfica do modelo de caminhos no formato dos modelos de equações estruturais proposto para o desenvolvimento de medicamentos genéricos é apresentada na Figura 28. Nos retângulos estão representados por letras e números os indicadores de cada um dos constructos exógenos, cuja relação está disponível no Apêndice XII desta tese.

Figura 28 - Modelo de caminhos para o desempenho de projetos de desenvolvimento de medicamentos genéricos e seus fatores contribuintes.

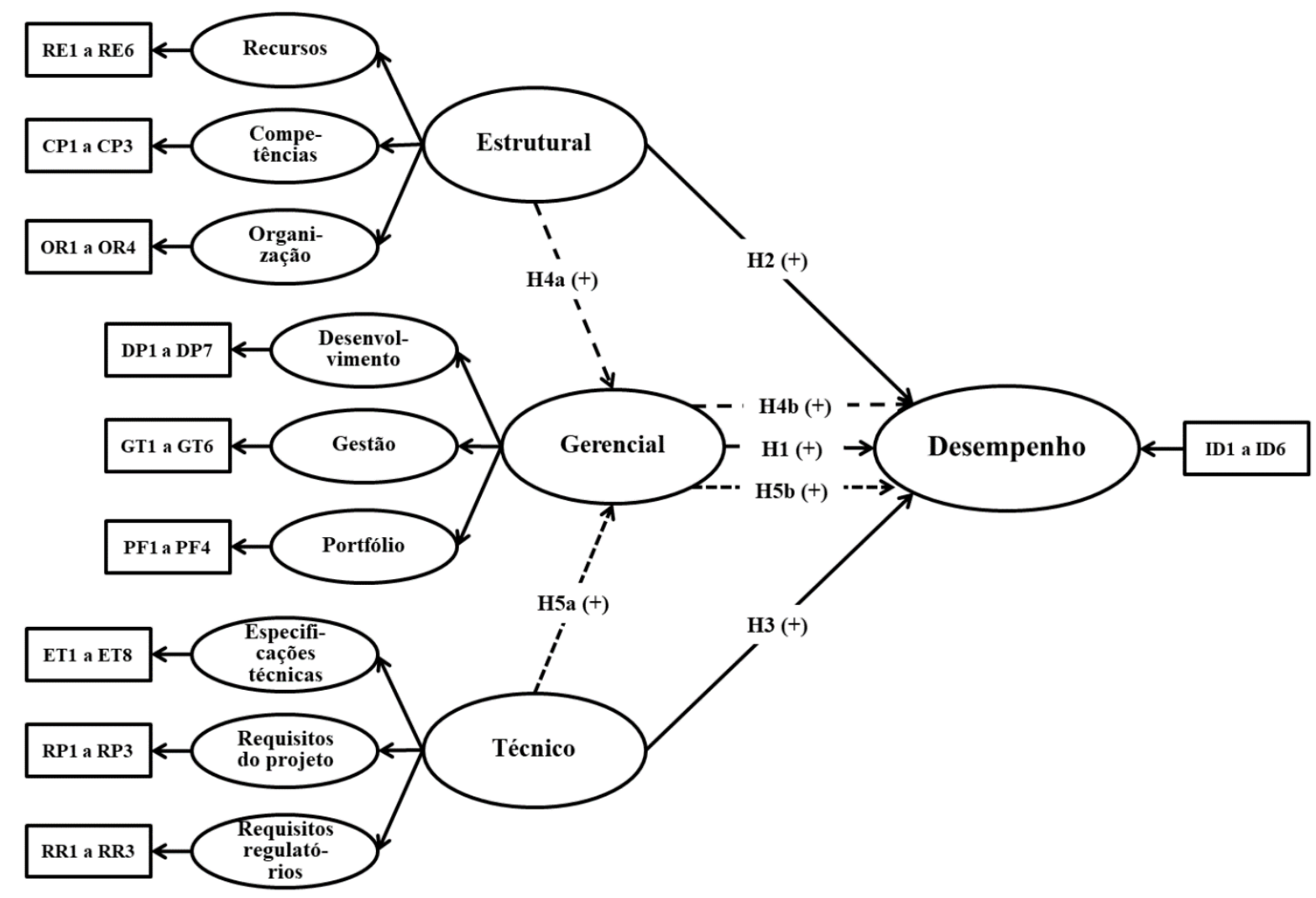

Fonte: dados da pesquisa. 
No caso do modelo de mensuração proposto, os nove constructos de primeira ordem que representam os fatores contribuintes são mensurados por escalas próprias compostas por indicadores reflexivos, pois considera-se que estes são causas externas ou antecedentes. As dimensões Gerencial, Estrutural e Técnico são constructos de segunda ordem manifestados pelos nove constructos de primeira ordem reflexivos. No caso do constructo Desempenho, da mesma forma, há uma relação de temporalidade, mas no sentido de que a estrutura precisa existir, os requisitos precisam ser conhecidos e os projetos necessitam ser executados para que o desempenho possa ser avaliado. As dimensões Gerencial, Estrutural e Técnico são formativas do constructo Desempenho. Isto posto, o modelo proposto (Figura 28) responde ao terceiro objetivo específico da pesquisa, ou seja, a proposição de um modelo teórico multidimensional para integrar o desempenho dos PDMG e seus fatores contribuintes.

Embora o estudo realizado por Mendigorri e colaboradoras (2016) tenha também sido utilizado como referencial para a definição dos indicadores formadores de primeira ordem, o aproveitamento da escala validada pelas pesquisadoras foi parcial, uma vez que o modelo proposto por elas teve como foco os projetos de desenvolvimento de medicamentos inovadores. Apesar da tentativa de incorporar todos os elementos identificados na literatura e na pesquisa empírica qualitativa, de acordo com Edwards e Bagozzi (2000, p. 161), os constructos representam uma perspectiva realista criativa, na medida em que são tentativas de descrever fenômenos reais que não podem ser conhecidos diretamente ou com precisão completa por causa do erro de medição e da lente epistemológica imperfeita que um constructo fornece. O modelo proposto foi o inicial e de mais alto nível. Só foi possível a proposição de um modelo mais avançado a partir dos resultados das análises dos dados empíricos que tanto mantiveram variáveis originais, como também levaram a exclusões, o que será detalhado nas análises dos dados coletados.

\subsubsection{Desenvolvimento das escalas}

Hinkin (1998) acreditava que a mensuração adequada de constructos abstratos seja talvez o maior desafio para a compreensão do comportamento das pessoas nas organizações ao considerar que desafios com a confiabilidade e validade das medidas utilizadas nos questionários de pesquisa continuam a levar a dificuldades na interpretação dos resultados das pesquisas de campo.

As escalas são desenvolvidas para avaliar várias atitudes, percepções ou opiniões de membros das organizações, a fim de examinar as relações hipotetizadas "a priori” com outras construções ou comportamentos. O sucesso na observação da covariância verdadeira entre as variáveis de interesse depende da capacidade de operacionalizar de forma precisa e confiável o constructo não observável (Hinkin, 1998).

Como os constructos e as escalas de mensuração deste esudo tem origem nas categorias e subcategorias de unidades de significado estabelecidos na primeira fase da pesquisa, foi realizado o ajuste de sua nomenclatura conforme a Tabela 26, que apresentou as equivalências entre as 
denominações e conceitos empregados na primeira e segunda fase da pesquisa. Os constructos estabelecidos para este estudo são descritos a seguir.

\subsubsection{Constructo Desempenho}

Estão incluídos neste constructo de primeira ordem os indicadores que representam o desempenho dos PDMG, os quais são mensurados por escalas próprias na forma de um modelo reflexivo direto. Os indicadores componentes dos constructos foram definidos a partir do referencial teórico e das unidades de significado apresentadas na Tabela 27 a seguir:

Tabela 27 - Indicadores do constructo Desempenho relacionados aos projetos de desenvolvimento de medicamentos genéricos

\section{Indicadores do constructo Desempenho}

1. Prazo para o desenvolvimento dos medicamentos genéricos

2. Custos totais para o desenvolvimento dos medicamentos genéricos

3. Aprovação do registro do medicamento genérico pela Anvisa

4. Custo de produção (preço-alvo de mercado)

5. Ajustes após o seu lançamento (qualidade)

6. Conclusão do desenvolvimento (independentemente dos demais requisitos)

Fonte: dados da pesquisa.

\subsubsection{Dimensão Gerencial}

Estão incluídos nesta dimensão os constructos de primeira ordem: Desenvolvimento, Gestão e Portfólio, os quais são mensurados por escalas próprias na forma de um modelo reflexivo indireto com mediação múltipla. Os indicadores componentes dos constructos foram definidos a partir do referencial teórico e das unidades de significado apresentadas na Tabela 28 a seguir.

Tabela 28 - Indicadores (fatores contribuintes) dos constructos da dimensão Gerencial

\begin{tabular}{ll}
\hline Constructo & \multicolumn{1}{c}{ Indicadores (fatores contribuintes) } \\
\hline & 1. Desenvolvimento farmacotécnico do medicamento \\
& 2. Transferência do medicamento para a produção ("scale up") \\
& 3. Documentação do desenvolvimento do medicamento \\
4. Dados e informaçães técnico-científicas sobre o medicamento \\
Desenvolvimento & 5. Lotes piloto, pré-validação e predefinição dos parâmetros do processo de \\
& produção do medicamento. \\
& 6. Metodologia científica para o desenvolvimento do medicamento (ex.: \\
& 7. Design of Experiments" e "Quality by Design") \\
8. Procedimentos para desenvolvimento dos medicamentos
\end{tabular}




\begin{tabular}{cl}
\hline Constructo & \multicolumn{1}{c}{ Indicadores (fatores contribuintes) } \\
\hline \multirow{3}{*}{ Portfólio } & 15. Seleção dos medicamentos a serem desenvolvidos \\
& 16. Estudos de viabilidade técnica para o desenvolvimento do medicamento \\
& 17. Acompanhamento dos projetos de desenvolvimento de medicamentos \\
& 18. Número e diversidade de projetos de medicamentos em desenvolvimento \\
\hline
\end{tabular}

Fonte: dados da pesquisa.

\subsubsection{Dimensão Estrutural}

Estão incluídos nesta dimensão os constructos de primeira ordem: Desenvolvimento, Gestão e Portfólio, os quais são mensurados por escalas próprias na forma de um modelo reflexivo indireto com mediação múltipla. Os indicadores componentes dos constructos foram definidos a partir do referencial teórico e das unidades de significado apresentadas na Tabela 29 a seguir.

Tabela 29 - Indicadores (fatores contribuintes) dos constructos da dimensão Estrutural

\section{Constructo}

Indicadores (fatores contribuintes)

19. Embalagem dos medicamentos

20. Fornecedor de matéria-prima

21. Seleção e qualificação dos fornecedores de matérias-primas

22. Aquisição de materiais e matérias-primas

Recursos 23. Infraestrutura (instalações, equipamentos e utilidades) para o desenvolvimento dos métodos analíticos

24. Infraestrutura para o desenvolvimento farmacotécnico dos medicamentos

25. Aquisição de equipamentos (laboratório e produção)

26. Profissionais e/ou serviços de terceiros para o desenvolvimento dos medicamentos

27. Tecnologia do medicamento (formulação, forma farmacêutica e/ou sistema de liberação do fármaco)

Competências 28. Tecnologia do processo de fabricação do medicamento

29. Profissionais experientes e/ou qualificados para o desenvolvimento do medicamento

30. Cultura da empresa para o desenvolvimento de medicamentos

31. Comunicação entre os participantes dos projetos e/ou entre as áreas da empresa

Organização 32. Estrutura da organização para o desenvolvimento dos medicamentos

33. Apoio de outras áreas e/ou dos superiores aos projetos de desenvolvimento dos medicamentos

Fonte: dados da pesquisa.

\subsubsection{Dimensão Técnico}

Estão incluídos nesta dimensão os constructos de primeira ordem: Especificações técnicas, Requisitos dos projetos e Requisitos regulatórios, os quais são mensurados por escalas próprias na forma de um modelo reflexivo indireto com mediação múltipla. Os indicadores componentes dos constructos foram definidos a partir do referencial teórico e das unidades de significado apresentadas na Tabela 30 a seguir: 
Tabela 30 - Indicadores (fatores contribuintes) dos constructos da dimensão Técnico

\begin{tabular}{cl}
\hline Constructo & \multicolumn{1}{c}{ Indicadores (fatores contribuintes) } \\
\hline & 34. Garantia da qualidade (validação e qualificação) do medicamento \\
& 35. Estudos de bioequivalência e/ou biodisponibilidade do medicamento \\
& 36. Perfil de dissolução do medicamento \\
37. Estudos clínicos do medicamento (eficácia) \\
técnicas & 38. Equivalência farmacêutica do medicamento \\
& 39. Desenvolvimento do método de análise do medicamento \\
& 40. Estudos de estabilidade e de produtos de degradação \\
& 41. Controle de qualidade do medicamento \\
& 42. Informações do fornecedor do fármaco e/ou do DMF ("Drug Master File”) \\
43. Custos para desenvolvimento dos medicamentos \\
44. Tempo necessário para o desenvolvimento dos medicamentos \\
projeto & 45. Riscos no processo de desenvolvimento do medicamento e para sua \\
& autorização para comercialização \\
46. Legislação para registro do medicamento & 47. Dossiê para registro do medicamento \\
regulatórios & 48. Processo de análise e registro do medicamento
\end{tabular}

Fonte: dados da pesquisa.

Há que se fazer aqui um esclarecimento sobre a variável prazo, pois ela aparece em indicadores de três constructos diferentes. Como parte do Constructo Desempenho, ela mensura o desempenho do PDMG com relação aos prazos planejados. Como parte do Constructo Gestão ela mensura a contribuição da decisão de prazo sobre o desempenho dos PDMG. Já como parte do Constructo Requisitos do Projeto, ela mensura a contribuição do prazo necessário para o desenvolvimento sobre o desempenho dos PDMG.

\subsubsection{Variáveis moderadoras}

De acordo com Hair Jr e colaboradores (2017), o efeito moderador ou de interação ocorre quando uma variável independente (variável moderadora) muda a forma da relação entre uma outra variável independente e a dependente. Para Frazier, Tix e Barron (2004), as perguntas envolvendo moderadores abordam "quando" ou "para quem" uma variável mais fortemente prediz ou causa uma variável de resultado. Mais especificamente, um moderador é uma variável que altera a direção ou a força da relação entre um preditor e um resultado, não sendo mais do que uma interação em que o efeito de uma variável depende do nível de outra. A representação gráfica da variável moderadora é dada pela Figura 29 a seguir. 
Figura 29 - Diagrama para o efeito moderador

Variável preditora $(X)$

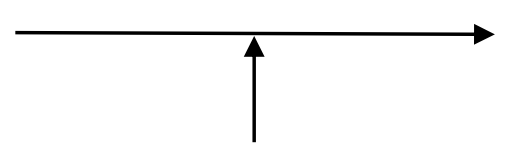

Variável moderadora $(Z)$

Variável resultante $(Y)$

Fonte: Frazier, Tix e Barron (2004, p. 116).

Embora não específicos para a indústria farmacêutica, estudos como o de Nicholas, Ledwith e Perks (2011) demonstram que há diferenças entre as práticas específicas entre os desenvolvedores de novos produtos de pequenas e médias empresas e grandes empresas. Uma possível razão é indicada por Lee, Jeong e Yoon (2017) que afirmam que as pequenas e médias empresas (PME) exigem eficiência de projetos de $\mathrm{P} \& \mathrm{D}$ devido às limitações de orçamento e recursos. Tsai e Wang (2005) estudaram a relação entre o desempenho de P\&D e o tamanho da empresa em termos de elasticidade de seus resultados. O tamanho da empresa foi tratado como um moderador ao invés de uma variável independente e os resultados da pesquisa empírica demonstram que há uma relação aproximada de "tipo U" entre a produtividade de P\&D e o tamanho da empresa. Os pesquisadores verificaram que a produtividade da $\mathrm{P} \& \mathrm{D}$ é maior em empresas pequenas e grandes do que em empresas de tamanho médio, confirmando parcialmente a hipótese schumpeteriana de que o desempenho de P\&D é uma função crescente do tamanho da empresa.

Foi avaliada a possibilidade de inclusão no estudo de uma variável moderadora ou mesmo uma variável de controle para o tamanho dos laboratórios que realizam os projetos de desenvolvimento dos medicamentos. No entanto, em razão dos requisitos obrigatórios para a produção de medicamentos e que dificultam que pequenas empresas possam atuar neste mercado e por não haver referencial na literatura que indique que, no caso dos medicamentos genéricos, há diferenças no desempenho de DP em razão do porte das empresas, a decisão foi por não incluí-la neste estudo.

Outra possibilidade de diferenças no desempenho poderia ser a influência da origem do laboratório, se brasileira ou estrangeira, em razão principalmente do fato das estrageiras ou multinacionais em geral serem os detentores das patentes dos medicamentos de referência e também por possivelmente terem maior acesso a recursos, insumos e tecnologias se comparadas às empresas nacionais. No entanto, neste caso, uma variável moderadora ou de controle para a origem da empresa não foi incluída no modelo em razão da necessidade de equilíbrio entre o número de respostas de cada grupo, o que seria difícil de conseguir sabendo-se que a grande maioria dos laboratórios farmacêuticos produtores de medicamentos genéricos e que atuam no mercado brasileiro é de origem nacional.

\subsubsection{Desenvolvimento do questionário para coleta de dados}

O instrumento escolhido para a coleta dos dados referentes aos indicadores dos constructos propostos, ou seja, os indicadores de desempenho e os indicadores de seus fatores contribuintes, foi um questionário. Basicamente, para cada indicador selecionado foi definida uma questão para que seu 
dado específico pudesse ser coletado. O artifício utilizado foi reescrever cada um dos indicadores na forma de assertivas que caracterizassem claramente os seus sentidos e contextos para a coleta correta dos dados.

Assim, para a coleta dos dados referentes ao constructo de desempenho, para que os indicadores pudessem ser representados como questões em um questionário, para cada um dos indicadores de desempenho selecionados foi formulada uma assertiva que caracterizasse claramente o indicador de forma a compor um item para a seguinte questão: considerando sua experiência, para cada um dos indicadores de desempenho dos projetos de desenvolvimento de medicamentos genéricos relacionadas abaixo, indique qual o grau de dificuldade para o seu atingimento.

O grau de dificuldade para atingimento do indicador foi definido como o sentimento em relação à complexidade, à insuficiência de recursos, às barreiras enfrentadas, às metas difíceis de serem atingidas ou ainda à alta frequência de ocorrência. Os indicadores do constructo Desempenho e suas descrições na forma de assertivas adequadas para a mensuração estão relacionados na Tabela 31 a seguir.

Tabela 31 - Indicadores componentes do constructo "Desempenho" para o desenvolvimento de medicamentos genéricos e assertivas para sua mensuração

\begin{tabular}{|c|c|}
\hline Indicador & Forma para mensuração (assertiva) \\
\hline $\begin{array}{l}\text { 1. Prazo para o desenvolvimento } \\
\text { dos medicamentos genéricos. } \\
\text { 2. Custos totais para o } \\
\text { desenvolvimento dos } \\
\text { medicamentos genéricos. }\end{array}$ & $\begin{array}{l}\text { Concluir o desenvolvimento do medicamento genérico até a data } \\
\text { planejada inicialmente. } \\
\text { Concluir o desenvolvimento do medicamento genérico com custos } \\
\text { totais dentro do orçamento. }\end{array}$ \\
\hline $\begin{array}{l}\text { 3. Aprovação do registro do } \\
\text { medicamento genérico pela }\end{array}$ & $\begin{array}{l}\text { Ter o registro do medicamento genérico aprovado pela Anvisa sem } \\
\text { exigências complementares ou somente com exigências não }\end{array}$ \\
\hline Anvisa. & significativas. \\
\hline $\begin{array}{l}\text { 4. Custo de produção (preço- } \\
\text { alvo de mercado). }\end{array}$ & $\begin{array}{l}\text { Concluir o desenvolvimento do medicamento genérico com custos } \\
\text { de produção / preço-alvo de mercado dentro do planejado. }\end{array}$ \\
\hline $\begin{array}{l}\text { 5. Ajustes após o seu } \\
\text { lançamento (qualidade). }\end{array}$ & $\begin{array}{l}\text { Concluir o desenvolvimento do medicamento genérico sem a } \\
\text { necessidade de ajustes após o seu lançamento. }\end{array}$ \\
\hline $\begin{array}{l}6 . \text { Concluir o desenvolvimento } \\
\text { (independentemente dos demais } \\
\text { requisitos) }\end{array}$ & $\begin{array}{l}\text { Concluir o desenvolvimento do medicamento (independentemente } \\
\text { dos demais requisitos) }\end{array}$ \\
\hline
\end{tabular}

Nota: o indicador destacado (células com fundo cinza) foi excluído do modelo após a análise da validade de conteúdo. Fonte: dados da pesquisa.

Da mesma forma que para os indicadores de desempenho, os indicadores relacionados aos seus fatores contribuintes foram reescritos na forma de assertivas para caracterizar as situações em que poderiam influenciar o desempenho fora do planejado dos PDMG. A reestruturação dos indicadores na forma de assertivas procurou manter as ideias centrais dos indicadores em seus constructos e em formato que pudesse compor a seguinte questão: tendo por referência a sua experiência em atividades relacionadas ao desenvolvimento de medicamentos genéricos, para cada uma das situações abaixo, 
indique qual o grau de contribuição para resultados insatisfatórios nos projetos de desenvolvimento de medicamentos genéricos.

A Tabela 32 a seguir apresenta os indicadores selecionados, os constructos aos quais pertencem e as assertivas formuladas para a sua mensuração.

Tabela 32 - Indicadores, constructos para mensuração dos fatores contribuintes para o desempenho nos projetos de desenvolvimento de genéricos e as assertivas formuladas para sua mensuração

\begin{tabular}{|c|c|c|}
\hline Indicador (fator contribuinte) & Constructo & Forma para mensuração (assertivas) \\
\hline $\begin{array}{l}\text { 1. Garantia da qualidade (validação } \\
\text { e qualificação) do medicamento }\end{array}$ & $\begin{array}{l}\text { Especificações } \\
\text { técnicas }\end{array}$ & $\begin{array}{l}\text { Deficiências nas práticas de garantia da } \\
\text { qualidade (ex.: dificuldade na validação de } \\
\text { processos, validação de métodos analíticos e/ou } \\
\text { qualificação de equipamentos) }\end{array}$ \\
\hline $\begin{array}{l}\text { 2. Estudos de bioequivalência e/ou } \\
\text { biodisponibilidade do medicamento }\end{array}$ & $\begin{array}{l}\text { Especificações } \\
\text { técnicas }\end{array}$ & $\begin{array}{c}\text { Dificuldades na realização dos estudos de } \\
\text { bioequivalência e/ou biodisponibilidade dos } \\
\text { medicamentos }\end{array}$ \\
\hline $\begin{array}{l}\text { 3. Perfil de dissolução do } \\
\text { medicamento }\end{array}$ & $\begin{array}{l}\text { Especificações } \\
\text { técnicas }\end{array}$ & $\begin{array}{c}\text { Dificuldades na realização dos estudos de } \\
\text { dissolução dos medicamentos }\end{array}$ \\
\hline $\begin{array}{l}\text { 4. Estudos clínicos do } \\
\text { medicamento (eficácia) }\end{array}$ & $\begin{array}{l}\text { Especificações } \\
\text { técnicas }\end{array}$ & $\begin{array}{l}\text { Dificuldades na realização dos estudos clínicos } \\
\text { dos medicamentos (eficácia) }\end{array}$ \\
\hline $\begin{array}{l}\text { 5. Equivalência farmacêutica do } \\
\text { medicamento }\end{array}$ & $\begin{array}{l}\text { Especificações } \\
\text { técnicas }\end{array}$ & $\begin{array}{l}\text { Dificuldades na realização dos estudos de } \\
\text { equivalência farmacêutica dos medicamentos }\end{array}$ \\
\hline $\begin{array}{l}\text { 6. Desenvolvimento do método de } \\
\text { análise do medicamento }\end{array}$ & $\begin{array}{l}\text { Especificações } \\
\text { técnicas }\end{array}$ & $\begin{array}{l}\text { Dificuldades no desenvolvimento dos métodos } \\
\text { analíticos dos medicamentos }\end{array}$ \\
\hline $\begin{array}{l}\text { 7. Estudos de estabilidade e de } \\
\text { produtos de degradação }\end{array}$ & $\begin{array}{l}\text { Especificações } \\
\text { técnicas }\end{array}$ & $\begin{array}{c}\text { Dificuldades na realização dos estudos de } \\
\text { estabilidade, de fotoestabilidade, de produtos de } \\
\text { degradação e/ou na obtenção da estabilidade do } \\
\text { medicamento. }\end{array}$ \\
\hline $\begin{array}{l}\text { 8. Controle de qualidade do } \\
\text { medicamento }\end{array}$ & $\begin{array}{l}\text { Especificações } \\
\text { técnicas }\end{array}$ & $\begin{array}{l}\text { Dificuldade no estabelecimento das } \\
\text { especificações e/ou realização dos testes para o } \\
\text { controle de qualidade dos medicamentos. }\end{array}$ \\
\hline $\begin{array}{l}\text { 9. Informações do fornecedor do } \\
\text { fármaco e/ou do DMF ("Drug } \\
\text { Master File") }\end{array}$ & $\begin{array}{l}\text { Especificações } \\
\text { técnicas }\end{array}$ & $\begin{array}{c}\text { Dificuldade na obtenção de informações sobre } \\
\text { os ingredientes farmacêuticos ativos utilizados } \\
\text { nos medicamentos e/ou deficiências no DMF } \\
\text { disponibilizado pelo fabricante }\end{array}$ \\
\hline $\begin{array}{l}\text { 10. Custos para desenvolvimento } \\
\text { dos medicamentos }\end{array}$ & $\begin{array}{l}\text { Requisitos do } \\
\text { projeto }\end{array}$ & $\begin{array}{c}\text { Custos elevados para desenvolvimento dos } \\
\text { medicamentos }\end{array}$ \\
\hline $\begin{array}{l}\text { 11. Tempo necessário para o } \\
\text { desenvolvimento dos medicamentos }\end{array}$ & $\begin{array}{l}\text { Requisitos do } \\
\text { projeto }\end{array}$ & $\begin{array}{c}\text { Longo tempo necessário para o } \\
\text { desenvolvimento dos medicamentos }\end{array}$ \\
\hline $\begin{array}{l}\text { 12. Riscos no processo de } \\
\text { desenvolvimento do medicamento e } \\
\text { para sua autorização para } \\
\text { comercialização }\end{array}$ & $\begin{array}{l}\text { Requisitos do } \\
\text { projeto }\end{array}$ & $\begin{array}{l}\text { Risco de insucesso no desenvolvimento do } \\
\text { medicamento e de indeferimento do registro }\end{array}$ \\
\hline $\begin{array}{l}\text { 13. Legislação para registro do } \\
\text { medicamento }\end{array}$ & $\begin{array}{l}\text { Requisitos } \\
\text { regulatórios }\end{array}$ & $\begin{array}{l}\text { Dificuldades no atendimento da legislação } \\
\text { sanitária para o desenvolvimento e/ou registro } \\
\text { de medicamentos genéricos }\end{array}$ \\
\hline $\begin{array}{l}\text { 14. Dossiê para registro do } \\
\text { medicamento }\end{array}$ & $\begin{array}{l}\text { Requisitos } \\
\text { regulatórios }\end{array}$ & $\begin{array}{l}\text { Deficiências e/ou dificuldades na elaboração } \\
\text { dossiê para registro dos medicamentos }\end{array}$ \\
\hline $\begin{array}{l}\text { 15. Processo de análise e registro do } \\
\text { medicamento }\end{array}$ & $\begin{array}{l}\text { Requisitos } \\
\text { regulatórios }\end{array}$ & $\begin{array}{l}\text { Deficiências e/ou dificuldades no atendimento } \\
\text { às exigências da Anvisa durante o processo de } \\
\text { análise dos pedidos de registro dos } \\
\text { medicamentos }\end{array}$ \\
\hline $\begin{array}{l}\text { 16. Desenvolvimento } \\
\text { farmacotécnico do medicamento }\end{array}$ & $\begin{array}{l}\text { Desenvolvi- } \\
\text { mento }\end{array}$ & $\begin{array}{c}\text { Dificuldade no desenvolvimento da formulação } \\
\text { (farmacotécnico) do medicamento }\end{array}$ \\
\hline $\begin{array}{l}\text { 17. Transferência do medicamento } \\
\text { para a produção ("scale up") }\end{array}$ & $\begin{array}{l}\text { Desenvolvi- } \\
\text { mento }\end{array}$ & $\begin{array}{l}\text { Dificuldade no processo de transferência dos } \\
\text { medicamentos do laboratório para a produção } \\
\text { (escalonamento ou "scale up") }\end{array}$ \\
\hline
\end{tabular}




\begin{tabular}{|c|c|c|}
\hline Indicador (fator contribuinte) & Constructo & Forma para mensuração (assertivas) \\
\hline $\begin{array}{l}\text { 18. Documentação do } \\
\text { desenvolvimento do medicamento }\end{array}$ & $\begin{array}{l}\text { Desenvolvi- } \\
\text { mento }\end{array}$ & $\begin{array}{l}\text { Deficiências e/ou dificuldades no } \\
\text { preenchimento da documentação do } \\
\text { desenvolvimento dos medicamentos }\end{array}$ \\
\hline $\begin{array}{l}\text { 19. Dados e informações técnico- } \\
\text { científicas sobre o medicamento }\end{array}$ & $\begin{array}{l}\text { Desenvolvi- } \\
\text { mento }\end{array}$ & $\begin{array}{l}\text { Deficiências e/ou dificuldades na obtenção e/ou } \\
\text { apresentação de dados e informações técnico- } \\
\text { científicas dos medicamentos }\end{array}$ \\
\hline $\begin{array}{l}\text { 20. Lotes piloto, pré-validação e } \\
\text { predefinição dos parâmetros do } \\
\text { processo de produção do } \\
\text { medicamento }\end{array}$ & $\begin{array}{l}\text { Desenvolvi- } \\
\text { mento }\end{array}$ & $\begin{array}{c}\text { Deficiências e/ou dificuldades para a realização } \\
\text { de lotes piloto, pré-validação e predefinição dos } \\
\text { parâmetros do processo de produção do novo } \\
\text { medicamento }\end{array}$ \\
\hline $\begin{array}{l}\text { 21. Metodologia científica para o } \\
\text { desenvolvimento do medicamento } \\
\text { (ex.: "Design of Experiments" e } \\
\text { "Quality by Design") }\end{array}$ & $\begin{array}{l}\text { Desenvolvi- } \\
\text { mento }\end{array}$ & $\begin{array}{c}\text { O laboratório não usar ou usar inadequadamente } \\
\text { metodologias científicas para o } \\
\text { desenvolvimento dos medicamentos (ex.: } \\
\text { Qualidade por Meio do Delineamento ou } \\
\text { "Quality by Design"). }\end{array}$ \\
\hline $\begin{array}{l}\text { 22. Estudos de pré-formulação do } \\
\text { novo medicamento }\end{array}$ & $\begin{array}{l}\text { Desenvolvi- } \\
\text { mento }\end{array}$ & $\begin{array}{l}\text { Dificuldades ou ausência de estudos de pré- } \\
\text { formulação do medicamento }\end{array}$ \\
\hline $\begin{array}{l}\text { 23. Procedimentos para } \\
\text { desenvolvimento dos medicamentos }\end{array}$ & $\begin{array}{l}\text { Desenvolvi- } \\
\text { mento }\end{array}$ & $\begin{array}{l}\text { Inexistência ou deficiências nos processos para } \\
\text { desenvolvimento dos medicamentos }\end{array}$ \\
\hline $\begin{array}{l}\text { 24. Definição do escopo do } \\
\text { medicamento a ser desenvolvido }\end{array}$ & Gestão & $\begin{array}{c}\text { Definições iniciais insuficientes ou incorretas } \\
\text { dos medicamentos a serem desenvolvidos } \\
\text { (necessidades, características e/ou } \\
\text { especificações dos medicamentos) }\end{array}$ \\
\hline $\begin{array}{l}\text { 25. Mudanças no projeto durante o } \\
\text { desenvolvimento do medicamento }\end{array}$ & Gestão & $\begin{array}{c}\text { Mudanças no projeto após o início do } \\
\text { desenvolvimento do medicamento }\end{array}$ \\
\hline $\begin{array}{l}\text { 26. Gerenciamento de riscos do } \\
\text { desenvolvimento dos medicamentos }\end{array}$ & Gestão & $\begin{array}{c}\text { Deficiências e/ou dificuldades no gerenciamento } \\
\text { de riscos no desenvolvimento dos } \\
\text { medicamentos }\end{array}$ \\
\hline $\begin{array}{l}\text { 27. Planejamento e gerenciamento } \\
\text { dos projetos de desenvolvimento } \\
\text { dos medicamentos }\end{array}$ & Gestão & $\begin{array}{c}\text { Deficiências e/ou dificuldades no gerenciamento } \\
\text { dos projetos de desenvolvimento dos } \\
\text { medicamentos }\end{array}$ \\
\hline $\begin{array}{l}\text { 28. Prazo para o desenvolvimento } \\
\text { do medicamento }\end{array}$ & Gestão & $\begin{array}{l}\text { Prazos muito curtos para o desenvolvimento dos } \\
\text { medicamentos }\end{array}$ \\
\hline $\begin{array}{l}\text { 29. Custo final de produção ou } \\
\text { preço-alvo para o medicamento }\end{array}$ & Gestão & $\begin{array}{l}\text { Objetivo de custo final para produção e/ou } \\
\text { preço-alvo de mercado muito baixo para o } \\
\text { medicamento em desenvolvimento em razão do } \\
\text { custo dos materiais e/ou processo de fabricação. }\end{array}$ \\
\hline $\begin{array}{l}\text { 30. Seleção dos medicamentos a } \\
\text { serem desenvolvidos }\end{array}$ & Portfólio & $\begin{array}{l}\text { Escolha inadequada e/ou equivocada dos } \\
\text { medicamentos para compor o portfolio de } \\
\text { projetos a serem desenvolvimentos }\end{array}$ \\
\hline $\begin{array}{l}\text { 31. Estudos de viabilidade técnica } \\
\text { para o desenvolvimento do } \\
\text { medicamento }\end{array}$ & Portfólio & $\begin{array}{c}\text { Inexistência ou deficiências nos estudos de } \\
\text { viabilidade técnica para escolha dos } \\
\text { medicamentos a serem desenvolvidos }\end{array}$ \\
\hline $\begin{array}{l}\text { 32. Acompanhamento dos projetos } \\
\text { de desenvolvimento de } \\
\text { medicamentos }\end{array}$ & Portfólio & $\begin{array}{c}\text { Inexistência ou deficiências na estrutura e/ou } \\
\text { procedimento de acompanhamento e/ou controle } \\
\text { dos projetos de desenvolvimento de } \\
\text { medicamentos em andamento }\end{array}$ \\
\hline $\begin{array}{l}\text { 33. Número e diversidade de } \\
\text { projetos de medicamentos em } \\
\text { desenvolvimento }\end{array}$ & Portfólio & $\begin{array}{c}\text { Número de projetos acima da capacidade e/ou } \\
\text { elevada diversidade de projetos de } \\
\text { desenvolvimento de medicamentos em } \\
\text { andamento }\end{array}$ \\
\hline 34. Embalagem dos medicamentos & Recursos & $\begin{array}{c}\text { Dificuldade no desenvolvimento da embalagem } \\
\text { para o medicamento (material, tecnologia e/ou } \\
\text { fornecedor) }\end{array}$ \\
\hline 35. Fornecedor de matéria-prima & Recursos & $\begin{array}{c}\text { Mudança de fornecedor de ingrediente } \\
\text { farmacêutico ativo durante o desenvolvimento } \\
\text { do medicamento }\end{array}$ \\
\hline
\end{tabular}




\begin{tabular}{|c|c|c|}
\hline Indicador (fator contribuinte) & Constructo & Forma para mensuração (assertivas) \\
\hline $\begin{array}{l}\text { 36. Seleção e qualificação dos } \\
\text { fornecedores de matérias-primas }\end{array}$ & Recursos & $\begin{array}{c}\text { Dificuldades na seleção e qualificação dos } \\
\text { fornecedores de ingredientes farmacêuticos } \\
\text { ativos }\end{array}$ \\
\hline $\begin{array}{l}\text { 37. Aquisição de materiais e } \\
\text { matérias-primas }\end{array}$ & Recursos & $\begin{array}{c}\text { Dificuldades para aquisição de ingrediente } \\
\text { farmacêutico ativo }\end{array}$ \\
\hline $\begin{array}{l}\text { 38. Infraestrutura (instalações, } \\
\text { equipamentos e utilidades) para o } \\
\text { desenvolvimento dos métodos } \\
\text { analíticos }\end{array}$ & Recursos & $\begin{array}{c}\text { Infraestrutura (instalações, equipamentos e } \\
\text { utilidades) inadequada para o desenvolvimento } \\
\text { dos métodos analíticos }\end{array}$ \\
\hline $\begin{array}{l}\text { 39. Infraestrutura para o } \\
\text { desenvolvimento farmacotécnico } \\
\text { dos medicamentos }\end{array}$ & Recursos & $\begin{array}{c}\text { Infraestrutura (instalações, equipamentos e } \\
\text { utilidades) inadequada para o desenvolvimento } \\
\text { da formulação (farmacotécnico) dos } \\
\text { medicamentos }\end{array}$ \\
\hline $\begin{array}{l}\text { 40. Aquisição de equipamentos } \\
\text { (laboratório e produção) }\end{array}$ & Recursos & Dificuldades para aquisição de equipamentos \\
\hline $\begin{array}{l}\text { 41. Profissionais e/ou serviços de } \\
\text { terceiros para o desenvolvimento } \\
\text { dos medicamentos }\end{array}$ & Recursos & $\begin{array}{l}\text { Dificuldades para contratação de profissionais } \\
\text { e/ou serviços de terceiros para as atividades de } \\
\text { desenvolvimento dos medicamentos }\end{array}$ \\
\hline $\begin{array}{l}\text { 42. Tecnologia do medicamento } \\
\text { (formulação, forma farmacêutica } \\
\text { e/ou sistema de liberação do } \\
\text { fármaco) }\end{array}$ & Competências & $\begin{array}{l}\text { O laboratório não ter domínio suficiente da } \\
\text { tecnologia dos medicamentos (forma de } \\
\text { liberação, tipo de insumo, etc.) }\end{array}$ \\
\hline $\begin{array}{l}\text { 43. Tecnologia do processo de } \\
\text { fabricação do medicamento }\end{array}$ & Competências & $\begin{array}{c}\text { O laboratório não ter domínio suficiente da } \\
\text { tecnologia do processo de fabricação dos } \\
\text { medicamentos }\end{array}$ \\
\hline $\begin{array}{l}\text { 44. Profissionais experientes e/ou } \\
\text { qualificados para o } \\
\text { desenvolvimento do medicamento }\end{array}$ & Competências & $\begin{array}{c}\text { O laboratório não ter profissionais experientes } \\
\text { e/ou com qualificação adequada em número } \\
\text { suficiente para o desenvolvimento dos } \\
\text { medicamentos }\end{array}$ \\
\hline $\begin{array}{l}\text { 45. Cultura da empresa para o } \\
\text { desenvolvimento de medicamentos }\end{array}$ & Organização & $\begin{array}{c}\text { Cultura da empresa ou organização que não } \\
\text { favorece e/ou dificulta o desenvolvimento } \\
\text { adequado dos medicamentos }\end{array}$ \\
\hline $\begin{array}{l}\text { 46. Comunicação entre os } \\
\text { participantes dos projetos e/ou entre } \\
\text { as áreas da empresa }\end{array}$ & Organização & $\begin{array}{l}\text { Deficiências e/ou dificuldades na comunicação } \\
\text { entre os profissionais e/ou entre as áreas da } \\
\text { empresa que participam do desenvolvimento } \\
\text { dos medicamentos }\end{array}$ \\
\hline $\begin{array}{l}\text { 47. Estrutura da organização para o } \\
\text { desenvolvimento dos medicamentos }\end{array}$ & Organização & $\begin{array}{c}\text { Estrutura (organizacional) da empresa que não } \\
\text { favorece e/ou dificulta os projetos de } \\
\text { desenvolvimento dos medicamentos }\end{array}$ \\
\hline $\begin{array}{l}\text { 48. Apoio de outras áreas e/ou dos } \\
\text { superiores aos projetos de } \\
\text { desenvolvimento dos medicamentos }\end{array}$ & Organização & $\begin{array}{l}\text { Ausência ou insuficiência de apoio de outras } \\
\text { áreas e/ou dos superiores aos projetos de } \\
\text { desenvolvimento dos medicamentos }\end{array}$ \\
\hline
\end{tabular}

Nota: os indicadores destacados (células com fundo cinza) foram excluídos do modelo após a análise da validade de conteúdo. Fonte: dados da pesquisa.

O grau de contribuição para resultados insatisfatórios foi definido como: presença da situação analisada nos resultados insatisfatórios de projetos de desenvolvimento de medicamentos genéricos. Quanto maiores forem a frequência e a intensidade da situação avaliada no desenvolvimento dos medicamentos genéricos, maior será o seu grau de contribuição para os resultados insatisfatórios.

Assim, para a mensuração dos constructos ligados aos fatores contribuintes para o desempenho dos PDMG, os indicadores reescritos foram avaliados em situações ou condições nos projetos que 
levam a resultados aquém dos esperados ou dos necessários para a aprovação do registro do medicamento pelo órgão regulador e para atendimento dos objetivos e metas do projeto.

Sobre a mensuração dos fatores contribuintes para o desempenho do PDMG, foi considerada inicialmente a possibilidade de ela ser realizada por meio da mensuração da frequência e do grau de impacto sobre o desempenho dos projetos separadamente. No entanto, dado o número de variáveis independentes que deveriam ser avaliadas, esta opção poderia dificultar a resposta completa do questionário pela sua extensão. Além disso, decisão foi pela mensuração no sentido dos resultados insatisfatórios (insucesso), pois, como já justificado, desta forma é possível a verificação do grau de contribuição mesmo dos indicadores considerados obrigatórios.

Além do tratamento dos indicadores, constructos e das escalas desenvolvidas para as suas mensurações, também houve cuidado para a estruturação das questões e do questionário considerando possíveis riscos de vieses. Podsakoff, MacKenzie e Podsakoff (2012) consideram que os efeitos dos fatores do método na validade e confiabilidade de itens são formas de vieses importantes e que devem ser controladas sempre que possível. Em específico, os pesquisadores alertam para os efeitos tendenciosos das estimativas sobre as relações entre dois ou mais constructos quando são mensuradas usando o mesmo método (viés do método comum). Isso em razão de haver risco de que pelo menos parte da covariância observada entre eles possa ser devida ao fato de que elas compartilham o mesmo método de medição. Os tipos de vieses de método na covariação entre construtos são: efeitos de fontes diferentes, efeitos da mesma fonte "versus" fontes diferentes, efeitos dos estilos de resposta, efeitos da proximidade e dos itens revertidos, efeitos da redação do item e efeitos do contexto do item.

Exemplos de medidas que foram tomadas e que serão detalhadas nas próximas páginas foram a validação do conteúdo e de face para reduzir possíveis efeitos de redação e de contexto; randomização dos itens nas questões referentes ao desempenho e aos fatores contribuintes para atenuar possíveis efeitos de proximidade e dos itens revertidos; amostra composta por profissionais de diferentes empresas, níveis hierárquicos, experiências, funções, áreas de atuação e papéis nos PDMG para reduzir o viés dos efeitos da mesma fonte "versus" fontes diferentes. O tratamento dos dados brutos coletados também procurou reduzir os efeitos dos estilos de resposta, como o da polarização.

\subsubsection{Validade do conteúdo}

O planejamento do método de coleta de dados deve incluir procedimentos que garantam a confiabilidade dos indicadores e a adequação ao desenho da pesquisa e ao instrumento de mensuração. São atributos de qualidade dos instrumentos de coleta de dados: validade, confiabilidade, praticabilidade, sensibilidade e responsividade (Alexandre \& Coluci, 2011). São basicamente três as formas de verificação da validade do instrumento de mensuração (Alexandre \& Coluci, 2011; 
Churchill \& Iacobucci, 2005; Donald S. Tull \& Del I. Hawkins, 1984; Flick, 2013): validade do conteúdo; validade relacionada a um critério ou preditivo; e validade do constructo.

Após a geração dos itens de pesquisa, Hinkin (1998) sugere que eles sejam submetidos a uma avaliação da validade do conteúdo como pré-teste, permitindo a supressão de itens conceitualmente inconsistentes. Um instrumento de coleta de dados é considerado válido quando mensura exatamente o que se propõem a mensurar, ou seja, tem capacidade de mensurar com precisão o fenômeno estudado e, consequentemente, de avaliar seu objetivo (Alexandre \& Coluci, 2011). Tull e Hawkins (1984) afirmam que a validade, da mesma forma que a confiabilidade, se preocupa com o erro consistente e sistemático, ou seja, a mensuração deve refletir somente a característica de interesse e o erro aleatório.

A mensuração não terá validade de conteúdo se os itens parecerem diferentes do domínio possível (Churchill \& Iacobucci, 2005). Isto porque não seria possível garantir que foi criada uma mensuração que possui validade de conteúdo, já que é em parte uma questão de julgamento. Desta forma, um dos elementos mais críticos no desenvolvimento de um instrumento com conteúdo válido seria a definição conceitual do domínio das características, ou seja, o que é e o que não é uma variável.

Flick (2013) considera que validade de um instrumento de pesquisa é centrada em responder se o método mensura o que se espera que ele mensure. A avaliação do conteúdo é componente importante do desenvolvimento de novas medidas por ser o primeiro passo do processo de associação entre conceitos abstratos e indicadores observáveis e mensuráveis (Alexandre \& Coluci, 2011). O conteúdo de um método ou instrumento de mensuração é validado quando ele capta a questão em estudo em seus aspectos essenciais e de maneira exaustiva (Flick, 2013). Churchill e Iacobucci (2005) definem validade do conteúdo como uma abordagem para validar uma medida ao determinar qual construto, conceito ou característica o instrumento está de fato medindo.

A validade de conteúdo também busca avaliar em que proporção os itens selecionados para medir uma construção teórica são representativos ou representam bem todas as facetas importantes do conceito a ser medido, ou seja, se o instrumento de medida contempla todas as questões que poderiam ser elaboradas sobre o objeto de pesquisa. De forma mais ampla, a validade de conteúdo avalia todos os aspectos do processo de medida que podem afetar a coleta de dados além das questões, incluindo as instruções de preenchimento e o formato das perguntas e respostas (Alexandre \& Coluci, 2011).

Em princípio, o próprio pesquisador poderia verificar a validade de conteúdo com base em seu julgamento ao refletir sobre se o alcance o instrumento ou método cobririam os aspectos importantes e de maneira apropriada a questão de pesquisa. No entanto, Flick (2013) recomenda que o instrumento de mensuração seja avaliado por especialistas ou mesmo por leigos com o intuito de identificar erros. Flick (2013) e Tull e Hawkins (1984) comentam que, apesar das estimativas de validade do conteúdo serem essencialmente avaliações sistemáticas que buscam verificar a adequação do instrumento de medição à tarefa em questão, são também subjetivas. 
O processo de validação envolve o desenvolvimento de um questionário específico para esta avaliação, além de uma carta-convite informando o objetivo da pesquisa, justificativas, responsabilidades, garantias, esclarecimentos e instruções para preenchimento do questionário. De certa forma, poder-se-ia considerar que a validade do conteúdo dos constructos identificados foi assegurada com a pesquisa qualitativa inicial, uma vez que os itens de pesquisa tem origem tanto teórica quanto empírica. No entanto, o questionário foi submetido à avaliação de profissionais que atuam em projetos de desenvolvimento de medicamentos para validação do seu conteúdo.

No estudo realizado por Alexandre e Coluci (2011), um dos pontos discutidos foi o número e a qualificação dos especialistas que participariam da avaliação do instrumento de mensuração. Quanto ao número, os pesquisadores encontraram indicações variando de no mínimo 5 e o máximo de 20 pessoas, sendo que, ao considerar subgrupos de participantes, o mínimo seria de 3 para cada um deles. Para se chegar ao número mais adequado sugerem que sejam consideradas as características do instrumento, a formação, a qualificação, a experiência e a disponibilidade dos participantes.

Os participantes da avaliação devem analisar o instrumento como um todo, ou seja, a sua abrangência, "se cada domínio ou conceito foi adequadamente coberto pelo conjunto de itens e se todas as dimensões foram incluídas" (Alexandre \& Coluci, 2011, p. 3064). Devem também analisar os itens individualmente quanto à sua clareza e pertinência. A clareza envolve analisar se a redação dos itens permite a compreensão do conceito e se expressa adequadamente o que se pretende medir. Por sua vez, a pertinência ou representatividade envolve analisar se os itens refletem corretamente os conceitos envolvidos e se são relevantes e adequados para os objetivos propostos. Os participantes também devem ter a oportunidade ou espaço para tecer comentários e sugerir melhorias.

A avaliação pode empregar técnicas de pesquisa qualitativa tais como entrevistas e discussões em grupo. Também pode empregar medidas quantitativas para avaliar a validade de conteúdo por meio da quantificação do grau de concordância entre os participantes. Uma das medidas sugeridas por Alexandre e Coluci (2011) é o índice de validade de conteúdo (IVC). Ele mede a proporção ou porcentagem de participantes que concordam sobre determinados itens e/ou aspectos dos instrumentos de mensuração, tanto individualmente quanto o conjunto ou o instrumento como um todo. Esta mensuração adota uma escala do tipo Likert que pode vai de "não relevante" ou "não representativo" a "relevante" ou "representativo". Pode também mensurar a necessidade de revisão e/ou o seu nível de clareza. O índice é calculado por meio da soma das respostas concordantes com cada item (exemplo: "relevante" e "muito relevante" ou "representativo" e "muito representativo") divido pelo total de respostas recebidas. Já a avaliação geral do conjunto de itens pode ser realizada por meio do cálculo pela média das proporções individuais considerados "relevante" e "muito relevante" ou "representativo" e "muito representativo" para cada item, ou seja, a média dos IVCs. 
$\mathrm{Na}$ avaliação dos resultados individualmente, Alexandre e Coluci (2011) consideram que se o número de participantes for de 5 ou menos pessoas, todos eles devem concordar para que os itens possam ser considerados representativos. Já no caso de 6 ou mais participantes, os pesquisadores recomendam uma taxa não inferior a 0,78. Assim, os itens com porcentagem representativa de avaliações "não relevante" e "pouco relevante" ou "não representativo" e "pouco representativo" (IVC menor que 0,78 ) devem ser revisados ou eliminados.

Outra avaliação que também pode ser realizada é o cálculo do coeficiente Kappa de concordância que é definido como: a proporção de vezes que os avaliadores concordam corrigida pela concordância devida ao acaso dividida pela proporção máxima de vezes que os avaliadores poderiam concordar também corrigida pela concordância devida ao acaso. Neste caso, os valores de Kappa variam de -1 (ausência total de concordância) a 1 (concordância total).

Alexandre e Coluci (2011) também indicam a possibilidade de participação de pessoas não especializadas relacionadas à população do estudo com o objetivo de assegurar a correção e o entendimento das frases e termos componentes do instrumento de mensuração. Assim, uma abordagem complementar para a validação do conteúdo é o julgamento por não especialistas, sendo neste caso chamada de validade de face ou aparente (Donald S. Tull \& Del I. Hawkins, 1984). Há objetivos específicos para este tipo de validação. O primeiro seria a verificação da facilidade de entendimento do conteúdo que está sendo avaliado. O segundo seria a avaliação por pessoas que não necessariamente fazem parte do público-alvo, mas que precisam tomar conhecimento e até mesmo aprovar o instrumento ou documento para que a pesquisa possa prosseguir.

A validade do critério ocorre quando o resultado de uma mensuração corresponde a um critério externo que pode ser definido em paralelo como forma de verificação da validade concorrente no que poderia ser uma segunda mensuração em paralelo (Flick, 2013). No caso desta pesquisa, seria verificar se os resultados das avaliações dos desempenhos dos projetos de desenvolvimento dos medicamentos genéricos corresponde aos resultados obtidos pelos processos de registro dos novos medicamentos. Um cuidado que deve ser tomado diz respeito a garantir que o critério externo seja válido em si, uma vez que será utilizado como um meio para a verificação das mensurações, ou seja, deve-se considerar a validade diferencial que significa que a concordância entre a pontuação do teste e o critério externo pode ser diferente em diferentes populações.

No caso da validade do constructo, o objetivo é verificar se o constructo que é captado pelo método está vinculado suficientemente às variáveis que podem ser teoricamente justificadas (Flick, 2013). O objetivo também é verificar até que ponto o constructo permite a derivação de hipóteses que possam ser testadas empiricamente. Uma das maneiras para verificar a validade do constructo é por meio da adoção de várias mensurações, ou seja, medindo os constructos por meio do uso de vários métodos. Neste caso, teríamos a validade convergente que significa que os vários métodos mensuram 
o mesmo constructo com resultados correspondentes, ou seja, produzem resultados que confirmam um ao outro. Outro indicativo de validade importante é a discriminante a qual se refere à capacidade das mensurações do constructo de distinguirem-se de outros constructos.

A participação dos profissionais que atuam na indústria farmacêutica na pesquisa para validação do conteúdo teve como principal objetivo avaliar se as variáveis tem relação com o domínio (Churchill \& Iacobucci, 2005), ou seja, verificar se cada domínio ou conceito foi adequadamente coberto pelo conjunto de variáveis selecionadas e se são relevantes e adequados para os objetivos propostos (Alexandre \& Coluci, 2011:3064). Em outras palavras, o objetivo foi verificar se os indicadores selecionados para mensurar o constructo Desempenho e os constructos dos fatores contribuintes estão presentes nas rotinas de desenvolvimento de medicamentos.

Foram convidados a participar profissionais de áreas diferentes com o objetivo de atender à recomendação de assegurar a correção e o entendimento das frases e termos componentes do instrumento de mensuração (validade de face ou aparente). Assim, também participaram da pesquisa profissionais que atuavam na área de desenvolvimento de novos medicamentos, mas sem experiência específica com medicamentos genéricos.

O questionário avaliou 6 indicadores de desempenho em PDMG quanto ao seu pertencimento ao domínio objeto do estudo. Para a mensuração foi adotada uma escala do tipo Likert com 7 pontos, ou seja, de 1 = "Irrelevante" a 7 = "Totalmente Relevante". Foram incluídas as opções de resposta "Não está claro" e "Não sei dizer" para cada uma das variáveis analisadas. A primeira teve o objetivo de verificar a clareza e facilidade de entendimento da assertiva. Já a segunda, deu a possibilidade do respondente indicar o seu desconhecimento do indicador avaliado.

Separados em 3 blocos de questões (Gerencial, Estrutural e Técnico), os 48 indicadores relacionados a fatores contribuintes para os resultados de desempenho insatisfatórios do PDMG foram avaliados também por meio de uma escala do tipo Likert com 7 pontos, ou seja, de 1 = "Irrelevante" a 7 = "Totalmente Relevante". Da mesma forma, foram incluídas as opções de resposta "Não está claro" e "Não sei dizer" para cada uma das assertivas avaliadas.

Outro recurso utilizado no questionário foi perguntar ao final de cada conjunto de variáveis se o respondente entendeu a questão e todos os seus itens; se encontrou problemas e/ou dificuldades para responder à questão; e se possuía comentários e/ou sugestões, havendo espaço para escrevê-los.

Assim, a validação do conteúdo dos itens selecionados para medir os constructos constantes do modelo proposto para a mensuração do desempenho dos PDMG e de seus fatores contribuintes foi realizada por meio da aplicação de um questionário eletrônico entre 26/06 e 5/07 de 2018 utilizando os recursos disponibilizados pelo provedor de soluções na internet QuestionPro ${ }^{\circledR}$ 
(www.questionpro.com). O texto integral do questionário pode ser consultado no Apêndice VII desta tese. A Tabela 33 apresenta resumidamente a estrutura do questionário.

Tabela 33 - Estrutura do questionário utilizado para validação do conteúdo

\begin{tabular}{|c|c|c|c|}
\hline Variáveis & $\begin{array}{l}\text { Núm. } \\
\text { Quest. }\end{array}$ & Forma de verificação & Resultados possíveis \\
\hline \multirow[t]{3}{*}{$\begin{array}{l}\text { Respondentes } \\
\text { (VI) }\end{array}$} & 1 & $\begin{array}{ll}\text { Tempo de experiência no } \\
\text { desenvolvimento } & \text { de } \\
\text { medicamentos } & \end{array}$ & $\begin{array}{l}\text { 1. Nunca trabalhei em atividades relacionadas ao } \\
\text { desenvolvimento de medicamentos genéricos; } 2 . \\
\text { Menos de } 1 \text { ano; } 3 \text {. Mais de } 1 \text { ano e menos de } 2 \text { anos; } \\
\text { 4. Mais de } 2 \text { anos e menos de } 5 \text { anos; } 5 \text {. Mais de } 5 \\
\text { anos e menos de } 10 \text { anos; 6. Mais de } 10 \text { anos e } \\
\text { menos de } 20 \text { anos; 7. Mais de } 20 \text { anos }\end{array}$ \\
\hline & 2 & $\begin{array}{l}\text { Relação predominante com } \\
\text { o desenvolvimento de } \\
\text { medicamentos genéricos }\end{array}$ & $\begin{array}{l}\text { 1. Nunca trabalhei em atividades relacionadas ao } \\
\text { desenvolvimento de medicamentos genéricos; } 2 \text {. Sou } \\
\text { ou fui decisor ou membro de comitê de decisão sobre } \\
\text { portfólio de projetos de desenvolvimento de } \\
\text { medicamentos genéricos; 3. Sou ou fui responsável } \\
\text { pela área de P\&D; 4. Sou ou fui responsável por } \\
\text { projetos de desenvolvimento de medicamentos } \\
\text { genéricos; 5. Sou ou fui membro de equipe de } \\
\text { gerenciamento de projetos de desenvolvimento de } \\
\text { medicamentos genéricos; } 6 \text {. Sou ou fui de áreas de } \\
\text { suporte aos projetos de desenvolvimento de } \\
\text { medicamentos genéricos; 7. Sou ou fui de áreas que } \\
\text { tem interesse nos resultados dos projetos de } \\
\text { desenvolvimento de medicamentos genéricos; } 8 \text {. } \\
\text { Outro tipo de atividade. }\end{array}$ \\
\hline & 3 & $\begin{array}{l}\text { Área de } \\
\text { predominante }\end{array}$ & $\begin{array}{l}\text { 1. Administração / Corporativo; 2. Comercial; } 3 . \\
\text { Consultoria; 4. Controle de qualidade; 5. Docência; } 6 . \\
\text { Engenharia / Manutenção; 7. Garantia da qualidade; } \\
\text { 8. Fiscalização; 9. Marketing; 10. Pesquisa e } \\
\text { desenvolvimento; 11. Produção; 12. Regulatório; } 13 . \\
\text { Suprimentos; 14. Outros }\end{array}$ \\
\hline \multirow{2}{*}{$\begin{array}{c}\text { Indicadores } \\
\text { de } \\
\text { desempenho } \\
\text { em projetos } \\
\text { de } \\
\text { desenvolvi- } \\
\text { mento de } \\
\text { medicamentos } \\
\text { genéricos } \\
\text { (VD) }\end{array}$} & \multirow[t]{2}{*}{4} & $\begin{array}{l}\text { Grau de relevância para a } \\
\text { avaliação do desempenho } \\
\text { dos projetos de } \\
\text { desenvolvimento de de } \\
\text { medicamentos genéricos (6 } \\
\text { indicadores) }\end{array}$ & $\begin{array}{l}\text { "Não está claro"; } 1=\text { "Irrelevante"; 2; 3; } 4= \\
\text { "Mediana"; 5; 6; "Totalmente Relevante"; "Não sei } \\
\text { dizer" (escala Likert de } 7 \text { pontos + Clareza + } \\
\text { Familiaridade) }\end{array}$ \\
\hline & & $\begin{array}{l}\text { Sugestão de melhoria, } \\
\text { comentário, correção e/ou } \\
\text { dúvida para o enunciado } \\
\text { e/ou itens avaliados. }\end{array}$ & $\begin{array}{l}\text { 1. Entendi a questão e todos os seus itens, não } \\
\text { encontrei problemas e/ou dificuldades; e não tenho } \\
\text { comentários e/ou sugestões; } 2 \text {. Tenho comentários } \\
\text { e/ou sugestões. Detalhe abaixo. }\end{array}$ \\
\hline \multirow[t]{2}{*}{$\begin{array}{l}\text { Fatores } \\
\text { contribuintes } \\
\text { para os } \\
\text { resultados de } \\
\text { desempenho } \\
\text { insatisfatórios } \\
\quad \text { (VI) }\end{array}$} & \multirow[t]{2}{*}{5} & $\begin{array}{l}\text { Grau de relevância das } \\
\text { situações para } \\
\text { desempenho abaixo } \\
\text { esperado para projetos } \\
\text { desenvolvimento } \\
\text { medicamentos genéricos } \\
\text { (48 indicadores) }\end{array}$ & $\begin{array}{l}\text { "Não está claro"; } 1=\text { "Irrelevante"; 2; 3; } 4= \\
\text { "Mediana"; 5; 6; "Totalmente Relevante"; "Não sei } \\
\text { dizer" (escala Likert de } 7 \text { pontos + Clareza + } \\
\text { Familiaridade) }\end{array}$ \\
\hline & & $\begin{array}{l}\text { Sugestão de melhoria, } \\
\text { comentário, correção e/ou } \\
\text { dúvida para o enunciado } \\
\text { e/ou itens avaliados. }\end{array}$ & $\begin{array}{l}\text { 1. Entendi a questão e todos os seus itens, não } \\
\text { encontrei problemas e/ou dificuldades; e não tenho } \\
\text { comentários e/ou sugestões; } 2 \text {. Tenho comentários } \\
\text { e/ou sugestões. Descreva abaixo. }\end{array}$ \\
\hline $\begin{array}{l}\text { Avaliação } \\
\text { geral do } \\
\text { questionário }\end{array}$ & 6 & $\begin{array}{l}\text { De uma forma geral, há } \\
\text { comentário, dúvida e/ou } \\
\text { sugestão adicional para o } \\
\text { questionário e/ou para a } \\
\text { pesquisa? }\end{array}$ & $\begin{array}{l}\text { 1. Não tenho comentários ou sugestões adicionais; } 2 \text {. } \\
\text { Sim tenho comentários e/ou sugestões. Descreva } \\
\text { abaixo. }\end{array}$ \\
\hline
\end{tabular}

Fonte: dados da pesquisa.

O questionário foi precedido por uma carta de apresentação da pesquisa contendo: objetivos da pesquisa, compromisso de uso apenas para fins acadêmicos, regras para participação, o endereço 
eletrônico do questionário e dados para contato. Amostragem foi do tipo não-probabilística e por indivíduo-tipo (Sampieri et al., 2006), ou seja, foram convidados a participar profissionais que atuam ou atuaram na indústria farmacêutica. $\mathrm{O}$ encaminhamento da carta-convite foi realizado por meio de mensagem eletrônica a participantes selecionados entre profissionais participantes da rede de relacionamentos LinkedIn ${ }^{\circledR}$. Participaram 19 profissionais. Para a análise da validade de conteúdo foi utilizado o conceito do Índice de validade de conteúdo (IVC) somando-se as respostas acima de relevância mediana (=4) na escala adotada, ou seja, 5, 6 e 7 (totalmente relevante). As indicações de melhorias e/ou ajustes recebidos foram incorporados à versão final do questionário.

\subsubsection{Versão final do questionário}

A definição dos indicadores, a forma de mensuração dos constructos e a validação do conteúdo permitiram a definição da versão final do instrumento de coleta de dados para aplicação, cujo texto integral está disponível no Apêndice XI. A estrutura do questionário é apresentada na Tabela 34.

Tabela 34 - Estrutura do questionário (fase quantitativa)

\begin{tabular}{|c|c|c|c|}
\hline Variáveis & $\begin{array}{c}\text { Núm. } \\
\text { questão }\end{array}$ & Forma de verificação & Resultados possíveis \\
\hline $\begin{array}{lr}\text { Indicadores } & \text { de } \\
\text { desempenho } & \text { em } \\
\text { PMDG (VD) } & \\
\end{array}$ & 9 & $\begin{array}{l}\text { Frequência com que é } \\
\text { alcançado }\end{array}$ & $\begin{array}{l}\text { Escala do tipo Likert de } 7 \text { pontos } \\
\text { variando de } 1=\text { "Nunca" a } 7= \\
\text { "Sempre" }\end{array}$ \\
\hline $\begin{array}{l}\text { Taxa de abandono dos } \\
\text { PDMG (VD) }\end{array}$ & 8 & $\begin{array}{l}\text { Percentagem dos projetos } \\
\text { iniciados que são abandonados } \\
\text { antes do término }\end{array}$ & Escala ordinal de $0 \%$ a $100 \%$ \\
\hline $\begin{array}{l}\text { Fatores contribuintes } \\
\text { para os resultados de } \\
\text { desempenho } \\
\text { insatisfatórios (VI) }\end{array}$ & 10 a 12 & $\begin{array}{l}\text { Grau de contribuição para os } \\
\text { resultados de desempenho } \\
\text { insatisfatórios }\end{array}$ & $\begin{array}{l}\text { Escala do tipo Likert de } 7 \text { pontos } \\
\text { variando de } 11=\text { "Nenhuma } \\
\text { contribuição" a } 7=\text { "Contribuição total" }\end{array}$ \\
\hline \multirow[t]{6}{*}{ Respondentes (VI) } & 1 & $\begin{array}{ll}\text { Tempo de experiência } & \text { no } \\
\text { desenvolvimento } & \text { de } \\
\text { medicamentos } & \\
\end{array}$ & Escala ordinal - tempo em anos \\
\hline & 2 & $\begin{array}{l}\text { Tipo de relação com projetos } \\
\text { de desenvolvimento de } \\
\text { genéricos }\end{array}$ & $\begin{array}{l}\text { Tipos de relação (decisor, responsável, } \\
\text { participante, suporte, etc.) }\end{array}$ \\
\hline & 3 & Área de trabalho & $\begin{array}{l}\text { Pesquisa e desenvolvimento, } \\
\text { regulatório, corporativo, etc. }\end{array}$ \\
\hline & 4 & Cargo ou função & $\begin{array}{l}\text { Presidência, diretoria, gerência, } \\
\text { coordenação, etc. }\end{array}$ \\
\hline & 13 e 14 & Nome e sobrenome & Perguntas abertas \\
\hline & 15 & Email & Pergunta aberta \\
\hline \multirow[t]{4}{*}{$\begin{array}{l}\text { Características } \\
\text { organização (VI) }\end{array}$} & 5 & Caracterização da organização & $\begin{array}{l}\text { Laboratório, prestador de serviços, } \\
\text { público ou privado, etc. }\end{array}$ \\
\hline & 6 & Origem & $\begin{array}{l}\text { País onde está localizada a matriz } \\
\text { (Brasil ou outro país) }\end{array}$ \\
\hline & 7 & Tamanho da empresa & $\begin{array}{l}\text { Escala intervalar com número de } \\
\text { projetos de desenvolvimento de } \\
\text { medicamentos genéricos }\end{array}$ \\
\hline & 16 & Nome da empresa & Relação de nomes de laboratório \\
\hline
\end{tabular}

Fonte: dados da pesquisa. 
Como foram estabelecidas hipóteses para a análise das relações entre os constructos componentes do modelo proposto, na matriz de amarração teórica (Tabela 35) são apresentadas as hipóteses, as perguntas incluídas no questionário e as respectivas técnicas de análise.

Tabela 35 - Matriz de amarração teórica com a relação entre a questão de pesquisa, as hipóteses, as perguntas e as técnicas estatísticas empregadas.

\begin{tabular}{|c|c|c|c|}
\hline $\begin{array}{l}\text { Questão de } \\
\text { pesquisa }\end{array}$ & Hipóteses de pesquisa & $\begin{array}{c}\text { Perguntas no } \\
\text { questionário }\end{array}$ & Técnicas \\
\hline \multirow[t]{2}{*}{$\begin{array}{l}\text { Quais são os } \\
\text { fatores que } \\
\text { contribuem } \\
\text { para o } \\
\text { desempenho } \\
\text { dos projetos } \\
\text { de } \\
\text { desenvolvi- } \\
\text { mento de } \\
\text { medicamen- } \\
\text { tos } \\
\text { genéricos? }\end{array}$} & $\begin{array}{l}\text { H2: As dificuldades estruturais da desenvolvedora estão } \\
\text { associadas positivamente com o desempenho fora do } \\
\text { planejado dos projetos de desenvolvimento de } \\
\text { medicamentos genéricos. }\end{array}$ & $\begin{array}{c}\text { Desenvolvimento } \\
\text { Q12.15 a Q12.21 } \\
\text { Gestão } \\
\text { Q15.22 a Q15.27 } \\
\text { Portfólio } \\
\text { Q15.28 a Q11.31 } \\
\text { Recursos } \\
\text { Q16.32 a Q16.37 } \\
\text { Competências } \\
\text { Q16.38 a Q16.40 } \\
\text { Organização } \\
\text { Q16.41 a Q16.44 } \\
\text { Especificações } \\
\text { técnicas } \\
\text { Q11.1 a Q11.8 } \\
\text { Requisitos do } \\
\text { projeto } \\
\text { Q11.9 a Q11.11 } \\
\text { Requisitos } \\
\text { regulatórios } \\
\text { Q11.12 a Q11.14 } \\
\text { Conclusão do } \\
\text { projeto } \\
\text { Q 10.5 a } 10.9 \\
\end{array}$ & $\begin{array}{l}\text { Métodos de } \\
\text { Análise } \\
\text { Multivariada } \\
\\
\text { Análise do } \\
\text { mínimo } \\
\text { quadrado } \\
\text { parcial }(P L S)\end{array}$ \\
\hline & $\begin{array}{l}\text { H4: A influência das dificuldades estruturais sobre o } \\
\text { desempenho fora do planejado dos projetos de } \\
\text { desenvolvimento de genéricos é mediada pelas dificuldades } \\
\text { gerenciais. } \\
\text { H4a: As dificuldades estruturais estão associadas } \\
\text { positivamente com as dificuldades gerenciais dos projetos } \\
\text { de desenvolvimento de medicamentos genéricos. } \\
\text { H4b: As dificuldades gerenciais estão associadas } \\
\text { positivamente com o desempenho fora do planejado dos } \\
\text { projetos de desenvolvimento de medicamentos genéricos. } \\
\text { H5: A influência das dificuldades técnicas sobre o } \\
\text { desempenho fora do planejado dos projetos de } \\
\text { desenvolvimento de genéricos é mediada pelas dificuldades } \\
\text { gerenciais. } \\
\text { H5a: As dificuldades técnicas estão associadas } \\
\text { positivamente com as dificuldades gerenciais dos projetos } \\
\text { de desenvolvimento de medicamentos genéricos. } \\
\text { H5b: As dificuldades gerenciais estão associadas } \\
\text { positivamente com o desempenho fora do planejado dos } \\
\text { projetos de desenvolvimento de medicamentos genéricos. }\end{array}$ & & $\begin{array}{l}\text { Análise de } \\
\text { caminhos } \\
\text { Efeitos } \\
\text { indiretos } \\
\text { Testes: } \\
\text { Sobel, } \\
\text { Aroian e } \\
\text { Goodman } \\
\text { VAF }\end{array}$ \\
\hline
\end{tabular}

Fonte: dados da pesquisa em matriz adaptada de Telles (2001). 
Marconi e Lakatos (2012) consideram importante a realização de uma pesquisa-piloto ou préteste para testar o instrumento de coleta de dados. No entanto, havia o risco de não obtenção de número suficiente de participantes considerando a experiência de outras pesquisas semelhantes realizadas com populações da mesma indústria (exemplos: R. T. Yugue, Maximiano e Sbragia (2018) e R. T. Yugue, Sbragia, Maximiano e Nascimento (2018)), ou seja, se mesmo que um pequeno número de indivíduos fosse utilizado em um pré-teste, ao não poderem compor a amostra da pesquisa, poderiam diminuir a probabilidade de que o número adequado de participantes fosse atingido.

Também havia o fato de já ter sido realizada a validação do conteúdo das questões centrais. As mudanças realizadas nas questões em razão da validação do conteúdo foram apenas de ajustes em seus enunciados, os quais foram submetidos à posterior avaliação de um especialista na área de pesquisa $\mathrm{e}$ desenvolvimento de medicamentos quanto às adequações realizadas.

Assim, embora Hinkin (1998) considere que a avaliação da validade do conteúdo possa ser equivalente a um pré-teste por verificar a consistência conceitual do questionário e considerando o risco de insuficiência de participantes, optou-se por avaliar eventuais necessidades de ajustes complementares por meio de análise dos dados inicialmente coletados pela aplicação do questionário. Assim, na medida em que as respostas foram sendo recebidas, estas foram sendo analisadas individualmente com relação a eventuais problemas de entendimento das questões e de preenchimento das respostas. Atingido o número de 30 participantes, o conjunto de dados coletados foi analisado conjuntamente com o objetivo de identificar tanto eventuais problemas sistemáticos nas questões e no preenchimento das respostas, quanto em relação ao modelo estrutural. O número de 30 respostas foi adotado, pois este é o número mínimo recomentado por Chin e Newsted (1999) e Henseler, Ringle e Sinkovics (2009) para as análises utilizando o método de modelagem de equações estruturais com estimação por mínimos quadrados parciais (PLS-SEM).

$\mathrm{Na}$ análise da amostra com as 30 primeiras respostas não foram encontrados problemas e/ou necessidades de ajustes relevantes no questionário. Os resultados da análise pelo uso do PLS-SEM por meio do software SmartPLS ${ }^{\circledR}$ Versão 2.0 M3 ${ }^{15}$ não indicou haver problema importante nas primeiras respostas recebidas. Sendo assim, considerando a sustentação teórica do instrumento de coleta e o atendimento aos critérios de validade e de confiabilidade, o questionário foi considerado adequado para prosseguimento da coleta de dados.

15 SmartPLS $^{\circledR}$ Versão 2.0 M3 é de uso gratuito, bastando apenas realizar o cadastro no site (https://www.smartpls.com/smartpls2) para receber a chave de ativação do programa que pode ser baixado por link no mesmo endereço na internet. 


\subsubsection{Universo da pesquisa}

Os dados da Anvisa (2018a) sobre o mercado de medicamentos regulado pela CMED - Câmara de Regulação do Mercado de Medicamentos apresentados na Tabela 36 dão a dimensão do mercado brasileiro de medicamentos.

Tabela 36 - Dados de mercado referentes ao ano de 2017

\begin{tabular}{crrrrr}
\hline $\begin{array}{c}\text { Tipo de } \\
\text { Produto }\end{array}$ & Empresas* & Produtos & $\begin{array}{c}\text { Apresentações } \\
\text { cadastradas com } \\
\text { comercialização }\end{array}$ & $\begin{array}{c}\text { Faturamento (R\$ } \\
\text { milhões) }\end{array}$ & $\begin{array}{c}\text { Apresentações } \\
\text { comercializadas } \\
\text { (milhões) }\end{array}$ \\
\hline Novos & 101 & 1.154 & 2.732 & 26.574 & 905 \\
Biológicos & 69 & 265 & 530 & 15.410 & 168 \\
Genéricos & 88 & 2.450 & 4.202 & 9.380 & 1.540 \\
Similares & 149 & 2.320 & 4.409 & 14.168 & 1.363 \\
Específicos & 91 & 398 & 932 & 3.955 & 470 \\
\hline Total & 214 & 6.587 & 12.805 & 69.487 & 4.446 \\
\hline
\end{tabular}

Nota: (*) O total de empresas não corresponde à somatória da coluna, pois uma mesma empresa pode ter medicamentos de mais de um tipo. Fonte: Anvisa (2018a)

Assim, segundo o relatório da Anvisa (2018a), em 2017 eram 88 empresas farmacêuticas atuando no mercado de medicamentos genéricos com um total de 2.450 produtos comercializados em 4.202 diferentes apresentações. Neste caso, o termo produto refere-se à marca do medicamento comercializado (o nome do(s) princípio(s)-ativo(s) no caso dos medicamentos genéricos). Já o termo apresentação refere-se às diferentes concentrações do(s) princípio(s) ativo(s), formas farmacêuticas, embalagem e quantidade de unidades na embalagem (exemplo: produto - dipirona; apresentações gotas adulto, gotas pediátrico, comprimido $500 \mathrm{mg}$, etc.).

Uma planilha com dados atualizados até o Diário Oficial da União de 30/06/2017, também disponibilizada pela Anvisa (2017a) e apresentada no Anexo II, indica a existência de 132 empresas responsáveis pelo registro de 3.723 medicamentos genéricos. Os números apresentados na Tabela 36 são diferentes destes, pois os primeiros são baseados em dados de comercialização acompanhados pela CMED e estes últimos em dados de registro do medicamento, ou seja, de autorização para comercialização. Portanto, há mais medicamentos registrados do que efetivamente comercializados, ou seja, nem todos os laboratórios que possuem medicamentos genéricos registrados no Brasil os comercializam efetivamente.

Complementarmente, é importante que se considere que alguns dos laboratórios farmacêuticos instalados no Brasil não possuem laboratório de desenvolvimento no país, uma vez que lhes é permitido importar os medicamentos fabricados por outras unidades ou laboratórios, desde que as normas específicas da Anvisa (2008) para importação de medicamentos sejam atendidas.

O universo considerado pela pesquisa é composto por profissionais que atuam na indústria farmacêutica de uso humano instalados no Brasil e que participam de PDMG. Não há referência ao número de profissionais que atuam nesta atividade no Brasil, mesmo porque não se trata de uma profissão específica, dado que podem trabalhar na área outros profissionais além dos farmacêuticos. 
Assim, para fins de cálculo da amostra mínima necessária para a adequada aplicação das técnicas selecionadas para a análise dos dados, o universo foi definido como infinito.

De acordo com Ringle e colaboradores (2014), no caso do uso do PLS-SEM, pode-se utilizar o software G*Power (Buchner, Erdfelder, Faul, \& Lang, 2019) para estimar o tamanho mínimo da amostra. Para o cálculo, é preciso alimentar o software com os dados relacionados na Tabela 37.

Tabela 37 - Dados para o cálculo do tamanho mínimo da amostra

\begin{tabular}{|c|c|c|}
\hline Dado a ser fornecido & Conceito & Referência adotada \\
\hline $\begin{array}{l}\text { Constructo } \\
\text { variável latente que } \\
\text { recebe o maior } \\
\text { número de setas ou } \\
\text { tem o maior número } \\
\text { de preditores }\end{array}$ & $\begin{array}{l}\text { O maior número de preditores de um constructo é } \\
\text { identificado no modelo de caminhos }\end{array}$ & $\begin{array}{l}\text { Pelo modelo de } \\
\text { caminhos o maior } \\
\text { número é } 3 \text { preditores } \\
\text { (todos os constructos } \\
\text { possuem } 3 \text { preditores) }\end{array}$ \\
\hline $\begin{array}{l}\text { Tamanho do efeito } \\
\left(\mathrm{f}^{2}\right) \text { ou Indicador de } \\
\text { Cohen }\end{array}$ & $\begin{array}{l}\text { Avalia-se quanto cada constructo é "útil" para o } \\
\text { ajuste do modelo }\end{array}$ & $\begin{array}{c}\mathrm{f}^{2} \text { efeito médio }=0,15 \\
(\mathrm{~J} . \text { Cohen, 1988; } \\
\text { Ringle et al., 2014) }\end{array}$ \\
\hline $\begin{array}{l}\text { Poder do teste } \\
\text { estatístico }\left(1-\beta_{\text {err prob }}\right)\end{array}$ & $\begin{array}{l}\text { O poder de um teste estatístico é a probabilidade de } \\
\text { que ele produza resultados estatisticamente } \\
\text { significativos. } \\
\text { Poder }=1-\beta_{\text {err prob. II }}=\text { probabilidade de rejeitar Ho } \\
\text { quando ele não é verdadeira }\end{array}$ & $\begin{array}{c}\text { Poder }=(1-\beta)= \\
0,80 \\
(\text { J. Cohen, 1988; } \\
\text { Ringle et al., 2014) }\end{array}$ \\
\hline $\begin{array}{l}\text { Nível de significância } \\
\text { ( } \alpha \text { err prob) }\end{array}$ & $\begin{array}{l}\text { Padrão de probabilidade para os resultados da } \\
\text { pesquisa e que fornece uma base para a rejeição da } \\
\text { hipótese nula e, portanto, para a prova da existência } \\
\text { do fenômeno sob teste. } \\
\alpha=\text { probabilidade de rejeitar Ho, quando ela é } \\
\text { verdadeira (Erro tipo I). }\end{array}$ & $\alpha_{\text {err prob }}=0,01$ \\
\hline
\end{tabular}

Fontes: Bido (2018); Cohen (1988); Ringle e colaboradores (2014)

Assim, considerando 3 preditores, efeito médio $\left(\mathrm{f}^{2}=0,15\right)$, poder $=0,8$ e nível de significância $\mathrm{p}<0,01$, os dados foram inseridos no software $G^{*}$ Power (Buchner et al., 2019) para o cálculo da amostra não probabilística por meio do teste de Regressão Linear Múltipla. O resultado do cálculo está reproduzido na Tabela 38.

Tabela 38 - Cálculo estimativo para amostragem utilizando o G*Power

\begin{tabular}{ll}
\hline F tests - Linear multiple regression: & Fixed model, $\mathrm{R}^{2}$ deviation from zero \\
Analysis: size & A priori: Compute required sample \\
Input: & $=0,15$ \\
Effect size $\mathrm{f}^{2}$ & $=0,01$ \\
$\alpha$ err prob & $=0,80$ \\
Power $(1-\beta$ err prob) & $=3$ \\
Number of predictors & $=16,3500000$ \\
Output: & $=3,9737726$ \\
Noncentrality parameter $\lambda$ & $=3$ \\
Critical F & $=105$ \\
Numerator df & $=109$ \\
Denominator df & $=0,8009686$ \\
Total sample size & Actual power
\end{tabular}

Fonte: G*Power (Buchner et al., 2019; Faul, Erdfelder, Buchner, \& Lang, 2009) 
Conforme os resultados apresentados na tabela 38, a estimativa do tamanho mínimo da amostra para os parâmetros considerados é de 109 participantes. Bido e Da Silva (2019) consideram que ao serem coletados dados com escalas de atitude, muitas respostas podem não ter boa qualidade por diversas razões e, assim como Ringle e colaboradores (2014), sugerem que o tamanho mínimo das amostras deva ser ao menos dobrado para se evitar que os dados de baixa qualidade prejudiquem a análise e os resultados. Portanto, o número mínimo seria de 109 participantes e o ideal seria de 218 participantes. Apenas como uma referência, nas publicações sobre o tema do DP, Page e Schirr (2008) verificaram que nos estudos daquela época que utilizaram técnicas de análise como a modelagem de equações estruturais (MEE), o tamanho médio das amostras foi de 192 indivíduos.

\subsubsection{Critério de elegibilidade e amostragem}

A amostragem pode ser considerada por indivíduos-tipo, uma vez que os participantes apresentam certas características dadas pela especificidade e a profundidade do conhecimento e/ou experiência requeridas pela situação problema estabelecida (Sampieri et al., 2013). Os critérios utilizados para seleção dos perfis dos profissionais contatados foram os seguintes:

- Atuação em laboratório farmacêutico instalado no Brasil;

- Ter participação de projetos de desenvolvimento de medicamentos genéricos;

- Áreas de atuação: pesquisa e desenvolvimento, desenvolvimento farmacotécnico (formulação), desenvolvimento analítico, assuntos regulatórios, desenvolvimento de novos negócios e áreas derivadas.

Apesar de ter havido a intenção de considerar o universo dos laboratórios farmacêuticos, ainda assim a amostragem foi do tipo não-probabilística, uma vez que dentre os profissionais que atuam nos laboratórios farmacêuticos instalados no Brasil e mesmo dentro de uma mesma empresa, a escolha dos indivíduos não dependeu de que todos tivessem a mesma probabilidade de serem participantes, principalmente em razão da dificuldade de acesso a todos eles e de randomização dos participantes (Sampieri et al., 2013). Vale lembrar que a opção por realizar uma pesquisa com base na experiência e percepção dos profissionais que atuavam em PDMG foi justificada pela impossibilidade de acesso aos registros e documentos dos projetos.

Foram convidados a responder à pesquisa os profissionais participantes da rede de relacionamento profissional LinkedIn ${ }^{\circledR}$. Mais especificamente, os profissionais que atuam no Brasil e identificados na base da ferramenta por meio de busca utilizando palavras-chaves como: "pharmaceutical development"; "R\&D"; "pharmacotechnical"; "regulatory affairs"; e "drug development". As palavras-chaves foram utilizadas na língua inglesa, pois a ferramenta pesquisa as palavras as palavras-chaves também traduzidas para a língua portuguesa. 


\subsubsection{Coleta dos dados}

O questionário foi aplicado por meio eletrônico, mais especificamente utilizando novamente os recursos disponibilizados pelo provedor de soluções na internet QuestionPro ${ }^{\circledR}$ (www.questionpro.com). O questionário (Apêndice XI) foi precedido por uma carta de capa da pesquisa contendo: objetivos da pesquisa, compromisso de confidencialidade dos dados, regras para participação, o endereço eletrônico do questionário e dados para contato. A carta de apresentação também informou o número de registro da pesquisa na Plataforma Brasil (CAAE 94791118.7.0000.0067). O conteúdo da carta de capa do questionário serviu como referência para a mensagem de convite para participação na pesquisa (Apêndice X).

Para a coleta dos dados foram realizadas as seguintes atividades:

- Envio da mensagem eletrônica com convite para participação para os profissionais participantes da rede de relacionamento selecionado (LinkedIn $\left.{ }^{\circledR}\right)$;

- Acompanhamento das respostas recebidas por meio de planilha de controle de mensagens enviadas e respostas recebidas (quando identificadas);

- Após uma semana do envio da primeira mensagem-convite, envio do segundo convite para os profissionais que ainda não haviam respondido ao questionário.

A coleta dos dados foi realizada no período entre 4 de fevereiro e 22 de maio de 2019. Foram contatados 2210 profissionais por meio de mensagem-convite para participar da pesquisa (Tabela 39). Destes, 2034 profissionais receberam a segunda mensagem-convite para participação, totalizando 4244 mensagens enviadas. De acordo com os registros da ferramenta utilizada para aplicação do questionário (QuestionPro ${ }^{\circledR}$ ), este foi acessado ou visto por 1.119 pessoas (51\% dos profissionais contatados), sendo que 593 iniciaram a resposta (27\% dos contatados). No entanto, 221 das respostas ( $10 \%$ dos contatos) foram consideradas completas com todas as questões respondidas.

Tabela 39 - Respostas ao questionário

\begin{tabular}{lccccc}
\hline & $\begin{array}{c}\text { Profissionais } \\
\text { convidados }\end{array}$ & $\begin{array}{c}\text { Acessaram o } \\
\text { questionário }\end{array}$ & $\begin{array}{c}\text { Iniciaram o } \\
\text { questionário }\end{array}$ & $\begin{array}{c}\text { Concluíram o } \\
\text { questionário }\end{array}$ & $\begin{array}{c}\text { Respostas } \\
\text { validadas }\end{array}$ \\
\hline $\begin{array}{l}\text { Número de eventos } \\
\% \text { sobre convidados }\end{array}$ & 2210 & 1.119 & 593 & 221 & 209 \\
\hline
\end{tabular}

Fonte: dados da pesquisa.

\subsubsection{Tratamento e validação dos dados brutos}

Apesar dos cuidados na elaboração das questões e na estruturação do questionário, há sempre a possibilidade da ocorrência de omissões e erros acidentais que não podem ser mantidos na base dos dados a serem analisados. Para estes casos, faz-se necessária avaliação e eventual limpeza da base de dados com o intuito de minimizar os seus efeitos negativos sobre a qualidade dos resultados do estudo (Van Den Broeck, Cunningham, Eeckels, \& Herbst, 2005). 
Os dados das respostas recebidas foram baixados da ferramenta de pesquisa na internet no formato de planilha MS-Excel. A planilha com os dados brutos da pesquisa foi mantida como base de referência e foi realizada uma cópia para tratamento inicial visando a triagem e limpeza dos dados seguindo os seguintes passos e critérios:

- exclusão das respostas incompletas - para fins desta pesquisa foram consideradas inválidas as respostas que não avaliaram os itens relacionados às variáveis do modelo proposto. Desta forma, embora a ferramenta de aplicação do questionário considerasse 253 respostas completas, em razão de omissões de respostas não consideradas pela ferramenta, no total 221 respostas atenderam a este requisito.

- exclusão das respostas com padrões considerados anormais - foram consideradas suspeitas as respostas ao questionário com variância muito baixa entre os itens que mensuravam as variáveis independentes do modelo proposto, ou seja, responderam a mesma opção em todos os itens questionados. Como no total foram 44 itens avaliados pelos respondentes, uma variância menor ou igual a 0,2 nas respostas foi considerada como ausência de variância, ou seja, todos os itens receberam as mesmas respostas. Por este critério foram excluídas 12 respostas, restando 209 respostas.

- exclusão das respostas com tempo muito curto para preenchimento - como a ferramenta indica o tempo utilizado para responder ao questionário, foi possível verificar este quesito. Participações que usaram muito pouco tempo para responder todo o questionário podem indicar atenção insuficiente às questões. Assim, as respostas com tempo de preenchimento menor que a média menos um desvio padrão foram verificados individualmente. Por este critério, nenhuma resposta foi excluída.

- exclusão de infração aos requisitos e/ou inconsistências das respostas. Para perguntas como sobre estar trabalhando ou ter trabalhado em projetos de desenvolvimento de medicamentos genéricos, não houve respostas que desqualificassem respondentes. Havia um procedimento de lógica no questionário que remetia o respondente para o final se ele indicasse qualquer atributo desqualificador. Não foram encontradas inconsistências importantes que justificassem suas exclusões.

Assim, concluída a análise dos dados brutos, restaram 209 respostas válidas para a análise quantitativa dos dados.

\subsubsection{Análise quantitativa dos dados}

Os dados coletados por meio da aplicação do questionário e validados foram submetidos às análises estatísticas divididas em três grupos: estatística descritiva para as características da amostra, análise univariada para as características do desempenho dos PDMG e de seus fatores contribuintes e análise multivariada para o modelo estrutural proposto. 


\subsubsection{Análise dos dados sócio-demográficos}

Para análise dos dados sócio-demográficos, foi empregada estatística descritiva que avaliou os dados por meio de suas distribuições ou frequências (Sampieri et al., 2013).

- Perfil dos respondentes - Apresentação (tabelas e gráficos) das características dos participantes da pesquisa em relação à área de atuação, cargo ou função e tempo de experiência em projetos de desenvolvimento de medicamentos genéricos.

- Perfil dos laboratórios farmacêuticos - Apresentação (tabelas e gráficos) das características dos laboratórios farmacêuticos onde trabalhavam os participantes da pesquisa em relação à origem, constituição da empresa e número de PDMG conduzidos.

3.3.8.2 Análises dos dados dos projetos de desenvolvimento de medicamentos genéricos

Para os dados referentes aos indicadores de desempenho dos PDMG e seus fatores contribuintes foram utilizadas análises univariadas compostas por estatísticas descritivas de medidas de posição e variabilidade. Assim, com o objetivo de avaliar pressupostos de normalidade nas variações, foram obtidos a média e o desvio padrão dos dados que foram coletados por meio de uma escala ordinal de 7 pontos.

Seguindo a mesma lógica de Bido e Da Silva (2019, p. 200) para definir a unidade de análise, como os constructos neste estudo são conceitos aplicados aos PDMG das empresas, medidos por indivíduos que atuam nesses projetos, então a unidade de análise pode ser definida como o conjunto de projetos de desenvolvimento de medicamentos genéricos das empresas.

\subsubsection{Análise do modelo de equações estruturais}

Para análise das inter-relações propostas no modelo conceitual foi aplicada a modelagem de equações estruturais ("Structural Equation Modeling” - SEM) por examinar simultaneamente múltiplas relações de dependência entre diferentes constructos (Bido \& Da Silva, 2019; Hair Jr. et al., 2017; Vinzi, Chin, Henseler, \& Wang, 2010). Esta decisão teve por razão principal o fato de estudos de desempenho de projetos envolverem relações ou associações complexas entre vários fatores e a análise de uma relação simples entre um fator e o desempenho do projeto (análises uni e bivariadas) em geral resultam em explicações incompletas quando há influência de múltiplas variáveis combinadas (Cooper, 2019; Montoya-Weiss \& Calantone, 1994; Murphy et al., 1974).

A SEM permite a análise das inter-relações em uma série de equações de regressão múltipla que descrevem simultaneamente as relações entre os constructos (Hair Jr. et al., 2017). Esta técnica de 
análise multivariada é classificada como de segunda geração ${ }^{16}$ por: considerar os erros de mensuração; incorporar variáveis teóricas (não-observáveis) e variáveis empíricas (observáveis) na análise; confrontar a teoria com dados (teste de hipótese); e permitir a combinação de teoria e dados empíricos (construção de teoria) (Chin, 1998). Mais especificamente, utilizou-se modelagem de equações estruturais com estimação por mínimos quadrados parciais (PLS-SEM) (Hair Jr. et al., 2017; Henseler et al., 2009; Ringle et al., 2014) para avaliar o modelo de influências sobre o desempenho dos projetos de desenvolvimento de medicamentos genéricos.

A PLS-SEM é um algoritmo iterativo que resolve separadamente os blocos do modelo de medição e, em seguida, estima os coeficientes dos caminhos no modelo estrutural. Uma vantagem da técnica advém do fato de não serem necessários pressupostos fortes (com relação às distribuições, tamanho da amostra e escala de medição) (Vinzi, Trinchera, \& Amato, 2010). Além disso, Hair Jr., Black, Babin, e Anderson (2014) consideram que a modelagem de equações estruturais possui habilidade para avaliar as relações em âmbito geral e fornecer uma transição da análise exploratória para a análise confirmatória, favorecendo o desenvolvimento de uma visão mais sistemática e holística dos problemas.

A decisão pelo uso da PLS-SEM considerou os seguintes requisitos da pesquisa e características do método (Bido \& Da Silva, 2019; Chin \& Newsted, 1999; Henseler et al., 2009; Ringle et al., 2014; Sarstedt, Henseler, \& Ringle, 2011; Sarstedt, Ringle, \& Hair Jr., 2017):

- Na avaliação de relações entre construtos (ou fatores, componentes, variáveis latentes, variáveis não observadas, etc.), a PLS-SEM é capaz de realizar estimativas em modelos de caminhos como o proposto que inclui vários constructos, várias relações de caminho e/ou muitos indicadores por constructo, ou seja, pode estimar relações de dependência múltiplas e inter-relacionadas;

- A PLS-SEM é mais flexível na aplicação a situações em que a teoria que sustenta as relações causais ainda não tem grande sedimentação e/ou os problemas são mais complexos e difíceis de estruturação e, assim, teriam uma abordagem exploratória em razão de não haver sido encontrado referencial específico sobre as relações estudadas, podendo inclusive auxiliar na construção da teoria. É capaz de representar conceitos não observados nas relações e corrigir erros de mensuração no processo de estimação;

- A PLS-SEM permite a especificação das relações entre os constructos e seus indicadores de forma mais flexível (reflexivas no caso do modelo proposto);

\footnotetext{
${ }^{16}$ São considerados métodos de primeira geração: análise de cluster, análise fatorial exploratória, análise de variância, regressão logística, regressão múltipla e análise fatorial confirmatória. Além do PLS-SEM, também é considerada de segunda geração o modelagem de equações estruturais baseada na covariância (CB-SEM) (Hair Jr. et al., 2017)
} 
- A PLS-SEM é robusta à falta de normalidade multivariada porque é estimado por métodos não paramétricos e os dados coletados podem não apresentar distribuição normal, o que não é restrição ao uso do PLS-SEM por não ser uma de suas suposições sobre os dados. De acordo com Bido e Da Silva (2019), as pesquisas que são realizadas nas áreas de ciências humanas, sociais e do comportamento muitas vezes utilizam dados provenientes de escalas de atitude ou do tipo de Likert e que raríssimas vezes são aderentes à distribuição normal multivariada;

- A PLS-SEM é baseado na variância, não exigindo a reprodução da matriz de covariâncias ou de correlações. A estimação por PLS-SEM é considerada por Hair Jr e colaboradores (2017) e por Sarstedt e colaboradores (2017) uma alternativa à estimação baseada em covariância (CB-SEM) para estimar modelos com relações teóricas de causa-efeito;

- Não é uma restrição ao uso da PLS-SEM se alguns dados tiverem sido coletados por meio de escalas ordinais;

- A PLS-SEM realiza estimativa em modelos com variáveis moderadoras, relações nãolineares ou modelos de componentes hierárquicos ${ }^{17}$. Em razão do modelo ser composto por uma única estrutura, torna-se facilitada a sua visualização e análise.

Guide e Ketokivi (2015) abordaram em um editorial os cuidados que devem ser tomados pelos pesquisadores na escolha e na aplicação dos métodos estatísticos, sobretudo nos artigos submetidos ao Journal of Operations Management do qual são editores. Embora não específicos para o uso da modelagem de equações estruturais (SEM), muitos dos cuidados citados são aplicáveis a este método. Assim, muitas características da SEM que são tratadas como pontos fortes pelos pesquisadores, podem, no contexto específico de uma pesquisa, se tornarem seus pontos fracos pela fundamentação equivocada do método e de suas premissas. Além disso, outra componente importante a ser observada diz respeito à evolução dos métodos com desenvolvimentos e novas abordagens metodológicas. São estes os principais pontos abordados pelos editores:

- Causalidade: "correlação não estabelece causalidade" (Guide \& Ketokivi, 2015). A interpretação de uma relação transversal de X e Y como suporte de uma afirmação causal ou mesmo de que a variância de $\mathrm{X}$ está direcionando a variância de $\mathrm{Y}$ deve ser criticamente avaliada para que não resulte em testes excessivamente permissivos de hipóteses substantivas (considerar evidências para hipóteses mesmo quando não há);

\footnotetext{
${ }^{17}$ Modelos de componentes hierárquicos geralmente envolvem estruturas de segunda ordem que contêm duas camadas de componentes, ou seja, componentes de primeira ordem podem formar o componente de segunda ordem mais abstrato (Hair Jr. et al., 2017).
} 
- Endogeneidade: ocorre quando são usados dados não experimentais para testar a hipótese de que $\mathrm{X}$ tem um efeito sobre $\mathrm{Y}$, sendo possível que a variância de $\mathrm{X}$ não seja exógena, mas endógena ao modelo. Neste caso, o modelo é mal especificado, podendo resultar de um viés assintótico na estimativa de parâmetros ou mesmo inflacionar os resultados;

- Escolha das regras a seguir: o problema está em construir os argumentos com base na premissa de que a aplicação da inferência estatística se resume ao uso de "regras práticas" não substanciadas e não inferenciais, pois, de acordo com Guide e Ketokivi (2015), é crucial fazer uma distinção entre regras que ligam diretamente a um teste inferencial e aquelas que não o fazem. Para tratar este problema, os editores sugerem começar com uma questão estatística elementar: ao aplicar qualquer teste estatístico, quais são as hipóteses que estão sendo testadas? Os pesquisadores devem demonstrar uma compreensão de quais regras têm base na inferência estatística formal e quais não. Um teste simples proposto é verificar se o procedimento usado produz uma estatística de teste (com um valor-p) ou não? Devem também contextualizar suas medições em vez de confiar em "regras práticas", ou seja, verificar como o erro de medição nas variáveis afeta a estimativa. Ainda segundo os editores, são absurdos todos os pontos de corte geralmente recomendados que ignoram o tamanho da amostra e sem incorporar o contexto. Para estabelecer qual estimador deve ser usado em um modelo é necessário descrever detalhadamente o modelo, os dados, as distribuições das variáveis e até que ponto se acredita que o modelo está especificado corretamente;

- Entendimento das ferramentas usadas: a crítica diz respeito ao uso (incorreto) generalizado da SEM tendo por justificativa a sua adequação para amostras pequenas, para quando se tem indicadores formativos em um modelo de medição ou para quando o estimador de máxima verossimilhança não consegue convergir para uma solução. Para Guide e Ketokivi (2015), não é aceitável a alegação simples de que o PLS corrige problemas ou supera as deficiências associadas a outros estimadores e sugerem que a sua escolha deve estar transparentemente justificativa, se possível baseada em sólido referencial teórico;

- Cautela com alegações sobre viés de método comum: segundo Guide e Ketokivi (2015) seria impossível abordar adequadamente o viés de método comum em pesquisas de levantamento porque o informante, que é uma das fontes conhecidas de viés potencial, simplesmente não pode ser testado mesmo aplicando testes. Se o desenho da pesquisa depender de apenas um informante por unidade de observação, não há como determinar que proporção da variância do item é a variância do traço. Desta forma, o que se sugere é que "a conclusão de não há viés de método comum deve ser feita com muita cautela (se houver) se o teste estatístico usado para examiná-lo for "fraco";

- Atualização sobre os desenvolvimentos metodológicos: o alerta de Guide e Ketokivi (2015) é para o fato de, embora a teoria estatística em si não tenha tantos progressos com o passar do tempo, o mesmo não ocorre com os aplicativos de software, com as soluções disponíveis, com as maneiras de 
tratar ou solucionar as questões e com a rigidez das suposições que adotamos. Os editores sugerem que os pesquisadores devam ser cautelosos com o "benchmarking" para pesquisa de metodologia publicada há mais de vinte anos, pois consideram que textos mais antigos têm muito material útil, mas não devem ser usados como manuais de pesquisa;

Bastante alinhado com as críticas de Guide e Ketokivi (2015) sobre as características da SEM que são tratadas como pontos fortes pelos pesquisadores e as considerações necessárias sobre o contexto específico de uma pesquisa, Petter (2018) analisou as principais razões pelas quais muito se fala do uso excessivo da PLS no campo dos sistemas de informação, ou seja:

- Muito "fácil de usar". O problema é que qualquer um pode usar a ferramenta e obter resultados, ou seja, independentemente de o indivíduo ter um entendimento verdadeiro de como a PLS desenvolve suas estimativas, de quão cuidadosamente ou impensadamente um pesquisador tenha desenvolvido um modelo de pesquisa, de quão bem um indivíduo entende a saída, mesmo que o modelo seja especificado incorretamente, mesmo que tenha um pequeno tamanho de amostra, mesmo que seja defeituoso em sua formulação, sempre há um resultado. Segundo Petter (2018), há confusão entre a falta de confiança em um projeto de pesquisa específico com a confiança na técnica da PLS;

- Uso da PLS para justificar pequenas amostras. Como a PLS fornece um resultado mesmo com amostras pequenas, os pesquisadores ignoram que talvez o seu pequeno tamanho não seja praticamente útil, pois há evidência de que a PLS não é robusto em amostras de tamanho menor (tão pequenas quanto 30-50 indivíduos). Há preocupações associadas à impossibilidade de detectar relacionamentos dentro do modelo e à limitação quanto à generalização dos resultados (Petter, 2018);

- Uso de justificativas inadequadas à escolha do PLS. Entre as muitas justificativas dadas para o uso da PLS estão: pesquisa "exploratória" ou "não testada", mesmo quando são simplesmente replicações de modelos existentes com um novo ou dois novos elementos adicionados ao modelo; modelo de pesquisa com constructos mensurados de forma artificial, mesmo quando o modelo também poderia ter sido testado utilizando modelagem de equações estruturais com estimação baseada em covariância (CB-SEM); e tamanho menor da amostra. De uma forma geral, para Petter (2018), o uso de justificativas incorretas ou fracas da PLS geram dúvidas sobre a qualidade da PLS como técnica de análise se comparado com o CB-SEM.

Por outro lado, Petter (2018) também cita situações em que a PLS é a melhor escolha para a analisar um modelo estrutural se comparado à CB-SEM.

- Requisitos. A PLS não possui o requisito da CB-SEM para especificar a medição e o modelo estrutural (identificação). Com frequência é necessário ajustar modelos para restringir um caminho de erro ou adicionar outro constructo para garantir que não se receba erros de "identificação" que impeçam que a CB-SEM forneça estimativas de parâmetros. Este requisito também protege contra 
amostras pequenas e insuficientes para estimar os parâmetros que impedem que o modelo seja executado (ou seja, nenhum resultado será fornecido). No entanto, Petter (2018) alerta para o risco de deixar o empirismo ditar os modelos de pesquisa, em vez da teoria quando o pesquisador pode ser forçado a desenvolver um modelo (e alterar o modelo criado com base na teoria) para atender às necessidades da ferramenta. Este raciocínio é próximo ao de Bido, Mantovani e Cohen (2018) que alertam para a possibilidade de destruição de escalas de mensuração em razão da avaliação dos resultados da aplicação de um análise fatorial exploratória desconectada da teoria.

- PLS é baseado na regressão. A PLS usa dados brutos para gerar estimativas e seu propósito é avaliar quão bem um modelo se ajusta a um conjunto de dados específico, o que não significa que o modelo se ajustará igualmente a outro conjunto de dados similar. Por outro lado, a PLS é baseada na regressão e usa o conceito de "variância explicada" para entender a relação entre o modelo e os dados, ou seja, o modelo procura identificar estimativas de parâmetros que maximizem a quantidade de variação explicada nas variáveis dependentes pelas variáveis independentes. Assim, a PLS seria mais adequada quando se quer conhecer e entender a variação nas variáveis dependentes que são explicadas pelas variáveis independentes Petter (2018, p. 12).

A PLS-SEM é calculada a partir de um modelo de equações estruturais (SEM) ou diagrama de caminhos desenvolvido (Figura 28) a partir do modelo conceitual proposto (Figura 21). A estimação por mínimos quadrados parciais (PLS-SEM) envolve basicamente dois conjuntos de avaliações, a avaliação do modelo de mensuração e a avaliação do modelo estrutural (Hair Jr. et al., 2017; Henseler et al., 2009). Considerando que também foram realizadas análises de mediação, o conjunto de análises e testes realizados nesta fase quantitativa do estudo estão representados na Figura 30.

Figura 30 - Esquema de avaliação do modelo de equações estruturais
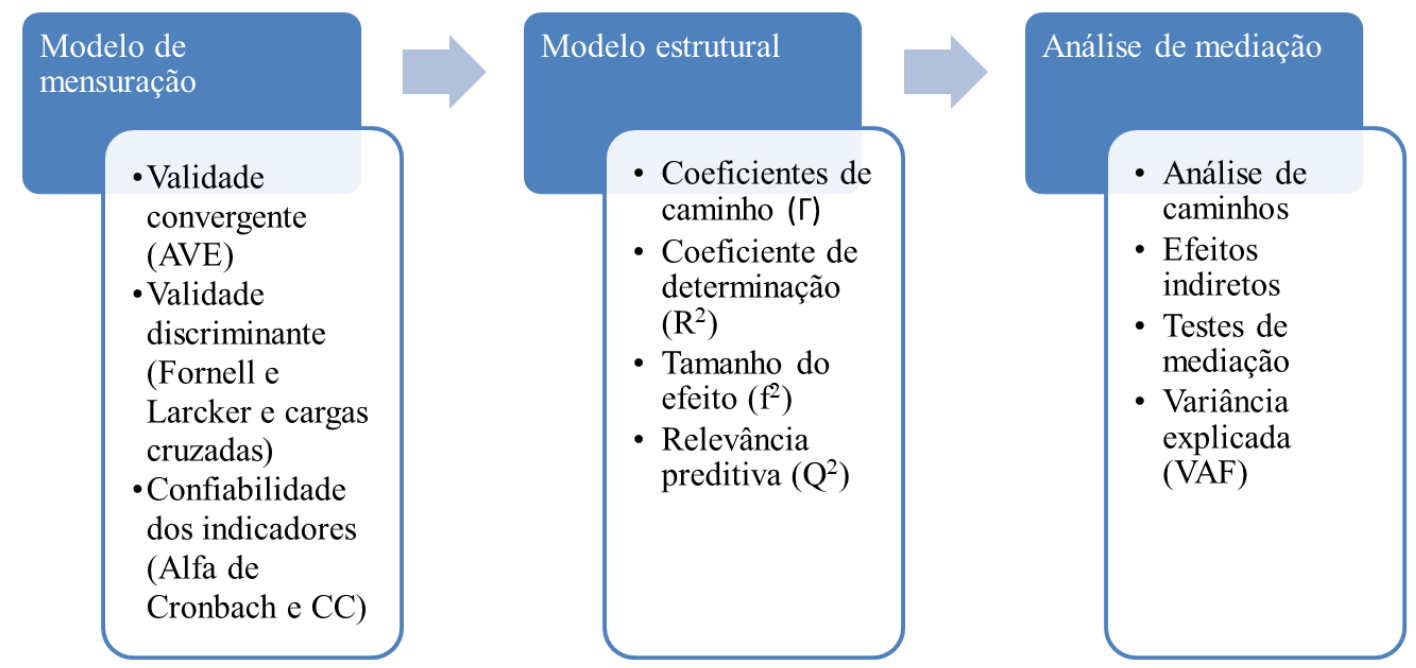

Fonte: dados da pesquisa.

Considerando o modelo conceitual proposto e a decisão pela análise utilizando a modelagem de equações estruturais com estimação por mínimos quadrados parciais (PLS-SEM), foi selecionada 
como ferramenta para tratamento dos dados empíricos quantitativos o software SmartPLS ${ }^{\circledR}$ (2019) versão 3.2. ${ }^{18}$. Esta decisão teve por base as seguintes razões (Avkiran \& Ringle, 2018) (Ringle et al., 2014):

- atendimento aos requisitos para a estimação por PLS-SEM e para a modelagem:

- modelo composto por uma única estrutura;

- modelo de caminhos recursivo (não há relação causal recíproca dentro do modelo);

- variáveis latentes ou constructos com pelo menos um indicador atribuído;

- indicadores atribuídos apenas uma vez para cada variável latente.

- a interface gráfica do software facilita a visualização dos modelo, análise dos resultados e eventuais ajustes necessários;

- a interface gráfica também auxilia na comunicação e na apresentação dos resultados.

\subsection{Avaliação do modelo de mensuração}

No modelo de mensuração reflexiva, o foco da análise da validade dos constructos está na convergência e discriminância entre eles. A validade convergente verifica se os itens de uma escala convergem ou têm cargas conjuntas em relação a um único constructo ou dimensão.

Já a validade discriminante representa o quanto cada medida de um dado constructo difere das medidas dos outros constructos do mesmo modelo. A verificação da confiabilidade e validade de cada um dos constructos e do modelo de influências inclui três testes estatísticos para avaliação das variáveis latentes reflexivas do modelo (Hair Jr. et al., 2017; Henseler et al., 2009; Vinzi, Chin, et al., 2010): confiabilidade dos indicadores ou de carga fatorial; confiabilidade de consistência interna e validade convergente; e validade discriminante.

Bido e Da Silva (2019) sugerem dois modelos de tabelas para se avaliar o modelo de mensuração, os quais são apresentados a seguir já com os dados da análise inicial (primeira rodada) desta pesquisa como exemplo. A primeira (Tabela 40) é usada para a análise no nível dos constructos e a segunda (Tabela 41) para a análise preferencialmente simultânea no nível dos indicadores. A Tabela 40 é composta pelos dados da análise da validade discriminante pelo critério de Fornell-Larcker e pelos dados da análise de confiabilidade e validade dos constructos.

${ }^{18}$ SmartPLS $^{\circledR}$ (2019) Professional Versão 3.2.8 - licença adquirida da SmartPLS GmbH em julho de 2019 (Invoice No.: 2019-16071). 
Tabela 40 - Matriz de correlação entre as variáveis latentes ( $\mathrm{n}=209)$

\begin{tabular}{|c|c|c|c|c|c|c|c|c|c|c|}
\hline & $\begin{array}{l}\text { Compe- } \\
\text { tências }\end{array}$ & $\begin{array}{c}\text { DE- } \\
\text { SEMPE- } \\
\text { NHO } \\
\end{array}$ & $\begin{array}{c}\text { Desen- } \\
\text { volvi- } \\
\text { mento } \\
\end{array}$ & $\begin{array}{c}\text { Especi- } \\
\text { ficações_- } \\
\text { Técnicas } \\
\end{array}$ & Gestão & $\begin{array}{l}\text { Organi- } \\
\text { zação }\end{array}$ & Portfolio & Recursos & $\begin{array}{c}\text { Requisi- } \\
\text { tos do } \\
\text { Projeto } \\
\end{array}$ & $\begin{array}{c}\text { Requisi- } \\
\text { tos_Re- } \\
\text { gulatórios }\end{array}$ \\
\hline Competências & 0,886 & & & & & & & & & \\
\hline DESEMPENHO & 0,260 & 0,730 & & & & & & & & \\
\hline Desenvolvimento & 0,697 & 0,335 & 0,738 & & & & & & & \\
\hline $\begin{array}{l}\text { Especificações_ } \\
\text { Técnicas }\end{array}$ & 0,589 & 0,296 & 0,736 & 0,676 & & & & & & \\
\hline Gestão & 0,576 & 0,383 & 0,768 & 0,655 & 0,715 & & & & & \\
\hline Organização & 0,635 & 0,286 & 0,639 & 0,504 & 0,683 & 0,859 & & & & \\
\hline Portfolio & 0,603 & 0,360 & 0,726 & 0,629 & 0,817 & 0,663 & 0,763 & & & \\
\hline Recursos & 0,773 & 0,244 & 0,690 & 0,604 & 0,585 & 0,722 & 0,589 & 0,716 & & \\
\hline $\begin{array}{l}\text { Requisitos do } \\
\text { Projeto }\end{array}$ & 0,402 & 0,254 & 0,566 & 0,618 & 0,578 & 0,443 & 0,544 & 0,533 & $\mathbf{0 , 7 5 7}$ & \\
\hline $\begin{array}{l}\text { Requisitos_Regu- } \\
\text { latórios }\end{array}$ & 0,438 & 0,263 & 0,612 & 0,654 & 0,532 & 0,390 & 0,531 & 0,458 & 0,553 & 0,785 \\
\hline Alfa de Cronbach & 0,862 & 0,769 & 0,860 & $\mathbf{0 , 8 2 7}$ & $\mathbf{0 , 8 0 3}$ & $\mathbf{0 , 8 8 1}$ & 0,759 & 0,809 & 0,621 & 0,688 \\
\hline $\begin{array}{l}\text { Confiabilidade } \\
\text { Composta }\end{array}$ & 0,916 & $\mathbf{0 , 8 4 5}$ & $\mathbf{0 , 8 9 3}$ & 0,869 & 0,860 & 0,918 & 0,847 & 0,862 & $\mathbf{0 , 8 0 0}$ & $\mathbf{0 , 8 2 8}$ \\
\hline $\begin{array}{l}\text { Variância Média } \\
\text { Extraída (AVE) }\end{array}$ & $\mathbf{0 , 7 8 4}$ & $\mathbf{0 , 5 3 3}$ & 0,545 & 0,457 & 0,511 & $\mathbf{0 , 7 3 7}$ & 0,582 & 0,513 & 0,573 & 0,616 \\
\hline
\end{tabular}

Notas: Resultado da primeira rodada de cálculo usando o SmartPLS ${ }^{\circledast}$ (2019).Os valores na diagonal (fundo escuro) são as raizes quadradas das AVE. Todas as correlações são significantes a 5\%. Alfa de Cronbach, Confiabilidade Composta (CC) e Variância Média Extraída (AVE) são medidas de confiabilidade. Em destaque (itálico e célula em tom mais escuro) os resultados fora dos parâmetros desejáveis. Fonte: baseado em Bido e Da Silva (2019, p. 496) com dados da pesquisa.

A Tabela 41, por sua vez, é composta pelos dados da análise da validade discriminante por meio das cargas fatoriais e das cargas cruzadas ("cross-loading").

Tabela 41 - Matriz de cargas fatoriais e cargas cruzadas ("crossloads") (n = 209)

\begin{tabular}{|l|c|c|c|c|c|c|c|c|c|c|}
\hline & $\begin{array}{c}\text { Competên- } \\
\text { cias }\end{array}$ & $\begin{array}{c}\text { Desenvol- } \\
\text { vimento }\end{array}$ & $\begin{array}{c}\text { Especifica- } \\
\text { céces } \\
\text { Técnicas }\end{array}$ & Gestão & $\begin{array}{c}\text { DESEM- } \\
\text { PENHO }\end{array}$ & $\begin{array}{c}\text { Organiza- } \\
\text { ção }\end{array}$ & Portfolio & Recursos & $\begin{array}{c}\text { Requisitos } \\
\text { do Projeto }\end{array}$ & $\begin{array}{c}\text { Requisitos } \\
\text { Regulató- } \\
\text { rios }\end{array}$ \\
\hline CP1 & $\mathbf{0 , 9 0 2}$ & 0,620 & 0,542 & 0,486 & 0,267 & 0,572 & 0,527 & 0,671 & 0,356 & 0,381 \\
\hline CP2 & $\mathbf{0 , 9 1 6}$ & 0,638 & 0,545 & 0,537 & 0,221 & 0,555 & 0,540 & 0,691 & 0,323 & 0,377 \\
\hline CP3 & $\mathbf{0 , 8 3 7}$ & 0,592 & 0,477 & 0,508 & 0,204 & 0,559 & 0,537 & 0,692 & 0,389 & 0,405 \\
\hline DP1 & 0,549 & $\mathbf{0 , 7 1 7}$ & 0,567 & 0,496 & 0,239 & 0,443 & 0,438 & 0,510 & 0,423 & 0,357 \\
\hline DP2 & 0,439 & $\mathbf{0 , 7 1 8}$ & 0,513 & 0,579 & 0,269 & 0,472 & 0,560 & 0,466 & 0,455 & 0,394 \\
\hline DP3 & 0,551 & $\mathbf{0 , 7 2 4}$ & 0,587 & 0,575 & 0,276 & 0,374 & 0,573 & 0,536 & 0,501 & 0,525 \\
\hline DP4 & 0,474 & $\mathbf{0 , 7 7 8}$ & 0,568 & 0,581 & 0,264 & 0,493 & 0,523 & 0,503 & 0,383 & 0,481 \\
\hline DP5 & 0,415 & $\mathbf{0 , 6 6 8}$ & 0,414 & 0,505 & 0,203 & 0,425 & 0,453 & 0,437 & 0,357 & 0,400 \\
\hline DP6 & 0,667 & $\mathbf{0 , 8 0 0}$ & 0,610 & 0,602 & 0,281 & 0,583 & 0,608 & 0,632 & 0,386 & 0,521 \\
\hline DP7 & 0,492 & $\mathbf{0 , 7 5 5}$ & 0,531 & 0,618 & 0,197 & 0,498 & 0,576 & 0,473 & 0,420 & 0,469 \\
\hline ET1 & 0,423 & 0,493 & $\mathbf{0 , 6 7 3}$ & 0,479 & 0,120 & 0,408 & 0,523 & 0,464 & 0,454 & 0,447 \\
\hline ET2 & 0,448 & 0,494 & $\mathbf{0 , 6 2 6}$ & 0,416 & 0,185 & 0,323 & 0,355 & 0,369 & 0,350 & 0,281 \\
\hline ET3 & 0,422 & 0,522 & $\mathbf{0 , 6 4 7}$ & 0,434 & 0,309 & 0,250 & 0,377 & 0,338 & 0,335 & 0,389 \\
\hline ET4 & 0,395 & 0,477 & $\mathbf{0 , 7 0 2}$ & 0,445 & 0,180 & 0,298 & 0,421 & 0,340 & 0,401 & 0,471 \\
\hline ET5 & 0,398 & 0,571 & $\mathbf{0 , 7 6 2}$ & 0,510 & 0,136 & 0,416 & 0,461 & 0,492 & 0,510 & 0,523 \\
\hline ET6 & 0,384 & 0,484 & $\mathbf{0 , 7 7 0}$ & 0,430 & 0,221 & 0,361 & 0,436 & 0,432 & 0,473 & 0,485 \\
\hline ET7 & 0,420 & 0,553 & $\mathbf{0 , 6 7 8}$ & 0,472 & 0,247 & 0,388 & 0,457 & 0,391 & 0,398 & 0,506 \\
\hline
\end{tabular}




\begin{tabular}{|c|c|c|c|c|c|c|c|c|c|c|}
\hline & \begin{tabular}{|c|}
$\begin{array}{c}\text { Competên- } \\
\text { cias }\end{array}$ \\
\end{tabular} & \begin{tabular}{|l|}
$\begin{array}{l}\text { Desenvol- } \\
\text { vimento }\end{array}$ \\
\end{tabular} & $\begin{array}{c}\text { Especifica- } \\
\text { cões_- } \\
\text { Técnicas }\end{array}$ & Gestão & $\begin{array}{l}\text { DESEM- } \\
\text { PENHO }\end{array}$ & $\begin{array}{c}\text { Organiza- } \\
\text { ção }\end{array}$ & Portfolio & Recursos & \begin{tabular}{l|} 
Requisitos \\
do Projeto
\end{tabular} & $\begin{array}{c}\text { Requisitos_- } \\
\text { Regulató- } \\
\text { rios }\end{array}$ \\
\hline ET8 & 0,306 & 0,376 & 0,514 & 0,344 & 0,233 & 0,255 & 0,355 & 0,435 & 0,393 & 0,399 \\
\hline GT1 & 0,546 & 0,651 & 0,568 & 0,775 & 0,312 & 0,498 & 0,659 & 0,454 & 0,390 & 0,450 \\
\hline GT2 & 0,328 & 0,515 & 0,437 & 0,728 & 0,229 & 0,449 & 0,557 & 0,398 & 0,405 & 0,342 \\
\hline GT3 & 0,473 & 0,677 & 0,558 & 0,812 & 0,313 & 0,562 & 0,701 & 0,487 & 0,509 & 0,442 \\
\hline GT4 & 0,408 & 0,604 & 0,498 & 0,782 & 0,321 & 0,583 & 0,637 & 0,426 & 0,446 & 0,458 \\
\hline GT5 & 0,380 & 0,435 & 0,328 & 0,624 & 0,195 & 0,438 & 0,436 & 0,352 & 0,297 & 0,264 \\
\hline GT6 & 0,304 & 0,326 & 0,372 & 0,522 & 0,259 & 0,368 & 0,460 & 0,392 & 0,433 & 0,278 \\
\hline ID1 & 0,252 & 0,297 & 0,242 & 0,317 & 0,805 & 0,262 & 0,328 & 0,189 & 0,171 & 0,229 \\
\hline ID2 & 0,196 & 0,280 & 0,297 & 0,357 & 0,856 & 0,242 & 0,332 & 0,258 & 0,281 & 0,212 \\
\hline ID3 & 0,196 & 0,121 & 0,172 & 0,139 & 0,418 & 0,082 & 0,159 & 0,186 & 0,168 & 0,217 \\
\hline ID4 & 0,165 & 0,213 & 0,151 & 0,263 & 0,749 & 0,206 & 0,249 & 0,132 & 0,187 & 0,185 \\
\hline ID5 & 0,154 & 0,271 & 0,201 & 0,272 & 0,742 & 0,206 & 0,206 & 0,126 & 0,116 & 0,142 \\
\hline OR1 & 0,534 & 0,562 & 0,431 & 0,626 & 0,255 & 0,873 & 0,594 & 0,607 & 0,347 & 0,273 \\
\hline OR2 & 0,524 & 0,565 & 0,416 & 0,566 & 0,267 & 0,851 & 0,566 & 0,589 & 0,396 & 0,378 \\
\hline OR3 & 0,510 & 0,520 & 0,427 & 0,590 & 0,244 & 0,868 & 0,560 & 0,619 & 0,422 & 0,335 \\
\hline OR4 & 0,609 & 0,547 & 0,454 & 0,563 & 0,217 & 0,843 & 0,556 & 0,662 & 0,357 & 0,354 \\
\hline PF1 & 0,458 & 0,490 & 0,375 & 0,535 & 0,187 & 0,479 & 0,731 & 0,462 & 0,417 & 0,325 \\
\hline PF2 & 0,483 & 0,537 & 0,482 & 0,637 & 0,266 & 0,536 & 0,806 & 0,480 & 0,407 & 0,443 \\
\hline PF3 & 0,467 & 0,610 & 0,527 & 0,664 & 0,292 & 0,475 & 0,822 & 0,452 & 0,426 & 0,480 \\
\hline PF4 & 0,434 & 0,570 & 0,524 & 0,646 & 0,346 & 0,534 & 0,686 & 0,405 & 0,411 & 0,359 \\
\hline RE1 & 0,552 & 0,498 & 0,412 & 0,380 & 0,124 & 0,506 & 0,406 & 0,718 & 0,409 & 0,362 \\
\hline RE2 & 0,377 & 0,440 & 0,369 & 0,377 & 0,240 & 0,351 & 0,346 & 0,590 & 0,364 & 0,255 \\
\hline RE3 & 0,422 & 0,444 & 0,430 & 0,345 & 0,138 & 0,453 & 0,326 & 0,691 & 0,384 & 0,276 \\
\hline RE4 & 0,683 & 0,514 & 0,504 & 0,456 & 0,192 & 0,619 & 0,465 & 0,785 & 0,350 & 0,334 \\
\hline RE5 & 0,680 & 0,589 & 0,476 & 0,479 & 0,175 & 0,554 & 0,469 & 0,788 & 0,383 & 0,378 \\
\hline RE6 & 0,540 & 0,470 & 0,392 & 0,466 & 0,194 & 0,573 & 0,493 & 0,705 & 0,421 & 0,346 \\
\hline RP1 & 0,198 & 0,322 & 0,458 & 0,406 & 0,132 & 0,255 & 0,372 & 0,339 & 0,784 & 0,410 \\
\hline RP2 & 0,361 & 0,497 & 0,507 & 0,491 & 0,275 & 0,417 & 0,444 & 0,483 & 0,822 & 0,404 \\
\hline RP3 & 0,353 & 0,464 & 0,434 & 0,412 & 0,163 & 0,329 & 0,418 & 0,383 & 0,656 & 0,445 \\
\hline RR1 & 0,322 & 0,508 & 0,505 & 0,460 & 0,233 & 0,370 & 0,434 & 0,403 & 0,457 & $\mathbf{0 , 8 0 3}$ \\
\hline RR2 & 0,351 & 0,467 & 0,537 & 0,389 & 0,174 & 0,276 & 0,424 & 0,327 & 0,415 & 0,771 \\
\hline RR3 & 0,357 & 0,467 & 0,498 & 0,404 & 0,213 & 0,271 & 0,391 & 0,348 & 0,431 & 0,780 \\
\hline
\end{tabular}

Notas: Resultado da primeira rodada de cálculo usando o SmartPLS ${ }^{\circledR}$ (2019). Todas as cargas fatoriais são significantes a 5\%. As cargas cruzadas altas em relação às cargas fatoriais estão em itálico. Os indicadores com a célula com fundo na cor branca são candidatos à serem excluídos do modelo. Fonte: baseado em Bido e Da Silva (2019, pp. 497-8) com dados da pesquisa.

A avaliação do modelo de mensuração a partir dos dados constantes das Tabelas 40 e 41 segue a sequência sugerida por Bido e Da Silva (2019), pois um dos pressupostos para a avaliação da confiabilidade é a unidimensionalidade do construto, ou seja, sua validade convergente e discriminante devem estar adequadas. Assim, a avaliação da confiabilidade só deve ser realizada se não houver 
problema de validade convergente ou discriminante. A confiabilidade da consistência interna e a validade convergente dos constructos validam as variáveis latentes para a composição do modelo.

\subsection{Confiabilidade dos indicadores ou de carga fatorial}

No modelo proposto, os constructos são mensurados de forma reflexiva. Assim, de acordo com Hair Jr e colaboradores (2017), a avaliação do modelo deve ser iniciada pelo exame das cargas fatoriais dos indicadores. Este procedimento permite verificar a consistência das variáveis reflexivas (indicadores) por meio da exposição da carga de cada uma (indicador) na composição do modelo.

As cargas fatoriais das variáveis do modelo podem ser observadas por meio de uma tabela que apresenta também as cargas cruzadas entre os indicadores e os constructos (exemplo: Tabela 41). Como regra geral, indicadores com cargas inferiores a 0,40 devem ser excluídas e indicadores com carga entre 0,40 e 0,70 devem passar pela análise do impacto da exclusão sobre os valores da AVE e da Confiabilidade Composta (Hair Jr. et al., 2017; Henseler et al., 2009; Vinzi, Chin, et al., 2010), as quais serão abordadas mais adiante. É realizada a exclusão dos indicadores do modelo que não atendem à regra, pois poderiam apresentar efeitos adversos na validade convergente e confiabilidade da consistência interna na mensuração do constructo, visto que cargas abaixo de 0,70 indicam que o constructo explica menos de 50\% da variação do indicador (Hair Jr. et al., 2017).

\subsection{Validade convergente dos constructos}

O exame da validade convergente dos constructos busca dimensionar o quanto um constructo converge em seus indicadores explicando a variação dos itens que o compõem (Hair Jr. et al., 2017; Vinzi, Chin, et al., 2010). O exame da consistência interna dos constructos busca verificar se os itens que o compõem não são redundantes, contribuindo assim com informação para a mensuração do constructo. Para examinar a confiabilidade da consistência interna são realizados os seguintes testes estatísticos:

- Confiabilidade do Alpha de Cronbach ( $\alpha$ ): este indicador de confiabilidade interna das escalas estima indiretamente o grau de confiança com que o conjunto de indicadores mede um constructo único (Hair Jr. et al., 2017; Vinzi, Chin, et al., 2010), ou seja, pela correlação entre os itens que constituem cada constructo. Hair Jr e colaboradores (2017)e Vinzi e colaboradores (2010) consideram desejáveis valores de $\alpha$ de no mínimo 0,7. No caso de estudos exploratórios, Hair Jr e colaboradores (2017) consideram aceitáveis valores a partir de 0,60;

- Variância extraída (“Average Variance Extracted” - AVE): o teste AVE é calculado por meio da média do quadrado das cargas para todos os indicadores associados a um constructo. Tem por objetivo verificar a proporção da variância da dimensão o constructo que é explicada a partir dos indicadores que o compõem. Hair Jr e colaboradores (2017) consideram aceitável quando em média o constructo explica mais de 50\% da variação de seus itens, ou seja, os valores da AVE devem ser no mínimo iguais 0,50 (exemplo: Tabela 40). Valores menores que 0,50 indicariam que, em média, mais 
variação permanece no erro dos itens do que na variação explicada pelo construto (Fornell \& Larcker, 1981);

- Confiabilidade Composta - CC (Composite Reliability - CR): avalia o grau de confiança de cada indicador na formação do construto ao qual pertence. Fornell e Larcker (1981) e Hair Jr e colaboradores (2017) consideram que são desejáveis valores acima de 0,70 para que o constructo tenha grau de confiança aceitável.

Bido e Da Silva (2019) indicam um cuidado a ser tomado ao tratar das relações entre os constructos de segunda ordem e seus constructos de primeira. Segundo os pesquisadores, é necessário calcular a AVE e a CC separadamente, porque o SmartPLS ${ }^{\circledR}$ (2019) na sua versão 3 faz esses cálculos com os indicadores que foram repetidos no constructo de segunda ordem. Assim, neste pesquisa a CC foi calculada a partir de dados empíricos coletados, processados pelo software SmartPLS ${ }^{\circledast}$ (2019) e tratados usando uma planilha MS Excel ${ }^{\circledR}$ elaborada por Bido (2008).

\subsection{Validade discriminante dos constructos}

A validade discriminante tem por objetivo avaliar se um constructo é empiricamente distinto dos demais constructos no modelo de caminho em termos do quanto se correlaciona com outros constructos e em termos de quão distintamente os indicadores representam apenas esse constructo. Duas avaliações são utilizadas (Fornell \& Larcker, 1981; Hair Jr. et al., 2017): cargas cruzadas dos indicadores e critério de Fornell-Larcker. O modelo possui indicativo de validade discriminante caso apresente resultados satisfatórias para estes dois critérios.

- Critério de Fornell-Larcker (Fornell \& Larcker, 1981). É considerado o critério mais rigoroso para avaliação da validade discriminante. A diagonal da matriz de correlação entre os constructos apresentada os valores das raízes quadradas das médias das variâncias extraídas (AVE) de cada constructo (exemplo: Tabela 40). A AVE de cada constructo deve ser maior do que a correlação entre qualquer par de constructos latentes, sendo necessária a comparação dos valores da raiz quadrada da AVE de cada constructo com seus índices de correlação com todos os constructos (Hair Jr. et al., 2017). Desta forma, a raiz quadrada da AVE deve ser maior que a correlação entre os constructos $\left(\sqrt{A V E}>r_{\mathrm{VL}}\right)$.

Caso sejam encontrados constructos com valores da raiz quadrada da AVE inferiores às suas correlações com outros constructos (possível problema de validade discriminante), sugere-se que sejam analisadas as cargas cruzadas dos indicadores antes que sejam decididas eventuais medidas corretivas para o ajuste do modelo.

- Cargas cruzadas dos indicadores - verifica se a carga compartilhada com o constructo ao qual o indicador está associado é maior do que as cargas associadas a outros constructos, ou seja, realiza-se o correlacionamento das cargas dos indicadores de cada constructo com todos os outros indicadores 
(exemplo: Tabela 41). Assim, se as cargas dos indicadores forem consistentemente mais altas no constructo com o qual estão associados do que em outro constructo tanto na horizontal quanto na vertical, considera-se que o constructo demonstra validade discriminante (Fornell \& Larcker, 1981; Hair Jr. et al., 2017). Assim, como regra geral, as cargas fatoriais devem ser maiores que as cargas cruzadas (na horizontal e vertical na tabela)

$\mathrm{Na}$ avaliação das cargas cruzadas dos indicadores, caso sejam encontrados indicadores cujas maiores cargas compartilhadas não sejam com os respectivos constructos aos quais estão associados e/ou que estiverem carregando cargas altas ou valores próximos em mais de um constructo, considerase haver indícios de problema com a validade discriminante. Neste caso, sugere-se retirar do modelo estes indicadores um a um, utilizando como critério de seleção os itens mais críticos a cada rodada. Depois de ajustado, deve-se realizar outra vez o processamento do modelo (rodada) no software SmartPLS ${ }^{\circledR}$ (2019) para uma nova avaliação e os ajustes eventualmente necessários até que os todos os critérios tenham sido atendidos.

Como regra geral, a criticidade do problema encontrado e exclusão do indicador atenderam aos seguintes critérios: a. os indicadores cujas maiores cargas compartilhadas não foram com os respectivos constructos aos quais estavam associados; b. entre os indicadores que apresentaram cargas altas ou valores próximos em mais de um constructo, foram considerados mais críticos os que apresentaram as menores diferenças entre suas cargas nos constructos com valores mais próximos.

Em resumo, nos casos em que os valores mínimos recomendados não são atingidos na rodada, Bido e Da Silva (2019) sugerem as seguintes ações (Tabela 42) para melhorar o ajuste do modelo:

Tabela 42 - Possíveis resultados da análise da validade discriminante e ações sugeridas

\begin{tabular}{|c|c|c|}
\hline Resultados & Decisão sugerida & Comentário \\
\hline $\begin{array}{c}\text { Algumas cargas }<0,7 \\
\text { AVE }>0,5 \\
\text { CR }>0,7\end{array}$ & Manter o modelo & $\begin{array}{l}\text { Sempre que possível, recomenda-se manter o } \\
\text { máximo de indicadores no modelo para não } \\
\text { prejudicar a validade de conteúdo. }\end{array}$ \\
\hline $\begin{array}{c}\text { Algumas cargas }<0,7 \\
\text { AVE }<0,5 \\
\text { CR }>0,7\end{array}$ & $\begin{array}{l}\text { Excluir indicador com carga } \\
\text { baixa e avaliar o modelo } \\
\text { novamente }\end{array}$ & $\begin{array}{l}\text { Esses pontos de corte não são inflexíveis, às vezes, } \\
\text { é melhor manter mais indicadores, mesmo com } \\
\text { AVE um pouco abaixo de } 0,5 \text {. }\end{array}$ \\
\hline$\sqrt{ } \mathrm{AVE}$ & $\begin{array}{l}\text { Eliminar indicadores com } \\
\text { cargas mais baixas } \\
\text { (aumenta-se a AVE) } \\
\text { Eliminar indicadores com } \\
\text { cargas cruzadas altas } \\
\text { (diminui-se a correlação } \\
\text { entre os constructos) }\end{array}$ & $\begin{array}{l}\text { Se ambas as providências não forem suficientes, } \\
\text { conclui-se que não há validade discriminante entre } \\
\text { os constructos e decide-se por: (i) eliminar uma } \\
\text { delas do modelo ou (ii) agrupá-las em um único } \\
\text { constructo, o que pode ser inadequado porque } \\
\text { demandaria uma revisão nas definições conceituais } \\
\text { para se manter a validade de conteúdo. }\end{array}$ \\
\hline
\end{tabular}

Notas: $\mathrm{AVE}=$ "average variance extracted". $\mathrm{CR}=$ "composite reliability". $r_{\mathrm{VL}}=$ correlação entre os constructos. Fonte: Bido e Da Silva (2019, p. 501).

Sempre que possível, recomenda-se manter o máximo de indicadores no modelo para não prejudicar a validade de conteúdo. Ao se eliminar muitos indicadores da mensuração podem ocorrer outros problemas como, por exemplo, a capitalização no acaso ("chance capitalization") levantando a 
dúvida sobre a replicabilidade dos resultados em nova amostra, inviabilização da comparação com resultados de outros estudos e prejuízo da aplicação da escala em estudos futuros (MacCallum, Roznowski, \& Necowitz, 1992).

\subsection{Avaliação do modelo estrutural}

O objetivo deste conjunto de testes é verificar a capacidade do modelo estrutural de prever os constructos endógenos, ou seja, comprovar as relações entre os constructos e a validade do modelo com base em cinco critérios: análise de multicolinearidade; coeficientes de determinação $\left(\mathrm{R}^{2}\right)$; relevância preditiva $\left(\mathrm{Q}^{2}\right)$; tamanho do efeito $\left(\mathrm{f}^{2}\right)$; e coeficientes de caminho do modelo estrutural.

\subsection{Coeficiente de determinação $\left(\mathrm{R}^{2}\right)$ de Pearson}

O coeficiente de determinação $\left(\mathrm{R}^{2}\right)$ traduz a precisão ou acurácia preditiva do modelo estrutural ao indicar a variância explicada de cada um dos constructos endógenos. Em outras palavras, ele representa os efeitos combinados dos constructos exógenas sobre os constructos endógenas e é calculado por meio da correlação quadrada entre os valores reais e preditos de um construto endógeno específico (Hair Jr. et al., 2017; Vinzi, Chin, et al., 2010). Portanto, avalia a porção da variância das variáveis endógenas que é explicada pelo modelo estrutural.

Os valores do coeficiente de determinação $\left(\mathrm{R}^{2}\right)$ vão de 0 a 1 , sendo que quanto mais próximo à unidade considera-se maior o grau de precisão preditiva. Hair Jr e colaboradores (2017) e Henseler e colaboradores (2009) consideram que modelos com valores de $\mathrm{R}^{2}$ a partir de 0,25 podem ser considerados com grau fraco de previsão preditiva. Já modelos com valores de $\mathrm{R}^{2}$ a partir de 0,50 seriam de grau moderado e valores de $\mathrm{R}^{2}$ a partir de 0,75 seriam de grau substancial. Entretanto, Guide e Ketokivi (2015) alertam para a necessidade de interpretar o $R^{2}$ no contexto do estudo em questão. De acordo com Cohen (1988) e Ringle e colaboradores (2014), para a área de ciências sociais e comportamentais, um $\mathrm{R}^{2}$ da ordem de $2 \%$ pode ser classificado como efeito pequeno, um $\mathrm{R}^{2}$ da ordem de $13 \%$ como efeito médio e um $\mathrm{R}^{2}$ da ordem de $26 \%$ como efeito grande. Como exemplo, quando o coeficiente da variável (constructo) dependente apresenta resultado de $\mathrm{R}^{2}=0,501$, os constructos (variáveis independentes) testados explicam substancialmente o valor criado na rede formada por eles em $50,1 \%$.

Bido e Da Silva (2019) adotam uma tabela (exemplo: Tabela 43) para avaliar o modelo estrutural contendo as hipóteses e os resultados para a estatística de multicolinearidade (VIF), $\mathrm{R}^{2}$ ajustado, $\mathrm{f}^{2}$ e coeficiente de caminho. 
Tabela 43 - Resultados do modelo estrutural $(\mathrm{n}=209)$

\begin{tabular}{|c|c|c|c|c|c|c|c|}
\hline & Hipótese & f2 & $\begin{array}{c}\text { Coefici- } \\
\text { ente } \\
\text { estrutural } \\
\end{array}$ & Média & $\begin{array}{c}\text { Erro } \\
\text { padrão }\end{array}$ & $\begin{array}{l}\text { Estatís- } \\
\text { tica T }\end{array}$ & Valor-p \\
\hline GERENCIAL -> DESEMPENHO & H1 (+) & & 0,326 & 0,329 & 0,145 & 2,246 & 0,025 \\
\hline GERENCIAL -> Desenvolvimento & & 0,877 & 0,937 & 0,937 & 0,009 & 99,140 & 0,000 \\
\hline GERENCIAL -> Gestão & & 0,714 & 0,845 & 0,846 & 0,022 & 38,006 & 0,000 \\
\hline GERENCIAL -> Portfolio & & 0,706 & 0,840 & 0,841 & 0,021 & 40,845 & 0,000 \\
\hline ESTRUTURAL -> Competências & & 0,743 & 0,862 & 0,861 & 0,023 & 37,446 & 0,000 \\
\hline ESTRUTURAL -> DESEMPENHO & H2 (+) & & 0,018 & 0,019 & 0,116 & 0,159 & $\mathbf{0 , 8 7 4}$ \\
\hline ESTRUTURAL -> GERENCIAL & & & 0,497 & 0,499 & 0,048 & 10,424 & 0,000 \\
\hline ESTRUTURAL -> Organização & & 0,805 & 0,897 & 0,897 & 0,016 & 57,132 & 0,000 \\
\hline ESTRUTURAL -> Recursos & & 0,734 & 0,857 & 0,857 & 0,024 & 36,192 & 0,000 \\
\hline TÉCNICO -> DESEMPENHO & H3 (+) & & 0,044 & 0,048 & 0,124 & $\mathbf{0 , 3 5 5}$ & $\mathbf{0 , 7 2 3}$ \\
\hline $\begin{array}{l}\text { TÉCNICO -> } \\
\text { Especificações_Técnicas }\end{array}$ & & 0,849 & 0,921 & 0,922 & 0,011 & 82,350 & 0,000 \\
\hline TÉCNICO -> GERENCIAL & & & 0,454 & 0,451 & 0,052 & 8,746 & 0,000 \\
\hline TÉCNICO -> Requisitos do Projeto & & 0630 & 0,794 & 0,795 & 0,029 & 27,073 & 0,000 \\
\hline $\begin{array}{l}\text { TÉCNICO -> } \\
\text { Requisitos_Regulatórios }\end{array}$ & & 0,666 & 0,816 & 0,817 & 0,027 & 29,905 & 0,000 \\
\hline
\end{tabular}

Nota: Valores-p estimados por bootstrapping com 1000 repetições. Legenda: $\mathrm{f}^{2}=$ tamanho do efeito de Cohen (1988), Maior VIF ("variance inflaction fator") = 3,810. Fonte: baseado em Bido e Da Silva (2019, p. 507) com dados da pesquisa.

\subsection{Relevância preditiva $\left(\mathrm{Q}^{2}\right)$}

A relevância preditiva $\left(\mathrm{Q}^{2}\right)$ avalia a qualidade da predição do modelo ou acurácia do modelo ajustado, ou seja, quanto o modelo se aproxima do que se esperava dele. Trata-se de uma técnica de resuso de amostra que omite os dados dos indicadores de cada constructo e utiliza as estimativas do modelo (dados remanescentes dos demais constructos) para predizer os dados omissos do respectivo constructo. Hair Jr e colaboradores (2017) consideram que um modelo com acurácia satisfatória deve apresentar valores positivos de relevância preditiva $\left(Q^{2}\right)$ e que um modelo perfeito teria sua relevância preditiva $\left(\mathrm{Q}^{2}\right)$ igual a 1 , pois indicaria que o modelo reflete a realidade sem erros.

\subsection{Tamanho do efeito $\left(\mathrm{f}^{2}\right)$ ou Indicador de Cohen}

Assim como a relevância preditiva $\left(\mathrm{Q}^{2}\right)$, o parâmetro de tamanho do efeito $\left(\mathrm{f}^{2}\right)$ tem por função estimar a qualidade de ajuste do modelo estrutural. Os resultados de ambos os indicadores são obtidos empregando-se o método "blindfolding" do software SmartPLS ${ }^{\circledR}$ (2019).

O tamanho do efeito $\left(\mathrm{f}^{2}\right)$ tem por função avaliar quanto cada constructo contribui ou é útil para o ajuste do modelo estrutural. Ele é calculado fazendo a inclusão e a exclusão um a um dos constructos do modelo, ou seja, ele avalia a mudança no valor $\mathrm{R}^{2}$ de um constructo endógeno quando um constructo exógeno é excluído do modelo. $\mathrm{O}^{2}{ }^{2}$ é avaliado pela razão entre a parte explicada pelo modelo e a parte não explicada $\left(\mathrm{f}^{2}=\mathrm{R}^{2} /\left(1-\mathrm{R}^{2}\right)\right)$ (Hair Jr. et al., 2017). 
De acordo com Cohen (1988) e Ringle e colaboradores (2014), valores de $\mathrm{f}^{2}$ acima de 0,02 indicam efeito fraco do constructo exógeno sobre o endógeno. Valores de $\mathrm{f}^{2}$ acima de 0,15 indicam efeito médio e acima de 0,35 indicam efeito forte do constructo exógeno sobre o constructo endógeno.

\subsection{Análise de multicolinearidade}

A análise de multicolinearidade foi realizada por meio do cálculo do fator de inflação da variância (VIF) ("Variance Inflation Factor" na língua inglesa). Como a estimativa dos coeficientes é baseada em regressões de mínimos quadrados ordinários, a presença de multicolinearidade pode gerar resultados tendenciosos (Hair Jr. et al., 2017). O VIF quantifica a gravidade da colinearidade entre os indicadores em um modelo de medição formativa e está diretamente relacionado ao valor de tolerância (VIFi = 1 / tolerância) (Hair et al., 2013:165).

No contexto do PLS-SEM, um valor de tolerância de 0,20 ou inferior e um valor de VIF de 5,00 e mais alto, respectivamente, indicam um problema de colinearidade potencial (Hair, Ringle, \& Sarstedt, 2011). Para Hair Jr e colaboradores (2017), se as relações apresentarem valores de VIF inferiores a 5,00, considera-se que há confiança de que os resultados do modelo estrutural não são afetados negativamente pela colinearidade e os constructos para a composição do modelo estão validados.

\subsection{Coeficientes de caminho do modelo estrutural}

Após a avaliação da qualidade de ajuste do modelo, foi realizada a verificação dos coeficientes de caminho ("path coefficients") do modelo estrutural com o objetivo de analisar a intensidade das relações (Hair Jr. et al., 2017). Os coeficientes de caminho são explicados como os betas ( $\beta$ ) das regressões lineares simples e representam as relações hipotetizadas entre os constructos do modelo (Ringle et al., 2014).

Os valores padronizados dos coeficientes de caminho variam entre -1 e +1 , sendo que valores próximos a +1 representam forte relação positiva. Por outro lado, próximos a -1 representam forte relação negativa. Como regra geral, Hair Jr e colaboradores (2017) consideram que coeficientes com valores acima e 0,20 são significativos e sugerem a manutenção da relação entre os constructos. Por outro lado, coeficientes abaixo de 0,20 são considerados pouco significativos, o que sugere a retirada da relação entre os constructos No entanto, a conclusão sobre a significância das relações deve considerar também a análise do erro padrão obtida por meio do teste $t$ de Student e da técnica de "bootstrapping".

Pela técnica de "bootstrapping" aplicada por meio do software SmartPLS ${ }^{\circledR}$ (2019), os dados originais foram reprocessados 1.000 vezes para a estimativa da significância dos caminhos a partir dos coeficientes originais e o erro padrão de cada caminho. Para este teste, definiu-se um nível mínimo de confiança de $95 \%(\alpha=$ ou $<0,05)$, ou seja, uma probabilidade de erro igual ou inferior a $5 \%$, 
objetivando obterem-se valores de $t$ superiores a 1,96 para relações válidas para a composição do modelo (Hair Jr. et al., 2017, p. 157).

\subsection{Testes de mediação}

Os testes de mediação relacionados às hipóteses 4 e 5 do modelo de caminhos foram realizados separadamente para cada hipótese. O objetivo foi avaliar se a mediação é total (quando o efeito indireto é significante, mas o direto é nulo) ou parcial (quando o efeito indireto e direto são significantes).

Preliminarmente aos testes específicos, deve-se observar por meio da análise do $\beta$ e do $t$ de Student se as relações entre a variável independente e a variável mediadora (VI -> Med) e entre a variável mediadora e a variável dependente (Med -> VD) são significativas. Se uma delas não for significativa, concluir-se desde já que não existe mediação.

Os testes de mediação incluíram as seguintes técnicas:

- Análise de caminhos de Baron e Kenny (1986) considera que há quatro condições que necessitam ser verificadas para a constatação da mediação:

- Passo 1 - a variável independente afeta significativamente a variável mediadora;

- Passo 2 - a variável independente afeta significativamente a variável dependente na ausência da mediadora;

- Passo 3 - a variável mediadora afeta única e significativamente a variável dependente na ausência da variável independente;

- Passo 4 - o efeito da variável independente sobre a variável dependente enfraquece quando há adição da variável mediadora.

- Efeitos indiretos - segundo Bido e Da Silva (2019), na verificação da existência de mediação e se ela é total ou parcial, são avaliados os efeitos diretos, indiretos e totais e os resultados interpretados conforme o esquema apresentado na Tabela 44. O efeito indireto da variável independente sobre a variável dependente deve ser estatisticamente significante ( $\mathrm{p}$-valor $<0,05$ ).

Tabela 44 - Mediação, efeitos diretos e indiretos

\begin{tabular}{ccc}
\hline Efeito direto & Efeito indireto & Mediação \\
\hline Significante $(\mathrm{p}<0,05)$ & Não significante $(\mathrm{p}>0,05)$ & Não há mediação \\
Significante $(\mathrm{p}<0,05)$ & Significante $(\mathrm{p}<0,05)$ & Mediação parcial \\
Não significante $(\mathrm{p}>0,05)$ & Significante $(\mathrm{p}<0,05)$ & Mediação total \\
\hline
\end{tabular}

Fonte: Bido e Da Silva (2019, p. 519).

- Testes Estatísticos de Aroian, Goodman e Sobel - Para execução destes testes foi utilizado o aplicativo disponibilizado por Preacher e Leonardelli (2001).

O teste de Sobel usa um teste $t$ de Student especializado para determinar se há uma redução significativa no efeito de uma variável independente em uma variável dependente na presença de uma 
variável mediadora. A hipótese de que não há diferença estatística entre o efeito total (ou seja, o efeito dessa mesma variável independente na variável dependente) é testada após ser considerada a influência de um potencial mediador (Sobel, 1982).

Alternativamente, como o teste de Sobel, são executados os testes de Aroian (1947) e Goodman (1960) para avaliar o efeito de mediação.

- VAF ("Variance Accounted For", em português: variância explicada por) - avalia a influência da mediação sobre uma variável dependente ou o quanto da variável dependente é explicada por meio da mediadora usando a seguinte equação (Hair Jr. et al., 2017):

$$
\mathrm{VAF}=\text { Efeito indireto } / \text { Efeito total }
$$

Como critério para a análise do resultado do cálculo, Hair Jr e colaboradores (2017) consideram que a mediação é considerada total ("full mediation") se o valor de VAF > 80\%; parcial ("partial mediation) se estiver entre o intervalo $20 \% \leq \mathrm{VAF} \leq 80 \%$; ou inexistente se o resultado for VAF < $20 \%$.

\subsection{Verificação das hipóteses de pesquisa}

Verificados o modelo de mensuração (relações entre os indicadores e os constructos) e o modelo estrutural (relação entre os constructos), foram realizados os testes de validade nomológica das hipóteses de pesquisa. Para tanto, foram utilizados como critérios para confirmação ou não confirmação das relações hipotetizadas o valor-p e o coeficiente de caminho ("path coefficients").

O valor-p (valor da probabilidade) é a probabilidade de erroneamente rejeitar uma hipótese nula verdadeira, ou seja, assumir um efeito significativo quando não há significância. Na maioria dos cenários, os pesquisadores escolhem um nível de significância de 5\%, o que implica que o valor de $\mathrm{p}$ deve ser menor que 0,05 a fim de tornar significativa a relação em questão (Hair Jr. et al., 2017).

Adicionalmente aos coeficientes de caminho e p-valor, foram também apresentados os valores do teste $t$ de Student, embora nesta análise, de acordo com Hair Jr e colaboradores (2017), ambos conduzam às mesmas conclusões. Assim foram definidos os seguintes parâmetros:

- coeficientes de caminho ("path coefficients”) - aceitação para valores superiores a 0,20

- valor-p - nível mínimo de confiança de 95\% $(\alpha \leq 0,05)$

- Teste $t$ de Student - aceitação para valores superiores a 1,96

\subsubsection{Resumo dos procedimentos metodológicos e das limitações}

Para manter o alinhamento do pesquisa em seu foco, considera-se importante relembrar a questão central da pesquisa, ou seja, quais são os fatores que contribuem para o desempenho dos projetos de desenvolvimento de medicamentos genéricos? Como os dois primeiros objetivos 
específicos do estudo dizem respeito à identificação dos indicadores de desempenho dos PDMG e dos fatores contribuintes a eles relacionados e não tendo sido encontradas publicações específicas sobre este tema na literatura, menos ainda com modelos e/ou escalas já desenvolvidas e/ou validadas, a decisão foi por identificá-los por meio de uma pesquisa qualitativa exploratória. Esta pesquisa buscou dados empíricos para compor a relação dos indicadores relacionados ao desempenho dos projetos de desenvolvimento de medicamentos e dos seus fatores contribuintes. Para tanto, foi elaborado e aplicado a um grupo de profissionais da indústria farmacêutica um questionário eletrônico com perguntas abertas sobre problemas nos projetos de desenvolvimento de medicamentos, as causas destes problemas e eventuais sugestões e oportunidades de melhoria nos projetos. Por meio do uso de análise de conteúdo dos dados coletados, foi possível identificar e classificar as principais unidades de significado que, após avaliação à luz do referencial teórico e utilizando o modelo conceitual proposto, deram origem às variáveis relacionadas ao desempenho e aos fatores contribuintes e que foram usadas na composição dos constructos analisados na fase quantitativa da pesquisa. Os resultados desta fase da pesquisa e o referencial teórico permitiram propor também o modelo conceitual da pesquisa.

A segunda parte da pesquisa empírica envolveu novamente a aplicação de questionário eletrônico, mas desta vez com perguntas em sua maioria fechadas. Em razão dos constructos para a modelagem de equações estruturais serem conceitos originalmente teorizados e não poderem ser medidos diretamente, foram definidos os indicadores (métricas) para cada constructo. Assim, as dimensões e unidades de significado identificados na fase qualitativa definiram os constructos e os indicadores utilizados para suas mensurações, sendo que a descrição dos indicadores passou a ter a forma de assertivas para composição do questionário. A definição dos indicadores permitiu a coleta dos dados a partir de questões com escalas capazes de mensurar indiretamente os constructos (Hair Jr. et al., 2017). Os itens do questionário passaram por uma avaliação da validade de seu conteúdo para a definição da versão final aplicada. A amostra foi composta por profissionais com experiência em PDMG em laboratórios farmacêuticos instalados no Brasil.

A análise dos dados teve enfoque quantitativo, ou seja, utilizou a coleta e a análise de dados para responder às questões de pesquisa e testar as hipóteses pré-definidas. Como técnicas estatísticas principais foram empregadas técnicas de análise multivariada, com destaque para a modelagem de equações estruturais (Hair et al., 2005). Mais especificamente, foi adotada a estimação por mínimos quadrados parciais (PLS-SEM) aplicada por meio do software SmartPLS ${ }^{\circledR}$ (2019).

Da mesma forma que os objetivos específicos colaboraram para a escolha dos procedimentos metodológicos adotados, vale também associar cada uma das hipóteses definidas aos métodos empregados para a coleta e tratamento dos dados, conforme apresentado esquematicamente na Tabela 45. 
Tabela 45 - Matriz de amarração teórica envolvendo a relação entre a questão central da pesquisa, os objetivos específicos, as hipóteses e os métodos de coleta e análise dos dados.

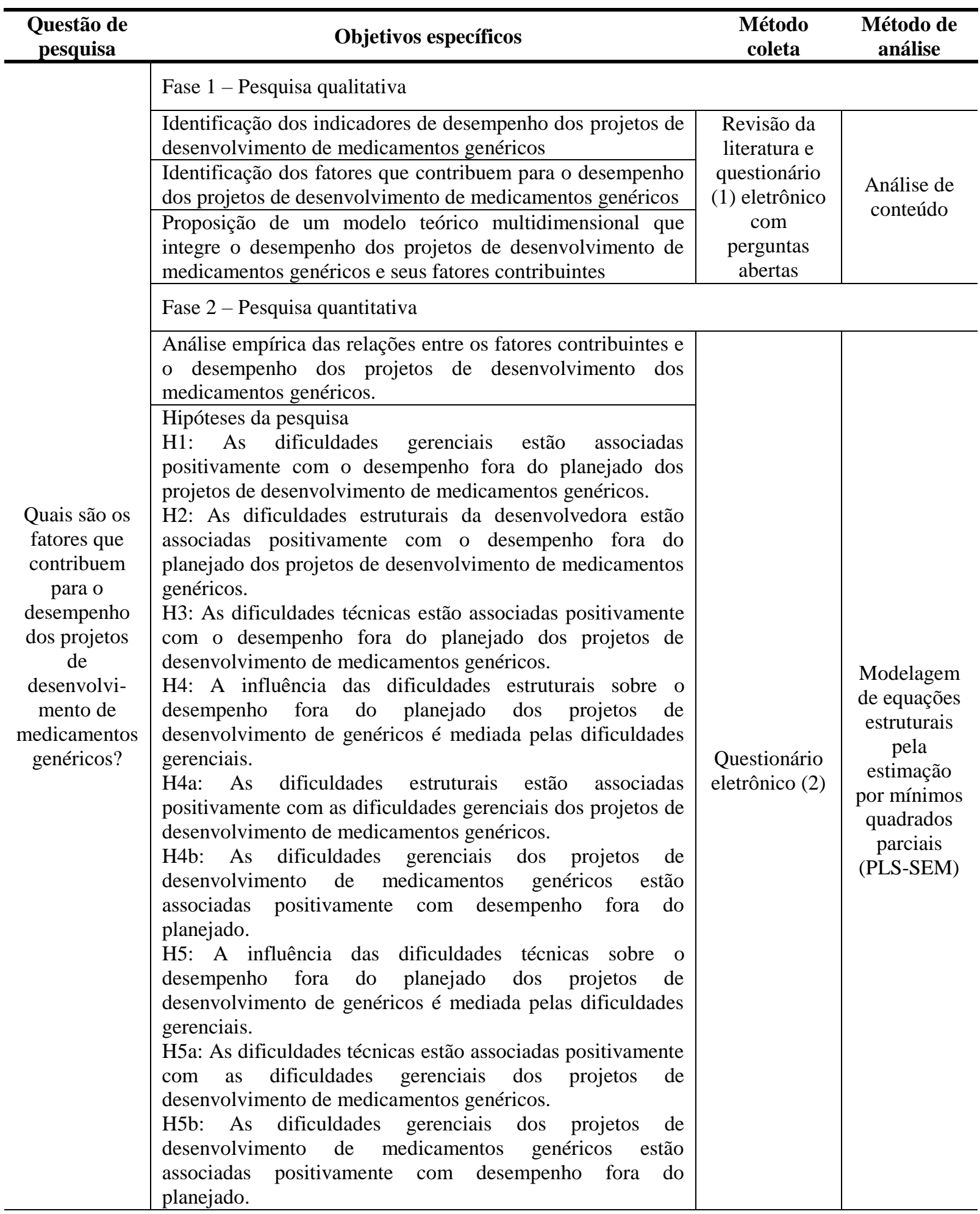

Fonte: dados da pesquisa em matriz adaptada de Telles (2001). 
As relações entre as variáveis e as técnicas de tratamento dos dados são resumidos na Tabela 46.

Tabela 46 - Técnicas de tratamento dos dados da pesquisa

\begin{tabular}{|c|c|c|}
\hline Variáveis & $\begin{array}{c}\text { Técnica de } \\
\text { tratamento e análise }\end{array}$ & $\begin{array}{c}\text { Informação/ } \\
\text { Objetivo }\end{array}$ \\
\hline 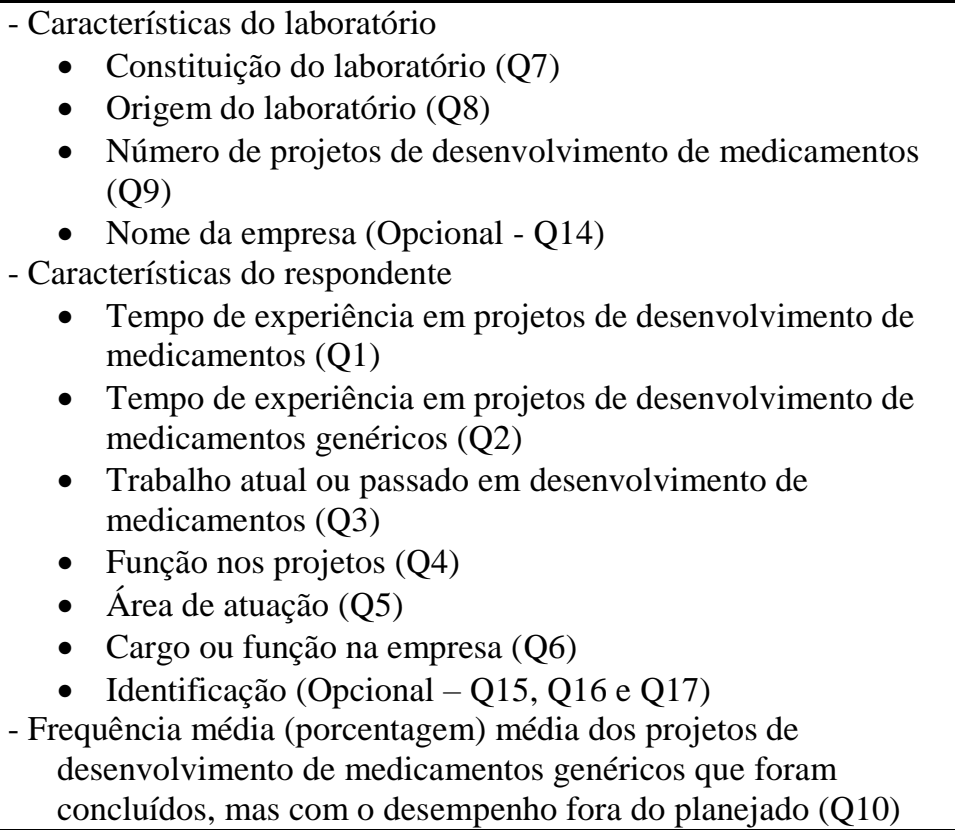 & Estatística descritiva & $\begin{array}{l}\text { Caracteriza- } \\
\text { ção do perfil } \\
\text { da amostra }\end{array}$ \\
\hline $\begin{array}{l}\text { - Indicadores de desempenho dos projetos de desenvolvimento de } \\
\text { medicamentos genéricos } \\
\text { - Frequência média (porcentagem) média dos projetos que } \\
\text { foram concluídos, mas com o desempenho fora do } \\
\text { planejado (Q10) } \\
\text { - Fatores contribuintes para o desempenho dos projetos de } \\
\text { desenvolvimento de medicamentos genéricos } \\
\text { - Grau de contribuição das dificuldades para o desempenho } \\
\text { fora do planejado dos projetos de desenvolvimento de } \\
\text { medicamentos genéricos. (Q11, Q12 e Q13) }\end{array}$ & Estatística descritiva & $\begin{array}{c}\text { Comporta- } \\
\text { mento e } \\
\text { distribuição } \\
\text { das variáveis }\end{array}$ \\
\hline $\begin{array}{l}\text { - Grau de contribuição das dificuldades para o desempenho fora do } \\
\text { planejado dos projetos de desenvolvimento de medicamentos } \\
\text { genéricos (Q11, Q12 e Q13) }\end{array}$ & $\begin{array}{c}\text { Modelagem de } \\
\text { equações estruturais } \\
\text { com estimação por } \\
\text { mínimos quadrados } \\
\text { parciais (PLS-SEM) }\end{array}$ & $\begin{array}{c}\text { Análise dos } \\
\text { modelos de } \\
\text { mensuração e } \\
\text { estrutural }\end{array}$ \\
\hline
\end{tabular}

Fonte: Dados da pesquisa

De acordo com Creswell (2010), em um estudo empírico, decisões são tomadas para definir a concepção ou as suposições sobre a pesquisa, as estratégias de investigação e os métodos. As decisões também delimitam o objeto e universo de estudo e, consequentemente, definem as características de seus resultados e contribuições e as ameaças à sua validade. As principais limitações e ações para garantir a confiabilidade e validade dos métodos aplicados a esta pesquisa foram relatadas nas respectivas seções e são resumidas na Tabela 47. 
Tabela 47 - Resumo das limitações, confiabilidade e validade dos métodos de pesquisa

\begin{tabular}{|c|c|}
\hline Atributo & Decisões e justificativas \\
\hline $\begin{array}{l}\text { Abrangência } \\
\text { dos } \\
\text { resultados da } \\
\text { pesquisa }\end{array}$ & $\begin{array}{l}\text { Os estudo não pode ser considerado } \mathrm{O} \text { modelo conceitual partiu de } 48 \text { fatores } \\
\text { extensivo no sentido de sua completude e contribuintes identificados pela própria pesquisa e } \\
\text { esgotamento sobretudo sobre os fatores } \\
\text { influenciadores. }\end{array}$ \\
\hline $\begin{array}{c}\text { Variáveis de } \\
\text { pesquisa }\end{array}$ & $\begin{array}{l}\text { Não foram encontradas na literatura A fase qualitativa buscou preencher a lacuna } \\
\text { estudos semelhantes com modelos e/ou existente na literatura. Os indicadores e fatores } \\
\text { escalas de mensuração validadas, contribuintes identificaram foram resultantes da } \\
\text { impossibilitando uma base consolidada pesquisa empírica (dedução) e da fundamentação } \\
\text { para o modelo, suas variáveis e escalas de teórica (indução). }\end{array}$ \\
\hline
\end{tabular}
mensuração.

Validade do A validade de conteúdo busca avaliar em Foram validados 5 indicadores de desempenho e 44 conteúdo do que proporção os itens selecionados para fatores contribuintes. Foi aplicado um questionário questionário medir uma construção teórica são para avaliar os 6 indicadores e 48 fatores (pesquisa representativos ou representam bem todas identificados pela pesquisa qualitativa e já ajustado quantitativa) as facetas importantes do conceito a ser ao formato para coleta dos dados (assertivas). medido (Alexandre \& Coluci, 2011).

Efeitos de Realização de pré-teste a fim de verificar a Não foram encontrados indicativos de efeitos redação, consistência conceitual e clareza redação importantes. Considerando o risco de insuficiência organização das questões e a fluidez e facilidade de de participantes, optou-se por avaliar eventuais e de contexto preenchimento do questionário. das questões. necessidades de ajustes complementares por meio de análise dos dados das 30 primeiras respostas recebidas.

Amostragem Considerando 3 preditores, efeito médio Foram obtidas 209 respostas válidas. Bido e Da $\left(\mathrm{f}^{2}=0,15\right)$, poder $=0,8$ e nível de Silva (2019) e Ringle e colaboradores (2014) significância $\mathrm{p} \leq 0,01$, a amostra mínima sugerem que o tamanho das amostras mínimas deva não probabilística calculada pelo software ser dobrado ou triplicado. Assim, o número ideal G*Power (Buchner et al., 2019) foi de 109 seria de 218 participantes. respostas válidas.

Viés de Efeitos tendenciosos sobre as estimativas Para reduzir a possibilidade de ocorrência, foram método sobre as relações entre dois ou mais realizados: randomização dos itens referentes ao comum constructos quando são mensuradas desempenho e aos fatores contribuintes (efeitos de usando o mesmo método (Podsakoff et al., proximidade e dos itens revertidos); amostra com 2012). profissionais de diferentes empresa, níveis hierárquicos, experiência, funções, áreas de atuação e papéis nos PDMG.

Validade Busca dimensionar o quanto um Os resultados obtidos pela aplicação dos testes de convergente constructo converge em seus indicadores Confiabilidade do Alpha de Cronbach $(\alpha)$, dos explicando a variação dos itens que o Variância extraída (AVE) e Confiabilidade indicadores compõem Hair $\mathrm{Jr}$ e colaboradores Composta (CC) indicaram a validade convergente (2017); (Vinzi, Chin, et al., 2010) dos indicadores.

Validade Tem por objetivo avaliar se um constructo $\mathrm{O}$ modelo apresentou validade discriminante. Duas

discriminant é empiricamente distinto dos demais avaliações foram utilizadas: cargas cruzadas dos e dos constructos no modelo de caminho indicadores e critério de Fornell-Larcker. Como indicadores (Fornell \& Larcker, 1981; Hair Jr e resultado, 7 indicadores relacionados aos fatores colaboradores, 2017). contribuintes foram excluídos do modelo.

Precisão ou $\mathrm{O}$ coeficiente de determinação $\left(\mathrm{R}^{2}\right)$ traduz $\mathrm{O}$ modelo foi validado. Considerando o principal acurácia a precisão ou acurácia preditiva do constructo dependente do modelo (Desempenho), o

preditiva do modelo estrutural ao indicar a variância $\mathrm{R}^{2}$ de 0,141 pode ser considerado um efeito médio modelo explicada de cada um dos constructos (Cohen, 1988), ou seja, o coeficiente de estrutural endógenos (Hair Jr e colaboradores, 2017; determinação é adequado para a validação do Vinzi, Chin, et al., 2010). modelo.

Tamanho do O parâmetro de tamanho do efeito $\left(\mathrm{f}^{2}\right)$ ou Os constructos são úteis para o ajuste do modelo. efeito Indicador de Cohen tem por função Os resultados indicam que os constructos Gerencial estimar a qualidade de ajuste do modelo e Estrutural apresentam grande efeito e que o estrutural (Hair Jr e colaboradores , 2017). constructo Técnico apresenta efeito médio.

Relevância $\mathrm{O} \mathrm{Q}^{2}$ avalia a qualidade da predição do Os valores de $\mathrm{Q}^{2}$ obtidos foram superiores a 0 e, preditiva modelo ou acurácia do modelo ajustado. portanto, considerados satisfatórios. 


\section{RESULTADOS DO ESTUDO}

Os resultados do estudo serão apresentados seguindo a sua ordem cronológica de execução, ou seja, terá início pela fase da pesquisa qualitativa e serão seguidos pelos resultados da fase quantitativa. De uma forma geral, as discussões são realizadas logo após a apresentação de cada um dos resultados. Vale mencionar ainda que, em razão de não terem sido encontradas pesquisas semelhantes na literatura e também considerando que as que tratam do mesmo tema terem sido em grande parte publicadas há algum tempo, não foi possível a realização de análises comparativas mais aprofundadas com base no referencial teórico.

\subsection{RESULTADOS DA FASE DE PESQUISA QUALITATIVA}

$\mathrm{Na}$ primeira fase da pesquisa empírica foi realizado um levantamento dos problemas enfrentados pelos laboratórios farmacêuticos instalados no Brasil em seus projetos de desenvolvimento de novos medicamentos. O objetivo foi identificar os problemas e as necessidades das organizações com relação aos seus projetos de desenvolvimento de novos produtos e que também se constituíssem em oportunidades para pesquisa acadêmica. Mais especificamente, a pesquisa questionou profissionais que atuavam em laboratórios farmacêuticos instalados no Brasil sobre os problemas que eles enfrentavam nesses projetos, as suas possíveis causas, os impactos resultantes, as oportunidades de melhoria e suas expectativas para o desenvolvimento dos medicamentos no futuro.

O questionário aplicado (disponível no Apêndice IV) foi composto por perguntas para caracterização do respondente e perguntas abertas sobre os problemas enfrentados por eles no desenvolvimento de novos medicamentos.

\subsubsection{Características da amostra da pesquisa qualitativa}

O questionário desta fase da pesquisa foi aplicado eletronicamente em junho de 2016. No total foram convidados a participar 297 profissionais. Foram consideradas válidas as respostas de 33 participantes, $70 \%$ destes (23 profissionais) com pelo menos 10 anos de experiência na área de desenvolvimento de novos medicamentos em laboratórios farmacêuticos instalados no Brasil. Destes 23 respondentes, 6 tinham mais de 20 anos de experiência. Em relação ao cargo ou função exercida, $20(60 \%)$ do total de respondentes trabalhavam no nível de supervisão (ou equivalente) ou acima, indicando uma elevada qualificação da amostra.

\subsubsection{Análise dos dados da pesquisa qualitativa}

Seguindo o procedimento definido para esta fase da pesquisa e que foi apresentado na Figura 23, os temas definidos inicialmente, aqui chamados de temas originais, foram formados pelas próprias questões do questionário, ou seja, problemas, causas, impactos, melhorias e futuro. A análise inicial das respostas recebidas resultou na identificação de 281 unidades de significado dentro. Neste 
momento, todas receberam o mesmo peso ou igual importância, sendo a distribuição delas entre as respostas recebidas apresentada na Tabela 48. As principais unidades de significado identificadas (em frequência) são apresentadas nos Apêndices V e VI.

Tabela 48 - Distribuição das unidades de significado entre as respostas recebidas

\begin{tabular}{|c|c|c|}
\hline $\begin{array}{l}\text { Temas } \\
\text { originais }\end{array}$ & Questão & $\begin{array}{c}\text { Total de } \\
\text { unidades }\end{array}$ \\
\hline Problemas & $\begin{array}{l}\text { Problemas e/ou erros que enfrenta(ou) no decorrer dos projetos de } \\
\text { desenvolvimento de novos medicamentos }\end{array}$ & 66 \\
\hline Causas & $\begin{array}{l}\text { Causas/origens dos problemas nos projetos de desenvolvimento de } \\
\text { novos medicamentos }\end{array}$ & 67 \\
\hline Impactos & $\begin{array}{l}\text { Impactos/resultados dos problemas nos } \\
\text { desenvolvimento de novos medicamentos }\end{array}$ & 41 \\
\hline Melhorias & $\begin{array}{l}\text { Estratégias, ações e oportunidades de melhoria das práticas de } \\
\text { desenvolvimento de novos medicamentos }\end{array}$ & 51 \\
\hline \multirow[t]{2}{*}{ Futuro } & $\begin{array}{l}\text { Mudanças que acredita que ocorrerão no processo de } \\
\text { desenvolvimento de novos medicamentos no futuro }\end{array}$ & 56 \\
\hline & Total & 281 \\
\hline
\end{tabular}

Fonte: dados da pesquisa.

4.1.2.1 Categorização das unidades de significado

Nesta atividade foi realizada uma análise inicial do conteúdo de cada unidade de significado extraída. Tendo por referência os temas redefinidos e suas operacionalizações, as unidades de significado foram analisadas e categorizadas, resultando na redistribuição apresentada na Tabela 49.

Tabela 49 - Distribuição das unidades de significado após análise inicial de conteúdo

\begin{tabular}{cccccc}
\hline & \multicolumn{2}{c}{ Categorização após análise (temas redefinidos) } & \\
Temas originais & $\begin{array}{c}\text { Fatores } \\
\text { contribuintes }\end{array}$ & $\begin{array}{c}\text { Indicadores } \\
\text { de } \\
\text { desempenho }\end{array}$ & Melhorias & Futuro & $\begin{array}{c}\text { Totais nas } \\
\text { respostas }\end{array}$ \\
\hline Causas & 67 & - & - & - & 67 \\
Problemas & 64 & 1 & - & 1 & 66 \\
Impactos & 21 & 19 & - & 1 & 41 \\
Melhorias & - & - & 49 & 2 & 51 \\
Futuro & - & - & - & 56 & 56 \\
Totais após análise & 152 & 20 & 49 & 60 & 281 \\
\hline
\end{tabular}

Nota: em número de unidades de significado. Fonte: dados da pesquisa.

$\mathrm{Na}$ continuação das análises, o estudo passou a ter como objeto apenas os indicadores de desempenho e seus fatores contribuintes. Desta forma, as unidades de significado extraídas das respostas recebidas e relacionadas aos indicadores de desempenho foram submetidas ao tratamento das equivalências e duplicidades, observando-se as decisões de delimitação da pesquisa e o referencial teórico. Após este procedimento, as 20 unidades de significado iniciais relacinadas aos indicadores de desempenho foram condensadas e reclassificadas restando apenas 6 unidades, as quais são apresentadas na Tabela 50 com a indicação do referencial teórico mais relevante e que lhes dá suporte. 
Tabela 50 - Unidades de significado relacionadas ao tema dos indicadores de desempenho de projetos de desenvolvimento de medicamentos

\begin{tabular}{|c|c|}
\hline $\begin{array}{l}\text { Unidades de significado relacionadas a } \\
\text { indicadores de desempenho }\end{array}$ & Referencial teórico \\
\hline $\begin{array}{l}\text { 1. Prazo para o desenvolvimento dos } \\
\text { medicamentos genéricos (prazo) }\end{array}$ & $\begin{array}{l}\text { (Thomas R. Dunson, 2010; Fatokun et al., 2013; } \\
\text { Jefferys, Matthews, \& Ritchie, 1991; Pete Harpum, } \\
\text { Jamieson, \& Fisher, 2010; PMI, 2017; Prašnikar \& } \\
\text { Škerlj, 2006; Reiffen \& Ward, 2005; Shenhar et al., } \\
\text { 1997; Worku et al., 2012). }\end{array}$ \\
\hline $\begin{array}{l}\text { 2. Custos totais para o desenvolvimento dos } \\
\text { medicamentos genéricos (custo) }\end{array}$ & $\begin{array}{l}\text { (Thomas R. Dunson, 2010; Mendigorri et al., 2016; } \\
\text { Morfin, 2010; PMI, 2017; Shenhar et al., 1997) }\end{array}$ \\
\hline $\begin{array}{l}\text { 3. Aprovação do registro do medicamento } \\
\text { genérico pela Anvisa (qualidade) }\end{array}$ & (Anvisa, 2019d; Do Carmo, Piras, et al., 2017) \\
\hline $\begin{array}{l}\text { 4. Custo de produção e consequente preço-alvo de } \\
\text { mercado (custo) }\end{array}$ & (Thomas R. Dunson, 2010; Morfin, 2010) \\
\hline 5. Ajustes após o seu lançamento (qualidade) & $\begin{array}{l}\text { (Ahmed, Naini, \& Wadgaonkar, 2005; Bhattacharyya, } \\
\text { 2005; Ciganek, Mehta, Mellina, \& Shargel, 2005; Do } \\
\text { Carmo, 2017; ICH, 2009; PMI, 2017; Worku et al., } \\
\text { 2012) }\end{array}$ \\
\hline $\begin{array}{l}\text { 6. Concluir o desenvolvimento do medicamento } \\
\text { (não há indicador para o desempenho) }\end{array}$ & $\begin{array}{l}\text { (PMI, 2017; Rozenfeld et al., 2006; Shenhar et al., } \\
\text { 1997) }\end{array}$ \\
\hline
\end{tabular}

Fonte: dados da pesquisa.

Entre as seis unidades de significado definidas para o tema dos indicadores de desempenho, o prazo para desenvolvimento e os custos totais estão entre os mais empregados classicamente para a avaliação de desempenho dos projetos (PMI, 2017). Shenhar e colaboradores (1997) afirmam que no curto prazo e particularmente durante a execução do projeto, os indicadores mais importantes são os ligados à dimensão de eficiência do projeto, sendo, de fato, a única dimensão que poderia ser mensurada naquele momento. Desta forma, concluem os pesquisadores, o atendimento às restrições de recursos, a mensuração dos desvios em relação ao planejado e a observação de diversas medidas de eficiência seriam as melhores maneiras para monitorar o progresso e controlar os projetos em andamento.

Embora não possam ser medidos no curto prazo, tendo por referência Carmo (2017) e ICH (2009), foram considerados entre as unidades de significado os ajustes necessários no medicamento após o seu lançamento como medida da qualidade técnica do produto desenvolvido. Já no caso do indicador de aprovação do registro do medicamento genérico, ele equipara-se à conclusão do projeto e aceite do produto do projeto. Sem esta aprovação, o medicamento não pode ser comercializado (Do Carmo, Piras, et al., 2017) e, portanto, o projeto não pode considerado um sucesso pleno.

Pode-se argumentar que do ponto de vista do projeto e respeitando as delimitações deste estudo, não estariam incluídas no escopo as atividades e entregas após o medicamento estar pronto para o seu registro. Pode-se ainda questionar a possibilidade de decisão da empresa em não submeter o novo medicamento para registro junto à Anvisa por razões que vão da estratégia para o produto ao custo do processo. Mesmo assim, o registro na Anvisa e a qualidade do medicamento desenvolvido certamente estavam entre os objetivos estabelecidos inicialmente para o projeto. 
A unidade de significado relacionada ao indicador de custo de produção é também peculiar aos medicamentos genéricos, uma vez que a competição em seu mercado se realiza com base no preço (Thomas R. Dunson, 2010; Morfin, 2010). Assim, custos de produção altos não permitem preços de venda competitivos.

Uma possibilidade que foi adicionada ao conjunto de unidades de significado relacionadas ao tema dos indicadores de desempenho de PDMG foi a conclusão do projeto sem que houvesse a mensuração do seu desempenho, ou seja, independentemente dos demais requisitos. Isso porque na pesquisa qualitativa alguns respondentes indicaram não haver controle e monitoramento adequado sobre os projetos. A literatura trata do não uso de indicadores e/ou do controle e monitoramento como prejudiciais ao desempenho, mas não há detalhamento ou aprofundamento da discussão, pois em geral as abordagens são no sentido prescritivo do uso dos indicadores (PMI, 2017; Rozenfeld et al., 2006; Shenhar et al., 1997).

Também considerando as delimitações do estudo e o referencial teórico, o mesmo procedimento foi feito para o caso das unidades de significado extraídas das respostas recebidas e classificadas sob o tema dos fatores contribuintes para o desempenho. Elas foram racionalizadas e reestruturadas resultando em 48 unidades de significado das 152 iniciais. O resultado é apresentada na Tabela 51 a seguir com a indicação do referencial teórico mais relevante e que lhes dá suporte.

Tabela 51 - Unidades de significado relacionadas ao tema dos fatores contribuintes para o desempenho de projetos de desenvolvimento de medicamentos genéricos

\begin{tabular}{|c|c|c|}
\hline & $\begin{array}{l}\text { Unidades de significado classificadas } \\
\text { como fatores contribuintes }\end{array}$ & Referências \\
\hline 1. & $\begin{array}{l}\text { Garantia da qualidade (validação e } \\
\text { qualificação) do medicamento }\end{array}$ & $\begin{array}{l}\text { Ahmed et al., 2005; Anvisa, 2017b; Bhattacharyya, 2005; Do } \\
\text { Carmo, 2017; Do Carmo, Piras, et al., 2017; Gelber \& Janulis, } \\
\text { 2005; Jefferys et al., 1991; Sathe, Raw, Ouderkirk, X., \& } \\
\text { Hussain, 2005; A. Srinivasan et al., 2011; Worku et al., } 2012\end{array}$ \\
\hline 2. & $\begin{array}{l}\text { Estudos de bioequivalência e/ou } \\
\text { biodisponibilidade do medicamento }\end{array}$ & $\begin{array}{l}\text { Anvisa, 2017b; Bolton, 2005; Conner \& Davit, 2005; Do Carmo, } \\
\text { 2017; Huang et al., 2013; Jefferys et al., 1991; Welage, Kirking, } \\
\text { Ascione, \& Gaither, 2001; Worku et al., } 2012\end{array}$ \\
\hline 3. & Perfil de dissolução do medicamento & $\begin{array}{l}\text { Anvisa, 2017b; Do Carmo, 2017; Do Carmo, Piras, et al., 2017; } \\
\text { Jefferys et al., 1991; Sathe et al., 2005; A. Srinivasan et al., } \\
\text { 2011; Worku et al., } 2012\end{array}$ \\
\hline 4. & $\begin{array}{l}\text { Estudos clínicos do medicamento } \\
\text { (eficácia) }\end{array}$ & $\begin{array}{l}\text { Anvisa, 2017b; I. Kanfer, Walker, \& Persicaner, 2005; Noonan, } \\
\text { 2005; Worku et al., } 2012\end{array}$ \\
\hline 5 . & $\begin{array}{l}\text { Equivalência farmacêutica do } \\
\text { medicamento }\end{array}$ & $\begin{array}{l}\text { Anvisa, 2017b; Do Carmo, 2017; Aloka Srinivasan et al., 2010; } \\
\text { Worku et al., } 2012\end{array}$ \\
\hline 6. & $\begin{array}{l}\text { Desenvolvimento do método de } \\
\text { análise do medicamento }\end{array}$ & $\begin{array}{l}\text { Anvisa, 2017b; Do Carmo, 2017; Gao, Sanvordeker, \& Vita, } \\
\text { 2005; Huang et al., 2013; Jefferys et al., 1991; A. Srinivasan et } \\
\text { al., 2011; Worku et al., } 2012\end{array}$ \\
\hline 7. & $\begin{array}{l}\text { Estudos de estabilidade e de produtos } \\
\text { de degradação }\end{array}$ & $\begin{array}{l}\text { Bhattacharyya, 2005; Do Carmo, 2017; Do Carmo, Piras, et al., } \\
\text { 2017; Huang et al., 2013; Jefferys et al., 1991; I. Kanfer et al., } \\
\text { 2005; Sathe et al., 2005; A. Srinivasan et al., 2011; Worku et al., } \\
2012\end{array}$ \\
\hline 8. & $\begin{array}{l}\text { Controle de qualidade do } \\
\text { medicamento }\end{array}$ & $\begin{array}{l}\text { Do Carmo, 2017; Do Carmo, Piras, et al., 2017; Gelber \& } \\
\text { Janulis, } 2005\end{array}$ \\
\hline
\end{tabular}


Unidades de significado classificadas como fatores contribuintes

9. Informações do fornecedor do fármaco e/ou do DMF ("Drug Master File")

10. Custos para desenvolvimento dos medicamentos

11. Tempo necessário para o desenvolvimento dos medicamentos

12. Riscos no processo de desenvolvimento do medicamento e para sua autorização para comercialização

13. Legislação para registro do medicamento

14. Dossiê para registro do medicamento

15. Processo de análise e registro do medicamento

16. Desenvolvimento farmacotécnico do medicamento

17. Transferência do medicamento para a produção ("scale up")

18. Documentação do desenvolvimento do medicamento

19. Dados e informações técnicocientíficas sobre o medicamento

20. Lotes piloto, pré-validação e predefinição dos parâmetros do processo de produção do medicamento

21. Metodologia científica para o desenvolvimento do medicamento (ex.: "Design of Experiments" e "Quality by Design")

22. Estudos de pré-formulação do novo medicamento

23. Procedimentos para desenvolvimento dos medicamentos

24. Definição do escopo do medicamento a ser desenvolvido

25. Mudanças no projeto durante o desenvolvimento do medicamento

Anvisa, 2017b; Bhattacharyya, 2005; E. M. Cohen \& Lin, 2005;

Do Carmo, 2017; Do Carmo, Piras, et al., 2017; Gao et al., 2005;

Genazzani \& Pattarino, 2008; Huang et al., 2013; Jefferys et al., 1991; I. Kanfer et al., 2005; Aloka Srinivasan \& Iser, 2010;

Worku et al., 2012

Reiffen \& Ward, 2005; Ricardo T. Yugue et al., 2010

Noonan, 2005; Prašnikar \& Škerlj, 2006; Ricardo T. Yugue et al., 2010

Do Carmo, Piras, et al., 2017; T. R. Dunson \& Morfin, 2010;

Thomas R. Dunson, 2010; P. Harpum \& Dunson, 2010; Pete Harpum, 2010; McNamee \& Celona, 2008; Pete Harpum et al., 2010; Aloka Srinivasan et al., 2010; Stewart-Long, 2010; Suchak \& Murray, 2017

Anvisa, 2017b; T. R. Dunson \& Morfin, 2010; Thomas R.

Dunson, 2010; Suchak \& Murray, 2017; Worku et al., 2012

Anvisa, 2017b; Worku et al., 2012

Anvisa, 2017b; Do Carmo, Piras, et al., 2017; Noonan, 2005;

Reiffen \& Ward, 2005; Aloka Srinivasan \& Iser, 2010

Ahmed et al., 2005; Anvisa, 2017b; Jefferys et al., 1991; I.

Kanfer et al., 2005; L. Shargel \& Kanfer, 2005; Worku et al., 2012

Ahmed et al., 2005; Anvisa, 2017b; Do Carmo, 2017; Genazzani \& Pattarino, 2008; Huang et al., 2013; Jefferys et al., 1991; I.

Kanfer et al., 2005

Anvisa, 2017b; Gelber \& Janulis, 2005; I. Kanfer et al., 2005;

Worku et al., 2012

Ahmed et al., 2005; Anvisa, 2017b; Bhattacharyya, 2005; Do

Carmo, 2017; Do Carmo, Piras, et al., 2017; Huang et al., 2013;

Jefferys et al., 1991; A. Srinivasan et al., 2011; Aloka Srinivasan

\& Iser, 2010; Aloka Srinivasan et al., 2010; Worku et al., 2012

Anvisa, 2017b; Worku et al., 2012

Ahmed et al., 2005; Do Carmo, Piras, et al., 2017; FDA, 2007; ICH, 2009; Kader, 2016; Varu \& Khanna, 2010; Worku et al., 2012

Ahmed et al., 2005; Huang et al., 2013; Worku et al., 2012

Morfin, 2010; Prašnikar \& Škerlj, 2006

I. Kanfer et al., 2005; Morfin, 2010; Pete Harpum et al., 2010

Allport \& Cooke-Davies, 2010; PMI, 2017 
Unidades de significado classificadas como fatores contribuintes

26. Gerenciamento de riscos do desenvolvimento dos medicamentos

27. Planejamento e gerenciamento dos projetos de desenvolvimento dos medicamentos

28. Prazo para o desenvolvimento do medicamento

29. Custo final de produção ou preço-alvo para o medicamento

30. Seleção dos medicamentos a serem desenvolvidos

31. Estudos de viabilidade técnica para o desenvolvimento do medicamento

32. Acompanhamento dos projetos de desenvolvimento de medicamentos

33. Número e diversidade de projetos de medicamentos em desenvolvimento

34. Embalagem dos medicamentos

35. Fornecedor de matéria-prima

36. Seleção e qualificação dos fornecedores de matérias-primas

37. Aquisição de materiais e matériasprimas

38. Infraestrutura (instalações, equipamentos e utilidades) para o desenvolvimento dos métodos analíticos

39. Infraestrutura para o desenvolvimento farmacotécnico dos medicamentos

40. Aquisição de equipamentos (laboratório e produção)

41. Profissionais e/ou serviços de terceiros para o desenvolvimento dos medicamentos

42. Tecnologia do medicamento (formulação, forma farmacêutica e/ou sistema de liberação do fármaco)

43. Tecnologia do processo de fabricação do medicamento
Referências

Do Carmo, Piras, et al., 2017; T. R. Dunson \& Morfin, 2010;

Thomas R. Dunson, 2010; P. Harpum \& Dunson, 2010; Pete

Harpum, 2010; McNamee \& Celona, 2008; Pete Harpum et al., 2010; Aloka Srinivasan et al., 2010; Stewart-Long, 2010; Suchak \& Murray, 2017

Thomas R. Dunson, 2010; Hynes III, 2010; Morfin, 2010; Noonan, 2005; Pete Harpum et al., 2010; PMI, 2017; Powell, 2010; Prašnikar \& Škerlj, 2006; Stewart-Long, 2010; Worku et al., 2012

Pete Harpum et al., 2010

Morgan, Grootendorst, Lexchin, Cunningham, \& Greyson, 2011

Hansen \& Tunnah, 2003; I. Kanfer et al., 2005; Morfin, 2010;

Pete Harpum et al., 2010; L. Shargel \& Kanfer, 2005; Suchak \& Murray, 2017

Thomas R. Dunson, 2010; Hynes III, 2010; Prašnikar \& Škerlj, 2006; Leon Shargel \& Kanfer, 2005; Suchak \& Murray, 2017

L. Brown \& Grundy, 2011; PMI, 2017

Morfin, 2010

Anvisa, 2017b; Bhattacharyya, 2005; Do Carmo, 2017; Jefferys et al., 1991; I. Kanfer et al., 2005; Aloka Srinivasan \& Iser, 2010; Worku et al., 2012

Anvisa, 2017b; Huang et al., 2013; I. Kanfer et al., 2005

Anvisa, 2017b; E. M. Cohen \& Lin, 2005; I. Kanfer et al., 2005;

Pete Harpum et al., 2010; Prašnikar \& Škerlj, 2006; Suchak \&

Murray, 2017

Anvisa, 2019f; Pete Harpum et al., 2010

Green, 1996

Pete Harpum, 2010; I. Kanfer et al., 2005; Moreira \& Cheng, 2010; Morfin, 2010; Pete Harpum et al., 2010; Worku et al., 2012

Ahmed et al., 2005; Gelber \& Janulis, 2005; I. Kanfer et al., 2005

Kaitin, 2010; Piachaud, 2002

T. M. Allen \& Cullis, 2004; Aulton \& Taylor, 2016; Thomas R. Dunson, 2010; Pete Harpum, 2010; Kale \& Little, 2007; Leon Shargel \& Kanfer, 2005; Suchak \& Murray, 2017

Anvisa, 2017b; Gelber \& Janulis, 2005; Genazzani \& Pattarino, 2008; Huang et al., 2013; Kale \& Little, 2007; Leon Shargel \& Kanfer, 2005; Suchak \& Murray, 2017 


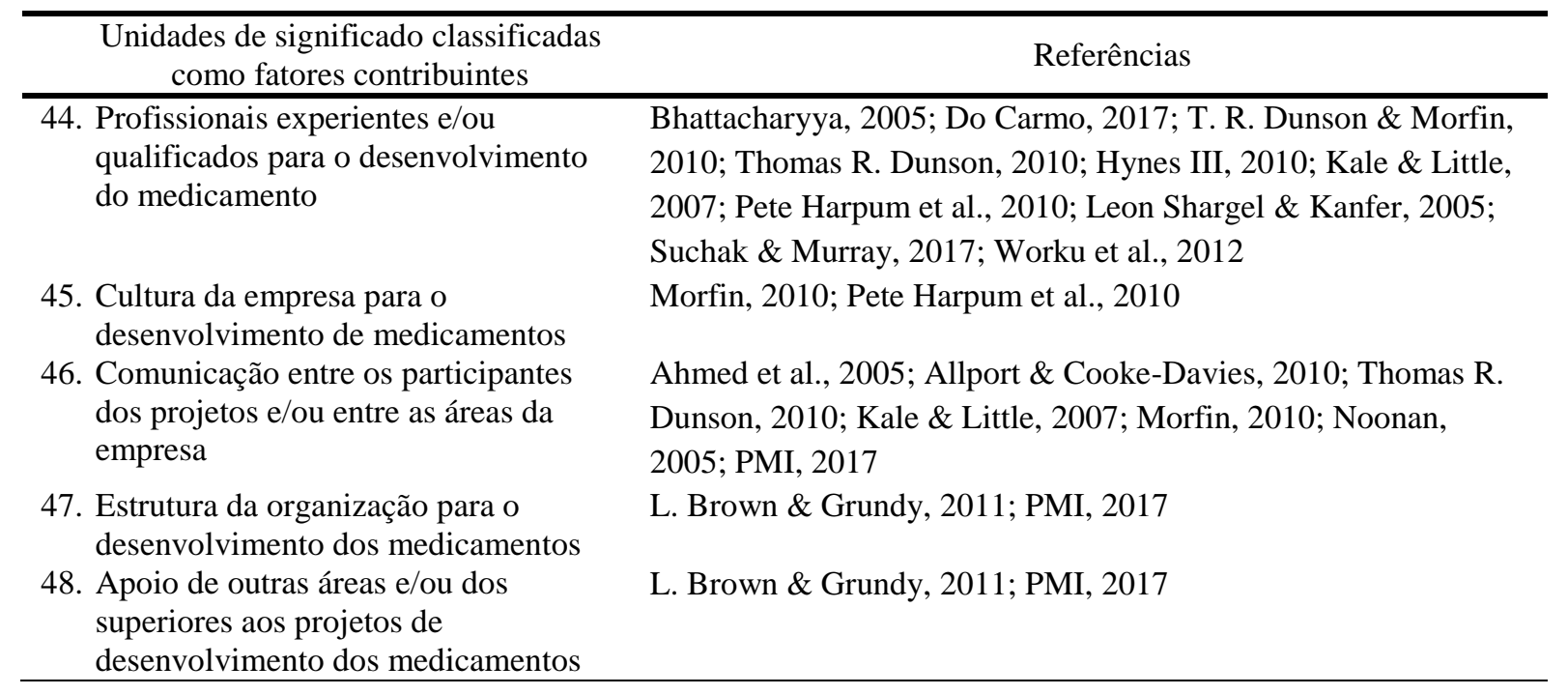

Fonte: dados da pesquisa

Tendo por referência a proximidade de seus conteúdos com as três categorias definidas, as 48 unidades de significado do tema fatores contribuintes foram então distribuídas da seguinte forma: Gerencial com 18 unidades, Estrutural com 15 unidades e Técnico com 15 unidades de significado. Cada uma das unidades de significado das três categorias foi então analisada em um contexto mais restrito e específico, dando origem a 9 subcategorias diferentes de unidades de significado, ou seja: Desenvolvimento, Gestão, Portfólio, Recursos, Competências, Organização, Especificações Técnicas, Requisitos do Projeto e Requisitos Regulatórios. Elas são apresentadas nas Tabelas 52, 53 e 54 e discutidas em seguida.

\subsubsection{Categoria Gerencial}

Esta categoria acolhe as unidades de significado extraídas das respostas recebidas e relacionadas às decisões gerenciais que afetam o desenvolvimento dos PDMG. Como referência principal para esta classificação foi adotada a abordagem do PMI (2017:56-57) para o gerenciamento estratégico, de negócios, operacional e técnico dos projetos. Complementarmente, para a classificação das unidades de significado para o gerenciamento técnico, foram observados os componentes específicos para os PDMG tratados por Shargel e Kanfer (2005). Também com base no referencial teórico, as unidades de significado desta categoria foram então subdivididas nas subcategorias: Desenvolvimento, Gestão e Portfólio, conforme a Tabela 52 a seguir. 
Tabela 52 - Unidades de significado relacionadas à categoria Gerencial divididas nas subcategorias.

\begin{tabular}{|c|c|}
\hline Subcategoria & Unidades de significado \\
\hline \multirow{8}{*}{ Desenvolvimento } & Desenvolvimento farmacotécnico do medicamento \\
\hline & Transferência do medicamento para a produção ("scale up") \\
\hline & Documentação do desenvolvimento do medicamento \\
\hline & Dados e informações técnico-científicas sobre o medicamento \\
\hline & $\begin{array}{l}\text { Lotes piloto, pré-validação e predefinição dos parâmetros do processo de produção do } \\
\text { medicamento. }\end{array}$ \\
\hline & $\begin{array}{l}\text { Metodologia científica para o desenvolvimento do medicamento (ex.: "Design of } \\
\text { Experiments" e "Quality by Design") }\end{array}$ \\
\hline & Estudos de pré-formulação do novo medicamento \\
\hline & Procedimentos para desenvolvimento dos medicamentos \\
\hline \multirow{6}{*}{ Gestão } & Definição do escopo do medicamento a ser desenvolvido \\
\hline & Mudanças no projeto durante o desenvolvimento do medicamento \\
\hline & Gerenciamento de riscos do desenvolvimento dos medicamentos \\
\hline & Planejamento e gerenciamento dos projetos de desenvolvimento dos medicamentos \\
\hline & Prazo para o desenvolvimento do medicamento \\
\hline & Custo final de produção ou preço-alvo para o medicamento \\
\hline \multirow{4}{*}{ Portfólio } & Seleção dos medicamentos a serem desenvolvidos \\
\hline & Estudos de viabilidade técnica para o desenvolvimento do medicamento \\
\hline & Acompanhamento dos projetos de desenvolvimento de medicamentos \\
\hline & Número e diversidade de projetos de medicamentos em desenvolvimento \\
\hline
\end{tabular}

Fonte: dados da pesquisa.

\subsection{Desenvolvimento}

Foram classificadas na subcategoria Desenvolvimento as unidades de significado relacionados à realização dos pacotes de trabalho técnicos (farmacotécnicos) dos PDMG e cujo gerenciamento pode influenciar o desempenho dos PDMG considerando como principal referencial Shargel e Kanfer (2005). Embora as unidades de significado possam estar mais relacionadas a atividades do projeto, o contexto em que aparecem nas respostas recebidas diziam mais respeito à forma como são gerenciadas e menos à forma como são executadas.

\subsection{Gestão}

As unidades de significado relacionadas à gestão dos PDMG foram classificadas na subcategoria Gestão. As principais características desta subcategoria estão relacionadas às decisões e à gestão de processos de gerenciamento dos PDMG tais como: escopo, cronograma, orçamento, riscos e mudanças, cujo principal referencial é o Guia PMBOK (PMI, 2017). 


\subsection{Portfólio}

Estão incluídas na subcategoria "Portfólio" as unidades de significado relacionadas à gestão do conjunto de PDMG e que influenciam o gerenciamento dos PDMG. Neste ponto é preciso esclarecer que, embora o estudo das decisões de seleção dos PDMG esteja fora do escopo desta pesquisa, as decisões de portfólio são aqui consideradas como influenciadores do gerenciamento dos projetos.

As decisões de portfólio de projetos devem maximizar os benefícios derivados de um conjunto de recursos escassos. Na indústria farmacêutica, um processo típico de portfólio pode envolver um grande número de pessoas e um longo período que deve ser cuidadosamente planejado (Bilyard \& Markland, 2008). Um dos principais referenciais utilizados foi também Shargel e Kanfer (2005) que consideram a tecnologia, a formulação e a experiência relacionadas ao medicamento genérico a ser desenvolvido como alguns dos fatores a serem considerados nas decisões de portfólio de projetos.

\subsubsection{Categoria Estrutural}

De acordo com o PMI (2017), os recursos necessários à realização dos projetos incluem recursos físicos e humanos. Os recursos físicos referem-se a equipamentos, materiais, instalações e infraestrutura, sendo que o seu gerenciamento visa o uso eficiente e eficaz de forma a atender as demandas do projeto por meio de sua disponibilização na qualidade, quantidade, tempo e locais corretos. Com base no referencial consultado para a classificação, as unidades de significado nesta categoria foram divididas nas subcategorias Recursos, Competências e Organização conforme o Tabela 53 a seguir.

Tabela 53 - Unidades de significado relacionadas à categoria Estrutural subdivididos nos subtemas.

\begin{tabular}{ll}
\hline Subcategoria & \multicolumn{1}{c}{ Unidades de significado } \\
\hline & Embalagem dos medicamentos \\
& Fornecedor de matéria-prima \\
& Seleção e qualificação dos fornecedores de matérias-primas \\
& Aquisição de materiais e matérias-primas \\
Recursos & Infraestrutura (instalações, equipamentos e utilidades) para o desenvolvimento dos \\
& métodos analíticos \\
& Infraestrutura para o desenvolvimento farmacotécnico dos medicamentos \\
& Aquisição de equipamentos (laboratório e produção) \\
& Profissionais e/ou serviços de terceiros para o desenvolvimento dos medicamentos
\end{tabular}

Tecnologia do medicamento (formulação, forma farmacêutica e/ou sistema de liberação do fármaco)

Competências Tecnologia do processo de fabricação do medicamento

Profissionais experientes e/ou qualificados para o desenvolvimento do medicamento 


\section{Subcategoria $\quad$ Unidades de significado \\ Cultura da empresa para o desenvolvimento de medicamentos \\ Comunicação entre os participantes dos projetos e/ou entre as áreas da empresa \\ Organização Estrutura da organização para o desenvolvimento dos medicamentos \\ Apoio de outras áreas e/ou dos superiores aos projetos de desenvolvimento dos medicamentos}

Fonte: dados da pesquisa

\subsection{Recursos}

Estão incluídas nesta subcategoria as unidades de significado relacionadas à infraestrutura, aos equipamentos, aos materiais necessários ao desenvolvimento dos PDMG e à aquisição deles. O PMI (2017) considera fatores do ambiente dos projetos como importantes influenciadores (Figura 18). Entre fatores internos são considerados: a estrutura, a infraestrutura, a tecnologia e os recursos. O PMI aborda estes fatores como restrições quando limitam as decisões do projeto. Shargel e Kanfer (2005) indicam a tecnologia como um dos principais itens necessários ao desenvolvimento dos medicamentos genéricos.

\subsection{Competências}

No modelo proposto por Mendigorri e colaboradores (2016) para a mensuração da eficiência das atividades de pesquisa e desenvolvimento, o constructo denominado habilidades dos recursos humanos é formado pelas variáveis habilidades do pessoal de P\&D e experiência do pessoal de P\&D. O levantamento bibliográfico realizado pelas pesquisadoras indicou que os estudos são particularmente unânimes em relação aos efeitos positivos do conhecimento, habilidades e capacidades dos profissionais de P\&D. Em um artigo do final da década de 1980, Cooper e Kleinschmidt (1987) identificaram a proficiência nas atividades tecnológicas e a sinergia tecnológica entre os fatores de sucesso em projetos de desenvolvimento de produtos.

As competências necessárias para o desenvolvimento dos medicamentos genéricos caracterizam as unidades de significado incluídas nesta subcategoria. São as competências basicamente relacionadas ao domínio das tecnologias necessárias ao desenvolvimento do produto e do processo de fabricação, tendo Shargel e Kanfer (2005) como principal referencial.

\subsection{Organização}

A subcategoria Organização recebe as unidades de significado relacionadas às características do laboratório desenvolvedor dos medicamentos genéricos. Estão incluídos aspectos envolvendo a cultura, a estrutura organizacional e a comunicação e a interação entre seus departamentos (PMI, 2017). Wheelwright e Clark (1992) consideram que o desenvolvimento de um produto com sucesso requer a ação efetiva de todas as funções mais importantes de um negócio. Ernst (2002) verificou que a cultura organizacional pode impactar os resultados dos projetos de desenvolvimento de novos 
produtos e que o papel e o comprometimento dos gestores nos níveis mais elevados, por tomarem decisões estratégicas sobre a alocação de recursos, também influenciam os projetos de novos produtos.

\subsubsection{Categoria Técnico}

As necessidades e requisitos técnicos de um projeto estabelecem a base para a definição e gerenciamento do escopo do produto e do projeto. O PMI (2017) trata os requisitos dos projetos como integrantes dos processos de gerenciamento do escopo do projeto, o qual é definido como todo o trabalho necessário para que um projeto seja finalizado com sucesso. Ao estudarem os pedidos de registro de novos medicamentos, Do Carmo, Piras e colaboradores (2017) apresentaram uma relação de razões encontradas para a não aprovação e verificaram que em geral estavam relacionadas ao não atendimento de requisitos técnicos estabelecidos pela Anvisa (2017b).

Foram incluídas na categoria denominada Técnico as unidades de significado relacionadas aos requisitos técnicos para o desenvolvimento dos medicamentos genéricos. Também com base no referencial teórico, as unidades de significado da categoria Técnico foram então divididas nas subcategorias Especificações Técnicas, Requisitos do Projeto e Requisitos Regulatórios conforme a Tabela 54 a seguir.

Tabela 54 - Unidades de significado relacionadas à categoria Técnico subdivididos nas subcategorias.

\begin{tabular}{|c|c|}
\hline Subcategoria & Unidades de significado \\
\hline \multirow{9}{*}{$\begin{array}{l}\text { Especificações } \\
\text { técnicas }\end{array}$} & Garantia da qualidade (validação e qualificação) do medicamento \\
\hline & Estudos de bioequivalência e/ou biodisponibilidade do medicamento \\
\hline & Perfil de dissolução do medicamento \\
\hline & Estudos clínicos do medicamento (eficácia) \\
\hline & Equivalência farmacêutica do medicamento \\
\hline & Desenvolvimento do método de análise do medicamento \\
\hline & Estudos de estabilidade e de produtos de degradação \\
\hline & Controle de qualidade do medicamento \\
\hline & Informações do fornecedor do fármaco e/ou do DMF ("Drug Master File") \\
\hline \multirow{3}{*}{$\begin{array}{l}\text { Requisitos do } \\
\text { projeto }\end{array}$} & Custos para desenvolvimento dos medicamentos \\
\hline & Tempo necessário para o desenvolvimento dos medicamentos \\
\hline & $\begin{array}{l}\text { Riscos no processo de desenvolvimento do medicamento e para sua autorização para } \\
\text { comercialização }\end{array}$ \\
\hline \multirow{3}{*}{$\begin{array}{l}\text { Requisitos } \\
\text { regulatórios }\end{array}$} & Legislação para registro do medicamento \\
\hline & Dossiê para registro do medicamento \\
\hline & Processo de análise e registro do medicamento \\
\hline
\end{tabular}

Fonte: dados da pesquisa 


\subsection{Especificações técnicas}

Estão incluídas na subcategoria Especificações Técnicas as unidades de significado relacionadas às normas e requisitos técnicos para o desenvolvimento dos medicamentos genéricos. $\mathrm{O}$ principal referencial teórico utilizado para a classificação das unidades de significado da categoria Técnico foram as resoluções da Diretoria Colegiada da Anvisa (2007, 2017b), mais especificamente a RDC ${ }^{\circ}$ 16 de 2 de março de 2007 (regulamento técnico para medicamentos genéricos) e a RDC no 200 de 26 de dezembro de 2017 (critérios para a concessão e renovação do registro de medicamentos).

\subsection{Requisitos do projeto}

Requisitos são condições ou capacidades que devem estar em um produto. Os requisitos de um projeto podem ser relacionados ao negócio, às partes interessadas, de solução (funcionais e não funcionais), de projeto e da qualidade (PMI, 2017). Embora os requisitos para o gerenciamento dos projetos possam abranger todas as áreas do conhecimento definidas pelo PMI (2017), no caso do desenvolvimento de medicamentos genéricos foram extraídas das respostas as unidades de significado relacionadas apenas ao gerenciamento do tempo, dos custos e dos riscos dos projetos. Tendo por referência esta definição, na subcategoria Requisitos do projeto estão incluídas as unidades de significado relacionadas às características intrínsecas dos projetos de desenvolvimento dos medicamentos genéricos.

\subsection{Requisitos regulatórios}

O guia elaborado pelo ISPE (2011) destaca a importância do contexto regulatório para os projetos desenvolvidos pela indústria farmacêutica. Segundo a entidade, os requisitos regulatórios devem ser gerenciados através do ciclo de vida do projeto para que a conformidade seja assegurada. A autorização para a comercialização de um novo medicamento genérico é realizada por meio da concessão de seu registro pela Anvisa (2007, 2017b) no caso do Brasil. Para a autorização, são analisados o cumprimento dos requisitos técnico-administrativo relacionados à eficácia, segurança e qualidade do medicamento (Do Carmo, Piras, et al., 2017). Estão incluídos na subcategoria Requisitos Regulatórios as unidades de significado relacionadas ao processo de registro (Figuras 14 e 15) e autorização para comercialização dos medicamentos genéricos, tendo por referencial teórico a norma estabelecida pela Anvisa (2007, 2017b).

\subsubsection{Proposição do modelo teórico}

A partir das categorias e subcategorias de unidades de significado definidas, do contexto em que aparecem nas respostas recebidas e com apoio do referencial teórico, foi elaborada uma representação gráfica das relações entre as categorias de dados, modelo esse já apresentado na Figura 21 no final da fundamentação teórica e reapresentado a seguir na Figura $31 \mathrm{com}$ as hipóteses formuladas. O modelo teórico proposto procurou representar as relações entre o desempenho dos PDMG e seus fatores contribuintes. Portanto, além da dimensão relacionada ao desempenho dos projetos de 
desenvolvimento dos medicamentos genéricos, o modelo conceitual proposto considera três dimensões para os fatores contribuintes: dimensão gerencial, dimensão estrutural e dimensão técnica.

Figura 31 - Modelo conceitual e as hipóteses de pesquisa

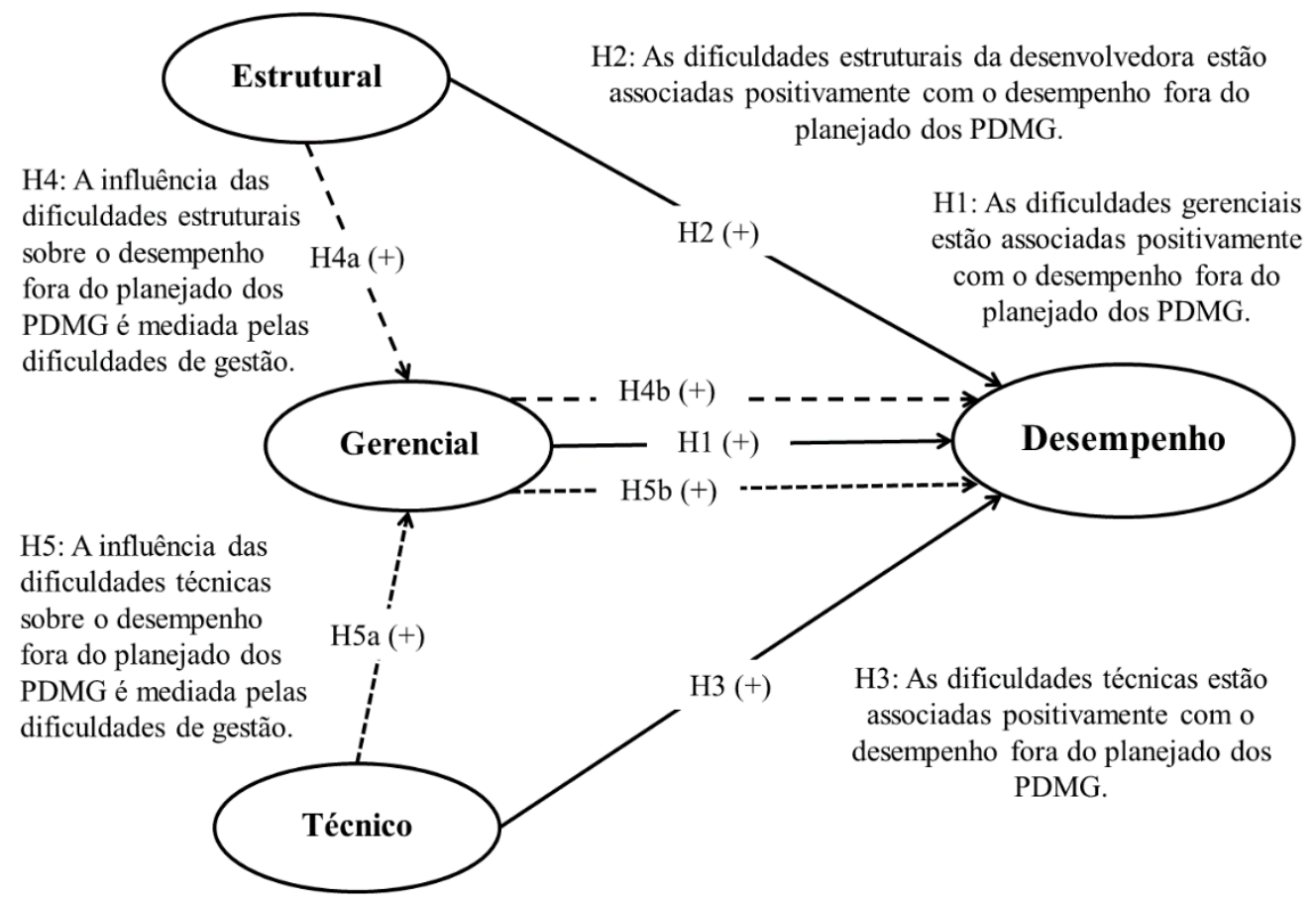

Fonte: elaborado pelo autor

\subsection{RESULTADOS DA FASE QUANTITATIVA}

A fim de responder à questão de pesquisa, nesta seção são apresentados e discutidos os resultados da pesquisa quantitativa realizada a partir do modelo teórico proposto, dos indicadores de desempenho e dos fatores contribuintes identificados na fase qualitativa.

Assim, são avaliados os constructos, seus respectivos indicadores e as relações hipotetizadas (caminhos) entre os constructos do modelo conceitual. Com isso, serão atendidos também os objetivos específicos estabelecidos para o estudo, ou seja:

a. Identificar os indicadores de desempenho dos projetos de desenvolvimento de medicamentos genéricos;

b. Identificar os fatores que contribuem para o desempenho dos projetos de desenvolvimento de medicamentos genéricos;

c. Propor de um modelo teórico multidimensional que integre o desempenho dos projetos de desenvolvimento de medicamentos genéricos e seus fatores contribuintes;

d. Analisar empiricamente as relações entre os fatores contribuintes e o desempenho dos projetos de desenvolvimento dos medicamentos genéricos. 
A apresentação dos resultados das análises quantitativas tem início com os resultados da pesquisa preliminar realizada para avaliação da validade do conteúdo e que definiu os indicadores de desempenho e dos fatores contribuintes que compuseram o questionário da pesquisa desta fase.

\subsubsection{Resultados da análise da validade do conteúdo do questionário}

Entre 26/06 e 5/07 de 2018 foi realizada a validação dos indicadores identificados para os constructos do modelo proposto para a mensuração do desempenho dos PDMG e de seus fatores contribuintes. Participaram da pesquisa de validação 19 profissionais cujo perfil é apresentado na Tabela 55 .

Tabela 55 - Perfil dos participantes da amostra para validação do conteúdo (n = 19)

\begin{tabular}{|c|c|c|c|c|c|c|c|c|}
\hline Área de atuação & $\mathrm{n}$ & $\%$ & $\begin{array}{l}\text { Tempo de } \\
\text { experiência }\end{array}$ & $\mathrm{n}$ & $\%$ & $\begin{array}{l}\text { Relação com os } \\
\text { projetos }\end{array}$ & $\mathrm{n}$ & $\%$ \\
\hline $\begin{array}{l}\text { Controle de } \\
\text { qualidade }\end{array}$ & 2 & $11 \%$ & $\begin{array}{l}\text { Mais de } 1 \text { ano e } \\
\text { menos de } 2 \text { anos }\end{array}$ & 1 & $5 \%$ & $\begin{array}{l}\text { Sou ou fui responsável } \\
\text { pela área de P\&D }\end{array}$ & 3 & $16 \%$ \\
\hline Engenharia & 1 & $5 \%$ & $\begin{array}{l}\text { Mais de } 2 \text { anos e } \\
\text { menos de } 5 \text { anos }\end{array}$ & 3 & $16 \%$ & $\begin{array}{l}\text { Sou ou fui responsável } \\
\text { por projetos de } P \& D\end{array}$ & 1 & $5 \%$ \\
\hline $\begin{array}{l}\text { Garantia da } \\
\text { qualidade }\end{array}$ & 4 & $22 \%$ & $\begin{array}{l}\text { Mais de } 5 \text { anos e } \\
\text { menos de } 10 \text { anos }\end{array}$ & 3 & $16 \%$ & $\begin{array}{l}\text { Sou ou fui membro de } \\
\text { equipe de } \\
\text { gerenciamento de } \\
\text { projetos }\end{array}$ & 2 & $11 \%$ \\
\hline $\begin{array}{c}\text { Pesquisa e } \\
\text { desenvolvimento }\end{array}$ & 7 & $36 \%$ & $\begin{array}{l}\text { Mais de } 10 \text { anos e } \\
\text { menos de } 20 \text { anos }\end{array}$ & 11 & $58 \%$ & $\begin{array}{l}\text { Sou ou fui de áreas de } \\
\text { suporte aos projetos de } \\
\text { desenvolvimento }\end{array}$ & 11 & $58 \%$ \\
\hline Regulatório & 3 & $16 \%$ & Mais de 20 anos & 1 & $5 \%$ & $\begin{array}{l}\text { Sou ou fui de áreas que } \\
\text { tem interesse nos } \\
\text { resultados dos projetos }\end{array}$ & 1 & $5 \%$ \\
\hline Suprimentos & 1 & $5 \%$ & & & & Outro tipo de atividade. & 1 & $5 \%$ \\
\hline Outros. & 1 & $5 \%$ & & & & & & \\
\hline
\end{tabular}

Fonte: dados da pesquisa.

A pesquisa teve a participação de 19 profissionais, número considerado suficiente para a validação do conteúdo dos indicadores selecionados (Alexandre \& Coluci, 2011). Dos 19 participantes, 7 (36\%) eram da área de pesquisa e desenvolvimento. Além disso, 6 estavam diretamente relacionados aos projetos de desenvolvimento de medicamentos, ou seja, responsáveis pela área de $\mathrm{P} \& \mathrm{D}$, responsáveis pelos projetos de $\mathrm{P} \& \mathrm{D}$ e membros das equipes dos projetos de $\mathrm{P} \& \mathrm{D}$. Outros 11 (58\%) participantes eram de áreas de suporte aos projetos. Neste ponto é importante lembrar que o desenvolvimento de novos medicamentos envolve a participação de profissionais de diferentes áreas e especializações além da área de P\&D (L. Brown \& Grundy, 2011). Outra característica que deve ser destacada é o tempo de experiência dos participantes em laboratórios farmacêuticos com 12 participantes (63\%) com mais de 10 anos de atuação.

A avaliação da validade de conteúdo buscou verificar em que proporção os itens selecionados para medir os constructos teóricos eram relevantes e/ou representam bem todas as facetas importantes do conceito que pretendiam mensurar (Alexandre \& Coluci, 2011). Para a composição das questões do 
questionário, os indicadores dos constructos foram reescritos na forma de assertivas que pudessem caracterizar claramente o seu sentido e contexto para a coleta correta do dado. Os indicadores reescritos foram então submetidas à avaliação de validade de conteúdo. Os resultados da avaliação da relevância dos indicadores do constructo Desempenho estão no Apêndice VIII.

A análise dos dados apontou que o indicador para a avaliação do desempenho dos PDMG sobre a conclusão do desenvolvimento do medicamento independentemente dos demais requisitos não apresentou resultado satisfatório para a validação do conteúdo. O indicador apresentou soma entre os pontos 5, 6 e 7 da escala adotada igual a 38\%, portanto, abaixo de $78 \%$ que, de acordo com Alexandre e Coluci (2011), seria o mínimo para validação. Este resultado sugere que empresas adotam ao menos um indicador para a avaliação do desempenho dos PDMG.

Os resultados da pesquisa para avaliação da relevância dos indicadores dos constructos relacionados aos fatores contribuintes para o desempenho fora do esperado dos PDMG estão no Apêndice IX desta tese. Os dados coletados apontaram que cinco dos 48 indicadores selecionados para a mensuração de situações relacionadas ao desempenho fora do planejado dos PDMG mostraram-se insatisfatórios para a validação do conteúdo, ou seja, a soma entre os pontos 5, 6 e 7 da escala adotada foi menor que o índice de referência de 0,78 ou 78\%. Destes, os indicadores "dificuldades para aquisição de ingrediente farmacêutico ativo" e "dificuldades para aquisição de equipamentos (laboratório e/ou produção)" apresentaram índices de $68 \%$ e a decisão foi de excluí-los da pesquisa.

Os outros três, "dificuldades na realização dos estudos de dissolução dos medicamentos", "deficiências e/ou dificuldades no preenchimento da documentação do desenvolvimento dos medicamentos" e "cultura da empresa ou organização que não favorece e/ou dificulta o desenvolvimento adequado dos medicamentos", obtiveram índices de $72 \%$ ou mais. Estes indicadores foram então analisados com base nas respostas dos profissionais que atuam especificamente na área de P\&D. Como neste para este grupo de respondentes o indicador "deficiências e/ou dificuldades no preenchimento da documentação do desenvolvimento dos medicamentos" também apresentou índice insatisfatório (67\%), ele também foi eliminado do estudo. Por outro lado, como os dois restantes apresentaram índices satisfatórios para grupo de profissionais de $\mathrm{P} \& \mathrm{D}$, a decisão foi a de mantê-los.

Nenhum dos indicadores teve a opção "não está claro" assinada. Por outro lado, o indicador "dificuldades na realização dos estudos clínicos dos medicamentos (eficácia)" teve a opção "não sei dizer" assinalada em 19\% das respostas. Em menor frequência, os indicadores "o laboratório não usar ou usar inadequadamente metodologias científicas para o desenvolvimento dos medicamentos" e "o laboratório não ter domínio suficiente da tecnologia dos medicamentos" tiveram a opção "não sei dizer" assinalada em $12 \%$ das respostas. Outros 10 indicadores tiveram a opção "não sei dizer" assinalada em $6 \%$ das respostas. Como esta é uma avaliação mais relacionada à familiaridade do respondente com o indicador analisado e considerando que também participaram da amostra 
profissionais que possuem relação com o desenvolvimento de novos medicamentos, mas não diretamente, já era esperado que alguns indicadores não fossem conhecidos por todos. No entanto, o índice de 19\% mereceu uma avaliação mais detalhada. Novamente, os indicadores com resultados insatisfatórios foram analisados com base nas respostas dos profissionais que atuam na área de P\&D. Desta vez, o indicador "dificuldades na realização dos estudos clínicos dos medicamentos (eficácia)" também apresentou índice insatisfatório (67\%) e também foi excluído do estudo. Os demais foram mantidos na pesquisa.

O indicador "dificuldades no desenvolvimento da formulação (farmacotécnico) dos medicamentos" teve a sua avaliação realizada por meio de pergunta enviada e respondida por meio de mensagem eletrônica. Isso porque, mesmo constando da relação de indicadores selecionados e sendo considerado de alta relevância, ao realizar a análise da base de dados da pesquisa, percebeu-se que o indicador não apareceu no questionário eletrônico disponibilizado. A solicitação para complementação das respostas foi enviada aos 19 respondentes da pesquisa, sendo que destes, 13 responderam ao pedido. Com $92 \%$ das respostas indicando relevância para o indicador, este foi considerado validado. Resumidamente, a validação do conteúdo definiu a exclusão de 5 indicadores (Tabela 56).

Tabela 56 - Indicadores excluídos do estudo após validação do conteúdo. (n = 19)

\begin{tabular}{|c|c|c|c|c|c|c|}
\hline Indicadores eliminados & $\begin{array}{c}\text { Mé- } \\
\text { dia }\end{array}$ & $\begin{array}{c}\text { Mo- } \\
\text { da }\end{array}$ & $\mathrm{NC}$ & $\begin{array}{c}\text { Relevante } \\
5,6 \text { e } 7\end{array}$ & NS & Motivo \\
\hline $\begin{array}{l}\text { Concluir o desenvolvimento do } \\
\text { medicamento (independentemente dos } \\
\text { demais requisitos) }\end{array}$ & 3,8 & 1 & $\begin{array}{l}11 \\
\%\end{array}$ & $38 \%$ & $0 \%$ & Baixa relevância \\
\hline $\begin{array}{l}\text { Dificuldades para aquisição de ingrediente } \\
\text { farmacêutico ativo }\end{array}$ & 5,2 & 6 & $0 \%$ & $68 \%$ & $0 \%$ & Baixa relevância \\
\hline $\begin{array}{l}\text { Dificuldades para aquisição de } \\
\text { equipamentos (laboratório e/ou produção) }\end{array}$ & 5,3 & 6 & $0 \%$ & $68 \%$ & $0 \%$ & Baixa relevância \\
\hline $\begin{array}{l}\text { Deficiências e/ou dificuldades no } \\
\text { preenchimento da documentação do } \\
\text { desenvolvimento dos medicamentos }\end{array}$ & 5,5 & 6 & $0 \%$ & $72 \%(67 \%)$ & $0 \%$ & $\begin{array}{c}\text { Baixa relevância } \\
\text { geral (e P\&D) }\end{array}$ \\
\hline $\begin{array}{l}\text { Dificuldades na realização dos estudos } \\
\text { clínicos dos medicamentos (eficácia) }\end{array}$ & 6,1 & 7 & $0 \%$ & $88 \%(67 \%)$ & $\begin{array}{l}19 \\
\%\end{array}$ & $\begin{array}{l}\text { Baixa relevância } \\
\text { (P\&D) e alto } \\
\text { desconhecimento }\end{array}$ \\
\hline
\end{tabular}

Fonte: dados da pesquisa.

Validado o conteúdo do questionário, foi finalizada a construção do questionário e iniciada a coleta de dados com a sua aplicação por meio da plataforma de pesquisa na internet QuestionPro ${ }^{\circledR}$. A seguir são apresentados os resultados das análises dos dados coletados. Foram obtidas 209 respostas validadas, número que é aproximadamente o dobro da amostra mínima calculada pelo G*Power (Buchner et al., 2019) e que foi de 109 participantes, ou seja, próximo ao ideal sugerido por Bido e Da Silva (2019) e Ringle e colaboradores (2014). 


\subsubsection{Resultados da análise descritiva dos dados}

Os resultados da análise descritiva das variáveis da pesquisa são apresentados em três subseções. Na primeira subseção são contempladas as variáveis associadas ao perfil dos respondentes e das empresas nas quais trabalhavam os respondentes, compreendendo: i) experiência profissional em projetos de desenvolvimento de medicamentos genéricos; ii) participação em projetos de desenvolvimento de medicamentos genéricos; iii) função nos projetos de desenvolvimento de medicamentos genéricos; iv) departamento ou área de atuação; v) cargo ou função; vi) tipo de empresa; vii) origem da empresa; viii) número de projetos de todas as classes de medicamentos desenvolvidos simultaneamente pela empresa; e ix) número de projetos somente de medicamentos genéricos desenvolvidos simultaneamente pela empresa.

$\mathrm{Na}$ segunda subseção são apresentadas as estatísticas descritivas associadas à conclusão e abandono de projetos, ou seja: i) número de projetos que foram abandonados antes do término em razão de mudanças nas prioridades e/ou estratégia da empresa; ii) número de projetos que foram abandonados antes do término em razão de insuficiência de recursos e/ou competências técnicas; iii) número de projetos que foram abandonados antes do término em razão de problemas técnicos no seu desenvolvimento; iv) número de projetos que foram concluídos, mas com o desempenho fora do planejado (além do prazo, do custo de desenvolvimento, do custo de produção/preço-alvo de mercado e/ou com problemas para aprovação pela Anvisa); e v) número de projetos que foram concluídos com o desempenho dentro do planejado (dentro do prazo, do custo de desenvolvimento, do custo de produção/preço-alvo de mercado e/ou sem problemas para aprovação pela Anvisa).

Por fim, na terceira subseção são apresentadas as estatísticas descritivas relacionadas aos indicadores que mensuram os constructos pertencentes ao modelo da pesquisa. São descritos a média e o desvio padrão dos constructos e dos seus respectivos indicadores: i) constructo Desempenho do Projeto (indicadores de ID1 a ID5); ii) constructo Desenvolvimento (indicadores DP1 a DP7); iii) constructo Gestão (indicadores de GT1 a GT6); iv) constructo Portfolio (indicadores de PF1 a PF4); v) constructo Recursos (indicadores de RE1 a RE6); vi) constructo Competências (indicadores de CP1 a CP3); vii) constructo Organização (indicadores de OR1 a OR4); viii) constructo Especificações Técnicas (indicadores de ET1 a ET8); ix) constructo Requisitos do Projeto (indicadores de RP1 a RP3); e x) constructo Requisitos Regulatórios (indicadores de RR1 a RR3). A relação dos indicadores e respectivos códigos estão no Apêndice XII desta tese.

\subsubsection{Descrição do perfil dos respondentes e dos laboratórios em que atuavam}

Em relação ao perfil dos respondentes, a Figura 32 apresenta a distribuição da amostra em relação à experiência profissional dos respondentes em PDMG. 
Figura 32 - Experiência em Projetos de Medicamentos Genéricos ( $\mathrm{n}=209)$

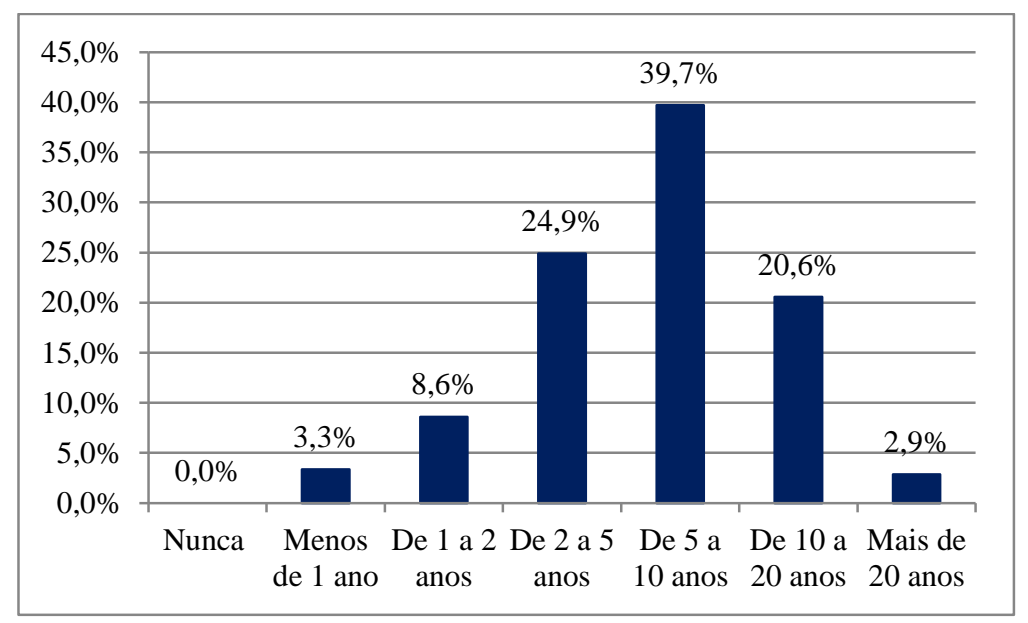

Fonte: dados da pesquisa.

Do total de 209 participantes, 39,7\% possuía entre 5 a 10 anos de experiência em PDMG. Na sequência, um segundo grupo correspondente a $24,9 \%$ da amostra possuía entre 2 a 5 anos de experiência. O terceiro grupo com destaque, correspondente a $20,6 \%$, foi formado por respondentes que possuíam entre 10 a 20 anos de experiência nesses projetos. Desta forma, o perfil dos participantes indica que a maioria $(63,2 \%)$ possuía considerável experiência em PDMG com a menos 5 anos de atuação em PDMG. Apenas 11,9\% dos respondentes possuía menos de 2 anos de experiência.

No que diz respeito à participação recente ou atual em projetos de medicamentos genéricos, os resultados são apresentados na Figura 33. A maior parcela dos entrevistados $(58,9 \%)$ trabalhava no momento da pesquisa em projetos de medicamentos genéricos. Já $21,1 \%$ dos entrevistados trabalhou nessa atividade há mais de 2 anos e outros 16,7\% trabalhou há menos de 2 anos.

Figura 33 - Participação recente ou atual em projetos de medicamentos genéricos ( $\mathrm{n}=209)$

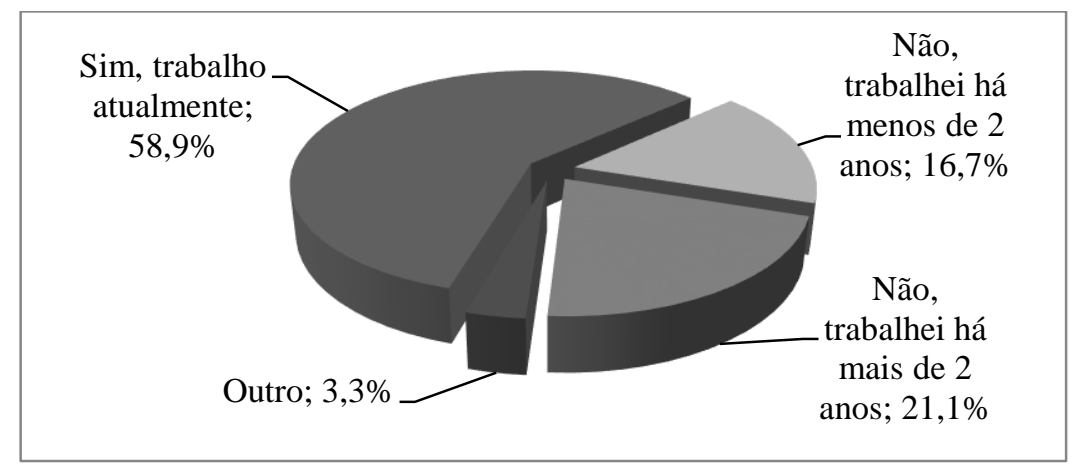

Fonte: dados da pesquisa.

Quanto à função dos respondentes nos PDMG, os resultados são apresentados na Figura 34. A função responsável ou participante de atividades dos projetos de desenvolvimento de medicamentos genéricos ou equivalente foi a mais representativa na amostra, correspondendo a 56,5\% do total de 
entrevistados. Somados aos $12,4 \%$ que responderam ter participado como membros da equipe dos projetos, temos que 68,9\% participaram diretamente em PDMG.

Figura 34 - Função nos Projetos de Desenvolvimento de Medicamentos Genéricos (n= 209)

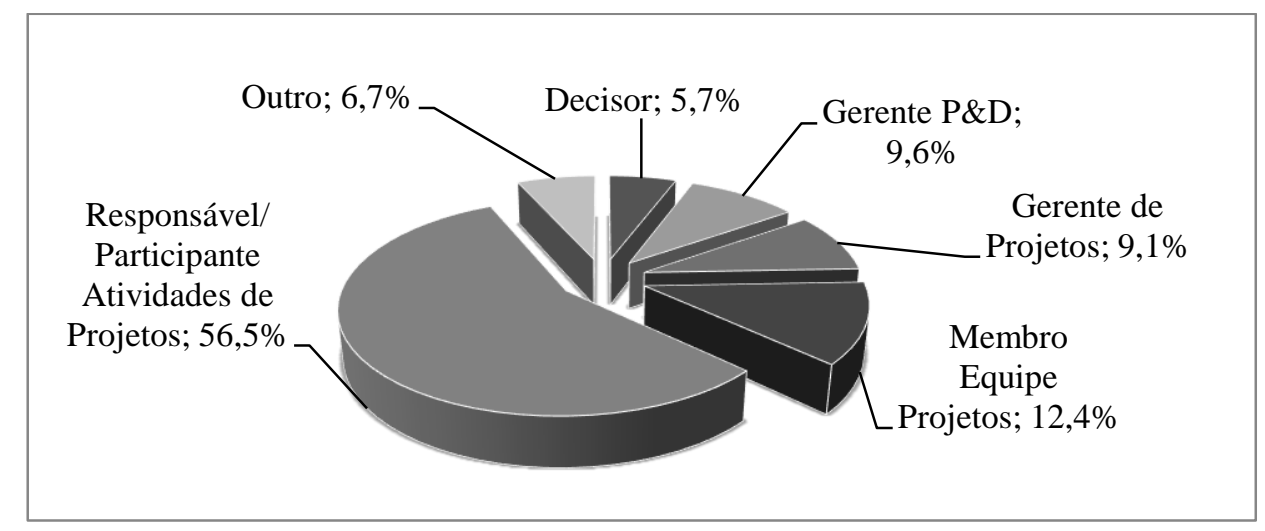

Nota: decisor é o profissional que decide ou é membro de comitê de decisão sobre o portfólio de PDMG. Fonte: dados da pesquisa.

Com respeito à área ou departamento em que atuavam predominante nos PDMG, os resultados são representados na Figura 35. A área de Pesquisa \& Desenvolvimento (P\&D) foi a que apresentou maior frequência, sendo apontada por 155 dos entrevistados da amostra, o que corresponde a 74,2\% do total. Este resultado reflete o fato da maioria das atividades dos PDMG serem realizadas e gerenciadas pela área de P\&D.

Figura 35 - Área ou departamento predominante nos Projetos de Desenvolvimento de Medicamentos Genéricos $(n=209)$

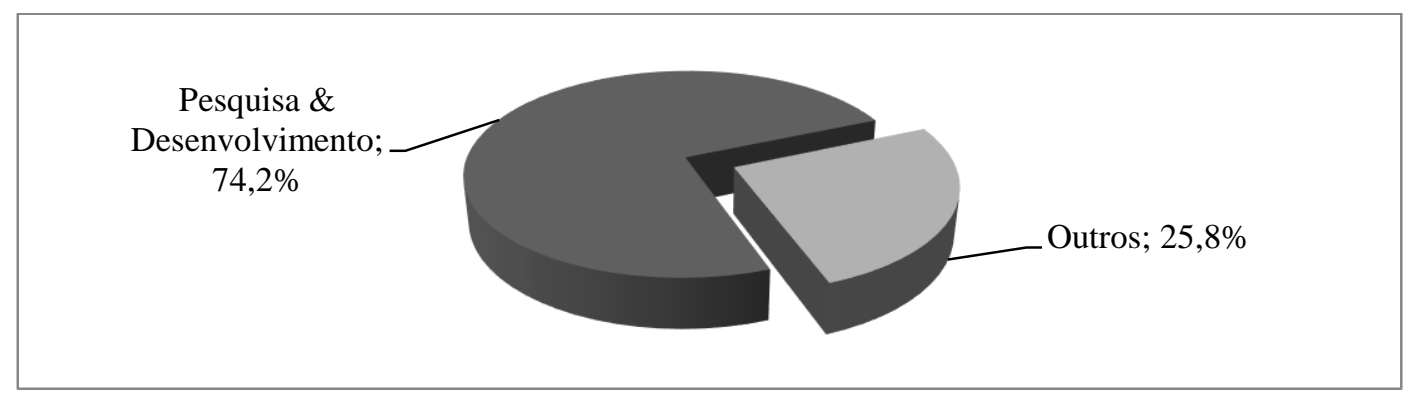

Fonte: dados da pesquisa.

$\mathrm{Na}$ categoria outros, algumas áreas e departamentos mencionados foram: Regulatório (7,7\%), Controle de Qualidade (4,8\%) e Engenharia/Manutenção (4,3\%). Estas são áreas que também tem participação nos PDMG (De Paula, 2004), pois partes dos projetos são desenvolvidos por elas, tais como: processo de registro, testes de qualidade e desenvolvimento do processo de fabricação, respectivamente.

Quanto ao cargo que era exercido na empresa pelo respondente, o resultado da análise das respostas dos participantes é apresentada na Figura 36. Do total de 209 respondentes, 52,6\% atuavam como analistas, pesquisadores e técnicos. 
Figura 36 - Cargo ou Função exercida pelo respondente na empresa $(\mathrm{n}=209)$

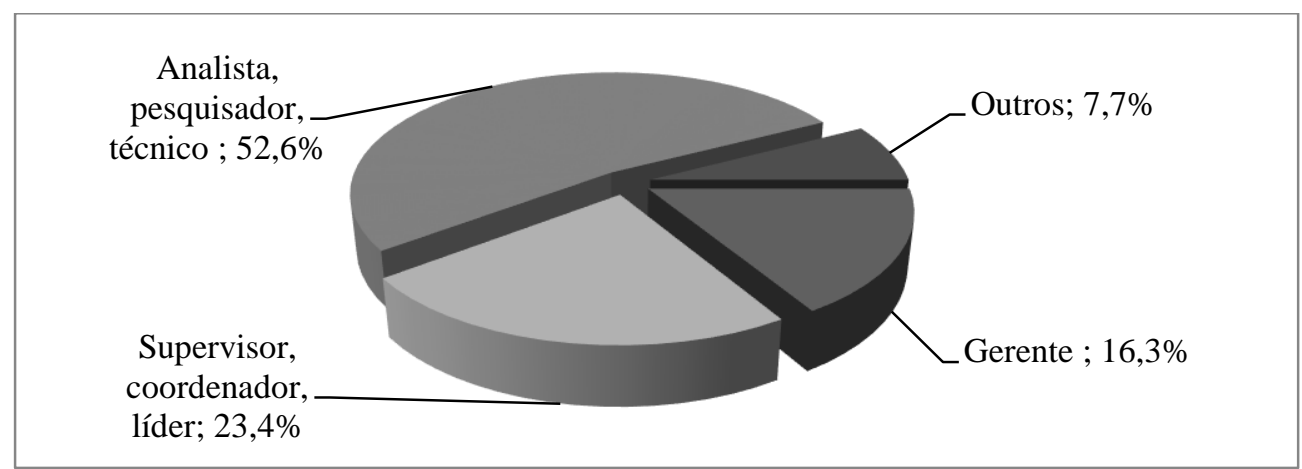

Fonte: dados da pesquisa.

Em destaque também estão 23,4\% que atuavam como supervisores, coordenadores e líderes e $16,3 \%$ que atuavam como gerentes. Assim, do total de respondentes, $40 \%$ estavam em cargos de gestão.

A seguir são apresentados e analisados os dados referentes às características dos laboratórios farmacêuticos onde os respondentes trabalhavam em PDMG (tipo de empresa, origem, constituição da empresa e número de projetos de desenvolvimento de medicamentos desenvolvidos).

Em relação à configuração jurídica da empresa onde os respondentes trabalhavam em PDMG, os dados são apresentados por meio da Figura 37. A maioria dos participantes da pesquisa indicou que trabalhava em laboratórios farmacêuticos privados, correspondendo a 91,4\% da amostra. Na categoria outros, que corresponde a 8,6\% da amostra, estão representados laboratórios farmacêuticos públicos $(2,9 \%)$, de economia mista $(1,4 \%)$ e prestadores de serviços privados (não fabricantes) $(1,4 \%)$.

Figura 37 - Tipo da empresa $(\mathrm{n}=209)$

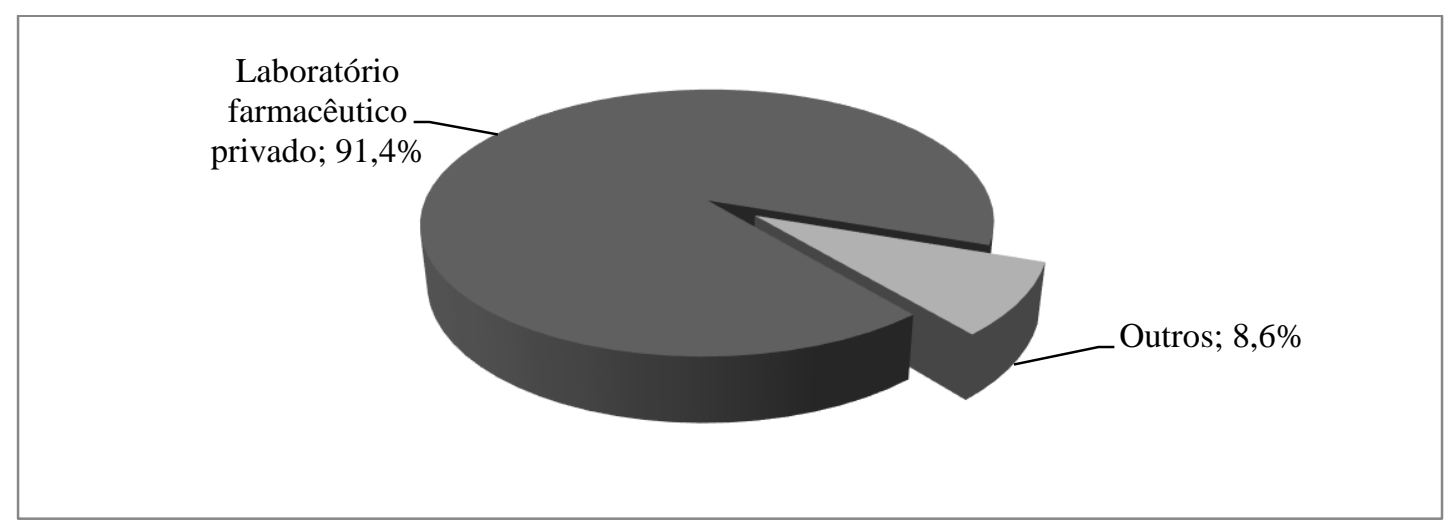

Fonte: dados da pesquisa.

No que diz respeito à origem da empresa, como pode ser observado na Figura 38, a maior parcela dos respondentes $(87,6 \%)$ informou que trabalhava em empresas com origem em capital nacional. Este dado reflete o domínio do mercado brasileiro de medicamentos genéricos pelos laboratórios nacionais (Sindusfarma, 2019). A relação de empresas que atuam no mercado brasileiro de genérico está disponível no Anexo I desta tese, incluindo dados do faturamento do ano de 2017. É 
importante esclarecer que os dados desta pesquisa não devem ser equiparados à participação de mercado de nacionais e multinacionais, uma vez que a pesquisa focou no desenvolvimento local dos medicamentos e parte das multinacionais apenas importam os produtos de suas plantas produtivas em outros países. Além disso, apesar de algumas multinacionais possuírem plantas produtivas no Brasil, o desenvolvimento em muitas delas é realizado em outras unidades fora do país.

Figura 38 - Origem da empresa $(n=209)$

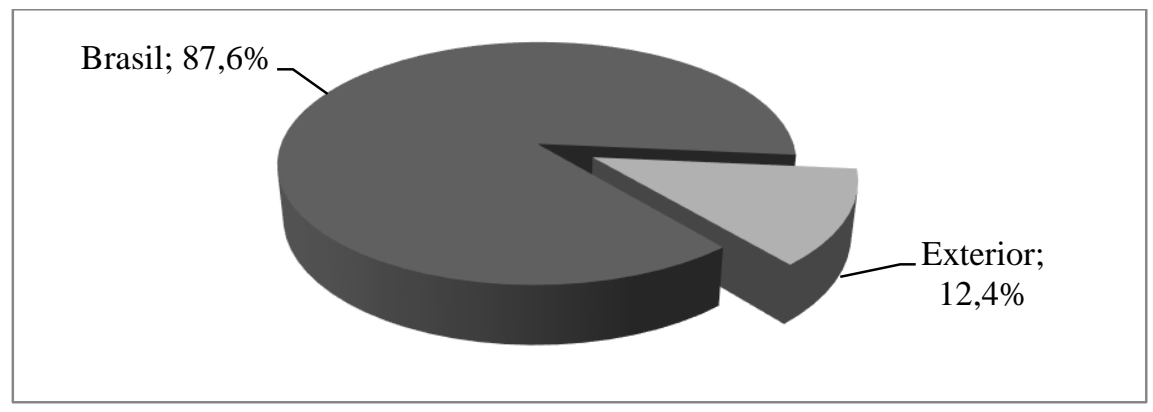

Fonte: dados da pesquisa.

Na sequência são apresentados os resultados associados às características do desenvolvimento de medicamentos pelas empresas em que os respondentes trabalhavam. Os dados apresentados na Figura 39 referem-se aos projetos de todas as classes de medicamentos desenvolvidos pelas empresas onde trabalhavam os respondentes da pesquisa. Decidiu-se utilizar o número de projetos como uma medida aproximada de tamanho, pois o foco está no desenvolvimento de medicamentos e, como já comentado, laboratórios multinacionais, por exemplo, tem grandes plantas de produção, muitas fora do país, mas pouco desenvolvimento local.

Figura 39 - Número de projetos de todas as classes de medicamentos $(\mathrm{n}=208)$

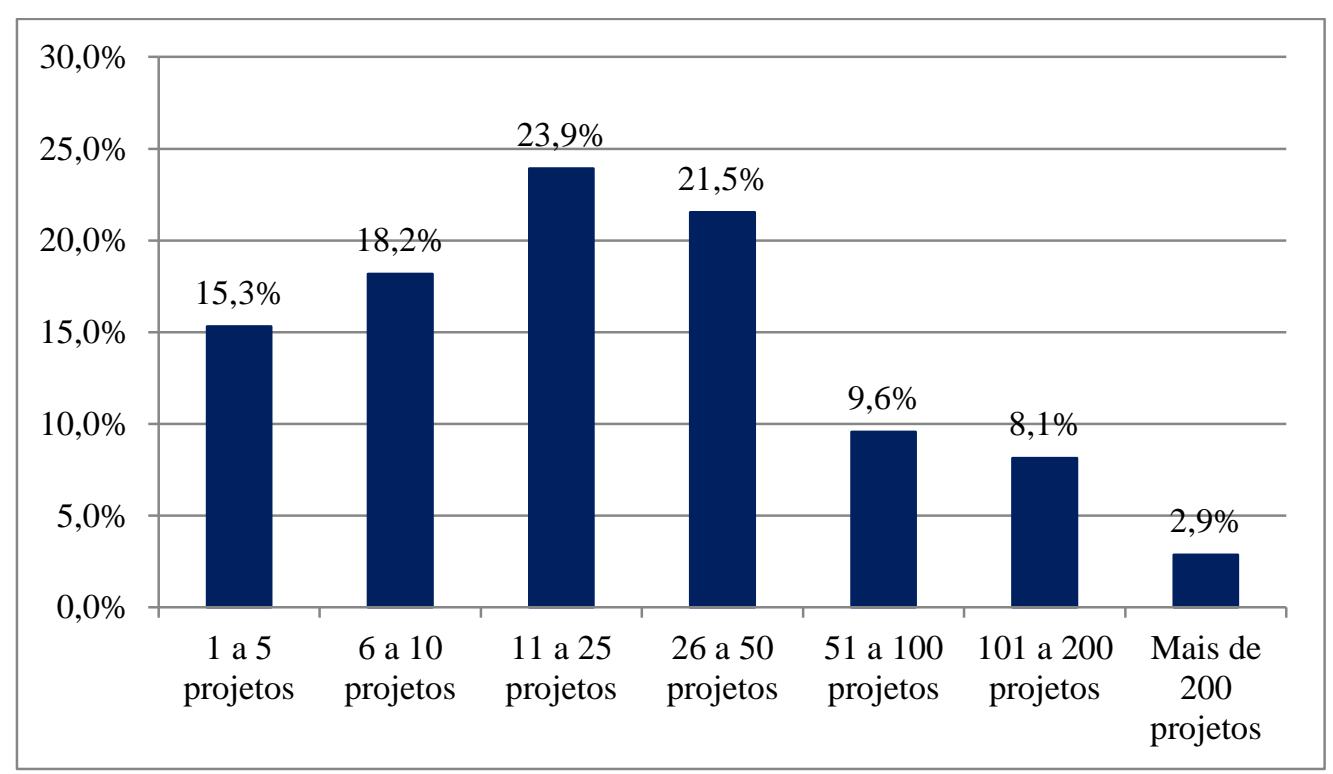

Fonte: dados da pesquisa. 
Uma parte importante das empresas (42,1\%) desenvolve entre 6 e 25 projetos de desenvolvimento de medicamentos de diferentes classes ao mesmo tempo. Um dado que se destaca é a existência no mercado brasileiro de empresas que desenvolvem mais de 100 projetos de desenvolvimento de medicamentos simultaneamente.

Com relação ao número somente de PDMG simultâneos, os dados apresentados pela Figura 40 revelam que $45,9 \%$ das empresas em que trabalhavam os respondentes desenvolviam entre 1 e 10 PDMG e 41,1\% das empresas desenvolviam entre 11 e 50 PDMG.

Figura 40 - Número de projetos somente de medicamentos genéricos $(\mathrm{n}=206)$

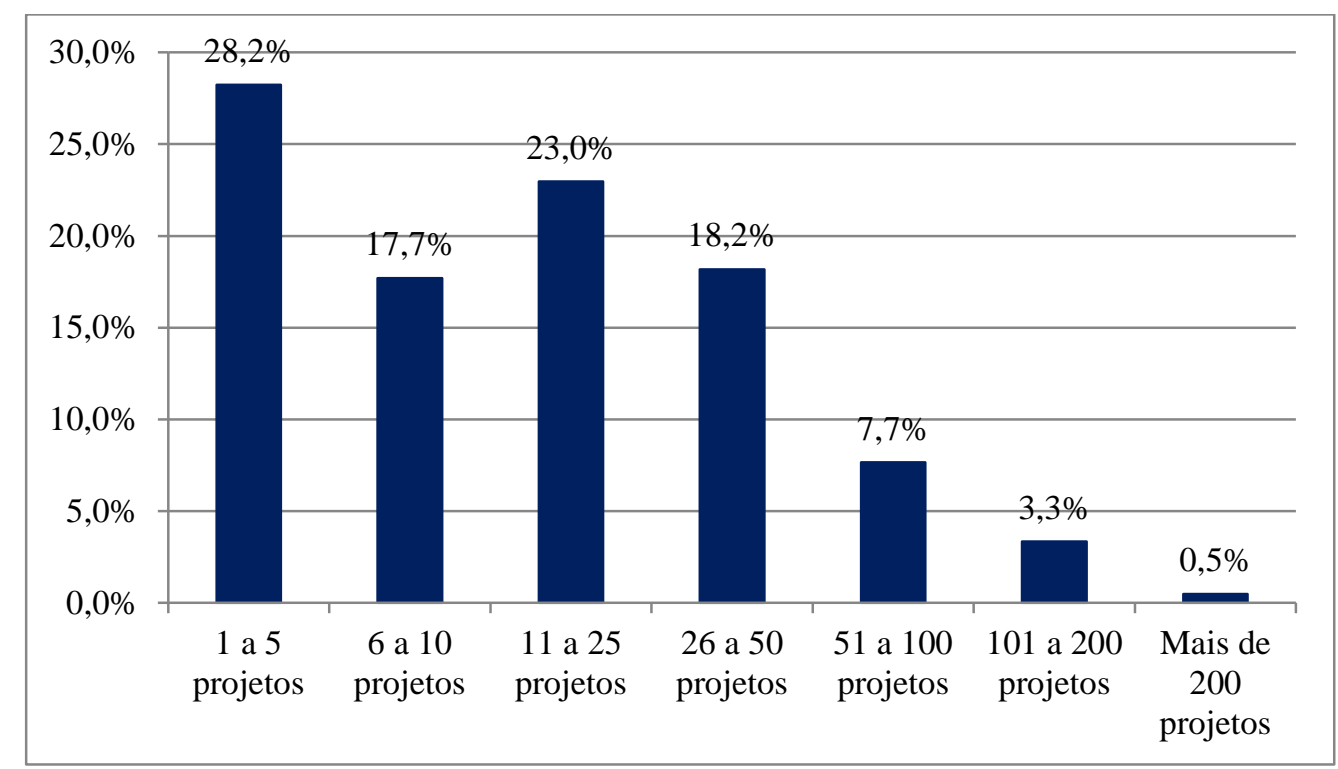

Fonte: dados da pesquisa.

Como esperado, o que se pode perceber em relação aos dados do gráfico anterior é que houve o deslocamento do perfil de frequência para um menor número de projetos e que, portanto, as empresas não desenvolvem somente medicamentos genéricos. Da mesma forma que para a análise anterior, um dado que se destaca é a existência no mercado brasileiro de empresas que desenvolvem mais de 100 PDMG simultaneamente. Embora não se tenha feito uma relação entre tamanho da empresa e número de PDMG, a distribuição dos dados sugere que o DPMG não é limitado a um tipo ou tamanho de empresa.

\subsubsection{Características dos projetos de desenvolvimento de medicamentos genéricos}

Uma das questões do questionário procurou identificar a frequência das causas para o abandono de PDMG. Três possíveis causas foram pesquisadas: mudança estratégica (Figura 41), insuficiência de recursos (Figura 42) e problemas técnicos (Figura 43). Os dados coletados são analisados a seguir.

Os resultados apresentados na Figura 41 para o abandono dos PDMG por decisões de ordem estratégica indicam que, embora seja relativamente baixa para a maioria dos respondentes $(53,6 \%)$, a faixa entre $1 \%$ e $20 \%$ de taxa de abandono não pode ser considerada insignificante, uma vez que os riscos nas decisões de portfólio não são elevados em se tratando de medicamentos genéricos, uma vez 
que seriam, com base na tipologia de Griffin e Page (1996), estratégias de desenvolvimento de um produto conhecido para um mercado também conhecido.

Figura 41 - Abandono de projetos por mudança estratégica $(\mathrm{n}=209)$

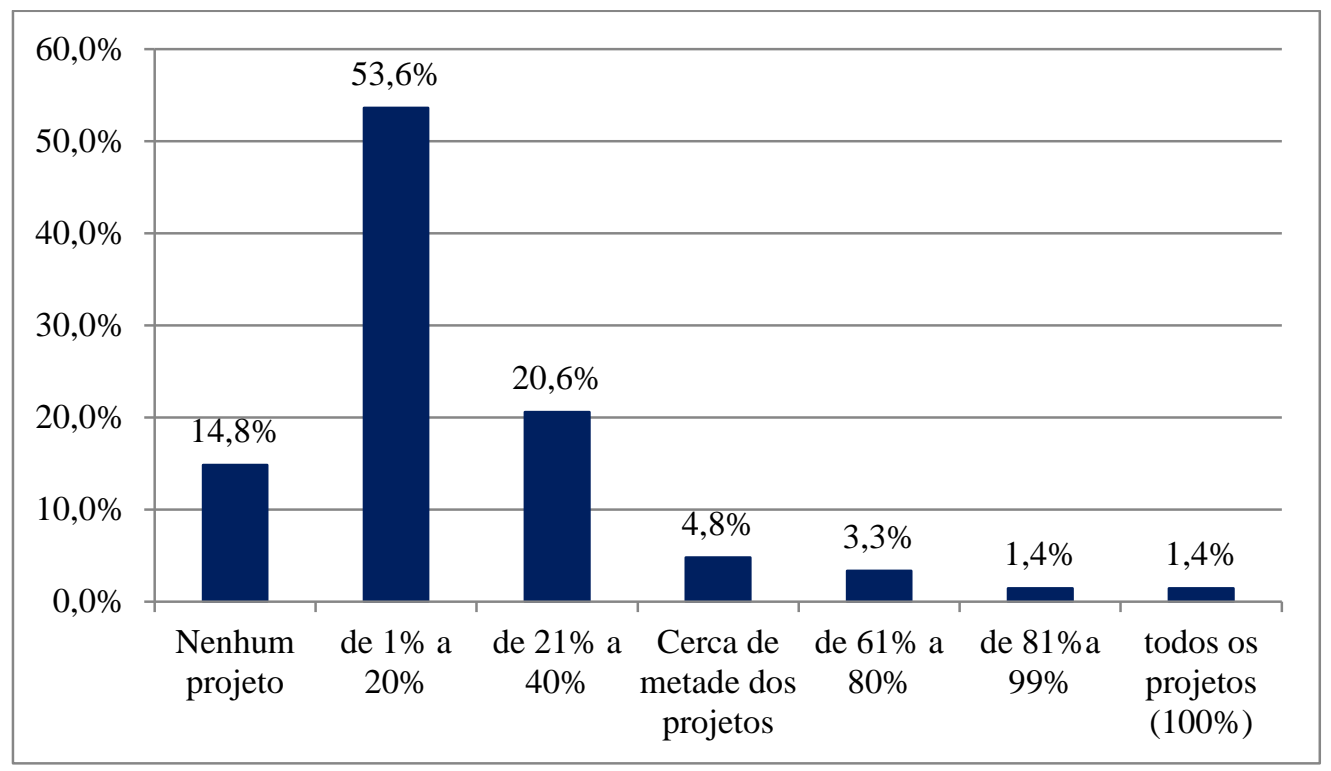

Fonte: dados da pesquisa.

Os resultados apresentados na Figura 42 indicam que para 50\% dos respondentes as empresas em que trabalhavam não abandonavam os PDMG em razão de insuficiência de recursos. Outros 39\% responderam que apenas entre $1 \%$ e $20 \%$ dos projetos eram abandonados. Estes dados sugerem que recursos não são fatores limitadores ou restritivos para os PDMG, no sentido de que não deve haver falta deles.

Figura 42 - Abandono de projetos por insuficiência de recursos $(n=209)$

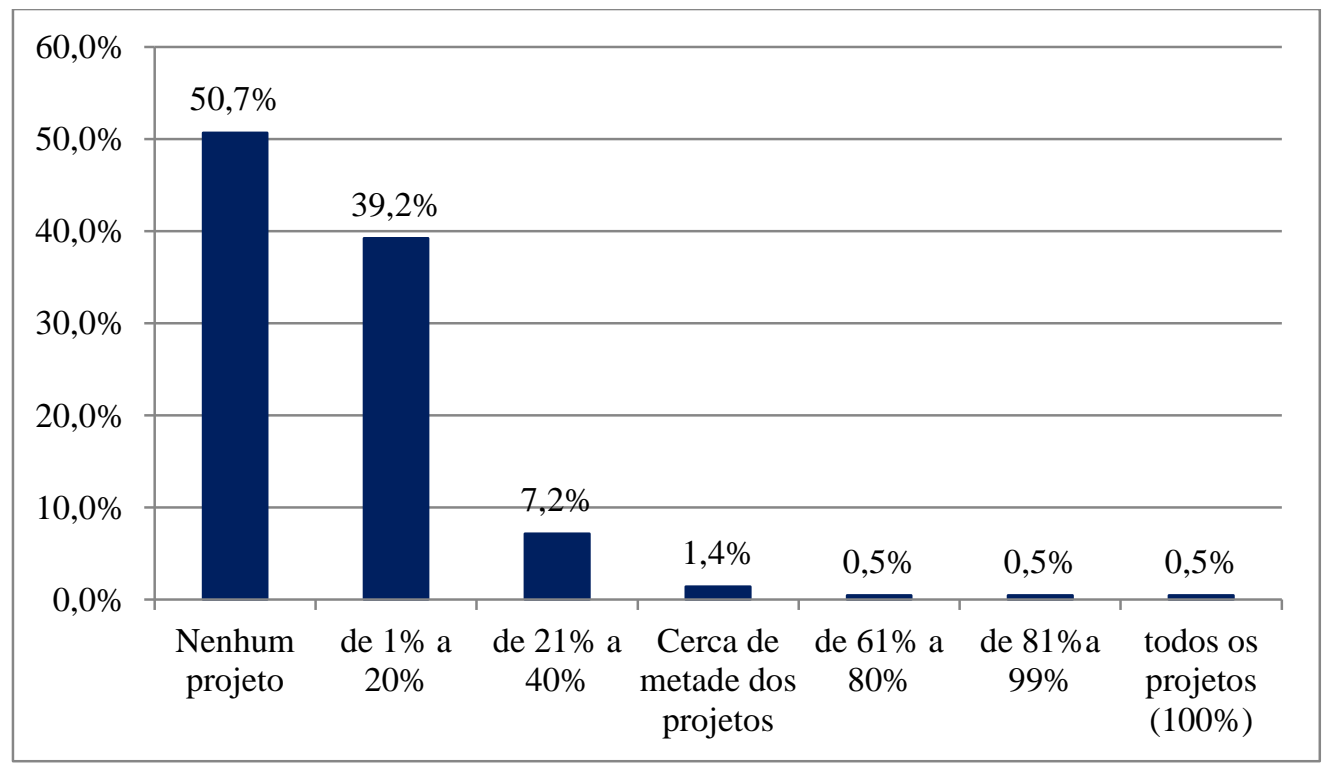

Fonte: dados da pesquisa. 
Por fim, em relação ao abandono por problemas técnicos, cuja distribuição é representada na Figura $43,52,6 \%$ dos participantes declararam que de $1 \%$ a $20 \%$ dos projetos eram abandonados por esse motivo. Há várias possibilidades de causas para os problemas técnicos. Pode ser pela complexidade em alguns casos para se obter um medicamento genérico com as mesmas características de seu medicamento de referência, como, por exemplo, apontado por Genazzani e Pattarino (2008). Também pode ser por avaliação inadequada da viabilidade técnica no processo de seleção do projeto, entre outras possíveis causas.

Figura 43 - Abandono de projetos por razões técnicas $(n=209)$

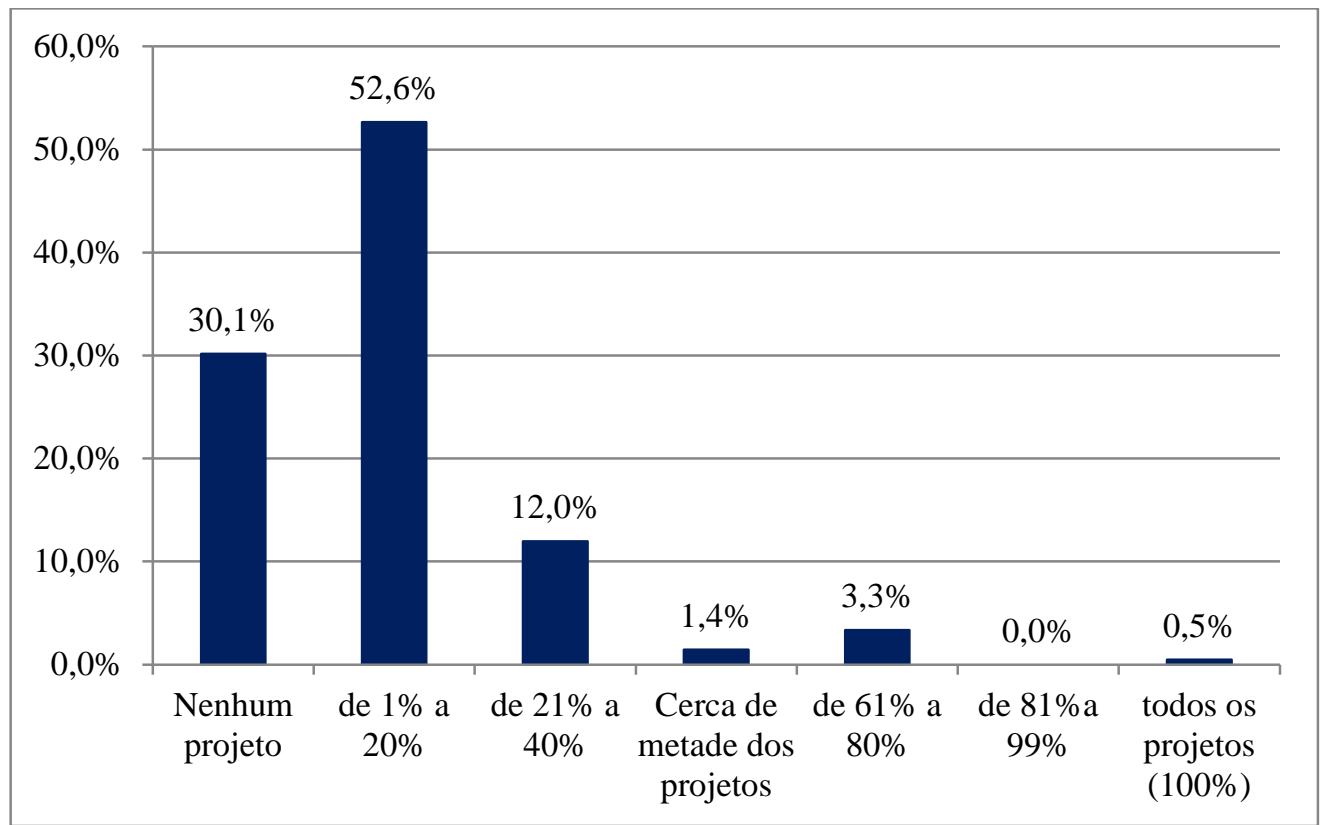

Fonte: dados da pesquisa.

Comparando os gráficos das três possíveis causas para o abandono dos PDMG, pode-se verificar que a causa mais frequente está relacionada a mudanças estratégicas (Figura 41), seguida pelas causas envolvendo problemas técnicos (Figura 42) e a insuficiência de recursos (Figura 43) como a menos frequente. Este resultado sugere a existência de ineficiências nas decisões estratégicas envolvendo os PDMG.

Ao contrário dos gráficos anteriores (Figura 41, 42 e 43), os próximos apresentarão os dados referentes à situação em que os PDMG são concluídos, primeiro com desempenho fora do planejado (Figura 44) e depois com desempenho dentro do planejado (Figura 45).

O gráfico representado na Figura 44 apresenta o percentual de PDMG que foram concluídos, mas com desempenho fora do planejado, ou seja, além do prazo, do custo de desenvolvimento, do custo de produção/preço-alvo de mercado e/ou com problemas para aprovação pela Anvisa. O gráfico permite verificar uma maior concentração (34\%) das respostas em falhas em 1 a $20 \%$ dos PDMG. Se somados aos 9,1\% dos que indicaram que nenhum projeto é concluído com desempenho fora do planejado, temos que $43,5 \%$ respondentes consideram que as empresas em atuavam tinham bom 
desempenho nos PDMG. Pode-se considerar este resultado relativamente baixo se comparado aos resultados de outras pesquisas como da última versão disponibilizada da pesquisa para projetos em geral denominada PMSURVEY 2014 (PMI, 2014a), que indicou que ocorria a conclusão dos projetos com atingimento dos objetivos na maioria das vezes em ao menos $59 \%$ das organizações.

Figura 44 - Conclusão de projetos com desempenho fora do planejado $(\mathrm{n}=209)$.

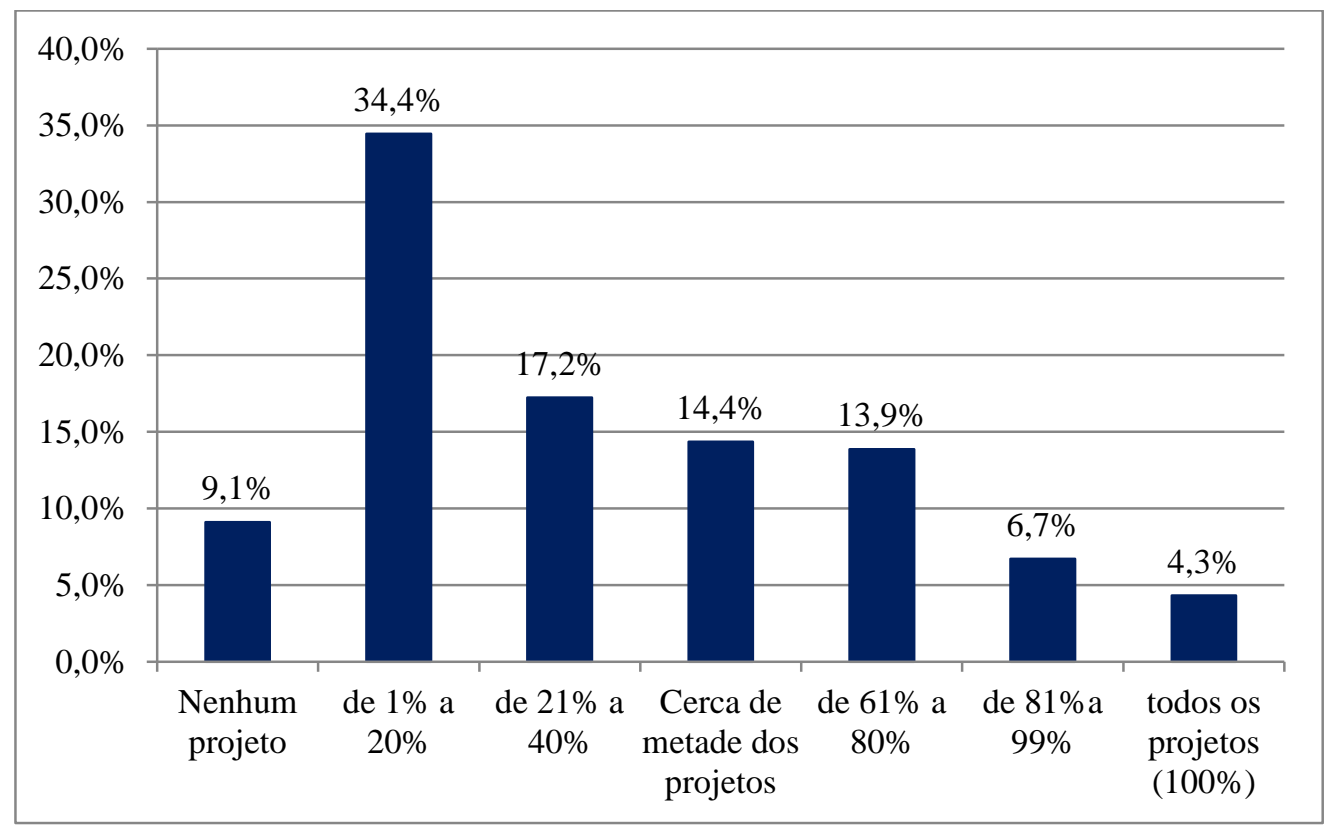

Fonte: dados da pesquisa.

Outra constatação é a de que mais de 90\% dos PDMG são concluídos sem atender ao menos um de seus indicadores de desempenho estabelecidos dentro dos parâmetros que foram planejados. Esta constatação colabora com a principal justificativa para este estudo, que foi baseada em dados da pesquisa de Do Carmo (2017) e que constatou que parcela significativa dos pedidos de registro dos medicamentos genéricos não tem sucesso, ou seja, possivelmente em razão de problemas em seus projetos de desenvolvimento.

Em uma abordagem inversa a esta última, o gráfico da Figura 45 apresenta a distribuição da frequência de respostas em relação à taxa de sucesso dos PDMG concluídos, ou seja, projetos que foram concluídos com desempenho dentro do planejado (dentro do prazo, do custo de desenvolvimento, do custo de produção/preço-alvo de mercado e/ou sem problemas para aprovação pela Anvisa). 
Figura 45 - Conclusão de projetos com desempenho dentro do planejado $(\mathrm{n}=209)$

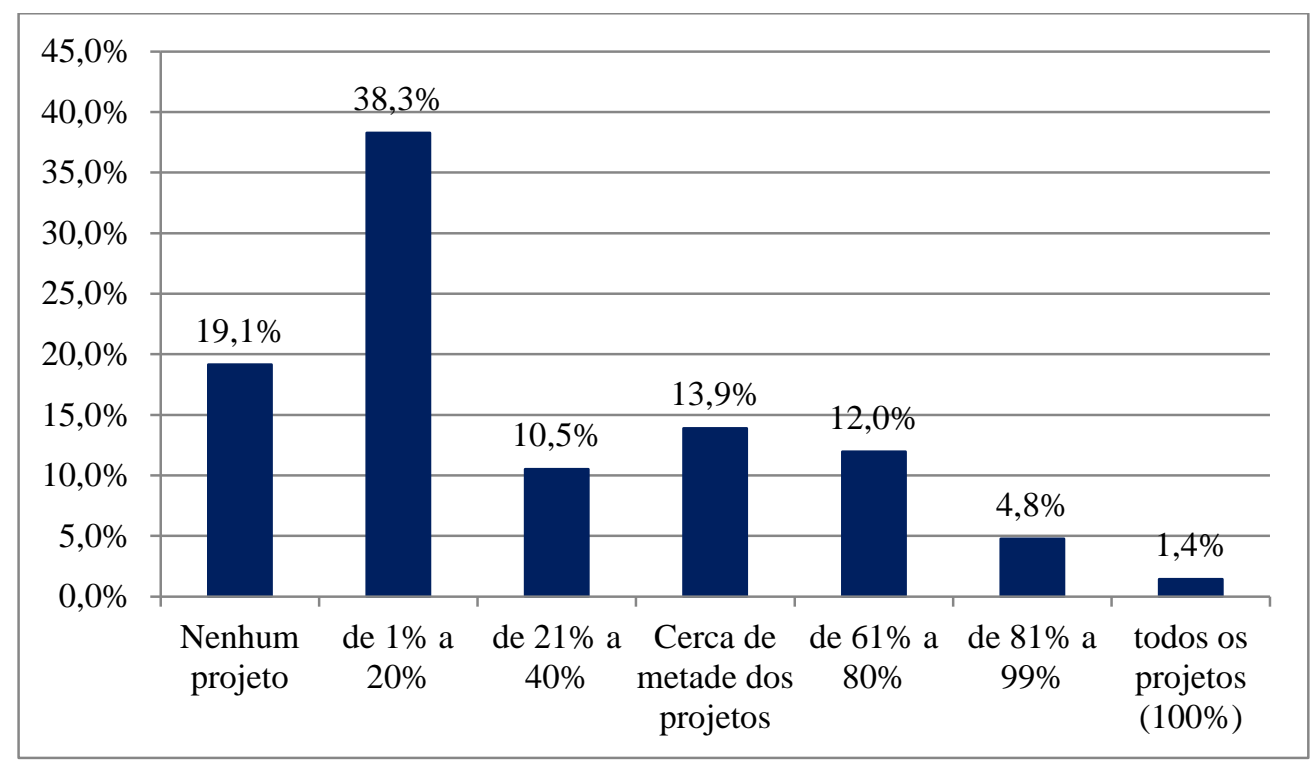

Fonte: dados da pesquisa.

Como destaques, o gráfico na Figura 45 apresenta que, do total da amostra, 38,3\% dos respondentes indicaram que entre $1 \%$ e $20 \%$ (raramente) dos PDMG desenvolvidos pelas empresas na qual trabalhavam foram concluídos dentro do desempenho planejado e 19,1\% indicaram que nenhum dos projetos foi concluído com pleno sucesso. Somando-se estes percentuais, tem-se que para 57,4\% dos respondentes, raramente (menos de 20\%) os PDMG desenvolvidos pelas empresas na qual trabalhavam foram concluídos dentro do desempenho planejado. No outro extremo, apenas 18,2\% atingiram plenamente os objetivos estabelecidos e foram concluídos com sucesso na maioria das vezes (acima de 60\%).

Há que se notar que, pela lógica, os resultados deste gráfico (Figura 45) e do anterior (Figura 44) deveriam ser complementares. Mas não é exatamente o que pode ser verificado. Esta constatação poderia ser considerada como uma inconsistência nos dados. No entanto, deve-se também considerar que não são dados baseados em documentos, mas sim nas percepções dos respondentes, portanto, susceptíveis a vieses provavelmente provocados pelas heurísticas adotadas nas respostas (McNamee \& Celona, 2008). Por exemplo, é possível observar que em ambas as distribuições, as maiores frequências ficaram nas opções com menor porcentagem de PDMG (1 a 20\%) concluídos tanto fora quanto dentro do planejado.

O resultado da análise entre os dois gráficos também pode ser visto como um sintoma de que as empresas não definem adequadamente os indicadores para o desempenho dos PDMG ou que não avaliam efetivamente o desempenho. Outra possibilidade é a de que a avaliação do desempenho dos PDMG não seja suficientemente clara ou objetiva, dando margem a interpretações, incluindo a ocorrência dos vieses. Uma quarta possibilidade é a de que as avaliações de desempenho dos PDMG são sejam adequadamente discutidos e comunicados, também provocando imprecisões sobre o 
verdadeiro desempenho. De qualquer forma, muito embora ajudem a compor o perfil dos PDMG, os dados destas duas questões não participam diretamente das análises do modelo de equações estruturais. Os dados que dizem respeito aos indicadores do modelo estrutural proposto, de desempenho inclusive, serão analisados junto com os demais indicadores nos próximos tópicos.

\subsubsection{Análise univariada dos indicadores dos constructos do modelo estrutural}

A coleta dos dados empregou escala ordinal de 7 pontos para a avaliação dos indicadores dos constructos que compõem o modelo estrutural proposto. Assim, para a análise inicial dos dados foi utilizada técnica de estatística descritiva, mais especificamente a análise univariada dos dados por meio do cálculo de medidas de posição (média) e de variabilidade (desvio-padrão). A apresentação dos resultados das análises foi organizada por constructo de primeira ordem. Lembrando apenas que a relação dos indicadores e respectivos códigos estão no Apêndice XII desta tese.

\subsection{Análise dos indicadores do constructo Desempenho}

O gráfico na Figura 46 apresenta as médias e desvios padrão para as mensurações obtidas para os indicadores do constructo Desempenho. A pergunta para a coleta dos dados foi a respeito da frequência (porcentagem) média de projetos que apresentaram o desempenho descrito por cada um dos indicadores. A média geral para os indicadores do constructo foi de 2,71, com um desvio padrão de 1,03 .

Figura 46 - Descrição dos indicadores do constructo Desempenho $(\mathrm{n}=209)$

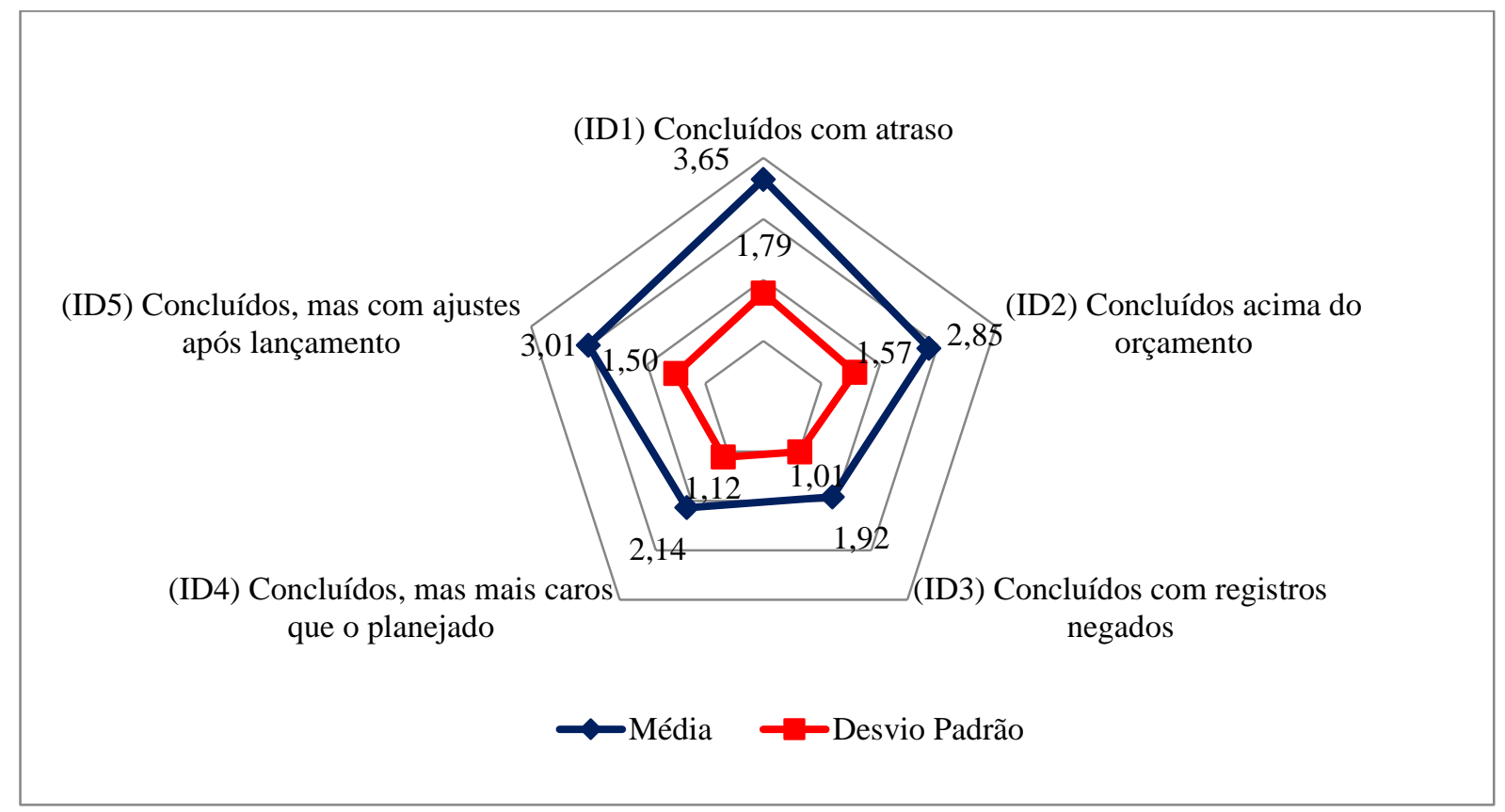

Nota: escala ordinal de 7 pontos $(1=$ "nenhum", 4 = "cerca de metade" e 7 = "todos" os projetos iniciados). Fonte: dados da pesquisa.

Pode-se observar pelos dados do gráfico da Figura 46 que a maior média $(3,65)$ e o maior desvio padrão $(1,79)$ foram apresentados pelo indicador ID1 que trata da conclusão dos PDMG com atraso, 
ou seja, os PDMG foram concluídos, mas após a data planejada inicialmente. Embora o PMSURVEY 2014 (PMI, 2014) não aborde especificamente os fatores contribuintes para o desempenho dos projetos, o não atendimento aos prazos aparece como o segundo problema mais frequente nos projetos em geral, atrás somente dos problemas de comunicação, o que corrobora com o resultado observado nesta pesquisa como um dos mais frequentes.

O indicador com a segunda maior média $(3,01)$ e terceiro maior desvio padrão no constructo Desempenho foi o ID5, que fez referência à conclusão dos projetos, porém com a necessidade de ajustes na sua formulação e/ou em seu processo de fabricação após o seu lançamento ("troubleshooting"). Este é basicamente um indicador de qualidade do produto. Infelizmente, não foi possível realizar uma análise comparativa, pois não foi encontrada outra pesquisa com dados que pudessem servir de referencial. Muito embora possa se considerar que ajustes nos produtos após o lançamento não são raros, este item possui relevância, pois dependendo da correção ou ajuste necessário, a empresa pode ser obrigada a retirar o medicamento do mercado, pelo menos até que o ajuste seja aprovado pela Anvisa e efetivamente realizado (Anvisa, 2007, 2017b).

$\mathrm{O}$ indicador ID2 relacionado à conclusão do PDMG, mas com custos totais acima do orçamento planejado, teve a terceira maior média $(2,85)$ e o segundo maior desvio padrão $(1,57)$. Este dado sugere que os custos não são fatores restritivos aos PDMG no sentido de que afetam em menor grau a avaliação do desempenho. O indicador ID4 relacionada à conclusão do PDMG, mas com custos de produção ou preço-alvo de mercado acima do planejado, por sua vez, teve a quarta maior média $(2,14)$. Este indicador tem implicações para a competitividade do medicamento, uma vez que o preço ao consumidor é crítico em se tratando de medicamento genérico. Também tem implicações para margem de lucro, pois é pressionada pelo preço de mercado (Dylst et al., 2013).

O indicador com a menor média $(1,92)$ foi o ID3, que é relacionado aos PDMG concluídos, mas que tiveram seus pedidos iniciais de registro reprovados pela Anvisa. Este também é um indicador de qualidade e equivale ao aceite do projeto pelo cliente. Embora tenha apresentado baixa frequência relativa, este pode ser considerado o principal indicador de desempenho dos PDMG, uma vez que sem a aprovação da Anvisa, um medicamento não pode ser colocado no mercado.

\subsection{Análise dos indicadores do constructo Desenvolvimento}

As médias e desvios padrão para as mensurações obtidas para os indicadores do constructo Desenvolvimento são apresentados no gráfico da Figura 47. A pergunta para a coleta dos dados foi a respeito do grau de contribuição de cada uma das situações de dificuldade para os resultados fora dos planejados dos PDMG concluídos. A média geral para os indicadores do constructo foi de 3,57, com um desvio padrão de 1,24 . 
Figura 47 - Descrição dos indicadores do constructo Desenvolvimento $(\mathrm{n}=209)$

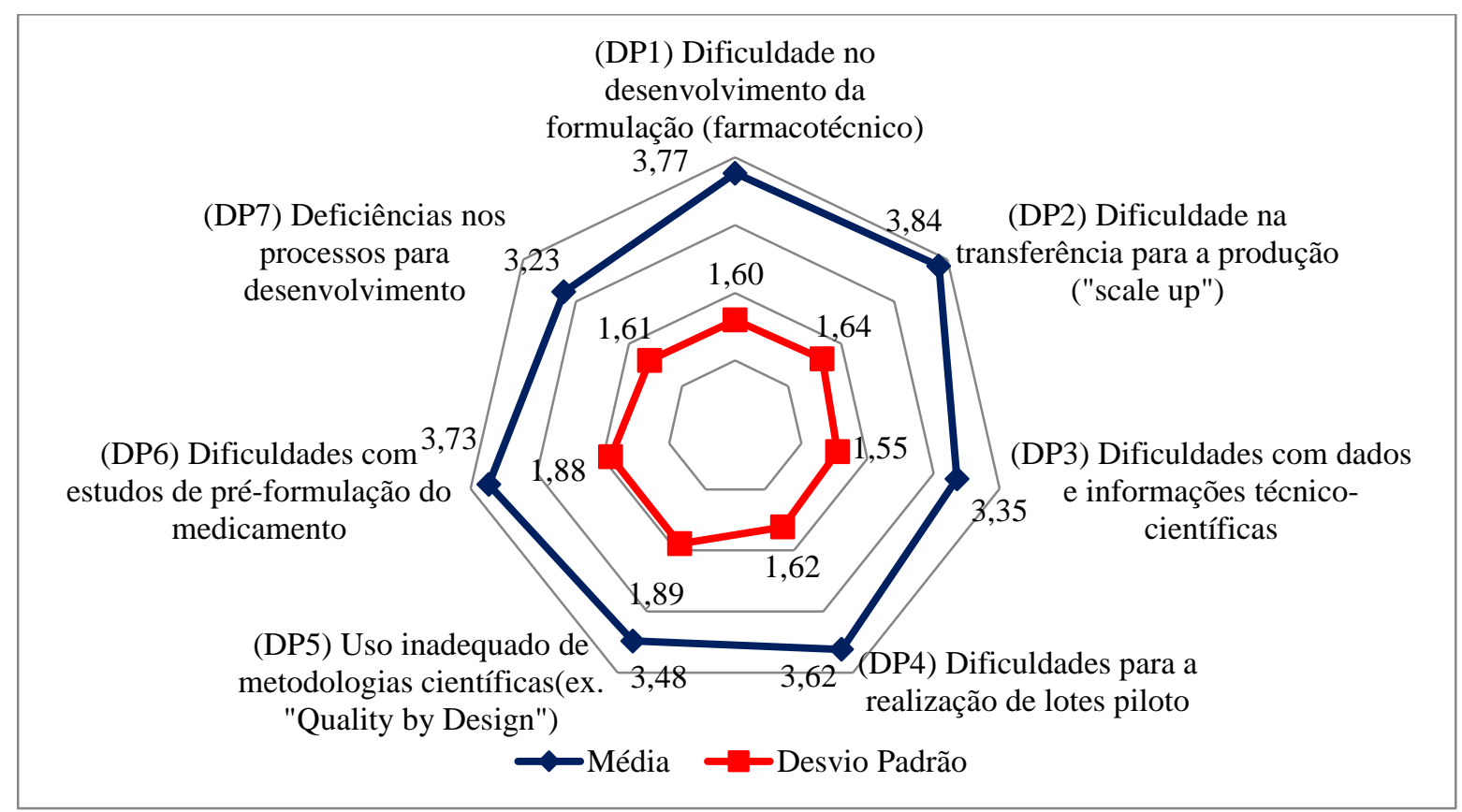

Nota: escala ordinal de 7 pontos $(1$ = "nenhuma contribuição para os resultados fora dos planejados" a 7 = "total contribuição para os resultados fora dos planejados"). Fonte: dados da pesquisa.

Neste construto, o indicador que apresentou a maior média $(3,84)$ e o terceiro maior desvio padrão $(1,64)$ foi o DP2, que mensurou a contribuição das dificuldade no processo de transferência dos medicamentos do laboratório para a produção (escalonamento ou "scale up") para os resultados fora dos planejados. Esta dificuldade pode ter origem no próprio desenvolvimento do medicamento, em específico se a formulação e/ou processo de fabricação forem inadequados para a produção em maior escala. Também pode ter origem em dificuldades para o trabalho conjunto com a área de produção na realização do escalonamento. Haveria dependência do apoio e recursos de outras áreas da empresa.

Em seguida em grau de contribuição, com a segunda maior média $(3,77)$, porém com o sexto maior desvio padrão $(1,60)$, aparece o indicador DP1, que tratou da dificuldade no desenvolvimento da formulação (farmacotécnico) do medicamento. O desenvolvimento da formulação está no centro dos PDMG (De Paula, 2004; Kanfer et al., 2014; Yugue, 2014). Por exemplo, formulações inadequadas dificilmente conseguem passar pelos testes de estabilidade, de equivalência e/ou de bioequivalência. A dificuldade de formulação de um medicamento pode provocar atrasos, aumentos nos custos e até o abandono do projeto. Sua complexidade advém principalmente dos requisitos que o medicamento deve cumprir como, por exemplo, a sua equivalência em relação ao medicamento de referência (Genazzani \& Pattarino, 2008). Além disso, deve também considerar aspectos da tecnologia necessária e dos recursos disponíveis, principalmente insumos e equipamentos.

O indicador DP6, que mensurou a contribuição das dificuldades ou ausência de estudos de préformulação do medicamento, aparece na classificação com a terceira maior média $(3,73)$ e o segundo maior desvio padrão $(1,88)$. Os estudos de pré-fomulação facilitam o planejamento e o 
desenvolvimento do PDMG, ao buscarem dados e informações e realizarem testes preliminares sobre os medicamentos que serão desenvolvidos (De Paula, 2004; Kanfer et al., 2014; Yugue, 2014).

Com a quarta maior média $(3,62)$ entre os indicadores do constructo Desenvolvimento, aparece o indicador DP4, que mensurou a contribuição das deficiências e/ou dificuldades para a realização de lotes-piloto, pré-validação e predefinição dos parâmetros do processo de produção do novo medicamento. Os lotes-piloto são importantes, pois fornecem dados preliminares da adequação da formulação e de seu processo de fabricação. Além disso, os medicamentos produzidos nestes lotes serão utilizados para testes como o de estabilidade e de bioequivalência (De Paula, 2004; Kanfer et al., 2014; Yugue, 2014).

O indicador DP5 referente ao fato do laboratório não usar ou usar inadequadamente metodologias científicas para o desenvolvimento dos medicamentos (ex.: Qualidade por Meio do Delineamento ou "Quality by Design") apresentou a quinta maior média $(3,48)$ entre os indicadores do constructo Desenvolvimento, porém o maior desvio padrão $(1,89)$. O uso de metodologia científica colabora para o desenvolvimento racional e mais eficiente dos medicamentos (ICH, 2009). Uma dessas metodologias é o QbD (“Quality by Design”), que é definido pela Anvisa (2019b) como uma abordagem sistemática que enfatiza o conhecimento/entendimento dos produtos, dos processos e dos controles em processos com base científica e no risco da qualidade.

Este resultado colocando as metodologias científicas abaixo da maioria dos demais indicadores do constructo Desenvolvimento poderia significar que deficiências na sua utilização teriam menor contribuição para os resultados fora dos planejados do PDMG. Ou mesmo que não haveria problema no uso ou na frequência do uso de metodologias científicas. No entanto, dados obtidos na fase qualitativa indicam que ainda não é prática disseminada no Brasil, tendo sido introduzido muito recentemente pela Anvisa (2019b) entre as práticas recomendadas.

Um resultado que chama a atenção é o relativamente alto desvio padrão (1,89), o que pode ser traduzido com uma maior dispersão dos dados ou variação dos dados em relação à media (Larson \& Farber, 2016). Do ponto de vista prático, os respondentes possuem opiniões que diferem entre si em maior amplitude, portanto, mais distante de um senso comum.

A sexta maior média $(3,35)$ foi a do indicador DP3, que mensurou a contribuição das deficiências e/ou dificuldades na obtenção e/ou apresentação de dados e informações técnicocientíficas dos medicamentos. Curiosamente os resultados indicam o menor desvio padrão $(1,55)$ para este indicador. A qualidade dos dados, das informações, de seu tratamento e de suas apresentações são incontestavelmente importantes nos PDMG. Uma das razões para esta dificuldade pode estar no acesso a dados de qualidade, sejam elas provenientes da literatura técnico-científica, ou seja dos próprios processos internos da empresa e do projeto. Outra possibilidade é a insuficiência de conhecimento sobre como explorar as bases de dados e a literatura técnico-científica. Uma possibilidade complementar e não excludente é a insuficiência de competências para o tratamento, análise e comunicação de dados e resultados. 
O indicador do constructo Desenvolvimento que teve a menor média $(3,23)$ das avaliações recebidas foi o DP7, que mensurou a contribuição da inexistência ou deficiências nos processos para desenvolvimento dos medicamentos. Vale lembrar que mesmo tendo a menor média, o indicador não deixa de contribuir para os resultados fora dos planejados dos PDMG concluídos. Como regra geral, os laboratórios farmacêuticos necessitam ter todos os seus processos relacionados à produção de medicamentos descritos na forma de procedimentos padronizados (Anvisa, 2019f). No entanto, no caso do processo de desenvolvimento de medicamentos, muito em razão dos necessários ajustes para cada projeto, os laboratórios desenvolvem apenas um documento com os principais conceitos, diretrizes e organização adotados para o desenvolvimento dos medicamentos. Este documento é comumente denominado plano ou estratégia de desenvolvimento. Este resultado parece indicar que, embora em relativamente menor grau, o processo de desenvolvimento dos PDMG não é suficiente ou adequadamente definido, gerando problemas para o desenvolvimento dos medicamentos.

\subsection{Análise dos indicadores do constructo Gestão}

As médias e desvios padrão para as mensurações obtidas para os indicadores do constructo Gestão são apresentados no gráfico da Figura 48. A pergunta para a coleta dos dados foi a respeito do grau de contribuição de cada uma das situações de dificuldade descritas para os resultados fora dos planejados dos PDMG concluídos. A média geral dos indicadores do constructo foi de 3,97, com um desvio padrão de 1,24 .

Figura 48 - Descrição dos indicadores do constructo Gestão $(\mathrm{n}=209)$

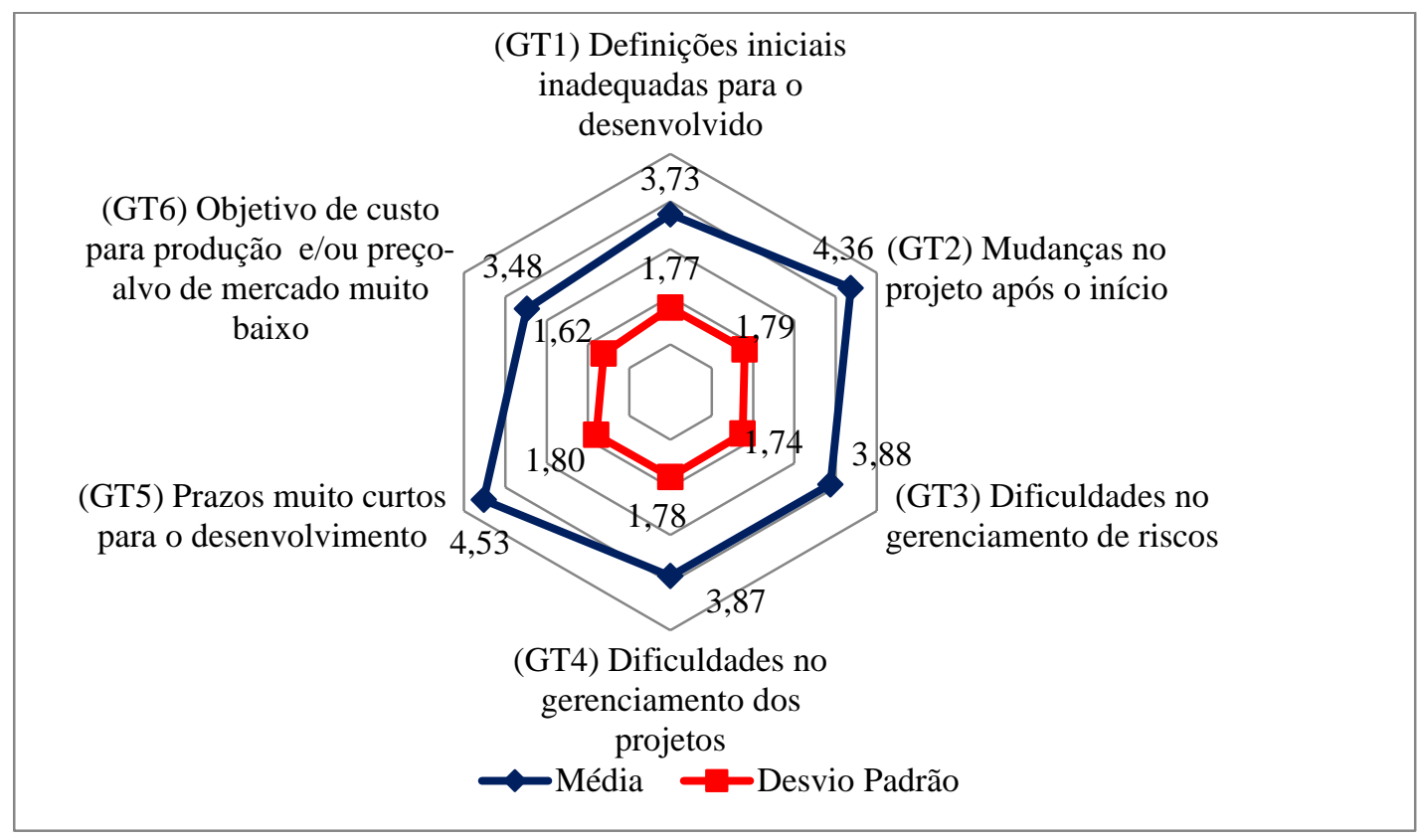

Nota: escala ordinal de 7 pontos $(1$ = "nenhuma contribuição para os resultados fora dos planejados" a 7 = "total contribuição para os resultados fora dos planejados"). Fonte: dados da pesquisa. 
O indicador componente deste constructo que apresentou a maior média $(4,53)$ e o maior desvio padrão $(1,80)$ foi o GT5, que mensurou a contribuição dos prazos muito curtos para o desenvolvimento dos medicamentos. De uma forma geral, como já comentado, os prazos definidos para a entrega dos PDMG são os menores possíveis em razão da expectativa de vantagem competitiva para o primeiro a lançar no mercado o novo medicamento genérico. No entanto, os prazos definidos por meio do sequenciamento e das estimativas de duração podem ser muito maiores que os requisitados pela alta administração, provocando um desequilíbrio entre as demandas. Este requisito de menor prazo em geral é compensado pelo aumento nos custos do projeto e nos riscos e pela diminuição das qualidades do projeto e do produto, ou seja, pelo ajuste do conflito entre as demandas e restrições (PMI, 2017).

O indicador GT2, que mensurou a contribuição das mudanças no projeto após o início do desenvolvimento do medicamento, teve a segunda maior média $(4,36)$ entre os contribuintes do constructo. Mudanças constantes no escopo é um problema comum nos projetos de uma forma geral (PMI, 2014) e podem levar ao abandono do projeto, dependendo da fase em que ocorre e da magnitude da mudança. Além de retrabalho e comprometimento do prazo do PDMG, uma variável que normalmente é bastante afetada é o custo, uma vez que a aquisição do IFA, que é normalmente o componente de maior custo nos medicamentos genéricos, é realizada logo no início do projeto. Para este indicador, as causas podem estar já na decisão de investimento ou de início do projeto, quando as primeiras definições do escopo são estabelecidas. Pode também surgir de problemas de comunicação, em que dúvidas e/ou incertezas sobre o escopo não são adequadamente tratadas.

Na classificação, o indicador com a terceira maior média $(3,88)$ foi o GT3, que é relacionado a deficiências e/ou dificuldades no gerenciamento de riscos no desenvolvimento dos medicamentos. De acordo com o PMI (2017), o gerenciamento de riscos do projeto busca aumentar as chances de sucesso do projeto. Desta forma, o gerenciamento deficiente dos riscos pode levar a resultados negativos que poderiam ser evitados, ou à perda de oportunidades que poderiam ter sido aproveitadas. $\mathrm{O}$ gerenciamento de riscos é um dos temas críticos para a produção de medicamentos. Há orientações específicas do ICH (2005) e a Anvisa (2019f) destacou o gerenciamento de riscos em suas mais recentes publicações. Entre as possíveis causas desta deficiência pode estar o uso incorreto do gerenciamento de riscos e/ou até mesmo o conhecimento apenas básico dos conceitos e das práticas.

Com uma média $(3,87)$, praticamente igual ao indicador referente ao gerenciamento de riscos, ficou em quarto lugar o indicador GT4, que mensurou a contribuição das deficiências e/ou dificuldades no gerenciamento dos projetos de desenvolvimento dos medicamentos para os resultados fora dos planejados dos PDMG concluídos. Dunson (2010) destaca a importância do gerenciamento de projetos para que os produtos cheguem ao mercado e para que a excelência no desenvolvimento de medicamentos seja atingida. Segundo o PMI (2017), o gerenciamento de projetos facilita que o produto certo seja entregue no momento certo, ajuda a resolver problemas, permite a otimização do 
uso dos recursos da empresa e ajuda na gestão das demandas e restrições conflitantes, aumentando assim as chances de sucesso dos projetos. Portanto, deficiências e/ou dificuldades no gerenciamento dos projetos de desenvolvimento dos medicamentos acabam por não possibilitar o aproveitamento das potenciais vantagens ou benefícios atribuídos ao adequado gerenciamento. De forma semelhante ao gerenciamento de riscos, entre as possíveis causas desta deficiência pode estar o uso incorreto do gerenciamento de projetos e/ou até mesmo o conhecimento apenas básico dos conceitos, dos métodos e das práticas.

O indicador GT1 referente às definições iniciais insuficientes ou incorretas dos medicamentos a serem desenvolvidos (necessidades, características e/ou especificações dos medicamentos) teve uma média $(3,73)$ pouco abaixo das duas anteriores. Trata-se basicamente de um problema de definição do escopo. Como já comentado, problema na definição do escopo é um dos mais comum nos projetos de uma forma geral (PMI, 2014) e podem levar ao abandono do projeto, dependendo dos detalhes do escopo que forem sendo definidos e da magnitude dos ajustes que necessitarem ser realizados caso o projeto já tenha sido iniciado. Da mesma forma que para os problemas com mudanças no escopo, neste caso, as causas podem estar já na decisão investimento ou de início do projeto, quando as primeiras definições do escopo são estabelecidas, podendo também surgir de dúvidas e/ou incertezas sobre o escopo que não são adequadamente tratadas por deficiências na comunicação, por exemplo.

$\mathrm{O}$ indicador do constructo Gestão que ficou com a menor média entre as avaliações dos respondentes foi o GT6, que abordou a contribuição do objetivo de custo final para produção e/ou preço-alvo de mercado muito baixo para o medicamento em desenvolvimento. Este indicador é atrelado a requisitos de mercado, pois, como já comentado, um fator competitivo crítico é o preço ao consumidor (De Paula, 2004; Dunson, 2010; Morfin, 2010). Em mecanismo semelhante ao da pressão pelo menor prazo de desenvolvimento, pressões por custos reduzidos podem provocar um desequilíbrio entre as demandas que podem ser contrabalanceado pelo aumento nos riscos e pela diminuição da qualidade do projeto e do produto (PMI, 2017).

\subsection{Análise dos indicadores do constructo Portfólio}

No gráfico da Figura 49 são apresentados as médias e desvios padrão para as mensurações obtidas para os indicadores do constructo Portfólio. A média geral dos indicadores do constructo foi de 3,80 e o desvio padrão de 1,40. A pergunta para a coleta dos dados foi a respeito do grau de contribuição de cada uma das situações de dificuldade para os resultados fora dos planejados dos PDMG concluídos. 
Figura 49 - Descrição dos indicadores do constructo Portfólio $(n=209)$

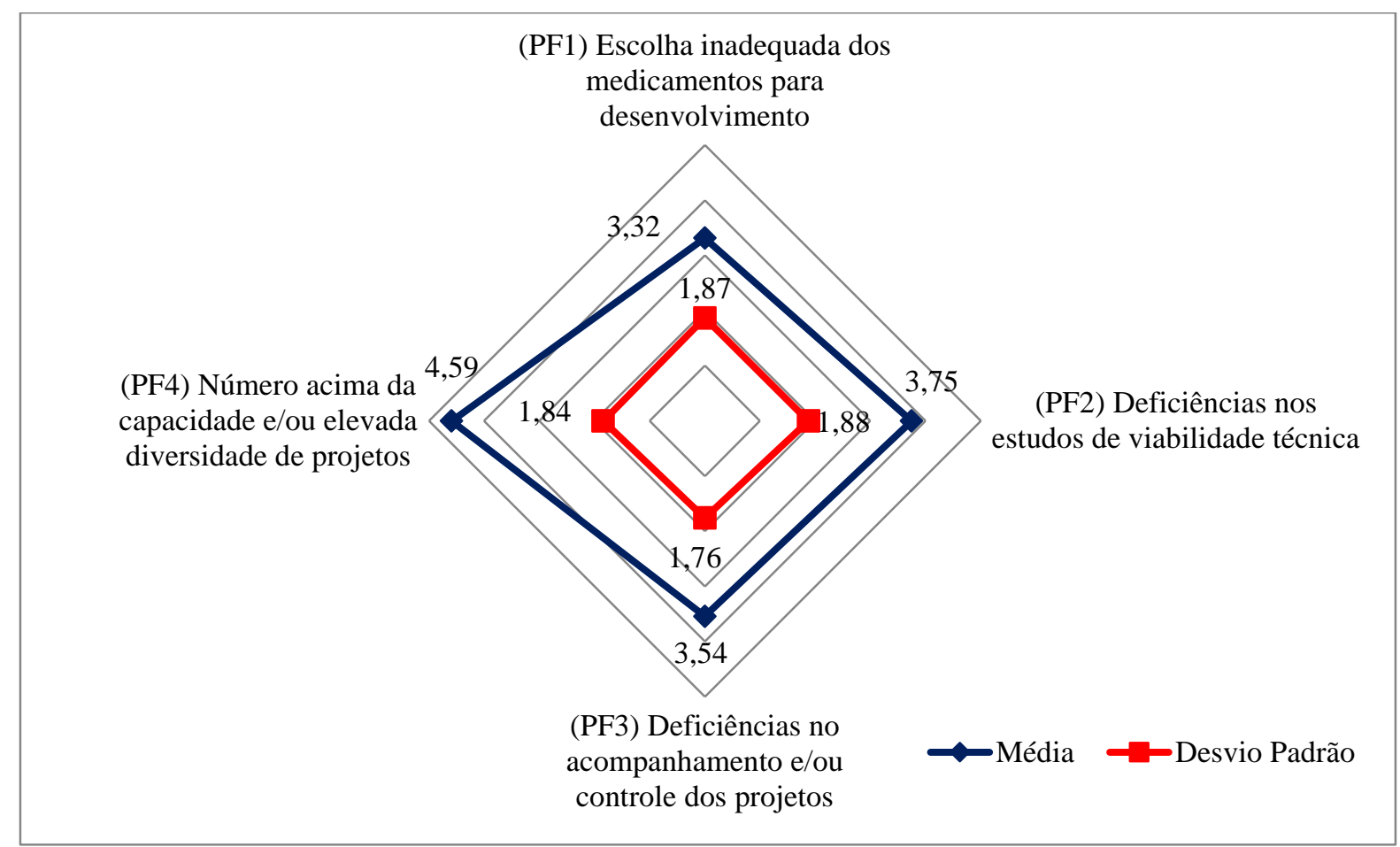

Nota: escala ordinal de 7 pontos $(1$ = "nenhuma contribuição para os resultados fora dos planejados" a 7 = "total contribuição para os resultados fora dos planejados"). Fonte: dados da pesquisa.

A maior média $(4,59)$ e o terceiro maior desvio padrão $(1,84)$ foi a do indicador PF4, que mensurou a contribuição para os resultados fora dos planejados do número de projetos acima da capacidade e/ou elevada diversidade de projetos de desenvolvimento de medicamentos em andamento. O excesso de projetos pode ser entendida também como falta de recursos para os seus desenvolvimentos e normalmente tem sua origem nas decisões de portfólio que, aparentemente, são desconectadas da estrutura e das competências técnicas disponíveis. A diversidade também pode ser traduzida da mesma forma, pois impede eventuais ganhos de escala existentes quando os produtos e projetos são semelhantes, uma vez que demandaria mais recursos e eventualmente de aprendizagem para que os projetos sejam desenvolvidos. As restrições em relação aos recursos levam também à situação do conflito entre as demandas e restrições (PMI, 2017). Neste caso, os resultados podem ser projetos entregues com atraso, com custo maior, e/ou com qualidade menor, portanto, com riscos maiores para o registro do medicamento.

O número de projetos acima da capacidade e/ou elevada diversidade de PDMG pode se dar por excesso de autoconfiança e/ou desconhecimento das necessidades dos projetos. Também indica possível centralização da decisão ou, pelo menos, sem a participação da área responsável pelo desenvolvimento dos medicamentos. Se os aspectos técnicos não são considerados, é plausível considerar que as decisões de portfólio de PDMG são tomadas possivelmente pelas áreas de marketing, comercial e/ou da alta administração, em conjunto ou isoladamente, mas sem ou com pouca participação da área de $\mathrm{P} \& \mathrm{D}$. De qualquer forma, há indicação de falta de integração entre a 
gestão do portfólio de projetos, a área que desenvolve PDMG e o gerenciamento das partes interessadas.

A segunda maior média $(3,75)$ foi a do indicador PF2, que abordou a inexistência ou deficiências nos estudos de viabilidade técnica para escolha dos medicamentos a serem desenvolvidos. Os estudos de viabilidade técnica estão entre os que fornecem dados e informações para a decisão de investimento e início de um PDMG (Moreira, 2008; Leon Shargel \& Kanfer, 2005; V. dos S. C. Yugue, 2014). Deficiências nestes estudos podem levar a investimentos em projetos que terão problemas em seus desenvolvimentos e, eventualmente, abandonados depois de iniciados. Mais ainda, consomem recursos que poderiam ter sido direcionados a projetos mais promissores e pressionam as equipe por resultados sobre projetos ruins. Pode ser causada pela ausência de uma prática ou procedimento para a análise e seleção dos PDMG. Também pode advir da pressão pelo lançamento de novos medicamentos, fazendo com que as atividades de avaliação preliminares sejam ignoradas. Por fim, pode ser fruto de uma prática de avaliação técnica deficiente, seja pela falta de competência, seja pelo uso incorreto das técnicas e ferramentas de análise, ou seja ainda pelo acesso limitado a dados e informações.

$\mathrm{O}$ indicador PF3, que mensurou a contribuição da inexistência ou deficiências na estrutura e/ou procedimento de acompanhamento e/ou controle dos projetos de desenvolvimento de medicamentos em andamento, teve a terceira maior média $(3,54)$ entre os contribuintes do constructo Portfólio. O PMI (2017) trata o controle e monitoramento dos projetos como um macroprocesso específico, dada a sua importância. A falta de acompanhamento pode levar a desvios importantes no projeto, dificultando que seus objetivos e requisitos sejam plenamente atingidos. Há várias razões para a ocorrência desta deficiência, a começar pela falta de uma rotina e/ou de empenho ou valorização do controle e acompanhamento dos PDMG como entrada para a gestão do portfólio de projetos. Outra razão pode estar relacionada a deficiências no próprio gerenciamento dos projetos, que pode não produzir adequadamente os dados e informações para a gestão do portfólio.

$\mathrm{O}$ indicador PF1, referente à escolha inadequada e/ou equivocada dos medicamentos para o compor o portfólio de projetos a serem desenvolvimentos, teve a menor média $(3,32)$ entre os indicadores do constructo Portfólio, porém o segundo maior desvio padrão $(1,87)$. Embora diferente do contexto do indicador PF2, que versa sobre deficiências nos estudos de viabilidade técnica, as deficiências tratadas por este indicador têm prováveis causas semelhantes. Este indicador vai além do indicador PF2, pois podem ser aprovados projetos sem viabilidade técnica e/ou econômica.

\subsection{Análise dos indicadores do constructo Especificações Técnicas}

O gráfico na Figura 50 apresenta as médias e desvios padrão para as mensurações obtidas para os indicadores do constructo Especificações Técnicas. A pergunta para a coleta dos dados foi a respeito do grau de contribuição de cada uma das situações de dificuldade para os resultados fora dos 
planejados dos PDMG concluídos. A média geral dos indicadores do constructo foi de 3,43, com um desvio padrão de 1,11 .

Figura 50 - Descrição dos indicadores do constructo Especificações Técnicas (n = 209)

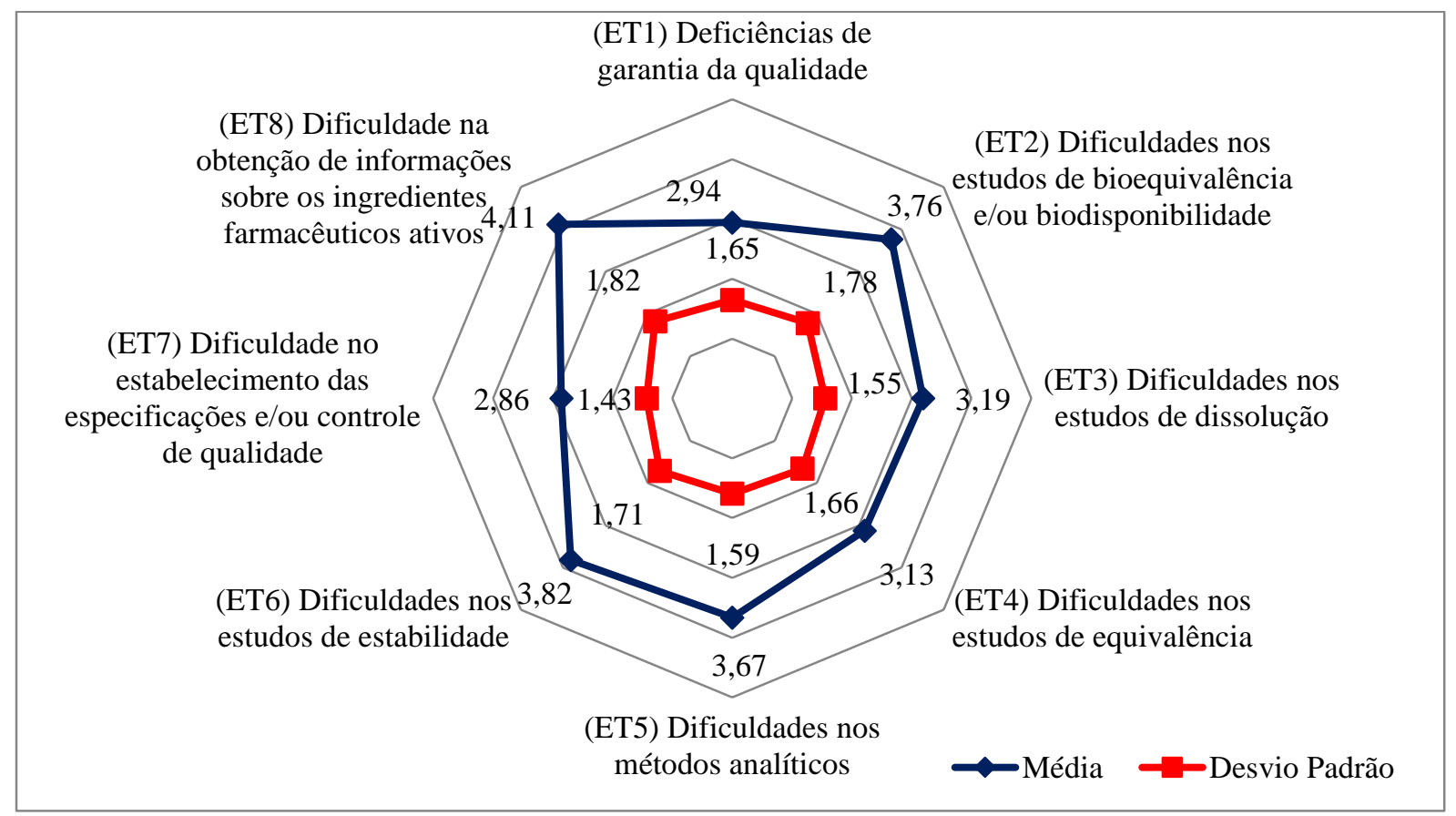

Nota: escala ordinal de 7 pontos $(1$ = "nenhuma contribuição para os resultados fora dos planejados" a 7 = "total contribuição para os resultados fora dos planejados"). Fonte: dados da pesquisa.

O indicador que apresentou a maior média $(4,11)$ e o maior desvio padrão $(1,82)$ foi o ET8, que fez referência à dificuldade na obtenção de informações sobre os ingredientes farmacêuticos ativos utilizados nos medicamentos e/ou deficiências no DMF ("Drug Master File") disponibilizado pelo fabricante. Este resultado é justificável na medida em que as informações sobre os IFAs são entradas importantes para os PDMG, desde os estudos de pré-formulação.

Em seguida, em grau de contribuição com a segunda maior média $(3,82)$, aparece o indicador ET6, que mensurou as dificuldades na realização dos estudos de estabilidade, de fotoestabilidade, de produtos de degradação e/ou na obtenção da estabilidade do medicamento. Este é talvez um dos mais complexos requisitos a serem atendidos pelos PDMG, pois a estabilidade de um medicamento depende de um conjunto de variáveis envolvendo ingredientes, formulação, processo de fabricação e embalagem, que em geral tem influência mútua. É com base na estabilidade, por exemplo, que se estabelece o prazo de validade do medicamento.

$\mathrm{O}$ indicador ET2 referente às dificuldades na realização dos estudos de bioequivalência e/ou biodisponibilidade dos medicamentos apresentou a terceira maior média $(3,76)$ entre os indicadores constituintes do constructo especificações técnicas. A bioequivalência é outro dos requisitos mais complexos de serem atendidos pelos PDMG, pois é o teste que comprova a igualdade entre o medicamento genérico desenvolvido e seu medicamento de referência. O estudo de Genazzani e Pattarino (2008) dá destaque a esta dificuldade. 
Na quarta posição em grau de contribuição, aparece o indicador ET5 sobre as dificuldades no desenvolvimento e validação dos métodos analíticos dos medicamentos. Os métodos analíticos são de especial importância para o desenvolvimento dos medicamentos, uma vez que sem eles não se pode verificar se produtos e seus insumos atendem aos requisitos. A dificuldade em geral vem da complexidade em desenvolver um método de análise que seja específico e robusto para os medicamentos que são, na maioria das vezes, compostos por diversos ingredientes que podem interferir ou dificultar as análises uns dos outros.

Em ordem decrescente das médias de contribuição para os resultados fora dos planejados com base nas avaliações dadas pelo respondentes, vem os indicadores ET3, ET4, ET1 e ET7. São indicadores referentes às dificuldades para: desenvolvimento e validação dos métodos analíticos dos medicamentos $(3,67)$, realização dos estudos de dissolução dos medicamentos $(3,19)$, realização dos estudos de equivalência farmacêutica dos medicamentos $(3,13)$, as práticas de garantia da qualidade $(3,13)$ e o estabelecimento das especificações e/ou realização dos testes para o controle de qualidade dos medicamentos $(2,86)$ respectivamente. Todos eles são requisitos técnicos para a aprovação do registro pela (Anvisa, 2007).

\subsection{Análise dos indicadores do constructo Requisitos do Projeto}

As médias e desvios padrão para as mensurações obtidas para os indicadores do constructo Requisitos do Projeto são apresentados no gráfico da Figura 51 A pergunta para a coleta dos dados foi a respeito do grau de contribuição de cada uma das situações de dificuldade para os resultados fora dos planejados dos PDMG concluídos. A média geral dos indicadores do constructo foi de 3,81, com um desvio padrão de 1,29 .

Figura 51 - Descrição dos indicadores do constructo Requisitos do Projeto $(\mathrm{n}=209)$

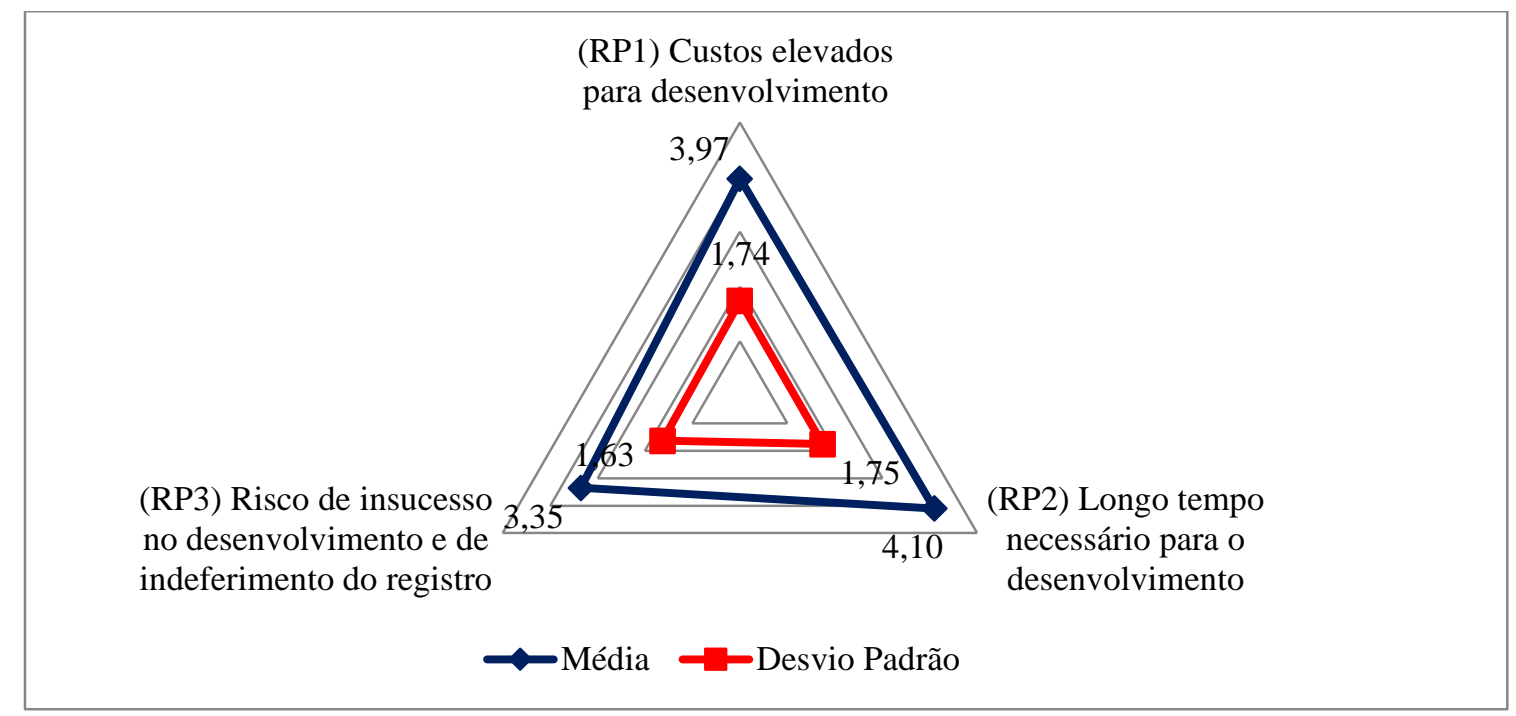

Nota: escala ordinal de 7 pontos $(1$ = "nenhuma contribuição para os resultados fora dos planejados" a 7 = "total contribuição para os resultados fora dos planejados"). Fonte: dados da pesquisa. 
Neste construto, o indicador que apresentou a maior média $(4,10)$ e o maior desvio padrão $(1,75)$ foi o RP2, que mensurou a contribuição do longo tempo necessário para o desenvolvimento dos medicamentos para os resultados fora dos planejados. Uma das possíveis explicações para a alta importância relativa dada pelos respondentes para este indicador pode estar relacionada com a pressão para que o medicamento seja o primeiro ou um dos primeiros genéricos a serem lançados em razão da perspectiva de vantagem competitiva (Chongprasert, 2016; Prašnikar \& Škerlj, 2006; Leon Shargel \& Kanfer, 2005; Sharma, 2012; D. Taylor, 2016; Yousefi et al., 2017).

O indicador ET6, que avaliou a contribuição dos custos elevados para desenvolvimento dos medicamentos aparece em seguida com a segunda maior média $(3,97)$ e o segundo maior desvio padrão (1,74), seguido pelo indicador que avaliou o risco de insucesso no desenvolvimento do medicamento e de indeferimento do registro (incertezas), que, por sua vez, obteve a menor média $(3,35)$ e o menor desvio padrão $(1,63)$ entre os indicadores do constructo Requisitos do Projeto.

Apesar do custo para o desenvolvimento de um medicamento genérico ser muito inferior ao do desenvolvimento de um medicamento inovador, ainda assim é um fator que afeta os PDMG e, pelo que indicam os dados, mais do que o risco de insucesso do projeto. O risco de insucesso permeia todo o projeto e afeta as decisões que são tomadas. Dependendo do nível de risco aceito pela empresa, as decisões podem eventualmente favorecer ou impor obstáculos ao projeto.

\subsection{Análise dos indicadores do constructo Requisitos Regulatórios}

O gráfico na Figura 52 apresenta as médias e desvios padrão para as mensurações obtidas para os indicadores do constructo Requisitos Regulatórios. A pergunta para a coleta dos dados foi a respeito do grau de contribuição de cada uma das situações de dificuldade para os resultados fora dos planejados dos PDMG concluídos. A média geral dos indicadores do constructo foi de 3,28, com um desvio padrão de 1,26. 
Figura 52 - Descrição dos indicadores do constructo Requisitos Regulatórios ( $\mathrm{n}=209)$

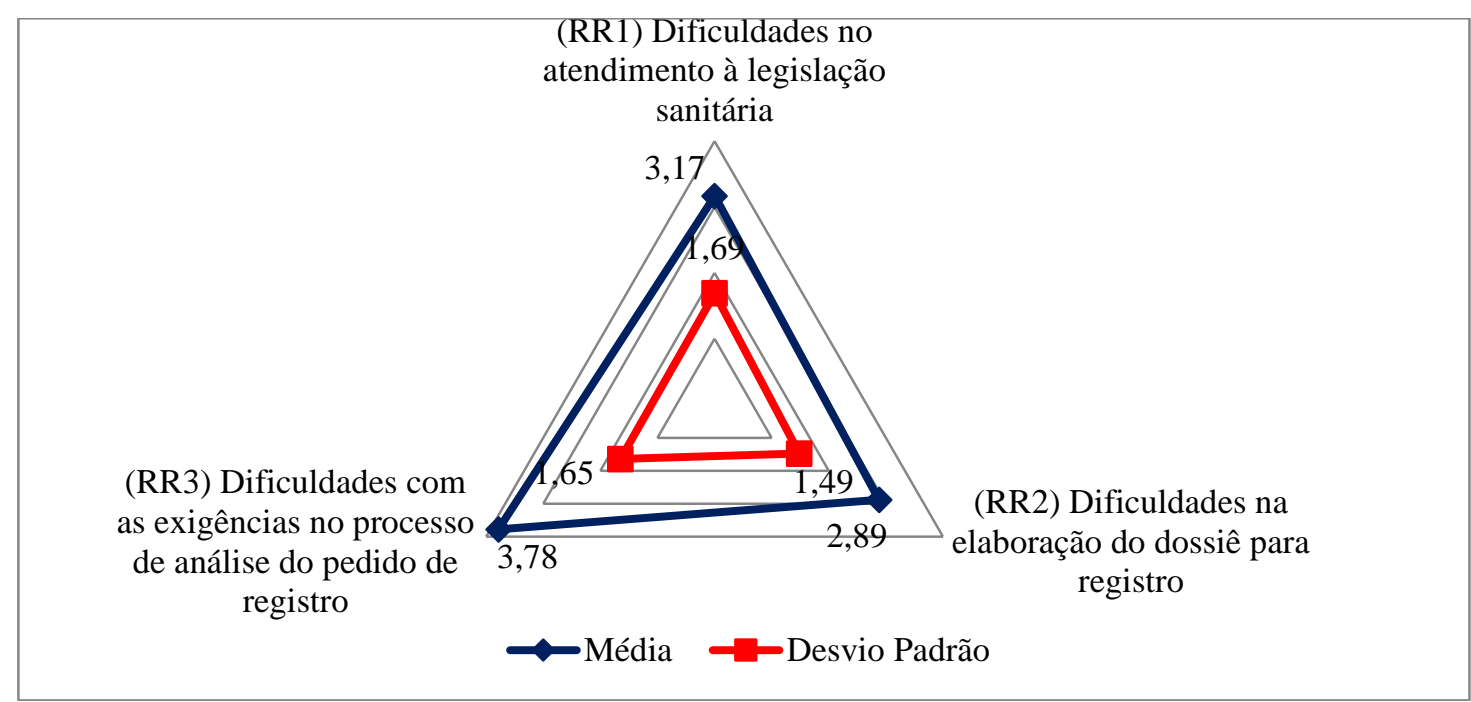

Nota: escala ordinal de 7 pontos $(1$ = "nenhuma contribuição para os resultados fora dos planejados" a 7 = "total contribuição para os resultados fora dos planejados"). Fonte: dados da pesquisa.

Entre os indicadores deste constructo, o que apresentou a maior média $(3,78)$, porém o segundo maior desvio padrão $(1,65)$, foi o RR3, que tratou das deficiências e/ou dificuldades no atendimento às exigências da Anvisa durante o processo de análise dos pedidos de registro dos medicamentos. Conforme as Figuras 14 e 15, após a entrada no processo de registro do novo medicamento na Anvisa, a documentação é analisada e, se houver necessidade de complementação das informações e/ou esclarecimentos, a agência envia à empresa solicitante uma exigência técnica (Anvisa, 2019e; Do Carmo, Piras, et al., 2017). De acordo com este resultado, há dificuldade no atendimento a estas exigências pelas empresas. Existem pelos menos três razões possíveis. Primeiro, o PDMG não realizou todos os desenvolvimentos e/ou testes e/ou não produziu todos os documentos requeridos pela legislação, portanto, uma falha do projeto. Segundo, a empresa não tem condições de atender às exigências da agência por restrições relacionadas mais diretamente à organização (externas ao projeto). Uma terceira possibilidade seria relacionada a dificuldades no entendimento das exigências da agência, ou mesmo a dificuldades de comunicação, que afetariam o atendimento às exigências.

$\mathrm{O}$ indicador RR1, que avaliou a contribuição das dificuldades no atendimento à legislação sanitária para o desenvolvimento e/ou registro de medicamentos genéricos teve a segunda maior média $(3,17)$ e o maior desvio padrão $(1,69)$. Este indicador está relacionado ao indicador que tratou das deficiências e/ou dificuldades no atendimento às exigências da Anvisa. Isso porque o não atendimento à legislação sanitária no desenvolvimento do projeto e na solicitação do registro do novo medicamento irão certamente gerar exigências pela Anvisa. As dificuldades em relação à legislação podem ter origem nas características do medicamento (complexidade técnica) e no projeto de desenvolvimento, mas também podem ter como fonte restrições relacionadas à própria empresa. Este indicador difere do anterior pelo momento em que a dificuldade aparece. Neste indicador a dificuldade é em relação ao 
atendimento à legislação em geral enquanto que no anterior está limitada à fase após o pedido de registro do medicamento.

O indicador RR2 teve a menor média $(2,89)$ e o menor desvio padrão $(1,49)$ entre os indicadores do constructo Requisitos Regulatórios e mensurou a contribuição das deficiências e/ou dificuldades na elaboração dossiê para registro dos medicamentos. Estas dificuldades podem ter origem na falta de dados, informações e/ou resultados para serem relatados e/ou mesmo na insuficiência de competência para a elaboração correta do dossiê para o registro.

\subsection{Análise dos indicadores do constructo Recursos}

As médias e desvios padrão para as mensurações obtidas para os indicadores do constructo Recursos são apresentados no gráfico da Figura 53. A pergunta para a coleta dos dados foi a respeito do grau de contribuição de cada uma das situações de dificuldade para os resultados fora dos planejados dos PDMG concluídos. A média geral dos indicadores do constructo foi de 3,44, com um desvio padrão de 1,30 .

Figura 53 - Descrição dos indicadores do constructo Recursos $(n=209)$

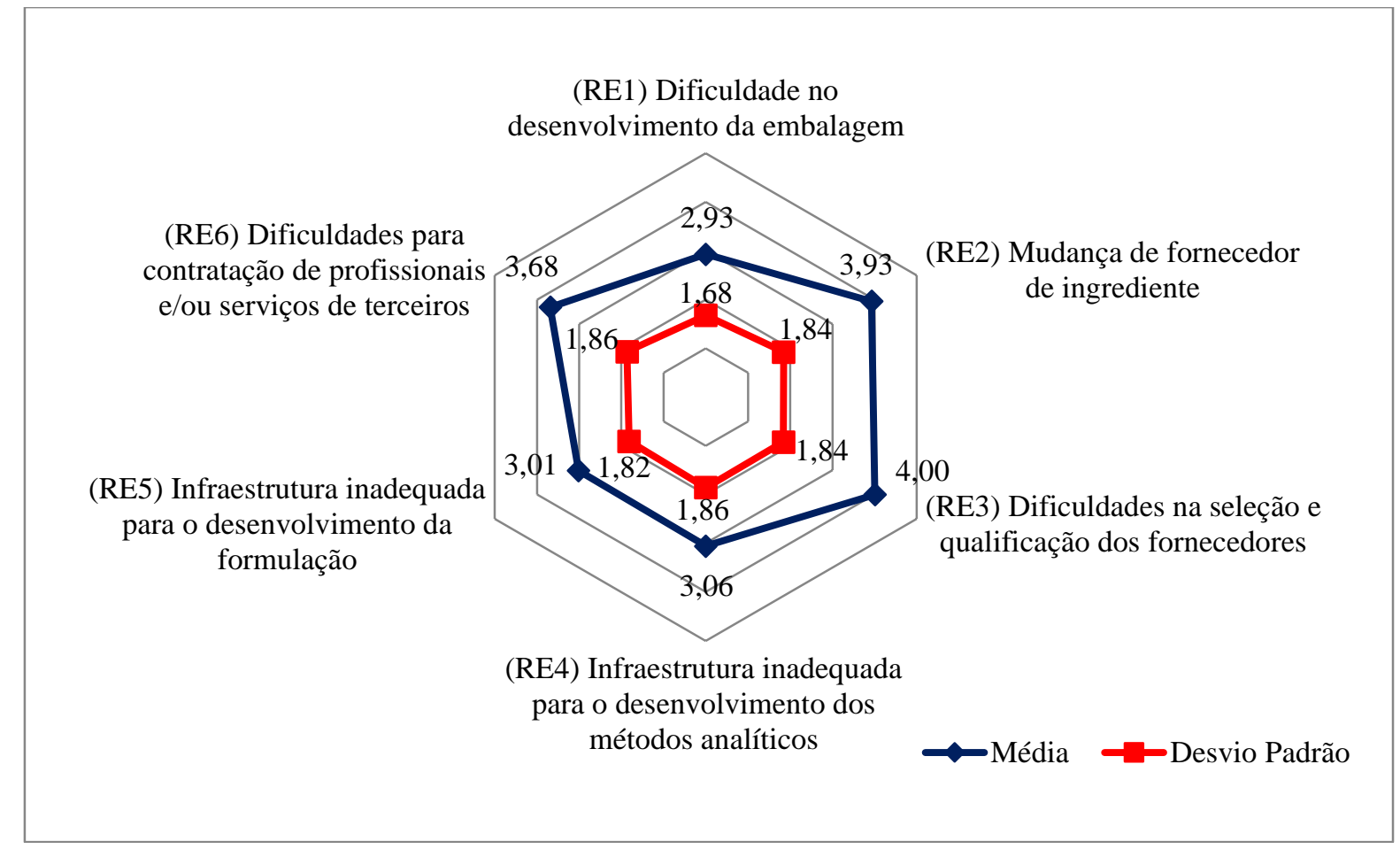

Nota: escala ordinal de 7 pontos $(1$ = "nenhuma contribuição para os resultados fora dos planejados" a 7 = "total contribuição para os resultados fora dos planejados"). Fonte: Dados da pesquisa.

O indicador componente deste constructo que apresentou a maior média $(4,00)$ e o quarto maior desvio padrão $(1,84)$ foi o RE3, o qual mensurou a contribuição das dificuldades na seleção e qualificação dos fornecedores de ingredientes farmacêuticos ativos (IFA) para os resultados fora dos planejados. Se a aquisição do IFA mais adequada para o medicamento que será desenvolvido é uma atividade que já não é tão simples, pois o atendimento aos requisitos pelo medicamento dependerá muito de suas qualidades, esta dificuldade de aquisição em geral a torna mais complexa, pois o seu 
fornecedor também deve atender a requisitos regulatórios, entre outros requisitos (Anvisa, 2007; De Paula, 2004). Dependendo do tipo de IFA, o fornecedor, por exemplo, pode ter que ser inspecionado pela Anvisa (2019b). Tudo isso sem considerar ainda os requisitos logísticos, comerciais e contratuais. Aspectos relacionados à integração com o fornecedor, foco de estudo de muitos pesquisadores (Cooper, 2019), também fazem parte deste indicador.

Um aparente conflito com este resultado foi a eliminação do indicador que tratava das dificuldades para aquisição de ingrediente farmacêutico ativo como resultado da análise de validade do conteúdo. A análise conjunta destes dois resultados parece indicar que as dificuldades para aquisição do IFA estão muito mais relacionadas a encontrar o fornecedor mais adequado do que ao ingrediente em si, muito embora, para o desenvolvimento da formulação, o ingrediente seja mais crítico do que o fornecedor. No entanto, é plausível supor que a dificuldade de aquisição do IFA seja muito maior do que a dificuldade de adequação aos requisitos técnicos e que não seria suficiente encontrar o IFA adequado se não for possível firmar contrato com o seu fornecedor.

Com a segunda maior média $(3,93)$, aparece o indicador RE2, que mensurou a contribuição da mudança de fornecedor de ingrediente farmacêutico ativo durante o desenvolvimento do medicamento. Como o desenvolvimento depende em grande parte do IFA, mudanças no fornecedor significam mudança de IFA e, consequentemente, a necessidade de ajustes na formulação e no processo de fabricação, por exemplo, uma vez que um mesmo ingrediente (do mesmo fabricante) dificilmente é vendido por fornecedores diferentes. Este tipo de mudança pode inviabilizar tecnicamente o desenvolvimento ou de ajustes em um medicamento genérico em razão de possíveis alterações necessárias na fórmula e no processo de fabricação considerando os requisitos regulatórios estritos.

Entre os indicadores do constructo Recursos, o que apresentou a terceira maior média $(3,68)$, porém o maior desvio padrão $(1,865)$, foi o RE6, que tratou das dificuldades para contratação de profissionais e/ou serviços de terceiros para as atividades de desenvolvimento dos medicamentos. Recursos complementares são necessários não só para atender a demandas geradas pelo número de PDMG realizados simultaneamente, mas também porque muitas vezes são requeridas competências que a organização não consegue suprir adequadamente. As dificuldades podem envolver desde barreiras orçamentárias à carência dos serviços e/ou profissionais disponíveis no mercado.

O indicador que apresentou a quarta maior média $(3,06)$ e o segundo maior desvio padrão $(1,857)$ foi o RE4, que mensurou a contribuição da inadequação da infraestrutura (instalações, equipamentos e utilidades) para o desenvolvimento dos métodos analíticos. Para a realização das análises da qualidade dos medicamentos, muitas vezes são necessários equipamentos, instalações e/ou processos específicos e que podem não estar disponíveis para uso, pelo menos da forma e prazo mais adequados. Esta deficiência pode atrasar o cronograma do projeto e, em seu extremo, inviabilizar o seu prosseguimento, mesmo havendo a possibilidade de terceirização das análises. 
O mesmo fundamento pode ser aplicado ao indicador RE5, que também mensurou a contribuição da inadequação da infraestrutura, mas agora para o desenvolvimento da formulação (farmacotécnico) dos medicamentos. Este indicador apresentou a quinta maior média $(3,01)$ entre os contribuintes para o constructo Recursos.

O indicador com a menor média $(2,93)$ deste constructo foi o RE1, que mensurou a contribuição da dificuldade no desenvolvimento da embalagem para o medicamento (material, tecnologia e/ou fornecedor). Nos medicamentos, a embalagem tem como principal função a proteção do produto. Neste sentido, os requisitos para as embalagens são muitas vezes extremamente rigorosos, pois vão desde dificultar a degradação do medicamento pela ação da luz e/ou pelo ar, até facilitar a sua aplicação por meio de válvulas, que muitas vezes envolvem alta tecnologia e que podem ser de difícil aquisição e/ou com custos que inviabilizam o produto.

\subsection{Análise dos indicadores do constructo Competências}

As médias e desvios padrão para as mensurações obtidas para os indicadores do constructo Competências são apresentados no gráfico da Figura 54. A pergunta para a coleta dos dados foi sobre o grau de contribuição de cada uma das situações de dificuldade para os resultados fora dos planejados dos PDMG concluídos. A média geral dos indicadores do constructo foi de 3,03, com um desvio padrão de 1,63 .

Figura 54 - Descrição dos indicadores do constructo Competências ( $(\mathrm{n}=209)$

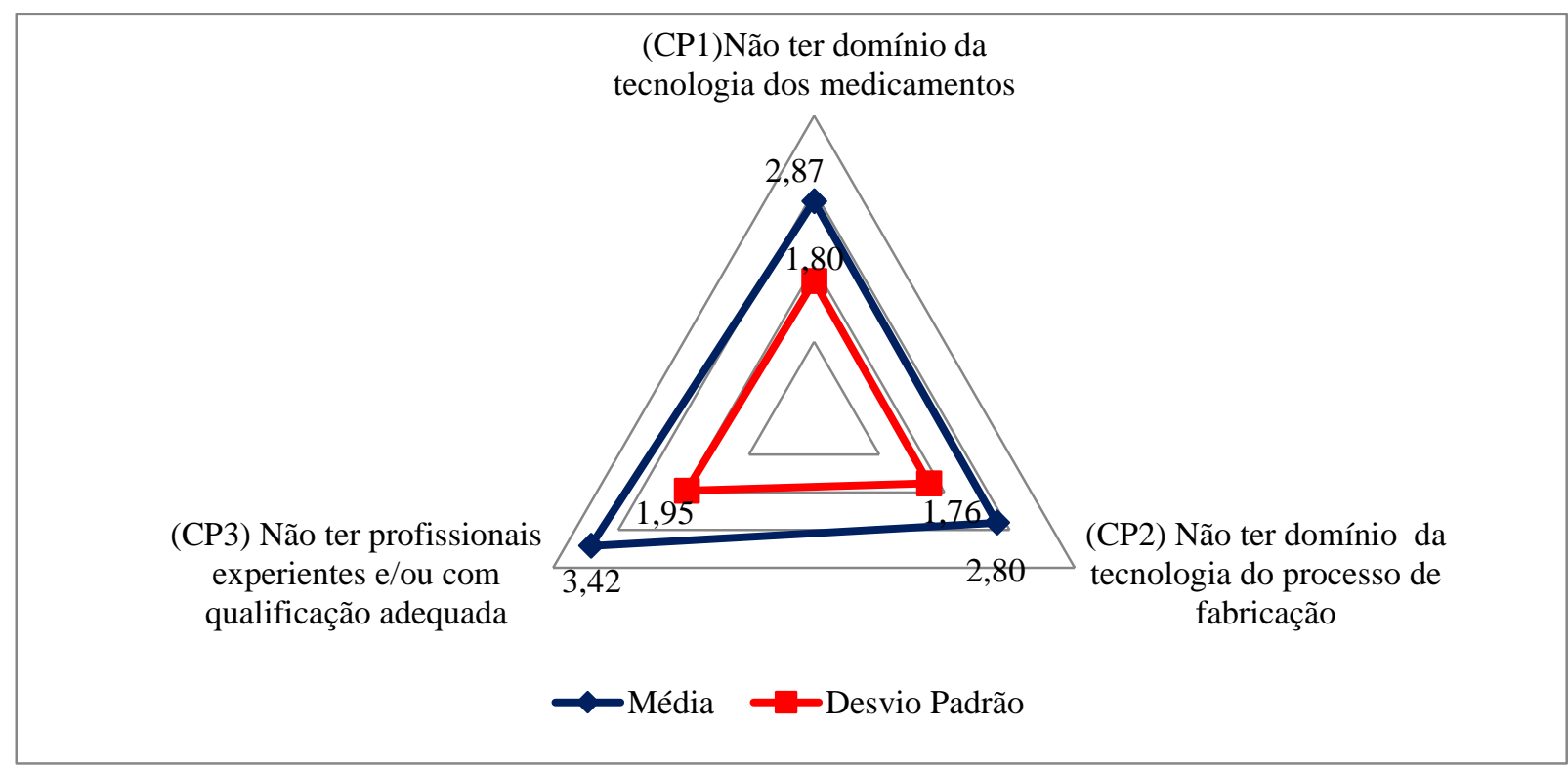

Nota: escala ordinal de 7 pontos $(1$ = "nenhuma contribuição para os resultados fora dos planejados" a 7 = "total contribuição para os resultados fora dos planejados"). Fonte: dados da pesquisa. 
Neste construto, o indicador que apresentou a maior média $(3,42)$ e o maior desvio padrão $(1,95)$ foi o CP3, que mensurou a contribuição da falta de profissionais experientes e/ou com qualificação adequada em número suficiente para o desenvolvimento dos medicamentos. Esta deficiência pode estar mais relacionada ao número insuficiente de profissionais do que às suas qualificações, se considerado o resultado para o índice que tratou do número excessivo de projetos.

A segunda maior média $(2,87)$ foi a do indicador CP1, que tratou da falta de domínio suficiente da tecnologia dos medicamentos (forma de liberação, tipo de insumo, etc.). Embora a maioria dos medicamentos genéricos sejam produzidos com tecnologias já bem conhecidas, sempre há exceções para as quais são necessários experiência e conhecimento específicos. Exemplos clássicos são os medicamentos que tem liberação controlada do princípio ativo e que podem utilizar tecnologias mais difíceis de serem reproduzidas.

O indicador CP2, que mensurou a contribuição da falta de domínio suficiente da tecnologia do processo de fabricação dos medicamentos, ficou com a terceira menor média $(2,80)$ entre os indicadores do constructo. Isso pode ser decorrência também do fato de que muitos medicamentos de referência podem ser produzidos utilizando tecnologias mais sofisticadas e, eventualmente, com custos também menos acessíveis (ex. leito fluidizado). Também pode ser em decorrência do desenvolvimento do processo de fabricação envolver outras áreas além da de P\&D, o que pode trazer dificuldades.

\subsection{Análise dos indicadores do constructo Organização}

O gráfico na Figura 55 apresenta as médias e desvios padrão para as mensurações obtidas para os indicadores do constructo Organização. A pergunta para a coleta dos dados foi a respeito do grau de contribuição de cada uma das situações de dificuldade para os resultados fora dos planejados dos PDMG concluídos. A média geral dos indicadores do constructo foi de 3,81, com um desvio padrão de 1,64 . 
Figura 55 - Descrição dos indicadores do constructo Organização $(\mathrm{n}=209)$

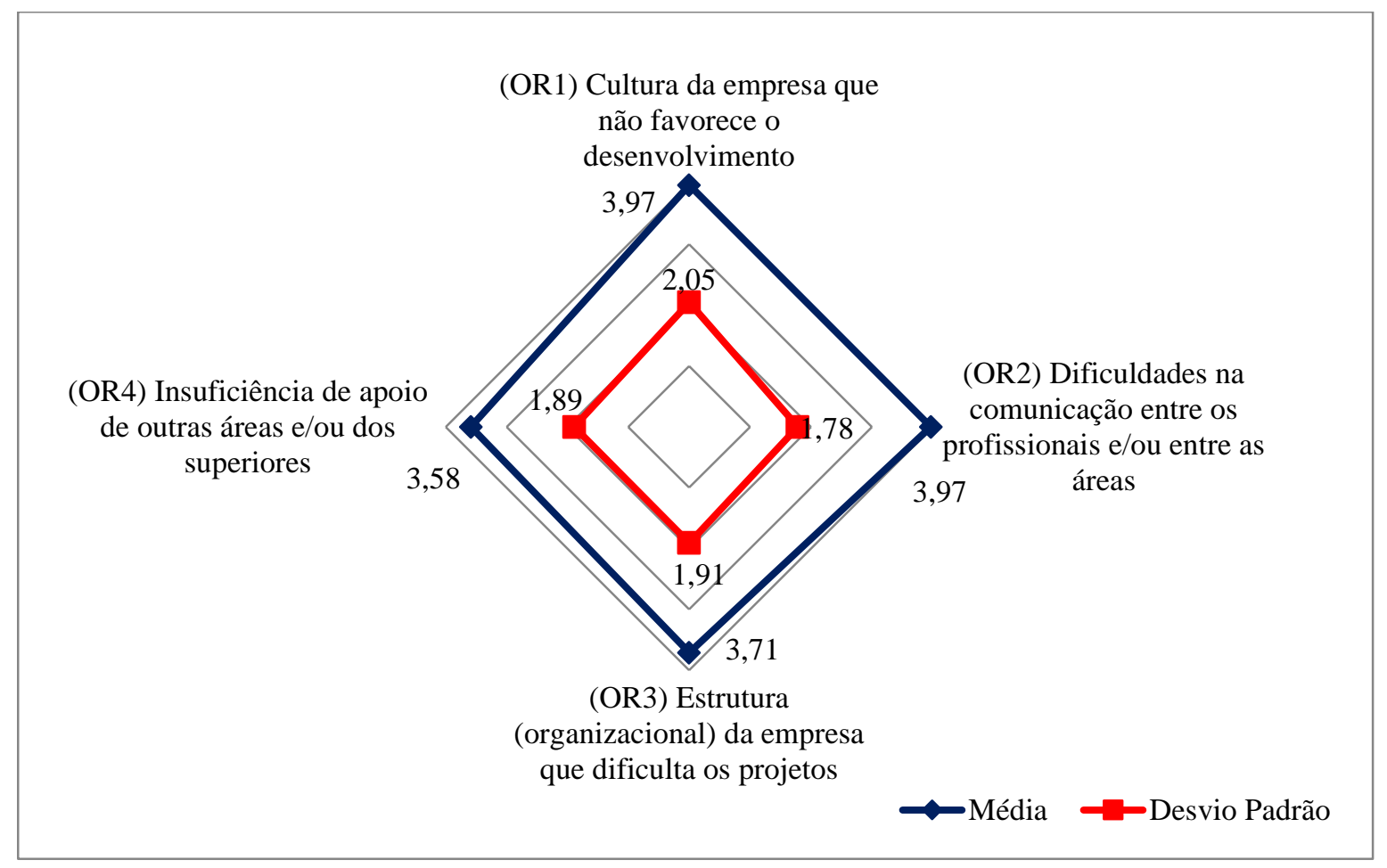

Nota: escala ordinal de 7 pontos $(1=$ "nenhuma contribuição para os resultados fora dos planejados" a 7 = "total contribuição para os resultados fora dos planejados"). Fonte: dados da pesquisa.

Os indicadores com maiores médias foram o OR1 e o OR2, ambos com valores médios de 3,97, sendo o primeiro com desvio padrão de 2,05 e o segundo com desvio padrão de 1,78.

O indicador OR1 mensurou a contribuição da cultura da empresa ou da organização que não favorece e/ou dificulta o desenvolvimento adequado dos medicamentos. A influência da cultura em projetos de desenvolvimento de produtos é bastante estudada (Robert G. Cooper, 2019). Alguns indícios desta contribuição negativa aparecem em outros indicadores como, por exemplo, a priorização dos prazos para entrega e a menor importância dada às análises de viabilidade.

Para mensurar a contribuição das deficiências e/ou dificuldades na comunicação entre os profissionais e/ou entre as áreas da empresa que participam do desenvolvimento dos medicamentos, o indicador OR2, juntamente com o indicador OR1, pode ser considerado entre os mais importantes para os PDMG. Este resultado é compatível com o relatório do PMSURVEY (PMI, 2014) que indicou os problemas de comunicação como os mais comuns nos projetos em geral. Este indicador é crítico em razão dos PDMG serem realizados com a participação de diferentes profissionais e departamentos (por exemplo, P\&D, suprimentos, marketing, controle de qualidade, garantia da qualidade, produção, engenharia e assuntos regulatórios) (De Paula, 2004)(De Paula, 2004) .

A terceira maior média foi apresentada pelo indicador OR3, que tratou das dificuldades aos PDMG relacionadas à estrutura (organizacional). Entre as várias formas de organização dos projetos (PMI, 2017), os PDMG são em geral desenvolvidos em estruturas com a presença de departamento especializado e detentor da maioria dos recursos necessários, incluindo instalações, equipamentos e 
profissionais dedicados em tempo integral. No entanto, a necessidade da participação de recursos de outras áreas, mesmo em algumas atividades dos projetos, pode sofrer influência de como estas áreas são organizadas, de como são distribuídas as responsabilidades e de como se dá o processo de decisão.

A menor média $(3,58)$ entre os indicadores deste constructo foi a do indicador OR4, que fez referência à ausência ou insuficiência de apoio de outras áreas e/ou dos superiores aos projetos de desenvolvimento dos medicamentos. Tanto a cooperação de outras áreas da empresa quanto o apoio da alta administração são objeto de muitos estudos (Cooper, 2019; De Paula, 2004). Com relação ao apoio dos superiores de alto nível, possivelmente este não seja um problema com grande influência, uma vez que os PDMG individualmente não demandam grandes volumes de recursos e/ou riscos, ou mesmo significativas mudanças estratégicas. No entanto, devido ao caráter multidepartamental dos PDMG, a falta de apoio dos gestores de outras áreas pode ser um fator bastante crítico para o andamento dos projetos.

4.2.2.4 Análise do conjunto de fatores contribuintes para resultados fora dos planejados

A tabela completa com todos os indicadores relacionados aos fatores contribuintes para os resultados fora dos planejados para os PDMG está disponível no Apêndice XIII. Um resultado que merece destaque e que pode ser visualizado por meio da tabela é que os indicadores com as maiores médias gerais contribuem para o constructo Gerencial (variável latente de segunda ordem).

Estes resultados indicam que os fatores mais críticos para o desempenho dos PDMG são de ordem gerencial, mais especificamente: PF4 - Número de projetos acima da capacidade e/ou elevada diversidade de projetos de desenvolvimento de medicamentos em andamento (constructo Portfólio e com média 4,59); GT5 - Prazos muito curtos para o desenvolvimento dos medicamentos (constructo Gestão e com média 4,53); e GT2 - Mudanças no projeto após o início do desenvolvimento do medicamento (constructo Gestão e com média 4,36).

A seguir aparecem dois indicadores referentes a fatores de ordem técnica: ET8 - Dificuldade na obtenção de informações sobre os ingredientes farmacêuticos ativos utilizados nos medicamentos e/ou deficiências no DMF disponibilizado pelo fabricante (constructo Especificações Técnicas e com média 4,11) e RP2 - Longo tempo necessário para o desenvolvimento dos medicamentos (constructo Requisitos do Projeto e com média 4,10). Por fim, entre os indicadores que apresentaram média igual ou maior a 4 aparece o constructo de ordem estrutural: RE3 - Dificuldades na seleção e qualificação dos fornecedores de ingredientes farmacêuticos ativos (constructo Recursos e com média 4,00). Neste segundo bloco de indicadores, é destaque o fato de dois deles fazerem referência ao IFA, indicando a sua criticidade para os PDMG.

\subsubsection{Análises das relações entre os fatores contribuintes e o desempenho dos PDMG}

Nesta seção são apresentados os resultados das análises dos constructos, das relações entre eles e os testes das hipóteses propostas no modelo da pesquisa. 
Como são tratados os resultados relacionados à questão central do estudo, vale retomá-la antes das análises deste conjunto de resultados, ou seja: quais são os fatores que contribuem para o desempenho dos projetos de desenvolvimento de medicamentos genéricos?

Para facilitar o acompanhamento da sequencia de análises, vale também rever o esquema adotado na análise do modelo de equações estruturais apresentado na Figura 32 e reapresentado a seguir na Figura 56.

Figura 56 - Reapresentação do esquema de análise do modelo de equações estruturais
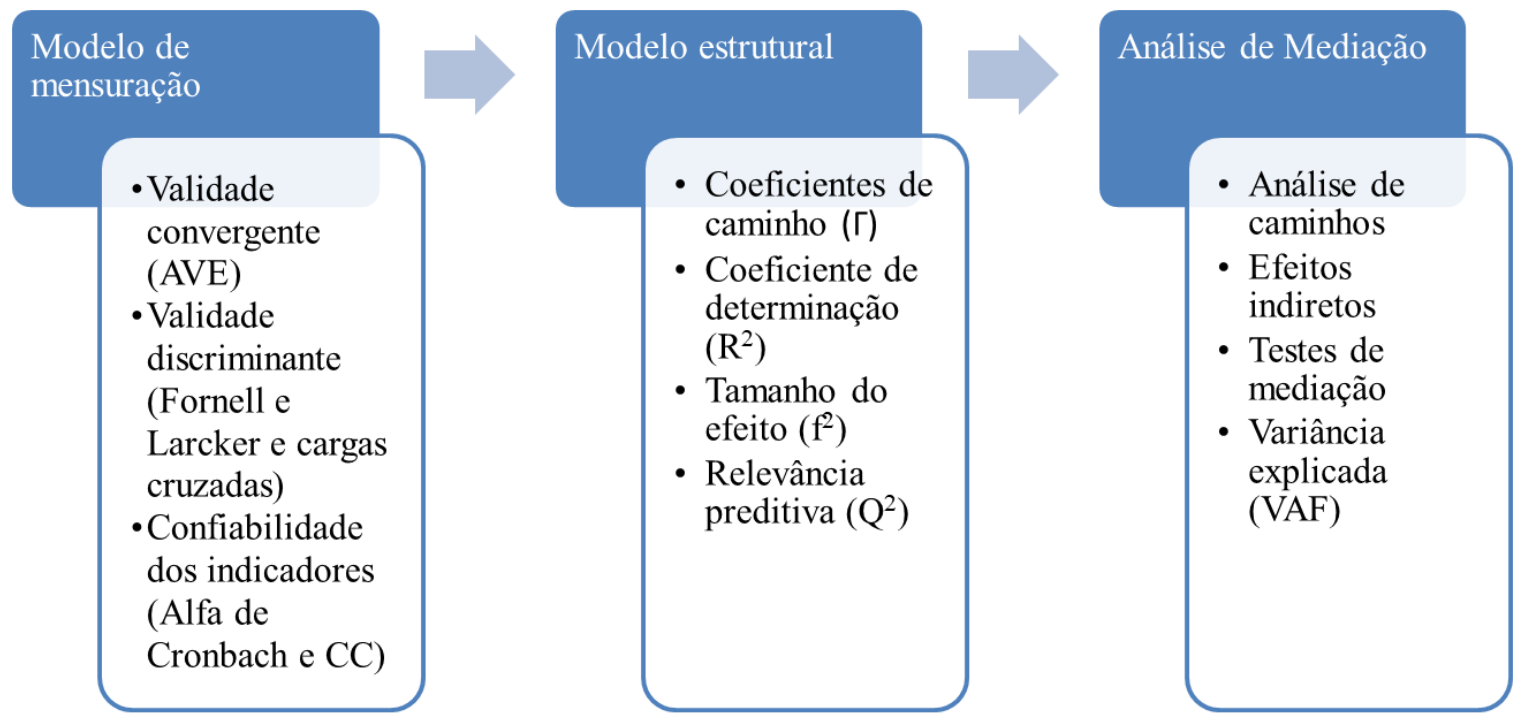

Fonte: dados da pesquisa.

Assim, para a apresentação e análise dos resultados da modelagem de equações estruturais, essa seção foi organizada em três subseções:

- Análise do modelo de mensuração (constructos Gerencial, Estrutural, Técnico e Desempenho e seus respectivos indicadores)

- Análise do modelo estrutural (hipóteses H1, H2 e H3);

- Análise de mediação (hipóteses H4 e H5).

O modelo estrutural, aqui também denominado de modelo principal, compreende a relação direta entre os constructos Gerencial, Estrutural e Técnico com o constructo Desempenho de PDMG, como apresentado na Figura 57. Os constructos Gerencial, Estrutural e Técnico são constructos de segunda ordem. O constructo Gerencial é composto pelos constructos de primeira ordem: Gestão, Desenvolvimento e Portfólio. Já o constructo Estrutural é composto pelos constructos de primeira ordem: Organização, Recursos e Competências. Por fim, o constructo Técnico é composto pelos constructos de primeira ordem: Requisitos do Projeto, Especificações Técnicas e Requisitos Regulatórios. 
Figura 57 - Modelo estrutural (versão inicial sem ajustes)

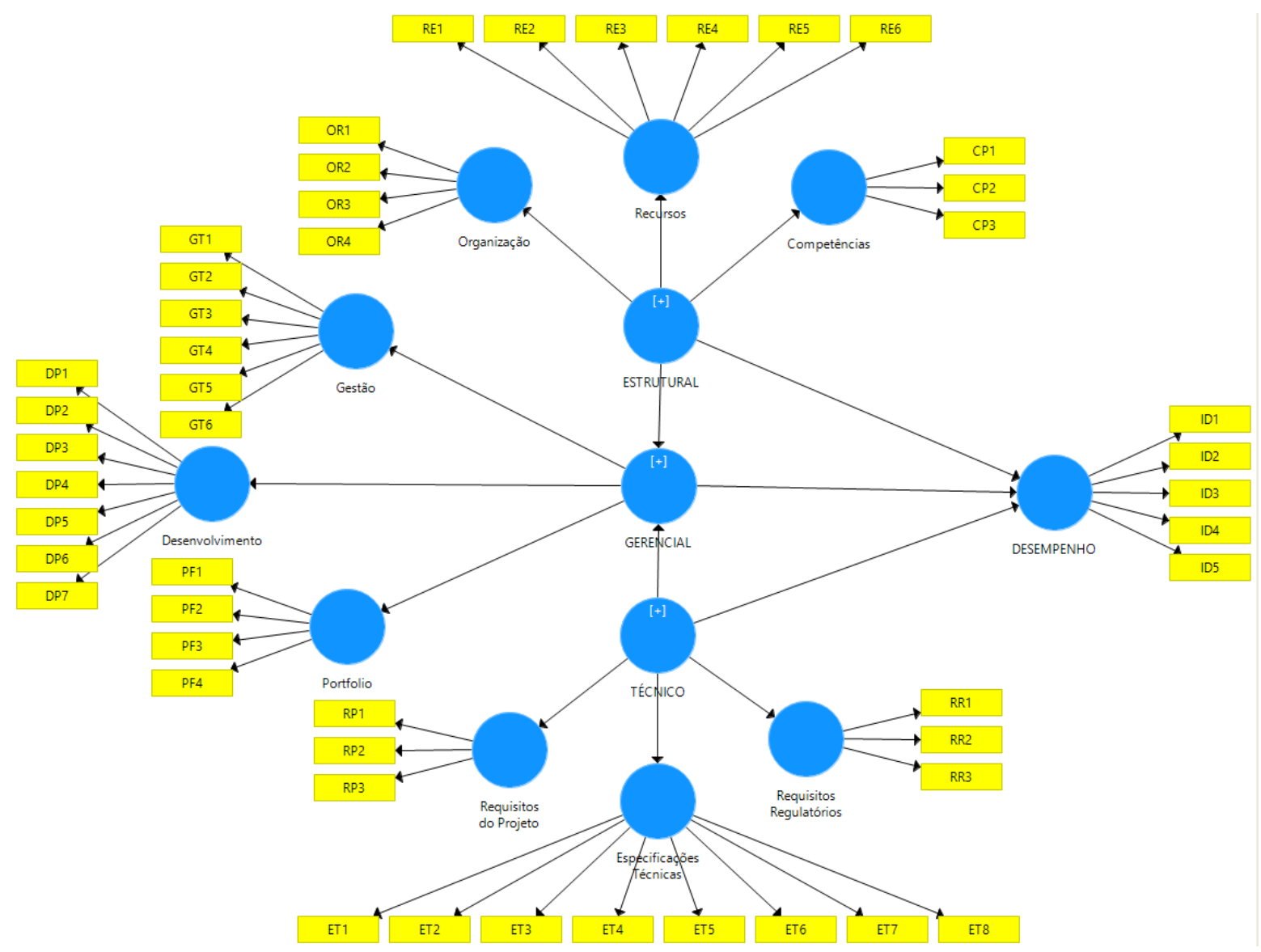

Nota: nos retângulos estão representados os indicadores do modelo; nos círculo internos os constructos de segunda ordem: Gerencial, Estrutural e Técnico; e nos círculos externos os constructos de mensuração. Fonte: dados da pesquisa tendo por referência Bido e Da Silva (2019) e Hair Jr e colaboradores (2017) e calculados usando o SmartPLS ${ }^{\circledR}$ (2019).

\subsubsection{Análise do modelo de mensuração}

Esta análise, além de ser o primeiro passo para a avaliação do modelo conceitual proposto, respondeu ao primeiro e ao segundo objetivos específicos (abaixo) ao validar os indicadores de desempenho e os relacionados aos fatores influenciadores que foram identificados nas fases anteriores.

a. Identificar os indicadores de desempenho dos projetos de desenvolvimento de medicamentos genéricos;

b. Identificar os fatores que contribuem para o desempenho dos projetos de desenvolvimento de medicamentos genéricos;

Tendo como referência Bido e Da Silva (2019) para a aplicação da técnica do PLS-SEM utilizando o software SmartPLS ${ }^{\circledR}$ (2019), foi realizado um conjunto de análises para avaliação das relações entre os constructos e de seus respectivos indicadores reflexivos. O SmartPLS ${ }^{\circledR}$ (2019) produz 
vários resultados que necessitam ser selecionados e organizados para facilitar a análise. Para avaliar o modelo de mensuração, os pesquisadores sugerem a estruturação de duas tabelas (Tabelas 40 e 41 já apresentadas) que devem ser analisadas simultaneamente. A primeira é usada para a análise no nível das constructos (variáveis latentes - VL) e a segunda para a análise no nível dos indicadores. Os critérios utilizados para a avaliação da qualidade do modelo de mensuração foram a validade convergente, a validade discriminante e a confiabilidade dos indicadores.

\subsection{Validade convergente}

$\mathrm{Na}$ análise da validade convergente, foram considerados os valores e as significâncias das cargas fatoriais assim como a variância média extraída (AVE). No modelo inicial, somente o indicador ID3 (os projetos foram concluídos, mas tiveram seus pedidos iniciais de registro reprovados pela Anvisa) do constructo Desempenho, não apresentou carga fatorial superior a 0,50 (carga fatorial = 0,418) (Apêndice XIV). Henseler e colaboradores (2009) e Hair Jr e colaboradores (2017) consideram que indicadores com carga entre 0,40 e 0,70 devem ser avaliados quanto aos reflexos da decisão sobre os valores da AVE e da Confiabilidade Composta (CC). Não sendo observados reflexos importantes sobre a AVE e a CC, optou-se pela sua manutenção, pois trata-se de indicador de desempenho que define o sucesso efetivo do projeto, uma vez que sem a aprovação da Anvisa o medicamento não pode ser comercializado (Anvisa, 2017b). Este resultado será discutido com mais profundidade mais adiante, em conjunto com os resultados dos demais indicadores do constructo Desempenho.

Com esta decisão, como todos os indicadores testados apresentaram carga fatorial satisfatória, pode-se considerar que todos contribuem para os seus constructos. Assim, não havendo exclusões em razão das cargas fatoriais menores que os valores de referência, conclui-se que todos os indicadores apresentaram relação com os constructos propostos, o que os valida e responde aos dois primeiros objetivos específicos da pesquisa.

- Considera-se que os 5 indicadores de desempenho testados foram validados. Eles respondem ao primeiro objetivo específico estabelecido para este estudo, ou seja: identificação dos indicadores de desempenho dos PDMG.

- Considera-se que os 44 indicadores referentes a situações relacionadas ao desempenho fora do planejado para projetos de desenvolvimento de medicamentos genéricos respondem ao segundo objetivo específico estabelecido para este estudo, ou seja: identificar os fatores relacionados ao desempenho dos PDMG.

$\mathrm{Na}$ análise da AVE dos constructos, somente o constructo de primeira ordem Especificações Técnicas não apresentou um valor superior ao recomendado de 0,50 (Apêndice XV). Este resultado foi tratado nos passos seguintes por meio de ajuste no modelo. 


\subsection{Validade discriminante}

Para a análise da validade discriminante, foram considerados dois critérios: o critério de Fornell e Larcker (1981) e a comparação das cargas fatoriais dos constructos com as cargas cruzadas.

Pelo critério de Fornell e Larcker (1981), as raízes quadradas dos valores das AVEs de cada constructo são comparadas com as correlações (de Pearson) entre os constructos ( $\mathrm{r}_{\mathrm{VL}}$ ). Para a validade discriminante, as raízes quadradas das AVEs devem ser superiores às correlações dos constructos (Ringle et al., 2014).

Considerando esse critério, o modelo inicialmente proposto não apresentou validade discriminante, pois, conforme demonstrado no Apêndice XVI, as raízes quadradas das AVEs dos constructos de primeira ordem Competências, Desenvolvimento, Especificações Técnicas, Gestão, Portfolio e Recursos apresentaram valores inferiores a algumas correlações entre os constructos.

Para fins de ajuste de validade discriminante e da AVE do constructo Especificações Técnicas, foram excluídos os indicadores que apresentavam a menor diferença de carga fatorial entre dois constructos dentre os constructos analisados. Portanto, considerando esse critério, os indicadores excluídos com base nos resultados da primeira rodada ${ }^{19}$ de cálculos foram:

- Indicador RE4 - Infraestrutura (instalações, equipamentos e utilidades) inadequada para o desenvolvimento dos métodos analíticos (constructo Recursos);

- Indicador ET7 - Dificuldade no estabelecimento das especificações e/ou realização dos testes para o controle de qualidade dos medicamentos (constructo Especificações Técnicas);

- Indicador GT3 - Deficiências e/ou dificuldades no gerenciamento de riscos no desenvolvimento dos medicamentos (constructo Gestão);

- Indicador PF4 - Número de projetos acima da capacidade e/ou elevada diversidade de projetos de desenvolvimento de medicamentos em andamento (constructo Portfolio).

Mesmo após essas exclusões, os resultados da segunda rodada de análise com o SmartPLS ${ }^{\circledR}$ (2019) indicaram que o critério de Fornell e Larcker (1981) ainda não fora atendido satisfatoriamente (Apêndice XVII), bem como não fora atendido o requisito de no mínimo 0,50 como valor da AVE do constructo Especificações Técnicas (Apêndice XVIII). Assim, a análise dos resultados sugeriu a exclusão dos três indicadores abaixo relacionados e a realização de uma terceira rodada de cálculos.

- Indicador RE5 - Infraestrutura (instalações, equipamentos e utilidades) inadequada para o desenvolvimento da formulação (farmacotécnico) dos medicamentos ) (constructo Recursos);

${ }^{19}$ Rodada - processamento dos dados do modelo no software SmartPLS ${ }^{\circledR}$ (2019) para avaliação e os ajustes eventualmente necessários. Após os ajustes (exclusões, rearranjos, etc.), é executado novo processamento do dados (rodada) e realizada nova análise e ajustes necessários até que os todos os critérios tenham sido atendidos. 
- Indicador ET8 - Dificuldade na obtenção de informações sobre os ingredientes farmacêuticos ativos utilizados nos medicamentos e/ou deficiências no DMF disponibilizado pelo fabricante (constructo Especificações Técnicas);

- Indicador GT1 - Definições iniciais insuficientes ou incorretas dos medicamentos a serem desenvolvidos (necessidades, características e/ou especificações dos medicamentos) (constructo Gestão).

Conforme a Tabela 57, após estas exclusões, o modelo apresentou valores de AVE satisfatórios, bem como o atendimento do critério de Fornell e Larcker (1981) para análise da validade discriminante.

Tabela 57 - Validade discriminante pelo critério de Fornell e Larcker (1981) (n = 209)

\begin{tabular}{lcccccccccc}
\hline & I & II & III & IV & V & VI & VII & VIII & IX & $\mathbf{X}$ \\
\hline I - Competências & $\mathbf{0 , 8 8 6}$ & & & & & & & & & \\
II - Desempenho & 0,262 & $\mathbf{0 , 7 3 0}$ & & & & & & & & \\
III - Desenvolvimento & 0,697 & 0,335 & $\mathbf{0 , 7 3 8}$ & & & & & & & \\
IV - Especificações Técnicas & 0,569 & 0,264 & 0,706 & $\mathbf{0 , 7 1 7}$ & & & & & & \\
V - Gestão & 0,495 & 0,353 & 0,671 & 0,558 & $\mathbf{0 , 7 1 7}$ & & & & & \\
VI - Organização & 0,635 & 0,285 & 0,638 & 0,480 & 0,650 & $\mathbf{0 , 8 5 9}$ & & & & \\
VII - Portfolio & 0,569 & 0,305 & 0,665 & 0,533 & 0,657 & 0,602 & $\mathbf{0 , 8 2 3}$ & & & \\
VIII - Recursos & 0,649 & 0,233 & 0,630 & 0,507 & 0,506 & 0,649 & 0,510 & $\mathbf{0 , 7 3 8}$ & & \\
IX - Requisitos do Projeto & 0,403 & 0,257 & 0,568 & 0,593 & 0,551 & 0,444 & 0,506 & 0,538 & $\mathbf{0 , 7 5 7}$ & \\
X - Requisitos Regulatórios & 0,438 & 0,265 & 0,612 & 0,611 & 0,479 & 0,390 & 0,510 & 0,425 & 0,553 & $\mathbf{0 , 7 8 5}$ \\
\hline \multicolumn{1}{c}{ AVE } & 0,784 & 0,534 & 0,545 & 0,514 & 0,514 & 0,737 & 0,678 & 0,545 & 0,573 & 0,616 \\
\hline
\end{tabular}

Notas: Os valores na diagonal são as raízes quadradas das AVEs. Todas as correlações são significantes a 5\%. Embora outras medidas de confiabilidade como o Alpha de Cronbach e a confiabilidade composta possam ser utilizadas, foi utilizada apenas a variância média extraída (AVE). Fonte: Dados da pesquisa tendo por referência Bido e Da Silva (2019) e Hair Jr e colaboradores (2017) e calculados pelo SmartPLS ${ }^{\circledR}$ (2019).

Na Tabela 57 observa-se que pelo critério de Fornell \& Larcker (1981), para todas os constructos, $\mathrm{AVE}>0,5$ e $\sqrt{\mathrm{AVE}}>\mathrm{r}_{\mathrm{VL}}$ (correlação entre os constructos), portanto, a validade convergente, discriminante e confiabilidade estão adequadas (Bido \& Da Silva, 2019).

O segundo critério para atestar a validade discriminante do modelo de mensuração também foi atendido, uma vez que, como pode ser verificado na Tabela 58, a carga fatorial de um indicador em seu constructo original é maior do que qualquer uma de suas cargas cruzadas (isto é, sua correlação) em outros constructos (Hair Jr. et al., 2017). Portanto, considera-se que o modelo de mensuração final apresenta validade discriminante. 
Tabela 58 - Cargas fatoriais e de cargas cruzadas do modelo final $(\mathrm{n}=209)$

\begin{tabular}{|c|c|c|c|c|c|c|c|c|c|c|}
\hline $\begin{array}{l}\text { Constructos/ } \\
\text { Indicadores }\end{array}$ & I & II & III & IV & $\mathbf{V}$ & VI & VII & VIII & IX & $\mathbf{X}$ \\
\hline $\mathrm{CP} 1$ & 0,902 & 0,267 & 0,621 & 0,518 & 0,400 & 0,571 & 0,506 & 0,568 & 0,357 & 0,382 \\
\hline $\mathrm{CP} 2$ & 0,915 & 0,223 & 0,638 & 0,548 & 0,453 & 0,555 & 0,511 & 0,563 & 0,324 & 0,377 \\
\hline $\mathrm{CP} 3$ & $\mathbf{0 , 8 3 7}$ & 0,205 & 0,592 & 0,445 & 0,461 & 0,559 & 0,495 & 0,594 & 0,390 & 0,405 \\
\hline ID1 & 0,253 & 0,799 & 0,297 & 0,206 & 0,258 & 0,262 & 0,273 & 0,190 & 0,173 & 0,229 \\
\hline ID2 & 0,196 & $\mathbf{0 , 8 5 5}$ & 0,280 & 0,273 & 0,331 & 0,242 & 0,292 & 0,233 & 0,281 & 0,212 \\
\hline ID3 & 0,195 & 0,433 & 0,121 & 0,140 & 0,159 & 0,082 & 0,150 & 0,184 & 0,169 & 0,217 \\
\hline ID4 & 0,165 & 0,752 & 0,213 & 0,127 & 0,260 & 0,206 & 0,230 & 0,090 & 0,187 & 0,185 \\
\hline ID5 & 0,154 & 0,739 & 0,271 & 0,192 & 0,253 & 0,206 & 0,136 & 0,155 & 0,117 & 0,142 \\
\hline DP1 & 0,549 & 0,238 & 0,719 & 0,550 & 0,452 & 0,443 & 0,388 & 0,488 & 0,425 & 0,358 \\
\hline DP2 & 0,439 & 0,267 & $\mathbf{0 , 7 1 7}$ & 0,505 & 0,521 & 0,472 & 0,494 & 0,432 & 0,456 & 0,395 \\
\hline DP3 & 0,551 & 0,277 & 0,726 & 0,544 & 0,505 & 0,374 & 0,576 & 0,474 & 0,501 & 0,526 \\
\hline DP4 & 0,474 & 0,265 & $\mathbf{0 , 7 7 7}$ & 0,557 & 0,524 & 0,493 & 0,449 & 0,493 & 0,384 & 0,480 \\
\hline DP5 & 0,415 & 0,203 & 0,664 & 0,379 & 0,398 & 0,425 & 0,401 & 0,368 & 0,358 & 0,399 \\
\hline DP6 & 0,666 & 0,280 & $\mathbf{0 , 8 0 0}$ & 0,585 & 0,515 & 0,583 & 0,549 & 0,563 & 0,387 & 0,520 \\
\hline DP7 & 0,492 & 0,195 & $\mathbf{0 , 7 5 5}$ & 0,512 & 0,539 & 0,498 & 0,558 & 0,422 & 0,421 & 0,469 \\
\hline ET1 & 0,423 & 0,121 & 0,493 & 0,685 & 0,407 & 0,408 & 0,487 & 0,444 & 0,455 & 0,448 \\
\hline ET2 & 0,448 & 0,183 & 0,495 & 0,654 & 0,367 & 0,322 & 0,276 & 0,325 & 0,350 & 0,281 \\
\hline ET3 & 0,422 & 0,308 & 0,522 & 0,683 & 0,388 & 0,250 & 0,349 & 0,301 & 0,336 & 0,389 \\
\hline ET4 & 0,395 & 0,179 & 0,478 & 0,724 & 0,400 & 0,297 & 0,378 & 0,248 & 0,401 & 0,471 \\
\hline ET5 & 0,398 & 0,137 & 0,571 & 0,777 & 0,471 & 0,416 & 0,395 & 0,465 & 0,510 & 0,523 \\
\hline ET6 & 0,384 & 0,223 & 0,485 & 0,771 & 0,364 & 0,361 & 0,394 & 0,383 & 0,474 & 0,484 \\
\hline GT2 & 0,327 & 0,230 & 0,516 & 0,418 & 0,791 & 0,449 & 0,503 & 0,385 & 0,405 & 0,341 \\
\hline GT4 & 0,408 & 0,320 & 0,605 & 0,488 & $\mathbf{0 , 7 9 0}$ & 0,584 & 0,595 & 0,406 & 0,447 & 0,458 \\
\hline GT5 & 0,380 & 0,195 & 0,434 & 0,309 & 0,669 & 0,438 & 0,319 & 0,280 & 0,298 & 0,264 \\
\hline GT6 & 0,304 & 0,262 & 0,327 & 0,362 & 0,600 & 0,367 & 0,432 & 0,379 & 0,432 & 0,278 \\
\hline OR1 & 0,534 & 0,254 & 0,561 & 0,412 & 0,617 & 0,873 & 0,513 & 0,538 & 0,348 & 0,272 \\
\hline OR2 & 0,524 & 0,266 & 0,565 & 0,396 & 0,539 & 0,853 & 0,528 & 0,561 & 0,397 & 0,377 \\
\hline OR3 & 0,510 & 0,244 & 0,520 & 0,390 & 0,533 & 0,867 & 0,525 & 0,553 & 0,423 & 0,335 \\
\hline OR4 & 0,609 & 0,217 & 0,547 & 0,449 & 0,543 & 0,841 & 0,503 & 0,574 & 0,358 & 0,354 \\
\hline PF1 & 0,458 & 0,188 & 0,491 & 0,352 & 0,489 & 0,479 & 0,771 & 0,438 & 0,417 & 0,325 \\
\hline PF2 & 0,483 & 0,265 & 0,537 & 0,450 & 0,545 & 0,536 & 0,850 & 0,451 & 0,407 & 0,443 \\
\hline PF3 & 0,467 & 0,293 & 0,610 & 0,503 & 0,584 & 0,475 & 0,846 & 0,376 & 0,427 & 0,480 \\
\hline RE1 & 0,552 & 0,126 & 0,499 & 0,389 & 0,358 & 0,506 & 0,416 & $\mathbf{0 , 7 1 7}$ & 0,410 & 0,362 \\
\hline RE2 & 0,377 & 0,240 & 0,440 & 0,354 & 0,387 & 0,352 & 0,300 & 0,693 & 0,364 & 0,255 \\
\hline RE3 & 0,422 & 0,139 & 0,444 & 0,385 & 0,329 & 0,453 & 0,300 & 0,793 & 0,385 & 0,276 \\
\hline RE6 & 0,540 & 0,195 & 0,471 & 0,368 & 0,419 & 0,572 & 0,464 & 0,746 & 0,422 & 0,346 \\
\hline RP1 & 0,198 & 0,134 & 0,322 & 0,422 & 0,408 & 0,255 & 0,340 & 0,330 & 0,779 & 0,410 \\
\hline RP2 & 0,361 & 0,275 & 0,498 & 0,501 & 0,474 & 0,416 & 0,419 & 0,509 & 0,824 & 0,404 \\
\hline RP3 & 0,353 & 0,165 & 0,465 & 0,417 & 0,362 & 0,329 & 0,388 & 0,373 & 0,658 & 0,445 \\
\hline RR1 & 0,322 & 0,234 & 0,507 & 0,462 & 0,411 & 0,370 & 0,426 & 0,376 & 0,457 & 0,802 \\
\hline RR2 & 0,351 & 0,175 & 0,467 & 0,520 & 0,336 & 0,276 & 0,427 & 0,313 & 0,415 & 0,774 \\
\hline RR3 & 0,357 & 0,216 & 0,466 & 0,456 & 0,380 & 0,271 & 0,345 & 0,311 & 0,431 & 0,778 \\
\hline
\end{tabular}

Legenda: Constructos (colunas) I - Competências; II - Desempenho; III -Desenvolvimento; IV - Especificações Técnicas; V - Gestão; VI - Organização; VII - Portfolio; VIII - Recursos, IX - Requisitos do Projeto; e X Requisitos Regulatórios. Indicadores (linhas) cujas descrições dos códigos estão no Apêndice IX. Fonte: Dados da pesquisa tendo por referência Bido e Da Silva (2019) e (Hair Jr e colaboradores (2017) e calculados usando o SmartPLS ${ }^{\circledR}$ (2019).

Resumindo os ajustes realizados no modelo estrutural, no total 7 indicadores foram excluídos para ajuste do modelo de mensuração, os quais são descritos na Tabela 59 a seguir: 
Tabela 59 - Relação de indicadores excluídos para ajuste do modelo de mensuração

\begin{tabular}{|c|c|c|c|}
\hline Cód. & Indicador & Decisão & Justificativa \\
\hline RE4 & $\begin{array}{c}\text { Infraestrutura (instalações, equipamentos e } \\
\text { utilidades) inadequada para o desenvolvimento dos } \\
\text { métodos analíticos. (Constructo Recursos) }\end{array}$ & \multirow{4}{*}{$\begin{array}{l}\text { Exclusão após a } \\
\text { análise da } 1^{\mathrm{a}} \\
\text { rodada de } \\
\text { cálculos }\end{array}$} & \multirow{7}{*}{$\begin{array}{l}\text { Na análise da matriz de } \\
\text { cargas fatoriais } \\
\text { ("crossloadings") da } \\
\text { primeira rodada, o } \\
\text { indicador apresentou } \\
\text { pequena diferença de } \\
\text { carga entre os } \\
\text { constructos. }\end{array}$} \\
\hline ET7 & $\begin{array}{c}\text { Dificuldade no estabelecimento das especificações } \\
\text { e/ou realização dos testes para o controle de } \\
\text { qualidade dos medicamentos. (Constructo } \\
\text { Especificações Técnicas) }\end{array}$ & & \\
\hline GT3 & $\begin{array}{l}\text { Deficiências e/ou dificuldades no gerenciamento de } \\
\text { riscos no desenvolvimento dos medicamentos. } \\
\text { (Constructo Gestão) }\end{array}$ & & \\
\hline PF4 & $\begin{array}{c}\text { Número de projetos acima da capacidade e/ou } \\
\text { elevada diversidade de projetos de desenvolvimento } \\
\text { de medicamentos em andamento. (Constructo } \\
\text { Portfolio) }\end{array}$ & & \\
\hline RE5 & $\begin{array}{l}\text { Infraestrutura (instalações, equipamentos e } \\
\text { utilidades) inadequada para o desenvolvimento da } \\
\text { formulação (farmacotécnico) dos medicamentos. } \\
\text { (Constructo Recursos) }\end{array}$ & \multirow{3}{*}{$\begin{array}{l}\text { Exclusão após a } \\
\text { análise da } 2^{\mathrm{a}} \\
\text { rodada de } \\
\text { cálculos }\end{array}$} & \\
\hline ET8 & $\begin{array}{c}\text { Dificuldade na obtenção de informações sobre os } \\
\text { ingredientes farmacêuticos ativos utilizados nos } \\
\text { medicamentos e/ou deficiências no DMF } \\
\text { disponibilizado pelo fabricante. (Constructo } \\
\text { Especificações Técnicas) }\end{array}$ & & \\
\hline GT1 & $\begin{array}{c}\text { Definições iniciais insuficientes ou incorretas dos } \\
\text { medicamentos a serem desenvolvidos (necessidades, } \\
\text { características e/ou especificações dos } \\
\text { medicamentos). (Constructo Gestão) }\end{array}$ & & \\
\hline
\end{tabular}

Fonte: Dados da pesquisa

Os 7 indicadores excluídos representaram $14,3 \%$ do total de 49 indicadores considerados no modelo inicial (5 de desempenho +44 de fatores contribuintes), não havendo indicação de que fosse necessário o uso de novo conjunto de dados por ser menor que os $20 \%$ sugeridos ("rule of thumb") por Hair Jr. e colaboradores (2017). Todos os itens excluídos foram em razão de apresentarem cargas cruzadas altas em mais de um constructo, o que não os tornavam úteis para a mensuração dos constructos esperados (Bido et al., 2018). Em outras palavras, como o modelo estrutural mensura a relação entre os constructos, indicadores que apresentam cargas fatoriais altas e próximas umas das outras em vários constructos não favorecem esta mensuração.

Dois dos indicadores excluídos pertenciam ao constructo Recursos: o indicador RE4 relacionado à infraestrutura (instalações, equipamentos e utilidades) inadequada para o desenvolvimento dos métodos analíticos e o indicador RE5 relacionado à infraestrutura inadequada para o desenvolvimento da formulação (farmacotécnico) dos medicamentos. Os recursos possuem relevante importância no gerenciamento de projetos, sendo inclusive uma das áreas do conhecimento definidos pelo PMI (2017).

Há aparente conflito entre a importância das deficiências tratadas por estes dois indicadores (RE4 e RE5) e o resultado da pergunta sobre o abandono dos projetos por insuficiência de recursos, o 
qual indicou que para 50\% dos respondentes as empresas em que trabalhavam não abandonavam os PDMG por esta razão, sugerindo que os recursos não são fatores limitadores ou restritivos para os PDMG. Parece então plausível supor que, em geral, não faltam recursos para o desenvolvimento dos PDMG, porém, quando ele é limitado, há influência sobre diferentes dimensões dos projetos.

O indicador RE4 relacionado à infraestrutura inadequada para o desenvolvimento dos métodos analíticos apresentou a maior carga fatorial em seu constructo (Recursos), mas também altas cargas nos constructos Competências e Organização, o que prejudica a validade discriminante. Este resultado sugere que problemas relacionados ao desenvolvimento dos métodos de análise dos medicamentos e de suas matérias-primas tenham várias relações importantes, mesmo considerando que o item questionado fizesse referência apenas à infraestrutura. $\mathrm{O}$ desenvolvimento e a validação dos métodos analítico são requisitos obrigatórios da Anvisa e são necessários para a verificação da qualidade do medicamento e de suas matérias-primas (Anvisa, 2017b), além de também serem necessários para outros testes, como os estudos de estabilidade que definem, por exemplo, o prazo de validade do medicamentos após a sua fabricação (Anvisa, 2019c). As deficiências deste requisito aparecem entre as respostas à pesquisa qualitativa quando um dos participantes responde da seguinte forma: "a infraestrutura da área de desenvolvimento analítico não atende às reais necessidades para dar cabo das análises exigidas'.

A alta carga também no constructo Competências pode ter origem na ligação que os profissionais fazem entre estrutura e pessoal qualificado. Esta composição entre recursos e competências foi considerada por Cooper e Kleinschmidt (1987a), pois os incluíram como componentes de um mesmo construto, o qual denominaram sinergia tecnológica. O PMI (2017) inclui as pessoas entre os recursos necessários ao desenvolvimento dos projetos e tornou mais explícita a relação entre recursos e pessoal em sua última edição ao transferir o processo de estimativa dos recursos das atividades, que estava na área de conhecimento de gerenciamento do tempo (PMI, 2013), para a área de conhecimento de gerenciamento dos recursos do projeto (nova denominação da área que era entitulada gerenciamento dos recursos humanos do projeto).

A alta carga do indicador RE4 relacionado à infraestrutura inadequada para o desenvolvimento dos métodos analíticos também no constructo Organização pode ser resultado de barreiras ao uso da infraestrutura necessária aos PDMG. No caso dos equipamentos analíticos, por exemplo, estes normalmente não ficam sob responsabilidade da área de P\&D. Seria basicamente um problema na gestão dos recursos necessários aos projetos (PMI, 2017).

O outro indicador, o RE5, também é relacionado à infraestrutura (instalações, equipamentos e utilidades) inadequada, mas desta vez para o desenvolvimento da formulação (farmacotécnico) dos medicamentos. A falta de um equipamento com as especificações necessárias para um determinado processo de fabricação é fator bastante crítico, considerando-se os requisitos rígidos para os medicamentos genéricos. Como praticamente não há margem de tolerância para diferenças técnicas 
entre o medicamento genéricos e o de referência, em geral é muito restrita a possibilidade de uso de uma tecnologia alternativa que consiga produzir o medicamento com as características requeridas. $\mathrm{O}$ indicador apresentou a maior carga fatorial em seu constructo (Recursos), mas também alta carga no constructo Competências. Este resultado também sugere que problemas relacionados ao desenvolvimento da formulação dos medicamentos possa ter origem na conexão que os profissionais podem estar fazendo entre infraestrutura e qualificação do pessoal.

Outros dois indicadores excluídos pertenciam ao constructo Especificações Técnicas. Os indicadores deste constructo tem origem nos requisitos técnicos que o medicamento deve atender para ser aprovado pela (Anvisa, 2017b). O indicador ET7, relacionado à dificuldade no estabelecimento das especificações e/ou realização dos testes para o controle de qualidade dos medicamentos, também apresentou alta carga no constructo Desenvolvimento. As altas cargas nos dois constructos pode ter como causa o fato de normalmente as especificações serem definidas pela área de desenvolvimento de métodos analíticos e a realização dos testes pela área de controle da qualidade. Assim, talvez a dificuldade esteja na participação coordenada destas áreas.

Embora esses resultados não contribuam para o modelo proposto, eles aponta para a multidisciplinaridade. Em específico para o desenvolvimento de medicamentos, Mendigorri e colaboradoras (2016) incluíram em seu modelo um constructo que denominaram "relações com outros departamentos" e que é composto por indicadores relacionados à multidisciplinaridade.

O segundo indicador excluído e que pertencia ao constructo Especificações Técnicas foi o ET8, que trata da dificuldade de obtenção de informações sobre os ingredientes farmacêuticos ativos (IFA) utilizados nos medicamentos e/ou deficiências no DMF ("Drug Master File" ou, em português, Documento Mestre do Fármaco) disponibilizado pelo fabricante do IFA. O indicador também apresentou cargas altas e próximas nos constructos Desenvolvimento, Recursos, Requisitos do Projeto e Requisitos Regulatórios. O DMF é item obrigatório para a obtenção do registro e autorização para comercialização de um novo medicamento (Anvisa, 2017b). Ele traz informações sobre o processo de síntese do IFA, eventuais produtos intermediários e resíduos, características do composto químico, além de dados sobre o método analítico e estabilidade, entre outros. Trata-se de documento usado tanto pela área de desenvolvimento quanto pela de assuntos regulatórios e é fonte de dados tanto para a definição do escopo do projeto, como também para as diferentes atividades dos PDMG, estando neste fato a possível justificativa para altas cargas em diferentes constructos.

O constructo Gestão também teve dois de seus indicadores originais excluídos. O primeiro foi o indicador GT3 referente às deficiências e/ou dificuldades no gerenciamento de riscos no desenvolvimento dos medicamentos. Este indicador também apresentou cargas altas nos constructos Desenvolvimento, Especificações Técnicas, Organização, Portfólio e Requisitos do Projeto. Os riscos nos PDMG foram citados várias vezes pelos participantes da fase qualitativa. Alguns exemplos são: (é necessária) "uma avaliação de risco técnico mais precisa no momento da avaliação do projeto" e 
"acredito que todo o desenvolvimento será mais embasado em planejamento e pesquisa bibliográfica, dando origem a um plano de desenvolvimento baseado QbD e avaliação de risco".

A gestão de riscos está cada vez mais presente na rotina da indústria farmacêutico, tendo como marco a publicação do guia Q9 do (ICH, 2005) com as recomendações sobre a gestão de riscos de qualidade que hoje são adotadas por países como EUA, Japão e europeus. Mais especificamente para o desenvolvimento de produtos, o guia Q8 do ( $\mathrm{ICH}, 2009)$ sobre o desenvolvimento farmacêutico, apresenta um tópico sobre a relação entre a gestão de riscos de qualidade e o desenvolvimento de produtos e processos. No Brasil, a resolução RDC 301/2019 (Anvisa, 2019f), recentemente publicada, inclui vários itens que remetem à gestão de riscos no desenvolvimento e produção de medicamentos, tendo por referência o guia Q8 do (ICH, 2009) que trata do desenvolvimento de medicamentos e do conceito de QbD (“Quality by Design”). Desta forma, considera-se que a disseminação de sua correta aplicação é fundamental para a melhoria do desempenho dos PDMG.

Em relação à gestão de projetos, o gerenciamento de riscos já estava presente na primeira edição do PMBOK (PMI Standards Committee, 1996). Na concepção do constructo, esperava-se que a gestão de riscos estive mais concentrada nas atividades de gestão do projeto. Porém, os resultados parecem indicar que ela está distribuída em outros aspectos dos PDMG, o que não deixa de ser um resultado que pode ser considerar positivo por possivelmente haver a disseminação do conceito, embora não contribua para o modelo conceitual proposto.

Entre as possíveis causas da deficiência em sua aplicação pode estar o uso incorreto de ferramentas de gerenciamento de riscos e/ou até mesmo o conhecimento apenas básico dos conceitos e das práticas. O PMI (2017, p. 390) considera que todos os projetos são arriscados, pois, por conceito, são empreendimentos únicos com graus variados de complexidade e são desenvolvidos em contextos de restrições e premissas. Ao mesmo tempo, os projetos devem responder às expectativas das partes interessadas que podem estar em conflito e, eventualmente, mudarem seus requisitos. O PMI acredita que as organizações devam assumir o risco do projeto de maneira controlada e intencional para que possam equilibrar a relação entre risco e retorno. A necessidade de gestão dos riscos está presente em todas as fases dos PDMG e afeta as decisões que são tomadas. Dependendo do nível de risco aceito pela empresa, as decisões podem eventualmente favorecer ou impor obstáculos ao projeto.

Outro indicador que também pertencia originalmente ao constructo Gestão e que foi excluído do modelo foi o GT1, este relacionado às definições iniciais insuficientes ou incorretas dos medicamentos a serem desenvolvidos (necessidades, características e/ou especificações dos medicamentos). Como já comentado, pode-se considerar que este é basicamente um problema de gestão do escopo tanto do projeto quanto do produto, mesmo que este último possa estar completamente definido desde o início do projeto, uma vez que trata-se de medicamento genérico e que, portanto, deve ser igual ao medicamento de referência. 
O conceito do produto está entre os indicadores mais importantes do constructo proposto por Cooper e Kleinschmidt (1987a) para mensurar o processo de DP. A razão para este indicador ter tido cargas altas também nos constructos Portfólio e Desenvolvimento pode ter relação com o processo de seleção dos medicamentos genéricos a serem desenvolvidos. Um processo de decisão de portfólio de projetos deficiente tem maior probabilidade de resultar em escolhas incorretas e/ou com informações insuficientes para o desenvolvimento dos produtos (Cooper, Edgett, \& Kleinschmidt, 1997; Thomas R. Dunson, 2010; Rozenfeld et al., 2006). Esta deficiência, por si só, seria um problema de gestão que tem reflexos sobre o gerenciamento dos PDMG, uma vez que são as decisões de portfolio que dão origem dos projetos e que definem seus prosseguimentos. Assim, a escolha dos projetos sem considerar a sua adequação aos recursos, incluindo infraestrutura, tecnologia e competências, traria dificuldades aos PDMG.

Como já comentado, uma das questões procurou avaliar a frequência com que os PDMG eram abandonados por decisões de ordem estratégica. Os dados indicaram uma taxa baixa de abandono (entre $1 \%$ e $20 \%$ do PDMG) para a maioria dos respondentes $(53,6 \%)$. Um das possíveis razões para o abandono dos projetos pode ser exatamente a gestão inadequada do portfólio de projetos, em especial em suas etapas iniciais de análise de viabilidade (Isadore Kanfer et al., 2014). Relacionado a esta possibilidade, o indicador referente às definições iniciais insuficientes ou incorretas dos medicamentos a serem desenvolvidos, é basicamente um problema de definição inicial do escopo. Da mesma forma que para os problemas com mudanças no escopo, neste caso, as causas podem estar já na decisão de investimento ou de início do projeto, quando as primeiras definições do escopo são estabelecidas. Pode também surgir de dúvidas e/ou incertezas sobre o escopo que não são adequadamente tratadas por deficiências na integração entre os participantes do PDMG e/ou na comunicação, por exemplo. A validação do indicador referente à escolha inadequada e/ou equivocada dos medicamentos para compor o portfólio de projetos a serem desenvolvidos também corrobora com este entendimento.

O estabelecimento de metas irreais para os PDMG poder ser um contribuinte para a falta de validade discriminante do indicador PF4, que fez referência ao número de projetos acima da capacidade e/ou elevada diversidade de projetos de desenvolvimento de medicamentos em andamento. Este indicador pertencente ao constructo Portfolio foi eliminado por também apresentar elevada carga no constructo Gestão. Os efeitos do número de projetos sobre o desempenho dos PDMG depende em parte do tempo disponível para desenvolvê-los e dos recursos disponíveis, sendo que essa relação poderia ser uma das causas do indicador ter apresentado cargas elevadas nos dois constructos (Portfólio e Gestão).

$\mathrm{Na}$ análise da matriz de cargas fatoriais da segunda rodada de testes, o indicador GT6, que faz referência ao objetivo de custo final para produção e/ou preço-alvo de mercado muito baixo para o medicamento em desenvolvimento em razão do custo dos materiais e/ou processo de fabricação, também poderia ter sido excluído do modelo em razão de apresentar cargas elevadas em mais de um constructo. No entanto, a decisão foi por mantê-lo no modelo e somente excluí-lo se permanecessem 
os problemas de validade discriminantes após a realização da terceira rodada de testes. Os resultados da rodada de teste mostraram-se adequados, não sendo necessária a exclusão do indicador.

\subsection{Confiabilidade dos indicadores}

Para análise da confiabilidade do modelo de mensuração foram consideradas as estatísticas de consistência interna pelos cálculos do Alfa de Cronbach $(\alpha)$ e da Confiabilidade Composta - CC (“Composite Reliability" - CR na lígua inglesa) (Tabela 60). A confiabilidade Alfa de Cronbach $(\alpha)$ estima indiretamente o grau de confiança no qual o conjunto de indicadores mede um constructo único, sendo que são desejáveis valores de ao menos 0,7 (Hair Jr. et al., 2017). A CC, por sua vez, estima o grau de confiança de cada indicador no constructo a que pertence, sendo desejáveis valores acima de 0,7 (Fornell \& Larcker, 1981; Hair Jr. et al., 2017).

Tabela 60 - Confiabilidade do modelo de mensuração: Alfa de Cronbach e Confiabilidade Composta

$$
(\mathrm{n}=209)
$$

\begin{tabular}{lcc}
\hline & $\begin{array}{c}\text { Alfa de } \\
\text { Cronbach }\end{array}$ & $\begin{array}{c}\text { Confiabilidade } \\
\text { Composta }\end{array}$ \\
\hline Competências & 0,862 & 0,916 \\
Desempenho & 0,769 & 0,846 \\
Desenvolvimento & 0,860 & 0,893 \\
Especificações Técnicas & 0,810 & 0,864 \\
Gestão & 0,682 & 0,807 \\
Organização & 0,881 & 0,918 \\
Portfolio & 0,762 & 0,863 \\
Recursos & 0,722 & 0,827 \\
Requisitos do Projeto & 0,621 & 0,800 \\
Requisitos Regulatórios & 0,688 & 0,828 \\
\hline Gerencial & 0,902 & 0,917 \\
Estrutural & 0,905 & 0,921 \\
Técnico & 0,868 & 0,892 \\
\hline
\end{tabular}

Fonte: Dados da pesquisa tendo por referência Bido e Da Silva (2019) e Hair Jr e colaboradores (2017) e calculados usando o SmartPLS ${ }^{\circledR}$ (2019).

Considerando os dados da Tabela 60, apesar de alguns constructos apresentarem valores de Alfa de Cronbach pouco abaixo de 0,70 (Gestão, Requisitos do Projeto e Requisitos Regulatórios), os valores da confiabilidade composta de todos os constructos são satisfatórios, o que é considerado por Hair Jr e colaboradores (2017) um indicativo da consistência interna dos constructos. Portanto, considera-se que estão validados os construtos para a composição do modelo de mensuração ajustado e que este apresenta confiabilidade.

A discussão dos resultados da análise dos constructos e de seus indicadores terá início com a análise da variável dependende, ou seja, o constructo Desempenho e seus indicadores. Na sequência serão avaliados os constructos independentes endógenos, seus constructos componentes e respectivos 
indicadores na seguinte ordem: Gerencial, Estrutural e Técnico. Por fim serão analisados o modelo estrutural e os efeitos mediadores.

\subsection{Constructo Desempenho}

O início da análise por este constructo tem por principal razão a necessidade de considerar os efeitos sobre ele quando são analisados os demais constructos a ele relacionados, uma vez que se trata da variável dependente. A Figura 58 a seguir apresenta os resultados das análises para o constructo Desempenho e de suas relações com seus indicadores.

Figura 58 - Constructo Desempenho e seus indicadores reflexivos $(n=209)$

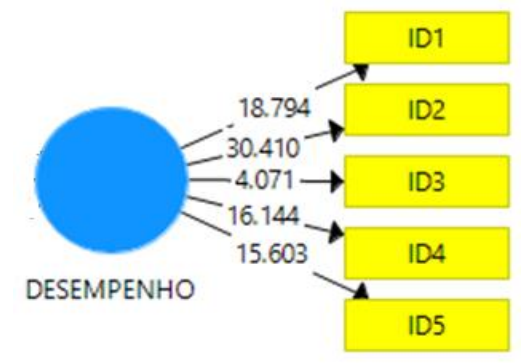

Nota: Modelo de mensuração com os valores dos testes $t$ de Student. Fonte: dados da pesquisa obtidos por meio do módulo Bootstrapping do SmartPLS ${ }^{\circledR}$ (2019).

O constructo Desempenho é composto por 5 indicadores reflexivos:

- conclusão após a data planejada inicialmente (com atraso) (ID1);

- conclusão com custos totais acima do orçamento planejado (acima do orçamento) (ID2);

- conclusão com pedidos iniciais de registro reprovados pela Anvisa (ID3);

- conclusão com custos de produção ou preço-alvo de mercado acima do planejado (medicamento mais caro que o planejado) (ID4);

- conclusão com necessidade de ajustes na sua formulação e/ou em seu processo de fabricação após o seu lançamento ("troubleshooting") (ID5).

O indicador com a maior contribuição $(30,410)$ para o desempenho fora do planejado dos PDMG é o relacionado a custos totais acima do orçamento planejado (acima do orçamento) (ID2). De certa forma, este resultado não era esperado em razão da literatura dar destaque ao tempo para lançamento no mercado como a principal preocupação dos PDMG (Prašnikar \& Škerlj, 2006; Leon Shargel \& Kanfer, 2005; Suchak \& Murray, 2017). Porém, pode estar exatamente neste requisito a razão dos PDMG terem mais problemas para serem concluídos dentro do orçamento. Entre atender cronograma ou ao orçamento, prioridade pode estar sendo dada ao cronograma em detrimento dos custos que podem, por esta razão, terem seus indicadores não atendidos. Quando dá maior importância ao cronograma, a literatura está correta, no entanto, ela deixa de enfatizar a contrapartida que é o comprometimento do orçamento. Apesar do custo para o desenvolvimento de um medicamento 
genérico ser muito inferior ao do desenvolvimento de um medicamento inovador, ainda assim é um fator que afeta os PDMG.

Nesta mesma linha de pensamento, um importante aspecto a ser considerado tem relação com o equilíbrio entre restrições conflitantes ("trade-offs), ou seja, entre escopo, cronograma, custo, qualidade, recursos e riscos (PMI, 2017). A priorização do cronograma de um PDMG pode, por exemplo, também significar deixar em segundo plano a qualidade, que é fator crítico para a aprovação do medicamento (Adeyeye \& Brittain, 2008; Prašnikar \& Škerlj, 2006).

O equilíbrio entre as restrições conflitantes, no entanto, parece ser favorável aos laboratórios que possuem mais recursos para os PDMG. É compreensível que os grande laboratórios busquem a liderança nos mercados em que atuam em razão de vantagens que incluem não só faturamento, mas também ganhos em escala. Chegar antes ao mercado facilita a presença no varejo farmacêutico, pois não há a necessidade de negociação de espaço ao lado de concorrentes já estabelecidos (Prašnikar \& Škerlj, 2006). O fato é que os maiores laboratórios tem melhores e mais recursos para investimento no desenvolvimento dos medicamentos, o que, de uma forma geral, favorece o desenvolvimento mais rápido dos medicamentos.

Lee e colaboradores (2017) afirmam que as pequenas e médias empresas (PME) exigem eficiência de projetos de $\mathrm{P} \& \mathrm{D}$ devido às limitações de orçamento e recursos. No caso dos laboratórios menores, talvez a priorização do cronograma possa trazer impactos maiores sobre os projetos na forma de custos e riscos mais elevados e possivelmente mais difíceis de serem suportados. Assim, os laboratórios não tão grandes, cientes desta desvantagem, podem não priorizar o prazo para lançamento, mas o uso mais eficiente dos recursos, que se supõe serem comparativamente mais restritivos. Portanto, devem buscar maior eficiência no uso dos recursos e custos melhores de produção.

O indicador com a segunda maior contribuição $(18,794)$ para o desempenho fora do planejado dos PDMG é o relacionado à conclusão dos PDMG após a data planejada inicialmente (com atraso) (ID1). Como já mencionado, esperava-se uma contribuição maior dos atrasos no cronograma para os resultados fora do planejado. É possível que, dada a elevada pressão pelo lançamento do medicamento o mais rápido possível (Prašnikar \& Škerlj, 2006), prioridade seja realmente dada ao cronograma para que não ocorram atrasos. No entanto, mesmo sendo priorizado, o prazo dado pode não estar sendo suficiente para a conclusão dos PDMG. Pode também haver contratempos em razão de problemas no desenvolvimento em si.

Colaborando com esta possibilidade, o indicador que trata da conclusão com custos de produção ou preço-alvo de mercado acima do planejado (medicamento mais caro que o planejado) (ID4) apresentou a terceira maior contribuição $(16,114)$ para o desempenho fora do planejado dos PDMG. A 
estratégia seria a busca pelo menor custo de produção e, consequentemente, a possibilidade de colocação do medicamento no mercado a um menor preço de venda, tornando-o competitivo em relação aos concorrentes e permitindo a conquista de espaço nas unidades de dispensação dos medicamentos (Torres \& Souza, 2010). Nem sempre é possível obter vantagem significativa em custos de insumos e/ou na melhoria dos processos de fabricação, mas é um objetivo que deve ser buscado para que o custo de produção não se torne uma desvantagem.

O indicador que apresentou a quarta maior contribuição para o constructo Desempenho $(15,603)$ foi a conclusão com necessidade de ajustes na sua formulação e/ou em seu processo de fabricação após o seu lançamento ("troubleshooting") (ID5). Diferentemente dos indicadores de desempenho anteriores, que podem ser considerados de eficiência dos PDMG, este indicador trata da eficácia ao abordar a qualidade do medicamento lançado, a qual é verificada por meio da realização de testes de acompanhamento, da análise de dados da produção e distribuição e do recebimento de reclamações e/ou notificações de farmacovigilância ${ }^{20}$. As necessidades de ajustes na formulação e/ou no processo de fabricação de um medicamento após o seu lançamento podem colocar em risco o registro obtido. A ocorrência de problemas com o medicamento já no mercado pode provocar desde o recolhimento dos lotes com problemas até o cancelamento do resgistro e consequente proibição de sua produção e comercialização (Anvisa, 2017b).

A relativamente baixa carga fatorial do indicador que tratou da reprovação dos pedidos iniciais de registro na Anvisa (ID3), principal indicador de eficácia dos PDMG, é compatível com a também relativa baixa média $(1,91)$ obtida entre as respostas recebidas para o item. No entanto, pode ser considerada divergente em relação aos dados da pesquisa de Do Carmo, Piras e colaboradores (2017) que indicam um alto percentual de indeferimento dos pedidos de registro de medicamentos genéricos. O registro na Anvisa pode ser considerado o objetivo maior dos PDMG, uma vez que é ele que libera o medicamento para sua comercialização. Assim, apesar desse resultado indicar que a reprovação do pedido de registro da Anvisa não seja um grande contribuinte para o constructo Desempenho, não se pode diminuir a sua importância, uma vez que seu impacto ainda assim é elevado.

É possível que esse resultado se deva em parte à departamentarização das responsabilidades, uma vez que o estudo também identificou a contribuição de fatores organizacionais para o desempenho fora do planejado do PDMG, como será visto mais adiante. O departamento de P\&D seria responsável tão somente por desenvolver o medicamento e o departamento de Assuntos Regulatório por aprovar o medicamento na Anvisa. Como a maior parte dos respondentes é da área de

\footnotetext{
${ }^{20}$ Farmacovigilância - identificar, avaliar e monitorar a ocorrência de: reações adversas de medicamentos, eventos adversos causados por desvios da qualidade de medicamentos, inefetividade terapêutica, erros de medicação, uso de medicamentos para indicações não aprovadas no registro, uso abusivo, intoxicações e interações medicamentosas (Anvisa, 2019a).
} 
P\&D, é possível que o perfil dos respondentes tenha conduzido à redução da importância deste indicador para a mensuração do desempenho dos PDMG.

\subsection{Constructo Gerencial}

O constructo endógeno Gerencial (constructos de segunda ordem) é o que apresenta maior correlação com os resultados fora do planejado dos PDMG $(\beta=0,326)$. O constructo Gerencial é composto por 3 constructos exógenos (constructos de primeira ordem): constructo Desenvolvimento ( $\beta=0,937)$, constructo Gestão $(\beta=0,845)$ e constructo Portfólio $(\beta=0,840)$. A Figura 59 a seguir apresenta os resultados das análises para o constructo Gerencial e de suas relações com seus constructos exógenos.

Figura 59 - Constructo Gerencial e seus constructos exógenos Gestão, Desenvolvimento e Portfólio

$$
(n=209)
$$

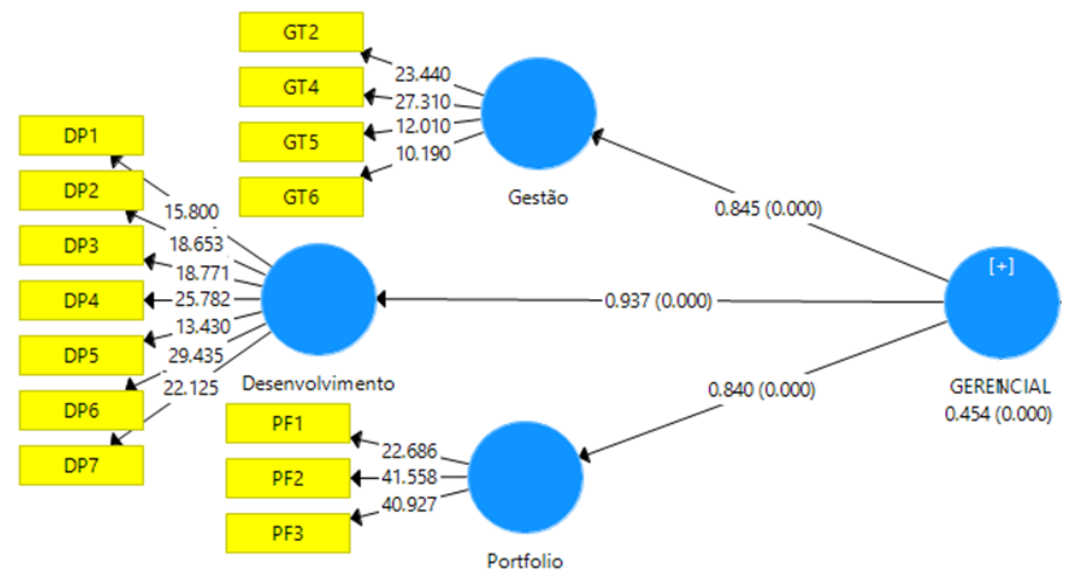

Nota: modelo de mensuração com os valores dos testes $t$ de Student e modelo estrutural com valores fora dos parênteses são coeficientes estruturais padronizados $(\beta)$ e os valores dentro dos parênteses são valores-p. Fonte: dados da pesquisa obtidos por meio do módulo bootstrapping do SmartPLS ${ }^{\circledR}$ (2019).

\subsection{Constructo Desenvolvimento}

Sete indicadores reflexivos formam o constructo Desenvolvimento:

- dificuldade no desenvolvimento da formulação (farmacotécnico) do medicamento (DP1);

- dificuldade no processo de transferência dos medicamentos do laboratório para a produção (escalonamento ou "scale up") (DP2);

- deficiências e/ou dificuldades na obtenção e/ou apresentação de dados e informações técnicocientíficas dos medicamentos (DP3)

- deficiências e/ou dificuldades para a realização de lotes piloto, pré-validação e predefinição dos parâmetros do processo de produção do novo medicamento (DP4); 
- o laboratório não usar ou usar inadequadamente metodologias científicas para o desenvolvimento dos medicamentos (ex.: Qualidade por Meio do Delineamento ou "Quality by Design") (DP5);

- dificuldades ou ausência de estudos de pré-formulação do medicamento (DP6); e

- inexistência ou deficiências nos processos para desenvolvimento dos medicamentos (DP7).

Entre estes indicadores, o relacionado às dificuldades ou ausência de estudos de pré-formulação apresentou a maior contribuição para o constructo Desenvolvimento $(t=29,434)$. Embora não sejam obrigatórios, os estudos de pré-formulação são recomendados e aparecem, por exemplo, nos modelos de desenvolvimento de medicamentos de Kanfer e colaboradores (2014), Silva (2015) e V. dos S. C. Yugue (2014). Entre a definição do escopo e o desenvolvimento da formulação propriamente dito, há a possibilidade de realização de análises de pré-formulação. Elas facilitam o planejamento e desenvolvimento do projeto ao buscarem dados e informações e realizarem testes preliminares sobre os medicamentos que serão desenvolvidos. Portanto, trata-se de um conjunto de atividades importantes para a racionalização do desenvolvimento dos medicamentos. Uma das respostas à pesquisa qualitativa relata que a "falta de estudos de pré-formulação mais aprofundados e de possíveis interações indesejadas nas fórmulas propostas propiciam produtos problemáticos”.

Apesar de acreditarem ser possível diferentes entendimentos para o que é a pré-formulação, Adeyeye e Brittain (2008) a consideram como um processo de caracterização das propriedades dos ingredientes farmacêuticos. Consideram ainda que restrições de tempo e recursos para o desenvolvimento dos medicamentos e a participação restrita dos formuladores (farmacotécnicos) no delineamento dos estudos de pré-formulação levam à relatórios de pré-formulação incompletos ou inadequados para o desenvolvimentos da formulação e/ou do processo de produção. Assim, as deficiências na pré-formulação podem levar à necessidade de levantamento de mais informações ou mesmo à necessidade de correção de formulações e, desta forma, resultar em retrabalho e até mesmo no abandono do projeto.

Para melhorar a contribuição dos estudos de pré-formulação para o desenvolvimento dos medicamentos, Adeyeye e Brittain (2008) sugerem antecipar o processo de desenvolvimento para que as atividades de pré-formulação apropriadas sejam incluídas no trabalho inicial. Também sugerem a utilização de recursos computacionais para auxílio na caracterização dos ingredientes.

O indicador relacionado às deficiências e/ou dificuldades para a realização de lotes piloto, prévalidação e predefinição dos parâmetros do processo de produção do novo medicamento (DP4) apresentou a segunda maior contribuição $(t=25,782)$ para o constructo Desenvolvimento. Há neste resultado pelo menos três possibilidades que o poderiam justificar. Primeiro, a dificuldade relacionada aos recursos, ou seja, à disponibilidade de equipamentos, materiais e pessoal para a produção dos lotes piloto, já que deve ser realizada em escala semi-industrial no ambiente da produção. Assim, é preciso 
ter a colaboração da área de produção para liberação do uso dos equipamentos e disponibilização dos operadores, por exemplo, cuja barreira é especificamente apontada pelo indicador OR4, que trata da dificuldade de apoio de outras áreas da organização e que será discutido mais adiante.

Outra resposta recebida na pesquisa qualitativa indica dificuldades na aprovação de quantidade de fármaco (IFA) suficiente para realização dos lotes pilotos. Ou seja, possivelmente relacionado aos custos, os lotes teriam dificuldades para serem produzidos nos volumes necessários para a realização dos testes de pré-validação e pré-definição do parâmetros de processo, por exemplo, os quais fornecem dados para que seja garantida a reprodutibilidade do processo no "scale-up" (escaloamento) para fabricação dos lotes em escala industrial.

A terceira possibilidade diz respeito a dificuldades relacionadas à produção dos lotes piloto, prévalidação e predefinição dos parâmetros do processo de produção do novo medicamento em si. Em outras palavras, dificuldades para conseguir produzir um medicamento (problema na formulação) e realizar a produção (problema no processo e/ou nos equipamentos) dentro dos parâmetros e requisitos estabelecidos pelas normas, ou mesmo reproduzir os resultados obtidos com os estudos em menor escala (lotes de bancada). Este pode ser considerado um dos pontos mais críticos do desenvolvimento, pois não é possível avançar para as próximas atividades do projeto se não houver um medicamento para os testes de estabilidade, equivalência e, se for o caso, bioequivalência.

A terceira maior contribuição $(t=22,125)$ para o construto Desenvolvimento foi apresentada pelo indicador referente à inexistência ou deficiências nos processos para desenvolvimento dos medicamentos (DP7). Embora o desenvolvimento de novos produtos seja realizado na forma de projeto, parte das ferramentas, técnicas, métodos e procedimentos pode ser comum para a maioria dos projetos, estabelecendo um padrão que pode ser tratado como um processo geral (Hinckeldeyn et al., 2010; Rozenfeld et al., 2006). Em atendimento às boas práticas de fabricação, que são parte obrigatória do sistema da qualidade farmacêutica, todos os processos empregados na produção de um medicamento devem ser documentados, principalmente na forma de procedimentos padronizados (Anvisa, 2019f). Assim, os profissionais desta indústria estão bastante habituados a ter procedimentos para todas as atividades produtivas.

Há que se considerar, no entanto, a característica única dos projetos, ou seja, dificilmente um processo ou procedimento geral irá abordar todas as peculiaridades de um projeto singular, podendo provocar uma percepção de inadequação e/ou incompletude. Os projetos em específico dependem, em certo grau, das decisões de seu gestor sobre as ações necessárias ao desenvolvimento adequado do medicamento. Diferenças nos requisitos e necessidades entre os PDMG podem até requerer abertura e flexibilidade dos processos para que os ajustes possam ser realizados mais eficientemente. Assim, não obstante a possibilidade das padronizações e orientações para os PDMG na forma de planos gerais ou estratégias serem realmente insuficientes, inadequados ou até mesmo inexistentes ou 
contraproducentes, pode também haver a percepção de que são não atendem às necessidades dos projetos como se tivessem que prever todas as situações específicas. Uma outra possível razão para a contribuição para o constructo Desenvolvimento pode ser também a divisão das atividades dos PDMG entre diferentes departamentos, o que dificultaria a organização e a gestão do processo de desenvolvimento dos medicamentos.

O indicador seguinte em termos de contribuição para o construto Desenvolvimento $(t=18,771)$ está relacionado a deficiências e/ou dificuldades na obtenção e/ou apresentação de dados e informações técnico-científicas dos medicamentos (DP3). Este indicador trata mais especificamente do levantamento do referencial teórico, da coleta e análise de dados empíricos e da apresentação e discussão dos resultados. Portanto, envolve uma das principais entradas para os PDMG que são as informações. Todos os projetos de desenvolvimento de produtos tem em suas fases iniciais algum levantamento de dados que são utilizados para avaliar preliminarmente as viabilidades técnica e econômica dos novos produtos e que depois vão se aprofundando e detalhando para suprir o próprio processo de desenvolvimento do produto (Dekkers et al., 2013; Hinckeldeyn et al., 2010). Esta obtenção de dados pode incluir a realização de engenharia reversa com o medicamento de referência (Bansal \& Koradia, 2005). Também envolve uma das principais saídas dos PDMG, que é o dossiê do medicamento desenvolvido, considerando que a avaliação dos pedidos de registro pela Anvisa é basicamente documental (Anvisa, 2017b). Assim, são fundamentais a adequada fundamentação, elaboração e apresentação dos dados nos dossiês de registro.

Esta deficiência em relação a dados e informações técnico-científicas podem estar relacionadas, por exemplo, às pressões de prazo que fazem com que os levantamentos de dados e as análises não recebam o tratamento necessário. Também pode estar relacionada à dificuldade de acesso a dados de qualidade provenientes da literatura técnico-científica e/ou dos próprios processos internos da empresa e do projeto, tanto por questões de acesso (ferramentas de pesquisa e bases de dados) quanto por dificuldade para o tratamento, análise e comunicação de dados e resultados. As dificuldades podem incluir também pouca familiaridade com publicações acadêmicas e até mesmo a possibilidade de barreira pela literatura técno-científica ser predominantemente na língua inglesa.

Com contribuição muito próxima do indicador anterior $(\mathrm{t}=18,653)$, a dificuldade no processo de transferência dos medicamentos do laboratório para a produção (escalonamento ou "scale up") (DP2) é mais comum quando os equipamentos utilizados na fase de desenvolvimento da formulação são significativamente diferentes dos utilizados na produção, muito embora problemas possam aparecer mesmo que os equipamentos só sejam diferentes no volume de produção (por exemplo, no tamanho do tanque). Além do problema da transferência em si, deficiências no escalomanento podem levar a simples ajustes no processo de fabricação ou mesmo à necessidade de revisão de todo o desenvolvimento. Deve-se considerar também as perdas, uma vez que o lote produzido nem sempre 
pode ser reprocessado, o que leva ao descarte de todo o lote produzido. Se o medicamento for de alto valor e/ou elevado volume de produção por lote, os custos podem ser bastante significativos.

$\mathrm{O}$ indicador referente à dificuldade no desenvolvimento da formulação (farmacotécnico) do medicamento (DP1) apresentou a segunda menor contribuição para o constructo Desenvolvimento $(\mathrm{t}=$ 15,800). De certa forma, não se esperava que este indicador apresentasse uma contribuição reativamente pequena, uma vez que esta atividade também é considerada uma das mais complexas dos PDMG (Genazzani \& Pattarino, 2008; Leon Shargel \& Kanfer, 2005), uma vez que são muitos os fatores a serem considerados na formulação de medicamento, desde as características do IFA até o requisito de desempenho equivalente ao do medicamento de referência. Formulações com falhas podem ter dificuldade para passar pelos testes de estabilidade, de equivalência e/ou de bioequivalência. Problemas na formulação também podem ser as causas dos problemas na transferência para os lotes industriais.

Entre as possíveis razões para este resultado pode também ser a departamentarização das partes do processo de desenvolvimento dos medicamentos, onde cada profissional da equipe do PDMG é responsável por apenas parte do processo, por exemplo, estudos de pré-formulação, formulação, estudos de estabilidade, estudos de equivalência farmacêutica e estudos de bioequivalência. Esta característica é muito próxima da abordagem do desenvolvimento sequencial, ou seja, tem como base os princípios da administração científica e adota a divisão de tarefas, o uso recursos especializados e a estruturação funcional da organização (Rozenfeld et al., 2006).

O indicador referente ao não uso ou ao uso inadequado de metodologias científicas para o desenvolvimento dos medicamentos (ex.: qualidade por meio do delineamento ou "quality by design" $\mathrm{QbD})$ (DP5) apresentou a menor contribuição para o constructo Desenvolvimento $(\mathrm{t}=13,430)$. São muito raros os casos relatados no Brasil de uso de técnicas mais avançadas no desenvolvimento de medicamentos. Um dos respondentes da pesquisa qualitativa indicou como ação necessária dar "ênfase no conhecimento do produto, em detrimento a simples abordagens arcaicas de 'tentativa e erro"'. O uso da abordagem de $\mathrm{QbD}$ deve aumentar gradativamente, principalmente em razão da Instrução Normativa $n^{\circ} 47$ recentemente publicada pela (Anvisa, 2019b) e que define o QbD como uma abordagem sistemática que enfatiza o conhecimento/entendimento dos produtos, dos processos e dos controles em processos com base científica e no risco da qualidade.

O que chama a atenção para este resultado é o fato dos respondentes enxergarem a falta de metodologias científicas como um fator que menos contribui para as ineficiências nos PDMG. É possível que este resultado seja em razão de que metodologias científicas para o desenvolvimento dos medicamentos de fato estão sendo usadas adequadamente. No entanto, isso parece não ser a realidade, pois há pelo menos duas barreiras para o uso da abordagem do QbD que estão intimamente relacionadas à sua aplicação e que foram identificadas pela análise dos dados coletados. Primeiro, a 
necessidade de sólido e profundo conhecimento dos medicamentos, suas formulações, seus processos de fabricação e de suas formas de controle. O indicador que trata da dificuldade de obtenção de dados e informações técnico-científicas (DP3) já dá conta desse problema. A segunda dificuldade está relacionada à gestão de riscos, não apenas o uso de técnicas e métodos, mas em parte pela falta de uma cultura de gerenciamento de riscos, a qual já foi comentada. O indicador específico sobre o gerenciamento de riscos (GT3) foi excluído do modelo por apresentar importância (alta carga fatorial) para mais de um constructo.

\subsection{Constructo Gestão}

Concluída a análise dos resultados para o constructo Desenvolvimento, serão analisados os resultados para o constructo com a segunda maior contribuição para o constructo Gerencial ( $\beta=$ 0,845), ou seja, o constructo exógeno Gestão. Este constructo é formado por 4 indicadores reflexivos:

- mudanças no projeto após o início do desenvolvimento do medicamento (GT2);

- deficiências e/ou dificuldades no gerenciamento dos projetos de desenvolvimento dos medicamentos (GT4);

- prazos muito curtos para o desenvolvimento dos medicamentos (GT5); e

- objetivo de custo final para produção e/ou preço-alvo de mercado muito baixo para o medicamento em desenvolvimento em razão do custo dos materiais e/ou processo de fabricação (GT6).

Entre estes indicadores, o relacionado às deficiências e/ou dificuldades no gerenciamento dos projetos de desenvolvimento dos medicamentos (GT4) apresentou a maior contribuição para o constructo Gestão $(t=27,310)$. Uma das respostas recebidas na pesquisa qualitativa dá o tom desta deficiência ao afirmar que a "cultura de gerenciamento de projetos ainda não permeia totalmente a indústria farmacêutica".

O desenvolvimento de métodos, técnicas e ferramentas de gerenciamento de projetos na área das ciências da vida só se estabeleceu de forma consistente a partir dos anos 1980 (Pete Harpum, 2010). A sua aplicação na indústria farmacêutica vem se desenvolvendo dentro do próprio PMI desde esta época. Estudos voltados especificamente para o gerenciamento de projetos farmacêuticos vem desde então sendo produzidas, tais como: Court e Fowler (2008), Garner (2014), Martin (2017), Nandeswara Rao e Jigeesh (2015) e Van Arnum (2012). A relação inclui livros como: Harpum (2010), ISPE (2011) e Kennedy (2008a). Estas publicações ressaltam a importância do gerenciamento de projetos para o desenvolvimento dos medicamentos.

O que chama atenção para este resultado, no entanto, é o fato de possivelmente existirem relevantes deficiências e/ou dificuldades no gerenciamento dos projetos, mesmo sendo uma prática tão importante e que deveria estar suficientemente desenvolvida a ponto de não ter influência negativa 
significativa sobre o desempenho dos PDMG. Há diferentes possibilidades não excludentes associadas a esta deficiência. Pode estar associada à falta de competência, experiência ou mesmo conhecimento de metodologias de gerenciamento aplicadas a PDMG. Neste caso, a causa também pode estar na falta de valorização da metodologia ou mesmo de conhecimento de que existem métodos e técnicas de gerenciamento de projetos que poderiam ajudar os PDMG. Mas para que isso tenha reflexos sobre os projetos de uma forma geral, este comportamento deve estar nos níveis acima dos projetos, pois envolvem políticas e estratégias que tem reflexos nos recursos e processos. Pode também haver uma cultura que não favorece o uso das metodologias de gerenciamento.

Além disso tudo, também pode haver o uso inadequado dos métodos, técnicas de ferramentas de gerenciamento de projetos. Neste caso, a questão estaria mais ao nível dos profissionais que atuam mais diretamente nos PDMG. Existe a possibilidade profissionais não serem adequadamente capacitados, o que exigia investimentos em treinamento e/ou na contratação de profissionais mais experientes no gerenciamento de projetos. Também existe a possibilidade das métodos, técnicas de ferramentas de gerenciamento de projetos não serem adequados ou mesmo restritivos. Como o setor é altamente regulamentado, controles e restrições são muito comuns e podem limitar o uso de determinados recursos, inclusive por receio dos próprios profissionais em inflingir as rígidas normas do setor. Por fim, pode haver a possibilidade das pressões relacionadas ao cronograma limitarem o adequado planejamento dos PDMG e, consequentemente, a execução, resultando em maior probabilidade de falhas.

$\mathrm{O}$ indicador relacionado às mudanças no projeto após o início do desenvolvimento do medicamento (GT2) apresentou a segunda maior contribuição $(t=23,440)$ para o constructo Gestão. Como já comentado, embora pareça estranho haver mudanças em projetos nos quais o escopo do produto é bem definido por se tratar de um medicamento genérico, este item apareceu na pesquisa qualitativa associado basicamente a duas possibilidades: mudanças na legislação e mudanças na estratégia.

A Anvisa vem atualizando a legislação para os medicamentos, principalmente em relação ao alinhamento com as práticas recomendadas pelo $\mathrm{ICH}$, com destaque para os guias: Q8 referente ao desenvolvimento de medicamentos (ICH, 2009), Q9 referente à gestão de riscos (ICH, 2005) e Q10 referente ao sistema da qualidade (ICH, 2008). Embora a legislação específica para o desenvolvimento de medicamentos já esteja relativamente estabelecida, melhorias sempre são possíveis, o que inclui a recente menção da Anvisa (2019b) ao uso da abordagem de QbD e que tem provocado a busca da indústria por aperfeiçoamento de seus processos de desenvolvimento de novos medicamentos.

As mudanças nas estratégias relacionadas aos PDMG em geral envolvem a priorização dos projetos e seus prazos para desenvolvimento, afetando mais diretamente a alocação dos recursos. Mudanças na estratégia também podem envolver o cancelamento de projetos, resultando muitas vezes 
em perdas financeiras e comprometimento do desempenho do portfólio de projetos como um todo. Como já comentando, mudanças nos projetos podem também ter origem nas atividades de análise e seleção dos projetos, o que envolve os estudos de viabilidade. Também podem estar relacionadas a estudos iniciais deficientes, como os de pré-formulação, fragilizando o planejamento e as decisões de projeto.

A terceira maior contribuição para o constructo Gestão $(t=12,010)$ foi dada pelo indicador relacionado a prazos muito curtos para o desenvolvimento dos medicamentos (GT5). Os projetos possuem um prazo ideal baseado no sequenciamento e nas estimativas de duração de suas atividades (PMI, 2017). Os PDMG tem um prazo relativamente longo. O estudo de Hajjar Júnior (2010), por exemplo, indicou um prazo estimado em 16 meses do início do projeto com os estudos de viabilidade até a preparação da documentação para o pedido de registro do novo medicamento genérico. $\mathrm{O}$ estabelecimento de prazos menores que os efetivamente necessários para os PDMG levam à compressão cronograma e, segundo o PMI (2017), pode ter consequências para a gestão dos projetos como aumento dos riscos e dos custos, como já visto anteriormente.

A restrição em relação aos prazos pode ser uma barreira para o aperfeiçoamento do processo de desenvolvimento dos medicamentos e para a diminuição das incertezas e dos riscos na medida em que dificulta a realização de estudos mais aprofundados que, por exemplo, são demandados pela abordagem do QbD. Além disso, pode também dificultar a realização de testes complementares que possam monitorar o andamento do projeto, assegurar a qualidade do desenvolvimento e do medicamento e assim aumentar a probabilidade de aprovação pela Anvisa.

O indicador relacionado ao objetivo de custo final para produção e/ou preço-alvo de mercado muito baixo para o medicamento em desenvolvimento em razão do custo dos materiais e/ou processo de fabricação (GT6) apresentou a menor contribuição $(t=10,190)$ para o constructo Gestão. Este é um item para o qual já se esperava uma menor contribuição. No entanto, o fato de ter apresentado carga significativa no constructo demonstra importância. A razão está no preço de venda ser um dos principais critérios para decisão de compra dos medicamentos genéricos, assim, o custo de produção do medicamento é fator crítico. Apesar de ser possível ajustar a margem de lucro para se chegar a um preço competitivo, dependendo do custo de produção, o ajuste pode ser limitado. O estabelecimento de um referencial de custo máximo para produção parte deste princípio.

\subsection{Constructo Portfólio}

O constructo exógeno Portfólio é o terceiro e último componente $(\beta=0,840)$ do constructo Gerencial. Ele é formado por 3 indicadores reflexivos:

- escolha inadequada e/ou equivocada dos medicamentos para o compor o portfólio de projetos a serem desenvolvimentos (PF1); 
- inexistência ou deficiências nos estudos de viabilidade técnica para escolha dos medicamentos a serem desenvolvidos (PF2); e

- inexistência ou deficiências na estrutura e/ou procedimento de acompanhamento e/ou controle dos projetos de desenvolvimento de medicamentos em andamento (PF3).

O indicador relacionado à inexistência ou deficiências nos estudos de viabilidade técnica para escolha dos medicamentos a serem desenvolvidos (PF2) apresentou a maior contribuição $(t=41,558)$ para o constructo Portfólio. Os estudos de viabilidade técnica são parte do processo de desenvolvimento de novos medicamentos como um pré-requisito para o início efetivo dos desenvolvimentos (De Paula, 2004; V. dos S. C. Yugue, 2014). Obviamente, se entram no portfólio projetos sem condições técnicas de serem desenvolvidas pela empresa, ou ele será abandonado nas fases seguintes ou terá grande dificuldade para que o produto final seja entregue, podendo consumir mais recursos e tempo do que o estimado inicialmente, os quais poderiam ter sido direcionados a projetos mais promissores. Há que se considerar também o seu efeito sobre a equipe do projeto no sentido das pressões para a conclusão destes projetos mais difíceis e de críticas sobre o desempenho menos eficiente.

Como já comentado, aparentemente este resultado indica desconexão entre as decisões de portfólio de projetos e a estrutura e as competências técnicas disponíveis. Pode ser por excesso de autoconfiança com relação ao sucesso do desenvolvimento, ou então por simples desconhecimento. Também indica possível centralização da decisão ou, pelo menos sem que haja a participação da área técnica responsável pelo desenvolvimento dos medicamentos. De qualquer forma, há evidente distanciamento das recomendações para gestão do portfólio de projetos, de integração para o desenvolvimento dos projetos (Griffin \& Hauser, 1996; Rozenfeld et al., 2006) e de gerenciamento das partes interessadas (PMI, 2017).

Com a segunda maior contribuição $(\mathrm{t}=40,924)$ para o constructo Portfólio, aparece o indicador relacionado à inexistência ou deficiências na estrutura e/ou procedimento de acompanhamento e/ou controle dos projetos de desenvolvimento de medicamentos em andamento (PF3). Neste item, há pelo menos dois aspectos a serem avaliados. O primeiro do ponto de vista da disponibilidade de informações sobre o progresso dos PDMG. As entregas dos PDMG são relativamente bem definidas, pois devem atender aos requisitos da legislação (Anvisa, 2017b), tais como: formulação, lotes piloto, testes de estabilidade e testes de equivalência e bioequivalência. Esta característica propicia o estabelecimento de um ciclo de vida do projeto usando estas entregas como marcos para o controle de seu andamento (Cooper, 1990), cujos relatórios de progresso podem ser utilizados para acompanhamento e análise do desempenho do portfólio de projetos (PMI, 2017). 
O segundo aspecto deste resultado, que não exclui o primeiro, seria a falta de uma rotina e/ou de empenho ou valorização do controle e acompanhamento dos PDMG do ponto de vista do portfólio de projetos. Mesmo havendo a disponibilidade de informações, o gestor do portfólio, ou o gerente da área de $\mathrm{P} \& \mathrm{D}$, ou o escritório de projetos ("PMO") ou mesmo um comitê de gestão não faz o acompanhamento adequado dos PDMG. Assim, a dificuldade estaria nas rotinas de controle e monitoramento dos projetos, podendo ter como causas a falta de procedimentos e de atividades específicas planejadas para tanto, ou mesmo pela falta de uma cultura de monitoramento e controle dos projetos. Este acompanhamento não envolve somente as análises de desempenho para decisões de suspensão ou prosseguimento dos PDMG (De Paula, 2004; Moreira \& Cheng, 2010), mas também o alinhamento com as estratégias de mercado e tecnológica e a destinação e redistribuição dos recursos (Henard \& Szymanski, 2001). Entre os possíveis resultados desta deficiência estão o uso ineficiente de recursos (pessoas, materiais e financeiros) e uma taxa reduzida de sucesso (ineficácia) (Griffin \& Page, 1996; Rozenfeld et al., 2006).

O terceiro e último indicador exógeno do constructo Portfólio $(\mathrm{t}=22,686)$ foi o relacionado à escolha inadequada e/ou equivocada dos medicamentos para o compor o portfólio de projetos a serem desenvolvidos (PF1). A análise das propostas e a decisão para aprovação de um novo projeto são centrais para a qualidade de um portfólio. Se a entrada não é adequadamente controlada, não se pode garantir que o projetos que estão dentro do portfólio sejam os melhores para a empresa. Há publicações como a de Sharpe e Keelin (1998) que tratam especificamente deste momento do desenvolvimento de novos produtos e os estudos de Braum (2014) e Moreira e Cheng (2010) tratam deste tema no contexto da indústria farmacêutica brasileira.

Pode-se considerar que o resultado deste indicador amplia o resultado obtido para a inexistência ou deficiências nos estudos de viabilidade técnica para escolha dos medicamentos a serem desenvolvidos (PF2). Isso porque a escolha dos PDMG não se limita a avaliar aspectos da viabilidade técnica, embora seja central para os projetos de desenvolvimento das formulações. Moreira e Cheng (2010) consideraram também a avaliação das patentes, a viabilidade financeira (retorno sobre os investimentos), a legislação sanitária e a relevância social. Um aspecto já levantado é a centralização de decisão. Se os aspectos técnicos não são considerados como já verificado, é plausível considerar que as decisões de portfólio de PDMG são tomadas possivelmente pelas áreas de marketing, comercial e/ou da alta administração, em conjunto ou isoladamente, mas sem ou com pouco poder e/ou participação da área de $\mathrm{P} \& \mathrm{D}$.

\subsubsection{Constructo Estrutural}

O constructo endógeno Estrutural é composto por 3 constructos exógenos (constructos de primeira ordem), ou seja (em ordem de decrescente de contribuição): constructo Organização ( $\beta=$ 0,897), constructo Competências $(\beta=0,862)$ e constructo Recursos $(\beta=0,857)$. A Figura 60 a seguir 
apresenta os resultados das análises para o constructo Estrutural e de suas relações com seus constructos exógenos.

Figura 60 - Constructo Estrutural e seus constructos exógenos Organização, Recursos e Competências $(\mathrm{n}=209)$

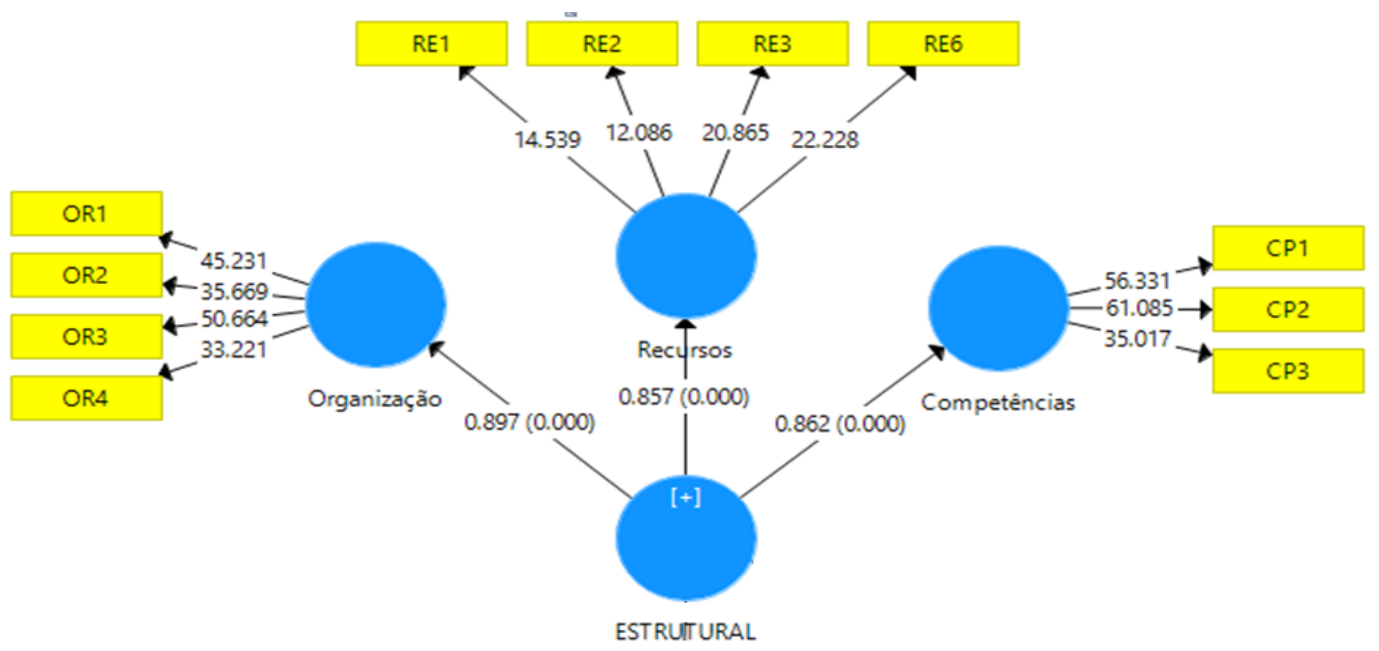

Nota: modelo de mensuração com os valores dos testes $t$ de Student e modelo estrutural com valores fora dos parênteses são coeficientes estruturais padronizados $(\beta)$ e os valores dentro dos parênteses são valores-p. Fonte: dados da pesquisa obtidos por meio do módulo Bootstrapping do SmartPLS ${ }^{\circledR}$ (2019).

Os constructos Organização, Competências e Recursos são formados basicamente por indicadores relacionados a fatores ambientais internos da empresa e que, segundo o PMI (2017, p. 66), se referem a condições que não estão sob o controle da equipe do projeto, mas que influenciam, restringem ou direcionam o projeto. No caso do constructo Estrutural, são condições internas à empresa e frequentemente fornecem dados de entrada para muitos processos do gerenciamento dos PDMG.

\subsection{Constructo Organização}

Embora apresentem coeficientes de caminho muito próximos, o maior foi apresentado pela relação entre os constructos Organização e Estrutural $(\beta=0,897)$. O constructo Organização é formado pelos indicadores reflexivos que representam as dificuldades ou deficiências relacionadas a:

- cultura da empresa ou organização (OR1);

- comunicação entre os profissionais e/ou entre as áreas da empresa que participam do desenvolvimento dos medicamentos (OR2);

- estrutura (organizacional) da empresa (OR3); e

- apoio de outras áreas e/ou dos superiores aos projetos de desenvolvimento dos medicamentos (OR4). 
Todos eles são relacionados aos fatores ambientais internos e à governança organizacional das empresas (PMI, 2017, p. 38-43). O indicador que apresentou a maior importância para a composição do constructo Organização $(t=50,664)$ foi o referente à estrutura (organizacional) da empresa (OR3). Rozenfeld e colaboradores (2006) explicam que é importante haver coerência e consistência entre todos os fatores que influenciam o DP, o que inclui, entre outros, a estratégia, a estrutura organizacional, os recursos, os processos e o tipo de cultura dominante na organização. O PMI (2017, p. 66) relaciona a estrutura organizacional entre os fatores ambientais internos às empresas que não estão sob o controle da equipe do projeto, mas que influenciam, restringem ou direcionam o projeto. Ainda segundo o PMI (2017, p. 70), o sistema organizacional resultante da interação de múltiplos fatores determina o poder, influência, interesses, competência e capacidade política das pessoas. Guo (2008) e Kalluri e Kodali (2014) são alguns dos pesquisadores que incluem a estrutura organizacional em seus modelos de desenvolvimento de produtos. Embora a influência das estruturas organizacionais seja tratada com certo detalhe pelo PMI (2017), este resultado surpreende de certa forma, pois é menos estudado que os aspectos do DP que compõem os demais indicadores do constructo Organização, como, por exemplo, a comunicação e o apoio de outras áreas e/ou superiores aos projetos.

Embora os PDMG tenham um sequência lógica de atividades com base principalmente nos requisitos regulatórios, com responsáveis por partes do processo e que muito se aproxima da abordagem do desenvolvimento sequencial, também apresentam componentes da abordagem da engenharia simultânea, na qual, segundo Rozenfeld e colaboradores (2006), a estrutura é composta por equipes multifuncionais de projeto lideradas por um gerente de projeto e que assumem algum grau de paralelismo entre as atividades de desenvolvimento.

Em específico para projetos de inovação na indústria farmacêutica brasileira, Yamaguishi (2014) observou em sua tese que, entre as melhores práticas, estaria na estrutura formada por uma equipe multidisciplinar de representantes de cada setor da empresa e que acompanha as diversas fases de desenvolvimento. Os laboratórios farmacêuticos normalmente possuem um departamento específico de $\mathrm{P} \& \mathrm{D}$, podendo incluir nele o desenvolvimento farmacotécnico (formulação), de método analítico, de embalagem e de inovação. Em geral, os gestores e os integrantes das equipe dos PDMG tem dedicação integral aos projetos.

Possivelmente esta alta importância dada à estrutura (organizacional) que não favorece e/ou dificulta os PDMG está relacionada a dois aspectos. Primeiro, o da dependência de recursos e atividades de outras áreas, que podem não priorizar ou atender adequadamente às necessidades dos PDMG. Entre estes recursos e atividades estão a aquisição de insumos (compras) e a realização dos testes de qualidade (controle de qualidade). Dependências podem gerar atrasos, riscos e, consequentemente, elevar a possibilidade de resultados insatisfatórios. 
A segunda possibilidade refere-se ao processo de tomada de decisão, uma vez que uma estrutura organizacional, além de alocar pessoas, também distribui funções e responsabilidades. Nesta possibilidade há dois componentes que são: a dependência de um processo inadequado para a tomada de decisão e a subordinação do projeto ou mesmo da área ou departamento de P\&D a outra, como, por exemplo, à área de produção ou industrial, ou mesmo à de marketing. Esta possibilidade pode trazer dificuldades aos PDMG em razão de, por exemplo, diferenças nos conhecimentos, nas competências e até mesmo nos interesses e nas prioridades.

Para o PMI (2017), como os projetos operam dentro das restrições impostas pela organização por meio de sua estrutura organizacional e estrutura de governança, para que o projeto possa se desenvolver de maneira eficaz e eficiente, o gerente do projeto precisa entender onde residem as responsabilidades e a autoridade dentro da organização. Isso o ajudaria a usar efetivamente e adequadamente seu poder, influência, competência, liderança e capacidade política no projeto.

O indicador que apresentou a segunda maior importância para a composição do constructo Organização $(t=45,231)$ foi o referente à cultura da empresa ou organização (OR1). Em específico para o desenvolvimento de produtos farmacêuticos, De Paula (2004) tem a cultura entre os componentes de seu modelo de referência. O PMI (2017) também relaciona a cultura organizacional entre os fatores ambientais internos às empresas que não estão sob o controle da equipe do projeto, mas que influenciam, restringem ou direcionam o projeto. Entre os itens relacionados à cultura organizacional estão: valores, crenças, normas culturais, estilo de liderança, ética e código de conduta. A importância dos fatores culturais aparecem claramente nas respostas recebidas na fase qualitativa da pesquisa.

De acordo com Rozenfeld e colaboradores (2006), o gerenciamento de projeto de DP é baseado na experiência das pessoas e é diferente entre as áreas funcionais em razão de culturas e padrões de trabalho próprios. A cultura também envolve valores, procedimentos e padrões diferentes, muitas vezes em um mesmo projeto, o que dificulta a integração e provoca a fragmentação do conhecimento e de informações.

Os resultados indicam haver contribuição de uma cultura que não favorece e/ou dificulta o desenvolvimento adequado dos medicamentos. Uma característica dos laboratórios produtos de genéricos é a priorização do volume de produção, do preço de venda e da diversificação de itens (Torres \& Souza, 2010). Moreira (2008) relata em sua dissertação que nas indústrias farmacêuticas nacionais há predominância da cultura da inovação incremental e reprodução de medicamentos já existentes, justificada à época pelo baixo nível de evolução tecnológica e pela escassez de recursos. Alguns indícios da influência da cultura aparecem em outros indicadores como, por exemplo, prazos muito curtos para os PDMG (prioridade para o lançamento) e falta de apoio de outras áreas ou departamentos (prioridade para a produção). Desta forma, na medida em que os requisitos regulatórios 
foram se tornando mais exigentes para a aprovação de um novo medicamento, mesmo que genérico, aparentemente resiste parte da cultura que considera os requisitos técnicos menos relevantes do que a obtenção de vantagem de mercado com o lançamento em menor tempo. Este pensamento teria influência, como já comentado, sobre a gestão e sobre a qualidade dos resultados dos projetos.

O indicador que apresentou a terceira maior importância para a composição do constructo Organização $(t=35,669)$ foi o referente às deficiências e/ou dificuldades na comunicação entre os profissionais e/ou entre as áreas da empresa que participam do desenvolvimento dos medicamentos (OR2). A comunicação é central para o desenvolvimento de projetos em geral, principalmente naqueles em que são envolvidas pessoas de funções, áreas e até mesmo organizações diferentes. $\mathrm{O}$ estudo realizado por Henard Szymanski (2001) dá suporte a esta relação ao indicar que elementos da diversidade funcional não estão diretamente relacionados ao desempenho de novos produtos por si só por haver efeitos moderadores da comunicação multifuncional.

O tema da comunicação em projetos de desenvolvimento de produtos já vem sendo estudado desde a década de 1960 (T. J. Allen, 1970) e continuou evoluindo com pesquisas como (em ordem cronológica): Ralph Katz (1982); Keller (1986); Ancona e Caldwell (1992); e Dougherty, Science e May (2008). Como já comentado, o relatório do PMSURVEY (PMI, 2014) apontou os problemas de comunicação como os mais comuns nos projetos em geral. $\mathrm{Na}$ atualidade, as comunicações em projetos continuam tendo destaque em novas abordagens como o desenvolvimento ágil de produtos (Cooper, 2019).

Cooper (2019) afirma que projetos de desenvolvimento mal sucedidos de produtos muito invariavelmente são resultantes de problemas na comunicação entre as áreas funcionais. O PMI (2017), por sua vez, afirma que as entregas de um projeto conforme planejado dependem da capacidade da equipe do projeto em manter uma comunicação proativa com as partes interessadas. Ocorre que nos PDMG há intensa interação, principalmente entre as áreas de desenvolvimento de produtos, de desenvolvimento de métodos analíticos e de controle de qualidade, uma vez que são responsáveis pelo atendimento a vários dos requisitos mandatórios para atendimento à legislação (Anvisa, 2017b) como, por exemplo, os testes de estabilidade do medicamento. Esta importância é destacada no modelo proposto por Mendigorri e coladoradoras (2016), onde as comunicações aparecem no processo de planejamento (no item denominado comunicação de atividades a serem realizadas) e no processo de relacionamento com outros departamentos (no item informações sobre $\mathrm{P} \& \mathrm{D}$ para o resto da empresa).

A comunicação envolve de forma mais intensa os participantes da equipe do projeto, muito embora um único profissional da área de P\&D possa ser o responsável por um PDMG como um todo e, assim, conduzir a maior parte das atividades planejadas e requerer suporte das outras áreas na forma de serviços e informações que não estiverem sob sua alçada. 
A falta de coordenação entre as áreas pode provocar não só atrasos, mas também a elevação dos riscos de resultados insatisfatórios para os PDMG. Rozenfeld e colaboradores (2006), Salgado e Dekkers (2018) e Boer e During (2001) defendem que deve-se facilitar a comunicação, a troca de informações, o entendimento e a coordenação entre as áreas envolvidas no DP com o objetivo de antecipar possíveis problemas e reduzir o tempo de desenvolvimento. Mesmo para os que não participam diretamente do projeto, há que haver comunicação com a equipe do projeto. Rozenfeld e colaboradores (2006), no entanto, comentam que, embora por um lado as tecnologias de comunicação estejam facilitando o relacionamento e contato entre pessoas e organizações, por outro lado, aumentam os desafios de integração.

Esta deficiência nas comunicações pode ter relação com a departamentalização do processo de desenvolvimento do medicamento, como já comentado nos resultados para os indicadores que abordam a reprovação dos pedidos iniciais de registro na Anvisa (ID3) e a dificuldade no desenvolvimento da formulação (farmacotécnico) do medicamento (DP1). Também pode ser influenciada pelas dificuldades em relação à estrutura organizacional (OR3). A estes se soma o resultado para o indicador que apresentou a menor importância relativa para a composição do constructo Organização $(t=33,221)$ e que faz referência à ausência ou insuficiência de apoio de outras áreas e/ou dos superiores aos projetos de desenvolvimento dos medicamentos (OR4).

As deficiências em relação ao apoio das outras áreas ou departamentos estão no mesmo âmbito dos indicadores destacados no parágrafo anterior. No entanto, há que se discutir também as deficiências no apoio de superiores e/ou da alta administração. Estes são em geral partes interessadas de grande relevância para os projetos de uma forma geral (PMI, 2017), não sendo diferente para os PDMG. No entanto, há aparentemente distanciamento da alta direção em relação aos PDMG. As deficiências no acompanhamento e/ou controle dos projetos de desenvolvimento de medicamentos em andamento (PF3) fornecem subsídio para esta suspeita.

Há algumas possibilidades para justificativas para esta falta de apoio. Uma pode estar exatamente na departamentarização por diferentes razões, começando por prioridades e interesses particulares de cada área e/ou de seu gestor. Pode envolver barreiras geradas pela própria estrutura organizacional e do processo de alocação dos recursos e de seus custos. Outra possibilidade pode envolver questões de ordem política. Também há que se considerar deficiências no gerenciamento dos projetos, tais como: deficiências no plano de aquisições, de alocação de recursos, no cronograma, nas comunicação e no engajamento das partes interessadas (PMI, 2017). Assim, há um componente importante que é a habilidade do responsável pelo projeto em negociar recursos e engajar as partes interessadas.

Também estão incluídas no âmbito das comunicações as reuniões de acompanhamento de um conjunto de projetos, em geral conduzidas pelos gestores das áreas de P\&D, gestores do escritório de 
projetos ("project management office" - PMO) e/ou por eventuais gestores de portfólio de projetos. Os resultados de outros indicadores, principalmente os relacionados ao constructo Portfolio sugerem ineficiências no acompanhamento dos projetos.

Em resumo, os resultados referentes aos indicadores do constructo Organização apoiados pelo resultados de outros indicadores apontam para falta de integração, coordenação e comunicação entre as várias partes que participam do projeto, influenciando assim o seu andamento e os seus resultados.

\subsection{Constructo Competências}

O constructo exógeno Competências é formado pelos indicadores reflexivos que representam as dificuldades ou deficiências relacionadas a:

- não ter domínio suficiente da tecnologia dos medicamentos (CP1);

- não ter domínio suficiente da tecnologia do processo de fabricação dos medicamentos (CP2); e

- não ter profissionais experientes e/ou com qualificação adequada em número suficiente para o desenvolvimento dos medicamentos (CP3).

O indicador que apresentou a maior importância para a composição do constructo Competências $(t=50,664)$ foi o referente à insuficiência de domínio da tecnologia do processo de fabricação dos medicamentos (CP2). Esta importância, de certa forma, não era esperada, considerando que as tecnologias utilizadas na fabricação dos medicamentos de referência já são conhecidos, uma vez que seus medicamentos de referência já são comerciazados há tempos. No entanto, como já comentado, há a possibilidade do uso de tecnologias específicas para o prcessamento das matérias-primas e para a produção de medicamentos que podem ser diferenciadas. Assim, as dificuldades com a tecnologia do processo de fabricação pode ter origem em barreiras de acesso à tecnologia relacionadas a eventuais proteções ainda existentes, tais como: patentes sobre processos de fabricação e equipamentos. Também podem estar relacionadas à dificuldade de aquisição de equipamentos em razão da relação custo-benefício desfavorável, por exemplo, um liofilizador que tem custo muito elevado. É alternativa para suprir esta deficiência a terceirização do processo específico ou de todo processo de produção do medicamento. Há também a possibilidade da dificuldade estar no fato do desenvolvimento do processo de produção necessitar da participação de outras áreas como as de engenharia e de produção.

O indicador que apresentou a segunda maior importância para a composição do constructo Competências $(t=56,331)$ foi o referente à insuficiência de domínio sobre a tecnologia dos medicamentos (CP1). A complexidade da tecnologia é fator dificultador quando, por exemplo, o medicamento de referência possui mecanismo diferenciado de liberação do fármaco. Como o medicamento genérico precisa apresentar o mesmo perfil de disponibilidade do fármaco do medicamento de referência, conseguir este mesmo desempenho pode ser um grande desafio (Genazzani \& Pattarino, 2008). Uma possibilidade para suprir esta deficiência é a contratação de 
serviços de consultoria, de assessoria técnica dos fabricantes dos insumos e/ou dos equipamentos de produção. Outra possibilidade seria a formação de parcerias para o desenvolvimento dos medicamentos, o que inclui as universidades, como o caso do Laboratório de Inovação e Desenvolvimento Farmacotécnico - Deinfar da Universidade de São Paulo (R. T. Yugue, Maximiano, et al., 2018).

O indicador referente à ausência de profissionais experientes e/ou com qualificação adequada em número suficiente para o desenvolvimento dos medicamentos (CP3) apresentou a relativamente menor importância para a composição do constructo Competências $(t=35,017)$. Esta insuficiência pode ser fruto da falta de treinamento especifico e até mesmo de experiência em sua aplicação, principalmente quando a tecnologia é nova para a empresa. Uma possível solução para esta deficiência seria a contratação de profissionais especializados e/ou com experiência na tecnologia, mesmo que temporariamente, até que se obtivesse o domínio da tecnologia. No entanto, a principal deficiência pode estar na insuficiência no número de profissionais, se considerada em conjunto com o indicador que apontou haver número de projetos acima da capacidade e/ou elevada diversidade de projetos de desenvolvimento de medicamentos.

\subsection{Constructo Recursos}

O constructo exógeno Recursos é formado pelos indicadores reflexivos que representam as dificuldades ou deficiências relacionadas a:

- dificuldade no desenvolvimento da embalagem para o medicamento (material, tecnologia e/ou fornecedor) (RE1);

- mudança de fornecedor de ingrediente farmacêutico ativo durante o desenvolvimento do medicamento (RE2);

- dificuldades na seleção e qualificação dos fornecedores de ingredientes farmacêuticos ativos (RE3); e

- dificuldades para contratação de profissionais e/ou serviços de terceiros para as atividades de desenvolvimento dos medicamentos (RE6).

O indicador que apresentou a maior importância para a composição do constructo Recursos $(t=$ 22,228 ) foi o referente às dificuldades para contratação de profissionais e/ou serviços de terceiros para as atividades de desenvolvimento dos medicamentos (RE6). O PMI (2017) considera que se os recursos não estiverem disponíveis devido a restrições tais como: fatores econômicos ou atribuição a outros projetos, desde que não haja violação de critérios legais, regulamentares, obrigatórios ou outros critérios específicos, o gerente e/ou a equipe de projeto podem ser obrigados a atribuir recursos alternativos que podem envolver competências ou custos diferentes. $\mathrm{O}$ resultado para este indicador possui as seguintes possíveis razões, entre outras: indisponibilidade de profissionais e/ou serviços de 
terceiros com os requisitos e/ou na quantidade demandados pelas empresas; dificuldades relacionadas ao processo de contratação; presença de barreiras relacionadas à cultura das empresas; e custos de contratação considerados elevados ou não previstos nos orçamentos.

Esta indisponibilidade para contratação de profissionais e/ou serviços de terceiros para as atividades de desenvolvimento dos medicamentos (RE6) é uma situação que dificulta a solução da ausência de profissionais experientes e/ou com qualificação adequada em número suficiente para o desenvolvimento dos medicamentos (CP3). Pode ser considerado coerente não ter a competência e ter dificuldade para contratar esta competência, ou seja, não se tem a competência, pois ela não está disponível no mercado. Uma alternativa para esta dificuldade, embora de médio e longo prazos, seria o desenvolvimento interno destes profissionais e destes serviços com programas específicos de treinamento e capacitação.

As dificuldades relacionadas ao processo de contratação também podem envolver o sistema de aprovação para a contratação, que pode encontrar resistências de seus responsáveis. Podem envolver o prazo necessário para o processo de contratação, que não atende ao cronograma do projeto. Podem ainda envolver outros requisitos do processo de contratação não necessariamente relacionados aos do projeto como, por exemplo, documentação dos profissionais e/ou das empresas.

Não há referências à questão cultural relacionada à contratação de profissionais e/ou serviços de terceiros, incluindo parcerias. É sintomático perceber que estudos que tratam do desenvolvimento de medicamentos no Brasil como os de Calixto e Siqueira Jr. (2008); Cunha e colaboradores (2016); Moreira (2008); e Nishijima, Biasoto e Lagroteria (2014) não enfatizarem a relação de cooperação ou parceria entre os laboratórios farmacêuticos, apesar de comentarem as parcerias com as universidades. Por esta constatação, parece plausível considerar que os laboratórios farmacêuticos não consideram os relacionamentos com terceiros no desenvolvimento de seus produtos, talvez por resistência ao compartilhamento de informações.

Pode-se também considerar que, se há deficiências e/ou dificuldades na comunicação entre as áreas da empresa que participam do desenvolvimento dos medicamentos (OR2); no gerenciamento dos projetos de desenvolvimento dos medicamentos (GT4); e na estrutura e/ou procedimento de acompanhamento e/ou controle dos projetos de desenvolvimento de medicamentos em andamento (PF3), é possível assumir que dificuldades também devam existir em relação à participação de terceiros nos PDMG. Outro possível entrave para a contratação de profissionais e/ou serviços de terceiros poderia estar relacionado aos custos, apesar da aparente ausência de restrições quanto à disponibilização de recursos de uma forma geral.

O indicador que faz referência às dificuldades na seleção e qualificação dos fornecedores de ingredientes farmacêuticos ativos - IFA (RE3) foi o segundo em importância $(t=20,865)$ para a composição do constructo Recursos. O IFA é o principal componente de um medicamento e é ele que 
influencia alguns dos principais requisitos para a aprovação de um medicamento genérico pela Anvisa. A busca pelo IFA que atenda aos requisitos regulatórios, às especificações da formulação e às necessidades de produção envolve todo o processo de aquisição de materiais, ou seja, pesquisar, avaliar e selecionar o fornecedor conforme o PMI (2017). Além disso, as normas pedem que o fornecedor de determinados insumos sejam qualificados (Anvisa, 2019b, 2019f). Como a grande maioria dos IFAs são importados, este processo é facilitado quando há um representante ou distribuidor estabelecido no Brasil. No entanto, invariavelmente, o IFA que atende às necessidades e requisitos do PDMG e tem condições técnicas e comerciais mais interessantes só está disponível no mercado externo, necessitando ser importado.

Um dos participantes da pesquisa qualitativa resume a dificuldade em relação aos fornecedores de ativos da seguinte forma: "há dificuldade de escolha dos insumos, pois é baseada apenas nos custos e não na relação custo/benefício". Para o profissional, o processo de escolha deveria levar em conta o histórico da empresa farmoquímica fabricante do IFA, sua capacidade de produção, atendimento às boas práticas de fabricação (com apresentação de certificado) e posse das licenças legais requeridas. Além disso, o laboratório deveria realizar uma auditoria prévia para qualificar o fornecedor já na fase de desenvolvimento. Este relato reforça a destacada dificuldade dos PDMG para a seleção adequada dos fornecedores dos IFAs.

Associado à seleção dos fornecedores, apesar de excluído, o indicador que trata da dificuldade de obtenção de informações sobre os ingredientes farmacêuticos ativos (IFA) disponibilizados pelo fabricante (principalmente as contidos no DMF - "Drug Master File"), ao apresentar cargas fatoriais altas no próprio constructo (Especificações Técnicas) e também nos constructos Desenvolvimento, Recursos, Requisitos do Projeto e Requisitos Regulatórios, apresentou importância para vários aspectos dos PDMG. Isso sem considerar ainda os requisitos comerciais, contratuais e operacionais para integração na cadeia logística. A dificuldade em relação ao fornecedor do insumo é agravada quando há necessidade de sua troca, principalmente em fases mais avançadas dos PDMG. A depender do impacto, o projeto pode ser abandonado e um novo projeto inicializado.

O indicador com a terceira maior importância $(t=14,539)$ para a composição do constructo Recursos foi o relacionado à dificuldade no desenvolvimento da embalagem para o medicamento (material, tecnologia e/ou fornecedor) (RE1). A escolha e/ou desenvolvimento da embalagem para uma grande parte dos produtos que são comercializados no varejo em geral considera basicamente os aspectos de "design" e de marketing. No caso dos medicamentos, a principal preocupação é com a proteção do produto, em especial na prevenção de sua degradação, ou seja, com sua estabilidade (Anvisa, 2019b, 2019c, 2019f). Por exemplo, medicamentos que se degradam mais facilmente na presença de oxigênio (oxidação) necessitam de uma embalagem que seja totalmente impermeável ao ar (gases). Além disso, o material da embalagem não deve reagir e/ou interagir com o medicamento e 
ser adequado ao processo de embalagem, aos equipamentos em especial. Sempre que fornecidos por terceiros, os fornecedores também devem ser qualificados (atender aos requisitos), além de confiáveis para atendimento à demanda e a contratos de longo prazo. Não se deve esquecer que a embalagem deve facilitar a aplicação e/ou uso do medicamento. Assim, por exemplo, muitas vezes são necessários tipos especiais de válvulas aplicadoras, em especial na forma de spray ou aerossol, quando a quantidade a ser liberada deve ser exata.

O quarto e último indicador que compôs o constructo Recursos foi o relacionado à mudança de fornecedor de ingrediente farmacêutico ativo durante o desenvolvimento do medicamento (RE2). Como a formulação e o processo de produção dos medicamentos dependem muito das características do IFA, mudanças durante o PDMG podem significar o início de um novo projeto e não somente mudanças no projeto que estava sendo desenvolvido, com consequentes perdas de recursos e de tempo. Daí a importância da escolha correta do IFA, com testes adequados de pré-formulação e de um fornecedor confiável.

\subsubsection{Constructo Técnico}

O constructo endógeno Técnico é composto por 3 constructos exógenos (constructos de primeira ordem), ou seja (em ordem de decrescente de contribuição): constructo Especificações Técnicas $(\beta=0,921)$, constructo Requisitos Regulatórios $(\beta=0,816)$ e constructo Requisitos do Projeto $(\beta=0,794)$. A Figura 61 a seguir apresenta os resultados das análises para o constructo Técnico e de suas relações com seus constructos exógenos.

Figura 61 - Constructo Técnico e seus constructos exógenos Requisitos do Projeto, Especificações

Técnicas e Requisitos Regulatórios ( $\mathrm{n}=209)$

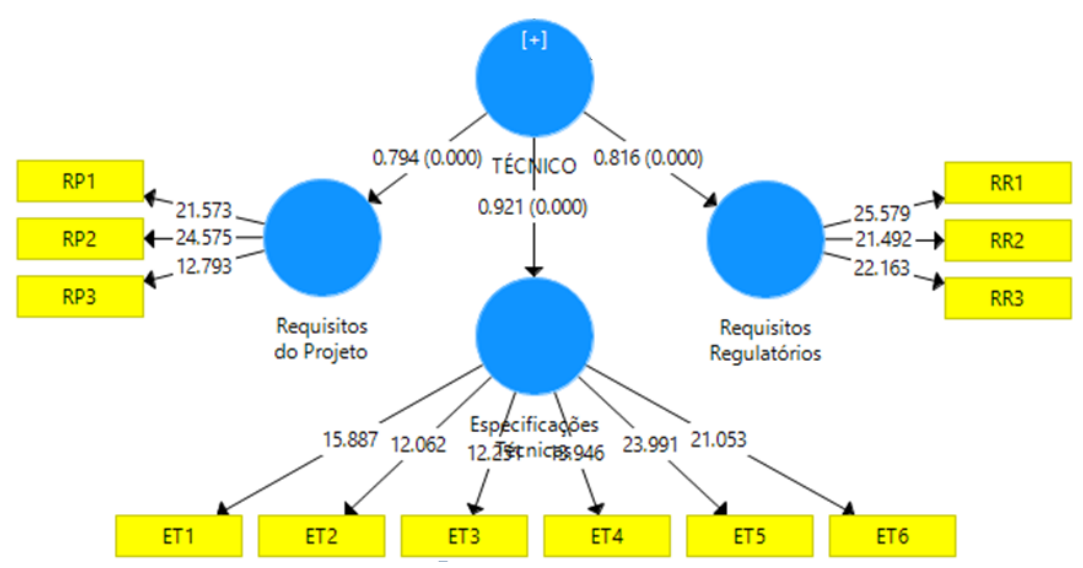

Nota: modelo de mensuração com os valores dos testes $t$ de Student e modelo estrutural com valores fora dos parênteses são coeficientes estruturais padronizados $(\beta)$ e os valores dentro dos parênteses são valores-p. Fonte: dados da pesquisa obtidos por meio do módulo Bootstrapping do SmartPLS ${ }^{\circledR}(2019)$.

Os constructos exógenos Requisitos Regulatórios e Especificações Técnicas contribuintes para o constructo endógeno Técnico são formados basicamente por indicadores relacionados a fatores externos à empresa e que se referem a condições que, segundo o PMI $(2017$, p. 66), não estão sob o 
controle da equipe do projeto, mas que influenciam, restringem ou direcionam o projeto. No caso do constructo Requisitos do Projetos, estes dependem das características intrínsecas dos PDMG e que normalmente estão somente parcialmente sob controle da equipe do projeto.

\subsection{Constructo Especificações Técnicas}

Fazem parte dos indicadores reflexivos do constructo Especificações Técnicas as dificuldades ou deficiências relacionadas a:

- práticas de garantia da qualidade (ex.: dificuldade nas validações e/ou qualificações) (ET1);

- realização dos estudos de bioequivalência e/ou biodisponibilidade dos medicamentos (ET2);

- realização dos estudos de dissolução dos medicamentos (ET3);

- realização dos estudos de equivalência farmacêutica dos medicamentos (ET4);

- desenvolvimento e validação dos métodos analíticos dos medicamentos (ET5); e

- realização dos estudos de estabilidade, de fotoestabilidade, de produtos de degradação e/ou na obtenção da estabilidade do medicamento (ET6).

Todos são requisitos técnicos exigidos pela legislação (Anvisa, 2017b).

$\mathrm{O}$ atendimento aos requisitos técnicos obrigatórios para os medicamentos genéricos estão entre os mais difíceis (Genazzani \& Pattarino, 2008), principalmente por que em geral são também critérios empregados pelo órgão regulador para aprovação do registro do novo medicamento, portanto, não flexíveis. Os indicadores referentes às dificuldades na realização dos estudos de bioequivalência e/ou biodisponibilidade dos medicamentos e na realização dos estudos de estabilidade com resultados satisfatórios estão entre os mais complexos requisitos a serem atendidos pelos PDMG e entre as causas mais frequentes de indeferimento dos pedidos de registro (Do Carmo, Piras, et al., 2017), pois dependem da combinação de um conjunto de variáveis envolvendo ingredientes, formulação, processo de fabricação e embalagem.

Ainda conforme a pesquisa de Do Carmo, Piras e colaboradores (2017), as três razões mais frequentes para o indeferimento dos pedidos de registro de medicamentos genéricos e similares (controle de qualidade do medicamento, estudo de estabilidade do medicamento e descumprimento dos prazos) curiosamente não são itens específicos para medicamentos genéricos como, por exemplo, os estudos de equivalência e bioequivalência. Dos três, pelos critérios adotados neste estudo, dois são de ordem técnica e eram indicadores do constructo Técnico original. O indicador ET7 referente à dificuldade no estabelecimento das especificações e/ou realização dos testes para o controle de qualidade dos medicamentos foi excluído por sua carga fatorial em mais de um constructo e não por não ter relação com o constructo.

Com excessão do indicador relacionado às práticas de garantia da qualidade (ex.: dificuldade nas validações e/ou qualificações) (ET1), que não necessita ocorrer em momento predefinidos no 
cronograma, todos os demais indicadores contribuintes para o constructo Especificações Técnicas possuem entregas que podem ser utilizadas como marcos dentro do ciclo de vida de um PDMG, uma vez que o prosseguimento do projeto depende de resultados positivos para os testes e avaliações que representam. De acordo com o PMI (2017), os ciclos preditivos de vida dos projetos são caracterizados por sua ênfase na especificação de requisitos e planejamento detalhado logo nas fases iniciais do projeto. Os planos detalhados e desenvolvidos com base nos requisitos e nas restrições identificadas contribuem para a redução dos riscos e dos custos, além de, por meio do planejamento de marcos de controle, facilitar a comunicação e o envolvimento das principais partes interessadas.

O indicador referente às dificuldades no desenvolvimento e validação dos métodos analíticos dos medicamentos (ET5) apresentou a maior relação com o constructo Especificações Técnicas $(t=$ 23,991). Há pelo menos quatro razões não excludentes para estas dificuldades. A primeira relacionada a própria complexidade para o desenvolvimento e validação dos métodos analíticos para o medicamento desenvolvido, especialmente quando há a necessidade de uso de técnicas mais sofisticadas. A segunda possibilidade está relacionada à falta das competência necessárias para o desenvolvimento e validação dos métodos analíticos. A terceira possibilidade pode estar na falta e na dificuldade de aquisição de recursos adequados, tais como: equipamentos e suprimentos. Por fim, como muitas vezes o desenvolvimento e validação analíticos estão sob responsabilidade de uma área ou departamento diferente do de $\mathrm{P} \& \mathrm{D}$, a dificuldade pode estar na priorização e no empenho para as suas realizações.

Estas quatro razões também podem ser aplicadas aos resultados para os demais indicadores relacionados a (em ordem decrescente de contribuição para o constructo Especificações Técnicas): realização dos estudos de estabilidade, de fotoestabilidade, de produtos de degradação e/ou na obtenção da estabilidade do medicamento (ET6) $(t=21,063)$; realização dos estudos de equivalência farmacêutica dos medicamentos (ET4) $(t=18,946)$; práticas de garantia da qualidade (ex.: dificuldade nas validações e/ou qualificações) (ET1) $(t=15,887)$; realização dos estudos de dissolução dos medicamentos $(\mathrm{ET} 3)(t=12,251)$; e realização dos estudos de bioequivalência e/ou biodisponibilidade dos medicamentos (ET2) $(t=12,062)$.

A razão mais frequente na pesquisa de Do Carmo, Piras e colaboradores (2017) para o indeferimento dos pedidos de registro de medicamentos genéricos e similares é relacionado ao indicador ET6, que faz referência à dificuldade na realização dos estudos de estabilidade, de fotoestabilidade, de produtos de degradação e/ou na obtenção da estabilidade do medicamento. Ele é o segundo indicador em importância $(t=14,539)$ para a composição do constructo Especificações Técnicas. Dada a criticidade deste requisito, a Anvisa possui uma resolução específica para os estudos de estabilidade de IFAs e medicamentos, a RDC 318/2019 (Anvisa, 2019c), que tem como referência o guia do ICH (ICH, 2003) sobre este tema. Dados referentes aos estudos de estabilidades estão 
também entre os motivos mais frequentes de problemas no programa de pré-qualificação de medicamentos genéricos da OMS (Worku et al., 2012).

\subsection{Constructo Requisitos Regulatórios}

O constructo Técnico tem a segunda maior correlação $(\beta=0,816)$ com o constructo Requisitos Regulatórios, que é formado pelo indicadores reflexivos que fazem referência às dificuldades ou deficiências relacionadas a:

- o atendimento da legislação sanitária para o desenvolvimento e/ou registro de medicamentos genéricos (RR1);

- a elaboração do dossiê para registro dos medicamentos (RR2); e

- o atendimento às exigências da Anvisa durante o processo de análise dos pedidos de registro dos medicamentos (RR3).

O indicador relacionado ao atendimento à legislação sanitária para o desenvolvimento e/ou registro de medicamentos genéricos (RR1) apresentou a maior contribuição para o constructo Requisitos Regulatórios $(t=25,579)$. Este resultado pode ter relação com as próprias dificuldades no desenvolvimento dos PDMG, pois muitos requisitos regulatórios são baseados nas características técnicas do medicamento e em seu processo de desenvolvimento. Também pode estar relacionado à percepção dos respondentes quanto à complexidade e rigidez da legislação para o registro dos medicamentos genéricos. Um outro problema relacionado ao atendimento à legislação sanitária apontado na pesquisa qualitativa fiz respeito a mudanças na legislação.

A pesquisa de Do Carmo, Piras e colaboradores (2017) apontou o descumprimento dos prazos do processo de registro como terceira razão mais frequente para o indeferimento dos pedidos de registo dos medicamentos. Esta constatação está incluído no âmbito do indicador que versa sobre as deficiências e/ou dificuldades no atendimento às exigências da Anvisa durante o processo de análise dos pedidos de registro dos medicamentos (RR3). Kennedy (2008b) indica que o não cumprimento dos prazos de envio do dossiê de registro para vários projetos pode ser resultante de recursos inadequados, gerenciamento inadequado, falha na priorização ou falha nas entregas pelos departamentos funcionais. Estas referências reforçam alguns dos resultados desta pesquisa como: a insuficiência e/ou deficiência em relação aos recursos; à integração e à participação de outras áreas ou departamentos; e à gestão do portfólio de PDMG.

Um aspecto sobre os requisitos regulatórios que necessita ser destacado é que normalmente são de responsabilidade da área de assuntos regulatórios da empresa, saindo do âmbito da área de $\mathrm{P} \& \mathrm{D}$. Se para os outros indicadores as outras deficiências e insuficiência encontradas nos PDMG poderiam ser resultado de faltas das áres que apoiam a de $\mathrm{P} \& \mathrm{D}$, no caso deste indicador, a área de $\mathrm{P} \& \mathrm{D}$ é que pode não estar apoiando adequadamente a área de assuntos regulatórios com informações e resultados, tanto 
para a elaboração do dossiê para registro dos medicamentos (RR2), quanto para o atendimento às exigências da Anvisa durante o processo de análise dos pedidos de registro dos medicamentos (RR3).

O estudo de Do Carmo, Piras e colaboradores (2017) corrobora com esta suspeita ao destacar, entre as razões para a rejeição dos pedidos, a ausência de documentos e/ou de testes obrigatórios nos processos de registro dos medicamentos. Este tipo de deficiência pode ter basicamente cinco possíveis razões. Primeira razão, os requisitos e testes não foram efetivamente realizados e/ou cumpridos, ou o foram, mas sem sucesso ou de maneira incorreta, o que configuraria deficiência nos próprios PDMG. Do Carmo, Piras e colaboradores (2017) acreditam que, por exemplo, a ausência não justificada de dados do teste de degradação forçada na documentação para registro do novo medicamento poderia indicar a falta de planejamento adequado no desenvolvimento do medicamento. Segunda razão, os testes e/ou requisitos foram efetivamente realizados e/ou cumpridos, mas não foram relatados e/ou demonstrados adequadamente ou a tempo, o que configuraria uma deficiência das funções regulatórias da empresa envolvendo, desta forma, a gestão dos documentos e do processo de solicitação de registro.

Terceira razão, a empresa não tem condições de atender as exigências da agência por restrições relacionadas mais diretamente à organização (externas ao projeto). Quarta razão, Do Carmo, Piras e colaboradores (2017) avaliam que a alta proporção de pedidos rejeitados indica também uma lacuna entre as expectativas regulatórias da Anvisa e as estratégias de desenvolvimento e submissão dos laboratórios farmacêuticos. A última possível razão estaria relacionada a dificuldades no entendimento das exigências da agência, ou mesmo a dificuldades de comunicação, que afetariam o atendimento às exigências. Estas razões também se aplicam aos indicadores que validaram as contribuições das dificuldades no atendimento à legislação sanitária para o desenvolvimento e/ou registro de medicamentos genéricos (RR1) e as contribuições das deficiências e/ou dificuldades na elaboração dossiê para registro dos medicamentos (RR2).

\subsection{Constructo Requisitos do Projeto}

O terceiro constructo exógeno do constructo Técnico é o referente aos Requisitos do Projeto, que apresentou o relativamente menor coeficiente de caminho em sua relação com o constructo Técnico $(\beta=0,794)$. Integram este constructo os indicadores que mensuraram as dificuldades relacionadas a:

- os custos elevados para desenvolvimento dos medicamentos (RP1);

- o longo tempo necessário para o desenvolvimento dos medicamentos (RP2); e

- o risco de insucesso no desenvolvimento do medicamento e de indeferimento do registro (incertezas) (RP3).

Há na literatura muitas publicações que tratam das dimensões de custo, prazo e riscos em projetos de desenvolvimento de medicamentos inovadores como ,por exemplo, os artigos de DiMasi, 
Hansen e Grabowski (2003); Sharpe e Keelin (1998); e Wu (2016). No entanto, apenas a dimensão prazo é abordada na literatura sobre o desenvolvimento dos medicamentos genéricos, considerando que os primeiros a lançar um novo produtos obtém importante vantagem competitiva (Chongprasert, 2016; Prašnikar \& Škerlj, 2006; Leon Shargel \& Kanfer, 2005; Sharma, 2012; Yousefi et al., 2017).

Gestão dos custos, do cronograma e dos riscos são dimensões do gerenciamento de projetos já consagradas na literatura, em especial pelo PMI (2017). Elas estão presentes nos resultados da pesquisa qualitativa. Os custos elevados (RP1) aparecem associados aos testes de bioequivalência que realmente demandam recursos consideráveis por envolverem estudos clínicos nos quais o medicamento é aplicado em pacientes voluntários. Os custos também apareceram em respostas preocupadas com a expectativa de seu crescimento em razão, principalmente, do aumento das exigências regulatórias.

Os resultados da pesquisa qualitativa também apresentam referências aos prazos em duas abordagens. A primeira em relação ao longo tempo necessário ao desenvolvimento de novos medicamentos. Como pode ser observado nas Figuras 10 e 11, o ciclo de vida dos PDNG envolve várias fases às quais estão associadas um grande número de entregas que, em geral, são respostas a demandas regulatórias e cujas atividades idealmente não podem ser realizadas em paralelo para compressão do prazo. A segunda abordagem diz respeito ao prazo definido pela alta administração como requisito a ser atendido pelo projeto e que é percebido muitas vezes pelos membros dos PDMG como irreais por serem muito reduzidos.

De acordo com o PMI (2017), a redução prazo de um projeto pode se dar de duas formas básicas não excludentes: a compressão e o paralelismo. Na compressão são alocados mais recursos (pessoas, equipamentos, etc.) para que as atividades possam ser realizadas em prazos menores. A contrapartida desta técnica é a elevação dos custos. No paralelismo, atividades que deveriam ser executadas sequencialmente em razão de pré-requisitos ou boas práticas passam a ser realizadas em paralelo, ou seja, ao mesmo tempo, ignorando os pré-requisitos.

Outro aspecto a ser considerado tem relação com o equilíbrio entre restrições conflitantes ("trade-offs), ou seja, entre escopo, prazo, custo, qualidade e riscos (PMI, 2017). A priorização do cronograma de um PDMG pode também significar deixar em segundo plano a qualidade, que é fator crítico para a aprovação do medicamento (Adeyeye \& Brittain, 2008; Prašnikar \& Škerlj, 2006).

O risco de insucesso no desenvolvimento do medicamento e de indeferimento do registro (RP3) foi citado por diversas vezes nas respostas recebidas pela pesquisa qualitativa, mais frequentemente no sentido da falta da gestão dos riscos e, em alguns casos, como necessidade de melhoria. Como comentado anteriormente, a gestão de riscos já é estudada no âmbito do gerenciamento de projetos há bastante tempo (PMI Standards Committee, 1996). Além disso, há um guia elaborado pelo (ICH, 
2005) específico para o gerenciamento de riscos de qualidade na indústria farmacêutica e está também presente no próprio (ICH, 2009) sobre o desenvolvimento de medicamentos associado ao conceito de QbD. No entanto, pelos resultados da pesquisa qualitativa, aparentemente o gerenciamento de riscos ainda tem espaço para desenvolvimento nos projetos da indústria farmacêutica brasileira.

É importante também registrar que o gerenciamento de riscos, muito além de ser um item relevante para a melhoria dos resultados dos PDMG, é hoje um requisito mandatório para a indústria farmacêutica brasileira em razão da recém publicada RDC 301 (Anvisa, 2019f), que trata do sistema de qualidade farmacêutico e que apresenta grande número de requisitos atrelados à gestão dos riscos.

Concluída a análise dos constructos e das relações com seus indicadores, a seguir são apresentados e discutidos os resultados da análise do modelo estrutural e das hipóteses da pesquisa.

\subsubsection{Análise do modelo estrutural}

A análise do modelo estrutural testou as relações entre os constructos que o compõem. Esta análise respondeu ao quarto objetivo específico ao qual estão atreladas as três primeiras hipóteses formuladas ( $\mathrm{H} 1, \mathrm{H} 2$ e $\mathrm{H} 3)$ para este estudo. Basicamente, foram avaliadas as influências das dificuldades gerenciais, técnicas e estruturais (variáveis independentes) sobre o desempenho dos PDMG fora do planejados (variável dependente). O modelo estrutural também considerou os efeitos mediadores das dificuldades gerenciais para as influências das dificuldades técnicas e das dificuldades estruturais sobre o desempenho fora do planejados dos PDMG. Estes efeitos mediadores estão atrelados às hipóteses H4 e H5.

\subsection{Análise de multicolinearidade}

O valores calculados para o VIF ("Variance Inflation Factor", fator de inflação da variância) foram empregados na análise de multicoliearidade. Hair Jr. e colaboradores (2017) adotam como parâmetro de aceitação valores do VIF inferiores 5,00 e que indicariam a ausência de multicolinearidade e a manutenção dos constructos do modelo. A Tabela 61 apresenta os valores do VIF calculados por meio do SmartPLS ${ }^{\circledR}$ (2019). Os resultados indicam a ausência de multicolinearidade e valida os constructos para a composição do modelo proposto.

Tabela 61 - Valores do VIF (fator de inflação da variância) $(n=209)$

\begin{tabular}{|c|c|c|}
\hline & Desempenho & Gerencial \\
\hline Estrutural & 2,601 & 1,660 \\
\hline Gerencial & 3,810 & - \\
\hline Técnico & 2,446 & 1,660 \\
\hline
\end{tabular}

Fonte: dados da pesquisa calculados pelo programa SmartPLS® (2019), tendo por referência Hair Jr e colaboradores (2017). 


\subsection{Coeficiente de determinação de Pearson $\left(R^{2}\right)$}

O coeficiente de determinação de Pearson $\left(\mathrm{R}^{2}\right)$ é adotado como uma medida da acurácia preditiva do modelo estrutural por representar os efeitos combinados dos constructos exógenos sobre os endógenos, sendo calculado como a correlação quadrada entre os valores reais e preditivos de um constructo endógeno (Hair Jr et al., 2017, p. 198). Em outras palavras, avalia a porção da variância das variáveis endógenas que é explicada pelo modelo estrutural. Este coeficiente indica a qualidade do modelo ajustado (Bido \& Da Silva, 2019). A Tabela 62 apresenta os valores do coeficiente de determinação ou poder de explicação $\left(\mathrm{R}^{2}\right)$; o tamanho do efeito ou indicador de Cohen $\left(\mathrm{f}^{2}\right)$; e a relevância preditiva ou indicador de Stone-Geisser $\left(\mathrm{Q}^{2}\right)$ para o modelo estrutural proposto.

Tabela 62 - Coeficiente de determinação $\left(\mathrm{R}^{2}\right)$, tamanho do efeito $\left(\mathrm{f}^{2}\right)$ e relevância preditiva $\left(\mathrm{Q}^{2}\right)(\mathrm{n}=$ 209)

\begin{tabular}{|c|c|c|c|c|c|c|}
\hline & \multicolumn{2}{|c|}{$\overline{\mathbf{R}^{2}}$} & \multicolumn{2}{|r|}{$\overline{Q^{2}}$} & \multicolumn{2}{|c|}{$\mathbf{f}^{2}$} \\
\hline Competências & 0,743 & & 0,550 & & 0,511 & \\
\hline Desempenho & 0,141 & Médio & 0,066 & Satisfatória & 0,320 & \\
\hline Desenvolvimento & 0,877 & & 0,445 & & 0,390 & \\
\hline Especificações Técnicas & 0,849 & & 0,407 & & 0,324 & \\
\hline Gestão & 0,714 & & 0,345 & & 0,223 & \\
\hline Organização & 0,805 & & 0,558 & & 0,525 & \\
\hline Portfolio & 0,706 & & 0,453 & & 0,352 & \\
\hline Recursos & 0,734 & & 0,372 & & 0,259 & \\
\hline Requisitos do Projeto & 0,630 & & 0,339 & & 0,189 & \\
\hline Requisitos Regulatórios & 0,666 & & 0,390 & & 0,252 & \\
\hline Gerencial & 0,738 & Grande & 0,304 & Satisfatória & 0,354 & Grande \\
\hline Estrutural & $*$ & & $*$ & & 0,406 & Grande \\
\hline Técnico & * & & $*$ & & 0,295 & Médio \\
\hline
\end{tabular}

Nota: *não aplicável - Variável Explicativa. Fonte: dados da pesquisa calculados pelo programa SmartPLS ${ }^{\circledR}$ (2019), tendo por referência Bido e Da Silva (2019) e Hair Jr e colaboradores (2017).

Diante dos valores da Tabela 61, verifica-se que os coeficientes de $\mathrm{R}^{2}$ apresentam efeitos médios e grandes, considerando os parâmetros para a área de ciências sociais e comportamentais de Cohen (1988), que propõe que $R^{2}=2 \%$ seja classificado como efeito pequeno, $R^{2}=13 \%$ como efeito médio e $\mathrm{R}^{2}=26 \%$ como efeito grande. Analisando o principal constructo dependente do modelo (Desempenho), o $\mathrm{R}^{2}$ de 0,141 indica que $14,1 \%$ das variações ocorridas no desempenho do projeto fora do planejado podem ser explicadas pelas variações ocorridas nas dificuldades gerenciais, estruturais e técnicas. De acordo com os critérios de Cohen (1988, p. 413), este pode ser considerado um efeito médio que, ainda segundo o pesquisador, pode parecer uma porcentagem insignificante de variação quando um conjunto composto por várias variáveis é usado. No entanto, lembra que são referentes a valores populacionais que não estão sujeitos à inflação (sobreajuste dos mínimos quadrados) que requer correção para o encolhimento de uma amostra $\mathrm{R}^{2}$.

Assim, com base neste resultado de $\mathrm{R}^{2}$, pode-se considerar que o coeficiente de determinação é adequado para a validação do modelo. 


\subsection{Tamanho do efeito $\left(f^{2}\right)$}

De acordo com Hair Jr. e colaboradores (2017), o tamanho do efeito (f $\left.{ }^{2}\right)$ avalia a alteração no valor de $\mathrm{R}^{2}$ de um constructo endógeno quando um constructo exógeno é omitido do modelo, ou seja, se o construto omitido tem um impacto substantivo nas construções endógenas. Segundo Bido e Da Silva (2019), o f $\mathrm{f}^{2}$ pode ser avaliado pela razão entre a parte explicada pelo modelo e a parte não explicada $\left(f^{2}=R^{2} /\left(1-R^{2}\right)\right.$. Cohen (1988) e Hair Jr. e colaboradores (2017) consideram os $\mathrm{f}^{2} \mathrm{de} 0,02$, 0,15 e 0,35 como pequeno, médio e grande, respectivamente.

Os resultados para o modelo proposto (Tabela 61) indicam que os constructos Estrutural $(0,406)$ e Gerencial $(0,354)$ apresentam grande efeito e que o constructo Técnico $(0,295)$ apresenta efeito médio. Esses resultados permitem dizer que os constructos são úteis para o ajuste do modelo, sendo que o constructo Estrutural exerce maior influência que o constructo Gerencial e este, por sua vez, maior influência que o constructo Técnico.

\subsection{Relevância preditiva $\left(Q^{2}\right)$}

O cálculo da relevância preditiva foi realizado por meio do procedimento "blindfolding" do SmartPLS $^{\circledR}$ (2019) que reusa a amostra omitindo os dados dos indicadores de cada constructo e utilizando as estimativas do modelo, mais especificamente dos dados remanescentes dos demais constructos, para predizer os dados omissos do respectivo constructo. Assim, quanto à relevância ou validade preditiva, como os valores de $\mathrm{Q}^{2}$ obtidos foram superiores a 0 (Tabela 61), foram considerados satisfatórios (Hair Jr. et al., 2017).

Assim, a interpretação dos valores de $\mathrm{Q}^{2}$ e de $\mathrm{f}^{2}$ na Tabela 61 indica que o modelo tem acurácia e que os constructos são importantes para o ajuste geral do modelo.

\subsection{Coeficientes de caminho entre constructos exógenos e endógenos}

Análise da relação entre os constructos do modelo foi realizada por meio do cálculo dos coeficientes de caminho (Hair Jr. et al., 2017). Os coeficientes de caminho são representados como betas $(\beta)$ das regressões lineares simples das relações hipotetizadas entre os constructos (Ringle et al., 2014). Seus valores padronizados variam entre -1 (relação negativa) e +1 (relação positiva), sendo que valores acima de 0,2 ou menores que -0,2 são considerados significativos (Hair Jr. et al., 2017).

A significância das relações também é avaliada por meio do erro padrão, ou seja, pelo valor-p usando o módulo "Bootstrapping" do SmartPLS ${ }^{\circledR}$ (2019) no qual os dados foram processados com 1000 repetições a partir dos coeficientes originais e dos erros padrão de cada caminho.

A Figura 62 e a Tabela 63 apresentam o modelo estrutural com os coeficientes de caminho das relações entre os constructos e os valores-p da estatística T. Adotou-se um nível mínimo de confiança de $95 \%(\alpha \leq 0,05)$, ou seja, uma probabilidade de erro igual ou inferior a 5\% (valores de $t$ superiores a 1,96) (Hair Jr. et al., 2017, p. 157). 
Figura 62 - Coeficientes de caminho e valor-p do modelo estrutural $(\mathrm{n}=209)$

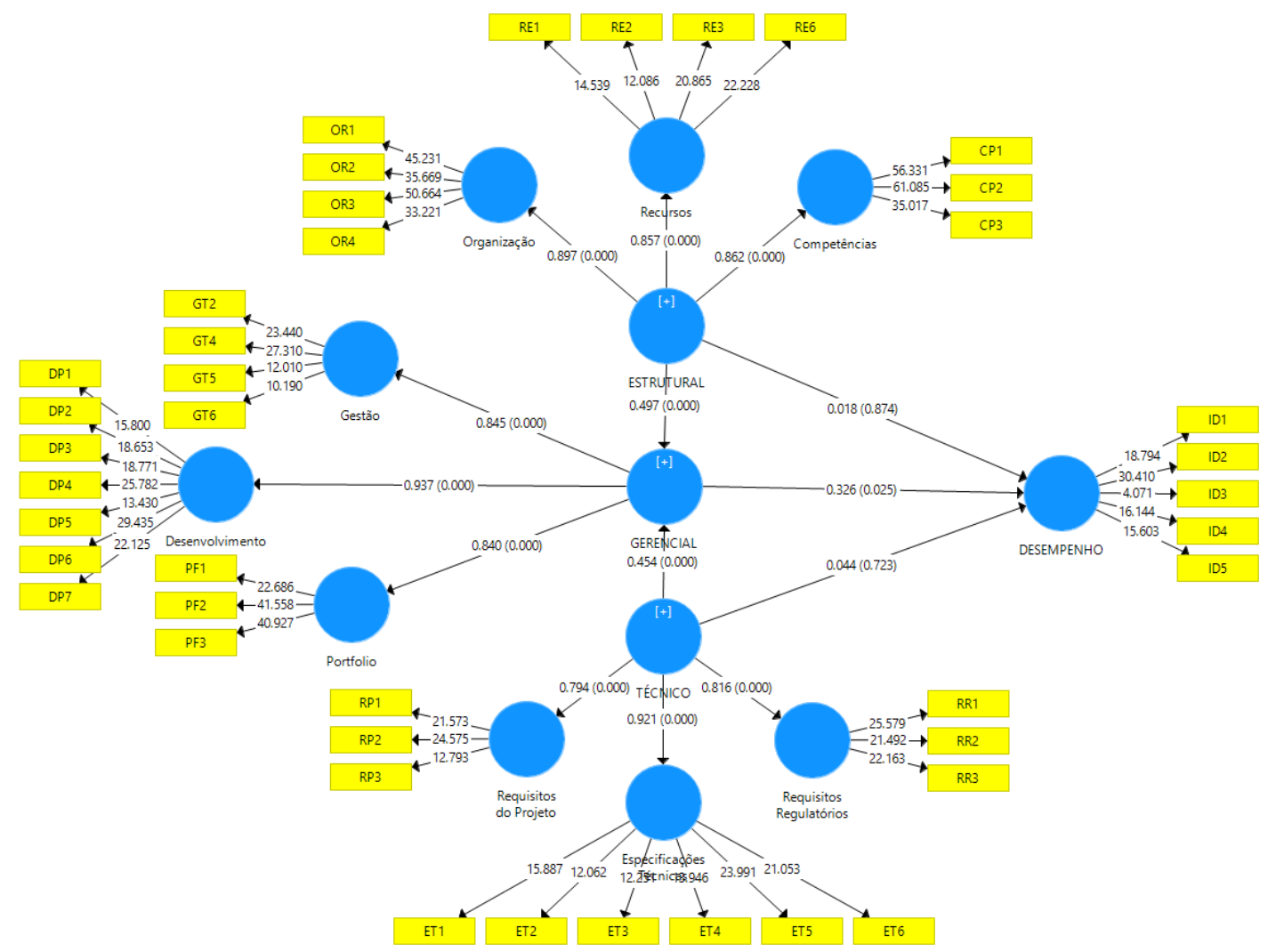

Nota: modelo de mensuração com os valores dos testes $t$ de Student e modelo estrutural com valores fora dos parênteses são coeficientes estruturais padronizados $(\beta)$ e os valores dentro dos parênteses são valores-p. Fonte: dados da pesquisa obtidos por meio do módulo "Bootstrapping" do SmartPLS ${ }^{\circledR}$ (2019).

Tabela 63 - Síntese dos resultados da análise do modelo estrutural (n=209)

\begin{tabular}{|c|c|c|c|c|}
\hline & Efeitos diretos & $\begin{array}{c}\text { Coeficiente de } \\
\text { Caminho ( } \beta \text { ) }\end{array}$ & $\begin{array}{c}\text { Significância } \\
\text { Estatística } \\
\text { (Valor-p) }\end{array}$ & Conclusão \\
\hline \multirow[t]{5}{*}{ H1 } & GERENCIAL -> DESEMPENHO & 0,326 & 0,025 & Suportada \\
\hline & GERENCIAL -> Desenvolvimento & 0,937 & 0,000 & \\
\hline & GERENCIAL -> Gestão & 0,845 & 0,000 & \\
\hline & GERENCIAL -> Portfolio & 0,840 & 0,000 & \\
\hline & ESTRUTURAL -> Competências & 0,862 & 0,000 & \\
\hline $\mathrm{H} 2$ & ESTRUTURAL -> DESEMPENHO & 0,018 & 0,874 & Rejeitada \\
\hline \multirow{3}{*}{$\mathrm{H} 4 \mathrm{a}$} & ESTRUTURAL -> GERENCIAL & 0,497 & 0,000 & Suportada \\
\hline & ESTRUTURAL -> Organização & 0,897 & 0,000 & \\
\hline & ESTRUTURAL -> Recursos & 0,857 & 0,000 & \\
\hline \multirow[t]{2}{*}{$\mathrm{H} 3$} & TÉCNICO -> DESEMPENHO & 0,044 & 0,723 & Rejeitada \\
\hline & TÉCNICO -> Especificações_Técnicas & 0,921 & 0,000 & \\
\hline \multirow[t]{3}{*}{$\mathrm{H} 5 \mathrm{a}$} & TÉCNICO -> GERENCIAL & 0,454 & 0,000 & Suportada \\
\hline & TÉCNICO -> Requisitos do Projeto & 0,794 & 0,000 & \\
\hline & TÉCNICO -> Requisitos_Regulatórios & 0,816 & 0,000 & \\
\hline
\end{tabular}

Nota: valores-p estimados por "Bootstrapping" com 1000 repetições. Fonte: dados da pesquisa tendo por referência Bido e Da Silva (2019) e Hair Jr e colaboradores (2017) e calculados usando o SmartPLS ${ }^{\circledR}$ (2019). 
A análise dos coeficientes de caminho indicou que as relações entre os constructos exógenos e os constructos endógenos foram significativas ao nível de significância de 5\% (valor-p $\leq 0,05$ ), como pode ainda ser verificado na Figura 62 e na Tabela 63 (linhas não hachuradas), não havendo, assim, a necessidade de exclusão de nenhum dos constructos exógenos do modelo. Os números de indicadores e de constructos validados traduzem a complexidade multidimensional do gerenciamento dos PDMG e, em especial, confirmam a contribuição de cada um deles para o modelo.

Os resultados da avaliação do modelo estrutural permitiram suportar apenas a hipótese H1, como pode ser observado na Tabela 63. Assim, as dificuldades gerenciais estão associadas positivamente com o desempenho fora do planejado dos PDMG (hipótese H1), ao nível de significância de 5\% (valor-p $\leq 0,05$ ), com um coeficiente de caminho de 0,326.

Ainda com base nos dados da Tabela 63, as hipóteses H2 e H3 foram rejeitadas. Assim, as dificuldades estruturais da desenvolvedora não estão diretamente associadas com o desempenho fora do planejado dos projetos de desenvolvimento de medicamentos genéricos (H2), considerando o nível de significância de 5\%. Da mesma forma, as dificuldades técnicas também não estão diretamente associadas com o desempenho fora do planejado dos projetos de desenvolvimento de medicamentos genéricos (H3), também considerando o nível de significância de 5\%. Portanto, não foi possível evidenciar uma relação estatística válida entre os constructos por meio do instrumento utilizado e da amostra da pesquisa.

Embora seja necessário considerar a análise de mediação para uma discussão mais ampla dos resultados obtidos até aqui, considera-se oportuno uma breve observação sobre as hipóteses H2 e H3 que foram rejeitadas. Sabendo-se que os indicadores associados aos construtos independentes (Estrutural e Técnico) haviam sido apontados nos resultados da pesquisa qualitativa e do referencial teórico como relacionados ao desempenho dos projetos de desenvolvimento de produtos, a questão que se colocou foi se a influência era direta ou mediada pela gestão, uma vez que o gerenciamento é considerado central em estudos como, por exemplo, de Murphy, Baker e Fisher (1974) já na década de 1970. Esta discussão será retomada após a apresentação dos resultados dos estudos de mediação.

Dito isso, a discussão dos resultados da análise do modelo estrutural será realizada a seguir para cada uma das relações entre os constructos independentes (Gerencial, Estrutural e Técnico) e o dependente (Desempenho), tendo como referência a Tabela 63 (já vista) e a Figura 63 a seguir, as quais apresentam os coeficientes de caminho e os valores-p do modelo estrutural. 
Figura 63 - Modelo estrutural com os constructos Desempenho, Gerencial, Estrutural e Técnico

$$
\text { (n= 209) }
$$

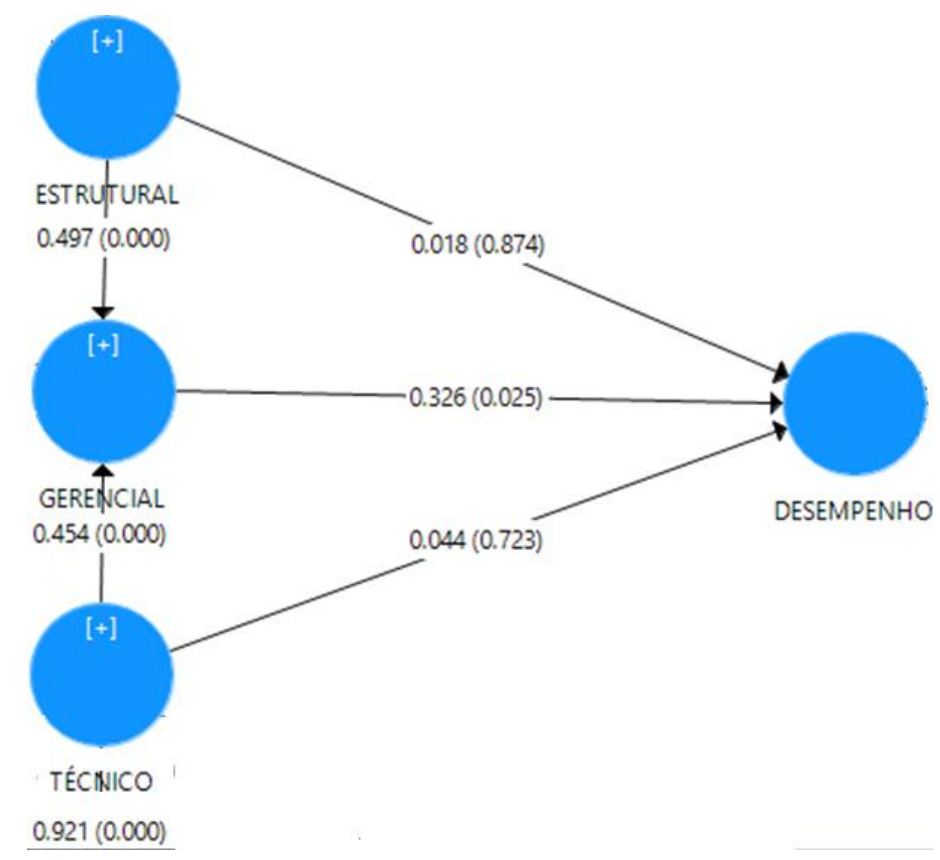

Nota: modelo estrutural com valores fora dos parênteses são coeficientes estruturais padronizados $(\beta)$ e os valores dentro dos parênteses são valores-p. Fonte: dados da pesquisa obtidos por meio do módulo "Bootstrapping" do SmartPLS ${ }^{\circledast}$ (2019).

\subsection{Relação entre o constructo Gerencial e o constructo Desempenho}

O resultado da análise de coeficiente de caminho na relação Gerencial $\rightarrow$ Desempenho apresentou um beta igual a 0,326, portanto acima do valor mínimo de referência de 0,20. A análise também resultou em um valor-p igual a 0,025 , portanto, abaixo do valor máximo de referência de 0,05 (Hair Jr. et al., 2017). Estes resultados indicam que a relação Gerencial $\rightarrow$ Desempenho é significativa, ou seja, houve evidência estatística de relação direta das dificuldades gerenciais com o desempenho dos projetos fora do planejado. Este resultado também faz com que a hipótese (H1) de que as dificuldades gerenciais estariam associadas positivamente com o desempenho fora do planejado dos projetos de desenvolvimento de medicamentos genéricos seja sustentada.

Esta conclusão é suportada pelo entendimento de que a aplicação do conhecimento, habilidades, ferramentas e técnicas de gerenciamento influenciam as chances de sucesso dos projetos (PMI, 2017; Shenhar et al., 1997). O estudo de Murphy, Baker e Fisher (1974), em especial, já apontava na década de 1970 para a importância da gestão dos projetos como determinante do sucesso. Harpum (2010), ISPE (2011) e Kennedy (2008a), mais especificamente, abordam a importância dos temas da gestão da estratégia, do portfólio, do planejamento e da execução para o desenvolvimento dos projetos 
farmacêuticos. Com relação ao gerenciamento de projetos farmacêuticos no Brasil, este é tratado por pesquisadores como, por exemplo: Braum (2014); Esteves (2018); Hajjar Júnior (2010); Moreira (2008); Moreira e Cheng (2010); e (Trassato, 2017), porém nenhum deles avalia as relações entre os resultados dos projetos e seus fatores contribuintes.

Este resultado do estudo também encontra amparo em parte das conclusões do estudo de Mendigorri e colaboradoras (2016) sobre a efetividade dos projetos de P\&D farmacêuticos e que encontrou relação entre o desempenho dos projetos e fatores gerenciais como: o planejamento de $\mathrm{P} \& \mathrm{D}$, a adequação dos processos de $\mathrm{P} \& \mathrm{D}$, o alinhamento entre objetivos e recursos e a integração entre departamentos.

\subsection{Relação entre o constructo Estrutural e o constructo Desempenho}

O resultado da análise de coeficiente de caminho na relação Estrutural $\rightarrow$ Desempenho apresentou um beta igual a 0,018 , portanto abaixo do valor mínimo de referência de 0,20. A análise também resultou em um valor-p igual a 0,874 , portanto, acima do valor máximo de referência de 0,05 (Hair Jr. et al., 2017). Estes resultados indicam que a relação Estrutural $\rightarrow$ Desempenho é pouco significativa, ou seja, não houve evidência estatística de relação direta das dificuldades estruturais com o desempenho dos projetos fora do planejado. Este resultado faz com que a hipótese (H2) de que as dificuldades estruturais estariam associadas positivamente com o desempenho fora do planejado dos projetos de desenvolvimento de medicamentos genéricos seja rejeitada.

Este resultado não era esperado, pois acreditava-se que haveria relação direta entre os dois constructos. Isso porque foram encontradas publicações que tratam da influência sobre os resultados dos projetos de fatores relacionados às restrições e inexistência: de recursos, de competências e de fatores organizacionais (S. Brown \& Eisenhardt, 1995; Clark, Chew e Fujimoto, 1987; Clark \& Fujimoto, 1991; Cooper \& Kleinschmidt, 1987b; Eisenhardt \& Tabrizi, 1995; Gupta \& Wilemon, 1990; Griffin \& Hauser, 1996; Hayes et al., 1988; Henard \& Szymanski, 2001; Imai, Nonaka e Takeuchi, 1985; PMI, 2017; Mendigorri et al., 2016; Rozenfeld et al., 2006; Womack et al., 1992; Zirger \& Maidique, 1990).

Cooper e Kleinschmidt (1987a) classificaram os fatores contribuintes para os resultados dos projetos de DP em variáveis controláveis e ambientais. Assim, assumiu-se a possibilidade de que os indicadores do constructo Estrutural seriam, até certo ponto, não controláveis e, portanto, afetariam diretamente os resultados dos PDMG.

A proposição da hipótese $\mathrm{H} 2$ considerava as dificuldades e deficiências estruturais como restrições ao projeto, ou seja, entre os fatores que afetam a execução de um projeto (PMI, 2017, p. 685), como apresentado na Figura 18. No entanto, adicionalmente foi assumida a possibilidade de que estes fatores também poderiam ser controlados de alguma forma, mesmo que parcialmente. Por esta 
razão foi introduzida a hipótese (H4) de mediação da relação Estrutural $\rightarrow$ Desempenho pelo constructo Gerencial. Esta hipótese será analisada mais adiante.

\subsection{Relação constructo Técnico e constructo Desempenho}

O resultado da análise de coeficiente de caminho na relação Técnico $\rightarrow$ Desempenho apresentou um beta igual a 0,044, portanto abaixo do valor mínimo de referência de 0,20 (Hair Jr. et al., 2017). A análise também resultou em um valor-p igual a 0,723 , portanto, acima do valor máximo de referência de 0,05. Estes resultados indicam que a relação Técnico $\rightarrow$ Desempenho é pouco significativa, ou seja, não houve evidência estatística de relação direta das dificuldades técnicas com o desempenho dos projetos fora do planejado. Este resultado faz com que a hipótese (H3) de que as dificuldades técnicas estariam associadas positivamente com o desempenho fora do planejado dos projetos de desenvolvimento de medicamentos genéricos também seja rejeitada.

Este resultado também não era esperado, pois também acreditava-se que haveria relação direta entre os dois constructos, uma vez que foram encontradas publicações que tratam da influência de fatores relacionados ao atendimento aos requisitos de produto, de projeto e da legislação sobre os resultados dos projetos na literatura (Anvisa, 2017b, 2019f; S. Brown \& Eisenhardt, 1995; K. B. Clark \& Fujimoto, 1991; Kim B. Clark et al., 1987; Cooper \& Kleinschmidt, 1987b; Do Carmo, 2017; Do Carmo, Piras, et al., 2017; Henard \& Szymanski, 2001; ISPE, 2011; Kennedy, 2008b; PMI, 2017). Assim, assumiu-se a possibilidade de que os indicadores do constructo Técnico também seriam, até certo ponto, não controláveis e, portanto, afetariam diretamente os resultados dos PDMG.

Este resultado também diverge de parte das conclusões do estudo de Mendigorri e colaboradoras (2016) sobre a efetividade dos projetos de P\&D farmacêuticos e que encontrou relação direta entre o desempenho dos projetos e fatores relacionados a parâmetros de qualidade (especificações técnicas), adequação aos objetivos e ao processo de $\mathrm{P} \& \mathrm{D}$ (requisitos do projeto) e legislação.

Assim como para o construto Técnico, adicionalmente foi assumida a possibilidade de que estes fatores também poderiam ser controlados de alguma forma, mesmo que parcialmente. Por esta razão foi introduzida a hipótese (H5) de mediação da relação Técnico $\rightarrow$ Desempenho pelo constructo Gerencial. Esta hipótese será analisada mais adiante.

\subsubsection{Análise das relações de mediação}

Esta análise verificou os efeitos mediadores das dificuldades gerenciais para as influências das dificuldades técnicas e das dificuldades estruturais sobre o desempenho fora do planejados dos PDMG. Esta análise respondeu às hipóteses H4 e H5 para este estudo. 


\subsection{Mediação gerencial da relação entre estrutural e desempenho (hipótese H4)}

A análise da mediação proposta na hipótese H4 verificou se a influência das dificuldades estruturais sobre o desempenho fora do planejado dos projetos de desenvolvimento de medicamentos genéricos é mediada pelas dificuldades gerenciais. Foram aplicadas quatro técnicas para avaliação da mediação proposta (Estrutural $\rightarrow$ Gerencial $\rightarrow$ Desempenho): 1) Análise de caminhos; 2) Efeitos indiretos; 3) Testes estatísticos de mediação e 4) "Variance accounted for" (VAF) (na língua portuguesa, variância explicada) (Baron \& Kenny, 1986; Bido \& Da Silva, 2019; Ringle et al., 2014). Os resultados da aplicação dessas técnicas são apresentados na Tabela 64 e descritos na sequência.

Tabela 64 - Análise de mediação Estrutural -> Gerencial -> Desempenho (hipótese H4) (n = 209)

\begin{tabular}{|c|c|c|c|c|c|}
\hline Técnica & & $\begin{array}{l}\text { Constructo } \\
\text { independente }\end{array}$ & Constructo dependente & Coef. $(\beta)$ & $\mathbf{R}^{2}$ \\
\hline \multirow{4}{*}{1} & \multirow{4}{*}{ 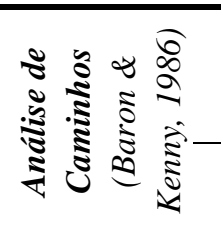 } & Estrutural & $\overline{\text { Gerencial }}$ & $0,783^{*}$ & 0,614 \\
\hline & & Estrutural & Desempenho & $0,304 *$ & 0,093 \\
\hline & & Gerencial & Desempenho & $0,374 *$ & 0,140 \\
\hline & & $\begin{array}{l}\text { Estrutural } \\
\text { Gerencial }\end{array}$ & Desempenho & $\begin{array}{c}\mathbf{0 , 0 2 1} \\
0,357^{*}\end{array}$ & 0,140 \\
\hline 2 & \multicolumn{3}{|c|}{ Estrutural -> Gerencial -> Desempenho } & $0,280 *$ & - \\
\hline \multirow{4}{*}{3} & \multicolumn{2}{|r|}{ Teste } & Estatística de teste & \multicolumn{2}{|c|}{ Valor $P$} \\
\hline & & 3,222 & \multicolumn{2}{|r|}{0,001} \\
\hline & \multicolumn{2}{|l|}{ Teste Aroian } & 3,219 & \multicolumn{2}{|r|}{0,001} \\
\hline & \multicolumn{2}{|l|}{ Teste Goodman } & 3,224 & \multicolumn{2}{|r|}{0,001} \\
\hline 4 & \multicolumn{3}{|c|}{ VAF } & \multicolumn{2}{|c|}{$\mathbf{0 , 9 3 0}$} \\
\hline
\end{tabular}

Nota: $* \mathrm{p}<0,05$. Fonte: dados da pesquisa.

- Análise de caminhos - quatro condições são necessárias para a caracterização da mediação: 1) o constructo independente afeta significativamente o constructo mediador; 2) o constructo independente afeta significativamente o constructo dependente, na ausência do constructo mediador; 3) o constructo mediador afeta significativamente o constructo dependente e 4) o efeito do constructo independente sobre o constructo dependente enfraquece no momento da adição do constructo mediador.

Conforme os dados apresentados na Tabela 64, o constructo independente Estrutural afeta significativamente o constructo mediador Gerencial, apresentando um coeficiente de caminho positivo $(0,783)$ e estatisticamente significativo ao nível de $5 \%$, atendendo assim à primeira condição. Verificou-se também o atendimento à segunda condição, pois o constructo independente Estrutural afeta positivamente $(0,304)$ e significativamente (ao nível de $5 \%$ ) o constructo dependente Desempenho na ausência do constructo mediador Gerencial. Na verificação da terceira condição, observou-se que o constructo mediador Gerencial afeta positivamente $(0,374)$ e significativamente (ao nível de 5\%) o constructo dependente Desempenho. Por fim, para a verificação da quarta condição, o 
efeito do constructo independente Estrutural sobre o constructo dependente Desempenho enfraquece no momento da adição do constructo mediador Gerencial, reduzindo de 0,304 (valor $\mathrm{p}<0,05$ ) na perspectiva isolada para 0,021 (valor $\mathrm{p}>0,05$ ) na condição conjunta. Em síntese, os resultados da aplicação da análise de caminhos de Baron e Kenny (1986) confirmaram a mediação, visto que as quatro condições foram atendidas.

- Efeitos indiretos Estrutural -> Gerencial -> Desempenho - por este critério, como apresentado na Tabela 64 (técnica 2), o efeito indireto de 0,280 resultante do caminho que parte da dificuldade Estrutural, passa pela Gerencial e chega ao Desempenho foi considerado estatisticamente significante ao nível de 5\%, demonstrando que há evidências da mediação.

- Testes estatísticos Sobel, Aroian e Goodman - estes testes avaliam se o constructo mediador (Gerencial) carrega significativamente a influência do constructo independente (Estrutural) sobre o constructo dependente (Desempenho). Desse modo, conforme exposto na Tabela 64 (técnica 3), os três testes foram estatisticamente significantes ao nível de 5\%, indicando a mediação proposta.

- VAF - o resultado de 93\% (Tabela 64 - técnica 4) reitera a existência de uma mediação completa no modelo proposto, ou seja, as dificuldades gerenciais assumem um papel mediador na relação entre as dificuldades estruturais e o desempenho fora do planejado dos PDMG.

Como a mediação é composta por duas relações entre construtos, estas deram origem às hipóteses componentes $\mathrm{H} 4 \mathrm{a}$ (as dificuldades estruturais estão associadas positivamente com as dificuldades gerenciais dos projetos de desenvolvimento de medicamentos genéricos) e H4b (as dificuldades gerenciais dos projetos de desenvolvimento de medicamentos genéricos estão associadas positivamente com desempenho fora do planejado).

A Figura 64 apresenta os coeficientes de caminho (betas) das relações entre os constructos e, entre parênteses, os valores-p da estatística T para esta análise de mediação: Estrutural -> Gerencial -> Desempenho. Pode-se verificar que as hipóteses H4a e H4b foram sustentadas. Portanto, constatou-se que as dificuldades estruturais estão associadas positivamente com as dificuldades gerenciais dos projetos de desenvolvimento de medicamentos genéricos ( $\mathrm{H} 4 \mathrm{a})$, apresentando um coeficiente positivo de 0,784, estatisticamente significante ao nível de 5\%. Também constatou-se que as dificuldades gerenciais dos PDMG estão associadas positivamente com desempenho fora do planejado (H4b), visto o coeficiente positivo de 0,357 , estatisticamente significativo ao nível de $5 \%$. 
Figura 64 - Coeficientes de caminho e valores-p da análise de mediação Estrutural -> Gerencial -> Desempenho (hipótese H4) $(\mathrm{n}=209)$

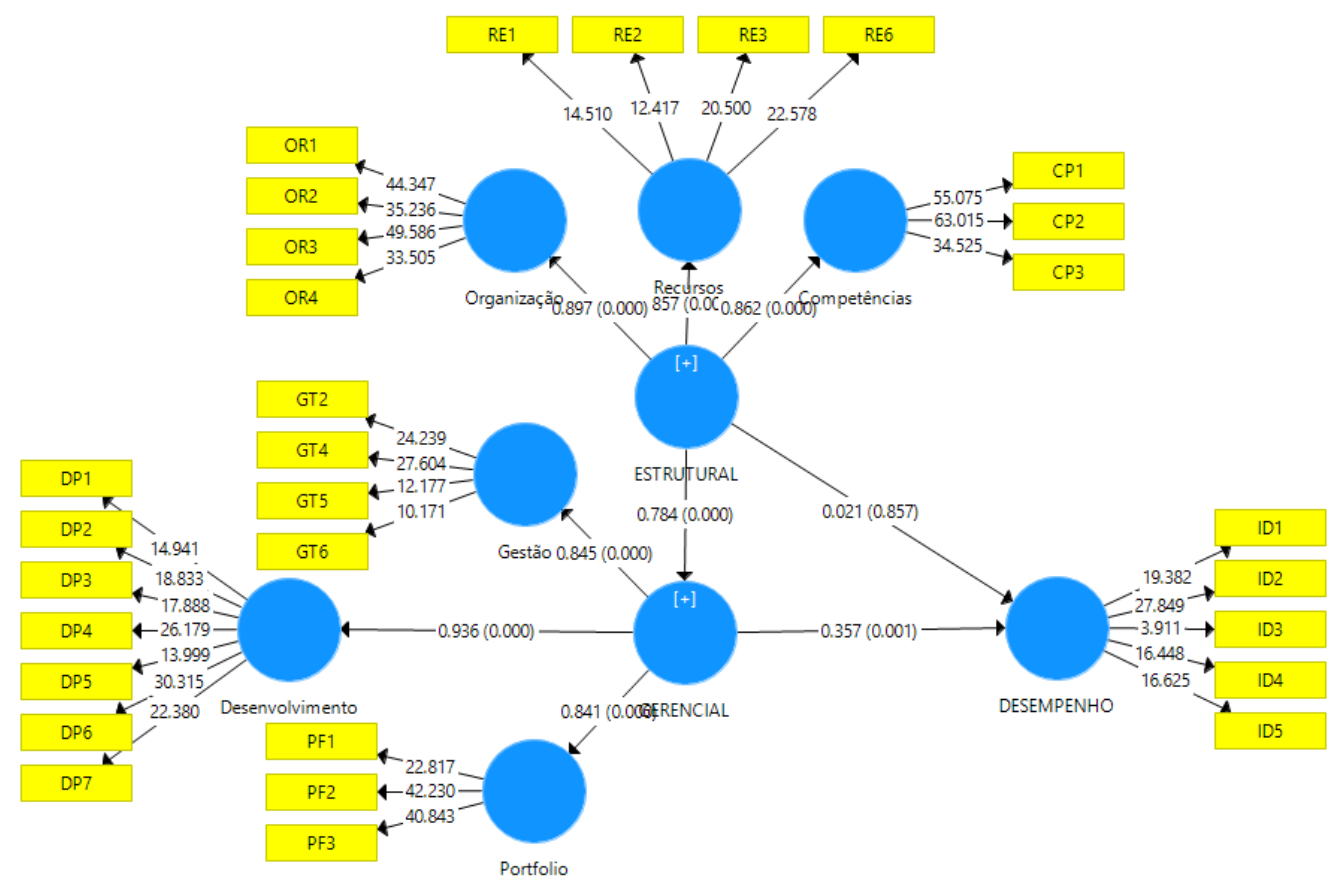

Nota: modelo de mensuração com os valores dos testes $t$ de Student e modelo estrutural com valores fora dos parênteses são coeficientes estruturais padronizados $(\beta)$ e os valores dentro dos parênteses são valores-p. Fonte: dados da pesquisa obtidos por meio do módulo Bootstrapping do SmartPLS ${ }^{\circledR}(2019)$.

Com base nos resultados apresentados na Tabela 64 e na Figura 64, verificou-se que a influência das dificuldades estruturais sobre o desempenho fora do planejado dos projetos de desenvolvimento de genéricos é mediada pelas dificuldades gerenciais (hipótese H4).

Como já mencionado anteriormente na análise da relação direta entre os constructos Estrutural e Desempenho, considerou-se na concepção do modelo conceitual que os fatores relacionados à estrutura disponibilizada para o desenvolvimento dos PDMG não seriam totalmente controláveis pela gestão do projeto. Entre estes fatores estão dificuldades relacionadas com: a infraestrutura para o desenvolvimento analítico e/ou farmacotécnico; com a tecnologia; com a cultura; e com a estrutura organizacional. A hipótese $\mathrm{H} 2$, no entanto, foi rejeitada, mas a hipótese $\mathrm{H} 4$ revelou que, mesmo os fatores relacionados a dificuldades estruturais e que estariam mais distantes do controle do projeto, podem ser influenciados pela gestão.

Considerando que as restrições como as mensuradas pelo constructo Estrutural podem ser gerenciadas aplicando técnicas recomendadas para o gerenciamento de recursos críticos e escassos (PMI, 2017, p. 310), esta mediação era esperada. O PMI (2017) considera que as restrições são diferentes para cada projeto e o gerente do projeto tem por responsabilidade adaptar a maneira como elas são administradas, considerando o ambiente do projeto, a cultura organizacional, as necessidades das partes interessadas, entre outras variáveis. Esta propriedade está presente inclusive na definição do 
PMI (2017,p. 319) para competência no contexto do gerenciamento de projetos, ou seja, a habilidade e a capacidade necessárias para concluir as atividades designadas dentro das restrições do projeto.

A importância de cada restrição é diferente para cada projeto, e, ainda de acordo com o PMI (2017), o gerente de projetos decide qual abordagem utilizará para gerenciar essas restrições com base no ambiente do projeto, organização, cultura, necessidades das partes interessadas, entre outras variáveis. O PMI vai além ao destacar que se os membros da equipe do projeto não possuírem as competências demandadas pelo projeto, o desempenho será prejudicado.

Com conclusão semelhante, embora os resultados de Cooper e Kleinschmidt (1987a) tenham indicado que fatores como os estruturais não seriam gerenciáveis, por outro lado, eles também consideraram que a maneira pela qual o projeto do novo produto é gerenciado e executado (quais atividades e o quão bem são executadas) influencia muito os resultados.

\subsection{Mediação gerencial da relação entre técnico e desempenho (hipótese H5)}

A análise de mediação proposta na hipótese H5 verificou se a influência das dificuldades técnicas sobre o desempenho fora do planejado dos projetos de desenvolvimento de medicamentos genéricos é mediada pelas dificuldades gerenciais. Assim como na análise anterior, foram aplicadas quatro técnicas para avaliação da mediação proposta (Técnico $\rightarrow$ Gerencial $\rightarrow$ Desempenho). Os resultados da aplicação das técnicas de avaliação da mediação proposta são apresentados na Tabela 65 e descritos a seguir.

Tabela 65 - Análise de mediação Técnico -> Gerencial -> Desempenho (hipótese H5) (n = 209)

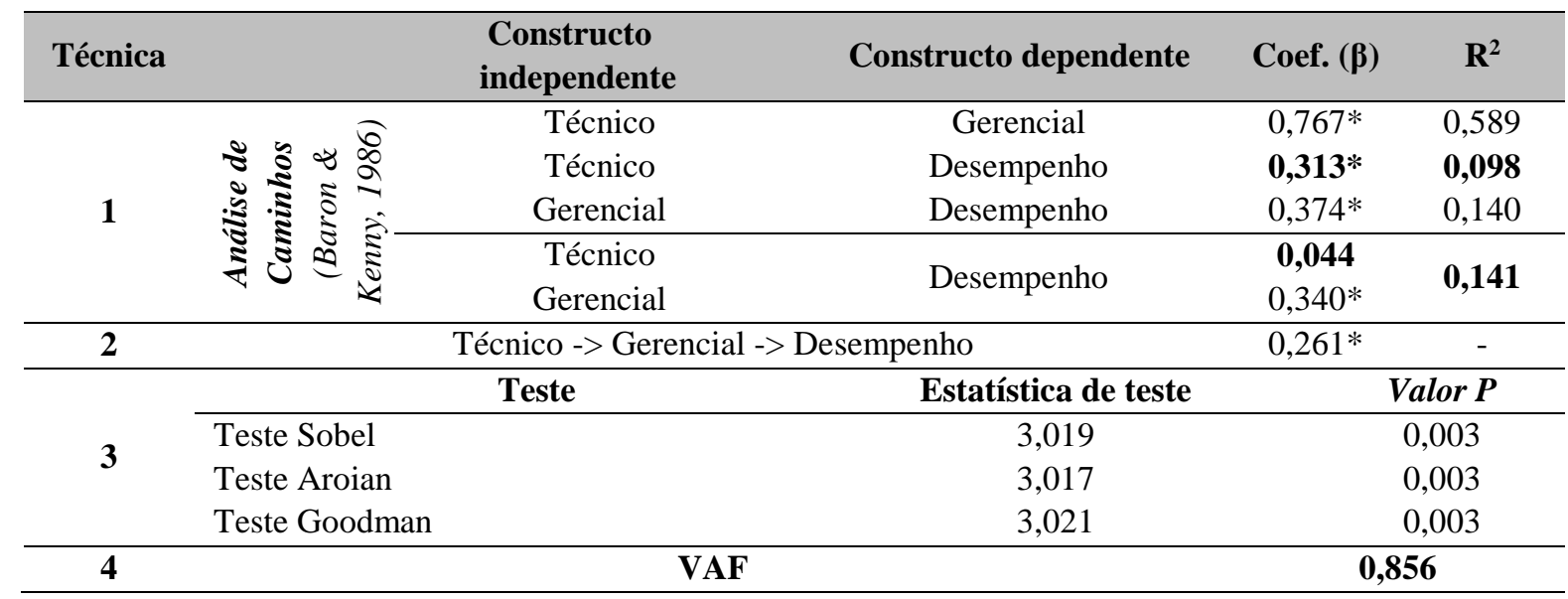

Nota: ${ }^{*} \mathrm{p}<0,05$. Fonte: dados da pesquisa.

- Análise de caminhos (Baron \& Kenny, 1986) - os resultados para as quatro condições requeridas por esta técnica são apresentados na Tabela 65 (técnica 1). O constructo independente Técnico afeta significativamente o constructo mediador Gerencial, apresentando um coeficiente de caminho positivo $(0,767)$ e estatisticamente significativo ao nível de $5 \%$, atendendo à primeira condição. Quanto ao atendimento à segunda condição, verificou-se que o constructo independente 
Técnico afeta positivamente $(0,313)$ e significativamente (ao nível de $5 \%$ ) o constructo dependente Desempenho na ausência do constructo mediador Gerencial. A verificação da terceira condição indicou que o constructo mediador Gerencial afeta positivamente $(0,374)$ e significativamente (ao nível de 5\%) o constructo dependente Desempenho. A verificação da quarta condição, por sua vez, indicou que o efeito do constructo independente Técnico sobre o constructo dependente Desempenho é enfraquecido no momento da adição do constructo mediador Gerencial, reduzindo de 0,313 (valor $\mathrm{p}<$ 0,05 ) na perspectiva isolada para 0,044 (valor $\mathrm{p}>0,05$ ) na condição conjunta. Em síntese, os resultados da aplicação da análise de caminhos de Baron e Kenny (1986) confirmaram a mediação, visto que as quatro condições foram atendidas.

- Efeitos indiretos Técnico -> Gerencial -> Desempenho - os resultados apresentados por meio da Tabela 65 (técnica 2) indicam efeito indireto de 0,261 resultante do caminho que parte da dificuldade Técnica, passa pela Gerencial e chega ao Desempenho, sendo assim considerado estatisticamente significante ao nível de 5\%, demonstrando que há evidências da mediação.

- Testes estatísticos Sobel, Aroian e Goodman - conforme exposto na Tabela 65 (técnica 3), os três testes foram estatisticamente significantes ao nível de 5\%, indicando a existência da mediação proposta.

- VAF - o resultado de 85,6\% (Tabela 65 - técnica 4) reforça a existência de uma mediação completa na relação proposta, ou seja, as dificuldades técnicas desempenham papel mediador na relação entre dificuldades técnicas e o desempenho fora do planejado dos PDMG.

Como a mediação é composta por duas relações entre construtos, foram também avaliadas as suas partes que são compostas pelas hipóteses H5a (as dificuldades técnicas estão associadas positivamente com as dificuldades gerenciais dos projetos de desenvolvimento de medicamentos genéricos) e H5b (as dificuldades gerenciais dos projetos de desenvolvimento de medicamentos genéricos estão associadas positivamente com desempenho fora do planejado).

A Figura 65 apresenta os coeficientes de caminho (betas) das relações entre os constructos e, entre parênteses, os valores-p da estatística $T$, desta vez para a análise de mediação: Técnico -> Gerencial -> Desempenho. Por meio dela, pode-se verificar que as hipóteses H5a e H5b foram confirmadas. Portanto, constatou-se que as dificuldades técnicas estão associadas positivamente com as dificuldades gerenciais dos projetos de desenvolvimento de medicamentos genéricos (H5a), apresentando um coeficiente positivo de 0,768 , que é estatisticamente significante ao nível de $5 \%$. Complementarmente, constatou-se que as dificuldades gerenciais dos PDMG estão associadas positivamente com o desempenho fora do planejado (H5b), o que é indicado pelo coeficiente positivo de 0,340 estatisticamente significativo ao nível de 5\%. 
Figura 65 - Coeficientes de caminho e valor p da análise de mediação Técnico -> Gerencial -> Desempenho (hipótese H5) $(\mathrm{n}=209)$

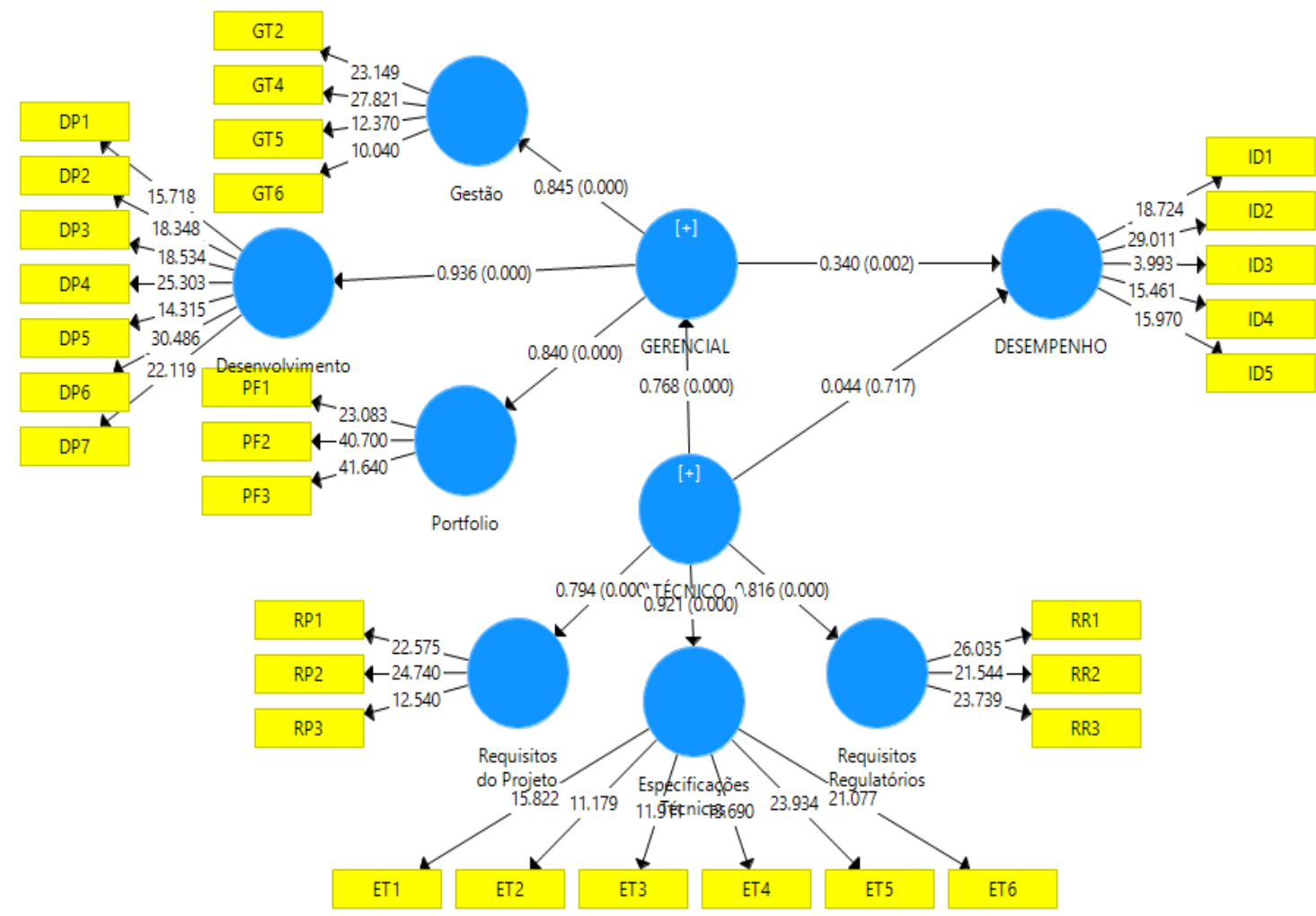

Nota: modelo de mensuração com os valores dos testes $t$ de Student e modelo estrutural com valores fora dos parênteses são coeficientes estruturais padronizados $(\beta)$ e os valores dentro dos parênteses são valores-p. Fonte: dados da pesquisa obtidos por meio do módulo Bootstrapping do SmartPLS ${ }^{\circledR}$ (2019).

A análise dos resultados apresentados na Tabela 65 e na Figura 65 indica que a influência das dificuldades técnicas sobre o desempenho fora do planejado dos projetos de desenvolvimento de genéricos é mediada pelas dificuldades gerenciais (hipótese H5).

Como já mencionado anteriormente, considerou-se na concepção do modelo conceitual que os fatores relacionados aos requisitos legais, regulatórios e de projeto não seriam totalmente controláveis pela gestão do projeto. A hipótese $\mathrm{H} 3$, no entanto, não se confirmou, mas revelou que mesmo os fatores relacionados a dificuldades técnicas que estariam fora do total controle do projeto podem ser gerenciados. Entre estes fatores estão: dificuldades relacionadas com as especificações técnicas dos produtos e processos, os requisitos do projeto e os requisitos regulatórios.

Os resultados das análises do modelo de mensuração já sugeriam a influência da gestão e de decisões da organização. Como já visto, no constructo exógeno Organização do constructo Estrutural, por exemplo, os indicadores com as maiores contribuições foram o que tratam das dificuldades relacionadas à estrutura organizacional e o que trata da cultura organizacional. Os indicadores com as maiores contribuições para o constructo Recursos foram o que tratam da contratação de profissionais e 
serviços de terceiros e o que trata da seleção e qualificação dos fornecedores dos IFAs. Nestes dois indicadores, há também que se considerar a possibilidade de influência das decisões da organização.

Voltando agora para o constructo Técnico, mais especificamente para o constructo Especificações Técnicas, o indicador com a maior contribuição foi o relacionado ao desenvolvimento e validação dos métodos analíticos. Não deixando de considerar a complexidade que pode existir em desenvolvimentos específicos, as análises indicaram a possibilidade de haver ineficiências nas relações entre as áreas que participam do projeto e que, portanto, podem ser melhoradas por meio da gestão. Vale destacar que a relação com as demais áreas parece estar entre as razões das contribuições de outros indicadores para os resultados desfavoráveis dos PDMG, em especial aqueles cuja responsabilidade e/ou controle dos recursos não está na área de P\&D.

No constructo Requisitos do Projeto, o indicador que trata do longo tempo necessário para os PDMG tem relação com decisões da organização. Influenciam o tempo necessário para o desenvolvimento dos PDMG decisões sobre os recursos que poderão utilizados pelo projeto e, sobretudo, o prazo dado para a conclusão do projeto. Os resultados sugerem que o estabelecimento de prazos muito curtos para os PDMG também tem influência sobre vários outros indicadores por razões principalmente relacionadas à concorrência entre as restrições, principalmente, entre prazo, custo e qualidade. No mesmo sentido do que já haviam concluido Murphy, Baker e Fisher (1974), os fatores contribuintes para o desempenho dos PDMG podem ser gerenciados, mesmo os complexos e os relacionadas a barreiras e restrições.

\subsubsection{Síntese dos resultados das análises}

Os principais resultados respondem à questão de pesquisa que buscou identificar quais são os fatores que contribuem para o desempenho dos projetos de desenvolvimento de medicamentos genéricos. Partindo da questão de pesquisa e de seus objetivos específicos, o estudo produziu os resultados que estão resumidos a seguir.

O primeiro objetivo específico foi identificar os indicadores de desempenho dos projetos de desenvolvimento de medicamentos genéricos e o segundo foi identificar os fatores que contribuem para o desempenho dos projetos de desenvolvimento de medicamentos genéricos. Para que ambos fossem atingidos foi realizada inicialmente a pesquisa qualitativa apoiada por fundamentação teórica. Da análise do conteúdo das respostas foram inicialmente identificadas 281 unidades de significados. Após tratamento envolvendo agrupamentos e eliminação de redundâncias, foram definidos 6 indicadores de desempenho e 48 fatores contribuintes para o desempenho. Estes indicadores foram então reescritos na forma de assertivas (Tabelas 31 e 32) para a composição do questionário de pesquisa que foi submetido a uma validação de seu conteúdo. Como resultado, os 5 dos 6 indicadores de desempenho e 44 dos 48 indicadores dos fatores contribuintes para o desempenho foram validados, 
respondendo aos dois primeiros objetivos específicos da pesquisa. O Apêndice XII apresenta todos os 49 indicadores que compõem os constructos validados para o modelo conceitual proposto.

O terceiro objetivo específico foi propor um modelo teórico multidimensional que integrasse o desempenho dos projetos de desenvolvimento de medicamentos genéricos e seus fatores contribuintes. O modelo conceitual ou teórico foi proposto com base no referencial teórico e foi apresentado na Figura 21. O modelo foi composto por 3 dimensões independentes (Gerencial, Estrutural e Técnico) e uma dimensão dependente (Desempenho). A partir deste modelo foram propostas as hipóteses de pesquisa para as relações entre as dimensões (constructos).

O quarto e último objetivo específico foi analisar empiricamente as relações entre os fatores contribuintes e o desempenho dos projetos de desenvolvimento dos medicamentos genéricos. Para atingir este objetivo foi adotada a modelagem de equações estruturais pelo método dos mínimos quadrados parciais (PLS-SEM). Em seus primeiros passos, o modelo conceitual foi detalhado com a definição do modelo estrutural. Aos três constructos (dimensões) independentes foram juntados os seus construtos formadores (variáveis latentes de primeira ordem ou exógenos), conforme apresentado na Figura 28.

Por meio da aplicação do PLS-SEM calculado usando o software SmartPLS ${ }^{\circledR}$ (2019) Versão 3, foi avaliado o modelo de mensuração. Os resultados indicaram validade convergente, pois foram considerados os valores e as significâncias das cargas fatoriais assim como a variância média extraída (AVE). Os 5 indicadores de desempenho e os 44 indicadores dos fatores contribuintes para o desempenho, apresentaram cargas fatoriais satisfatórios, confirmando as suas relações com o modelo proposto e reforçando as respostas ao primeiro e segundo objetivos específicos.

$\mathrm{Na}$ análise da validade discriminante, foram considerados dois critérios: o critério Fornell e Larcker (1981) e a comparação das cargas fatoriais dos constructos com as cargas cruzadas. Para fins de ajuste de validade discriminante e das AVEs dos constructos, foram excluídos 7 indicadores (Tabela 59), todos fatores contribuintes que apresentaram a menor diferença das altas cargas fatoriais entre dois constructos. Ao final dos ajustes, os resultados indicaram que o modelo apresenta validade discriminante.

Para análise da confiabilidade do modelo de mensuração foram consideradas as estatísticas de consistência interna pelos cálculos do Alfa de Cronbach $(\alpha)$ e da Confiabilidade Composta (CC) (Tabela 60). Os resultados de ambos indicaram que o modelo apresenta confiabilidade.

A análise do modelo estrutural testou as relações entre os constructos que o compõem e respondeu ao quarto objetivo específico ao qual estão atreladas as três primeiras hipóteses formuladas (H1, H2 e H3), ou seja, as influências das dificuldades gerenciais, técnicas e estruturais (variáveis independentes) sobre o desempenho dos PDMG fora do planejados (variável dependente). Para avaliar 
o tamanho e a significância das relações entre os constructos foram calculados os coeficientes de caminho $(\beta)$ e o valor-p da estatística T. A Tabela 66 apresenta uma síntese dos resultados da avaliação do modelo por meio da verificação das relações hipotetizadas.

Tabela 66 - Síntese dos resultados das hipóteses propostas $(\mathrm{n}=209)$

\begin{tabular}{|c|c|c|c|c|}
\hline & Hipóteses & $\begin{array}{c}\text { Coeficiente de } \\
\text { Caminho }(\beta)\end{array}$ & $\begin{array}{c}\text { Significância } \\
\text { Estatística } \\
\text { (Valor-p) }\end{array}$ & Resultado \\
\hline H1 & $\begin{array}{l}\text { As dificuldades gerenciais estão associadas } \\
\text { positivamente com o desempenho fora do } \\
\text { planejado dos projetos de desenvolvimento de } \\
\text { medicamentos genéricos. }\end{array}$ & 0,326 & 0,025 & Suportada \\
\hline H2 & $\begin{array}{l}\text { As dificuldades estruturais da desenvolvedora } \\
\text { estão associadas positivamente com o } \\
\text { desempenho fora do planejado dos projetos de } \\
\text { desenvolvimento de medicamentos genéricos. }\end{array}$ & 0,018 & 0,874 & Rejeitada \\
\hline H3 & $\begin{array}{l}\text { As dificuldades técnicas estão associadas } \\
\text { positivamente com o desempenho fora do } \\
\text { planejado dos projetos de desenvolvimento de } \\
\text { medicamentos genéricos. }\end{array}$ & 0,044 & 0,723 & Rejeitada \\
\hline H4 & $\begin{array}{l}\text { A influência das dificuldades estruturais sobreo } \\
\text { desempenho fora do planejado dos projetos de } \\
\text { desenvolvimento de genéricos é mediada pelas } \\
\text { dificuldades gerenciais. }\end{array}$ & 0,280 & 0,001 & Suportada \\
\hline $\mathrm{H} 4 \mathrm{a}$ & $\begin{array}{l}\text { As dificuldades estruturais estão associadas } \\
\text { positivamente com as dificuldades gerenciais } \\
\text { dos projetos de desenvolvimento de } \\
\text { medicamentos genéricos. }\end{array}$ & 0,784 & 0,000 & Suportada \\
\hline$H 4 b$ & $\begin{array}{l}\text { As dificuldades gerenciais dos projetos de } \\
\text { desenvolvimento de medicamentos genéricos } \\
\text { estão associadas positivamente com } \\
\text { desempenho fora do planejado. }\end{array}$ & 0,357 & 0,001 & Suportada \\
\hline H5 & $\begin{array}{l}\text { A influência das dificuldades técnicas sobre o } \\
\text { desempenho fora do planejado dos projetos de } \\
\text { desenvolvimento de genéricos é mediada pelas } \\
\text { dificuldades gerenciais. }\end{array}$ & 0,261 & 0,003 & Suportada \\
\hline$H 5 a$ & $\begin{array}{l}\text { As dificuldades técnicas estão associadas } \\
\text { positivamente com as dificuldades gerenciais } \\
\text { dos projetos de desenvolvimento de } \\
\text { medicamentos genéricos. }\end{array}$ & 0,768 & 0,000 & Suportada \\
\hline$H 5 b$ & $\begin{array}{l}\text { As dificuldades gerenciais dos projetos de } \\
\text { desenvolvimento de medicamentos genéricos } \\
\text { estão associadas positivamente com } \\
\text { desempenho fora do planejado. }\end{array}$ & 0,340 & 0,002 & Suportada \\
\hline
\end{tabular}

Nota: nível mínimo de confiança de $95 \%(\alpha \leq 0,05)$. Parâmetros para rejeição das hipóteses tendo por referência Bido e Da Silva (2019) e Hair Jr e colaboradores (2017). Fonte: dados da pesquisa.

Em relação às hipóteses de relações diretas, H1, H2 e H3, somente a hipótese H1 foi suportada, ou seja, as dificuldades gerenciais estão positivamente associadas ao desempenho dos projetos fora do planejado. Quanto às dificuldades estruturais $(\mathrm{H} 2)$ e técnicas $(\mathrm{H} 3)$, não houve evidências estatísticas de relações diretas com o desempenho dos projetos fora do planejado. 
O último conjunto de testes do modelo teve por objetivo analisar as relações com mediação que foram definidas no modelo teórico. A análise da mediação proposta na forma da hipótese H4 verificou se a influência das dificuldades estruturais sobre o desempenho fora do planejado dos PDMG é mediada pelas dificuldades gerenciais. Já a análise de mediação proposta na forma da hipótese H5 verificou se a influência das dificuldades técnicas sobre o desempenho fora do planejado dos PDMG é mediada pelas dificuldades gerenciais. Os resultados da aplicação das técnicas estatísticas são apresentados na Tabela 65 e indicam que as hipóteses para as relações de mediação propostas (H4 e H5) foram suportadas. Assim, evidenciou-se a importância do constructo Gerencial relacionado às dificuldades gerenciais, seja pela relação direta com o desempenho fora do prazo, seja pelo papel mediador a partir das dificuldades estruturais e das dificuldades técnicas.

Considera-se que foi obtida validação parcial (2 das 5 hipóteses foram rejeitas) do modelo conceitual proposto, uma vez que as influências diretas dos fatores relacionados a dificuldades estruturais e técnicas sobre o desempenho fora do planejado não se mostraram estatisticamente significativas. A Tabela 67 condensa todos os resultados da pesquisa empírica.

Tabela 67 - Resultados gerais da pesquisa

\begin{tabular}{|c|c|c|}
\hline $\begin{array}{c}\text { Fase / } \\
\text { Objetivo } \\
\end{array}$ & $\begin{array}{c}\text { Item / método de } \\
\text { pesquisa }\end{array}$ & Principais resultados \\
\hline $\begin{array}{l}\text { Fase } \\
\text { qualitativa - } \\
\text { Identificação } \\
\text { dos desafios } \\
\text { presentes } \\
\text { nos PDMG e } \\
\text { seus fatores } \\
\text { contribuintes }\end{array}$ & $\begin{array}{l}\text { Levantamento } \\
\text { do referencial } \\
\text { teórico }\end{array}$ & $\begin{array}{l}\text { - Identificados as teorias e os conceitos relacionados ao tema da pesquisa: } \\
\text { desenvolvimento de produtos, desempenho de projetos de desenvolvimento } \\
\text { de produtos e fatores contribuintes para o desempenho de projetos de } \\
\text { desenvolvimento. } \\
\text { - Proposição de modelo conceitual com } 3 \text { constructos independentes } \\
\text { (Gerencial, Estrutural e Técnico) e um constructo dependente (Desempenho) } \\
\text { (Figura 21) }\end{array}$ \\
\hline & $\begin{array}{c}\text { Questionário } \\
\text { com perguntas } \\
\text { abertas (survey) } \\
\text { Análise de } \\
\text { conteúdo }\end{array}$ & $\begin{array}{l}\text { OE A: Identificar os indicadores de desempenho dos projetos de } \\
\text { desenvolvimento de medicamentos genéricos } \\
\text { - Identificação de } 6 \text { indicadores de desempenho dos projetos de } \\
\text { desenvolvimento de medicamentos (Tabela 50) } \\
\text { OE B: Identificar os fatores relacionados ao desempenho dos projetos de } \\
\text { desenvolvimento de medicamentos genéricos } \\
\text { - Identificação de } 48 \text { indicadores dos fatores contribuintes para o } \\
\text { desempenho dos projetos de desenvolvimento de medicamentos (Tabela 51) }\end{array}$ \\
\hline $\begin{array}{l}\text { Fase } \\
\text { quantitativa } \\
\text { - verificação } \\
\text { das relações } \\
\text { entre os } \\
\text { indicadores } \\
\text { no modelo } \\
\text { proposto }\end{array}$ & $\begin{array}{c}\text { Proposição de } \\
\text { modelo de } \\
\text { equações } \\
\text { estruturais e } \\
\text { desenvolvimento } \\
\text { das escalas }\end{array}$ & $\begin{array}{l}\text { OE C: Propor um modelo teórico multidimensional que integre o } \\
\text { desempenho dos projetos de desenvolvimento de medicamentos genéricos e } \\
\text { seus fatores contribuintes } \\
\text { - Modelo de caminhos com a definição da composição dos construtos do } \\
\text { modelo conceitual e seus indicadores (Figura 28). } \\
\text { Constructo Desempenho - } 6 \text { indicadores } \\
\text { Constructo Gerencial }-3 \text { constructos exógenos (Desenvolvimento, } \\
\text { Gestão e Portfólio) }-18 \text { indicadores }\end{array}$ \\
\hline
\end{tabular}




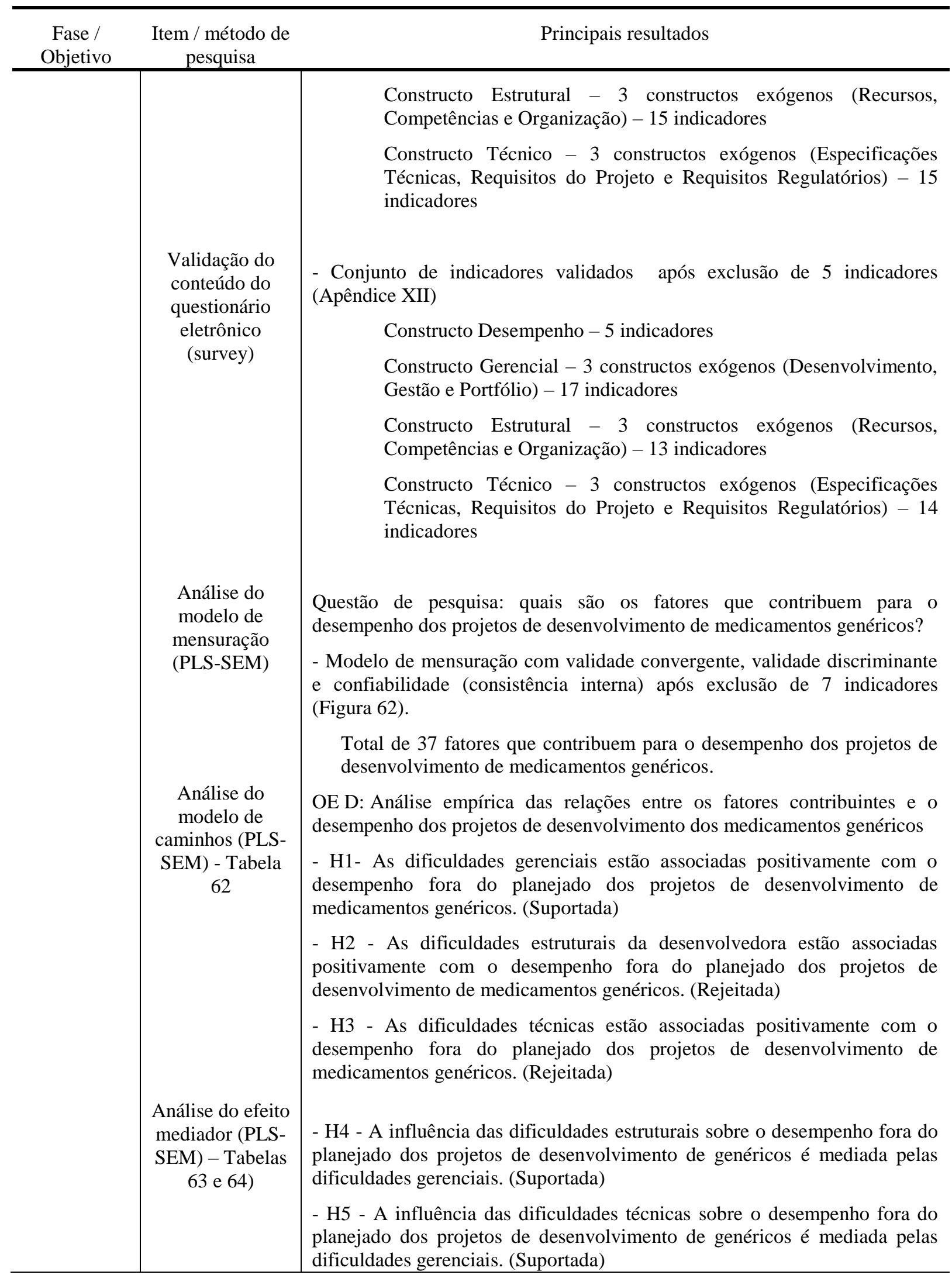

Nota: $\mathrm{OE}=$ Objetivo específico. Fonte: dados da pesquisa. 


\section{CONCLUSÕES E CONSIDERAÇÕES FINAIS}

Os medicamentos genéricos tem extrema importância para o sistema de saúde, uma vez que facilitam o acesso não só por meio do varejo de produtos farmacêuticos, mas, sobretudo, ao abastecerem a rede pública de atendimento à população. Em um mercado com expressivo crescimento desde a sua introdução no Brasil em 1999, os medicamentos genéricos foram responsáveis por impulsionar o desenvolvimento da indústria farmacêutica brasileira e cuja expansão depende do desenvolvimento de novos produtos.

Análises de dados recentes da Agência Nacional de Vigilância Sanitária - Anvisa mostram que parcela significativa das solicitações de registros de novos medicamentos genéricos não são aprovados. Estes dados deram origem a várias questões sobre as possíveis causas para a elevada taxa de insucesso, considerando que geralmente os projetos de desenvolvimento de medicamentos genéricos possuem relativamente baixa complexidade e risco.

Um aumento na aprovação de medicamentos genéricos tem relevante importância para o sistema de saúde, não apenas por possibilitar o acesso a um número maior de produtos e por aumentar a concorrência, mas também por permitir que medicamentos genéricos ainda não disponíveis cheguem ao mercado mais rapidamente. Também tem relevância para os laboratórios produtores ao poder resultar na ampliação de suas linhas de produtos e no aumento de faturamento. Além disso, os medicamentos genéricos possibilitam a participação de laboratórios farmacêuticos de menor porte neste mercado.

Assim, considerando a importância dos medicamentos genéricos para o sistema de saúde, a elevada taxa de indeferimento dos pedidos de registro dos medicamentos genéricos e a lacuna encontrada na literatura, a questão definida para este estudo foi: quais são os fatores que contribuem para o desempenho dos projetos de desenvolvimento de medicamentos genéricos?

A revisão da literatura não identificou publicações que respondessem à questão formulada, mesmo que parcialmente, uma vez que não foram encontrados estudos sobre o desempenho dos projetos de desenvolvimento de medicamentos genéricos e nem sobre os fatores que influenciam ou contribuem para o seu desempenho. Tampouco foram encontrados modelos e/ou escalas para a mensuração do desempenho desses projetos. A literatura disponível sobre PDMG é composta basicamente por livros com foco nas tecnologias de produção das diferentes formas farmacêuticas (farmacotécnica); artigos com foco na adoção dos medicamentos genéricos pela população e pelos agentes de saúde; e em teses e dissertações. 
$\mathrm{Na}$ primeira fase da pesquisa empírica foi empregado método qualitativo com aplicação de questionário eletrônico com perguntas abertas sobre problemas nos projetos de desenvolvimento de medicamentos e sobre suas características. O conteúdo das respostas recebidas foi analisado e as unidades de significado encontradas deram origem aos indicadores de desempenho dos PDMG e de seus fatores contribuintes. As unidades de conteúdo encontradas também subsidiaram a estruturação do modelo conceitual proposto que teve por fundamento o referencial teórico. As relações entre as dimensões estabelecidas no modelo conceitual proposto definiram as hipóteses da pesquisa. $\mathrm{Na}$ segunda fase da pesquisa, foi realizada pesquisa quantitativa para avaliação do modelo e empregou novo questionário eletrônico para a coleta dos dados. O modelo de mensuração, o modelo estrutural e as relações hipotetizadas foram analisados utilizando a modelagem de equações estruturais pelo método dos mínimos quadrados parciais (PLS-SEM).

\subsection{SINTESE E CONCLUSÕES DO ESTUDO}

Para possibilitar o atendimento aos objetivos estabelecidos, foi realizada inicialmente uma pesquisa qualitativa para identificar os problemas e causas relacionadas aos projetos de desenvolvimento de medicamentos em laboratórios farmacêuticos estabelecidos no Brasil. A análise do conteúdo das respostas de 33 profissionais ao questionário eletrônico aplicado deu origem a 281 unidades de significado que, após decisões de delimitação e definição das classes de informações, resultaram em 6 unidades de conteúdo relacionadas aos indicadores de desempenho dos projetos de desenvolvimento de medicamentos e 48 unidades relacionadas aos fatores contribuintes para o desempenho.

Tendo por referência a revisão da literatura e o resultado da pesquisa qualitativa, foi proposto um modelo conceitual para indicar os conjuntos de fatores relacionados ao desempenho dos projetos de desenvolvimento de medicamentos genéricos e as relações entre eles. $\mathrm{O}$ modelo foi composto por uma dimensão de resultado (variável dependente) denominada Desempenho e três dimensões (variáveis independentes) relacionadas a ela e denominadas: Gerencial, Estrutural e Técnico, sendo que as relações entre as elas definiram as hipóteses da pesquisa.

As unidades de conteúdo identificados na pesquisa qualitativa foram reclassificados tendo por orientação as dimensões do modelo conceitual e o referencial teórico. Assim, as unidades de conteúdo deram origem aos indicadores para os constructos (variáveis latentes) definidos a partir das dimensões do modelo conceitual. Os indicadores foram então subdivididos em 9 constructos de segunda ordem. 
Para a mensuração do modelo estrutural assim definido, os indicadores selecionados (6 de desempenho e 48 de fatores contribuintes) foram então descritos na forma de assertivas para que pudessem compor o questionário para coleta dos dados. Estas assertivas foram então submetidas á validação de seus conteúdos por meio da aplicação de um questionário específico. Responderam ao questionário 19 profissionais que atuam na indústria farmacêutica. Como resultado, foram validados os conteúdos de 5 indicadores de desempenho (variáveis dependentes) e de 44 indicadores relacionados aos fatores contribuintes para o desempenho fora do planejado (variáveis independentes), os quais estão relacionados Apêndice XII.

Estes resultados responderam ao primeiro e ao segundo objetivos específicos do estudo. Pode-se considerar que a validação deste relativamente grande número de indicadores confirma a contribuição de múltiplas variáveis para o desempenho dos PDMG e, portanto, a complexidade dos PDMG, mesmo em se tratando do desenvolvimento de produtos não inovadores.

A coleta dos dados da fase quantitativa foi realizada por meio da aplicação de novo questionário eletrônico. Foram recebidas e validadas 209 respostas de profissionais que atuam em laboratórios farmacêuticos estabelecidos no Brasil. A análise dos dados coletados foi realizada empregando modelagem de equações estruturais com estimação por mínimos quadrados parciais (PLS-SEM).

Em razão das cargas fatoriais satisfatórias encontradas na análise da validade convergente do modelo de mensuração, concluiu-se que todos os indicadores do modelo estrutural inicialmente avaliado apresentaram relação com os constructos propostos. Este resultado reforçou a resposta aos dois primeiros objetivos específicos da pesquisa.

Para que a validade discriminante fosse satisfatoriamente atingida, foram realizados ajustes no modelo estrutural, sendo que, no total, sete indicadores foram excluídos em razão de apresentarem cargas altas em mais de um constructo. É importante salientar que o fato dos indicadores terem sido retirados do modelo para que fosse obtida a validade discriminante do modelo não significa que não contribuam para os resultados dos PDMG, uma vez que apresentaram cargas fatoriais altas, porém, sem diferença suficiente para distinguirem os constructos com os quais tem relações.

Desta forma, o modelo ajustado (Figura 62) passou a contar com 5 indicadores de desempenho (variáveis dependentes) e 37 indicadores relacionados aos fatores contribuintes para o desempenho fora do planejado (variáveis independentes). Após este procedimento, os resultados dos testes indicaram que o modelo apresentava validade discriminante.

A seguir são tratadas as principais conclusões em relação aos constructos e seus indicadores. A Tabela 68 traz os indicadores que mais contribuíram para os seus constructos. 
Tabela 68 - Indicadores que mais contribuíram para os seus constructos

\begin{tabular}{|c|c|c|}
\hline $\begin{array}{l}\text { Constructo } \\
\text { endógeno }\end{array}$ & $\begin{array}{l}\text { Constructo } \\
\text { exógeno }\end{array}$ & Indicador (assertiva) \\
\hline- & $\begin{array}{l}\text { Desempenho } \\
\text { (variável } \\
\text { dependente) } \\
\end{array}$ & $\begin{array}{l}\text { Foram concluídos, mas com custos totais acima do } \\
\text { orçamento planejado (acima do orçamento). }\end{array}$ \\
\hline \multirow{3}{*}{ Gerencial } & Desenvolvimento & $\begin{array}{l}\text { Dificuldades ou ausência de estudos de pré-formulação do } \\
\text { medicamento. }\end{array}$ \\
\hline & Gestão & $\begin{array}{l}\text { Deficiências e/ou dificuldades no gerenciamento dos } \\
\text { projetos de desenvolvimento dos medicamentos. }\end{array}$ \\
\hline & Portfólio & $\begin{array}{l}\text { Inexistência ou deficiências nos estudos de viabilidade } \\
\text { técnica para escolha dos medicamentos a serem } \\
\text { desenvolvidos. }\end{array}$ \\
\hline \multirow{3}{*}{ Estrutural } & Recursos & $\begin{array}{l}\text { Dificuldades para contratação de profissionais e/ou } \\
\text { serviços de terceiros para as atividades de } \\
\text { desenvolvimento dos medicamentos. }\end{array}$ \\
\hline & Competências & $\begin{array}{l}\text { O laboratório não ter domínio suficiente da tecnologia do } \\
\text { processo de fabricação dos medicamentos. }\end{array}$ \\
\hline & Organização & $\begin{array}{l}\text { Estrutura (organizacional) da empresa que não favorece } \\
\text { e/ou dificulta os projetos de desenvolvimento dos } \\
\text { medicamentos. }\end{array}$ \\
\hline \multirow{3}{*}{ Técnica } & $\begin{array}{l}\text { Especificações } \\
\text { técnicas }\end{array}$ & $\begin{array}{l}\text { Dificuldades no desenvolvimento e validação dos } \\
\text { métodos analíticos dos medicamentos. }\end{array}$ \\
\hline & $\begin{array}{l}\text { Requisitos do } \\
\text { projeto }\end{array}$ & $\begin{array}{l}\text { Longo tempo necessário para o desenvolvimento dos } \\
\text { medicamentos. }\end{array}$ \\
\hline & $\begin{array}{l}\text { Requisitos } \\
\text { regulatórios }\end{array}$ & $\begin{array}{l}\text { Dificuldades no atendimento da legislação sanitária para o } \\
\text { desenvolvimento e/ou registro de medicamentos } \\
\text { genéricos. }\end{array}$ \\
\hline
\end{tabular}

Fonte: dados da pesquisa.

A análise do constructo Desempenho apontou como seu maior contribuinte o indicador relacionado a custos totais acima do orçamento planejado. Este resultado não era esperado em razão da literatura dar mais destaque à preocupação com o prazo para lançamento no mercado. Porém, pode estar na priorização do prazo a razão pela qual o orçamento seja o maior contribuinte a para o desempenho fora do planejado, já que seria menos importante do que o atendimento ao indicador de prazo. Por outro lado, chama a atenção a menor contribuição do indicador de desempenho referente à aprovação do medicamento pela Anvisa, que é um importante indicador da eficácia dos PDMG.

$\mathrm{O}$ indicador com maior contribuição para o constructo Portfólio diz respeito à inexistência ou deficiências nos estudos de viabilidade técnica, que é uma importante entrada para as decisões de portfólio de PDMG. Esta deficiência invariavelmente tem por consequência resultados insatisfatórios ou mesmo o abandono do projeto. Mais ainda, consomem recursos que poderiam ter sido direcionados a projetos mais promissores e pressionam as equipe por resultados sobre projetos ruins.

Deficiências na realização das análises de pré-formulação também podem ter como consequência o desempenho insatisfatórios dos PDMG, uma vez que tem por objetivo facilitar o planejamento e desenvolvimento do projeto ao fornecerem dados preliminares que ajudam a definir o 
escopo e tomada das decisões. No entanto, o resultado da análise dos dados indicou ser este o maior contribuintes para o constructo Desenvolvimento.

$\mathrm{O}$ indicador relacionado às deficiências e/ou dificuldades no gerenciamento dos PDMG apresentou a maior contribuição para o constructo Gestão. Uma das respostas recebidas na pesquisa qualitativa afirmar que a "cultura de gerenciamento de projetos ainda não permeia totalmente a indústria farmacêutica". Este indicador tem sua importância destacada pelos resultados das análises dos efeitos de mediação que indicam que mesmo as deficiências e/o dificuldades estruturais e técnicas são mediadas pelas deficiências na gestão.

O indicador que apresentou a maior contribuição para o constructo Recursos foi o referente às dificuldades para contratação de profissionais e/ou serviços de terceiros para as atividades de desenvolvimento dos medicamentos. A análise considerando outros resultados referentes à influência dos recursos indica ser plausível acreditar que, em geral, não faltam recursos para o desenvolvimento dos PDMG, porém, quando ele são limitados, há importante influência sobre diferentes dimensões dos projetos.

Em relação ao constructo Competências, os resultados dão importância para a insuficiência de domínio da tecnologia do processo de fabricação dos medicamentos, o que, de certa forma, não era esperada, considerando que as tecnologias utilizadas na fabricação dos medicamentos de referência já são conhecidos há tempos. Por outro lado, os resultados das análises univariadas apresentaram maior importância dada à falta de profissionais experientes e/ou com qualificação adequada em número suficiente para o desenvolvimento dos medicamentos. Uma explicação que pode ser considerada é a de que a tecnologia não deva ser complexa, porém falta domínio sobre ela.

O indicador que apresentou a maior importância para a composição do constructo Organização foi o referente à estrutura (organizacional) da empresa. Esta destacada influência da estrutura organizacional sobre o desempenho do PDMG, de certa forma, não era esperada, uma vez que o desenvolvimento de medicamentos é um dos principais processos dos laboratórios farmacêuticos, é realizado há bastante tempo e, portanto, já deveria estar em um certo nível de maturidade.

De uma forma geral, esta importância dada à estrutura (organizacional) que não favorece e/ou dificulta os PDMG pode estar relacionada à dependência de recursos e atividades de outras áreas, que muitas vezes não priorizam ou não atendem adequadamente às necessidades dos PDMG. Entre estes recursos e atividades estão: contratação dos fornecedores e a aquisição de insumos (compras); a realização dos testes de qualidade (controle de qualidade), a produção dos lotes-piloto e escalonamento para escala industrial (produção) e a preparação da documentação para registro do medicamento (assuntos regulatórios). Dependências podem gerar atrasos, riscos e, consequentemente, levar a resultados insatisfatórios. A orientação para o mercado está entre as possíveis condicionantes das prioridades das demais áreas. 
No entanto, é importante considerar que não é só a área de $\mathrm{P} \& \mathrm{D}$ que depende de outras áreas. $\mathrm{O}$ atendimento aos requisitos regulatórios, por exemplo, é normalmente de responsabilidade da área de assuntos regulatórios da empresa, saindo do âmbito da área de P\&D. Neste caso, a área de P\&D é que pode não estar apoiando adequadamente a área de assuntos regulatórios com informações e resultados, tanto para a elaboração do dossiê para registro do medicamento, quanto para o atendimento às exigências da Anvisa durante o processo de análise dos pedidos de registro dos medicamentos. É possível que esse efeito também tenha influenciado a menor avaliação recebida pelo indicador de desempenho referente à aprovação do medicamento pela Anvisa. Como a maior parte dos respondentes é da área de $\mathrm{P} \& \mathrm{D}$, é plausível considerar que isso tenha reduzido a importância deste indicador para a mensuração do desempenho dos PDMG.

Alguns dos indicadores que foram excluídos do modelo por apresentaram cargas fatoriais elevadas em mais de um constructo podem ter relação com a falta de apoio de outras áreas e/ou de superiores. São exemplos os indicadores que trataram de dificuldades em relação à infraestrutura e que apresentaram altas cargas em seu constructo (Recursos) e no constructo Organização. O indicador referente à cultura da empresa também apresentou relevante contribuição para as dificuldades organizacionais.

Outro aspecto refere-se ao processo de tomada de decisão, uma vez que uma estrutura organizacional, além de alocar pessoas, também distribui funções e autoridade. Nesta possibilidade há duas subsequentes que são: a dependência de um processo inadequado para a tomada de decisão e a subordinação do projeto ou mesmo da área ou departamento de P\&D a outra área, como, por exemplo, à de produção ou à de marketing. Esta última possibilidade pode trazer dificuldades aos PDMG em razão de, por exemplo, diferenças nos conhecimentos, nas competências e até mesmo nos interesses e nas prioridades. Um aspecto complementar diz respeito à gestão do apoio necessário ao desenvolvimento dos PDMG. O gerente e/ou a equipe do projeto deve administrar a integração com as demais áreas e obter o engajamento das partes interessadas.

Os resultados também evidenciaram haver contribuição das deficiências e/ou dificuldades na comunicação entre os profissionais e/ou entre as áreas da empresa que participam dos PDMG. O PMI (2017) afirma que as entregas de um projeto dependem da capacidade da equipe do projeto em manter uma comunicação proativa com as partes interessadas. A comunicação é central para o desenvolvimento dos PDMG, principalmente por envolver equipes multifuncionais e interdisciplinares. É possível que haja relação entre as dificuldades de comunicação, a falta de apoio das demais áreas e a forma na qual a empresa é organizada.

O indicador que apresentou a maior relação com o constructo Especificações Técnicas foi o referente às dificuldades no desenvolvimento e validação dos métodos analíticos dos medicamentos. Além das dificuldades intrinsecamente relacionadas ao próprio produto e a seu método de análise, 
muitas vezes o desenvolvimento e validação analítica estão sob responsabilidade de uma área diferente da de P\&D e a dificuldade pode estar também relacionada aos tópicos já comentados, tais como: comunicação, falta de apoio e estrutura organizacional.

Com relação ao constructo Requisitos Regulatórios, os resultados apontaram haver contribuição do indicador que tratou das deficiências e/ou dificuldades no atendimento às exigências da Anvisa durante o processo de análise dos pedidos de registro dos medicamentos. Esta dificuldade, por si só, pode resultar no indeferimento do pedido de registro do medicamento, sendo assim de especial criticidade. Neste indicador, deve-se considerar que a deficiência pode ser causada pela própria área de assuntos regulatórios, mas também pode ser causada por deficiências no PDMG e/ou em suas entregas, principalmente dados e relatórios que são requisitos para o processo de registro do medicamento.

No constructo Requisitos do Projeto, o indicador que trata do longo tempo necessário para os PDMG foi o indicador que apresentou maior contribuição. Projetos com longos prazos tendem ter maior nível de incertezas. A sua combinação com o estabelecimento de prazos muito curtos para os PDMG gera conflitos que provocam reflexos em outras dimensões dos projetos e nos resultados uma vez que as demandas concorrentes ("trade offs") necessitam ser equilibradas..

A análise do modelo estrutural testou as relações entre os constructos que o compõem. Esta análise respondeu ao quarto objetivo específico ao qual estão atreladas às três primeiras hipóteses formuladas (H1, H2 e H3) para este estudo. A análise dos coeficientes de caminho indicou que as relações entre os constructos exógenos e os constructos endógenos foram consideradas significativas e confirmam a contribuição de cada um deles para o modelo. A Tabela 69 a seguir resume os resultados das análises das relações hipotetizadas no modelo conceitual proposto.

Tabela 69 - Resultados das análises das relações hipotetizadas no modelo conceitual proposto

\begin{tabular}{c|c|l}
\hline Hipótese & Resultado & \multicolumn{1}{c}{ Conclusão } \\
\hline H1 & Suportada & $\begin{array}{l}\text { As dificuldades gerenciais estão associadas positivamente com o } \\
\text { desempenho fora do planejado dos projetos de desenvolvimento de } \\
\text { medicamentos genéricos. }\end{array}$ \\
\hline H2 & Rejeitada & $\begin{array}{l}\text { As dificuldades estruturais da desenvolvedora não estão associadas } \\
\text { positivamente com o desempenho fora do planejado dos projetos de } \\
\text { desenvolvimento de medicamentos genéricos. }\end{array}$ \\
\hline H3 & Rejeitada & $\begin{array}{l}\text { As dificuldades técnicas não estão associadas positivamente com o } \\
\text { desempenho fora do planejado dos projetos de desenvolvimento de } \\
\text { medicamentos genéricos. }\end{array}$ \\
\hline H4 & Suportada & $\begin{array}{l}\text { A influência das dificuldades estruturais sobre o desempenho fora do } \\
\text { planejado dos projetos de desenvolvimento de genéricos é mediada } \\
\text { pelas dificuldades gerenciais. }\end{array}$ \\
\hline H5 & Suportada & $\begin{array}{l}\text { A influência das dificuldades técnicas sobre o desempenho fora do } \\
\text { planejado dos projetos de desenvolvimento de genéricos é mediada } \\
\text { pelas dificuldades gerenciais. }\end{array}$ \\
\hline
\end{tabular}

Fonte: dados da pesquisa. 
O resultado da análise de coeficiente de caminho na relação entre o constructo Gerencial e o constructo Desempenho indica que a relação é significativa, ou seja, houve evidência estatística de relação direta das dificuldades gerenciais com o desempenho dos projetos fora do planejado. Este resultado faz com que fosse suportada a hipótese (H1). Desta forma, as dificuldades gerenciais estão associadas positivamente com o desempenho fora do planejado dos projetos de desenvolvimento de medicamentos genéricos.

Por outro lado, não foi possível evidenciar uma relação estatística válida entre os constructos por meio do instrumento utilizado e da amostra da pesquisa para as hipóteses H2 e H3 e que, portanto, foram rejeitadas. Assim, as dificuldades estruturais da desenvolvedora não estão diretamente associadas com o desempenho fora do planejado dos projetos de desenvolvimento de medicamentos genéricos (H2). Este resultado não era esperado, pois acreditava-se que haveria relação direta entre os dois constructos.

Da mesma forma, as dificuldades técnicas não estão diretamente associadas com o desempenho fora do planejado dos projetos de desenvolvimento de medicamentos genéricos (H3). Este resultado também não era esperado, pois, da mesma forma, acreditava-se que haveria relação direta entre os dois constructos, já que a literatura aborda a influência de fatores relacionados a requisitos de produtos, legais e de projeto sobre os resultados dos projetos como restritores, portanto, fora do alcance das decisões do projeto.

Adicionalmente, foi assumida a possibilidade de que fatores estruturais e técnicos também poderiam ser mediados, mesmo que parcialmente. Por esta razão foram estabelecidas as hipóteses (H4) e (H5) de mediação pelo constructo Gerencial. A análise da mediação proposta na hipótese H4 concluiu que a influência das dificuldades estruturais sobre o desempenho fora do planejado dos projetos de desenvolvimento de genéricos é mediada pelas dificuldades gerenciais, ou seja, sustentou a hipótese H4. Da mesma forma, a análise de mediação proposta na hipótese H5 concluiu que a influência das dificuldades técnicas sobre o desempenho fora do planejado dos projetos de desenvolvimento de genéricos é mediada pelas dificuldades gerenciais, ou seja, sustentou a hipótese H5.

Os resultados das análises univariadas já indicavam que os fatores mais críticos para o desempenho dos PDMG são de ordem gerencial. Os indicadores que apresentaram as maiores médias foram: número de projetos acima da capacidade e/ou elevada diversidade de projetos de desenvolvimento de medicamentos em andamento (constructo Portfólio); prazos muito curtos para o desenvolvimento dos medicamentos (constructo Gestão); e mudanças no projeto após o início do desenvolvimento do medicamento (constructo Gestão). 
Conforme os resultados apresentados na Tabela 70, é possível considerar que o estudo respondeu à questão de pesquisa ao identificar quais são os fatores contribuintes para o desempenho dos projetos de desenvolvimento dos medicamentos genéricos na indústria farmacêutica instalada no Brasil. A partir da questão definida para o estudo, foram definidos objetivos específicos para este estudo, os quais também estão relacionados na Tabela 70 juntamente com os resultados a eles relacionados.

Tabela 70 - Objetivos da pesquisa e síntese dos resultados

\begin{tabular}{|c|c|c|}
\hline & Objetivos & Resultados \\
\hline & $\begin{array}{l}\text { Identificar os indicadores } \\
\text { desempenho dos projetos de } \\
\text { desenvolvimento de medicamentos } \\
\text { genéricos; }\end{array}$ & 5 indicadores de desempenho validados \\
\hline b. & $\begin{array}{l}\text { Identificar os fatores contribuintes } \\
\text { para o desempenho dos projetos de } \\
\text { desenvolvimento de medicamentos } \\
\text { genéricos; }\end{array}$ & $\begin{array}{l}44 \text { indicadores dos fatores contribuintes para o } \\
\text { desempenho fora do planejado validados }\end{array}$ \\
\hline c. & $\begin{array}{l}\text { Propor de um modelo teórico } \\
\text { multidimensional que integre o } \\
\text { desempenho dos projetos de } \\
\text { desenvolvimento de medicamentos } \\
\text { genéricos e seus fatores } \\
\text { contribuintes; }\end{array}$ & $\begin{array}{l}\text { Modelo validado com } 5 \text { indicadores de } \\
\text { desempenho (constructo Desempenho) e } 37 \\
\text { indicadores dos fatores contribuintes para o } \\
\text { desempenho fora do planejado validados } \\
\text { (constructos Estrutural, Técnico e Gerencial) }\end{array}$ \\
\hline & $\begin{array}{l}\text { Analisar empiricamente as relações } \\
\text { entre os fatores contribuintes e o } \\
\text { desempenho dos projetos de } \\
\text { desenvolvimento dos medicamentos } \\
\text { genéricos. }\end{array}$ & $\begin{array}{l}\text { Vide Tabela } 68 \text { com hipóteses da pesquisa, } \\
\text { resultados e conclusões }\end{array}$ \\
\hline
\end{tabular}

Fonte: dados da pesquisa.

Considerando o conjunto de indicadores de desempenho e de seus fatores contribuintes ou influenciadores que foram objetivo deste estudo. Considerando também as delimitações do estudo e o contexto dos PDMG, comprovou-se a tese de que as dificuldades e deficiências no gerenciamento tem influência direta sobre o desempenho fora do planejado dos projetos de desenvolvimento de medicamentos genéricos. Também comprovou-se que as dificuldades e deficiências no gerenciamento exercem efeito mediador entre as dificuldades e deficiências estruturais e técnicas e o desempenho fora do planejado dos projetos desenvolvimento de medicamentos genéricos.

\subsection{CONTRIBUIÇÕES DO ESTUDO}

Embora já haja uma amplo referencial sobre o desenvolvimento de produtos, seus indicadores de desempenho, os fatores influenciadores ou facilitadores e o papel do gerenciamento de projetos, no 
caso específico dos projetos de desenvolvimento de medicamentos genéricos, poucos são os estudos já realizados. Do ponto de vista acadêmico, ao pesquisar os fatores que contribuem para os desempenho fora do planejado dos PDMG, este estudo considera como contribuições:

- a identificação e validação de cinco indicadores de desempenho (prazo, custo, aprovação pela Anvisa, preço de mercado e necessidade de ajustes após o lançamento) para os PDMG;

- a identificação e validação de 44 indicadores dos fatores contribuintes para o desempenho fora do planejado (constructos Estrutural, Técnico e Gerencial) dos PDMG;

- a proposição e a validação de um modelo multidimensional que representa a relação entre o desempenho fora do planejado dos PDMG e seus fatores contribuintes na indústria farmacêutica instalada no Brasil;

- a proposição e aplicação de escalas para a mensuração dos constructos propostos;

- a comprovação da tese de que as dificuldades e deficiências no gerenciamento tem influência direta sobre o desempenho fora do planejado dos projetos de desenvolvimento de medicamentos genéricos;

- a comprovação das teses de que as dificuldades e deficiências no gerenciamento exerce efeito mediador entre as dificuldades e deficiências estruturais e técnicas e o desempenho fora do planejado dos projetos desenvolvimento de medicamentos genéricos.

Como pontos relevantes para a gestão dos PDMG e melhoria do desempenho, os resultados os estudo sugerem:

- melhoria da integração entre as áreas participantes;

- melhorias no processo de gerenciamento do portfólio de projeto;

- o estabelecimento de cronogramas que considerem mais atentamente as restrições de recursos e os requisitos de qualidade do projeto e do produto.;

- aumento do uso dos conceitos e técnicas de gestão de riscos que, combinado com o aprofundamento do conhecimento dos medicamento enquanto produtos e processos, permitam a aplicação adequada da abordagem do "Quality by Design" - QbD.

Desta forma, do ponto de vista da aplicação gerencial dos resultados do estudo, espera-se:

- que os laboratórios farmacêuticos e seus profissionais possam concentrar suas atenções nos elementos mais relevantes e melhorar o desempenho e resultados de seus projetos ao possibilitar a ampliação do entendimento dos PDMG e de seus fatores contribuintes;

- estimular os laboratórios a aprofundarem a avaliação de seus próprios PDMG, reconhecerem os fatores mais críticos neles presentes e desenvolver soluções que facilitem o seu desenvolvimento. 
- possibilitar a identificação de oportunidades de melhorias nos PDMG desenvolvidos pelos laboratórios farmacêuticos estabelecidos no Brasil e que resultem em custos mais baixos e em menor tempo para o lançamento dos novos medicamentos;

- possibilitar a diminuição da taxa de rejeição dos pedidos de registro dos medicamentos pelo órgão regulador;

- favorecer a ampliação e aprofundamento do uso de metodologia científica nos PDMG, em especial o uso da abordagem de QbD.

No constructo gestão, o indicador com maior contribuição foi o relacionado a deficiências no gerenciamento de projetos. Este resultado, de certa forma, além de apontar uma deficiência, também indica uma das possíveis soluções para a melhoria do desempenho dos PDMG, justamente o do melhor gerenciamento dos projetos, mas em um escopo ampliado, envolvendo desde a estrutura da organização em que estão inseridos, até as decisões mais estratégicas e o engajamento das pessoas interessadas. O PMI (2017) indica que as restrições relacionadas a um fator limitante que afeta a execução de um projeto ou processo podem gerar oportunidades quando são removidas ou reduzidas.

Mais uma vez, como observado por Cooper e Kleinschmidt (1987a); Kalluri e Kodali (2014); Montoya-Weiss e Calantone (1994), os estudos como este, que tem foco no insucesso ou fracasso, fornecem análises retrospectivas de falhas no passado e problemas comuns no processo de desenvolvimento e para os quais os gestores poderiam tomar ações para sobrepor ou evitar nos futuros projetos.

Por fim, do ponto de vista da sociedade em geral, ao poder contribuir para a oferta de medicamentos a custos mais baixos e/ou em menores tempos para lançamento e disponibilização aos pacientes, como possíveis contribuições deste estudo espera-se:

- ao possibilitar a melhoria do desempenho dos PDMG, o benefício à população com mais acesso aos medicamentos;

- o lançamento de medicamentos genéricos inéditos em menor tempo;

- a sua oferta dos medicamentos genéricos a preços menores;

- o maior acesso e a melhor distribuição pelos serviços de saúde pública que atendem parte significativa e necessitada da população brasileira.

Do ponto de vista da agência reguladora, Do Carmo (2017) considera que o indeferimento dos pedidos de registro de medimentos resulta também em desperdício dos recursos empregados nos processos de avaliação. Assim, melhorias nos PDMG também trariam benefícios para órgãos reguladores. 


\subsection{LIMITAÇÕES DO MÉTODO DE PESQUISA}

Os estudo não pode ser considerado extensivo no sentido de sua completude e esgotamento sobre o tema. Embora o modelo conceitual proposto tenha abordado as várias dimensões ambientais, institucionais e operacionais envolvidas nos projetos de desenvolvimento de medicamentos genéricos, outros fatores podem interferir nos resultados dos projetos, tais como: sociais, econômicas e políticas.

É possível que a forma como foi estruturado o instrumento de coleta da dados tenha influenciado as respostas no sentido da introdução de vieses, apesar dos cuidados tomados. Esta é uma das razões pelas quais, apesar da amostragem ser considerada satisfatória, é possível que a replicação do questionário, mas em um outro período ou com outra amostra da mesma população, possam coletar dados que irão resultar em conclusões diferentes, dada também a subjetividade característica deste tipo de pesquisa.

Ressalta-se também a impossibilidade de generalização dos resultados, mesmo havendo cuidado na aplicação dos conceitos e técnicas estatísticas, principalmente porque a amostragem não é aleatória. Estas são algumas das razões para que as conclusões deste estudo sejam utilizadas com cuidado em situações específicas ou mesmo em situações semelhantes.

Se por um lado a participação de membros das equipes dos PDMG e de profissionais da área de $\mathrm{P} \& \mathrm{D}$ os qualifica para responder ao questionário da pesquisa, há que se considerar que a predominância de profissionais com estas características pode teoricamente ter introduzido um viés nas respostas por resultar em maior participação da visão de dentro do projeto e das áreas diretamente envolvidas. No entanto, também há que se considerar que profissionais com atuação indireta nos PDMG possivelmente não teriam acesso a especificidades de seus desenvolvimentos e tampouco teriam compromissos com os resultados dos projetos.

Diferentemente do estudo de Murphy, Baker e Fisher (1974), esta pesquisa limitou-se à relação entre deficiências e ausências dos fatores e os resultados fora do planejado dos projetos, ou seja, condições contribuintes para o insucesso. Desta forma, é preciso cuidado ao interpretá-los como situações que, se diminuídas ou eliminadas, contribuiriam para o sucesso dos projetos.

Vale lembrar que, em razão de não terem sido encontradas na literatura referências a pesquisas semelhantes e também considerando que as que tratam do mesmo tema terem sido publicadas há algum tempo, não foi possível a realização de análises comparativas mais aprofundadas com base em referencial teórico específico e mais atual. 


\subsection{OPORTUNIDADES PARA ESTUDOS NO FUTURO}

As oportunidades de estudo tem início com os próprios dados coletados por esta pesquisa, uma vez que há sempre questões e hipóteses complementares a serem pesquisadas utilizando a mesma base. Como exemplo, poderiam ser realizadas análises bivariadas para relações específicas entre as variáveis estudadas e sobre as possíveis razões hipotetizadas para os resultados obtidos.

O fato de não terem sido identificados estudos semelhantes na literatura implica em lacunas que não são preenchidas com um único estudo e que também pode ampliar as questões sobre o tema. $\mathrm{O}$ fato é que para cada relação constante do constructo proposto, há inúmeras possibilidades de estudos específicos e aprofundados. Assim, há que se considerar estudos descritivos e correlacionais em escopos mais delimitados ou recortes do estudo, uma vez que, ao identificar vários itens relacionados ao desempenho dos PDMG, no limite, cada um deles pode ser objeto de estudos específicos.

Algumas questões que surgem mais de imediato com base nas conclusões deste estudo são, por exemplo: Quais seriam as características da influência da limitação do prazo para lançamento sobre o PDMG e seu desempenho? Quais os impactos da cultura da indústria farmacêutica brasileira sobre os PDMG? Quais as características da aplicação da abordagem de "Quality by Design" nos PDMG em laboratórios farmacêuticos brasileiros?

Considerando a conclusão dando conta da importância do gerenciamento para o desempenho dos PDMG, pode-se considerar crítico o papel do gerente do projeto. Assim, embora esta pesquisa tenha identificado que há influência do uso de metodologia de gerenciamento de projetos sobre as dificuldades de gestão, não foi aprofundado o papel do gerente do projeto, o que seria potencialmente o tema de um novo estudo.

À semelhança do estudo de Murphy, Baker e Fisher (1974), uma nova pesquisa poderia ter por objetivos classificar os fatores entre os que, se presentes, contribuem para o sucesso ou insucesso e os fatores que, se ausentes, também contribuem para o sucesso ou insucesso.

A replicação da pesquisa para estudos longitudinais é uma possibilidade. Tomadas as devidas precauções e realizados os ajustes necessários, há também a possibilidade de replicação da pesquisa em outras amostras, ou mesmo, outras populações. Assim, uma possibilidade seria a realização de estudo semelhante a outras classes de medicamentos como os similares e até mesmo aos inovadores. Em uma amplitude maior o estudo poderia ser também aplicados a outros grupos de produtos que devem respeitar normas técnicas e requisitos regulatórios como outros produtos para saúde e outros setores como o aeronáutico, por exemplo.

Considerando a validação parcial do modelo conceitual e que nem todas as possíveis hipóteses foram estabelecidas a partir do modelo base, uma vez que há sempre a possibilidade de modelos concorrentes, e o fato de se tratar de pesquisa com características também exploratórias, o modelo proposto pode ser submetido a mais testes e eventualmente complementado e/ou melhorado. Assim, 
seguindo o comentário de Montoya-Weiss e Calantone (1994), descobertas que não confirmam as hipóteses formuladas ou que não apresentam significância devem ser relatadas pelos pesquisadores para que o pensamento atual no campo possa ser refinado e as implicações gerenciais desse achado sejam adequadamente abordadas. 


\section{REFERÊNCIAS BIBLIOGRÁFICAS}

Adeyeye, M. C., \& Brittain, H. G. (Eds.). (2008). Preformulation in solid dosage form development (Drugs and). New York: Informa Healthcare.

Ahmed, S. U., Naini, V., \& Wadgaonkar, D. (2005). Scale-Up, Process Validation, and Technology Transfer. In L. Sharge \& K. I. (Eds.), Generic Drug Product Development. Solid Oral Dosage Forms (pp. 95-136). New York: Marcel Dekker.

Alegre, J., Lapiedra, R., \& Chiva, R. (2006). A measurement scale for product innovation performance. European Journal of Innovation Management, 9(4), 333-346. https://doi.org/10.1108/14601060610707812

Alexandre, N. M. C., \& Coluci, M. Z. O. (2011). Validade de conteúdo nos processos de construção e adaptação de instrumentos de medidas. Ciência \& Saúde Coletiva, 16(7), 3061-3068. https://doi.org/10.1590/S1413-81232011000800006

Allen, T. J. (1970). Communication networks in R \& D Laboratories. R\&D Management, 1(1), 14-21. https://doi.org/10.1111/j.1467-9310.1970.tb01193.x

Allen, T. J. (1971). Communications, technology transfer, and the role of technical gatekeeper. $R \& D$ Management, 1(1), 14-21.

Allen, T. J. (1977). Managing the flow of technologytechnology transfer and the dissemination of technological information within the $R \& D$ organization. Cambridge, MA: MIT Press.

Allen, T. M., \& Cullis, P. R. (2004). Drug Delivery Systems: Entering the Mainstream. Science, 303(5665), 1818-1822. https://doi.org/10.1126/science.1095833

Allport, S., \& Cooke-Davies, T. (2010). Integrated drug development: from cradle to grave and from lab to market. In Pete Harpum (Ed.), Portfolio, Program, and Project Management in the Pharmaceutical and Biotechnology Industries (pp. 239-258). Hoboken, NJ: John Wiley \& Sons.

Anand, O., Yu, L. X., Conner, D. P., \& Davit, B. M. (2011). Dissolution Testing for Generic Drugs: An FDA Perspective. The AAPS Journal. https://doi.org/10.1208/s12248-011-9272-y

Ancona, D. G., \& Caldwell, D. F. (1990). Beyond boundary spanning: Managing external dependence in product development teams. Journal of High Technology Management Research, 1(2), 119135. https://doi.org/10.1016/1047-8310(90)90001-K

Ancona, D. G., \& Caldwell, D. F. (1992a). Bridging the Boundary: External Activity and Performance in Organizational Teams. Administrative Science Quarterly, 37(4), 634. https://doi.org/10.2307/2393475

Ancona, D. G., \& Caldwell, D. F. (1992b). Demography and Design: Predictors of New Product Team Performance. Organization Science, 3(3), 321-341. https://doi.org/10.1287/orsc.3.3.321

Andrade, C. A. A. de. (2010). Inovação e externalização: uma análise de capabilities na indústria farmacêutica. Universidade de São Paulo. Retrieved from http://www.teses.usp.br/teses/disponiveis/3/3136/tde-17082010-112747/en.php

Andreassi, T., \& Sbragia, R. (2002). Relações entre indicadores de P \& D e de resultado empresarial. Revista de Administração, 37(1), 72-84.

Anvisa. RDC No 16, de 2 de Março de 2007 (2007). Brasil, Brasil.

Anvisa. RDC No 81, de 05 de novembro de 2008 (2008). Brasil: DOU n ${ }^{\circ} 219$, de 11 de novembro de 2008. Retrieved from http://portal.anvisa.gov.br/documents/10181/2718376/RDC_81_2008_COMP.pdf/096e030a4cdb-4675-b930-72c41368a5bb

Anvisa. RDC No 73 de 7 de abril de 2016, DOU Nº67 de 08/04/2016 § (2016). Brasil. Retrieved from http://portal.anvisa.gov.br/documents/10181/2785365/RDC_73_2016_COMP.pdf/270eddaf5f15-4b2d-a939-0038161a2187\%0Ahttps://www20.anvisa.gov.br/coifa/pdf/rdc166.pdf

Anvisa. (2017a). Número de Medicamentos Genéricos registrados por empresa. Retrieved February 4, 2019 , from

http://portal.anvisa.gov.br/documents/33836/352400/Número+de+Medicamentos+Genéricos+reg istrados+por+empresa/603dd921-b5f3-47b3-9306-b70abc86eb67 
Anvisa. RDC No 200, de 26 de Dezembro de 2017. (2017). Brasil: DOU n ${ }^{\circ} 248$, de 28 de dezembro de 2017. Retrieved from http://portal.anvisa.gov.br/documents/10181/3836387/RDC_200_2017_COMP.pdf/3b8c3b3124cb-4951-a2d8-8e6e2a48702f

Anvisa. (2018a). Anuário Estatístico do Mercado Farmacêutico 2017. Brasília. Retrieved from http://portal.anvisa.gov.br/documents/374947/3413536/Anuário+Estatístico+do+Mercado+Farm acêutico+-+2017/3179a522-1af4-4b4c-8014-cc25a90fb5a7

Anvisa. (2018b). Conceitos e definições de medicamentos. Retrieved November 24, 2019, from http://portal.anvisa.gov.br/medicamentos/conceitos-e-definicoes

Anvisa. (2018c). Genéricos e similares ocupam 65\% do mercado nacional (Vol. d). Brasilia.

Retrieved from http://portal.anvisa.gov.br/noticias?p_p_id=101_INSTANCE_FXrpx9qY7FbU\&p_p_col_id=col umn-

2\&p_p_col_pos=1\&p_p_col_count=2\&_101_INSTANCE_FXrpx9qY7FbU_groupId=219201\& _101_INSTANCE_FXrpx9qY7FbU_urlTitle=genericos-e-similares-ocupam-65-do-mercadonacional\&_101_

Anvisa. (2019a). Farmacovigilância. Retrieved from http://portal.anvisa.gov.br/farmacovigilancia?inheritRedirect=true

Anvisa. Instrução Normativa - IN n ${ }^{\circ} 47$ de 21 de agosto de 2019, Pub. L. No. 162-22 de agosto de 2019, 96 (2019). Brasil: DOU - Diário Oficial da União. Retrieved from http://pesquisa.in.gov.br/imprensa/jsp/visualiza/index.jsp?data=22/08/2019\&jornal=515\&pagina $=99 \&$ totalArquivos $=112$

Anvisa. RDC N 318 de 06 de novembro de 2019 (2019). Brasil, Brasil.

Anvisa. (2019d). Registro de Medicamentos Novos. Retrieved December 22, 2019, from http://portal.anvisa.gov.br/registros-e-autorizacoes/medicamentos/produtos/medicamentosnovos/registro

Anvisa. (2019e). Registro de Medicamentos Novos. Retrieved from http://portal.anvisa.gov.br/medicamentos/conceitos-e-definicoes

Anvisa. Resolução - RDC No 301, DE 21 DE AGOSTO DE 2019 (2019). Brasil: DOU - Diário Oficial da União. Retrieved from

http://pesquisa.in.gov.br/imprensa/jsp/visualiza/index.jsp?data=22/08/2019\&jornal=515\&pagina $=64 \&$ totalArquivos $=112$

Aroian, L. A. (1947). The Probability Function of the Product of Two Normally Distributed Variables. The Annals of Mathematical Statistics, 18(2), 265-271. https://doi.org/10.1214/aoms/1177730442

Aulton, M. E., \& Taylor, K. M. G. (2016). Aulton Delineamento de Formas Farmacêuticas (4th ed., Vol. 66). Rio de janeiro - RJ: Elsevier.

Avkiran, N. K., \& Ringle, C. M. (Eds.). (2018). Partial Least Squares Structural Equation Modeling Recent Advances in Banking and Finance. Cham: Springer.

Bansal, A. K., \& Koradia, V. (2005). The role of reverse engineering in the development of generic formulations. Pharmaceutical Technology.

Bañuelas, R., \& Antony, J. (2003). Going from six sigma to design for six sigma: An exploratory study using analytic hierarchy process. TQM Magazine, 15(5), 334-344. https://doi.org/10.1108/09544780310487730

Barczak, G., Griffin, A., \& Kahn, K. B. (2009). Perspective: Trends and drivers of success in NPD practices: Results of the 2003 PDMA best practices study. Journal of Product Innovation Management, 26(1), 3-23. https://doi.org/10.1111/j.1540-5885.2009.00331.x

Bardin, L. (2015). Análise de conteúdo (Edição revista e actualizada). Lisboa: Edições 70. https://doi.org/10.1017/CBO9781107415324.004

Baron, R. M., \& Kenny, D. A. (1986). The Moderator-Mediator Variable Distinction in Social Psychological Research. Conceptual, Strategic, and Statistical Considerations. Journal of Personality and Social Psychology, 51(6), 1173-1182. https://doi.org/10.1037/00223514.51.6.1173

Basadur, M., \& Finkbeiner, C. T. (1985). Measuring Preference for Ideation in Creative ProblemSolving Training. The Journal of Applied Behavioral Science, 21(1), 37-49. 
https://doi.org/10.1177/002188638502100104

Basavaraj, S., \& Betageri, G. V. (2014). Can formulation and drug delivery reduce attrition during drug discovery and development - review of feasibility, benefits and challenges. Acta Pharmaceutica Sinica B. https://doi.org/10.1016/j.apsb.2013.12.003

Bassler, D., Oehmen, J., Seering, W., \& Ben-Daya, M. (2011). A comparison of the integration of risk management principles in product development approaches. ICED 11 - 18th International Conference on Engineering Design - Impacting Society Through Engineering Design, 3(August), 306-316.

Beck, K., \& et al. (2001). Manifesto for Agile Software Development. Retrieved from http://agilemanifesto.org/

Benito-Osorio, D., Guerras-Martín, Á., \& Zuñiga-Vicente, J. Á. (2012). Four decades of research on product diversification : a literature review. Management Decision, 50(2), 325-344. https://doi.org/10.1108/00251741211203597

Bhattacharyya, P. K. (2005). Drug Stability. In L. Shargel \& I. Kanfer (Eds.), Generic Drug Product Development. Solid Oral Dosage Forms (pp. 137-172). New York: Marcel Dekker.

Bickman, L., \& Debra J. Rog. (2009). The Sage handbook of applied social research methods (2nd ed.). Thousand Oaks, CA: SAGE.

Bido, D. de S. (2008). AVE_CC_2a_ordem. Planilha Excel. São Paulo.

Bido, D. de S. (2018). Tamanho da Amostra e Poder Estatístico. Apresentação. São Paulo.

Bido, D. de S., \& Da Silva, D. (2019). SmartPLS 3: Especificação, Estimação, Avaliação e Relato. Administração: Ensino e Pesquisa, 20(2), 488-536. https://doi.org/10.13058/raep.2019.v20n2.1545

Bido, D. de S., Mantovani, D. M. N., \& Cohen, E. D. (2018). Destruction of measurement scale through exploratory factor analysis in production and operations research. Gestao e Producao, 25(2), 384-397. https://doi.org/10.1590/0104-530X3391-16

Birou, L. M., \& Fawcett, S. E. (1994). Supplier Involvement in Integrated Product Development. International Journal of Physical Distribution \& Logistics Management, 24(5), 4-14. https://doi.org/10.1108/09600039410063982

Blau, G. E., Pekny, J. F., Varma, V. A., \& Bunch, P. R. (2004). Managing a portfolio of interdependent new product candidates in the pharmaceutical industry. Journal of Product Innovation Management, 21(4), 227-245. https://doi.org/10.1111/j.0737-6782.2004.00075.x

Boer, H., \& During, W. E. (2001). Innovation, what innovation? a comparison between product, process and organizational innovation. International Journal of Technology Management, 22(13), 83-107. https://doi.org/10.1504/ijtm.2001.002956

Bolton, S. (2005). Statistical Considerations for Establishing Bioequivalence. In L. Shargel \& I. Kanfer (Eds.), Generic Drug Product Development. Solid Oral Dosage Forms (pp. 257-279). New York: Marcel Dekker.

Booz, Allen, \& Hamilton. (1982). New Product Development in the 1980's. New York, 11-18.

Botelho, S. F., Martins, P. M. A., \& Reis, A. M. M. (2018). Análise de medicamentos novos registrados no Brasil na perspectiva do Sistema Único de Saúde e da carga de doença. Ciência \& Saúde Coletiva, 23, 215-228. https://doi.org/10.1590/1413-81232018231.21672015

Brasil. LEI No 5.991, de 17 de dezembro de 1973 - Controle de Medicamentos.pdf (1973). Brasil.

Brasil. Lei No 9.787, de 10 de fevereiro de 1999 - Medicamentos Genéricos (1999). Brasilia, Brasil.

Braum, C. A. (2014). Adaptação de Modelo de Gestão de Portfólio de Produtos para Indústria Farmacêutica. Universidade Federal do Rio Grande do Sul.

Brown, L., \& Grundy, T. (2011). Project Management for the Pharmaceutical Industry. Abingdon: Routledge. https://doi.org/10.4324/9781315602400

Brown, S., \& Eisenhardt, K. (1995). Product development: Past research, present findings, and future directions. Academy of Management Review. https://doi.org/10.5465/AMR.1995.9507312922

Brown, S. L., \& Eisenhardt, K. M. (1995). Product development: Past research, present findings, and future directions. Academy of Management Review. https://doi.org/10.5465/AMR.1995.9507312922

Brown, T. E. (2004). Skunk works: a sign of failure, a sign of hope? In T. E. Brown \& J. Ulijn (Eds.), 
Innovation, Entrepreneurship and Culture. The Interaction between Technology, Progress and Economic Growth (pp. 130-146). Northampton, MA, MA: Edward Elgar.

Buchner, A., Erdfelder, E., Faul, F., \& Lang, A.-G. (2019). G*Power. Dusseldorf: Heinrich-HeineUniversität Düsseldorf. Retrieved from http://www.psychologie.hhu.de/arbeitsgruppen/allgemeine-psychologie-undarbeitspsychologie/gpower.html

Bullinger, H. J., Fähnrich, K. P., \& Meiren, T. (2003). Service engineering - Methodical development of new service products. International Journal of Production Economics, 85(3), 275-287. https://doi.org/10.1016/S0925-5273(03)00116-6

Calixto, J. B., \& Siqueira Jr, J. M. (2008). Desenvolvimento de Medicamentos no Brasil : Desafios The Drug Development in Brazil : Challenges. Gazeta Médica Da Bahia, 78(1), 98-106. Retrieved from http://www.gmbahia.ufba.br/index.php/gmbahia/article/view/269/260

Chang, L. C., \& Gau, C. S. (2013). Statistics, Quality Review Issues, and Beyond for Generic Drug Applications in Taiwan. Therapeutic Innovation and Regulatory Science, 47(6), 670-677. https://doi.org/10.1177/2168479013495687

Chang, R.-K., Raw, A., Lionberger, R., \& Yu, L. (2013). Generic Development of Topical Dermatologic Products: Formulation Development, Process Development, and Testing of Topical Dermatologic Products. The AAPS Journal. https://doi.org/10.1208/s12248-012-9411-0

Chaudhuri, A. (2013). Simultaneous improvement in development time, cost and quality: A practical framework for generic pharmaceuticals industry. $R$ and D Management, 43(3), 227-241. https://doi.org/10.1111/j.1467-9310.2012.00675.x

Chen, J., Damanpour, F., \& Reilly, R. R. (2010). Understanding antecedents of new product development speed: A meta-analysis. Journal of Operations Management. https://doi.org/10.1016/j.jom.2009.07.001

Chin, W. W. (1998). The Partial Least Squares Approach to Structural Modeling. Modern Methods for Business Research, (JANUARY 1998), 295-336.

Chin, W. W., \& Newsted, P. R. (1999). Structural Equation Modeling Analysis with Small Samples using Partial Lesst Squares. In Rick H. Hoyle (Ed.), Statistical Strategies for Small Sample Research (pp. 307-339). Thousand Oaks, CA: Sage.

Chongprasert, S. (2016). Successful generic drug product development: From research to marketing approval. Asian Journal of Pharmaceutical Sciences. https://doi.org/10.1016/j.ajps.2015.10.023

Chrissis, M. B., Konrad, M., \& Shrum, S. (2011). CMMI® for Development. Guidelines for Process Integration and Product Improvement (3rd ed.). Boston, MA: Pearson Education.

Churchill, G. A., \& Iacobucci, D. (2005). Marketing Research: Methodological Foundations. Structural Equation Modeling (9th ed.). Mason, OH: South-Western.

Ciganek, S. M., Mehta, A. J., Mellina, F. J., \& Shargel, L. (2005). Scale-up, Post-approval Changes, and Post-marketing Surveillance. In L. Shargel \& I. Kanfer (Eds.), Generic Drug Product Development. Solid Oral Dosage Forms (pp. 281-298). New York: Marcel Dekker.

Clark, K. B., \& Fujimoto, T. (1991). Product Development Performance: Strategy, Organization, and Management in the World Auto Industry. Harvard Business School Press.

Clark, Kim B., Chew, W. B., \& Fujimoto, T. (1987). Product Development in the World Auto Industry. Brookings Papers on Economic Activity, 3, 734. https://doi.org/10.2307/2534453

Clark, Kim B., \& Wheelwright, S. C. (1992). Organizing and Leading "Heavyweight" Development Teams. California Management Review, 34(3), 9-28. https://doi.org/10.2307/41167421

Clark, Kim B., \& Wheelwright, S. C. (1993). Managing New Product and Process Development. New York: Free Press.

Cleland, D. I. (1999). Project management: strategic design and implementation (3rd ed.). Singapore: McGraw-Hill.

Cohen, E. M., \& Lin, L.-Y. (2005). Active Pharmaceutical Ingredients. In L. Shargel \& I. Kanfer (Eds.), Generic Drug Product Development. Solid Oral Dosage Forms (pp. 17-29). New York: Marcel Dekker.

Cohen, J. (1988). Statistical Power Analysis for the Behavioral Sciences (2nd ed.). New York: Lawrence Erlbaum.

Conforto, E. C., Amaral, D. C., \& Silva, S. L. Da. (2011). Roteiro para revisão bibliográfica sistemática : aplicação no desenvolvimento de produtos e gerenciamento de projetos. $8^{\circ}$ 
Congresso Brasileiro de Gestão de Desenvolviemnto de Produto - CNGDP 2011, (1998), 1-12. Retrieved from http://www.ufrgs.br/cbgdp2011/downloads/9149.pdf

Conner, D. P., \& Davit, B. M. (2005). Bioequivalence and Drug Product Assessment, In Vivo. In L. Shargel \& I. Kanfer (Eds.), Generic Drug Product Development. Solid Oral Dosage Forms (pp. 227-255). New York: Marcel Dekker.

Cooper, R. G. (1979). The Dimensions of Industrial New Product Success and Failure. Journal of Marketing, 43(3), 93-103. https://doi.org/https://doi.org/10.1177/002224297904300310

Cooper, R. G. (1984). How new product strategies impact on performance. The Journal of Product Innovation Management, 1(1), 5-18. https://doi.org/10.1016/S0737-6782(84)80038-7

Cooper, R. G. (1985). Industrial firms' new product strategies. Journal of Business Research, 13(2), 107-121. https://doi.org/10.1016/0148-2963(85)90034-7

Cooper, R. G. (1990). Stage-Gate Systems: A New Tool for Managing New Products. Business Horizon, May-Jun, 44-54.

Cooper, R. G. (2017). Winning at new products: Creating value through innovation (4th ed.). New York: Basic Books.

Cooper, R. G. (2019). The drivers of success in new-product development. Industrial Marketing Management, 76(July 2018), 36-47. https://doi.org/10.1016/j.indmarman.2018.07.005

Cooper, R. G., Edgett, S. J., \& Kleinschmidt, E. J. (1997). Portfolio management in new product development : Lessons from the leaders--I. Portfolio The Magazine Of The Fine Arts.

Cooper, R. G., \& Kleinschmidt, E. J. New products - What separates winners from losers, The Journal of Product Innovation Management § (1987). https://doi.org/10.1016/0737-6782(87)90002-6

Cooper, R. G., \& Kleinschmidt, E. J. (1987b). What makes a new product a winner: Success factors at the project level. R\&D Management, 17(3), 175-189. https://doi.org/10.1111/j.14679310.1987.tb00052.x

Court, J., \& Fowler, M. (2008). Project Management and Outsourcing Drug Development. In T. Kennedy (Ed.), Pharmaceutical Project Management (2nd ed., pp. 201-220). New York: Informa Healthcare.

Creswell, J. W. (2014). Investigação Qualitativa e Projeto de Pesquisa: Escolhendo entre Cinco Abordagens (3rd ed.). Porto Alegre: Penso.

Creswell, John W. (2010). Projeto de pesquisa. Método qualitativo, quantitativo e misto (3rd ed.). Porto Algre: Artmed.

Cunha, A. V. M., Rodrigues, G. C., Mendonça, P. G. B., Cunha, S. S., \& Araujo, C. de. (2016). Inovação e desenvolvimento de novos produtos : Características do ramo farmacêutico brasileiro. In FAGEN - UFU (Ed.), EGEN - Encontro de Gestão e Negócio (pp. 1-13). Uberlândia - MG: researchgate.net.

Davis, B., Lundsberg, L., \& Cook, G. (2008). PQLI control strategy model and concepts. Journal of Pharmaceutical Innovation, 3(2), 95-104. https://doi.org/10.1007/s12247-008-9035-1

Davit, B. M., Nwakama, P. E., Buehler, G. J., Conner, D. P., Haidar, S. H., Patel, D. T., ... Woodcock, J. (2009). Comparing generic and innovator drugs: A review of 12 years of bioequivalence data from the United States Food and Drug Administration. Annals of Pharmacotherapy, 43(10), 1583-1597. https://doi.org/10.1345/aph.1M141

De Paula, I. C. (2004). Proposta de um modelo de referência para o processo de desenvolvimento de produtos farmacêuticos. Universidade Federal do Rio Grande do Sul - UFRGS. Retrieved from https://lume.ufrgs.br/handle/10183/5785

De Paula, I. C., \& Ribeiro, J. L. D. (2007). A Reference Model for the Pharmaceutical PDP Management - an architecture. In G. Loureiro \& R. Curran (Eds.), Complex Systems Concurrent Engineering. Collaboration, Technology Innovation and Sustainability (pp. 765-772). London: Springer. https://doi.org/https://doi.org/10.1007/978-1-84628-976-7

Dekkers, R., Chang, C. M., \& Kreutzfeldt, J. (2013). The interface between product design and engineering and manufacturing: A review of the literature and empirical evidence. International Journal of Production Economics, 144, 316-333. https://doi.org/10.1016/j.ijpe.2013.02.020

Dimasi, J. A., Feldman, L., Seckler, A., \& Wilson, A. (2009). Trends in Risks Associated With New Drug Development : Success Rates for Investigational Drugs. Clinical Pharmacology \& 
Therapeutics, 87(3), 272-277. https://doi.org/10.1038/clpt.2009.295

DiMasi, J. A., Hansen, R. W., \& Grabowski, H. G. (2003). The price of innovation: New estimates of drug development costs. Journal of Health Economics, 22(2), 151-185. https://doi.org/10.1016/S0167-6296(02)00126-1

Do Carmo, A. C. M. (2017). Panorama de indeferimento de registro de medicamentos sintéticos em 2015. Universidade de Brasília.

Do Carmo, A. C. M., Cunha-Filho, M. S. S., Gelfuso, G. M., \& Gratieri, T. (2017). Evolution of quality on pharmaceutical design: regulatory requirement? Accreditation and Quality Assurance, 22(4), 199-205. https://doi.org/10.1007/s00769-017-1270-z

Do Carmo, A. C. M., Nogueira, E., \& Gratieri, T. (2017). Principais razões não técnicas para o indeferimento de registro de medicamentos em 2015. Vigilância Sanitária Em Debate, 5(2), 127. https://doi.org/10.22239/2317-269x.00835

Do Carmo, A. C. M., Piras, S. S., Rocha, N. F. M., \& Gratieri, T. (2017). Main Reasons for Registration Application Refusal of Generic and Similar Pharmaceutical Drug Products by the Brazilian Health Regulatory Agency (ANVISA). BioMed Research International, 2017. https://doi.org/10.1155/2017/7894937

do Couto, M. V. L. (2014). A Pré-Qualificação de medicamentos: Análise comparativa entre as Boas Práticas de Fabricação da OMS e da ANVISA Rio de Janeiro. Instituto de Tecnologia em Fármacos - FIOCRUZ. Retrieved from https://www.arca.fiocruz.br/handle/icict/11632

Donald S. Tull, \& Del I. Hawkins. (1984). Marketing research: measurement and method: a text with cases (3 ed). New York: Macmillan.

Dooley, K., Subra, A., \& Anderson, J. (2001). Maturity and its impact on new product development project performance. Research in Engineering Design - Theory, Applications, and Concurrent Engineering, 13(1), 23-29. https://doi.org/10.1007/s001630100003

Dougherty, D. (1990). Understanding New Markets for New Products. Strategic Management Journal. https://doi.org/10.2307/2486670

Dougherty, D. (1992a). A practice-centered model of organizational renewal through product innovation. Strategic Management Journal. Retrieved from https://www.jstor.org/stable/2486353

Dougherty, D. (1992b). Interpretive_Barriers_to_Successful_Prod.pdf. Organization Science.

Dougherty, D., \& Corse, S. M. (1995). When it comes to product innovation, what is so bad about bureaucracy? Journal of High Technology Management Research, 6(1), 55-76. https://doi.org/10.1016/1047-8310(95)90006-3

Dougherty, D., Science, S. O., \& May, N. (2008). Interpretive Barriers to Successful Product Innovation in Large Firms, 3(2), 179-202.

Drews, J. (2000). Drug discovery: A historical perspective. Science, 287(5460), 1960-1964. https://doi.org/10.1126/science.287.5460.1960

Driva, H., Pawar, K. S., \& Menon, U. (2000). Measuring product development performance in manufacturing organizations. International Journal of Production Economics, 63(2), 147-159. https://doi.org/10.1016/S0925-5273(99)00007-9

Dunson, T. R., \& Morfin, E. (2010). Managing Drug Safety Risk. In Pete Harpum (Ed.), Portfolio, Program, and Project Management in the Pharmaceutical and Biotechnology Industries (pp. 155-174). Hoboken, NJ: John Wiley \& Sons.

Dunson, Thomas R. (2010). A Review of Project Management in Life Science Industry Sectors. In Pete Harpum (Ed.), Portfolio, program, and project management in the pharmaceutical and biotechnology industries (pp. 3-19). Hoboken, NJ, NJ: John Wiley \& Sons.

Dwyer, L., \& Mellor, R. (1991). Organizational environment, new product process activities, and project outcomes. J. Prod. Innov. Manag., 8, 39-48.

Dylst, P., Vulto, A., Godman, B., \& Simoens, S. (2013). Generic medicines: Solutions for a sustainable drug market? Applied Health Economics and Health Policy, 11(5), 437-443. https://doi.org/10.1007/s40258-013-0043-z

Edwards, J. R., \& Bagozzi, R. P. (2000). On the Nature and Direction of Relationships Between Constructs and Measures. Psychological Methods, 5(2), 155-174. https://doi.org/10.1037//1082989X.5.2.155

Eisenhardt, K. M., \& Tabrizi, B. N. (1995). Accelerating Adaptive Processes: Product Innovation in the Global Computer Industry. Administrative Science Quarterly, 40(1), 84. 
https://doi.org/10.2307/2393701

Elliott, R. (2000). Mixed WTO ruling on generic drug development. Canadian HIV-AIDS Policy \& Law Newsletter / Canadian HIV-AIDS Legal Network = Réseau Juridique Canadien VIH-SIDA.

Ernst, H. (2002). Success factors of new product development: a review of he empirical literature. International Journal of Management Reviews, 4(1), 1-40. https://doi.org/10.1111/14682370.00075

Esteves, A. L. (2018). Gerenciamento de projetos de desenvolvimento de medicamentos sintéticos em um laboratório farmacêutico oficial brasileiro: proposta para melhoria da gestão a partir da modelagem de um processo padrão. Farmanguinhos da Fundação Oswaldo Cruz - FIOCRUZ. Retrieved from https://www.arca.fiocruz.br/handle/icict/26198

Esteves, V. S. D. (2009). Da invenção à inovação: gestão do processos de desenvolvimento de novos produtos farmacêuticos. Escola Nacional de Saúde Pública Sérgio Arouca.

Fatokun, O., Mohamed Ibrahim, M. I., \& Ahmad Hassali, M. A. (2013). Generic industry's perceptions of generic medicines policies and practices in Malaysia. Journal of Pharmacy Research, 7(1), 80-84. https://doi.org/10.1016/j.jopr.2013.01.005

Faul, F., Erdfelder, E., Buchner, A., \& Lang, A. G. (2009). Statistical power analyses using G* Power 3.1: Tests for correlation and regression analyses. Behavior Research Methods, 41(4), 11491160.

FDA. (2004). Pharmaceutical CGMPs for the 21s century-A risk-based approach. FDA Official Document, (September), 32. Retrieved from http://www.fda.gov/Drugs/DevelopmentApprovalProcess/Manufacturing/QuestionsandAnswerso nCurrentGoodManufacturingPracticescGMPforDrugs/UCM071836

FDA. (2007). Critical Path Opportunities for Generic Drugs. Retrieved July 8, 2016, from https://www.fda.gov/oc/initiatives/criticalpath/reports/generic.html

Figueiras, M. J., Alves, N. C., Marcelino, D., Cortes, M. A., Weinman, J., \& Horne, R. (2009). Assessing lay beliefs about generic medicines: Development of the generic medicines scale. Psychology, Health and Medicine, 14(3), 311-321. https://doi.org/10.1080/13548500802613043

Figueiredo, P. S., \& Loiola, E. (2012). Enhancing new product development (NPD) portfolio performance by shaping the development funnel. Journal of Technology Management and Innovation, 7(4), 20-35. https://doi.org/10.4067/s0718-27242012000400002

Flick, U. (2013). Introdução à pesquisa qualitativa. iIntroduçao a pesquisa qualitativa. Porto Alegre: Penso.

Fornell, C., \& Larcker, D. F. (1981). Evaluating Structural Equation Models with Unobservable Variables and Measurement Error. Journal of Marketing Research, 18(1), 39. https://doi.org/10.2307/3151312

Frazier, P. A., Tix, A. P., \& Barron, K. E. (2004). Testing moderator and mediator effects in counseling psychology research. Journal of Counseling Psychology, 51(1), 115-134. https://doi.org/10.1037/0022-0167.51.1.115

Fucina, G. (2012). Desenvolvimento de medicamento fitoterápico semissólido contendo extrato seco padronizado de Sphagneticola trilobata (L.) Pruski. Universidade do Vale do Itajaí. Retrieved from https://siaiap39.univali.br/repositorio/bitstream/repositorio/1419/1/Giovana Fucina.pdf

Fuhr, T., Holcomb, M., \& Rutten, P. (2009). Why quality-by-design should be on the executive team's agenda: Developing New Strategies for New Times. In M. Losch \& U. Schrader (Eds.), Outpacing Change in Pharma Operations (December20 ed., pp. 195-203). McKinsey \& Co.

Gao, Q., Sanvordeker, D. R., \& Vita, R. (2005). Analytical Methods Development and Methods Validation for Solid Oral Dosage Forms. In L. Shargel \& I. Kanfer (Eds.), Generic Drug Product Development. Solid Oral Dosage Forms (pp. 31-51). New York: Marcel Dekker.

Garcia, R., \& Calantone, R. (2002). A critical look at technological innovation typology and innovativeness terminology: A literature review. Journal of Product Innovation Management. https://doi.org/10.1016/S0737-6782(01)00132-1

Garner, R. (2014). Project execution planning: The key to successful pharmaceutical project delivery. Pharmaceutical Engineering.

Gelber, L., \& Janulis, J. (2005). Quality Control and Quality Assurance. In L. Shargel \& I. Kanfer 
(Eds.), Generic drug product development: solid oral dosage forms (pp. 173-186). New York: Marcel Dekker.

Genazzani, A. A., \& Pattarino, F. (2008). Difficulties in the production of identical drug products from a pharmaceutical technology viewpoint. Drugs in $R$ and $D, 9(2), 65-72$. https://doi.org/10.2165/00126839-200809020-00001

Goodman, L. A. (1960). On the Exact Variance of Products. Journal of the American Statistical Association, 55(292), 708-713. https://doi.org/10.16194/j.cnki.31-1059/g4.2011.07.016

Gota, V. S., \& Patial, P. (2014). Toward better quality of anticancer generics in India. Indian Journal of Cancer, 51(3), 366-368. https://doi.org/10.4103/0019-509X.146723

Green, J. . M. (1996). A Practical Guide to Analytical Method Validation. Analytical Chemistry News \& Features, 305-309.

Griffin, A., \& Hauser, J. R. (1996). Integrating R \& D and marketing: A review and analysis of the literature. Journal of Product Innovation Management, 13(3), 191-215. https://doi.org/10.1016/0737-6782(96)00025-2

Griffin, A., \& Page, A. L. (1996). PDMA Success Measurement Project: Recommended Measures for Product Development Success and Failure. Journal of Product Innovation Management, 13, 478-496.

Guide, V. D. R., \& Ketokivi, M. (2015). Notes from the Editors: Redefining some methodological criteria for the journal. Journal of Operations Management, 37, v-viii. https://doi.org/10.1016/S0272-6963(15)00056-X

Guo, L. (2008). Perspective: An analysis of 22 years of research in JPIM. Journal of Product Innovation Management, 25(3), 249-260. https://doi.org/10.1111/j.1540-5885.2008.00298.x

Gupta, A. K., \& Wilemon, D. L. (1990). Accelerating the Development of Technologe Based on New Products Californial Management Review. California Management Review, 32(2), 24-44. Retrieved from http://cmr.ucpress.edu/content/32/2/24.abstract

Hair Jr., J. F., Black, W. C., Babin, B. J., \& Anderson, R. E. (2014). Multivariate Data Analysis (7th ed.). Essex: Pearson.

Hair Jr., J. F., Hult, G. T. M., Ringle, C. M., \& Sarstedt, M. (2017). A Primer on Partial Least Squares Structural Equation Modeling (PLS-SEM). (C. Homburg, M. Klarmann, \& A. Vomberg, Eds.), Handbook of Market Research (2nd ed.). Los Angeles: Sage. https://doi.org/10.1017/CBO9781107415324.004

Hajjar Júnior, G. (2010). Modelo de Gerência de Projetos para Lançamento de Medicamentos Genéricos pela Indústria Farmacêutica. PUC Goias / Universidade Estadual de Goiás. Retrieved from http://tede2.pucgoias.edu.br:8080/handle/tede/2044

Hansen, N., \& Tunnah, P. (2003). The generics R and D challenge: Seeking the elusive profit margin. Journal of Generic Medicines. https://doi.org/10.1057/palgrave.jgm.4940012

Harpum, P., \& Dunson, T. R. (2010). Managing Uncertainty in Drug Projects. In Pete Harpum (Ed.), Portfolio, program, and project management in the pharmaceutical and biotechnology industries (pp. 135-154). Hoboken, NJ: John Wiley \& Sons.

Harpum, Pete (Ed.). (2010). Portfolio, Program, and Project Management in the Pharmaceutical and Biotechnology Industries. Hoboken, NJ: John Wiley \& Sons.

Hayes, R. H., Wheelwright, S. C., \& Clark., K. B. (1988). Dynamic manufacturing: Creating the learning organization. Free Press. https://doi.org/10.1016/0923-4748(89)90006-4

Henard, D. H., \& Szymanski, D. M. (2001). Why Some New Products Are More Successful Than Others. Journal of Marketing Research, 38(August), 362-375.

Henderson, R., \& Cockburn, I. (1996). Scale, Scope, and Spillovers: The Determinants of Research Productivity in Drug Discovery. The RAND Journal of Economics, 27(1), 32. https://doi.org/10.2307/2555791

Henke, J. W., Krachenberg, A. R., \& Lyons, T. F. (1993). Perspective: Cross-functional teams: Good concept, poor implementation! The Journal of Product Innovation Management, 10(3), 216-229. https://doi.org/10.1016/0737-6782(93)90027-N

Henseler, J., Ringle, C. M., \& Sinkovics, R. R. (2009). The use of partial least squares path modeling in international marketing. Advances in International Marketing, 20(2009), 277-319.

https://doi.org/10.1108/S1474-7979(2009)0000020014

Hicks, C., \& McGovern, T. (2009). Product life cycle management in engineer-to-order industries. 
International Journal of Technology Management, 48(2), 153-167.

Hillery, A. M., \& Park, K. (2017). Drug Delivery: Fundamental \& Applications (2nd ed.). Boca Raton, FL: CRC Press. https://doi.org/10.1017/CBO9781107415324.004

Hinckeldeyn, J., Dekkers, R., \& Kreutzfeldt, J. (2010). Application of production management principles to engineering processes: An explorative study. IEEM2010 - IEEE International Conference on Industrial Engineering and Engineering Management, 158-162. https://doi.org/10.1109/IEEM.2010.5674441

Hinkin, T. R. (1998). A brief tutorial on the development of measures for use in survey questionnaires. Organizational Research Methods, 1(1), 104-121. https://doi.org/10.1177/109442819800100106

Hottinger, M., \& Liang, B. A. (2012). Deficiencies of the FDA in evaluating Generic formulations: Addressing narrow therapeutic index drugs. American Journal of Law and Medicine, 38(4), 667689. https://doi.org/10.1177/009885881203800403

Huang, B., Barber, S. L., Smid, M., Hoet, P., Kupferman, A., Sun, J., \& Wu, C. (2013). Technical gaps faced by Chinese generic medicine manufacturers to achieve the standards of WHO medicines Prequalification. Journal of Generic Medicines, 10(1), 14-21. https://doi.org/10.1177/1741134313483748

Hynes III, M. D. (2010). Integrated Business Processes to Support Cross-Functional Drug Development. In Pete Harpum (Ed.), Portfolio, Program, and Project Management in the Pharmaceutical and Biotechnology Industries (pp. 227-238). Hoboken, NJ: John Wiley \& Sons.

Iansiti, M. (1993). Real-World R\&D: Jumping the Product Generation Gap. Harvard Business Review.

ICH. Stability Testing of New Drug Substances and Products - Q1A(R2), ICH Harmonized Tripartite Guideline § (2003). https://doi.org/10.3109/9781420081244-10

ICH. Quality Risk Management Q9, Guideline, ICH Harmonised Tripartite § (2005). https://doi.org/10.1002/9781118895238.ch2

ICH. Pharmaceutical Quality System ICH Q10, ICH Harmonized Tripartite Guideline § (2008).

ICH. Pharmaceutical Development Q8(R2), ICH Harmonized Tripartite Guideline § (2009). https://doi.org/10.1007/s11356-015-5849-9

Imai, K., Nonaka, I., \& Takeuchi, H. (1985). Managing the New Product Development Process : How Japanese Learn and Unlearn. The Uneasy Alliance Managing the Productivity Technology Dilemna.

ISPE. (2011). ISPE Good Practice Guide: Project Management for the Pharmaceutical Industry. Tampa, FL: ISPE.

Isse, K. F. (2011). A indústria farmacêutica nacional e a importância dos medicamentos genéricos no seu desenvolvimento., 32-73.

Jain, K. K. (2008). Drug Delivery Systems. (K. K. Jain, Ed.), Journal of Chemical Information and Modeling (Vol. 53). Totowa, NJ: Humana Press. https://doi.org/10.1017/CBO9781107415324.004

Jefferys, D. B., Matthews, B. R., \& Ritchie, J. C. (1991). Defects in applications - An Analysis. In A. C. Cartwright \& B. R. Matthews (Eds.), Pharmaceutical product licensing: requirements for Europe (pp. 190-215). London: CRC Press.

Jen, H.-Y. H.-Y., \& Liu, Y.-L. Y.-L. (2012). Project risk evaluation with design of experiment: A case of developing a generic drug analytic method development project. https://doi.org/10.1080/14783363.2011.637791

Jorgensen, W. L. (2004). The Many Roles of Computation in Drug Discovery. Science, 303(5665), 1813-1818. https://doi.org/10.1126/science.1096361

Kader, M. (2016). Mitigating the risks of generic drug product development: An application of quality by design $(\mathrm{QbD})$ and question based review (QbR) approaches. Journal of Excipients and Food Chemicals, 7(2), 35-75.

Kaitin, K. I. (2010). Deconstructing the drug development process: The new face of innovation. Clinical Pharmacology and Therapeutics, 87(3), 356-361. https://doi.org/10.1038/clpt.2009.293

Kale, D., \& Little, S. (2007). From imitation to innovation: The evolution of R\&D capabilities and learning processes in the Indian pharmaceutical industry. Technology Analysis and Strategic Management, 19(5), 589-609. https://doi.org/10.1080/09537320701521317 
Kalluri, V., \& Kodali, R. (2014). Analysis of new product development research: 1998-2009. Benchmarking: An International Journal, 21(4), 527-618. https://doi.org/10.1108/BIJ-06-20120040

Kaló, Z., Holtorf, A. P., Alfonso-Cristancho, R., Shen, J., Ágh, T., Inotai, A., \& Brixner, D. (2015). Need for multicriteria evaluation of generic drug policies. Value in Health, 18(2), 346-351. https://doi.org/10.1016/j.jval.2014.12.012

Kanfer, I., Walker, R. B., \& Persicaner, P. (2005). Experimental Formulation Development. In L. Shargel \& I. Kanfer (Eds.), Generic Drug Product Development. Solid Oral Dosage Forms (pp. 53-3). New York: Marcel Dekker.

Kanfer, Isadore, Walker, R. B., Löbenberg, R., \& Bou-Chacra, N. A. (2014). Experimental Formulation Development. In Leon Shargel \& I. Kanfer (Eds.), Generic Drug. Product Development. Solid Oral Dosage Forms (2nd ed., pp. 51-93). Boca Raton, FL: CRC.

Katz, R., \& Allen, T. J. (1985). Project Performance and the Locus of Influence in the R\&D Matrix. Academy of Management Journal, 28(1), 67-87. https://doi.org/10.2307/256062

Katz, Ralph. (1982). The Effects of Group Longevity on Project Communication and Performance. Administrative Science Quarterly. https://doi.org/10.2307/2392547

Katz, Ralph, \& Tushman, M. (1981). An investigation into the managerial roles and career paths of gatekeepers and project supervisors in a major $\mathrm{R} \& \mathrm{D}$ facility. R\&D Management, 11(3), 103110. Retrieved from https://dspace.mit.edu/bitstream/handle/1721.1/48244/investigationint00katz.pdf?sequence=1

Keller, R. T. (1986). Predictors of performance of project groups in R\&D organizations. Academy of Management Journal. https://doi.org/10.2307/255941

Kennedy, T. (Ed.). (2008a). Pharmaceutical Project Management. Drugs and the pharmaceutical sciences (2nd ed., Vol. 182). New York: Informa Healthcare. https://doi.org/10.3109/9781420013924

Kennedy, T. (2008b). The Project Management Function. In T. Kennedy (Ed.), Pharmaceutical Project Management (2nd ed., pp. 221-242). New York: Informa Healthcare.

Kerlinger, F. N. (2007). Metodologia da pesquisa em ciências sociais: um tratamento conceitual. São Paulo: EPU.

Koufteros, X., Vonderembse, M., \& Doll, W. (2001). Concurrent engineering and its consequences. Journal of Operations Management, 19(1), 97-115. https://doi.org/10.1016/S02726963(00)00048-6

Krishnan, V., Eppinger, S. D., \& Whitney, D. E. (1997). A model-based framework to overlap product development activities. Management Science, 43(4), 437-451.

Krishnan, V., \& Ulrich, K. T. (2001). Product Development Decisions: A Review of the Literature. Management Science, 47(1), 1-21. https://doi.org/10.1287/mnsc.47.1.1.10668

Larson, R., \& Farber, B. (2016). Estatística aplicada (6th ed.). São Paulo: Pearson Education.

Lee, C.-Y. Y., Chen, X., Romanelli, R. J., \& Segal, J. B. (2016). Forces influencing generic drug development in the United States: a narrative review. Journal of Pharmaceutical Policy and Practice, 9(26), 1-6. https://doi.org/10.1186/s40545-016-0079-1

Lee, K., Jeong, Y., \& Yoon, B. (2017). Developing an research and development (R\&D) process improvement system to simulate the performance of R\&D activities. Computers in Industry, 92 93, 178-193. https://doi.org/10.1016/j.compind.2017.08.001

Lima, A. C. F. (2016). Gestão e melhoria de processos em uma indústria farmacêutica pública: estudo de caso da gestão de projetos de desenvolvimento de medicamentos. Universidade Federal Fluminense. Retrieved from https://app.uff.br/riuff/bitstream/1/4104/3/Dissert Ana Carolina Felizardo Lima.pdf

Lionberger, R. (2019). Decision Science for Generic Drug Development and Review. Journal of Clinical Pharmacology, 59(9), 1249-1251. https://doi.org/10.1002/jcph.929

Lionberger, R. A. (2008). FDA Critical Path Initiatives: Opportunities for Generic Drug Development. The AAPS Journal. https://doi.org/10.1208/s12248-008-9010-2

Loch, C., \& Kavadias, S. (2008). Handbook of New Product Development Management. Igarss 2014. https://doi.org/10.1007/s13398-014-0173-7.2

Loveday, D. E. E. (1985). Managing change in pharmaceutical industry R\&D. Technovation, 3(2), 89109. https://doi.org/10.1016/0166-4972(85)90003-3 
Lucas-Dominguez, R., Vidal-Infer, A., Alonso-Arroyo, A., Navarro, C., Valderrama-Zurián, J. C., \& Aleixandre-Benavent, R. (2016). Patterns and Trends in Scientific Research on Generic Drugs. Clinical Therapeutics, 38(12), 2684-2689.e1. https://doi.org/10.1016/j.clinthera.2016.10.010

MacCallum, R. C., Roznowski, M., \& Necowitz, L. B. (1992). Model modifications in covariance structure analysis: The problem of capitalization on chance. Psychological Bulletin, 111(3), 490504.

Maidique, M. A., \& Zirger, B. J. (1984). A study of success and failure in product innovation: The case of the U.S. electronics industry. IEEE Transactions on Engineering Management. https://doi.org/10.1109/TEM.1984.6447537

Maidique, M. A., \& Zirger, B. J. (1985). The new product learning cycle. Research Policy. https://doi.org/10.1016/0048-7333(85)90001-0

Mallam, N., Byalakere Rudraiah, C. S., \& Rudraswamy, S. (2017). Generic drugs: Current status and future potential. Journal of Generic Medicines. https://doi.org/10.1177/1741134317691803

Mallu, U. R., Nair, A. K., Bapatu, H. R., M, P. K., Narla, S., Sankar, J., .. Raman, N. (2015). API Supplier Change or Addition of Alterate API Supplier in Generic Drug Products: Cost, Quality and Regulatory Factors. Pharmaceutica Analytica Acta. https://doi.org/10.4172/21532435.1000364

Mallu, U. R., Nair, A. K., Sankar, J., Bapatu, H. R., Kumar, M. P., Narla, S., ... Raman, N. V. V. S. S. (2015). Impact of API (Active Pharmaceutical Ingredient) Source Selection on Generic Drug Products. Pharmaceut Reg Affairs. https://doi.org/10.4172/2167-7689.1000136

Marconi, M. de A., \& Lakatos, E. M. (2012). Metodologia do Trabalho Científico (7th ed.). São Paulo: Atlas.

Martin, P. (2017). Speeding Time to Market With Better Pharmaceutical Project Management. Pharmaceutical Technology.

Maximiano, A. C. A. (2002). Administração de Projetos (2nd ed.). São Paulo: Atlas.

McNally, R. C., Cavusgil, E., \& Calantone, R. J. (2010). Product innovativeness dimensions and their relationships with product advantage, product financial performance, and project protocol. Journal of Product Innovation Management, 27(7), 991-1006. https://doi.org/10.1111/j.15405885.2010.00766.x

McNamee, P., \& Celona, J. (2008). Decision Analysis for the Professional. The Journal of Risk and Insurance (4th ed., Vol. 55). EUA: AmartOrg. https://doi.org/10.2307/253158

Mendigorri, E. M., Valderrama, T. G., \& Cornejo, V. R. (2016). Measuring the effectiveness of R\&D activities: Empirical validation of a scale in the Spanish pharmaceutical sector. Management Decision, 54(2), 321-362. https://doi.org/10.1108/MD-06-2014-0378

Meyer, M. H., \& Utterback, J. M. (1992). The product family and the dynamics of core capability. Management Science, 43(1), 88-111.

Miles, R. E., Snow, C. C., Meyer, A. D., \& Coleman, H. J. (1978). Organizational Strategy, Structure, and Process. The Academy of Management Review, 3(3), 546-562. Retrieved from https://www.jstor.org/stable/257544

Moenaert, R. K., \& Souder, W. E. (1990). An information transfer model for integrating marketing and R\&D personnel in new product development projects. Journal of Product Innovation Management. https://doi.org/10.1016/0737-6782(90)90052-G

Montoya-Weiss, M. M., \& Calantone, R. J. (1994). Determinants of new product performance: A review and meta-analysis. Journal of Product Innovation Management, 11(5), 397-417. https://doi.org/10.1111/1540-5885.1150397

Moreira, R. A. (2008). Proposta de um Padrão Gerencial de Gestão de Portfólio de Novos Produtos para Indústrias Farmacêuticas Nacionais. Universidade Federal de Minas Gerais.

Moreira, R. A., \& Cheng, L. C. (2010). Proposal of managerial standards for new product portfolio management in Brazilian pharmaceutical companies. Brazilian Journal of Pharmaceutical Sciences, 46(1), 53-66. https://doi.org/10.1590/S1984-82502010000100007

Morfin, E. (2010). The Impact of Organizational Size on Drug Project Management. In P. Harpum (Ed.), Portfolio, program, and project management in the pharmaceutical and biotechnology (pp. 21-32). Hoboken, NJ: John Wiley \& Sons. 
Morgan, S., Grootendorst, P., Lexchin, J., Cunningham, C., \& Greyson, D. (2011). The cost of drug development: A systematic review. Health Policy, 100(1), 4-17.

https://doi.org/10.1016/j.healthpol.2010.12.002

Murphy, D. C., Baker, B. N., \& Fisher, D. (1974). Determinants of Project Success. Chestnut Hill, Massachusetts for. Retrieved from https://ntrs.nasa.gov/archive/nasa/casi.ntrs.nasa.gov/19740022279.pdf

Myers, S., \& Marquis, D. . (1969). Successful industrial innovation: a study of factors underlying innovation in selected firms. National Science Foundation.

Nandeswara Rao, N. S., \& Jigeesh, N. (2015). Analysis and control of issues that delay pharmaceutical projects. Verslas: Teorija Ir Praktika. https://doi.org/10.3846/btp.2015.491

Neely, A., Gregory, M., \& Platts, K. (2005). Performance measurement system design: A literature review and research agenda. International Journal of Operations and Production Management, 25(12), 1228-1263. https://doi.org/10.1108/01443570510633639

Nicholas, J., Ledwith, A., \& Perks, H. (2011). New product development best practice in SME and large organisations: Theory vs practice. European Journal of Innovation Management, 14(2), 227-251. https://doi.org/10.1108/14601061111124902

Nishijima, M., Biasoto, G., \& Lagroteria, E. (2014). A competição no mercado farmacêutico brasileiro após uma década de medicamentos genéricos : uma análise de rivalidade em um mercado regulado. Economia e Sociedade, 23(1), 155-186.

Niso, P. K. A., Reis, L. G., \& Bagno, R. B. (2018). O processo de desenvolvimento de novas vacinas sob a ótica da Gestão do Desenvolvimento de Produtos. In Universidade de Juiz de Fora (Ed.), XIV Encontro Mineiro de Engenharia de Produção. Juiz de Fora - MG: Researchgate. Retrieved from https://www.researchgate.net/publication/326092673_O_processo_de_desenvolvimento_de_nov as_vacinas_sob_a_otica_da_Gestao_do_Desenvolvimento_de_Produtos

Nonaka, I, \& Takeuchi, H. (1986). The new new product development game. Harvard Business Review. Retrieved from https://hbr.org/1986/01/the-new-new-product-development-game

Nonaka, Ikujiro, Takeuchi, H., \& Nonaka, I. (1986). The New New Product Development Game. Harvard Business Review. https://doi.org/10.1016/0737-6782(86)90053-6

Noonan, P. K. (2005). Outsourcing Bioavailability and Bioequivalence Studies to Contract Research Organizations. In L. Shargel \& I. Kanfer (Eds.), Generic Drug Product Development. Solid Oral Dosage Forms (pp. 399-342). New York: Marcel Dekker.

Ohba, M. (2005). Alianças estratégicas e suas implicações para a configuração de capacidades tecnológicas: evidências da indústria farmacêutica multinacional. Fundação Getúlio Vargas São Paulo. Retrieved from https://bibliotecadigital.fgv.br/dspace/handle/10438/3679

Page, A. L., \& Schirr, G. (2008). Growth and Development of a Body of Knowledge: 16 Years of New Product Development Research, 1989-2004*. Journal of Product Innovation Management, 25(May 2008), 233-248. https://doi.org/10.1111/j.1540-5885.2008.00297.x

Pandey, N., Patwardhan, A., \& Rao, S. (2019). Four decades of new product development research : an integrative review Four decades of new product development research : an integrative review Neeraj Pandey * Swarnima Rao. International Journal of Product Development, 23(1), 1-13.

Pattikawa, L. H., Verwaal, E., \& Commandeur, H. R. (2006). Understanding new product project performance. European Journal of Marketing, 40(11-12), 1178-1193. https://doi.org/10.1108/03090560610702768

Pete Harpum, Jamieson, A., \& Fisher, I. (2010). Implementing Portfolio, Program, and Project Management Best Practices in Drug Development Organizations. In Pete Harpum (Ed.), Portfolio, Program, and Project Management in the Pharmaceutical and Biotechnology Industries (pp. 287-312). Hoboken, NJ: John Wiley \& Sons.

Petter, S. (2018). "Haters Gonna Hate": PLS and Information Systems Research. ACM SIGMIS Database: The DATABASE for Advances in Information Systems, 49(1), 10-13. https://doi.org/10.1145/3229335.3229337

Piachaud, B. S. (2002). Outsourcing in the pharmaceutical manufacturing process: An examination of the CRO experience. Technovation, 22(2), 81-90. https://doi.org/10.1016/S0166-4972(01)000815

Pinheiro, A. A., Siani, A. C., Guilhermino, J. D. F., Henriques, M. das G. M. de O., Quental, C. M., 
Pizarro, A. P. B., \& Pizarro, B. (2006). Metodologia para gerenciar projetos de pesquisa e desenvolvimento com foco em produtos : uma proposta *. Rev Adm Publica, 40(3), 457-478.

Pinto, C. M. D. P. (2007). Mercado brasileiro de medicamentos genéricos: análise do desemprenho de uma subsidiária de laboratório estrangeiro. Fundação Getúlio Vargas Rio de Janeiro. Retrieved from https://bibliotecadigital.fgv.br/dspace/handle/10438/3882

Pinto, J. K. (2013). Project Management. Achieving Competitive Advantage (3rd ed.). Upper Saddle River, NJ, NJ: Pearson.

Pinto, M. B., \& Pinto, J. K. (1990). Project Team Communication and Cross-Functional Cooperation in New Program Development. Journal of Product Innovation Management, 7(3), 200-2012.

PMI. (2004). Project Management Body of Knowledge (PMBOK Guide) (3rd ed.). planeje, faça, verifique e aja: PMI. https://doi.org/10.1201/b13755-4

PMI. (2013). A guide to the project management body of knowledge (PMBOK® guide) (5th ed.). Newtown Square, Pennsylvania: Project Management Institute.

PMI. (2014). PMSURVEY.ORG 2014. https://doi.org/10.4324/9781315853178

PMI. (2017). A Guide to the Project Management Body of Knowledge (PMBOK Guide) (6th ed.). Newtown Square, USA: PMI. https://doi.org/10.1201/b13755-4

PMI Standards Committee. (1996). A Guide to the Project Management Body of Knowledge (PMBOK Guide) (1st ed.). Newtown Square, PA, PA: PMI.

Podsakoff, P. M., MacKenzie, S. B., \& Podsakoff, N. P. (2012). Sources of Method Bias in Social Science Research and Recommendations on How to Control It. Annual Review of Psychology, 63(1), 539-569. https://doi.org/10.1146/annurev-psych-120710-100452

Poolton, J., \& Barclay, I. (1998). New product development from past research to future applications. Industrial Marketing Management, 27(3), 197-212. https://doi.org/10.1016/S00198501(97)00047-3

Porter, M. E. (1985). Competitive advantage, creating and sustaining superior performance. New York: Free Press. https://doi.org/10.1590/s0034-75901985000200009

Powell, M. (2010). Project Control. In P. Harpum (Ed.), Portfolio, program, and project management in the pharmaceutical and biotechnology industries (pp. 101-134). Hoboken, NJ: John Wiley \& Sons.

Prachi, G., B, S. D., \& Dilip, M. (2015). Comparative Study of Reference Products in Generic Drug Development in U.S. and Europe. International Journal of Scientific Research.

Prado, A. R. M. (2011). A indústria farmacêutica brasileira a partir dos anos 1990 : a Lei dos Genéricos e os impactos na dinâmica competitiva. Leituras de Economia Política, 19, 111-145.

Prašnikar, J., \& Škerlj, T. (2006). New product development process and time-to-market in the generic pharmaceutical industry. Industrial Marketing Management. https://doi.org/10.1016/j.indmarman.2005.06.001

Preacher, K. J., \& Leonardelli, G. J. (2001). Calculation for the Sobel test: An interactive calculation tool for mediation tests. Nashville, TN: Kristopher J. Preacher. Retrieved from http://quantpsy.org/sobel/sobel.htm

Quinn, J. B. (1985). Managing Innovation: Controlled Chaos. Harvard Business Review, (May). Retrieved from http://papers.ssrn.com/abstract=1504499

Rachit, K., Arvind, G., \& Geeta, A. (2011). Generic Drugs - A Ground Discussion. Int. J. Drug Dev. \& Res., 3(1), 178-184.

Radaelli, V. (2012). Trajetórias inovativas do setor farmacêutico no Brasil: tendências recentes e desafios futuros. Universidade Estadual de Campinas. Retrieved from http://repositorio.unicamp.br/handle/REPOSIP/287652

Raka, C., \& Liangrokapart, J. (2017). An Analytical Hierarchy Process (AHP) Approach to Risk Analysis: A Case Study of a New Generic Drug Development Process. Journal of Pharmaceutical Innovation, 12(4), 319-326. https://doi.org/10.1007/s12247-017-9298-5

Reiffen, D., \& Ward, M. R. (2005). Generic Drug Industry Dynamics. Review of Economics and Statistics. https://doi.org/10.1162/0034653053327694

Ringle, C. M., Da Silva, D., \& Bido, D. de S. (2014). Structural Equation Modeling with the Smartpls. Revista Brasileira de Marketing, 13(02), 56-73. https://doi.org/10.5585/remark.v13i2.2717 
Rothwell, R., Freeman, C., Horlsey, A., Jervis, V. T. P., Robertson, A. B., \& Townsend, J. (1974). SAPPHO updated - Project SAPPHO phase II. Research Policy. https://doi.org/10.1016/00487333(74)90010-9

Rothwell, Roy. (1972). Factors for success in industrial innovations from project SAPPHO - A comparative study of success and failure in industrial innovation. Science Policy Research Unit.

Rozenfeld, H., Forcellini, F. A., Amaral, D. C., Toledo, J. C. de, Silva, S. L. da, Alliprandini, D. H., \& Scalice, R. K. (2006). Gestão de Desenvolvimento de Produtos. Uma Referência para a Melhoria do Processo. São Paulo: Saraiva.

Rubenstein, A. H., Chakrabarti, A. K., O'Keefe, R. D., Souder, W. E., \& Young, H. C. (1976). Factors Influencing Innovation Success At the Project Level. Research Management, 19(3), 15-20. https://doi.org/10.1080/00345334.1976.11756350

Sá, I. M. de. (2013). Resignificando a natureza: a $P \& D$ de medicamentos antimaláricos a partir da artemisia аппиа - 1960 a 2010. Casa de Oswaldo Cruz - FIOCRUZ. Retrieved from https://www.arca.fiocruz.br/handle/icict/17782

Salerno, M. S., Matsumoto, C., \& Ferraz, I. (2018). Biofármacos no Brasil: Características, Importância e Delineamento de Políticas Públicas para seu Desenvolvimento. Braslia. Retrieved from http://www.ipea.gov.br/portal/publicacoes

Salgado, E. G., \& Dekkers, R. (2018). Lean Product Development: Nothing New Under the Sun? International Journal of Management Reviews, 20(4), 903-933. https://doi.org/10.1111/ijmr.12169

Samaan, M., Salgado, E. G., Silva, C. E. S. da, \& Mello, C. H. P. (2012). Identificação dos fatores críticos de sucesso no desenvolvimento de produtos de empresas de biotecnologia do estado de Minas Gerais. Production, 22(3), 436-447. https://doi.org/10.1590/s0103-65132012005000055

Sampieri, R. H., Collado, C. F., \& Lucio, M. D. P. B. (2013). Metodologia de Pesquisa (5th ed.). Porto Alegre - RS: Penso.

Santos, F. L. A. dos, Lyra, M. A. M., Alves, L. D. S., da Silva, K. E. R., Rolim, L. A., Gomes, T. C. B. de L., ... Rolim-Neto, P. J. (2012). Pesquisa , desenvolvimento e inovação para o controle das doenças negligenciadas. Revista de Ciências Farmacêuticas Básica e Aplicada, 33(1), 37-47.

Sarstedt, M., Henseler, J., \& Ringle, C. M. (2011). Multigroup analysis in partial least squares (PLS) path modeling: Alternative methods and empirical results. Advances in International Marketing, 22(June 2014), 195-218. https://doi.org/10.1108/S1474-7979(2011)0000022012

Sarstedt, M., Ringle, C. M., \& Hair Jr., J. F. (2017). Partial Least Squares Structural Equation Modeling. In C. Homburg, M. Klarmann, \& A. Vomberg (Eds.), Handbook of Market Research (pp. 2-41). Cham: Springer. https://doi.org/10.1007/978-3-319-05542-8

Sathe, P. M., Raw, A. S., Ouderkirk, L. A. Y., X., L., \& Hussain, A. S. (2005). Drug Product Performance, In Vitro. In L. Shargel \& I. Kanfer (Eds.), Generic Drug Product Development. Solid Oral Dosage Forms (pp. 187-209). New York: Marcel Dekker.

Selltiz, C., Jahoda, M., Deutsch, M., \& Cook, S. W. (1975). Métodos de pesquisa nas relações sociais. São Paulo: E.P.U. EDUSP.

Shamsuzzoha, A., \& Kekale, T. (2010). Platform-oriented product development: Prospects and limitations. International Journal of Business Innovation and Research, 4(3), 179-194. https://doi.org/10.1504/IJBIR.2010.032382

Shargel, L., \& Kanfer, I. (2005). Introduction to Generic Drug Product Development. In L. Shargel \& I. Kanfer (Eds.), Generic Drug Product Development. Solid Oral Dosage Forms (pp. 1-16). New York: Marcel Dekker.

Shargel, Leon, \& Kanfer, I. (Eds.). (2005). Generic Drug Product Development: Solid Oral Dosage Forms. New York: Marcel Dekker.

Sharma, C. (2012). R \& D and firm performance : evidence from the Indian pharmaceutical industry, 7860. https://doi.org/10.1080/13547860.2012.668094

Sharpe, P., \& Keelin, T. (1998). How SmithKline Beecham makes better resource-allocation decisions. Harvard Business Review, 76(2).

Shenhar, A. J., Levy, O., \& Dvir, D. (1997). Mapping the Dimensions of Project Success. Project Management Journal, 28(2), 5-13.

Silva, E. M. L. da. (2015). Desenvolvimento de um modelo de simulação para apoio ao gerenciamento de projetos de desenvolvimento de medicamento genérico em uma empresa farmacêutica. 
Universidade Nove de Julho - UNINOVE. Retrieved from http://bibliotecatede.uninove.br/bitstream/tede/1367/2/Ellen Martins Lopes Da Silva.pdf

Sindusfarma. (2019). Sindusfarma - Indicadores Econômicos. Retrieved November 10, 2019, from https://sindusfarma.org.br/mercado/indicadores-economicos

SmartPLS®. (2019). Bönningstedt: SmartPLS GmbH. Retrieved from www.smartpls.com

Soares, D. L., \& Mancilha, R. A. F. (2008). Implantação de um sistema de gerenciamento de projetos no desenvolvimento de produtos farmacêuticos. Universidade de São Paulo.

Sobel, M. E. (1982). Asymptotic Confidence Intervals for Indirect Effects in Structural Equation Models. Sociological Methodology, 13(1982), 290. https://doi.org/10.2307/270723

Srinivasan, A., Iser, R., \& Gill, D. (2011). FDA Perspectives: Deficiencies in Abbreviated New Drug Applications: Part 3- Control of the Drug Product and Stability. Pharmaceurtical Technology, 35(2), 1-8.

Srinivasan, Aloka, \& Iser, R. (2010). FDA Perspectives: Common deficiencies in abbreviated new drug applications: part 1: Drug substance. Pharmaceutical Technology, 34(1), 50-59.

Srinivasan, Aloka, Iser, R., \& Gill, D. S. (2010). FDA Perspectives: Common Deficiencies in Abbreviated New Drug Applications: Part 2: Description, composition, and excipients. Pharmaceutical Technology, 34(8), 50-59.

Stewart-Long, P. (2010). Program Management in Drug Development. In P. Harpum (Ed.), Portfolio, Program, and Project Management in the Pharmaceutical and Biotechnology Industries (pp. 8599). Hoboken, NJ: John Wiley \& Sons.

Su, W.-P., Song, R.-L., Wang, Y.-T., \& Shi, L.-W. (2011). Strategy for development of generic drug superstars in China. Chinese Journal of New Drugs.

Suchak, K., \& Murray, L. J. (2017). Generic portfolio management: A paradigm for minimizing risk and maximizing value. Journal of Generic Medicines, 13(2), 60-63. https://doi.org/10.1177/1741134316677850

Swarbrick, J., Carolina, N., Augsburger, L. L., Brittain, H. G., Hickey, A. J., \& Hill, C. (2005). Generic Drug Product Development.

Taylor, B. (1975). Strategies for Planning. Long Range Planning, August, 27-40.

Taylor, D. (2016). The pharmaceutical industry and the future of drug development. Issues in Environmental Science and Technology, 2016-Janua(41), 1-33. https://doi.org/10.1039/9781782622345-00001

Teixeira, A. (2015). A indústria farmacêutica no Brasil: um estudo do impacto socioeconômico dos medicamentos genéricos. Aleph.

Telles, R. (2001). A efetividade da matriz de amarração de Mazzon nas pesquisas em Administração. Revista de Administração, 36(4), 64-72. https://doi.org/1 929667-00-0

Testa, C. G. (2014). Desenvolvimento de medicamento similar de olanzapina comprimidos revestidos. FIOCRUZ. Retrieved from https://www.arca.fiocruz.br/bitstream/icict/13010/1/6.pdf

Thakur, A., Mahata, P. P., Thakur, D., \& Chakraborty, P. (2015). Generic drug: Where it stands in pharma industry? International Journal of Pharmacy and Technology, 6(3), 2998-3009.

Tiwari, G., Tiwari, R., Bannerjee, S., Bhati, L., Pandey, S., Pandey, P., \& Sriwastawa, B. (2012). Drug delivery systems: An updated review. International Journal of Pharmaceutical Investigation, 2(1), 2. https://doi.org/10.4103/2230-973x.96920

Torres, R. P., \& Souza, M. A. F. de. (2010). A Dinâmica do Mercado Farmacêutico Brasileiro Segundo o Modelo das Estratégias Genéricas de Porter. Sociedade, Contabilidade e Gestão, 5(Especial), 118-132. https://doi.org/10.21446/scg_ufrj.v5i3.13220

Trassato, P. (2017). Gerenciamento de projetos na indústria farmacêutica qualificação de projetos farmacêuticos. ESALQ - USP.

Tsai, K. H., \& Wang, J. C. (2005). Does R\&D performance decline with firm size? - A re-examination in terms of elasticity. Research Policy, 34(6), 966-976. https://doi.org/10.1016/j.respol.2005.05.017

Van Arnum, P. (2012). Case Studies in Pharmaceutical Project Management. Pharmaceutical Technology.

Van Den Broeck, J., Cunningham, S. A., Eeckels, R., \& Herbst, K. (2005). Data cleaning: Detecting, 
diagnosing, and editing data abnormalities. PLoS Medicine, 2(10), 0966-0970.

https://doi.org/10.1371/journal.pmed.0020267

Varu, R. K., \& Khanna, A. (2010). Opportunities and challenges to implementing Quality by Design approach in generic drug development. Journal of Generic Medicines. https://doi.org/10.1057/jgm.2009.37

Vidotti, C. C. F. (2007). Medicamentos novos e as necessidades do Sistema Único de Saúde : políticas públicas para pesquisa e desenvolvimento de fármacos no Brasil Medicamentos novos e as necessidades do Sistema Único de Saúde : políticas públicas para pesquisa e desenvolvimento d. Universidade de Brasília. Retrieved from http://repositorio.unb.br/handle/10482/2775

Vieira, V. M. da M., \& Ohayon, P. (2006). Inovação em fármacos e medicamentos: estado-da-arte no Brasil e políticas de P\&D Innovation for pharmaceuticals and drugs: state of the art in Brazil and R\&D policies. Revista Economia \& Gestão, 6(13), 1-23.

Vinzi, V. E., Chin, W. W., Henseler, J., \& Wang, H. (2010). Handbook of Partial Least Squares. Concepts, Methods and Applications. (V. E. Vinzi, W. W. Chin, J. Henseler, \& H. Wang, Eds.), Springer Handbooks of Computational Statistics. Berlin: Springer. https://doi.org/10.1007/978-3540-32827-8_34

Vinzi, V. E., Trinchera, L., \& Amato, S. (2010). PLS Path Modeling: From Foundations to Recent Developments and Open Issues for Model Assessment and Improvement. In V. E. Vinzi, W. W. Chin, J. Henseler, \& H. Wang (Eds.), PLS Path Modeling: From Foundations to Recent Developments and Open Issues for Model Assessment and Improvement (pp. 47-82). Heildelberg: Springer. https://doi.org/10.1007/978-3-540-32827-8

Violin, L. C. (2011). A Gestão da inovação tecnológica: um estudo de caso na indústria farmacêutica nacional. Universidade Federal de Santa Catarina. Retrieved from https://repositorio.ufsc.br/xmlui/handle/123456789/95254

Vvssn, R., Useni, R. M., Krishnakumar, A. N., Reddy, M. M., Reddy, H. B., Kumar, N. T., ... Narendra, K. T. (2015). Quality Improvement with Scientific Approaches (QbD, AQbD and PAT) in Generic Drug Substance Development: Review. International Journal of Research and Development in Pharmacy \& Life Science, 04(06). https://doi.org/10.4172/2278-0238.1000102

Wang, Y. (Iris), Li, J., \& Anupindi, R. (2018). Manufacturing and Regulatory Barriers to Generic Drug Competition: A Structural Model Approach. SSRN Electronic Journal, 1-41. https://doi.org/10.2139/ssrn.3145635

Welage, L. S., Kirking, D. M., Ascione, F. J., \& Gaither, C. A. (2001). Understanding the scientific issues embedded in the generic drug approval process. Journal of the American Pharmaceutical Association (Washington, D.C. : 1996). https://doi.org/10.1016/S1086-5802(16)31327-4

Wheelwright, S. C., \& Clark, K. B. (1992). Creating project plans to focus product development. Harvard Business Review. https://doi.org/10.16373/j.cnki.ahr.150049

Wheelwright, Steven C., \& Clark, K. B. (1992). Revolutionizing product development. Quantum leaps in Speed, Efficiebcy, an Quality. New York: The Free Press.

WHO. (2016). Interchangeability of WHO-prequalified generics Generic. WHO Drug Information, 30(3), 370-375. Retrieved from http://www.ema.europa.eu/ema/index.jsp?curl=pages/special_topics/document_listing/document _listing_000335.jsp\&mid=WC0b01ac0580514d5c

Womack, J. P., \& Jones, D. T. (1996). Beyond Toyota: How to Root Out Waste and Pursue Perfection. Harvard Business Review, (September-October), 140-158. https://doi.org/Article

Womack, J. P., Jones, D. T., \& Roos, D. (1992). The machine that changed the world. Business Horizons. https://doi.org/10.1016/0007-6813(92)90074-J

Worku, W. Z., Gordon, J., Stahl, M. M., \& Rago, L. (2012). Deficiencies in generic product dossiers as submitted to the WHO Prequalification of Medicines Programme Deficiencies in generic product dossiers as submitted to the WHO Prequalification of Medicines Programme. Journal of Generic Medicines, 2(9), 63-74. https://doi.org/10.1177/1741134312448062

$\mathrm{Wu}, \mathrm{Y}$. (2016). Low R \& D Efficiency In Large Pharmaceutical Companies, 3(July), 141-151.

Yamaguishi, S. H. (2014). Gestão da inovação na indústria farmacêutica no brasil: estudo de múltiplos casos. Instituto de Pesquisas Energéticas e Nucleares. Retrieved from https://www.arca.fiocruz.br/handle/icict/11632

Yousefi, N., Mehralian, G., Rasekh, H. R., \& Yousefi, M. (2017). New product development in the 
pharmaceutical industry: Evidence from a generic market. Iranian Journal of Pharmaceutical Research, 16(2), 831-843. https://doi.org/10.22037/ijpr.2017.2058

Yu, L. X. (2008). Pharmaceutical Quality by Design: Product and Process Development, Understanding, and Control. Pharmaceutical Research, 25(4), 781-791. https://doi.org/10.1007/s11095-007-9511-1

Yu, L. X., Raw, A., Lionberger, R., Rajagopalan, R., Lee, L. M., Holcombe, F., ... Buehler, G. (2007). US FDA question-based review for generic drugs: A new pharmaceutical quality assessment system. Journal of Generic Medicines, 4(4), 239-248. https://doi.org/10.1057/palgrave.jgm.4950073

Yugue, R. T., Maximiano, A. C. A., Sbragia, R., \& Nascimento, P. T. S. (2018). Innovation on Expired Patent Medicines in the Brazilian Pharmaceutical Industry. In 2018 Portland International Conference on Management of Engineering and Technology (PICMET) (pp. 1-12). Honolulu HI: IEEE. https://doi.org/10.23919/PICMET.2018.8481933

Yugue, R. T., Sbragia, R., \& Maximiano, A. C. A. (2018). Decisões de desenvolvimento de novos medicamentos: O Papel da Inteligência Competitiva. In XXI SEMEAD (pp. 1-17). São Paulo: FEA-USP. Retrieved from http://login.semead.com.br/21semead/anais/arquivos/861.pdf

Yugue, Ricardo T., Yoshida, N. D., Vidal, T. L., \& Tavares, P. D. (2010). Gestão de Portfólio de Projetos: um estudo exploratório sobre a seleção de projetos de desenvolvimento de novos produtos na indústria farmacêutica brasileira. In $10^{\circ}$ Seminário Internacional de Gerenciamento de Projetos do PMI São Paulo. São Paulo: PMI Capítulo São Paulo.

Yugue, Ricardo Toshio, Maximiano, A. C. A., \& Sbragia, R. (2018). Prospects for the development of new drug products in emerging economies: the case of Brazil. In 2018 AIB-LAT Conference. Buenos Aires: AIB-LAT.

Yugue, V. dos S. C. (2014). Desenvolvimento de Novos Medicamentos. Retrieved November 22, 2016, from http://yugue.com/pluginfile.php/27/mod_page/content/24/YUGUE DESENVOLVIMENTO DE MEDICAMENTOS.pdf

Zhao, L., Kim, M. J., Zhang, L., \& Lionberger, R. (2019). Generating Model Integrated Evidence for Generic Drug Development and Assessment. Clinical Pharmacology and Therapeutics, 105(2), 338-349. https://doi.org/10.1002/cpt.1282

Zirger, B. J., \& Maidique, M. A. (1990). A model of new product development: an empirical test. Management Science. https://doi.org/10.1287/mnsc.36.7.867 
ANEXO I - Mercado Farmacêutico Brasileiro - Medicamentos Genéricos 2017

MERCADO FARMACÊUTICO BRASILEIRO - MEDICAMENTOS GENÉRICOS 2017

Produtos, Apresentações, Princípios ativos e Associações, Subclasses Terapêuticas, Faturamento por Empresa ou Grupo Econômico - Medicamentos Genéricos.

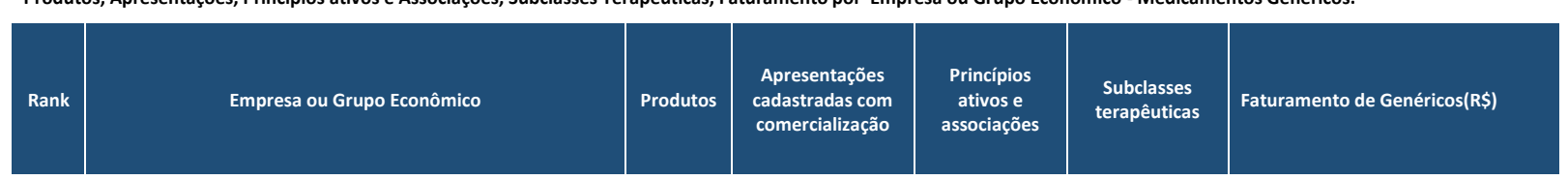

\begin{tabular}{|c|c|c|c|c|c|c|}
\hline & Total & 2.450 & 4.202 & 507 & 192 & $9.380 .233 .596,00$ \\
\hline \multirow{6}{*}{1} & $\begin{array}{l}\text { GRUPO E.M.S (E.M.S./SIGMA/LEGRAND/NOVA } \\
\text { QUIMICA/GERMED) }\end{array}$ & 611 & 1244 & 241 & 108 & Entre 2 bilhões e 3 bilhões \\
\hline & EMS S/A & 215 & 486 & 209 & 50 & Entre 1 bilhão e 2 bilhões \\
\hline & \begin{tabular}{|l} 
EMS SIGMA PHARMA LTDA \\
\end{tabular} & 30 & 47 & 32 & 6 & Entre 10 milhões e 50 milhões \\
\hline & \begin{tabular}{|l} 
GERMED FARMACEUTICA LTDA \\
\end{tabular} & 159 & 317 & 163 & 25 & Entre 250 milhões e 500 milhões \\
\hline & LEGRAND PHARMA INDÚSTRIA FARMACÊUTICA LTDA & 120 & 212 & 117 & 15 & Entre 100 milhões e 250 milhões \\
\hline & NOVA QUIMICA FARMACÊUTICA S/A & 87 & 182 & 87 & 12 & Entre 100 milhões e 250 milhões \\
\hline 2 & PRATI DONADUZZI \& CIA LTDA & 94 & 300 & 93 & 54 & Entre 500 milhões e 1 bilhão \\
\hline 3 & EUROFARMA LABORATÓRIOS S.A. & 106 & 207 & 111 & 71 & Entre 500 milhões e 1 bilhão \\
\hline \multirow{3}{*}{4} & GRUPO SANOFI/MEDLEY/GENZYME & 119 & 284 & 118 & 66 & Entre 500 milhões e 1 bilhão \\
\hline & MEDLEY FARMACÊUTICA LTDA & 116 & 279 & 116 & 65 & Entre 500 milhões e 1 bilhão \\
\hline & \begin{tabular}{|l} 
SANOFI-AVENTIS FARMACÊUTICA LTDA \\
\end{tabular} & 3 & 5 & 3 & 1 & Entre 10 milhões e 50 milhões \\
\hline 5 & LABORATÓRIO TEUTO BRASILEIRO S/A & 132 & 303 & 134 & 79 & Entre 500 milhões e 1 bilhão \\
\hline \multirow{3}{*}{6} & GRUPO SANDOZ/NOVARTIS/ALCON & 71 & 143 & 66 & 42 & Entre 500 milhões e 1 bilhão \\
\hline & NOVARTIS BIOCIENCIAS S.A & 7 & 10 & 7 & 3 & Entre 10 milhões e 50 milhões \\
\hline & SANDOZ DO BRASIL INDÚSTRIA FARMACÊUTICA LTDA & 64 & 133 & 63 & 39 & Entre 500 milhões e 1 bilhão \\
\hline \multirow{5}{*}{7} & $\begin{array}{l}\text { GRUPO HYPERMARCAS (HYPERMARCAS/LUPER/NEO } \\
\text { QUÍMICA/BRAINFARMA/NEOLATINA/COSMED/MANTECORP) }\end{array}$ & 118 & 194 & 104 & 67 & Entre 250 milhões e 500 milhões \\
\hline & BRAINFARMA INDÚSTRIA QUÍMICA E FARMACÊUTICA S.A & 100 & 169 & 98 & 60 & Entre 250 milhões e 500 milhões \\
\hline & COSMED INDUSTRIA DE COSMETICOS E MEDICAMENTOS S.A. & 2 & 2 & 2 & 1 & Menor do que 10 milhões \\
\hline & HYPERMARCAS S/A & 1 & 1 & 1 & 0 & Menor do que 10 milhões \\
\hline & LABORATÓRIO NEO QUÍMICA COMÉRCIO E INDÚSTRIA LTDA & 15 & 22 & 16 & 6 & Entre 10 milhões e 50 milhões \\
\hline \multirow{3}{*}{8} & GRUPO RANBAXY/SUN & 48 & 88 & 46 & 30 & Entre 250 milhões e 500 milhões \\
\hline & RANBAXY FARMACÊUTICA LTDA & 41 & 75 & 41 & 24 & Entre 250 milhões e 500 milhões \\
\hline & SUN FARMACÊUTICA DO BRASIL LTDA & 7 & 13 & 7 & 6 & Entre 10 milhões e 50 milhões \\
\hline \multirow{3}{*}{9} & GRUPO ACHÉ/BIOSINTÉTICA & 111 & 222 & 106 & 63 & Entre 250 milhões e 500 milhões \\
\hline & ACHÉ LABORATÓRIOS FARMACÊUTICOS S.A & 3 & 4 & 3 & 0 & Menor do que 10 milhões \\
\hline & BIOSINTÉTICA FARMACÊUTICA LTDA & 108 & 218 & 106 & 63 & Entre 250 milhões e 500 milhões \\
\hline 10 & FUNDAÇÃO OSWALDO CRUZ & 6 & 10 & 6 & 6 & Entre 250 milhões e 500 milhões \\
\hline \multirow{3}{*}{11} & GRUPO CIMED/NECKERMAN & 78 & 140 & 48 & 33 & Entre 100 milhões e 250 milhões \\
\hline & 1FARMA INDUSTRIA FARMACEUTICA LTDA & 32 & 55 & 32 & 14 & Entre 10 milhões e 50 milhões \\
\hline & \begin{tabular}{|l|} 
CIMED INDÚSTRIA DE MEDICAMENTOS LTDA \\
\end{tabular} & 46 & 85 & 46 & 19 & Entre 100 milhões e 250 milhões \\
\hline \multirow{3}{*}{12} & \begin{tabular}{|l|} 
GRUPO HIPOLABOR/SANVAL \\
\end{tabular} & 57 & 76 & 58 & 41 & Entre 100 milhões e 250 milhões \\
\hline & HIPOLABOR FARMACEUTICA LTDA & 52 & 71 & 53 & 38 & Entre 100 milhões e 250 milhões \\
\hline & SANVAL COMÉRCIO E INDÚSTRIA LTDA & 5 & 5 & 5 & 3 & Menor do que 10 milhões \\
\hline 13 & ANTIBIÓTICOS DO BRASIL LTDA & 15 & 25 & 16 & 9 & Entre 100 milhões e 250 milhões \\
\hline 14 & UNIÃO QUÍMICA FARMACÊUTICA NACIONAL S/A & 35 & 48 & 35 & 29 & Entre 100 milhões e 250 milhões \\
\hline 15 & GEOLAB INDÚSTRIA FARMACÊUTICA S/A & 72 & 112 & 70 & 47 & Entre 100 milhões e 250 milhões \\
\hline 16 & \begin{tabular}{|l|} 
ACCORD FARMACÊUTICA LTDA \\
\end{tabular} & 22 & 42 & 22 & 17 & Entre 100 milhões e 250 milhões \\
\hline 17 & MERCK S/A & 19 & 53 & 19 & 18 & Entre 100 milhões e 250 milhões \\
\hline 18 & AUROBINDO PHARMA INDÚSTRIA FARMACÊUTICA LIMITADA & 26 & 43 & 26 & 14 & Entre 100 milhões e 250 milhões \\
\hline 19 & ASTRAZENECA DO BRASIL LTDA & 2 & 7 & 2 & 2 & Entre 50 milhões e 100 milhões \\
\hline 20 & INSTITUTO BIOCHIMICO INDÚSTRIA FARMACÊUTICA LTDA & 10 & 14 & 10 & 5 & Entre 50 milhões e 100 milhões \\
\hline 21 & MYLAN LABORATORIOS LTDA & 2 & 4 & 3 & 1 & Entre 50 milhões e 100 milhões \\
\hline 22 & \begin{tabular}{|l|} 
NOVAFARMA INDÚSTRIA FARMACÊUTICA LTDA \\
\end{tabular} & 20 & 24 & 20 & 15 & Entre 50 milhões e 100 milhões \\
\hline 23 & LABORATÓRIO FARMACÊUTICO DA MARINHA & 3 & 4 & 3 & 3 & Entre 50 milhões e 100 milhões \\
\hline 24 & COMANDO DO EXÉRCITO & 1 & 2 & 1 & 1 & Entre 50 milhões e 100 milhões \\
\hline 25 & CRISTÁLIA PRODUTOS QUÍMICOS FARMACÊUTICOS LTDA. & 23 & 34 & 23 & 18 & Entre 50 milhões e 100 milhões \\
\hline 26 & $\begin{array}{l}\text { FARMACE INDÚSTRIA QUÍMICO-FARMACÊUTICA CEARENSE } \\
\text { LTDA }\end{array}$ & 11 & 30 & 11 & 10 & Entre 50 milhões e 100 milhões \\
\hline 27 & \begin{tabular}{|l|} 
MEDQUIMICA INDUSTRIA FARMACEUTICA LTDA. \\
\end{tabular} & 19 & 37 & 19 & 17 & Entre 50 milhões e 100 milhões \\
\hline 28 & PHARLAB INDÚSTRIA FARMACÊUTICA S.A. & 34 & 54 & 34 & 28 & Entre 50 milhões e 100 milhões \\
\hline 29 & \begin{tabular}{|l} 
ACTAVIS FARMACEUTICA LTDA. \\
\end{tabular} & 19 & 38 & 20 & 17 & Entre 10 milhões e 50 milhões \\
\hline 30 & INSTITUTO VITAL BRAZIL S/A & 2 & 6 & 2 & 2 & Entre 10 milhões e 50 milhões \\
\hline 31 & \begin{tabular}{|l|} 
FUNDAÇÃO PARA O REMÉDIO POPULAR - FURP \\
\end{tabular} & 19 & 23 & 19 & 14 & Entre 10 milhões e 50 milhões \\
\hline 32 & BLAU FARMACÊUTICA S.A. & 19 & 27 & 19 & 17 & Entre 10 milhões e 50 milhões \\
\hline 33 & ALTHAIA S.A INDÚSTRIA FARMACÊUTICA & 11 & 22 & 10 & 10 & Entre 10 milhões e 50 milhões \\
\hline 34 & $\begin{array}{l}\text { MULTILAB INDÚSTRIA E COMÉRCIO DE PRODUTOS } \\
\text { FARMACÊUTICOS LTDA }\end{array}$ & 21 & 37 & 21 & 17 & Entre 10 milhões e 50 milhões \\
\hline 35 & $\begin{array}{l}\text { HYPOFARMA - INSTITUTO DE HYPODERMIA E FARMÁCIA } \\
\text { LTDA }\end{array}$ & 14 & 16 & 13 & 10 & Entre 10 milhões e 50 milhões \\
\hline \multirow[t]{3}{*}{36} & GRUPO PFIZER/WYETH & 7 & 9 & 7 & 6 & Entre 10 milhões e 50 milhões \\
\hline & LABORATÓRIOS PFIZER LTDA & 1 & 2 & 1 & 1 & Menor do que 10 milhões \\
\hline & WYETH INDÚSTRIA FARMACÊUTICA LTDA & 6 & 7 & 6 & 5 & Entre 10 milhões e 50 milhões \\
\hline 37 & ZYDUS NIKKHO FARMACÊUTICA LTDA & 18 & 22 & 18 & 12 & Entre 10 milhões e 50 milhões \\
\hline \multirow{3}{*}{38} & GRUPO CIFARMA/MABRA & 8 & 8 & 8 & 5 & Entre 10 milhões e 50 milhões \\
\hline & \begin{tabular}{|l} 
CIFARMA CIENTÍFICA FARMACÊUTICA LTDA \\
\end{tabular} & 4 & 4 & 4 & 3 & Menor do que 10 milhões \\
\hline & MABRA FARMACÊUTICA LTDA. & 4 & 4 & 4 & 2 & Entre 10 milhões e 50 milhões \\
\hline 39 & \begin{tabular}{|l|} 
ISOFARMA INDUSTRIAL FARMACÊUTICA LTDA \\
\end{tabular} & 4 & 5 & 4 & 3 & Entre 10 milhões e 50 milhões \\
\hline
\end{tabular}




\begin{tabular}{|c|c|c|c|c|c|c|}
\hline 40 & COLBRÁS INDÚSTRIA E COMÉRCIO LTDA & 1 & 1 & 1 & 1 & Entre 10 milhões e 50 milhões \\
\hline 41 & VITAMEDIC INDUSTRIA FARMACEUTICA LTDA & 14 & 25 & 13 & 11 & Entre 10 milhões e 50 milhões \\
\hline 42 & GLENMARK FARMACÊUTICA LTDA & 7 & 14 & 7 & 6 & Entre 10 milhões e 50 milhões \\
\hline 43 & TORRENT DO BRASIL LTDA & 10 & 26 & 10 & 8 & Entre 10 milhões e 50 milhões \\
\hline 44 & LABORATÓRIO GLOBO LTDA & 26 & 38 & 26 & 21 & Entre 10 milhões e 50 milhões \\
\hline 45 & HOSPIRA PRODUTOS HOSPITALARES LTDA & 1 & 1 & 1 & 1 & Entre 10 milhões e 50 milhões \\
\hline 46 & NATIVITA IND. COM. LTDA. & 6 & 12 & 6 & 6 & Entre 10 milhões e 50 milhões \\
\hline 47 & LABORATÓRIO QUÍMICO FARMACÊUTICO BERGAMO LTDA & 7 & 7 & 7 & 7 & Entre 10 milhões e 50 milhões \\
\hline 48 & THEODORO F SOBRAL \& CIA LTDA & 7 & 19 & 7 & 6 & Entre 10 milhões e 50 milhões \\
\hline 49 & DR. REDDYS FARMACÊUTICA DO BRASIL LTDA & 3 & 3 & 3 & 3 & Menor do que 10 milhões \\
\hline 50 & BEKER PRODUTOS FÁRMACO HOSPITALARES LTDA & 1 & 1 & 1 & 1 & Menor do que 10 milhões \\
\hline 51 & ELI LILLY DO BRASIL LTDA & 1 & 4 & 1 & 1 & Menor do que 10 milhões \\
\hline 52 & ACTELION PHARMACEUTICALS DO BRASIL LTDA & 1 & 2 & 1 & 1 & Menor do que 10 milhões \\
\hline 53 & HALEX ISTAR INDÚSTRIA FARMACÊUTICA SA & 8 & 11 & 8 & 7 & Menor do que 10 milhões \\
\hline 54 & INDÚSTRIA FARMACÊUTICA MELCON DO BRASIL S.A. & 2 & 3 & 2 & 2 & Menor do que 10 milhões \\
\hline 55 & SANTISA LABORATÓRIO FARMACÊUTICO S/A & 3 & 4 & 3 & 3 & Menor do que 10 milhões \\
\hline 56 & WASSER FARMA LTDA & 1 & 1 & 1 & 1 & Menor do que 10 milhões \\
\hline 57 & UNICHEM FARMACÊUTICA DO BRASIL LTDA & 5 & 13 & 5 & 5 & Menor do que 10 milhões \\
\hline 58 & MARIOL INDUSTRIAL LTDA & 7 & 18 & 7 & 5 & Menor do que 10 milhões \\
\hline 59 & GREENPHARMA QUÍMICA E FARMACÊUTICA LTDA & 2 & 2 & 2 & 2 & Menor do que 10 milhões \\
\hline 60 & BRASTERAPICA INDÚSTRIA FARMACÊUTICA LTDA & 4 & 7 & 4 & 4 & Menor do que 10 milhões \\
\hline 61 & APSEN FARMACEUTICA S/A & 1 & 1 & 1 & 1 & Menor do que 10 milhões \\
\hline 62 & LABORATÓRIO SANOBIOL LTDA & 1 & 1 & 1 & 1 & Menor do que 10 milhões \\
\hline 63 & PHARMASCIENCE INDÚSTRIA FARMACÊUTICA EIRELI & 3 & 6 & 4 & 3 & Menor do que 10 milhões \\
\hline 64 & LABORATÓRIOS OSÓRIO DE MORAES LTDA & 2 & 2 & 2 & 2 & Menor do que 10 milhões \\
\hline 65 & ABBOTT LABORATÓRIOS DO BRASIL LTDA & 2 & 4 & 2 & 2 & Menor do que 10 milhões \\
\hline 66 & ASPEN PHARMA INDÚSTRIA FARMACÊUTICA LTDA & 1 & 1 & 1 & 1 & Menor do que 10 milhões \\
\hline 67 & BLISFARMA INDÚSTRIA FARMACÊUTICA LTDA - ME & 2 & 3 & 2 & 2 & Menor do que 10 milhões \\
\hline 68 & FRESENIUS KABI BRASIL LTDA & 1 & 1 & 1 & 1 & Menor do que 10 milhões \\
\hline 69 & BIOLAB SANUS FARMACÊUTICA LTDA & 1 & 2 & 1 & 1 & Menor do que 10 milhões \\
\hline 70 & JP INDUSTRIA FARMACEUTICA S/A & 1 & 1 & 1 & 1 & Menor do que 10 milhões \\
\hline 71 & BELFAR LTDA & 7 & 7 & 7 & 7 & Menor do que 10 milhões \\
\hline 72 & ALLERGAN PRODUTOS FARMACÊUTICOS LTDA & 2 & 3 & 2 & 2 & Menor do que 10 milhões \\
\hline 73 & VISA ESTADUAL SP TESTE & 1 & 1 & 1 & 1 & Menor do que 10 milhões \\
\hline
\end{tabular}

Fonte: (Anvisa, 2018a) 
ANEXO II - Contagem de medicamentos genéricos registrados por laboratório farmacêutico.

Atualizado até Diário Oficial da União de 30 de junho de 2017

\begin{tabular}{|c|c|c|c|c|c|}
\hline$\#$ & Detentor do registro & $\begin{array}{c}\text { Contagem de } \\
\text { Medicamento } \\
\text { Genérico }\end{array}$ & $\#$ & Detentor do registro & $\begin{array}{c}\text { Contagem de } \\
\text { Medicamento } \\
\text { Genérico } \\
\end{array}$ \\
\hline 1 & EMS S/A & 312 & 67 & Farmace & 8 \\
\hline 2 & Germed & 257 & 68 & Farmasa & 8 \\
\hline 3 & Teuto & 190 & 69 & Belfar & 7 \\
\hline 4 & Nova Química & 177 & 70 & Brasterápica & 7 \\
\hline 5 & Eurofarma & 175 & 71 & Lafepe & 7 \\
\hline 6 & Medley & 161 & 72 & Mylan & 7 \\
\hline 7 & Prati Donaduzzi & 161 & 73 & Lab. Marinha & 6 \\
\hline 8 & Legrand & 156 & 74 & Beker & 5 \\
\hline 9 & Brainfarma & 131 & 75 & Greenpharma & 5 \\
\hline 10 & EMS Sigma Pharma & 125 & 76 & IVB & 5 \\
\hline 11 & Aché & 118 & 77 & Luper & 5 \\
\hline 12 & Geolab & 116 & 78 & Mabra & 5 \\
\hline 13 & Sandoz & 108 & 79 & Zydus Nikkho & 5 \\
\hline 14 & Cimed & 78 & 80 & Blanver & 4 \\
\hline 15 & Hipolabor & 77 & 81 & Teva & 4 \\
\hline 16 & Cristália & 66 & 82 & Astrazeneca & 3 \\
\hline 17 & Ranbaxy & 66 & 83 & Ativus & 3 \\
\hline 18 & União Química & 65 & 84 & FUNED & 3 \\
\hline 19 & Pharlab & 53 & 85 & Glaxosmithkline & 3 \\
\hline 20 & FURP & 48 & 86 & Instituto Biochimico & 3 \\
\hline 21 & Aurobindo & 41 & 87 & LIFAL & 3 \\
\hline 22 & Merck & 35 & 88 & Melcon & 3 \\
\hline 23 & Biosintética & 33 & 89 & Neckerman & 3 \\
\hline 24 & Medquímica & 33 & 90 & Neolatina & 3 \\
\hline 25 & Onefarma & 32 & 91 & Osório Moraes & 3 \\
\hline 26 & Actavis & 31 & 92 & Pfizer & 3 \\
\hline 27 & Novartis & 31 & 93 & Pharma Limirio & 3 \\
\hline 28 & Sanofi-Aventis & 31 & 94 & Santisa & 3 \\
\hline 29 & Novafarma & 30 & 95 & UCB & 3 \\
\hline 30 & Accord & 29 & 96 & Apsen & 2 \\
\hline 31 & Globo & 29 & 97 & Bahiafarma & 2 \\
\hline 32 & Multilab & 29 & 98 & Dr. Reddys & 2 \\
\hline 33 & Zydus & 29 & 99 & Equiplex & 2 \\
\hline 34 & Sun & 28 & 100 & Evolabis & 2 \\
\hline 35 & Sanval & 27 & 101 & Lab. Aeronáutica & 2 \\
\hline 36 & Torrent & 26 & 102 & Lab. Exército & 2 \\
\hline 37 & Blau & 24 & 103 & Libbs & 2 \\
\hline 38 & Antibióticos do Brasil & 23 & 104 & Natcofarma & 2 \\
\hline 39 & Biolab Sanus & 20 & 105 & Opem & 2 \\
\hline 40 & 1Farma & 18 & 106 & Pharmascience & 2 \\
\hline 41 & Halex Istar & 17 & 107 & UCI-Farma & 2 \\
\hline 42 & Hypofarma & 17 & 108 & UFRN & 2 \\
\hline 43 & Cellera & 16 & 109 & Volpharma & 2 \\
\hline 44 & Mariol & 16 & 110 & Zambon & 2 \\
\hline 45 & Sanofi-Medley & 16 & 111 & Airela & 1 \\
\hline 46 & Cifarma & 15 & 112 & Balm-Labor & 1 \\
\hline 47 & Vitapan & 15 & 113 & Besins & 1 \\
\hline 48 & Wyeth & 15 & 114 & Blisfarma & 1 \\
\hline 49 & Accord & 13 & 115 & Cazi & 1 \\
\hline 50 & Althaia & 13 & 116 & Chiesi & 1 \\
\hline
\end{tabular}




\begin{tabular}{|l|l|l|l|l|c|}
\hline 51 & Bergamo & 13 & 117 & Colbrás & 1 \\
\hline 52 & Vitamedic & 13 & 118 & Dr. Reddys & 1 \\
\hline 53 & Abbott & 12 & 119 & Eli Lilly & 1 \\
\hline 54 & Dr Reddys & 12 & 120 & Elofar & 1 \\
\hline 55 & Zodiac & 12 & 121 & Farma Vision & 1 \\
\hline 56 & Fiocruz & 11 & 122 & Farmace & 1 \\
\hline 57 & Glenmark & 11 & 123 & Farmoquimica & 1 \\
\hline 58 & Nativita & 11 & 124 & Janssen & 1 \\
\hline 59 & Aspen & 10 & 125 & JP & 1 \\
\hline 60 & Biochimico & 10 & 126 & MR Laboratórios & 1 \\
\hline 61 & Lab. Globo & 10 & 127 & Natulab & 1 \\
\hline 62 & Unichem & 10 & 128 & Sanobiol & 1 \\
\hline 63 & Fresenius & 9 & 129 & Schering-Plough & 1 \\
\hline 64 & Theodoro F Sobral & 9 & 130 & União Química & 1 \\
\hline 65 & Althaia & 8 & 131 & United Medical & 1 \\
\hline 66 & Ariston & 8 & 132 & Wasser & 1 \\
\hline & \multicolumn{2}{|c|}{ detal genéricos } & $\mathbf{3 7 2 3}$ \\
\hline
\end{tabular}

Extraído de: (Anvisa, 2017a) 


\section{APÊNDICE I - Pesquisa do referencial teórico}

\section{Esquema de pesquisa de referência bibliográficas - critérios de pesquisa* e número de documentos indexados pelo Scopus.}

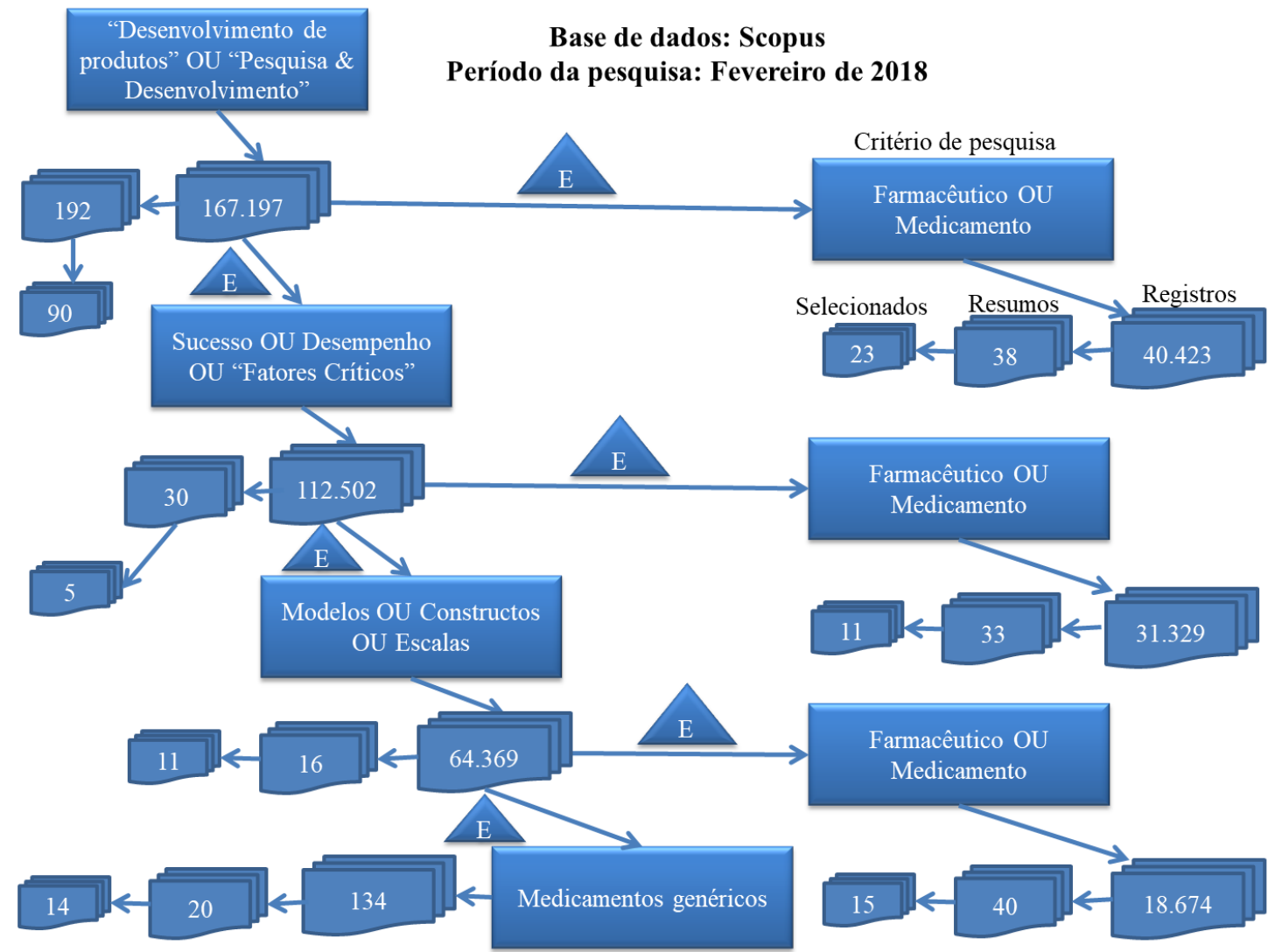

Nota: operadores booleanos (Pizzani, da Silva, Bello, \& Hayashi, 2012): "OU” (“OR”) - utilizado para agrupar termos (em geral sinônimos ou equivalentes); "E" (“AND") - utilizado para combinar os termos (em geral sinônimos ou equivalentes). Fonte: dados da pesquisa

\section{Palavras pesquisadas, resultados e classificação}

- Base de dados de publicações acadêmicas: Scopus ${ }^{\circledR}$ (www.scopus.com)

- Campos pesquisados (atributos das publicações): Título, Resumo e Palavras-chaves ("article title", "abstract" e "keywords")

- Operadores booleanos (Pizzani et al., 2012):

"OR" (ou) - utilizado para agrupar termos (em geral sinônimos ou equivalentes)

"AND” (e) - utilizado para combinar os termos (em geral sinônimos ou equivalentes)

Siglas: Desenvolvimento de novos produtos (DP); Fatores Críticos no Desenvolvimento de Novos Produtos (fDP); Desempenho e Indicadores para Desenvolvimento de Novos Produtos (iDP);Desenvolvimento de Medicamentos (DM); Desempenho e Indicadores para o Desenvolvimento de Medicamentos (iDM); Desenvolvimento de Medicamentos Genéricos (DMG); e Outros assuntos 
relacionados $(O A)$

\begin{tabular}{|c|c|c|c|c|c|c|c|c|c|}
\hline & & & \multicolumn{7}{|c|}{ Artigos selecionados } \\
\hline $\begin{array}{l}\text { Palavra(s)/conjunto(s) } \\
\text { pesquisado(s)* }\end{array}$ & $\begin{array}{l}N^{\circ} \text { de } \\
\text { registros }\end{array}$ & $\begin{array}{l}\text { Resumos } \\
\text { anali- } \\
\text { sados }\end{array}$ & $D P$ & $f D P$ & $i D P$ & $D M$ & $i D M$ & $\begin{array}{c}D M \\
G\end{array}$ & $O A$ \\
\hline $\begin{array}{c}\text { TITLE-ABS-KEY ( "drug? } \\
\text { development" OR "medicine? } \\
\text { development" OR } \\
\text { "medication? development" } \\
\text { OR "drug product? } \\
\text { development" OR "product? } \\
\text { development" OR "DP" OR } \\
\text { "research and development" } \\
\text { OR "R\&D" OR "research and } \\
\text { development" OR "R \& D" ) }\end{array}$ & 167197 & $\begin{array}{l}192 \\
\text { (entre } \\
500 \text { mais } \\
\text { citados e } \\
\text { os } 500 \\
\text { mais } \\
\text { citados } \\
\text { desde } \\
2010) \\
\end{array}$ & 25 & 34 & 27 & 2 & & 1 & 1 \\
\hline $\begin{array}{c}\text { TITLE-ABS-KEY ( "drug? } \\
\text { development" OR "medicine? } \\
\text { development" OR "medication } \\
\text { ? development" OR "drug } \\
\text { product? } \\
\text { development" OR "product? } \\
\text { development" OR "DP" OR " } \\
\text { research and } \\
\text { development" OR "R\&D" OR } \\
\text { "research and } \\
\text { development" OR "R \& } \\
\left.D^{\prime \prime}\right) \text { AND ("pharma*" OR } \\
\text { "drug*" OR "medic*" OR " } h \\
\text { ealth*") }\end{array}$ & 40423 & $\begin{array}{l}38 \text { (entre } \\
\text { os } 1000 \\
\text { mais } \\
\text { citados) }\end{array}$ & 2 & 7 & 2 & 8 & 3 & & 1 \\
\hline 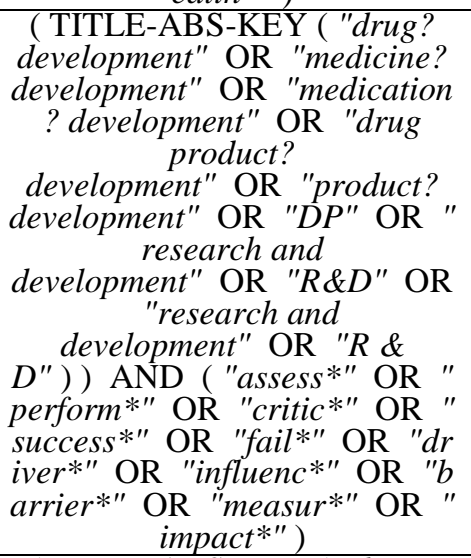 & 112502 & $\begin{array}{c}30 \text { (entre } \\
\text { os } 500 \\
\text { mais } \\
\text { relevante } \\
\text { s) }\end{array}$ & & 2 & & 2 & 1 & & \\
\hline 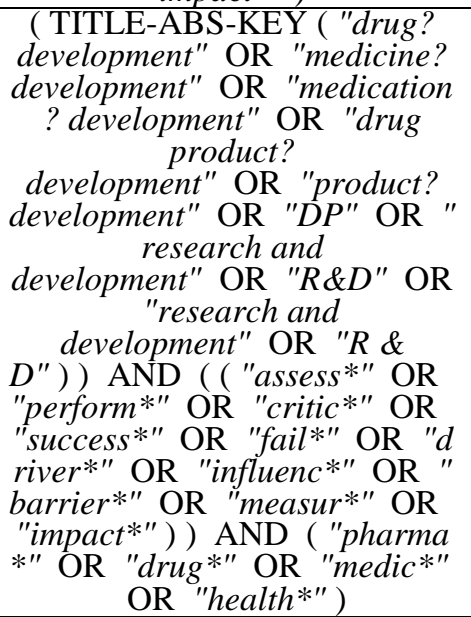 & 31329 & $\begin{array}{c}33 \text { (entre } \\
\text { os } 500 \\
\text { mais } \\
\text { relevante } \\
\text { s) }\end{array}$ & & 3 & 2 & 5 & & & 1 \\
\hline
\end{tabular}




\begin{tabular}{|c|c|c|c|c|c|c|c|c|c|}
\hline \multirow[b]{2}{*}{$\begin{array}{l}\text { Palavra(s)/conjunto(s) } \\
\text { pesquisado(s)* }\end{array}$} & \multirow[b]{2}{*}{$\begin{array}{l}N^{\circ} \text { de } \\
\text { registros }\end{array}$} & \multirow[b]{2}{*}{$\begin{array}{c}\text { Resumos } \\
\text { anali- } \\
\text { sados }\end{array}$} & \multicolumn{7}{|c|}{ Artigos selecionados } \\
\hline & & & $D P$ & $f D P$ & $i D P$ & $D M$ & $i D M$ & $\stackrel{D M}{G}$ & $O A$ \\
\hline $\begin{array}{c}\text { ( TITLE-ABS-KEY ( "drug? } \\
\text { development" OR "medicine? } \\
\text { development" OR } \\
\text { "medication? development" } \\
\text { OR "drug product? } \\
\text { development" OR "product? } \\
\text { development" OR "DP" OR } \\
\text { "research and development" } \\
\text { OR "R\&D" OR "research and } \\
\text { development" OR "R \& D" ) } \\
\text { AND ( "assess*" OR } \\
\text { "perform*" OR "critic*" OR } \\
\text { "success*" OR "faik*" OR } \\
\text { "driver*" OR "influenc*" OR } \\
\text { "barrier*" OR "measur*" OR } \\
\text { "impart*" )) AND ( "model*" } \\
\text { OR "construct*" OR "scale*" }\end{array}$ & 64369 & $\begin{array}{c}16 \text { (entre } \\
\text { os 500 } \\
\text { mais } \\
\text { relevante } \\
\text { s) }\end{array}$ & 1 & 5 & 3 & 1 & 1 & & \\
\hline $\begin{array}{c}\text { ( TITLE-ABS-KEY ( "drug? } \\
\text { development" OR "medicine? } \\
\text { development" OR } \\
\text { "medication? development" } \\
\text { OR "drug product? } \\
\text { development" OR "product? } \\
\text { development" OR "DP" OR } \\
\text { "research and development" } \\
\text { OR "R\&D" OR "research and } \\
\text { development" OR "R \& D" ) } \\
\text { AND ( ( ( "asses*"* OR ) } \\
\text { "perform*" OR "critic*" OR } \\
\text { "success*" OR "fail*" OR } \\
\text { "driver*" OR "influenc*" OR } \\
\text { "barrier*" OR "measur*" OR } \\
\text { "impact*" ) ) AND ( "model*" } \\
\text { OR "construct*" OR "scale*" } \\
\text { ) AND ( "pharma*" OR } \\
\text { "drug*" OR "medic*" OR } \\
\text { "health*" ) } \\
\end{array}$ & 18674 & $\begin{array}{c}40 \text { (entre } \\
\text { os } 500 \\
\text { mais } \\
\text { relevante } \\
\text { s) }\end{array}$ & 1 & 3 & 8 & 1 & 1 & & 1 \\
\hline $\begin{array}{c}\text { ( TITLE-ABS-KEY ( "drug? } \\
\text { development" OR "medicine? } \\
\text { development" OR } \\
\text { "medication? development" } \\
\text { OR "drug product? } \\
\text { development" OR "product? } \\
\text { development" OR "DP" OR } \\
\text { "research and development" } \\
\text { OR "R\&D" OR "research and } \\
\text { development" OR "R \& D" ) ) } \\
\text { AND ( ( ( "assess*" OR } \\
\text { "perform*" OR "critic*" OR } \\
\text { "success*" OR "fail*" OR } \\
\text { "driver*" OR "influenc*" OR } \\
\text { "barrier*" OR "measur*" OR } \\
\text { "impact*" )) AND ( "model*" } \\
\text { OR "construct*" OR "scale*" } \\
\text { )) AND ( "pharma*" OR } \\
\text { "drug*" OR "medic*" OR } \\
\text { "health*")) AND ( "generic } \\
\text { drug*" OR "generic } \\
\text { medicine*" ) }\end{array}$ & 134 & 20 & 12 & & 3 & 8 & & & 3 \\
\hline Totais & & 369 & 41 & 54 & 45 & 27 & 6 & 1 & 7 \\
\hline
\end{tabular}




\section{APÊNDICE II - Resultados das pesquisa do referencial teórico}

- Bases de dados de publicações acadêmicas consultadas: Scopus ${ }^{\circledR}$ (www.scopus.com) e Google Acadêmico (www.scholar.google.com.br)

- Datas: Dezembro de 2018 e Novembro de 2019

- Principais palavras-chaves: "generic drug development", "generic drug formulation"

\begin{tabular}{|c|c|c|}
\hline & Autores & Título \\
\hline 1. & (Elliott, 2000) & Mixed WTO ruling on generic drug development \\
\hline 2. & (Welage et al., 2001) & $\begin{array}{l}\text { Understanding the scientific issues embedded in the generic } \\
\text { drug approval process }\end{array}$ \\
\hline 3. & (Hansen \& Tunnah, 2003) & $\begin{array}{l}\text { The generics } \mathrm{R} \text { and } \mathrm{D} \text { challenge: Seeking the elusive profit } \\
\text { margin }\end{array}$ \\
\hline 4. & (Bansal \& Koradia, 2005) & $\begin{array}{l}\text { The role of reverse engineering in the development of generic } \\
\text { formulations }\end{array}$ \\
\hline 5. & (Reiffen \& Ward, 2005) & Generic Drug Industry Dynamics \\
\hline 6. & (Leon Shargel \& Kanfer, 2005) & Generic Drug Product Development Solid Oral Dosage Forms \\
\hline 7. & (Swarbrick et al., 2005) & Generic Drug Product Development \\
\hline 8. & (Prašnikar \& Škerlj, 2006) & $\begin{array}{l}\text { New product development process and time-to-market in the } \\
\text { generic pharmaceutical industry }\end{array}$ \\
\hline 9. & (Yu et al., 2007) & $\begin{array}{l}\text { US FDA question-based review for generic drugs: A new } \\
\text { pharmaceutical quality assessment system }\end{array}$ \\
\hline 10. & (R. A. Lionberger, 2008) & $\begin{array}{l}\text { FDA Critical Path Initiatives: Opportunities for Generic Drug } \\
\text { Development }\end{array}$ \\
\hline 11. & (Figueiras et al., 2009) & $\begin{array}{l}\text { Assessing lay beliefs about generic medicines: Development of } \\
\text { the generic medicines scale }\end{array}$ \\
\hline 12. & (Hajjar Júnior, 2010) & $\begin{array}{l}\text { Modelo de Gerência de Projetos para Lançamento de } \\
\text { Medicamentos Genéricos pela Indústria Farmacêutica }\end{array}$ \\
\hline 13. & (Pete Harpum, 2010) & $\begin{array}{l}\text { Portfolio, Program, and Project Management in the } \\
\text { Pharmaceutical and Biotechnology Industries }\end{array}$ \\
\hline 14. & (Aloka Srinivasan \& Iser, 2010) & $\begin{array}{l}\text { FDA Perspectives: Common deficiencies in abbreviated new } \\
\text { drug applications: part 1: Drug substance }\end{array}$ \\
\hline 15. & (Aloka Srinivasan et al., 2010) & $\begin{array}{l}\text { FDA Perspectives: Common Deficiencies in Abbreviated New } \\
\text { Drug Applications: Part 2: Description, composition, and } \\
\text { excipients }\end{array}$ \\
\hline 16. & (Varu \& Khanna, 2010) & $\begin{array}{l}\text { Opportunities and challenges to implementing Quality by } \\
\text { Design approach in generic drug development }\end{array}$ \\
\hline 17. & (Isse, 2011) & $\begin{array}{l}\text { A indústria farmacêutica nacional e a importância dos } \\
\text { medicamentos genéricos no seu desenvolvimento. }\end{array}$ \\
\hline 18. & (Rachit, Arvind, \& Geeta, 2011) & Generic Drugs - A Ground Discussion \\
\hline 19. & (Su, Song, Wang, \& Shi, 2011) & Strategy for development of generic drug superstars in China \\
\hline 20. & (Hottinger \& Liang, 2012) & $\begin{array}{l}\text { Deficiencies of the FDA in evaluating Generic formulations: } \\
\text { Addressing narrow therapeutic index drugs }\end{array}$ \\
\hline 21. & (Worku et al., 2012) & $\begin{array}{l}\text { Deficiencies in generic product dossiers as submitted to the } \\
\text { WHO Prequalification of Medicines Programme Deficiencies in } \\
\text { generic product dossiers as submitted to the WHO } \\
\text { Prequalification of Medicines Programme }\end{array}$ \\
\hline 22. & (L. C. Chang \& Gau, 2013)gau & $\begin{array}{l}\text { Statistics, Quality Review Issues, and Beyond for Generic Drug } \\
\text { Applications in Taiwan }\end{array}$ \\
\hline 23. & (R.-K. Chang et al., 2013) & $\begin{array}{l}\text { Generic Development of Topical Dermatologic Products: } \\
\text { Formulation Development, Process Development, and Testing } \\
\text { of Topical Dermatologic Products }\end{array}$ \\
\hline 24. & (Chaudhuri, 2013) & $\begin{array}{l}\text { Simultaneous improvement in development time, cost and } \\
\text { quality: A practical framework for generic pharmaceuticals } \\
\text { industry }\end{array}$ \\
\hline 25. & (Huang et al., 2013) & $\begin{array}{l}\text { Technical gaps faced by Chinese generic medicine } \\
\text { manufacturers to achieve the standards of WHO medicines }\end{array}$ \\
\hline
\end{tabular}




\begin{tabular}{|c|c|c|}
\hline & & Prequalification \\
\hline 26. & (Isadore Kanfer et al., 2014) & Generic Drug Product Development. Solid Oral Dosage Forms \\
\hline 27. & (Kaló et al., 2015) & Need for multicriteria evaluation of generic drug policies \\
\hline 28. & (Teixeira, 2015) & $\begin{array}{l}\text { A indústria farmacêutica no Brasil: um estudo do impacto } \\
\text { socioeconômico dos medicamentos genéricos }\end{array}$ \\
\hline 29. & $\begin{array}{l}\text { (Thakur, Mahata, Thakur, \& } \\
\text { Chakraborty, 2015) }\end{array}$ & Generic drug: Where it stands in pharma industry? \\
\hline 30. & (Mallu, Nair, Sankar, et al., 2015) & $\begin{array}{l}\text { Impact of API (Active Pharmaceutical Ingredient) Source } \\
\text { Selection on Generic Drug Products }\end{array}$ \\
\hline 31. & (Mallu, Nair, Bapatu, et al., 2015) & $\begin{array}{l}\text { API Supplier Change or Addition of Alterate API Supplier in } \\
\text { Generic Drug Products: Cost, Quality and Regulatory Factors }\end{array}$ \\
\hline 32. & (Prachi, B, \& Dilip, 2015) & $\begin{array}{l}\text { Comparative Study of Reference Products in Generic Drug } \\
\text { Development in U.S. and Europe }\end{array}$ \\
\hline 33. & (Vvssn et al., 2015) & $\begin{array}{l}\text { Quality Improvement with Scientific Approaches (QbD, AQbD } \\
\text { and PAT) in Generic Drug Substance Development: Review }\end{array}$ \\
\hline 34. & (Lucas-Dominguez et al., 2016) & Patterns and Trends in Scientific Research on Generic Drugs \\
\hline 35. & (WHO, 2016) & Interchangeability of WHO-prequalified generics Generic \\
\hline 36. & (Chongprasert, 2016) & $\begin{array}{l}\text { Successful generic drug product development: From research to } \\
\text { marketing approval }\end{array}$ \\
\hline 37. & (Kader, 2016) & $\begin{array}{l}\text { Mitigating the risks of generic drug product development: An } \\
\text { application of quality by design (QbD) and question based } \\
\text { review (QbR) approaches }\end{array}$ \\
\hline 38. & (C.-Y. Y. Lee et al., 2016) & $\begin{array}{l}\text { Forces influencing generic drug development in the United } \\
\text { States: a narrative review }\end{array}$ \\
\hline 39. & (Raka \& Liangrokapart, 2017) & $\begin{array}{l}\text { An Analytical Hierarchy Process (AHP) Approach to Risk } \\
\text { Analysis: A Case Study of a New Generic Drug Development } \\
\text { Process }\end{array}$ \\
\hline 40. & (Suchak \& Murray, 2017) & $\begin{array}{l}\text { Generic portfolio management: A paradigm for minimizing risk } \\
\text { and maximizing value }\end{array}$ \\
\hline 41. & (Yousefi et al., 2017) & $\begin{array}{l}\text { New product development in the pharmaceutical industry: } \\
\text { Evidence from a generic market }\end{array}$ \\
\hline 42. & (Do Carmo, Piras, et al., 2017) & $\begin{array}{l}\text { Main Reasons for Registration Application Refusal of Generic } \\
\text { and Similar Pharmaceutical Drug Products by the Brazilian } \\
\text { Health Regulatory Agency (ANVISA) }\end{array}$ \\
\hline 43. & $\begin{array}{l}\text { (Mallam, Byalakere Rudraiah, \& } \\
\text { Rudraswamy, 2017) }\end{array}$ & Generic drugs: Current status and future potential \\
\hline 44. & (Wang, Li, \& Anupindi, 2018) & $\begin{array}{l}\text { Manufacturing and Regulatory Barriers to Generic Drug } \\
\text { Competition: A Structural Model Approach }\end{array}$ \\
\hline 45. & (R. Lionberger, 2019) & Decision Science for Generic Drug Development and Review \\
\hline 46. & $\begin{array}{l}\text { (Zhao, Kim, Zhang, \& Lionberger, } \\
\text { 2019) }\end{array}$ & $\begin{array}{l}\text { Generating Model Integrated Evidence for Generic Drug } \\
\text { Development and Assessment }\end{array}$ \\
\hline
\end{tabular}




\section{APÊNDICE III - Levantamento da literatura sobre o desenvolvimento de medicamentos no Brasil}

- Base de dado de publicações acadêmicas: Google Acadêmico (www.scholar.google.com.br)

- Datas: Dezembro de 2018 e Novembro de 2019

- Principais palavras-chaves: "generic drug", "generic drug development", "Brazil", "Brazilian"

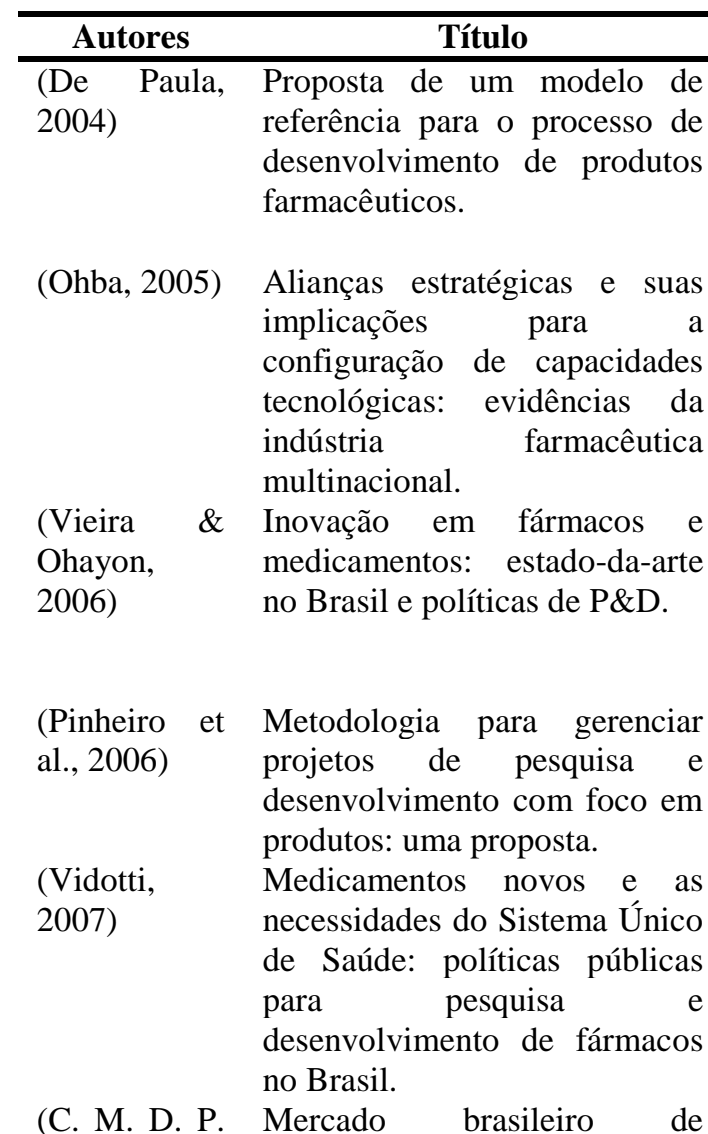

Pinto, 2007) medicamentos genéricos: análise do desemprenho de uma subsidiária de laboratório estrangeiro.

(De Paula \& A Reference Model for the Ribeiro, Pharmaceutical processo de DP 2007) Management - an architecture

(Calixto \& Desenvolvimento

Siqueira Jr, Medicamentos no Brasil: 2008) Desafios

(Soares \& Implantação de um sistema de Mancilha, gerenciamento de projetos no 2008) desenvolvimento de produtos farmacêuticos.

(V. S. D. Da invenção à inovação: gestão Esteves, dos processos de 2009) desenvolvimento de novos produtos farmacêuticos.

(Andrade, Inovação e externalização: uma
Resumo
Propõe um modelo de referência para o
processo de desenvolvimento de produtos
farmacêuticos. Também determinou seus
componentes em termos de: processo,
princípios, práticas, cultura e ferramentas.
Analisou as capacidades tecnológicas envolvidas em alianças estratégicas pela indústria farmacêutica multinacional, assim como suas principais implicações.

Método Tipo

EM

TD

Indicam fatores a serem considerados no planejamento estratégico, estabelecimento do portfólio de projetos e construção do pipeline para inovação na indústria farmacêutica.

Este artigo propõe uma metodologia de gestão de projetos de $P \& D$ para o Instituto de Tecnologia de Fármacos da Fiocruz.

$\mathrm{AD}$

$\mathrm{DM}$

Aborda as iniciativas e a tendência de lançamento de medicamentos novos e sua influência sobre o tratamento de doenças prioritárias para o Sistema Único de Saúde.

EC AP

EC AP

EC TD

Identificou os motivos que levaram uma subsidiária de um laboratório estrangeiro a não obter a liderança no mercado brasileiro de medicamentos genéricos.

EC DM

Artigo derivado da tese de doutorado. Apresentam o desenvolvimento de um modelo de referência para o processo de desenvolvimento de produtos farmacêuticos.

EM SL

Discutem os avanços e as iniciativas governamentais lançadas na década de 2000 que visaram estimular a P\&D do setor farmacêutico brasileiro.

Realizou uma análise crítica da situação do sistema de gerenciamento de projetos de desenvolvimento de produtos em uma indústria farmacêutica.

Apresenta uma proposta de um modelo teórico-conceitual de gestão do processo de desenvolvimento de novos medicamentos para aplicação na Farmanguinhos (FIOCRUZ).

Abordou como os processos inovativos
RL AP

EC $\quad$ MO

EC DM

RL TD 


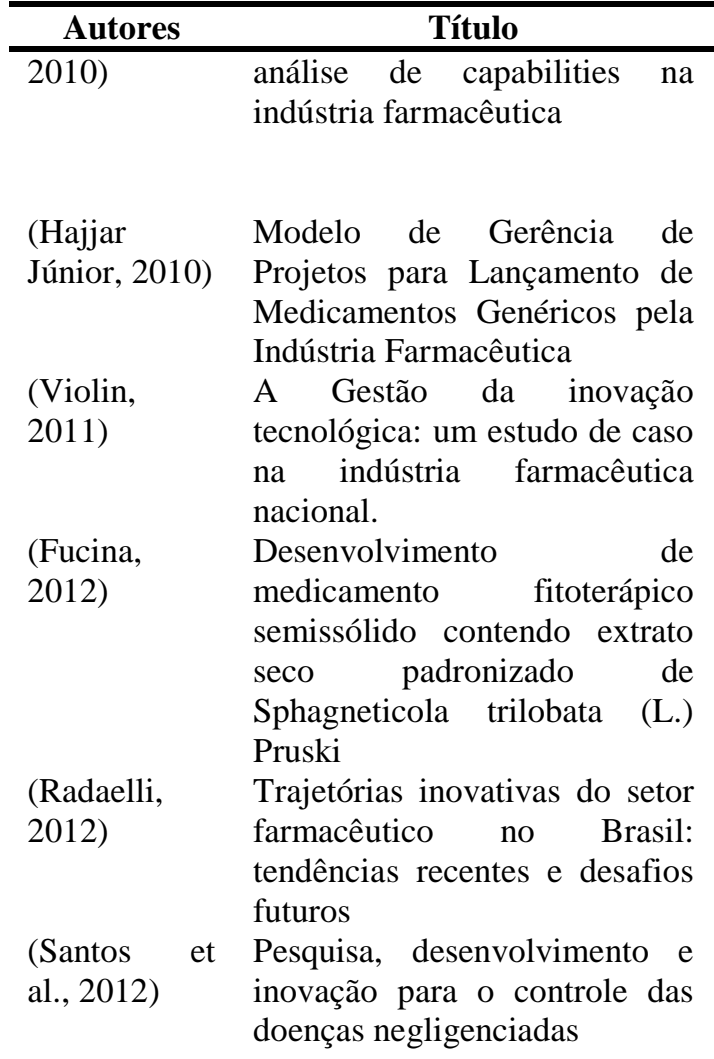

(Sá, 2013) Resignificando a natureza: a P\&D de medicamentos antimaláricos a partir da artemisia annua - 1960 a 2010

(Testa, 2014) Desenvolvimento de medicamento similar de olanzapina comprimidos revestidos.

(Yamaguishi, Gestão da inovação na 2014) indústria farmacêutica no Brasil: estudo de múltiplos casos

(do Couto, A Pré-Qualificação de 2014) medicamentos: análise comparativa entre as Boas Práticas de Fabricação da OMS e da ANVISA.

(Silva, 2015) Desenvolvimento de um modelo de simulação para apoio ao gerenciamento de projetos de desenvolvimento de medicamento genérico em uma empresa farmacêutica

(Cunha et al., Inovação e desenvolvimento de 2016) novos produtos: Características do ramo farmacêutico brasileiro
Resumo

Método Tipo

podem ser viabilizados e estimulados a partir da externalização de "capabilities" de pesquisa, desenvolvimento e manufatura.

Propôs um modelo de gerenciamento de projetos para o lançamento de novos produtos na indústria farmacêutica de medicamentos genéricos.

Analisou a aplicação de uma metodologia de gestão da inovação em uma indústria farmacêutica nacional.

EC DM

Descreveu o desenvolvimento de um medicamento fitoterápico semissólido tópico e a respectiva metodologia para o controle de qualidade do derivado vegetal e do fitoterápico.

Avaliou as possibilidades das empresas farmacêuticas nacionais conseguirem ocupar posições competitivas considerando suas trajetórias e o investimento em P\&D.

Analisaram as publicações sobre a pesquisa e o desenvolvimento de medicamentos destinados à prevenção e controle das doenças negligenciadas no Brasil e no mundo.

Analisa a história da P\&D de medicamentos oriundos de plantas medicinais utilizando o caso do desenvolvimento de antimaláricos a partir da planta Artemisia annua.

Descreve o processo de desenvolvimento de um medicamento similar de comprimidos revestidos de olanzapina.

EC

DM

EX DM

EM

Identificou os processos de inovação, estrutura organizacional, práticas e ferramentas utilizadas pelas organizações pesquisadas e observou suas deficiências.

Identificou e comparou os principais requisitos técnicos recomendados pela OMS e exigidos pela Anvisa para o cumprimento e reconhecimento das BPFs para fins de pré-qualificação de medicamentos.

Desenvolveu um modelo computacional de simulação de eventos discretos voltado para a análise dos PDMG de uma empresa farmacêutica.

EX DM

Descrevem são realizados os processos de desenvolvimento de novos produtos farmacêuticos e verificaram que os laboratórios brasileiros em geral inovam por meio da engenharia reversa (medicamentos genéricos) 


\begin{tabular}{|c|c|c|c|c|}
\hline Autores & Título & Resumo & Método & Tipo \\
\hline (Lima, 2016) & $\begin{array}{l}\text { Gestão e melhoria de processos } \\
\text { em uma indústria farmacêutica } \\
\text { pública: estudo de caso da } \\
\text { gestão de projetos de } \\
\text { desenvolvimento }\end{array}$ & $\begin{array}{l}\text { Identificou as causas da grande quantidade } \\
\text { de projetos de redesenvolvimento e propôs } \\
\text { ações corretivas. Identificou interligações } \\
\text { entre as causas principais dos problemas } \\
\text { levantados. }\end{array}$ & $\mathrm{EC}$ & DM \\
\hline $\begin{array}{l}(\text { A. L. } \\
\text { Esteves, } \\
\text { 2018) }\end{array}$ & $\begin{array}{l}\text { Gerenciamento de projetos de } \\
\text { desenvolvimento de } \\
\text { medicamentos sintéticos em } \\
\text { um laboratório farmacêutico } \\
\text { oficial brasileiro: proposta para } \\
\text { melhoria da gestão a partir da } \\
\text { modelagem de um processo } \\
\text { padrão }\end{array}$ & $\begin{array}{l}\text { Propôs melhorias à gestão de projetos a } \\
\text { partir da modelagem de um processo } \\
\text { padrão de desenvolvimento de } \\
\text { medicamentos em um laboratório } \\
\text { farmacêutico público. }\end{array}$ & $\mathrm{EC}$ & DM \\
\hline $\begin{array}{l}\text { (Botelho, } \\
\text { Martins, \& } \\
\text { Reis, 2018) }\end{array}$ & $\begin{array}{l}\text { Análise de medicamentos } \\
\text { novos registrados no Brasil na } \\
\text { perspectiva do Sistema Único } \\
\text { de Saúde e da carga de doença. }\end{array}$ & $\begin{array}{l}\text { Analisaram os medicamentos novos } \\
\text { registrados no Brasil de } 2003 \text { a } 2013 \text {, sob a } \\
\text { perspectiva da carga de doenças e da } \\
\text { assistência farmacêutica no SUS. }\end{array}$ & $\mathrm{AD}$ & AP \\
\hline $\begin{array}{l}\text { (Niso, Reis, } \\
\& \quad \text { Bagno, } \\
2018)\end{array}$ & $\begin{array}{l}\text { O processo r de } \\
\text { desenvolvimento de novas } \\
\text { vacinas sob a ótica da Gestão } \\
\text { do Desenvolvimento de } \\
\text { Produtos }\end{array}$ & $\begin{array}{l}\text { Propuseram um modelo para o processo de } \\
\text { desenvolvimento de vacinas e } \\
\text { identificaram particularidades, pontos } \\
\text { críticos e demandas. }\end{array}$ & EM & AA \\
\hline $\begin{array}{l}\text { (Salerno, } \\
\text { Matsumoto, } \\
\& \quad \text { Ferraz, } \\
\text { 2018) }\end{array}$ & 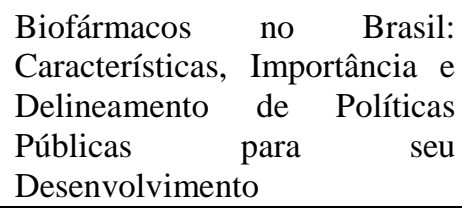 & $\begin{array}{l}\text { Analisam as possíveis políticas públicas } \\
\text { para o desenvolvimento de biofármacos no } \\
\text { Brasil, em especial anticorpos monoclonais }\end{array}$ & $\mathrm{RE}$ & $\mathrm{RB}$ \\
\hline
\end{tabular}

Notas: Tipo de publicação $=(\mathrm{AA}=$ artigo publicado nos anais de congresso; $\mathrm{AP}=$ artigo publicado em periódico; $\mathrm{DM}=$ dissertação de mestrado; $\mathrm{MO}=$ monografia; $\mathrm{SL}=$ seção de livro; $\mathrm{TD}=$ tese de doutorado; $\mathrm{RE}=$ relatório $)$. Método de pesquisa $=(\mathrm{AD}=$ análise documental; $\mathrm{EC}=$ estudo de caso; $\mathrm{EM}=$ estudo de multicasos; $\mathrm{EX}=$ experimento; $\mathrm{RB}=$ revisão da literatura). Fonte: dados da pesquisa. 


\section{APÊNDICE IV - Questionário (etapa qualitativa)}

\section{"DESAFIOS NO DESENVOLVIMENTO DE NOVOS MEDICAMENTOS NO BRASIL"}

O objetivo deste projeto é a identificação dos fatores contribuintes para o desempenho dos projetos de desenvolvimento dos medicamentos genéricos na indústria farmacêutica instalada no Brasil. O foco é nos problemas no processo de desenvolvimento, em especial as provocadas pelas decisões de portfólio de novos projetos, e identificar possíveis alternativas para a melhoria das práticas atuais e aumento da taxa de sucesso dos projetos.

A participação é absolutamente voluntária e o respondente poderá desistir de sua participação a qualquer momento da pesquisa. Participam da pesquisa profissionais com conhecimento e experiência verificáveis no desenvolvimento farmacotécnico de novos medicamentos.

O método eDelphi de pesquisa será aplicado por meio de questionários eletrônicos que serão enviados ao grupo de especialistas selecionados, preservando o anonimato dos participantes e de suas respostas.

O estudo será composto pelas seguintes etapas:

Primeira rodada de perguntas com aplicação de questionário eletrônico com perguntas de múltipla escolha sobre sua experiência profissional e abertas sobre os problemas enfrentados no desenvolvimento de novos medicamentos. A cada nova rodada será distribuído um relatório sintético com os resultados da rodada anterior.

Segunda rodada de perguntas com aplicação de questionário eletrônico contendo perguntas do tipo múltipla escolha sobre o seu grau de concordância com os problemas para o desenvolvimento de novos medicamentos identificadas na primeira rodada. Participarão somente alguns dos profissionais que responderam a primeira rodada de perguntas.

Se necessário, terceira rodada de perguntas com aplicação de questionário eletrônico com as mesmas perguntas da segunda rodada com o objetivo de obter consenso nas respostas.

Ao final da pesquisa será distribuído aos participantes o relatório com as principais conclusões da pesquisa.

Esta pesquisa possui objetivos estritamente acadêmicos visando a publicação de artigos científicos e/ou apresentações. Os dados da pesquisa serão tratados de forma consolidada, preservando a identidade dos participantes e eventuais informações que façam referência às empresas que trabalham ou em que trabalharam, mantendo-se assim a confidencialidade dos dados.

Muito obrigado por participar!

Estou à disposição para quaisquer dúvidas e/ou esclarecimentos.

Atenciosamente,

Ricardo Yugue

Doutorando FEA-USP

Contato: yugue@usp.br

Para participar, por favor clique no botão abaixo. 
1. Você trabalha atualmente em uma indústria farmacêutica?

1.Sim, estou trabalhando atualmente em um laboratório farmacêutico

2. Não, mas já trabalharei em um laboratório farmacêutico

3. Não, nunca trabalhei em um laboratório farmacêutico

4. Não, mas presto(ei) consultoria para um laboratório farmacêutico

5.Outros. Qual?

2. Qual a(s) sua(s) área(s) de atuação na indústria farmacêutica?

1. Administração / Corporativo

2. Comercial

3. Controle de qualidade

4. Garantia da qualidade

5. Marketing

6. Engenharia / Manutenção

7.Pesquisa e desenvolvimento

8.Produção

9. Regulatório

10. Suprimentos

11. Consultoria

12. Outros. Qual?

3. Qual o seu cargo/função atual ou o último que exerceu na indústria farmacêutica?

1.Proprietário/Acionista

2. Conselheiro

3.Presidente/CEO

4. Diretor ou equivalente

5. Gerente ou equivalente

6. Supervisor/Coordenador ou equivalente

7. Técnico

8. Consultor

9. Outros. Qual?

4. No total, quanto tempo trabalha(ou) na indústria farmacêutica?

1. Menos de 1 ano

2. Mais de 1 ano e menos de 2 anos

3. Mais de 2 anos e menos de 5 anos

4. Mais de 5 anos e menos de 10 anos

5. Mais de 10 anos e menos de 20 anos

6. Mais de 20 anos

5. Com quais classes de medicamentos trabalha(ou)?

1. Novos (referência)

2. Similares

3. Genéricos

4. Biológicos

5.Fitoterápicos

6. Homeopáticos

7.Específicos

8. Outros. Qual?

6. Em que país está localizada a matriz do laboratório farmacêutico em que trabalha ou no último em que trabalhou? $*$

1.Brasil

2. Outro. Qual?

7. Quem toma(va) a decisão final sobre quais os novos medicamentos que serão(iam) desenvolvidos no laboratório farmacêutico em que trabalha ou no último em que trabalhou? (Assinale mais de uma alternativa se a decisão era tomada em conjunto) *

1. a matriz da empresa

2. o conselho administrativo ou equivalente 
3.o proprietário ou equivalente

4.o presidente ou equivalente

5.a área de marketing ou seu representante

6. a área comercial ou seu representante

7. a área de pesquisa e desenvolvimento ou seu representante

8. a área regulatória ou seu representante

9. a área médica ou seu representante

10. a área de suprimento ou seu representante

11. Outro(s). Qual(is)?

Relacione os problemas e/ou erros que enfrenta(ou) no decorrer dos projetos de desenvolvimento de novos medicamentos, que se inicia após a decisão de qual(is) medicamento(s) será(ão) desenvolvido(s) e se encerra com o início da produção industrial.

Relacione as causas/origens dos problemas nos projetos de desenvolvimento de novos medicamentos que relacionou na questão 8 .

Relacione os impactos/resultados dos problemas nos projetos de desenvolvimento de novos medicamentos que relacionou na questão 8 .

Relacione estratégias, ações e oportunidades de melhoria das práticas de desenvolvimento de novos medicamentos lembrando dos problemas que relacionou na questão 8 .

Relacione as mudanças que acredita que ocorrerão o durante o processo de desenvolvimento de novos medicamentos. Problemas que deixarão de existir, os que vão surgir, os que vão ter maior importância e os que terão sua importância diminuída. Esclareça se possível.

Primeiro(s) nome(s)

Sobrenome(s)

Fone (para eventual necessidade de validação de suas respostas)

Email (para envio do relatório com os resultados sintéticos desta fase)

14. Qual o nome do laboratório farmacêutico em que trabalha atualmente ou a última em que trabalhou no desenvolvimento de medicamentos? (Apesar da resposta não ser obrigatória, pois a pesquisa não está focada em casos individuais, essa informação é importante para fins operacionais desta pesquisa como item de validação). 


\section{APÊNDICE V - Unidades de significado (impactos/resultados dos problemas nos projetos)}

Identificadas nas respostas à questão sobre impactos/resultados dos problemas nos projetos de desenvolvimento de novos medicamentos.

Número de participantes $=33$

\begin{tabular}{|l|c|}
\hline \multicolumn{1}{|c|}{ Resultados dos problemas nos projetos } & Contagem \\
\hline Dificuldades/desvios técnicos no desenvolvimento & 13 \\
\hline Atraso / elevação do tempo de desenvolvimento & 10 \\
\hline Cancelamento do projeto & 8 \\
\hline Não cumprimento de itens regulatórios / indeferimento do registro & 7 \\
\hline Elevação do custo de desenvolvimento & 4 \\
\hline Transferência do projeto - "Scale up" & 4 \\
\hline Outros & 4 \\
\hline
\end{tabular}




\section{APÊNDICE VI - Unidades de significado (causas/origens dos problemas nos projetos)}

Identificadas nas respostas à questão sobre causas/origens dos problemas nos projetos de desenvolvimento de novos medicamentos (unidades de significado com frequência $\geq 5$ )

Número de participantes $=33$

\begin{tabular}{|c|c|}
\hline Causas dos problemas nos projetos & Contagem \\
\hline Mudanças na legislação sanitária & 9 \\
\hline Deficiências na prestação de serviços pelo órgão regulador & 9 \\
\hline Deficiências nos estudos clínicos & 9 \\
\hline Deficiências nos estudos de estabilidade do medicamento & 9 \\
\hline Deficiências nos documentos para registro do medicamento & 9 \\
\hline Seleção inadequada dos novos medicamentos & 8 \\
\hline Deficiência na comunicação entre as áreas & 8 \\
\hline Mudanças de fornecedores & 8 \\
\hline Complexidade da legislação sanitária & 8 \\
\hline Número insuficiente de técnicos & 7 \\
\hline Infra-estrutura inadequada & 7 \\
\hline Equipamentos inadequados & 7 \\
\hline Restrições de recursos (orçamento) & 7 \\
\hline DMF (Drug Mastre File) com insuficiência de informações & 7 \\
\hline Deficiências nos documentos de desenvolvimento do medicamento & 7 \\
\hline Insuficiência dos estudos preliminares de viabilidade técnica & 7 \\
\hline Falhas na gestão da área de desenvolvimento & 6 \\
\hline Falha no processo de transferência do novo medicamento para a produção (scale up) & 6 \\
\hline Cultura da organização & 6 \\
\hline Falhas no planejamento das atividades dos projetos de desenvolvimento dos novos medicamentos & 6 \\
\hline Reduções nos prazos & 6 \\
\hline Reduções nos custos & 6 \\
\hline Complexidade ou deficiências no conhecimento dos fármacos & 6 \\
\hline Insuficiência de informações sobre os objetivos e diretrizes estratégicas da organização & 6 \\
\hline Dificuldade na aquisição de materiais & 5 \\
\hline Dificuldade na aquisição de equipamentos & 5 \\
\hline Fornecedor não qualificável & 5 \\
\hline Falta de domínio da tecnologia do produto & 5 \\
\hline Falta de domínio da tecnologia do processo & 5 \\
\hline Custos não estimados no planejamento inicial & 5 \\
\hline Definição inicial inadequada/incompleta do medicamento a ser desenvolvido & 5 \\
\hline Alterações nas definições iniciais do medicamento durante o desenvolvimento & 5 \\
\hline Deficiências nos métodos/processos de desenvolvimento de novos medicamentos & 5 \\
\hline Deficiência no compartilhamento do andamento do projeto com outras áreas & 5 \\
\hline Falta de análise e gerenciamento de riscos & 5 \\
\hline
\end{tabular}




\section{APÊNDICE VII - Questionário para Validação do Conteúdo}

\section{VARIÁVEIS RELACIONADAS AOS DESAFIOS EM PROJETOS DE DESENVOLVIMENTO DE NOVOS MEDICAMENTOS}

"Desafios em Projetos de Desenvolvimento de Medicamentos Genéricos - Validação do conteúdo das variáveis de pesquisa" Este é um convite para que participe desta pesquisa como conhecedor do processo de desenvolvimento de medicamentos genéricos e, portanto, competente para avaliar as variáveis que estou propondo para compor o instrumento de mensuração. O estudo tem foco no desempenho dos projetos de desenvolvimento de medicamentos genéricos e nos seus fatores contribuintes. O objetivo desta fase da pesquisa é avaliar as variáveis identificadas sob o ponto de vista de sua relação como o desempenho dos projetos de desenvolvimento. Esta pesquisa possui objetivos estritamente acadêmicos. A sua participação é absolutamente voluntária e você poderá desistir de sua participação a qualquer momento da pesquisa. Agradeço muito desde já por sua participação e fico a disposição para mais informações. Cordialmente, Ricardo Yugue Doutorando Administração - FEA-USPNUSP 2021223 Email: yugue @usp.br. Para participar, por favor, marque o botão abaixo e depois clique em avançar.

No total, quanto tempo trabalha(ou) em atividades relacionadas a medicamentos genéricos?

1.Nunca trabalhei em atividades relacionadas ao desenvolvimento de medicamentos genéricos

2. Menos de 1 ano

3. Mais de 1 ano e menos de 2 anos

4. Mais de 2 anos e menos de 5 anos

5. Mais de 5 anos e menos de 10 anos

6. Mais de 10 anos e menos de 20 anos

7. Mais de 20 anos

Qual a sua relação predominante com o desenvolvimento de medicamentos genéricos?

1. Nunca trabalhei em atividades relacionadas ao desenvolvimento de medicamentos genéricos

2. Sou ou fui decisor ou membro de comitê de decisão sobre portfólio de projetos de desenvolvimento de medicamentos genéricos

3. Sou ou fui responsável pela área de pesquisa e desenvolvimento

4. Sou ou fui responsável por projetos de desenvolvimento de medicamentos genéricos

5. Sou ou fui membro de equipe de gerenciamento de projetos de desenvolvimento de medicamentos genéricos

6. Sou ou fui de áreas de suporte aos projetos de desenvolvimento de medicamentos genéricos

7. Sou ou fui de áreas que tem interesse nos resultados dos projetos de desenvolvimento de medicamentos genéricos

8.Outro tipo de atividade. Por favor, descreva a seguir:

Qual a sua área de atuação predominante?

1. Administração / Corporativo

2. Comercial

3. Consultoria

4. Controle de qualidade

5. Docência

6. Engenharia / Manutenção

7. Garantia da qualidade

8. Fiscalização

9. Marketing

10. Pesquisa e desenvolvimento

11. Produção

12. Regulatório

13. Suprimentos

14. Outros. Qual?

Para cada um dos indicadores relacionadas abaixo, com base em sua experiência indique qual o grau de 
relevância* para a avaliação do desempenho dos projetos de desenvolvimento de medicamentos genéricos? * Grau de relevância = representa o seu sentimento quanto à importância e frequência de uso do indicador na avaliação do desempenho dos projetos de desenvolvimento de medicamentos genéricos. Responda utilizando uma escala de 1 a 7, sendo 1 para "irrelevante" e 7 para "total relevância". Há ainda as opções "Não está claro" se o item estiver confuso, dúbio ou mesmo para dizer que ele precisa ser corrigido ou possuir oportunidade de melhoria e a opção "Não sei dizer" caso considere que tem conhecimento insuficiente do indicador. As sugestões de melhoria e/ou correções para esta questão poderão ser indicadas na questão seguinte onde haverá espaço para os comentários.

\begin{tabular}{|c|c|c|c|c|c|c|c|c|c|}
\hline & $\begin{array}{l}\text { "Não } \\
\text { está } \\
\text { claro" }\end{array}$ & \begin{tabular}{|c|}
$1=$ \\
"Irrele- \\
vante"
\end{tabular} & 2 & 3 & $\begin{array}{c}4= \\
\text { mediana }\end{array}$ & 5 & 6 & $\begin{array}{c}7=\text { "Total } \\
\text { relevân- } \\
\text { cia" }\end{array}$ & $\begin{array}{c}\text { "Não } \\
\text { sei } \\
\text { dizer" } \\
\end{array}$ \\
\hline $\begin{array}{l}\text { Concluir o desenvolvimento do medicamento } \\
\text { genérico até a data planejada inicialmente }\end{array}$ & $\square$ & $\square$ & $\square$ & $\square$ & $\square$ & $\square$ & $\square$ & $\square$ & $\square$ \\
\hline $\begin{array}{l}\text { Concluir o desenvolvimento do medicamento } \\
\text { genérico com custos totais dentro do orçamento }\end{array}$ & D & $\square$ & $\square$ & $\square$ & $\square$ & $\square$ & $\square$ & $\square$ & $\square$ \\
\hline $\begin{array}{l}\text { Ter o registro do medicamento genérico } \\
\text { aprovado pela Anvisa sem exigências } \\
\text { complementares ou com apenas poucas } \\
\text { exigências não significativas }\end{array}$ & $\square$ & $\square$ & $\square$ & $\square$ & $\square$ & $\square$ & $\square$ & $\square$ & $\square$ \\
\hline $\begin{array}{l}\text { Concluir o desenvolvimento do medicamento } \\
\text { genérico com custos de produção dentro do } \\
\text { planejado (dado a competição no mercado se dá } \\
\text { por preço) }\end{array}$ & $\square$ & $\square$ & $\square$ & $\square$ & $\square$ & $\square$ & $\square$ & $\square$ & $\square$ \\
\hline $\begin{array}{l}\text { Concluir o desenvolvimento do medicamento } \\
\text { genérico sem a necessidade de ajustes após o seu } \\
\text { lançamento }\end{array}$ & $\square$ & $\square$ & $\square$ & $\square$ & $\square$ & $\square$ & $\square$ & $\square$ & $\square$ \\
\hline
\end{tabular}

Por favor, considerando suas respostas na questão anterior, informe se há alguma sugestão de melhoria, comentário, correção e/ou dúvida para o enunciado e/ou itens avaliados.

1.Entendi a questão e todos os seus itens, não encontrei problemas e/ou dificuldades e não tenho comentários e/ou sugestões.

2. Tenho comentários e/ou sugestões. Por favor, utilize as linhas abaixo para detalhar suas contribuições.

(Este conjunto de perguntas e muito importante para a pesquisa! Por favor, não deixe de respondê-lo)

Tendo por referência a sua experiência, qual o grau de relevância das situações relacionadas a seguir para um desempenho abaixo do esperado para projetos de desenvolvimento de medicamentos genéricos? * Grau de relevância $=$ representa o seu sentimento quanto à importância e impacto da situação analisada para o desempenho dos projetos de desenvolvimento de medicamentos genéricos. Responda utilizando uma escala de 1 a 7, sendo 1 para "nenhuma relevância" e 7 para "totalmente relevante". Há ainda as opções "Não está claro" se o item estiver confuso, dúbio ou mesmo para dizer que ele precisa ser corrigido ou possuir oportunidade de melhoria e a opção "Não sei dizer" caso considere que tem conhecimento insuficiente do indicador. As sugestões de melhoria e/ou correções para esta questão poderão ser indicadas na questão seguinte onde haverá espaço para os comentários.

\begin{tabular}{|c|c|c|c|c|c|c|c|c|c|}
\hline & $\begin{array}{l}\text { "Não } \\
\text { está } \\
\text { claro" }\end{array}$ & \begin{tabular}{|c|}
$1=$ \\
"Irrele- \\
vante"
\end{tabular} & 2 & 3 & $\begin{array}{c}4= \\
\text { mediana }\end{array}$ & 5 & 6 & $\begin{array}{c}7=\text { "Total } \\
\text { relevân- } \\
\text { cia" }\end{array}$ & $\begin{array}{c}\text { "Não } \\
\text { sei } \\
\text { dizer" }\end{array}$ \\
\hline $\begin{array}{c}\text { Deficiências nas práticas de garantia da } \\
\text { qualidade (ex.: dificuldade na validação de } \\
\text { processos, validação de métodos analíticos e/ou } \\
\text { qualificação de equipamentos) }\end{array}$ & $\square$ & $\square$ & $\square$ & $\square$ & $\square$ & $\square$ & $\square$ & $\square$ & $\square$ \\
\hline $\begin{array}{c}\text { Dificuldades na realização dos estudos de } \\
\text { bioequivalência e/ou biodisponibilidade dos } \\
\text { medicamentos }\end{array}$ & $\square$ & $\square$ & $\square$ & $\square$ & $\square$ & $\square$ & $\square$ & $\square$ & $\square$ \\
\hline Dificuldades na realização dos estudos de & $\square$ & $\square$ & $\square$ & $\square$ & $\square$ & $\square$ & $\square$ & $\square$ & $\square$ \\
\hline
\end{tabular}




\begin{tabular}{|c|c|c|c|c|c|c|c|c|c|}
\hline dissolução dos medicamentos & & & & & & & & & \\
\hline $\begin{array}{c}\text { Dificuldades na realização dos estudos clínicos } \\
\text { dos medicamentos (eficácia) }\end{array}$ & $\square$ & $\square$ & $\square$ & $\square$ & $\square$ & $\square$ & $\square$ & $\square$ & $\square$ \\
\hline $\begin{array}{c}\text { Dificuldades na realização dos estudos de } \\
\text { equivalência farmacêutica dos medicamentos }\end{array}$ & $\square$ & $\square$ & $\square$ & $\square$ & $\square$ & $\square$ & $\square$ & $\square$ & $\square$ \\
\hline $\begin{array}{c}\text { Dificuldades no desenvolvimento dos métodos } \\
\text { analíticos dos medicamentos }\end{array}$ & $\square$ & $\square$ & $\square$ & $\square$ & $\square$ & $\square$ & $\square$ & $\square$ & $\square$ \\
\hline $\begin{array}{c}\text { Dificuldades na realização dos estudos de } \\
\text { estabilidade, de fotoestabilidade, de produtos de } \\
\text { degradação e/ou na obtenção da estabilidade do } \\
\text { medicamento. }\end{array}$ & $\square$ & $\square$ & $\square$ & $\square$ & $\square$ & $\square$ & $\square$ & $\square$ & $\square$ \\
\hline $\begin{array}{c}\text { Dificuldade no estabelecimento das } \\
\text { especificações e/ou realização dos testes para o } \\
\text { controle de qualidade dos medicamentos. }\end{array}$ & $\square$ & $\square$ & $\square$ & $\square$ & $\square$ & $\square$ & $\square$ & $\square$ & $\square$ \\
\hline $\begin{array}{c}\text { Dificuldade na obtenção de informações sobre os } \\
\text { ingredientes farmacêuticos ativos utilizados nos } \\
\text { medicamentos e/ou deficiências no DMF } \\
\text { disponibilizado pelo fabricante }\end{array}$ & $\square$ & $\square$ & $\square$ & $\square$ & $\square$ & $\square$ & $\square$ & $\square$ & $\square$ \\
\hline $\begin{array}{c}\text { Custos elevados para desenvolvimento dos } \\
\text { medicamentos }\end{array}$ & $\square$ & $\square$ & $\square$ & $\square$ & $\square$ & $\square$ & $\square$ & $\square$ & $\square$ \\
\hline $\begin{array}{c}\text { Longo tempo necessário para o desenvolvimento } \\
\text { dos medicamentos }\end{array}$ & $\square$ & $\square$ & $\square$ & $\square$ & $\square$ & $\square$ & $\square$ & $\square$ & $\square$ \\
\hline $\begin{array}{c}\text { Risco de insucesso no desenvolvimento do } \\
\text { medicamento e de indeferimento do registro }\end{array}$ & $\square$ & $\square$ & $\square$ & $\square$ & $\square$ & $\square$ & $\square$ & $\square$ & $\square$ \\
\hline $\begin{array}{c}\text { Dificuldades no atendimento da legislação } \\
\text { sanitária para o desenvolvimento e/ou registro de } \\
\text { medicamentos genéricos }\end{array}$ & $\square$ & $\square$ & $\square$ & $\square$ & $\square$ & $\square$ & $\square$ & $\square$ & $\square$ \\
\hline $\begin{array}{c}\text { Deficiências e/ou dificuldades na elaboração } \\
\text { dossiê para registro dos medicamentos }\end{array}$ & $\square$ & $\square$ & $\square$ & $\square$ & $\square$ & $\square$ & $\square$ & $\square$ & $\square$ \\
\hline $\begin{array}{c}\text { Deficiências e/ou dificuldades no atendimento às } \\
\text { exigências da Anvisa durante o processo de } \\
\text { análise dos pedidos de registro dos } \\
\text { medicamentos }\end{array}$ & $\square$ & $\square$ & $\square$ & $\square$ & $\square$ & $\square$ & $\square$ & $\square$ & $\square$ \\
\hline
\end{tabular}

Por favor, considerando suas respostas na questão anterior, informe se há alguma sugestão de melhoria, comentário, correção e/ou dúvida para o enunciado e/ou itens avaliados.

1.Entendi a questão e todos os seus itens, não encontrei problemas e/ou dificuldades e não tenho comentários e/ou sugestões.

2.Tenho comentários e/ou sugestões. Por favor, utilize as linhas abaixo para detalhar suas contribuições.

(Este conjunto de perguntas é continuação do anterior e também muito importante para a pesquisa! Por favor, não deixe de respondê-lo).

Tendo por referência a sua experiência, qual o grau de relevância das situações relacionadas a seguir para um desempenho abaixo do esperado para projetos de desenvolvimento de medicamentos genéricos? * Grau de relevância $=$ representa o seu sentimento quanto à importância e impacto da situação analisada para o desempenho dos projetos de desenvolvimento de medicamentos genéricos. Responda utilizando uma escala de 1 a 7, sendo 1 para "nenhuma relevância" e 7 para "totalmente relevante". Há ainda as opções "Não está claro" se o item estiver confuso, dúbio ou mesmo para dizer que ele precisa ser corrigido ou possuir oportunidade de melhoria e a opção "Não sei dizer" caso considere que tem conhecimento insuficiente do indicador. As sugestões de melhoria e/ou correções para esta questão poderão ser indicadas na questão seguinte onde haverá espaço para os comentários.

\begin{tabular}{|c|c|c|c|c|c|c|c|c|c|}
\hline & $\begin{array}{c}\text { "Não } \\
\text { está } \\
\text { claro" }\end{array}$ & $\begin{array}{c}1= \\
\text { "Irrele- } \\
\text { vante" }\end{array}$ & 2 & 3 & $\begin{array}{c}4= \\
\text { mediana }\end{array}$ & 5 & 6 & $\begin{array}{c}7= \\
\text { "Total } \\
\text { relevân- } \\
\text { cia" }\end{array}$ & $\begin{array}{c}\text { "Não } \\
\text { sei } \\
\text { dizer" }\end{array}$ \\
\hline $\begin{array}{c}\text { Dificuldade no processo de transferência dos } \\
\text { medicamentos do laboratório para a produção } \\
\text { (escalonamento ou "scale up") }\end{array}$ & $\square$ & $\square$ & $\square$ & $\square$ & $\square$ & $\square$ & $\square$ & $\square$ & $\square$ \\
\hline
\end{tabular}




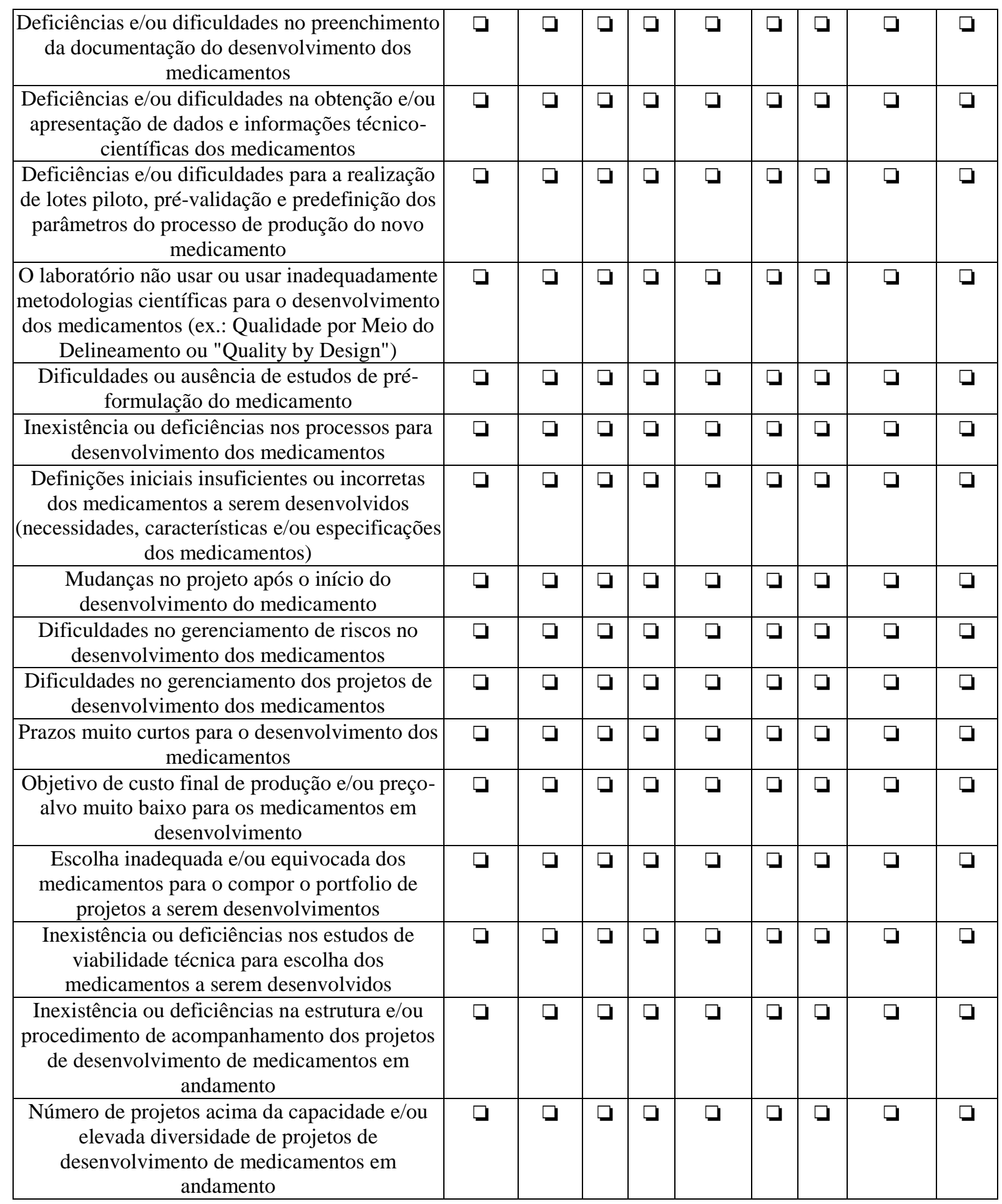

Por favor, considerando suas respostas na questão anterior, informe se há alguma sugestão de melhoria, comentário, correção e/ou dúvida para o enunciado e/ou itens avaliados.

1.Entendi a questão e todos os seus itens, não encontrei problemas e/ou dificuldades e não tenho comentários e/ou sugestões.

2. Tenho comentários e/ou sugestões. Por favor, utilize as linhas abaixo para detalhar suas contribuições.

(Este é o ÚLTIMO conjunto de perguntas, continuação do anterior e também muito importante para a pesquisa! Por favor, não deixe de respondê-lo). Tendo por referência a sua experiência, qual o grau de relevância das situações relacionadas a seguir para um desempenho abaixo do esperado para projetos de desenvolvimento de 
medicamentos genéricos? * Grau de relevância = representa o seu sentimento quanto à importância e impacto da situação analisada para o desempenho dos projetos de desenvolvimento de medicamentos genéricos. Responda utilizando uma escala de 1 a 7, sendo 1 para "nenhuma relevância" e 7 para "totalmente relevante". Há ainda as opções "Não sei dizer" caso considere que tem conhecimento insuficiente do indicador e a opção "Não está claro" se o item estiver confuso, dúbio ou mesmo para dizer que ele precisa ser corrigido ou possuir oportunidade de melhoria. As sugestões de melhoria e/ou correções para esta questão poderão ser indicadas na questão seguinte onde haverá espaço para os comentários.

\begin{tabular}{|c|c|c|c|c|c|c|c|c|c|}
\hline & $\begin{array}{c}\text { "Não } \\
\text { está } \\
\text { claro" }\end{array}$ & \begin{tabular}{c|}
$1=$ \\
"Irrele- \\
vante"
\end{tabular} & 2 & 3 & $\begin{array}{c}4= \\
\text { mediana }\end{array}$ & 5 & 6 & $\begin{array}{c}7= \\
\text { "Total } \\
\text { relevân- } \\
\text { cia" }\end{array}$ & \begin{tabular}{|l} 
"Não \\
sei \\
dizer"
\end{tabular} \\
\hline $\begin{array}{c}\text { Dificuldade no desenvolvimento da embalagem para } \\
\text { o medicamento }\end{array}$ & $\square$ & $\square$ & $\square$ & $\square$ & $\square$ & $\square$ & $\square$ & $\square$ & $\square$ \\
\hline $\begin{array}{l}\text { Mudança de fornecedor de ingrediente farmacêutico } \\
\text { ativo durante o desenvolvimento do medicamento }\end{array}$ & $\square$ & $\square$ & $\square$ & $\square$ & $\square$ & $\square$ & $\square$ & $\square$ & $\square$ \\
\hline \begin{tabular}{|c|} 
Dificuldades na seleção e qualificação dos \\
fornecedores de ingredientes farmacêuticos ativos
\end{tabular} & $\square$ & $\square$ & $\square$ & $\square$ & $\square$ & $\square$ & $\square$ & $\square$ & $\square$ \\
\hline $\begin{array}{c}\text { Dificuldades para aquisição de ingrediente } \\
\text { farmacêutico ativo }\end{array}$ & $\square$ & $\square$ & $\square$ & $\square$ & $\square$ & $\square$ & $\square$ & $\square$ & $\square$ \\
\hline \begin{tabular}{|c|} 
Infraestrutura (instalações, equipamentos e \\
utilidades) inadequada para o desenvolvimento dos \\
métodos analíticos
\end{tabular} & $\square$ & $\square$ & $\square$ & $\square$ & $\square$ & $\square$ & $\square$ & $\square$ & $\square$ \\
\hline $\begin{array}{l}\text { Infraestrutura (instalações, equipamentos e } \\
\text { utilidades) inadequada para o desenvolvimento da } \\
\text { formulação (farmacotécnico) dos medicamentos }\end{array}$ & $\square$ & $\square$ & $\square$ & $\square$ & $\square$ & $\square$ & $\square$ & $\square$ & $\square$ \\
\hline $\begin{array}{l}\text { Dificuldades para aquisição de equipamentos } \\
\text { (laboratório e/ou produção) }\end{array}$ & $\square$ & $\square$ & $\square$ & $\square$ & $\square$ & $\square$ & $\square$ & $\square$ & $\square$ \\
\hline \begin{tabular}{|c|} 
Dificuldades para contratação de profissionais e/ou \\
serviços de terceiros para o desenvolvimento dos \\
medicamentos
\end{tabular} & $\square$ & $\square$ & $\square$ & $\square$ & $\square$ & $\square$ & $\square$ & $\square$ & $\square$ \\
\hline $\begin{array}{l}\text { O laboratório não ter domínio suficiente da } \\
\text { tecnologia dos medicamentos }\end{array}$ & $\square$ & $\square$ & $\square$ & $\square$ & $\square$ & $\square$ & $\square$ & $\square$ & $\square$ \\
\hline $\begin{array}{l}\text { O laboratório não ter domínio suficiente da } \\
\text { tecnologia do processo de fabricação dos } \\
\text { medicamentos }\end{array}$ & $\square$ & $\square$ & $\square$ & $\square$ & $\square$ & $\square$ & $\square$ & $\square$ & $\square$ \\
\hline \begin{tabular}{|c|} 
O laboratório não ter profissionais experientes e/ou \\
com qualificação adequada em número suficiente \\
para o desenvolvimento dos medicamentos
\end{tabular} & $\square$ & $\square$ & $\square$ & $\square$ & $\square$ & $\square$ & $\square$ & $\square$ & $\square$ \\
\hline $\begin{array}{c}\text { Cultura da empresa ou organização que não favorece } \\
\text { e/ou dificulta o desenvolvimento adequado dos } \\
\text { medicamentos }\end{array}$ & $\square$ & $\square$ & $\square$ & $\square$ & $\square$ & $\square$ & $\square$ & $\square$ & $\square$ \\
\hline $\begin{array}{l}\text { Deficiências e/ou dificuldades na comunicação entre } \\
\text { os profissionais e/ou entre as áreas da empresa que } \\
\text { participam do desenvolvimento dos medicamentos }\end{array}$ & $\square$ & $\square$ & $\square$ & $\square$ & $\square$ & $\square$ & $\square$ & $\square$ & $\square$ \\
\hline $\begin{array}{c}\text { Estrutura (organizacional) da empresa que não } \\
\text { favorece e/ou dificulta os projetos de } \\
\text { desenvolvimento dos medicamentos }\end{array}$ & $\square$ & $\square$ & $\square$ & $\square$ & $\square$ & $\square$ & $\square$ & $\square$ & $\square$ \\
\hline $\begin{array}{c}\text { Ausência ou insuficiência de apoio de outras áreas } \\
\text { e/ou dos superiores aos projetos de desenvolvimento } \\
\text { dos medicamentos }\end{array}$ & $\square$ & $\square$ & $\square$ & $\square$ & $\square$ & $\square$ & $\square$ & $\square$ & $\square$ \\
\hline
\end{tabular}

Por favor, considerando suas respostas na questão anterior, informe se há alguma sugestão de melhoria, comentário, correção e/ou dúvida para o enunciado e/ou itens avaliados.

1.Entendi a questão e todos os seus itens, não encontrei problemas e/ou dificuldades e não tenho comentários e/ou sugestões.

2. Tenho comentários e/ou sugestões. Por favor, utilize as linhas abaixo para detalhar suas contribuições.

Por favor, de uma forma geral, há algum comentário, dúvida e/ou sugestão adicional para o questionário e/ou 
para a pesquisa?

1. Não tenho comentários ou sugestões adicionais.

2.Sim tenho comentários e/ou sugestões. Por favor, utilize as linhas abaixo.

Primeiro(s) nome(s)

Sobrenome(s)

Email 


\section{APÊNDICE VIII - Resultados para o grau de relevância das variáveis para a avaliação do desempenho dos projetos de desenvolvimento de medicamentos genéricos. $(\mathbf{n}=19)$}

\begin{tabular}{|c|c|c|c|c|c|c|c|c|c|c|c|c|}
\hline $\begin{array}{c}\text { Indicadores de } \\
\text { desempenho }\end{array}$ & $\mathrm{n}$ & $\begin{array}{c}\text { Mé- } \\
\text { dia }\end{array}$ & $\begin{array}{c}\text { Mo- } \\
\text { da }\end{array}$ & $\mathrm{NC}$ & 1 & 2 & 3 & 4 & 5 & 6 & 7 & NS \\
\hline $\begin{array}{lr}\text { Concluir } & \text { o } \\
\text { desenvolvimento do } \\
\text { medicamento genérico até } \\
\text { a data planejada } \\
\text { inicialmente }\end{array}$ & 19 & 6,7 & 7 & $0 \%$ & $0 \%$ & $0 \%$ & $0 \%$ & $5 \%$ & $0 \%$ & $11 \%$ & $84 \%$ & $0 \%$ \\
\hline $\begin{array}{l}\text { Concluir o } \\
\text { desenvolvimento do } \\
\text { medicamento genérico } \\
\text { com custos totais dentro } \\
\text { do orçamento }\end{array}$ & 19 & 5,8 & 7 & $0 \%$ & $0 \%$ & $5 \%$ & $0 \%$ & $5 \%$ & $26 \%$ & $21 \%$ & $42 \%$ & $0 \%$ \\
\hline $\begin{array}{l}\text { Ter o registro do } \\
\text { medicamento genérico } \\
\text { aprovado pela Anvisa } \\
\text { sem exigências } \\
\text { complementares ou com } \\
\text { apenas poucas exigências } \\
\text { não significativas }\end{array}$ & 19 & 6,3 & 7 & $0 \%$ & $5 \%$ & $0 \%$ & $0 \%$ & $11 \%$ & $0 \%$ & $11 \%$ & $74 \%$ & $0 \%$ \\
\hline $\begin{array}{l}\text { Concluir } \\
\text { desenvolvimento do } \\
\text { medicamento genérico } \\
\text { com custos de produção } \\
\text { dentro do planejado (dado } \\
\text { a competição no mercado } \\
\text { se dá por preço) }\end{array}$ & 19 & 6,2 & 7 & $0 \%$ & $0 \%$ & $5 \%$ & $0 \%$ & $5 \%$ & $5 \%$ & $26 \%$ & $58 \%$ & $0 \%$ \\
\hline $\begin{array}{l}\text { Concluir } \\
\text { desenvolvimento } \\
\text { medicamento genérico } \\
\text { sem a necessidade de } \\
\text { ajustes após o seu } \\
\text { lançamento }\end{array}$ & 19 & 6,1 & 7 & $0 \%$ & $0 \%$ & $11 \%$ & $0 \%$ & $11 \%$ & $0 \%$ & $11 \%$ & $68 \%$ & $0 \%$ \\
\hline $\begin{array}{lr}\text { Concluir } & \mathrm{o} \\
\text { desenvolvimento } & \text { do } \\
\text { medicamento } & \\
\text { (independentemente } & \text { dos } \\
\text { demais requisitos) } & \\
\end{array}$ & 19 & 3,8 & 1 & $11 \%$ & $21 \%$ & $5 \%$ & $11 \%$ & $16 \%$ & $16 \%$ & $11 \%$ & $11 \%$ & $0 \%$ \\
\hline
\end{tabular}

Nota: NC = "Não está claro"; NS = "Não sei dizer"; 1 = "Irrelevante"; 7 = "Totalmente irrelevante". Relevância em frequência percentual das respostas. Célula hachurada (cinza escuro) identifica o indicador não validado. Fonte: Dados da pesquisa. 
APÊNDICE IX - Resultados para o grau de relevância das situações relacionadas ao desempenho fora do planejado para os projetos de desenvolvimento de medicamentos genéricos.

\begin{tabular}{|c|c|c|c|c|c|c|c|}
\hline Situações relacionadas ao desempenho & $\mathrm{n}$ & $\begin{array}{l}\text { Mé- } \\
\text { dia }\end{array}$ & $\begin{array}{c}\text { Mo- } \\
\text { da }\end{array}$ & $\mathrm{NC}$ & $\begin{array}{l}\text { Não } \\
\text { relevante } \\
1,2,3 \text { e } 4\end{array}$ & $\begin{array}{l}\text { Relevante } \\
5,6 \text { e } 7\end{array}$ & NS \\
\hline $\begin{array}{l}\text { Deficiências nas práticas de garantia da } \\
\text { qualidade (ex.: dificuldade na validação de } \\
\text { processos, validação de métodos analíticos } \\
\text { e/ou qualificação de equipamentos) }\end{array}$ & 19 & 5,8 & 7 & $0 \%$ & $22 \%$ & $78 \%$ & $6 \%$ \\
\hline $\begin{array}{l}\text { Dificuldades na realização dos estudos de } \\
\text { bioequivalência e/ou biodisponibilidade dos } \\
\text { medicamentos }\end{array}$ & 19 & 6,2 & 7 & $0 \%$ & $11 \%$ & $89 \%$ & $6 \%$ \\
\hline $\begin{array}{l}\text { Dificuldades na realização dos estudos de } \\
\text { dissolução dos medicamentos }\end{array}$ & 19 & 5,8 & 7 & $0 \%$ & $28 \%$ & $72 \%$ & $6 \%$ \\
\hline $\begin{array}{l}\text { Dificuldades na realização dos estudos } \\
\text { clínicos dos medicamentos (eficácia) }\end{array}$ & 19 & 6,1 & 7 & $0 \%$ & $13 \%$ & $88 \%$ & $19 \%$ \\
\hline $\begin{array}{l}\text { Dificuldades na realização dos estudos de } \\
\text { equivalência farmacêutica dos medicamentos }\end{array}$ & 19 & 5,7 & 7 & $0 \%$ & $17 \%$ & $83 \%$ & $6 \%$ \\
\hline $\begin{array}{l}\text { Dificuldades no desenvolvimento dos } \\
\text { métodos analíticos dos medicamentos }\end{array}$ & 19 & 6,2 & 7 & $0 \%$ & $6 \%$ & $94 \%$ & $0 \%$ \\
\hline $\begin{array}{l}\text { Dificuldades na realização dos estudos de } \\
\text { estabilidade, de fotoestabilidade, de produtos } \\
\text { de degradação e/ou na obtenção da } \\
\text { estabilidade do medicamento. }\end{array}$ & 19 & 6,5 & 7 & $0 \%$ & $0 \%$ & $100 \%$ & $6 \%$ \\
\hline $\begin{array}{l}\text { Dificuldade no estabelecimento das } \\
\text { especificações e/ou realização dos testes para } \\
\text { o controle de qualidade dos medicamentos. }\end{array}$ & 19 & 5,6 & 7 & $0 \%$ & $17 \%$ & $83 \%$ & $0 \%$ \\
\hline $\begin{array}{l}\text { Dificuldade na obtenção de informações } \\
\text { sobre os ingredientes farmacêuticos ativos } \\
\text { utilizados nos medicamentos e/ou } \\
\text { deficiências no DMF disponibilizado pelo } \\
\text { fabricante }\end{array}$ & 19 & 6,4 & 7 & $0 \%$ & $6 \%$ & $94 \%$ & $6 \%$ \\
\hline $\begin{array}{l}\text { Custos elevados para desenvolvimento dos } \\
\text { medicamentos }\end{array}$ & 19 & 5,3 & 6 & $0 \%$ & $17 \%$ & $83 \%$ & $0 \%$ \\
\hline $\begin{array}{l}\text { Longo tempo necessário para o } \\
\text { desenvolvimento dos medicamentos }\end{array}$ & 19 & 5,7 & 7 & $0 \%$ & $12 \%$ & $88 \%$ & $6 \%$ \\
\hline $\begin{array}{l}\text { Risco de insucesso no desenvolvimento do } \\
\text { medicamento e de indeferimento do registro }\end{array}$ & 19 & 6,1 & 7 & $0 \%$ & $11 \%$ & $89 \%$ & $0 \%$ \\
\hline $\begin{array}{l}\text { Dificuldades no atendimento da legislação } \\
\text { sanitária para o desenvolvimento e/ou registro } \\
\text { de medicamentos genéricos }\end{array}$ & 19 & 5,8 & 7 & $0 \%$ & $17 \%$ & $83 \%$ & $0 \%$ \\
\hline $\begin{array}{l}\text { Deficiências e/ou dificuldades na elaboração } \\
\text { dossiê para registro dos medicamentos }\end{array}$ & 19 & 5,5 & 7 & $0 \%$ & $22 \%$ & $78 \%$ & $0 \%$ \\
\hline $\begin{array}{l}\text { Deficiências e/ou dificuldades no } \\
\text { atendimento às exigências da Anvisa durante } \\
\text { o processo de análise dos pedidos de registro } \\
\text { dos medicamentos }\end{array}$ & 19 & 6,2 & 7 & $0 \%$ & $6 \%$ & $94 \%$ & $0 \%$ \\
\hline $\begin{array}{llr}\begin{array}{l}\text { Dificuldades } \\
\text { formulação }\end{array} & \text { (farmacotécnico) } & \text { dos } \\
\text { medicamentos } & & \text { dos }\end{array}$ & 13 & 6,3 & 7 & $0 \%$ & $8 \%$ & $92 \%$ & $0 \%$ \\
\hline $\begin{array}{l}\text { Dificuldade no processo de transferência dos } \\
\text { medicamentos do laboratório para a produção } \\
\text { (escalonamento ou "scale up") }\end{array}$ & 19 & 5,7 & 6 & $0 \%$ & $17 \%$ & $83 \%$ & $0 \%$ \\
\hline
\end{tabular}




\begin{tabular}{|c|c|c|c|c|c|c|c|}
\hline Situações relacionadas ao desempenho & $\mathrm{n}$ & $\begin{array}{l}\text { Mé- } \\
\text { dia }\end{array}$ & $\begin{array}{c}\text { Mo- } \\
\text { da }\end{array}$ & $\mathrm{NC}$ & $\begin{array}{l}\text { Não } \\
\text { relevante } \\
1,2,3 \text { e } 4 \\
\end{array}$ & $\begin{array}{l}\text { Relevante } \\
5,6 \text { e } 7\end{array}$ & NS \\
\hline $\begin{array}{lccc}\text { Deficiências } & \text { e/ou dificuldades } & \text { no } \\
\text { preenchimento da documentação } & \text { do } \\
\text { desenvolvimento dos medicamentos } & \end{array}$ & 19 & 5,5 & 6 & $0 \%$ & $28 \%$ & $72 \%$ & $0 \%$ \\
\hline $\begin{array}{l}\text { Deficiências e/ou dificuldades na obtenção } \\
\text { e/ou apresentação de dados e informações } \\
\text { técnico-científicas dos medicamentos }\end{array}$ & 19 & 5,9 & 6 & $0 \%$ & $17 \%$ & $83 \%$ & $6 \%$ \\
\hline $\begin{array}{l}\text { Deficiências e/ou dificuldades para a } \\
\text { realização de lotes piloto, pré-validação e } \\
\text { predefinição dos parâmetros do processo de } \\
\text { produção do novo medicamento }\end{array}$ & 19 & 6,3 & 7 & $0 \%$ & $6 \%$ & $94 \%$ & $0 \%$ \\
\hline $\begin{array}{l}\text { O laboratório não usar ou usar } \\
\text { inadequadamente metodologias científicas } \\
\text { para o desenvolvimento dos medicamentos } \\
\text { (ex.: Qualidade por Meio do Delineamento ou } \\
\text { "Quality by Design") }\end{array}$ & 19 & 6,1 & 7 & $0 \%$ & $12 \%$ & $88 \%$ & $12 \%$ \\
\hline $\begin{array}{l}\text { Dificuldades ou ausência de estudos de pré- } \\
\text { formulação do medicamento }\end{array}$ & 19 & 6,1 & 7 & $0 \%$ & $11 \%$ & $89 \%$ & $6 \%$ \\
\hline $\begin{array}{l}\text { Inexistência ou deficiências nos processos } \\
\text { para desenvolvimento dos medicamentos }\end{array}$ & 19 & 6,0 & 7 & $0 \%$ & $6 \%$ & $94 \%$ & $6 \%$ \\
\hline $\begin{array}{l}\text { Definições iniciais insuficientes ou incorretas } \\
\text { dos medicamentos a serem desenvolvidos } \\
\text { (necessidades, características e/ou } \\
\text { especificações dos medicamentos) }\end{array}$ & 19 & 6,1 & 7 & $0 \%$ & $11 \%$ & $89 \%$ & $6 \%$ \\
\hline $\begin{array}{l}\text { Mudanças no projeto após o início do } \\
\text { desenvolvimento do medicamento }\end{array}$ & 19 & 6,1 & 7 & $0 \%$ & $16 \%$ & $84 \%$ & $0 \%$ \\
\hline $\begin{array}{l}\text { Dificuldades no gerenciamento de riscos no } \\
\text { desenvolvimento dos medicamentos }\end{array}$ & 19 & 6,0 & 7 & $0 \%$ & $17 \%$ & $83 \%$ & $6 \%$ \\
\hline $\begin{array}{l}\text { Dificuldades no gerenciamento dos projetos } \\
\text { de desenvolvimento dos medicamentos }\end{array}$ & 19 & 5,6 & 6 & $0 \%$ & $21 \%$ & $79 \%$ & $0 \%$ \\
\hline $\begin{array}{l}\text { Prazos muito curtos para o desenvolvimento } \\
\text { dos medicamentos }\end{array}$ & 19 & 5,8 & 5 & $0 \%$ & $11 \%$ & $89 \%$ & $0 \%$ \\
\hline $\begin{array}{l}\text { Objetivo de custo final de produção e/ou } \\
\text { preço-alvo muito baixo para os medicamentos } \\
\text { em desenvolvimento }\end{array}$ & 19 & 5,6 & 7 & $0 \%$ & $16 \%$ & $84 \%$ & $0 \%$ \\
\hline $\begin{array}{l}\text { Escolha inadequada e/ou equivocada dos } \\
\text { medicamentos para o compor o portfolio de } \\
\text { projetos a serem desenvolvimentos }\end{array}$ & 19 & 5,4 & 7 & $0 \%$ & $21 \%$ & $79 \%$ & $0 \%$ \\
\hline $\begin{array}{l}\text { Inexistência ou deficiências nos estudos de } \\
\text { viabilidade técnica para escolha dos } \\
\text { medicamentos a serem desenvolvidos }\end{array}$ & 19 & 5,9 & 6 & $0 \%$ & $17 \%$ & $83 \%$ & $6 \%$ \\
\hline $\begin{array}{l}\text { Inexistência ou deficiências na estrutura e/ou } \\
\text { procedimento de acompanhamento dos } \\
\text { projetos de desenvolvimento de } \\
\text { medicamentos em andamento }\end{array}$ & 19 & 6,1 & 6 & $0 \%$ & $0 \%$ & $100 \%$ & $6 \%$ \\
\hline $\begin{array}{l}\text { Número de projetos acima da capacidade e/ou } \\
\text { elevada diversidade de projetos de } \\
\text { desenvolvimento de medicamentos em } \\
\text { andamento }\end{array}$ & 19 & 6,0 & 7 & $0 \%$ & $5 \%$ & $95 \%$ & $0 \%$ \\
\hline $\begin{array}{l}\text { Dificuldade no desenvolvimento da } \\
\text { embalagem para o medicamento }\end{array}$ & 19 & 5,3 & 5 & $0 \%$ & $21 \%$ & $79 \%$ & $0 \%$ \\
\hline $\begin{array}{lccc}\text { Mudança de } & \text { fornecedor } & \text { de ingrediente } \\
\text { farmacêutico } & \text { ativo } & \text { durante } & \text { o }\end{array}$ & 19 & 6,4 & 7 & $0 \%$ & $6 \%$ & $94 \%$ & $6 \%$ \\
\hline
\end{tabular}




\begin{tabular}{|c|c|c|c|c|c|c|c|}
\hline Situações relacionadas ao desempenho & $\mathrm{n}$ & $\begin{array}{l}\text { Mé- } \\
\text { dia }\end{array}$ & $\begin{array}{c}\text { Mo- } \\
\text { da }\end{array}$ & $\mathrm{NC}$ & $\begin{array}{l}\text { Não } \\
\text { relevante } \\
1,2,3 \text { e } 4 \\
\end{array}$ & $\begin{array}{c}\text { Relevante } \\
5,6 \text { e } 7\end{array}$ & NS \\
\hline \multicolumn{8}{|l|}{ desenvolvimento do medicamento } \\
\hline $\begin{array}{l}\text { Dificuldades na seleção e qualificação dos } \\
\text { fornecedores de ingredientes farmacêuticos } \\
\text { ativos }\end{array}$ & 19 & 6,2 & 6 & $0 \%$ & $6 \%$ & $94 \%$ & $6 \%$ \\
\hline $\begin{array}{l}\text { Dificuldades para aquisição de ingrediente } \\
\text { farmacêutico ativo }\end{array}$ & 19 & 5,2 & 6 & $0 \%$ & $32 \%$ & $68 \%$ & $0 \%$ \\
\hline $\begin{array}{lcc}\text { Infraestrutura } & \text { (instalações, equipamentos } & \text { e } \\
\text { utilidades) inadequada para } & \text { o } \\
\text { desenvolvimento dos métodos analíticos } & \end{array}$ & 19 & 5,9 & 6 & $0 \%$ & $11 \%$ & $89 \%$ & $0 \%$ \\
\hline $\begin{array}{lccc}\text { Infraestrutura } & \text { (instalações, } & \text { equipamentos e } \\
\text { utilidades) inadequada } & \text { para } & \text { o } \\
\text { desenvolvimento da da formulação } \\
\text { (farmacotécnico) dos medicamentos }\end{array}$ & 19 & 5,5 & 6 & $0 \%$ & $21 \%$ & $79 \%$ & $0 \%$ \\
\hline $\begin{array}{l}\text { Dificuldades para aquisição de equipamentos } \\
\text { (laboratório e/ou produção) }\end{array}$ & 19 & 5,3 & 6 & $0 \%$ & $32 \%$ & $68 \%$ & $0 \%$ \\
\hline $\begin{array}{l}\text { Dificuldades para contratação de } \\
\text { profissionais e/ou serviços de terceiros para o } \\
\text { desenvolvimento dos medicamentos }\end{array}$ & 19 & 5,9 & 6 & $0 \%$ & $11 \%$ & $89 \%$ & $0 \%$ \\
\hline $\begin{array}{l}\text { O laboratório não ter domínio suficiente da } \\
\text { tecnologia dos medicamentos }\end{array}$ & 19 & 6,0 & 6 & $0 \%$ & $6 \%$ & $94 \%$ & $12 \%$ \\
\hline $\begin{array}{l}\text { O laboratório não ter domínio suficiente da } \\
\text { tecnologia do processo de fabricação dos } \\
\text { medicamentos }\end{array}$ & 19 & 6,1 & 7 & $0 \%$ & $17 \%$ & $83 \%$ & $6 \%$ \\
\hline $\begin{array}{l}\text { O laboratório não ter profissionais } \\
\text { experientes e/ou com qualificação adequada } \\
\text { em número suficiente para o desenvolvimento } \\
\text { dos medicamentos }\end{array}$ & 19 & 6,1 & 6 & $0 \%$ & $11 \%$ & $89 \%$ & $0 \%$ \\
\hline $\begin{array}{l}\text { Cultura da empresa ou organização que não } \\
\text { favorece e/ou dificulta o desenvolvimento } \\
\text { adequado dos medicamentos }\end{array}$ & 19 & 6,0 & 7 & $0 \%$ & $26 \%$ & $74 \%$ & $0 \%$ \\
\hline $\begin{array}{l}\text { Deficiências e/ou dificuldades na } \\
\text { comunicação entre os profissionais e/ou entre } \\
\text { as áreas da empresa que participam do } \\
\text { desenvolvimento dos medicamentos }\end{array}$ & 19 & 5,7 & 7 & $0 \%$ & $21 \%$ & $79 \%$ & $0 \%$ \\
\hline $\begin{array}{l}\text { Estrutura (organizacional) da empresa que } \\
\text { não favorece e/ou dificulta os projetos de } \\
\text { desenvolvimento dos medicamentos }\end{array}$ & 19 & 5,9 & 7 & $0 \%$ & $21 \%$ & $79 \%$ & $0 \%$ \\
\hline $\begin{array}{l}\text { Ausência ou insuficiência de apoio de outras } \\
\text { áreas e/ou dos superiores aos projetos de } \\
\text { desenvolvimento dos medicamentos }\end{array}$ & 19 & 5,7 & 7 & $0 \%$ & $21 \%$ & $79 \%$ & $0 \%$ \\
\hline
\end{tabular}

Nota: NC = "Não está claro"; NS = "Não sei dizer"; 1 = "Irrelevante"; 7 = "Totalmente irrelevante". Relevância em frequência percentual das respostas. Célula hachurada (cinza escuro) identifica o indicador não validado. Fonte: Dados da pesquisa. 


\section{APÊNDICE X - Carta-convite}

\section{"Fatores Contribuintes para o Desempenho em Projetos de Desenvolvimento de Produtos - Medicamentos Genéricos"}

Este é um convite para que participe desta pesquisa como conhecedor do processo de desenvolvimento de medicamentos genéricos. O estudo tem foco no desempenho dos projetos de desenvolvimento de medicamentos genéricos e nos seus fatores contribuintes. Esta pesquisa possui objetivos estritamente acadêmicos e atende às diretrizes e normas regulamentadoras da ética em pesquisa definidas pela Resolução CNS 466/2012 e está registrada na Plataforma Brasil sob o número CAAE 94791118.7.0000.0067.

O Termo de Consentimento Livre e Esclarecido - TCLE será apresentado na próxima página desta pesquisa. Sua participação é absolutamente voluntária e você poderá desistir de sua participação a qualquer momento da pesquisa.

Desde já agradeço muito por sua participação e fico à disposição para mais informações.

Cordialmente,

Ricardo Yugue

Doutorando - Administração - FEA-USP

NUSP 2021223

Email:yugue@usp.br

Para participar, por favor, marque o botão abaixo e depois clique em avançar. 


\section{APÊNDICE XI - Questionário aplicado na etapa quantitativa}

Pesquisa "Fatores Contribuintes para o Desempenho em Projetos de Desenvolvimento de Produtos Medicamentos Genéricos"Esta pesquisa para tese de doutorado da FEA-USP tem como foco os fatores que contribuem para o desempenho em projetos de desenvolvimento dos medicamentos genéricos. O objetivo é prover dados e análises que contribuam para a melhoria do desempenho dos projetos de desenvolvimento a partir de informações dos próprios profissionais que neles trabalham. Esta pesquisa tem objetivos estritamente acadêmicos e segue as diretrizes e normas regulamentadoras da ética em pesquisa definidas pela Resolução CNS 466/2012 e está registrada na Plataforma Brasil sob o número CAAE 94791118.7.0000.0067. O Termo de Consentimento Livre e Esclarecido - TCLE é apresentado na próxima página desta pesquisa. Sua participação é absolutamente voluntária e você poderá desistir de sua participação a qualquer momento da pesquisa. Caso tenha interesse em receber uma apresentação com os resultados desta pesquisa e outras informações e documentos, basta indicar ao final do questionário.Desde já agradeço muito por sua participação e fico à disposição para mais informações. Cordialmente, Ricardo Toshio YugueDoutorando - Administração - FEAUSPNUSP 2021223Email:yugue@usp.brPara participar, por favor clique em "Continue".

COMPROMISSO DA PESQUISA COM OS FUNDAMENTOS ÉTICOS E CIENTÍFICOSTERMO DE CONSENTIMENTO LIVRE E ESCLARECIDO - TCLE Resolução do Conselho Nacional de Saúde 466/2012 Pesquisa "Fatores contribuintes para o desempenho em projetos de desenvolvimento de produtos: O caso dos medicamentos genéricos”Meu nome é Ricardo Toshio Yugue, sou doutorando do programa de pósgraduação em administração da Faculdade de Economia, Administração e Contabilidade da Universidade de São Paulo - FEA/USP e estou realizando a pesquisa para minha tese de doutorado intitulada "Fatores contribuintes para o desempenho em projetos de desenvolvimento de produtos: O caso dos medicamentos genéricos".O objetivo da pesquisa é analisar o desempenho dos projetos de desenvolvimento de novos produtos da indústria de medicamentos genéricos e seus fatores contribuintes e se justifica pela importância dos medicamentos genéricos para o sistema de saúde brasileiro e pelo elevado índice de falhas nos processos de registro desses produtos. Para participar da pesquisa você deverá consentir com este TCLE ao marcar a opção "Li, entendi e aceito o Termo de Consentimento Livre e Esclarecido" após seu entendimento e eventuais esclarecimentos. O consentimento neste documento eletrônico corresponderá à assinatura do TCLE.O questionário contem perguntas sobre o desempenho dos projetos de desenvolvimento de medicamentos genéricos e os fatores que contribuem para seus resultados. Também inclui perguntas para caracterização dos participantes e dos laboratórios em que atuam. Não são solicitados dados considerados estratégicos ou confidenciais sobre os projetos e/ou empresas.A base de dados com as respostas será mantida em ambiente seguro e terá acesso restrito. Nenhum dado ou resposta individual será divulgado ou tratado isoladamente, mas analisado coletivamente com as demais respostas, preservando o sigilo dos respondentes e das empresas. No entanto, é dever informar que, mesmo em ambientes seguros, há sempre o risco de invasão de sistemas e de roubo dos dados da pesquisa ("hackeamento"). Os dados coletados serão analisados com a aplicação de técnicas estatísticas descritivas para caracterização da amostra, de frequência das respostas e de relação entre as variáveis.A sua participação na pesquisa é voluntária e, se houver algum desconforto ou receito, o preenchimento do questionário pode ser interrompido a qualquer momento. Seus dados serão descartados se assim desejar, sem que isso acarrete qualquer penalidade.A participação nesta pesquisa não envolve qualquer custo e nem vantagem financeira. Assim, esta pesquisa não prevê ressarcimento de eventuais despesas por se tratar de participação voluntária em que o principal recurso necessário é o tempo para preenchimento. No entanto, na hipótese de violação de quaisquer dos direitos do participante relacionados neste termo, poderão ser aplicadas todas as sanções e penalidades nos termos da legislação brasileira, sem prejuízo de eventuais perdas e danos. O TCE também se estende ao uso dos resultados da pesquisa para finalidades acadêmicas, incluindo a elaboração de tese de doutorado, apresentação em eventos e publicações em revistas científicas nacionais e/ou internacionais.Caso tenha alguma dúvida ou necessite de informações complementares antes, durante o preenchimento do questionário ou mesmo após, basta entrar em contato. Pesquisador: Ricardo Toshio Yugue. Email: yugue@usp.br . Telefone (11) 99145-2220.Para qualquer questão, dúvida, esclarecimento ou reclamação sobre aspectos éticos relativos a esta pesquisa, favor entrar em contato com o Comitê de Ética em Pesquisa da Faculdade de Ciências Farmacêuticas da Universidade de São Paulo: Av. Prof. Lineu Prestes, 580, Bloco 13 A, Butantã, São Paulo, CEP 05508-000, Telefones 3091-3622 e 3091-3677, e-mail: cepfcf@usp.br. Consentimento Pós-EsclarecidoDeclaro que, após ter lido e entendido o Termo de Consentimento Livre e Esclarecido e esclarecidas eventuais dúvidas, ao selecionar a opção "Li, entendi e aceito o Termo de Consentimento Livre e Esclarecido" abaixo, consinto eletronicamente com os termos para participação na pesquisa "Fatores contribuintes para o desempenho em projetos de desenvolvimento 
de produtos: O caso dos medicamentos genéricos". Sei que a qualquer momento poderei solicitar mais informações e modificar minha decisão de participar. Cópia do Termo de Consentimento Livre e Esclarecido pode ser obtida por meio da impressão da página do TCLE.Caso tenha alguma dúvida ou necessite de informações complementares basta entrar em contato. Pesquisador: Ricardo Toshio Yugue. Email: yugue@usp.br. Telefone (11) 99145-2220.Para qualquer questão, dúvida, esclarecimento ou reclamação sobre aspectos éticos relativos a este protocolo de pesquisa, favor entrar em contato com o Comitê de Ética em Pesquisa da Faculdade de Ciências Farmacêuticas da Universidade de São Paulo: Av. Prof. Lineu Prestes, 580, Bloco 13 A, Butantã, São Paulo, CEP 05508-000, Telefones 3091-3622 e 3091-3677, e-mail: cepfcf@usp.br.

1. Li, entendi e aceito o Termo de Consentimento Livre e Esclarecido

1. (EXPERIÊNCIA PROFISSIONAL EM PROJETOS DE DESENVOLVIMENTO DE MEDICAMENTOS) No total, por quanto tempo (contínuo ou não) trabalha ou trabalhou em projetos de desenvolvimento de medicamentos em geral (inovadores, similares, genéricos, etc.)?

1. Nunca trabalhei em projetos de desenvolvimento de medicamentos

2. Menos de 1 ano

3. Mais de 1 ano e menos de 2 anos

4. Mais de 2 anos e menos de 5 anos

5. Mais de 5 anos e menos de 10 anos

6. Mais de 10 anos e menos de 20 anos

7. Mais de 20 anos

2. (EXPERIÊNCIA PROFISSIONAL EM PROJETOS DE DESENVOLVIMENTO DE MEDICAMENTOS GENÉRICOS) No total, por quanto tempo (contínuo ou não) trabalha ou trabalhou em específico em projetos de desenvolvimento de medicamentos genéricos?

1. Nunca trabalhei em projetos de desenvolvimento de medicamentos genéricos

2. Menos de 1 ano

3. Mais de 1 ano e menos de 2 anos

4. Mais de 2 anos e menos de 5 anos

5. Mais de 5 anos e menos de 10 anos

6. Mais de 10 anos e menos de 20 anos

7. Mais de 20 anos

3. (PARTICIPAÇÃO EM PROJETOS DE DESENVOLVIMENTO DE MEDICAMENTOS GENÉRICOS) No momento você está trabalhando em projetos de desenvolvimento de medicamentos genéricos?

1. Sim, trabalho atualmente em projetos de desenvolvimento de medicamentos genéricos.

2. Não, mas trabalhei em projetos de desenvolvimento de medicamentos genéricos há menos de 2 anos.

3. Não, mas trabalhei em projetos de desenvolvimento de medicamentos genéricos há mais de 2 anos.

4. Outro. Por favor descreva a seguir.

\section{4. (FUNÇÃO NOS PROJETOS DE DESENVOLVIMENTO DE MEDICAMENTOS GENÉRICOS)}

Qual é ou foi a sua função predominante em relação aos projetos na empresa* em que trabalha ou na última em que trabalhou no desenvolvimento de medicamentos genéricos?

*Por favor, mantenha sempre como referência esta empresa em que trabalha ou em que trabalhou para responder às demais questões deste questionário.

1. Decisor ou membro de comitê de decisão sobre os projetos (portfólio) de medicamentos que são ou seriam desenvolvidos pela empresa ou equivalente.

2. Gerente ou responsável pela área de pesquisa e desenvolvimento de medicamentos ou equivalente.

3. Gerente ou responsável por projetos de desenvolvimento de medicamentos genéricos ou equivalente.

4. Membro da equipe de gerenciamento de projetos de desenvolvimento de medicamentos genéricos ou equivalente.

5. Responsável ou participante de atividades dos projetos de desenvolvimento de medicamentos genéricos ou equivalente.

6. Outro tipo de função. Por favor, informe qual a seguir:

5. (DEPARTAMENTO OU ÁREA DE ATUAÇÃO) Qual a área ou departamento em que atua ou atuou predominante na empresa atual ou na que trabalhou mais recentemente em projetos de desenvolvimento de medicamentos genéricos?

1. Administração / Corporativo ou equivalente

2. Comercial ou equivalente 
3. Consultoria ou equivalente

4. Controle de qualidade ou equivalente

5. Docência ou equivalente

6. Engenharia / Manutenção ou equivalente

7. Garantia da qualidade ou equivalente

8. Fiscalização ou equivalente

9. Marketing ou equivalente

10. Pesquisa e desenvolvimento ou equivalente

11. Produção ou equivalente

12. Regulatório ou equivalente

13. Suprimentos ou equivalente

14. Outro. Por favor, informe qual a seguir.

6. (CARGO OU FUNÇÃO) Qual o cargo ou função que mais se aproxima do que exerce ou exerceu na empresa em que trabalha ou trabalhou mais recentemente em projetos de desenvolvimento de medicamentos genéricos?

1. Proprietário, sócio, acionista ou equivalente

2. Conselheiro ou equivalente

3. Presidente, superintendente, $\mathrm{CEO}$ ou equivalente

4. Vice-presidente, diretor ou equivalente

5. Gerente ou equivalente

6. Supervisor, coordenador, líder ou equivalente

7. Analista, pesquisador, técnico ou equivalente

8. Consultor, assessor ou equivalente

9. Inspetor, auditor ou equivalente

10. Docente ou equivalente

11. Prestador de serviços ou equivalente

12. Trainee, estagiário ou equivalente

13. Outro. Por favor, informe qual a seguir.

7. (TIPO DE EMPRESA) Como pode ser caracterizada a empresa em que trabalha ou em que trabalhou mais recentemente em projetos de desenvolvimento de medicamentos genéricos?

1. Laboratório farmacêutico privado

2. Laboratório farmacêutico público

3. Laboratório farmacêutico de economia mista

4. Laboratório privado prestador de serviços (não fabricante) de desenvolvimento de medicamentos

5. Laboratório público prestador de serviços (não fabricante) de desenvolvimento de medicamentos

6. Serviços de consultoria de desenvolvimento de medicamentos

7. Órgão de fiscalização

8. Fornecedor de insumos e/ou materiais empregados no desenvolvimento e produção de medicamentos

9. Fornecedor de ferramentas e/ou equipamentos empregados no desenvolvimento e produção de medicamentos

10. Outro. Por favor, descreva a seguir.

8. (ORIGEM DA EMPRESA) Onde está localizada a matriz da empresa em que trabalha ou trabalhou mais recentemente em projetos de desenvolvimento de medicamentos genéricos?

1. No Brasil

2. Fora do Brasil. Por favor, informe em que país.

\section{9. (NÚMERO DE PROJETOS DE NOVOS MEDICAMENTOS DESENVOLVIDOS PELA EMPRESA)}

$\mathrm{Na}$ primeira linha responda, em média, quantos projetos de novos medicamentos* (de todas as classes inovadores, genéricos, similares, etc.) são ou eram desenvolvidos interna** e simultaneamente*** pela empresa em que trabalha ou em que trabalhou mais recentemente em projetos de desenvolvimento de medicamentos genéricos.

Na segunda linha responda, em média, quantos projetos somente de medicamentos genéricos são ou eram desenvolvidos interna** e simultaneamente*** pela empresa em que trabalha ou em que trabalhou mais recentemente em projetos de desenvolvimento de medicamentos genéricos. 
* Para indicar o total de projetos, considere como um único projeto o desenvolvimento de uma formulação de um medicamento em uma forma farmacêutica específica, mesmo que com mais de uma apresentação ou dosagem.

** Internamente $=$ não considera projetos desenvolvidos por terceiros.

*** Simultaneamente $=$ número médio de projetos em andamento (ativos) atualmente ou no último período em que trabalhou em projetos de desenvolvimento de medicamentos.

\begin{tabular}{|c|c|c|c|c|c|c|c|c|}
\hline & $\begin{array}{l}\text { Nenhum } \\
\text { projeto }\end{array}$ & $\begin{array}{c}1 \text { a } 5 \\
\text { projetos }\end{array}$ & $\begin{array}{l}6 \mathrm{a} \\
10\end{array}$ & $\begin{array}{l}11 \mathrm{a} \\
25\end{array}$ & $\begin{array}{c}26 a \\
50\end{array}$ & $\begin{array}{l}51 \mathrm{a} \\
100\end{array}$ & $\begin{array}{c}101 \\
\mathrm{a} \\
200\end{array}$ & $\begin{array}{l}\text { Mais de } \\
200 \\
\text { projetos }\end{array}$ \\
\hline $\begin{array}{c}\text { Média do total de projetos de todas as classes de } \\
\text { medicamentos desenvolvidos simultaneamente pela } \\
\text { empresa }\end{array}$ & $\square$ & $\square$ & $\square$ & $\square$ & $\square$ & $\square$ & $\square$ & $\square$ \\
\hline $\begin{array}{l}\text { Média do total de projetos somente de medicamentos } \\
\text { genéricos desenvolvidos simultaneamente pela empresa }\end{array}$ & $\square$ & $\square$ & $\square$ & $\square$ & $\square$ & $\square$ & $\square$ & $\square$ \\
\hline
\end{tabular}

\section{0. (CONCLUSÃO E ABANDONO DE PROJETOS)}

Considerando todos os projetos de desenvolvimento somente de medicamentos genéricos que são ou foram desenvolvidos na empresa em que você trabalha atualmente ou em que trabalhou mais recentemente em projetos de desenvolvimento de medicamentos genéricos, responda qual frequência (porcentagem) média dos projetos que: Responda cada item desta questão utilizando uma escala que vai de 1 a 7 , sendo $1=$ "nenhum" e $7=$ "todos" os projetos iniciados.

\begin{tabular}{|c|c|c|c|c|c|c|c|}
\hline & $\begin{array}{c}1 \text { nenhum } \\
\text { projeto } \\
(0 \%)\end{array}$ & $\begin{array}{l}2 \mathrm{de} \\
1 \% \mathrm{a} \\
20 \%\end{array}$ & \begin{tabular}{c|}
$3 \mathrm{de}$ \\
$21 \% \mathrm{a}$ \\
$40 \%$ \\
\end{tabular} & $\begin{array}{c}4 \text { cerca de } \\
\text { metade dos } \\
\text { projetos }\end{array}$ & \begin{tabular}{|c|}
$5 \mathrm{de}$ \\
$61 \% \mathrm{a}$ \\
$80 \%$ \\
\end{tabular} & \begin{tabular}{c|}
6 de \\
$81 \%$ a \\
$99 \%$ \\
\end{tabular} & $\begin{array}{l}7 \text { todos os } \\
\text { projetos } \\
(100 \%)\end{array}$ \\
\hline $\begin{array}{c}\text { 1. foram abandonados antes do término em razão } \\
\text { de mudanças nas prioridades e/ou estratégia da } \\
\text { empresa? }\end{array}$ & $\square$ & $\square$ & $\square$ & $\square$ & $\square$ & $\square$ & $\square$ \\
\hline $\begin{array}{c}\text { 2. foram abandonados antes do término em razão } \\
\text { de insuficiência de recursos e/ou competências } \\
\text { técnicas? }\end{array}$ & $\square$ & $\square$ & $\square$ & $\square$ & $\square$ & $\square$ & $\square$ \\
\hline $\begin{array}{l}\text { 3. foram abandonados antes do término em razão } \\
\text { de problemas técnicos no seu desenvolvimento? }\end{array}$ & $\square$ & $\square$ & $\square$ & $\square$ & $\square$ & $\square$ & $\square$ \\
\hline $\begin{array}{c}\text { 4. foram concluídos, mas com o desempenho fora } \\
\text { do planejado (além do prazo, do custo de } \\
\text { desenvolvimento, do custo de produção/preço-alvo } \\
\text { de mercado e/ou com problemas para aprovação } \\
\text { pela Anvisa)? }\end{array}$ & $\square$ & $\square$ & $\square$ & $\square$ & $\square$ & $\square$ & $\square$ \\
\hline $\begin{array}{l}\text { 5. foram concluídos, mas após a data planejada } \\
\text { inicialmente (com atraso)? (ID1) }\end{array}$ & $\square$ & $\square$ & $\square$ & $\square$ & $\square$ & $\square$ & $\square$ \\
\hline $\begin{array}{l}\text { 6. foram concluídos, mas com custos totais acima } \\
\text { do orçamento planejado (acima do orçamento)? } \\
\text { (ID2) }\end{array}$ & $\square$ & $\square$ & $\square$ & $\square$ & $\square$ & $\square$ & $\square$ \\
\hline \begin{tabular}{|c|} 
7. foram concluídos, mas tiveram seus pedidos \\
iniciais de registro reprovados pela Anvisa? (ID3)
\end{tabular} & $\square$ & $\square$ & $\square$ & $\square$ & $\square$ & $\square$ & $\square$ \\
\hline $\begin{array}{l}\text { 8. foram concluídos, mas com custos de produção } \\
\text { ou preço-alvo de mercado acima do planejado } \\
\text { (medicamento mais caro que o planejado)? (ID4) }\end{array}$ & $\square$ & $\square$ & $\square$ & $\square$ & $\square$ & $\square$ & $\square$ \\
\hline \begin{tabular}{|} 
9. foram concluídos, mas tiveram a necessidade de \\
ajustes na sua formulação e/ou em seu processo de \\
fabricação após o seu lançamento \\
("troubleshooting")? (ID5) \\
\end{tabular} & $\square$ & $\square$ & $\square$ & $\square$ & $\square$ & $\square$ & $\square$ \\
\hline \begin{tabular}{|c|} 
10. foram concluídos com o desempenho dentro \\
do planejado (dentro do prazo, do custo de \\
desenvolvimento, do custo de produção/preço-alvo
\end{tabular} & $\square$ & $\square$ & $\square$ & $\square$ & 口 & $\square$ & $\square$ \\
\hline
\end{tabular}


de mercado e/ou sem problemas para aprovação pela Anvisa)?

\section{1. (FATORES CONTRIBUINTES PARA RESULTADOS FORA DO PLANEJADO)}

Este conjunto de perguntas é o mais importante para a pesquisa! Por favor, responda-o com atenção!Tendo por referência todos os projetos de desenvolvimento de medicamentos genéricos na empresa em que atua ou atuou mais recentemente, qual o grau de contribuição* das situações relacionadas a seguir para os projetos concluídos, mas com resultados fora dos planejados**?

* Grau de contribuição = representa a combinação entre a frequência e o impacto da situação analisada para o desempenho fora do planejado (no sentido negativo) dos projetos de desenvolvimento de medicamentos genéricos da empresa. Quanto mais frequente e maior o impacto da situação analisada sobre os resultados fora dos planejados, maior será o seu grau de contribuição.

** Resultados fora dos planejados $=$ projetos concluídos, mas não aprovados pela Anvisa, concluídos com atraso, com custo de desenvolvimento acima do previsto, com ajustes a serem realizados após o seu lançamento e/ou com custo de produção acima do ideal para o preço-alvo de mercado. Responda utilizando uma escala de 1 a 7 , sendo 1 = "nenhuma contribuição para os resultados fora dos planejados" a 7 = "total contribuição (um dos principais fatores) para os resultados fora dos planejados".

\begin{tabular}{|c|c|c|c|c|c|c|c|}
\hline & $\begin{array}{c}1= \\
\text { "Nenhuma } \\
\text { contribuição" }\end{array}$ & 2 & \begin{tabular}{|l|l|}
3 \\
\end{tabular} & $\begin{array}{c}4= \\
\text { contribuição } \\
\text { mediana }\end{array}$ & \begin{tabular}{|l|}
5 \\
\end{tabular} & 6 & $\begin{array}{c}7=\text { "Total } \\
\text { Contribuição" }\end{array}$ \\
\hline $\begin{array}{l}\text { 1. Deficiências nas práticas de garantia da qualidade (ex.: } \\
\text { dificuldade nas validações e/ou qualificações) }\end{array}$ & $\square$ & $\square$ & $\square$ & $\square$ & $\square$ & $\square$ & $\square$ \\
\hline $\begin{array}{l}\text { 2. Dificuldades na realização dos estudos de } \\
\text { bioequivalência e/ou biodisponibilidade dos } \\
\text { medicamentos }\end{array}$ & $\square$ & \begin{tabular}{|l|}
$\square$ \\
\end{tabular} & $\square$ & $\square$ & \begin{tabular}{|l|}
$\square$ \\
\end{tabular} & $\square$ & $\square$ \\
\hline $\begin{array}{l}\text { 3. Dificuldades na realização dos estudos de dissolução } \\
\text { dos medicamentos }\end{array}$ & $\square$ & $\square$ & $\square$ & $\square$ & $\square$ & $\square$ & $\square$ \\
\hline $\begin{array}{l}\text { 4. Dificuldades na realização dos estudos de equivalência } \\
\text { farmacêutica dos medicamentos }\end{array}$ & $\square$ & $\square$ & $\square$ & $\square$ & $\square$ & $\square$ & $\square$ \\
\hline $\begin{array}{l}\text { 5. Dificuldades no desenvolvimento e validação dos } \\
\text { métodos analíticos dos medicamentos }\end{array}$ & $\square$ & $\square$ & $\square$ & $\square$ & $\square$ & $\square$ & $\square$ \\
\hline $\begin{array}{c}\text { 6. Dificuldades na realização dos estudos de estabilidade, } \\
\text { de fotoestabilidade, de produtos de degradação e/ou na } \\
\text { obtenção da estabilidade do medicamento. }\end{array}$ & $\square$ & $\square$ & $\square$ & $\square$ & $\square$ & $\square$ & $\square$ \\
\hline $\begin{array}{l}\text { 7. Dificuldade no estabelecimento das especificações e/ou } \\
\text { realização dos testes para o controle de qualidade dos } \\
\text { medicamentos. }\end{array}$ & $\square$ & $\square$ & $\square$ & $\square$ & $\square$ & $\square$ & $\square$ \\
\hline $\begin{array}{c}\text { 8. Dificuldade na obtenção de informações sobre os } \\
\text { ingredientes farmacêuticos ativos utilizados nos } \\
\text { medicamentos e/ou deficiências no DMF disponibilizado } \\
\text { pelo fabricante }\end{array}$ & $\square$ & $\square$ & $\square$ & $\square$ & $\square$ & $\square$ & $\square$ \\
\hline $\begin{array}{l}\text { 9. Custos elevados para desenvolvimento dos } \\
\text { medicamentos }\end{array}$ & $\square$ & $\square$ & $\square$ & $\square$ & $\square$ & $\square$ & $\square$ \\
\hline $\begin{array}{l}\text { 10. Longo tempo necessário para o desenvolvimento dos } \\
\text { medicamentos }\end{array}$ & $\square$ & $\square$ & $\square$ & $\square$ & $\square$ & $\square$ & $\square$ \\
\hline $\begin{array}{l}\text { 11. Risco de insucesso no desenvolvimento do } \\
\text { medicamento e de indeferimento do registro (incertezas) }\end{array}$ & $\square$ & $\square$ & $\square$ & $\square$ & $\square$ & $\square$ & $\square$ \\
\hline $\begin{array}{l}\text { 12. Dificuldades no atendimento da legislação sanitária } \\
\text { para o desenvolvimento e/ou registro de medicamentos } \\
\text { genéricos }\end{array}$ & $\square$ & $\square$ & $\square$ & $\square$ & $\square$ & $\square$ & $\square$ \\
\hline $\begin{array}{l}\text { 13. Deficiências e/ou dificuldades na elaboração dossiê } \\
\text { para registro dos medicamentos }\end{array}$ & $\square$ & $\square$ & $\square$ & $\square$ & $\square$ & $\square$ & $\square$ \\
\hline
\end{tabular}


14. Deficiências e/ou dificuldades no atendimento às exigências da Anvisa durante o processo de análise dos pedidos de registro dos medicamentos

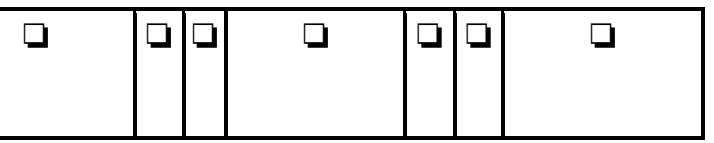

12. (FATORES CONTRIBUINTES PARA OS RESULTADOS FORA DO PLANEJADO) segunda parte.

Este conjunto de questões é continuação da pergunta anterior e segue os mesmos critérios! Por favor, responda-o com atenção! Tendo por referência todos os projetos de desenvolvimento de medicamentos genéricos na empresa em que atua ou atuou mais recentemente, qual o grau de contribuição* das situações relacionadas a seguir para os projetos concluídos, mas com resultados fora dos planejados**?

* Grau de contribuição = representa a combinação entre a frequência e o impacto da situação analisada para o desempenho fora do planejado (no sentido negativo) dos projetos de desenvolvimento de medicamentos genéricos da empresa. Quanto mais frequente e maior o impacto da situação analisada sobre os resultados fora dos planejados, maior será o seu grau de contribuição.

** Resultados fora dos planejados = projetos concluídos, mas não aprovados pela Anvisa, concluídos com atraso, com custo de desenvolvimento acima do previsto, com ajustes a serem realizados após o seu lançamento e/ou com custo de produção acima do ideal para o preço-alvo de mercado. Responda utilizando uma escala de 1 a 7 , sendo 1 = "nenhuma contribuição para os resultados fora dos planejados" a 7 = "total contribuição (um dos principais fatores) para os resultados fora dos planejados".

\begin{tabular}{|c|c|c|c|c|c|c|c|}
\hline & $\begin{array}{c}1= \\
\text { "Nenhuma } \\
\text { contribuição" }\end{array}$ & 2 & 3 & $\begin{array}{c}4= \\
\text { contribuição } \\
\text { mediana }\end{array}$ & 5 & 6 & $\begin{array}{c}7=\text { "Total } \\
\text { Contribuição" }\end{array}$ \\
\hline $\begin{array}{l}\text { 15. Dificuldade no desenvolvimento da formulação } \\
\text { (farmacotécnico) do medicamento }\end{array}$ & $\square$ & $\square$ & $\square$ & $\square$ & $\square$ & $\square$ & $\square$ \\
\hline $\begin{array}{l}\text { 16. Dificuldade no processo de transferência dos } \\
\text { medicamentos do laboratório para a produção } \\
\text { (escalonamento ou "scale up") }\end{array}$ & $\square$ & \begin{tabular}{|l|}
$\square$ \\
\end{tabular} & $\square$ & $\square$ & $\square$ & $\square$ & $\square$ \\
\hline $\begin{array}{l}\text { 17. Deficiências e/ou dificuldades na obtenção e/ou } \\
\text { apresentação de dados e informações técnico-científicas } \\
\text { dos medicamentos }\end{array}$ & $\square$ & $\square$ & $\square$ & $\square$ & $\square$ & $\square$ & $\square$ \\
\hline \begin{tabular}{|c|} 
18. Deficiências e/ou dificuldades para a realização de \\
lotes piloto, pré-validação e predefinição dos parâmetros \\
do processo de produção do novo medicamento
\end{tabular} & $\square$ & $\square$ & $\square$ & $\square$ & $\square$ & $\square$ & $\square$ \\
\hline $\begin{array}{c}\text { 19. O laboratório não usar ou usar inadequadamente } \\
\text { metodologias científicas para o desenvolvimento dos } \\
\text { medicamentos (ex.: Qualidade por Meio do Delineamento } \\
\text { ou "Quality by Design") }\end{array}$ & $\square$ & $\square$ & $\square$ & $\square$ & $\square$ & $\square$ & $\square$ \\
\hline $\begin{array}{l}\text { 20. Dificuldades ou ausência de estudos de pré- } \\
\text { formulação do medicamento }\end{array}$ & $\square$ & $\square$ & $\square$ & $\square$ & D & $\square$ & $\square$ \\
\hline $\begin{array}{l}\text { 21. Inexistência ou deficiências nos processos para } \\
\text { desenvolvimento dos medicamentos }\end{array}$ & $\square$ & $\square$ & $\square$ & $\square$ & $\square$ & $\square$ & $\square$ \\
\hline $\begin{array}{l}\text { 22. Definições iniciais insuficientes ou incorretas dos } \\
\text { medicamentos a serem desenvolvidos (necessidades, } \\
\text { características e/ou especificações dos medicamentos) }\end{array}$ & $\square$ & $\square$ & $\square$ & $\square$ & $\square$ & $\square$ & $\square$ \\
\hline $\begin{array}{l}\text { 23. Mudanças no projeto após o início do } \\
\text { desenvolvimento do medicamento }\end{array}$ & $\square$ & $\square$ & $\square$ & $\square$ & $\square$ & $\square$ & $\square$ \\
\hline $\begin{array}{l}\text { 24. Deficiências e/ou dificuldades no gerenciamento de } \\
\text { riscos no desenvolvimento dos medicamentos }\end{array}$ & $\square$ & $\square$ & $\square$ & $\square$ & $\square$ & $\square$ & $\square$ \\
\hline $\begin{array}{l}\text { 25. Deficiências e/ou dificuldades no gerenciamento dos } \\
\text { projetos de desenvolvimento dos medicamentos }\end{array}$ & $\square$ & $\square$ & $\square$ & $\square$ & $\square$ & $\square$ & $\square$ \\
\hline $\begin{array}{l}\text { 26. Prazos muito curtos para o desenvolvimento dos } \\
\text { medicamentos }\end{array}$ & $\square$ & $\square$ & $\square$ & $\square$ & $\square$ & $\square$ & $\square$ \\
\hline $\begin{array}{l}\text { 27. Objetivo de custo final para produção e/ou preço- } \\
\text { alvo de mercado muito baixo para o medicamento em } \\
\text { desenvolvimento em razão do custo dos materiais e/ou }\end{array}$ & $\square$ & $\square$ & $\square$ & $\square$ & $\square$ & $\square$ & $\square$ \\
\hline
\end{tabular}




\begin{tabular}{|c|c|c|c|c|c|c|c|}
\hline processo de fabricação & & & & & & & \\
\hline $\begin{array}{l}\text { 28. Escolha inadequada e/ou equivocada dos } \\
\text { medicamentos para o compor o portfólio de projetos a } \\
\text { serem desenvolvimentos }\end{array}$ & $\square$ & $\square$ & $\square$ & $\square$ & $\square$ & $\square$ & $\square$ \\
\hline $\begin{array}{l}\text { 29. Inexistência ou deficiências nos estudos de } \\
\text { viabilidade técnica para escolha dos medicamentos a } \\
\text { serem desenvolvidos }\end{array}$ & $\square$ & $\square$ & $\square$ & $\square$ & $\square$ & $\square$ & $\square$ \\
\hline $\begin{array}{l}\text { 30. Inexistência ou deficiências na estrutura e/ou } \\
\text { procedimento de acompanhamento e/ou controle dos } \\
\text { projetos de desenvolvimento de medicamentos em } \\
\text { andamento }\end{array}$ & $\square$ & $\square$ & $\square$ & $\square$ & D & $\square$ & $\square$ \\
\hline $\begin{array}{l}\text { 31. Número de projetos acima da capacidade e/ou elevada } \\
\text { diversidade de projetos de desenvolvimento de } \\
\text { medicamentos em andamento }\end{array}$ & $\square$ & $\square$ & $\square$ & $\square$ & $\mid$ & $\square$ & $\square$ \\
\hline
\end{tabular}

13. (FATORES CONTRIBUINTES PARA OS RESULTADOS FORA DO PLANEJADO) - última parte.

Este conjunto de questões é a última parte da pergunta anterior e segue os mesmos critérios! Por favor, respondao com atenção!Tendo por referência todos os projetos de desenvolvimento de medicamentos genéricos na empresa em que atua ou atuou mais recentemente, qual o grau de contribuição* das situações relacionadas a seguir para os projetos concluídos, mas com resultados fora dos planejados**?

* Grau de contribuição = representa a combinação entre a frequência e o impacto da situação analisada para o desempenho fora do planejado (no sentido negativo) dos projetos de desenvolvimento de medicamentos genéricos da empresa. Quanto mais frequente e maior o impacto da situação analisada sobre os resultados fora dos planejados, maior será o seu grau de contribuição.

** Resultados fora dos planejados = projetos concluídos, mas não aprovados pela Anvisa, concluídos com atraso, com custo de desenvolvimento acima do previsto, com ajustes a serem realizados após o seu lançamento e/ou com custo de produção acima do ideal para o preço-alvo de mercado. Responda utilizando uma escala de 1 a 7 , sendo 1 = "nenhuma contribuição para os resultados fora dos planejados" a 7 = "total contribuição (um dos principais fatores) para os resultados fora dos planejados".

\begin{tabular}{|c|c|c|c|c|c|c|c|}
\hline & $\begin{array}{c}1= \\
\text { "Nenhuma } \\
\text { contribuição" }\end{array}$ & 2 & 3 & $\begin{array}{c}4= \\
\text { contribuição } \\
\text { mediana }\end{array}$ & 5 & 6 & $\begin{array}{c}7=\text { "Total } \\
\text { Contribuição" }\end{array}$ \\
\hline $\begin{array}{c}\text { 32. Dificuldade no desenvolvimento da embalagem para } \\
\text { o medicamento (material, tecnologia e/ou fornecedor) }\end{array}$ & $\square$ & $\square$ & $\square$ & $\square$ & $\square$ & $\square$ & $\square$ \\
\hline $\begin{array}{c}\text { 33. Mudança de fornecedor de ingrediente farmacêutico } \\
\text { ativo durante o desenvolvimento do medicamento }\end{array}$ & $\square$ & $\square$ & $\square$ & $\square$ & $\square$ & $\square$ & $\square$ \\
\hline $\begin{array}{c}\text { 34. Dificuldades na seleção e qualificação dos } \\
\text { fornecedores de ingredientes farmacêuticos ativos }\end{array}$ & $\square$ & $\square$ & $\square$ & $\square$ & $\square$ & $\square$ & $\square$ \\
\hline $\begin{array}{c}\text { 35. Infraestrutura (instalações, equipamentos e utilidades) } \\
\text { inadequada para o desenvolvimento dos métodos } \\
\text { analíticos }\end{array}$ & $\square$ & $\square$ & $\square$ & $\square$ & $\square$ & $\square$ & $\square$ \\
\hline $\begin{array}{c}\text { 36. Infraestrutura (instalaçôes, equipamentos e utilidades) } \\
\text { inadequada para o desenvolvimento da formulação } \\
\text { (farmacotécnico) dos medicamentos }\end{array}$ & $\square$ & $\square$ & $\square$ & $\square$ & $\square$ & $\square$ & $\square$ \\
\hline $\begin{array}{c}\text { 37. Dificuldades para contratação de profissionais e/ou } \\
\text { serviços de terceiros para as atividades de } \\
\text { desenvolvimento dos medicamentos }\end{array}$ & $\square$ & $\square$ & $\square$ & $\square$ & $\square$ & $\square$ & $\square$ \\
\hline $\begin{array}{c}\text { 38. O laboratório não ter domínio suficiente da tecnologia } \\
\text { dos medicamentos (forma de liberação, tipo de insumo, } \\
\text { etc.) }\end{array}$ & $\square$ & $\square$ & $\square$ & $\square$ & $\square$ & $\square$ & $\square$ \\
\hline $\begin{array}{c}\text { 39. O laboratório não ter domínio suficiente da tecnologia } \\
\text { do processo de fabricação dos medicamentos }\end{array}$ & $\square$ & $\square$ & $\square$ & $\square$ & $\square$ & $\square$ & $\square$ \\
\hline 40. O laboratório não ter profissionais experientes e/ou & $\square$ & $\square$ & $\square$ & $\square$ & $\square$ & $\square$ & $\square$ \\
\hline
\end{tabular}




\begin{tabular}{|c|c|c|c|c|c|c|c|}
\hline $\begin{array}{c}\text { com qualificação adequada em número suficiente para o } \\
\text { desenvolvimento dos medicamentos }\end{array}$ & & & & & & & \\
\hline $\begin{array}{c}\text { 41. Cultura da empresa ou organização que não favorece } \\
\text { e/ou dificulta o desenvolvimento adequado dos } \\
\text { medicamentos }\end{array}$ & $\square$ & $\square$ & $\square$ & $\square$ & $\square$ & $\square$ & $\square$ \\
\hline $\begin{array}{c}\text { 42. Deficiências e/ou dificuldades na comunicação entre } \\
\text { os profissionais e/ou entre as áreas da empresa que } \\
\text { participam do desenvolvimento dos medicamentos }\end{array}$ & $\square$ & $\square$ & $\square$ & $\square$ & $\square$ & $\square$ & $\square$ \\
\hline $\begin{array}{c}\text { 43. Estrutura (organizacional) da empresa que não } \\
\text { favorece e/ou dificulta os projetos de desenvolvimento } \\
\text { dos medicamentos }\end{array}$ & $\square$ & $\square$ & $\square$ & $\square$ & $\square$ & $\square$ & $\square$ \\
\hline $\begin{array}{c}\text { 44. Ausência ou insuficiência de apoio de outras áreas } \\
\text { e/ou dos superiores aos projetos de desenvolvimento dos } \\
\text { medicamentos }\end{array}$ & $\square$ & $\square$ & $\square$ & $\square$ & $\square$ & $\square$ & $\square$ \\
\hline
\end{tabular}

14. (EMPRESA) Identifique na relação abaixo a empresa (atual ou a última em que trabalhou em projetos de medicamentos genéricos) que utilizou como referência para responder a este questionário. O objetivo é verificar se pelo menos um profissional de cada empresa participou da pesquisa (representatividade da amostra). Clique na seta para abrir a caixa de opções.Importante: Uma mesma organização ou grupo pode ter mais de um laboratório fabricante, assim, verifique qual o mais adequado ao seu caso. A relação abaixo foi extraída do site da Anvisa e, portanto, pode estar defasada e/ou incompleta.

\begin{tabular}{|c|c|c|c|}
\hline 1. AB Farmoquímica & 37. Brasterápica & 73. Hospira & 106.Novo Nordisk \\
\hline 2. Abbott & 38. Bristol & 74. Hypofarma & 107.Onefarma \\
\hline 3. Accord & 39. Bunker & 75. Instituto Biochimico & 108.Opem \\
\hline 4. Aché & 40. Cazi & 76. IPCA & 109.Osório Moraes \\
\hline 5. Actelion & 41. Cellofarm & 77. IQUEGO & 110.Pfizer \\
\hline 6. Airela & 42. Cifarma & 78. Isofarma & 111.Pharlab \\
\hline 7. Alcon & 43. Cimed & 79. IVB & 112.Pharma Limirio \\
\hline 8. Allergan & 44. Cinfa & 80. JP & 113.Pharmascience \\
\hline 9. Altana Pharma & 45. Colbrás & 81. Kinder & 114.Prati, Donaduzzi \\
\hline 10. Althaia & 46. Cristália & 82. Laboratório & 115.Prodotti \\
\hline 11. Antibióticos do Brasil & 47. Dr. Reddy`s & Exército & 116.Ranbaxy \\
\hline 12. Apotex & 48. Ducto & 83. Laboratório & 117.Rioquímica \\
\hline 13. Apsen & 49. Eli Lilly & Marinha & 118.Sandoz \\
\hline 14. Ariston & 50. Elofar & 84. Lafepe & 119.Sanobiol \\
\hline 15. Aspen & 51. EMS & 85. Legrand & 120.Sanofi-Aventis \\
\hline 16. Ativus & 52. EMS Sigma Pharma & 86. LFM & 121.Santisa \\
\hline $\begin{array}{l}\text { 11. Asta Medica } \\
\text { 18. Astrazeneca }\end{array}$ & $\begin{array}{l}\text { 53. Equiplex } \\
\text { 54. Esterlina }\end{array}$ & $\begin{array}{l}\text { 87. Libbs } \\
\text { 88. LIFAL }\end{array}$ & $\begin{array}{l}\text { 122.Sanval } \\
\text { 123.Schering-Plough }\end{array}$ \\
\hline 19. Arrow (Erow) & 55. Eurofarma & 89. Luper & 124. Sobral \\
\hline 20. Ativus & 56. Evolabis & 90. Mabra & 125.Sun \\
\hline 21. Aurobindo & 57. Farmace & 91. Mariol & 126.Teuto \\
\hline 22. Avert & 58. Farmasa & 92. Medley & 127.Teva \\
\hline 23. B. Braun & 59. Fiocruz & 93. Medqứmica & 128. Theodoro F. Sobral \\
\hline 24. Bahiafarma & 60. Fresenius & 94. Melcon & 129. Torrent \\
\hline 25. Balm-Labor & 61.FUNED & 95. Merck & 130.UCB \\
\hline 26. Beker & 62. FURP & 96. Mepha (Ratiopharm) & 131.UCI-Farma \\
\hline 27. Belfar & 63. Genom (Formil) & 97. Multilab & 132.União Química \\
\hline 28. Bergamo & 64. Geolab & 98. Nativita & 133.Unichem \\
\hline 29. Besins & 65. Germed & 99. Natulab & 134.United Medical \\
\hline 30. Biochimico & 66. Glaxosmithkline & 100.Nature's & 135.Vitamedic \\
\hline 31. Biolab Sanus & 67. Glenmark & (Germed) & 136. Vitapan \\
\hline 32. Biosintética & 68. Globo & 101.Neckerman & 137. Wasser \\
\hline 33. Blanver & 69. Greenpharma & 102.Neolatina & 138. Wyeth \\
\hline 34. Blau & 70. Halex Istar & 103.Neo Química & 139.Zambon \\
\hline 35. Bli & 71. Hexal & 104.Novafarma & 140.Zodiac \\
\hline 36. Brainfarma & 72. Hipolabor & 105.Novartis & $\begin{array}{l}\text { 141.Zydus } \\
\text { 142.Zydus Nikkho } \\
\text { Nao desejo } \\
\text { informar }\end{array}$ \\
\hline
\end{tabular}

1. Outro. Por favor informe o nome.

\section{Primeiro(s) nome(s)}

16. Sobrenome(s) 
17. Email pessoal 


\section{APÊNDICE XII - Indicadores que compõem os constructos definidos no modelo de caminhos proposto e seus códigos de identificação}

\begin{tabular}{|c|c|c|}
\hline CONSTRUCTO & COD & INDICADOR \\
\hline \multirow{5}{*}{$\begin{array}{l}\text { DESEMPENHO } \\
\text { (variável } \\
\text { dependente) }\end{array}$} & (ID1) & Foram concluídos, mas após a data planejada inicialmente (com atraso)? \\
\hline & (ID2) & $\begin{array}{l}\text { Foram concluídos, mas com custos totais acima do orçamento planejado (acima do } \\
\text { orçamento)? }\end{array}$ \\
\hline & (ID3) & $\begin{array}{l}\text { Foram concluídos, mas tiveram seus pedidos iniciais de registro reprovados pela } \\
\text { Anvisa? }\end{array}$ \\
\hline & (ID4) & $\begin{array}{l}\text { Foram concluídos, mas com custos de produção ou preço-alvo de mercado acima do } \\
\text { planejado (medicamento mais caro que o planejado)? }\end{array}$ \\
\hline & (ID5) & $\begin{array}{l}\text { Foram concluídos, mas tiveram a necessidade de ajustes na sua formulação e/ou em } \\
\text { seu processo de fabricação após o seu lançamento ("troubleshooting")? }\end{array}$ \\
\hline \multirow[t]{6}{*}{ Recursos } & (RE1) & $\begin{array}{l}\text { Dificuldade no desenvolvimento da embalagem para o medicamento (material, } \\
\text { tecnologia e/ou fornecedor) }\end{array}$ \\
\hline & (RE2) & $\begin{array}{l}\text { Mudança de fornecedor de ingrediente farmacêutico ativo durante o } \\
\text { desenvolvimento do medicamento }\end{array}$ \\
\hline & (RE3) & $\begin{array}{l}\text { Dificuldades na seleção e qualificação dos fornecedores de ingredientes } \\
\text { farmacêuticos ativos }\end{array}$ \\
\hline & (RE4) & $\begin{array}{l}\text { Infraestrutura (instalações, equipamentos e utilidades) inadequada para o } \\
\text { desenvolvimento dos métodos analíticos }\end{array}$ \\
\hline & (RE5) & $\begin{array}{l}\text { Infraestrutura (instalações, equipamentos e utilidades) inadequada para o } \\
\text { desenvolvimento da formulação (farmacotécnico) dos medicamentos }\end{array}$ \\
\hline & (RE6) & $\begin{array}{l}\text { Dificuldades para contratação de profissionais e/ou serviços de terceiros para as } \\
\text { atividades de desenvolvimento dos medicamentos }\end{array}$ \\
\hline \multirow[t]{3}{*}{ Competências } & (CP1) & $\begin{array}{l}\text { O laboratório não ter domínio suficiente da tecnologia dos medicamentos (forma de } \\
\text { liberação, tipo de insumo, etc.) }\end{array}$ \\
\hline & $(\mathrm{CP} 2)$ & $\begin{array}{l}\text { O laboratório não ter domínio suficiente da tecnologia do processo de fabricação } \\
\text { dos medicamentos }\end{array}$ \\
\hline & (CP3) & $\begin{array}{l}\text { O laboratório não ter profissionais experientes e/ou com qualificação adequada em } \\
\text { número suficiente para o desenvolvimento dos medicamentos }\end{array}$ \\
\hline \multirow[t]{4}{*}{ Organização } & $(\mathrm{OR} 1)$ & $\begin{array}{l}\text { Cultura da empresa ou organização que não favorece e/ou dificulta o } \\
\text { desenvolvimento adequado dos medicamentos }\end{array}$ \\
\hline & $(\mathrm{OR} 2)$ & $\begin{array}{l}\text { Deficiências e/ou dificuldades na comunicação entre os profissionais e/ou entre as } \\
\text { áreas da empresa que participam do desenvolvimento dos medicamentos }\end{array}$ \\
\hline & (OR3) & $\begin{array}{l}\text { Estrutura (organizacional) da empresa que não favorece e/ou dificulta os projetos de } \\
\text { desenvolvimento dos medicamentos }\end{array}$ \\
\hline & $(\mathrm{OR} 4)$ & $\begin{array}{l}\text { Ausência ou insuficiência de apoio de outras áreas e/ou dos superiores aos projetos } \\
\text { de desenvolvimento dos medicamentos }\end{array}$ \\
\hline \multirow[t]{7}{*}{ Desenvolvimento } & (DP1) & Dificuldade no desenvolvimento da formulação (farmacotécnico) do medicamento \\
\hline & $(\mathrm{DP} 2)$ & $\begin{array}{l}\text { Dificuldade no processo de transferência dos medicamentos do laboratório para a } \\
\text { produção (escalonamento ou "scale up") }\end{array}$ \\
\hline & (DP3) & $\begin{array}{l}\text { Deficiências e/ou dificuldades na obtenção e/ou apresentação de dados e } \\
\text { informações técnico-científicas dos medicamentos }\end{array}$ \\
\hline & (DP4) & $\begin{array}{l}\text { Deficiências e/ou dificuldades para a realização de lotes piloto, pré-validação e } \\
\text { predefinição dos parâmetros do processo de produção do novo medicamento }\end{array}$ \\
\hline & (DP5) & $\begin{array}{l}\text { O laboratório não usar ou usar inadequadamente metodologias científicas para o } \\
\text { desenvolvimento dos medicamentos (ex.: Qualidade por Meio do Delineamento ou } \\
\text { "Quality by Design") }\end{array}$ \\
\hline & (DP6) & Dificuldades ou ausência de estudos de pré-formulação do medicamento \\
\hline & (DP7) & Inexistência ou deficiências nos processos para desenvolvimento dos medicamentos \\
\hline \multirow[t]{4}{*}{ Gestão } & (GT1) & $\begin{array}{l}\text { Definições iniciais insuficientes ou incorretas dos medicamentos a serem } \\
\text { desenvolvidos (necessidades, características e/ou especificações dos medicamentos) }\end{array}$ \\
\hline & (GT2) & Mudanças no projeto após o início do desenvolvimento do medicamento \\
\hline & (GT3) & $\begin{array}{l}\text { Deficiências e/ou dificuldades no gerenciamento de riscos no desenvolvimento dos } \\
\text { medicamentos }\end{array}$ \\
\hline & (GT4) & Deficiências e/ou dificuldades no gerenciamento dos projetos de desenvolvimento \\
\hline
\end{tabular}




\begin{tabular}{|c|c|c|}
\hline CONSTRUCTO & COD & INDICADOR \\
\hline & & dos medicamentos \\
\hline & (GT5) & Prazos muito curtos para o desenvolvimento dos medicamentos \\
\hline & (GT6) & $\begin{array}{l}\text { Objetivo de custo final para produção e/ou preço-alvo de mercado muito baixo para } \\
\text { o medicamento em desenvolvimento em razão do custo dos materiais e/ou processo } \\
\text { de fabricação }\end{array}$ \\
\hline \multirow[t]{4}{*}{ Portfólio } & (PF1) & $\begin{array}{l}\text { Escolha inadequada e/ou equivocada dos medicamentos para o compor o } \\
\text { portfólio de projetos a serem desenvolvimentos }\end{array}$ \\
\hline & (PF2) & $\begin{array}{l}\text { Inexistência ou deficiências nos estudos de viabilidade técnica para escolha dos } \\
\text { medicamentos a serem desenvolvidos }\end{array}$ \\
\hline & (PF3) & $\begin{array}{l}\text { Inexistência ou deficiências na estrutura e/ou procedimento de acompanhamento } \\
\text { e/ou controle dos projetos de desenvolvimento de medicamentos em andamento }\end{array}$ \\
\hline & (PF4) & $\begin{array}{l}\text { Número de projetos acima da capacidade e/ou elevada diversidade de projetos de } \\
\text { desenvolvimento de medicamentos em andamento }\end{array}$ \\
\hline \multirow[t]{8}{*}{$\begin{array}{l}\text { Especificações } \\
\text { técnicas }\end{array}$} & (ET1) & $\begin{array}{l}\text { Deficiências nas práticas de garantia da qualidade (ex.: dificuldade nas validações } \\
\text { e/ou qualificações) }\end{array}$ \\
\hline & $(\mathrm{ET} 2)$ & $\begin{array}{l}\text { Dificuldades na realização dos estudos de bioequivalência e/ou biodisponibilidade } \\
\text { dos medicamentos }\end{array}$ \\
\hline & (ET3) & Dificuldades na realização dos estudos de dissolução dos medicamentos \\
\hline & (ET4) & $\begin{array}{l}\text { Dificuldades na realização dos estudos de equivalência farmacêutica dos } \\
\text { medicamentos }\end{array}$ \\
\hline & (ET5) & $\begin{array}{l}\text { Dificuldades no desenvolvimento e validação dos métodos analíticos dos } \\
\text { medicamentos }\end{array}$ \\
\hline & (ET6) & $\begin{array}{l}\text { Dificuldades na realização dos estudos de estabilidade, de fotoestabilidade, de } \\
\text { produtos de degradação e/ou na obtenção da estabilidade do medicamento. }\end{array}$ \\
\hline & (ET7) & $\begin{array}{l}\text { Dificuldade no estabelecimento das especificações e/ou realização dos testes para o } \\
\text { controle de qualidade dos medicamentos. }\end{array}$ \\
\hline & (ET8) & $\begin{array}{l}\text { Dificuldade na obtenção de informações sobre os ingredientes farmacêuticos ativos } \\
\text { utilizados nos medicamentos e/ou deficiências no DMF disponibilizado pelo } \\
\text { fabricante }\end{array}$ \\
\hline \multirow{3}{*}{$\begin{array}{l}\text { Requisitos do } \\
\text { projeto }\end{array}$} & (RP1) & Custos elevados para desenvolvimento dos medicamentos \\
\hline & (RP2) & Longo tempo necessário para o desenvolvimento dos medicamentos \\
\hline & (RP3) & $\begin{array}{l}\text { Risco de insucesso no desenvolvimento do medicamento e de indeferimento do } \\
\text { registro (incertezas) }\end{array}$ \\
\hline \multirow[t]{3}{*}{$\begin{array}{l}\text { Requisitos } \\
\text { regulatórios }\end{array}$} & $(\mathrm{RR} 1)$ & $\begin{array}{l}\text { Dificuldades no atendimento da legislação sanitária para o desenvolvimento e/ou } \\
\text { registro de medicamentos genéricos }\end{array}$ \\
\hline & $(\mathrm{RR} 2)$ & Deficiências e/ou dificuldades na elaboração dossiê para registro dos medicamentos \\
\hline & (RR3) & $\begin{array}{l}\text { Deficiências e/ou dificuldades no atendimento às exigências da Anvisa durante o } \\
\text { processo de análise dos pedidos de registro dos medicamentos }\end{array}$ \\
\hline
\end{tabular}




\section{APÊNDICE XIII - Médias e desvios padrões dos constructos e de seus indicadores}

Tabela - Indicadores em ordem decrescente das médias das respostas (escala Likert de 7 pontos)

\begin{tabular}{|c|c|c|c|c|c|c|}
\hline \multirow[b]{2}{*}{ Codigo e Indicador } & \multirow{2}{*}{$\begin{array}{l}\text { Mé- } \\
\text { dia }\end{array}$} & \multirow{2}{*}{$\begin{array}{l}\text { Desvio } \\
\text { Padrão }\end{array}$} & \multicolumn{2}{|c|}{ Classificação } & \multicolumn{2}{|c|}{ Constructo } \\
\hline & & & Geral & $\begin{array}{l}\text { No cons- } \\
\text { tructo }\end{array}$ & $\begin{array}{l}\text { Exógeno } \\
\left(1^{\mathrm{a}} \text { ordem }\right)\end{array}$ & $\begin{array}{l}\text { Endógeno } \\
\left(2^{\mathrm{a}} \text { ordem }\right)\end{array}$ \\
\hline $\begin{array}{l}\text { (PF4) Número de projetos acima da capacidade } \\
\text { e/ou elevada diversidade de projetos de } \\
\text { desenvolvimento de medicamentos em } \\
\text { andamento }\end{array}$ & 4,59 & 1,84 & 1 & 1 & Portfólio & Gerencial \\
\hline $\begin{array}{l}\text { (GT5) Prazos muito curtos para o } \\
\text { desenvolvimento dos medicamentos }\end{array}$ & 4,53 & 1,80 & 2 & 1 & Gestão & Gerencial \\
\hline $\begin{array}{l}\text { (GT2) Mudanças no projeto após o início do } \\
\text { desenvolvimento do medicamento }\end{array}$ & 4,36 & 1,79 & 3 & 2 & Gestão & Gerencial \\
\hline $\begin{array}{l}\text { (ET8) Dificuldade na obtenção de informações } \\
\text { sobre os ingredientes farmacêuticos ativos } \\
\text { utilizados nos medicamentos e/ou deficiências } \\
\text { no DMF disponibilizado pelo fabricante }\end{array}$ & 4,11 & 1,82 & 4 & 1 & $\begin{array}{l}\text { Especifica- } \\
\text { ções } \\
\text { técnicas }\end{array}$ & Técnico \\
\hline $\begin{array}{l}\text { (RP2) Longo tempo necessário para o } \\
\text { desenvolvimento dos medicamentos }\end{array}$ & 4,10 & 1,75 & 5 & 1 & $\begin{array}{l}\text { Requisitos } \\
\text { do projeto }\end{array}$ & Técnico \\
\hline $\begin{array}{l}\text { (RE3) Dificuldades na seleção e qualificação } \\
\text { dos fornecedores de ingredientes farmacêuticos } \\
\text { ativos }\end{array}$ & 4,00 & 1,84 & 6 & 1 & Recursos & Estrutural \\
\hline $\begin{array}{l}\text { (OR1) Cultura da empresa ou organização que } \\
\text { não favorece e/ou dificulta o desenvolvimento } \\
\text { adequado dos medicamentos }\end{array}$ & 3,97 & 2,05 & 8 & 1 & Organização & Estrutural \\
\hline $\begin{array}{l}\text { (OR2) Deficiências e/ou dificuldades na } \\
\text { comunicação entre os profissionais e/ou entre } \\
\text { as áreas da empresa que participam do } \\
\text { desenvolvimento dos medicamentos }\end{array}$ & 3,97 & 1,78 & 9 & 2 & Organização & Estrutural \\
\hline $\begin{array}{l}\text { (RP1) Custos elevados para desenvolvimento } \\
\text { dos medicamentos }\end{array}$ & 3,97 & 1,74 & 7 & 2 & $\begin{array}{l}\text { Requisitos } \\
\text { do projeto }\end{array}$ & Técnico \\
\hline $\begin{array}{l}\text { (RE2) Mudança de fornecedor de ingrediente } \\
\text { farmacêutico ativo durante o desenvolvimento } \\
\text { do medicamento }\end{array}$ & 3,93 & 1,84 & 10 & 2 & Recursos & Estrutural \\
\hline $\begin{array}{l}\text { (GT3) Deficiências e/ou dificuldades no } \\
\text { gerenciamento de riscos no desenvolvimento } \\
\text { dos medicamentos }\end{array}$ & 3,88 & 1,74 & 11 & 3 & Gestão & Gerencial \\
\hline $\begin{array}{l}\text { (GT4) Deficiências e/ou dificuldades no } \\
\text { gerenciamento dos projetos de desenvolvimento } \\
\text { dos medicamentos }\end{array}$ & 3,87 & 1,78 & 12 & 4 & Gestão & Gerencial \\
\hline $\begin{array}{l}\text { (DP2) Dificuldade no processo de transferência } \\
\text { dos medicamentos do laboratório para a } \\
\text { produção (escalonamento ou "scale up") }\end{array}$ & 3,84 & 1,64 & 13 & 1 & $\begin{array}{l}\text { Desenvolvi- } \\
\text { mento }\end{array}$ & Gerencial \\
\hline $\begin{array}{l}\text { (ET6) Dificuldades na realização dos estudos } \\
\text { de estabilidade, de fotoestabilidade, de produtos } \\
\text { de degradação e/ou na obtenção da estabilidade } \\
\text { do medicamento. }\end{array}$ & 3,82 & 1,71 & 14 & 2 & $\begin{array}{l}\text { Especifica- } \\
\text { ções } \\
\text { técnicas }\end{array}$ & Técnico \\
\hline $\begin{array}{l}\text { (RR3) Deficiências e/ou dificuldades no } \\
\text { atendimento às exigências da Anvisa durante o } \\
\text { processo de análise dos pedidos de registro dos } \\
\text { medicamentos }\end{array}$ & 3,78 & 1,65 & 15 & 1 & $\begin{array}{l}\text { Requisitos } \\
\text { regulatórios }\end{array}$ & Técnico \\
\hline $\begin{array}{l}\text { (DP1) Dificuldade no desenvolvimento da } \\
\text { formulação (farmacotécnico) do medicamento }\end{array}$ & 3,77 & 1,60 & 16 & 2 & $\begin{array}{l}\text { Desenvolvi- } \\
\text { mento }\end{array}$ & Gerencial \\
\hline $\begin{array}{l}\text { (ET2) Dificuldades na realização dos estudos } \\
\text { de bioequivalência e/ou biodisponibilidade dos } \\
\text { medicamentos }\end{array}$ & 3,76 & 1,78 & 17 & 3 & $\begin{array}{l}\text { Especifica- } \\
\text { ções } \\
\text { técnicas }\end{array}$ & Técnico \\
\hline
\end{tabular}


(PF2) Inexistência ou deficiências nos estudos de viabilidade técnica para escolha dos medicamentos a serem desenvolvidos (GT1) Definições iniciais insuficientes ou incorretas dos medicamentos a serem desenvolvidos (necessidades, características e/ou especificações dos medicamentos) (DP6) Dificuldades ou ausência de estudos de pré-formulação do medicamento

(OR3) Estrutura (organizacional) da empresa que não favorece e/ou dificulta os projetos de desenvolvimento dos medicamentos

(RE6) Dificuldades para contratação de profissionais e/ou serviços de terceiros para as atividades de desenvolvimento dos medicamentos

(ET5) Dificuldades no desenvolvimento e validação dos métodos analíticos dos medicamentos

(DP4) Deficiências e/ou dificuldades para a realização de lotes piloto, pré-validação e predefinição dos parâmetros do processo de produção do novo medicamento

(OR4) Ausência ou insuficiência de apoio de outras áreas e/ou dos superiores aos projetos de desenvolvimento dos medicamentos

(PF3) Inexistência ou deficiências na estrutura e/ou procedimento de acompanhamento e/ou controle dos projetos de desenvolvimento de medicamentos em andamento

(DP5) O laboratório não usar ou usar inadequadamente metodologias científicas para o desenvolvimento dos medicamentos (ex.:

Qualidade por Meio do Delineamento ou

"Quality by Design")

(GT6) Objetivo de custo final para

produção e/ou preço-alvo de mercado muito

baixo para o medicamento em desenvolvimento

em razão do custo dos materiais e/ou processo

de fabricação

(CP3) O laboratório não ter profissionais

experientes e/ou com qualificação adequada em

número suficiente para o desenvolvimento dos

medicamentos

(DP3) Deficiências e/ou dificuldades na

obtenção e/ou apresentação de dados e

informações técnico-científicas dos

medicamentos

(RP3) Risco de insucesso no desenvolvimento do medicamento e de indeferimento do registro (incertezas)

(PF1) Escolha inadequada e/ou equivocada dos medicamentos para o compor o portfólio de projetos a serem desenvolvimentos (DP7) Inexistência ou deficiências nos processos para desenvolvimento dos medicamentos

\begin{tabular}{|c|c|c|c|c|c|}
\hline 3,75 & 1,88 & 18 & 2 & Portfólio & Gerencial \\
\hline 3,73 & 1,77 & 19 & 5 & Gestão & Gerencial \\
\hline 3,73 & 1,88 & 20 & 3 & $\begin{array}{l}\text { Desenvolvi- } \\
\text { mento }\end{array}$ & Gerencial \\
\hline 3,71 & 1,91 & 21 & 3 & Organização & Estrutural \\
\hline 3,68 & 1,86 & 22 & 3 & Recursos & Estrutural \\
\hline 3,67 & 1,59 & 23 & 4 & $\begin{array}{c}\text { Especifica- } \\
\text { ções } \\
\text { técnicas }\end{array}$ & Técnico \\
\hline 3,62 & 1,62 & 24 & 4 & $\begin{array}{l}\text { Desenvolvi- } \\
\text { mento }\end{array}$ & Gerencial \\
\hline 3,58 & 1,89 & 25 & 4 & Organização & Estrutural \\
\hline 3,54 & 1,76 & 26 & 3 & Portfólio & Gerencial \\
\hline
\end{tabular}

$3,48 \quad 1,89 \quad 27 \quad 5 \quad$ Desenvolvi-

Gerencial mento

Gestão

Gerencial

$3,48 \quad 1,62 \quad 28 \quad 6 \quad$ Gestão $\quad$ Gerencial

$3,42 \quad 1,95 \quad 29 \quad 1 \quad \begin{gathered}\text { Competên- } \\ \text { cias }\end{gathered}$

$\begin{array}{lllll}3,35 & 1,55 & 30 & 6 & \begin{array}{c}\text { Desenvolvi- } \\ \text { mento }\end{array}\end{array}$ Gerencial

$3,35 \quad 1,63 \quad 31 \quad 3 \quad$ Requisitos

Técnico

$\begin{array}{lllll}3,32 & 1,87 & 32 & 4 & \text { Portfólio }\end{array}$

$\begin{array}{lllll}3,23 & 1,61 & 33 & 7 & \begin{array}{c}\text { Desenvolvi- } \\ \text { mento }\end{array}\end{array}$ Gerencial 
(ET3) Dificuldades na realização dos estudos de dissolução dos medicamentos

(RR1) Dificuldades no atendimento da legislação sanitária para o desenvolvimento e/ou registro de medicamentos genéricos (ET4) Dificuldades na realização dos estudos de equivalência farmacêutica dos medicamentos

(RE4) Infraestrutura (instalações, equipamentos e utilidades) inadequada para o desenvolvimento dos métodos analíticos (RE5) Infraestrutura (instalações, equipamentos e utilidades) inadequada para o desenvolvimento da formulação (farmacotécnico) dos medicamentos (ET1) Deficiências nas práticas de garantia da qualidade (ex.: dificuldade nas validações e/ou qualificações)

(RE1) Dificuldade no desenvolvimento da embalagem para o medicamento (material, tecnologia e/ou fornecedor)

(RR2) Deficiências e/ou dificuldades na elaboração dossiê para registro dos medicamentos

(CP1) O laboratório não ter domínio suficiente da tecnologia dos medicamentos (forma de liberação, tipo de insumo, etc.)

(ET7) Dificuldade no estabelecimento das especificações e/ou realização dos testes para o controle de qualidade dos medicamentos.

(CP2) O laboratório não ter domínio suficiente da tecnologia do processo de fabricação dos medicamentos

Fonte: Dados da pequisa

\begin{tabular}{|c|c|c|c|c|c|}
\hline 3,19 & 1,55 & 34 & 5 & $\begin{array}{c}\text { Especifica- } \\
\text { ções } \\
\text { técnicas }\end{array}$ & Técnico \\
\hline 3,17 & 1,69 & 35 & 2 & $\begin{array}{l}\text { Requisitos } \\
\text { regulatórios }\end{array}$ & Técnico \\
\hline 3,13 & 1,66 & 36 & 6 & $\begin{array}{c}\text { Especifica- } \\
\text { ções } \\
\text { técnicas }\end{array}$ & Técnico \\
\hline 3,06 & 1,86 & 37 & 4 & Recursos & Estrutural \\
\hline 3,01 & 1,82 & 38 & 5 & Recursos & Estrutural \\
\hline 2,94 & 1,65 & 39 & 7 & $\begin{array}{c}\text { Especifica- } \\
\text { ções } \\
\text { técnicas }\end{array}$ & Técnico \\
\hline 2,93 & 1,68 & 40 & 6 & Recursos & Estrutural \\
\hline 2,89 & 1,49 & 41 & 3 & $\begin{array}{l}\text { Requisitos } \\
\text { regulatórios }\end{array}$ & Técnico \\
\hline 2,87 & 1,80 & 42 & 2 & $\begin{array}{l}\text { Competên- } \\
\text { cias }\end{array}$ & Estrutural \\
\hline 2,86 & 1,43 & 43 & 8 & $\begin{array}{c}\text { Especifica- } \\
\text { ções } \\
\text { técnicas }\end{array}$ & Técnico \\
\hline 2,80 & 1,76 & 44 & 3 & $\begin{array}{l}\text { Competên- } \\
\text { cias }\end{array}$ & Estrutural \\
\hline
\end{tabular}

Tabela - Constructos em ordem decrescente das médias das respostas aos seus indicadores

\begin{tabular}{lcc}
\hline \multicolumn{1}{c}{ Contructo } & Média & Desvio Padrão \\
\hline Especificações técnicas & 4,11 & 1,82 \\
Gestão & 3,97 & 1,24 \\
Requisitos do projeto & 3,81 & 1,29 \\
Organização & 3,81 & 1,64 \\
Portfólio & 3,80 & 1,40 \\
Desenvolvimento & 3,57 & 1,24 \\
Recursos & 3,44 & 1,30 \\
Requisitos regulatórios & 3,28 & 1,26 \\
Competências & 3,03 & 1,63 \\
\hline
\end{tabular}

Fonte: Dados da pequisa 


\section{APÊNDICE XIV - Matriz de cargas cruzadas ("cross loadings")}

\begin{tabular}{|c|c|c|c|c|c|c|c|c|c|c|}
\hline & $\begin{array}{l}\text { Compe- } \\
\text { tências }\end{array}$ & $\begin{array}{l}\text { Desen- } \\
\text { volvi- } \\
\text { mento }\end{array}$ & $\begin{array}{c}\text { Especi- } \\
\text { ficações } \\
\text { Técni-cas }\end{array}$ & Gestão & $\begin{array}{c}\text { DESEMP } \\
\text { ENHO }\end{array}$ & $\begin{array}{c}\text { Organi- } \\
\text { zação }\end{array}$ & Portfo-lio & $\begin{array}{l}\text { Recur- } \\
\text { sos }\end{array}$ & $\begin{array}{l}\text { Requisi- } \\
\text { tos do } \\
\text { Projeto }\end{array}$ & $\begin{array}{l}\text { Requisi- } \\
\text { tos } \\
\text { Regula- } \\
\text { tórios }\end{array}$ \\
\hline $\mathrm{CP} 1$ & 0,902 & 0,620 & 0,542 & 0,486 & 0,267 & 0,572 & 0,527 & 0,671 & 0,356 & 0,381 \\
\hline CP2 & 0,916 & 0,638 & 0,545 & 0,537 & 0,221 & 0,555 & 0,540 & 0,691 & 0,323 & 0,377 \\
\hline CP3 & $\mathbf{0 , 8 3 7}$ & 0,592 & 0,477 & 0,508 & 0,204 & 0,559 & 0,537 & 0,692 & 0,389 & 0,405 \\
\hline DP1 & 0,549 & 0,717 & 0,567 & 0,496 & 0,239 & 0,443 & 0,438 & 0,510 & 0,423 & 0,357 \\
\hline DP2 & 0,439 & 0,718 & 0,513 & 0,579 & 0,269 & 0,472 & 0,560 & 0,466 & 0,455 & 0,394 \\
\hline DP3 & 0,551 & 0,724 & 0,587 & 0,575 & 0,276 & 0,374 & 0,573 & 0,536 & 0,501 & 0,525 \\
\hline DP4 & 0,474 & 0,778 & 0,568 & 0,581 & 0,264 & 0,493 & 0,523 & 0,503 & 0,383 & 0,481 \\
\hline DP5 & 0,415 & 0,668 & 0,414 & 0,505 & 0,203 & 0,425 & 0,453 & 0,437 & 0,357 & 0,400 \\
\hline DP6 & 0,667 & 0,800 & 0,610 & 0,602 & 0,281 & 0,583 & 0,608 & 0,632 & 0,386 & 0,521 \\
\hline DP7 & 0,492 & 0,755 & 0,531 & 0,618 & 0,197 & 0,498 & 0,576 & 0,473 & 0,420 & 0,469 \\
\hline ET1 & 0,423 & 0,493 & 0,673 & 0,479 & 0,120 & 0,408 & 0,523 & 0,464 & 0,454 & 0,447 \\
\hline ET2 & 0,448 & 0,494 & 0,626 & 0,416 & 0,185 & 0,323 & 0,355 & 0,369 & 0,350 & 0,281 \\
\hline ET3 & 0,422 & 0,522 & 0,647 & 0,434 & 0,309 & 0,250 & 0,377 & 0,338 & 0,335 & 0,389 \\
\hline ET4 & 0,395 & 0,477 & 0,702 & 0,445 & 0,180 & 0,298 & 0,421 & 0,340 & 0,401 & 0,471 \\
\hline ET5 & 0,398 & 0,571 & 0,762 & 0,510 & 0,136 & 0,416 & 0,461 & 0,492 & 0,510 & 0,523 \\
\hline ET6 & 0,384 & 0,484 & 0,770 & 0,430 & 0,221 & 0,361 & 0,436 & 0,432 & 0,473 & 0,485 \\
\hline ET7 & 0,420 & 0,553 & 0,678 & 0,472 & 0,247 & 0,388 & 0,457 & 0,391 & 0,398 & 0,506 \\
\hline ET8 & 0,306 & 0,376 & 0,514 & 0,344 & 0,233 & 0,255 & 0,355 & 0,435 & 0,393 & 0,399 \\
\hline GT1 & 0,546 & 0,651 & 0,568 & 0,775 & 0,312 & ,498 & 0,659 & 0,454 & 0,390 & 0,450 \\
\hline GT2 & 0,328 & 0,515 & 0,437 & 0,728 & 0,229 & 0,449 & 0,557 & 0,398 & 0,405 & 0,342 \\
\hline GT3 & 0,473 & 0,677 & 0,558 & 0,812 & 0,313 & 0,562 & 0,701 & 0,487 & 0,509 & 0,442 \\
\hline GT4 & 0,408 & 0,604 & 0,498 & 0,782 & 0,321 & 0,583 & 0,637 & 0,426 & 0,446 & 0,458 \\
\hline GT5 & 0,380 & 0,435 & 0,328 & 0,624 & 0,195 & 0,438 & 0,436 & 0,352 & 0,297 & 0,264 \\
\hline GT6 & 0,304 & 0,326 & 0,372 & 0,522 & 0,259 & 0,368 & 0,460 & 0,392 & 0,433 & 0,278 \\
\hline ID1 & 0,252 & 0,297 & 0,242 & 0,317 & $\mathbf{0 , 8 0 5}$ & 0,262 & 0,328 & 0,189 & 0,171 & 0,229 \\
\hline ID2 & 0,196 & 0,280 & 0,297 & 0,357 & $\mathbf{0 , 8 5 6}$ & 0,242 & 0,332 & 0,258 & 0,281 & 0,212 \\
\hline ID3 & 0,196 & 0,121 & 0,172 & 0,139 & 0,418 & 0,082 & 0,159 & 0,186 & 0,168 & 0,217 \\
\hline ID4 & 0,165 & 0,213 & 0,151 & 0,263 & $\mathbf{0 , 7 4 9}$ & 0,206 & 0,249 & 0,132 & 0,187 & 0,185 \\
\hline ID5 & 0,154 & 0,271 & 0,201 & 0,272 & 0,742 & 0,206 & 0,206 & 0,126 & 0,116 & 0,142 \\
\hline OR1 & 0,534 & 0,562 & 0,431 & 0,626 & 0,255 & 0,873 & 0,594 & 0,607 & 0,347 & 0,273 \\
\hline OR2 & 0,524 & 0,565 & 0,416 & 0,566 & 0,267 & $\mathbf{0 , 8 5 1}$ & 0,566 & 0,589 & 0,396 & 0,378 \\
\hline OR3 & 0,510 & 0,520 & 0,427 & 0,590 & 0,244 & $\mathbf{0 , 8 6 8}$ & 0,560 & 0,619 & 0,422 & 0,335 \\
\hline OR4 & 0,609 & 0,547 & 0,454 & 0,563 & 0,217 & 0,843 & 0,556 & 0,662 & 0,357 & 0,354 \\
\hline PF1 & 0,458 & 0,490 & 0,375 & 0,535 & 0,187 & 0,479 & 0,731 & 0,462 & 0,417 & 0,325 \\
\hline PF2 & 0,483 & 0,537 & 0,482 & 0,637 & 0,266 & 0,536 & $\mathbf{0 , 8 0 6}$ & 0,480 & 0,407 & 0,443 \\
\hline PF3 & 0,467 & 0,610 & 0,527 & 0,664 & 0,292 & 0,475 & $\mathbf{0 , 8 2 2}$ & 0,452 & 0,426 & 0,480 \\
\hline PF4 & 0,434 & 0,570 & 0,524 & 0,646 & 0,346 & 0,534 & 0,686 & 0,405 & 0,411 & 0,359 \\
\hline RE1 & 0,552 & 0,498 & 0,412 & 0,380 & 0,124 & 0,506 & 0,406 & 0,718 & 0,409 & 0,362 \\
\hline RE2 & 0,377 & 0,440 & 0,369 & 0,377 & 0,240 & 0,351 & 0,346 & 0,590 & 0,364 & 0,255 \\
\hline
\end{tabular}




\begin{tabular}{|c|c|c|c|c|c|c|c|c|c|c|}
\hline & $\begin{array}{l}\text { Compe- } \\
\text { tências }\end{array}$ & $\begin{array}{l}\text { Desen- } \\
\text { volvi- } \\
\text { mento }\end{array}$ & \begin{tabular}{|c|} 
Especi- \\
ficações \\
Técni-cas \\
\end{tabular} & Gestão & $\begin{array}{c}\text { DESEMP } \\
\text { ENHO }\end{array}$ & $\begin{array}{c}\text { Organi- } \\
\text { zação }\end{array}$ & Portfo-lio & $\begin{array}{l}\text { Recur- } \\
\text { sos }\end{array}$ & $\begin{array}{c}\text { Requisi- } \\
\text { tos do } \\
\text { Projeto }\end{array}$ & $\begin{array}{l}\text { Requisi- } \\
\text { tos } \\
\text { Regula- } \\
\text { tórios }\end{array}$ \\
\hline RE3 & 0,422 & 0,444 & 0,430 & 0,345 & 0,138 & 453 & 0,326 & 0,691 & 0,384 & 0,276 \\
\hline RE4 & 0,683 & 0,514 &, 504 & 0,456 & 192 & 19 &, 465 & 785 & 0,350 & 0,334 \\
\hline RE5 & 0,680 & 0,589 & 0,476 & 0,479 & 0,175 & 0,554 & 0,469 & $\mathbf{0 , 7 8 8}$ & 0,383 & 0,378 \\
\hline RE6 & 0,540 & 0,470 & 0,392 & 0,466 & 0,194 & 0,573 & 0,493 & 0,705 & 0,421 & 0,346 \\
\hline RP1 & 0,198 & 0,322 & 0,458 & 0,406 & 0,132 & 0,255 & 0,372 & 0,339 & 0,784 & 0,410 \\
\hline RP2 & 0,361 & 0,497 & 0,507 & 0,491 & 0,275 & 0,417 & 0,444 & 0,483 & 0,822 & 0,404 \\
\hline RP3 & 0,353 & 0,464 & 0,434 & 0,412 & 0,163 & 0,329 & 0,418 & 0,383 & 0,656 & 0,445 \\
\hline RR1 & 0,322 & 0,508 & 0,505 & 0,460 & 0,233 & 0,370 & 0,434 & 0,403 & 0,457 & 0,803 \\
\hline RR2 & 0,351 & 0,467 & 0,537 & 0,389 & 0,174 & 0,276 & 0,424 & 0,327 & 0,415 & 0,771 \\
\hline RR3 & 0,357 & 0,467 & 0,498 & 0,404 & 0,213 & 0,271 & 0,391 & 0,348 & 0,431 & 0,780 \\
\hline
\end{tabular}

Fonte: Dados da pequisa 
APÊNDICE XV - Confiabilidade e validade dos constructos

\begin{tabular}{|l|r|r|r|r|}
\hline & $\begin{array}{c}\text { Cronbach's } \\
\text { Alpha }\end{array}$ & \multicolumn{1}{c|}{ rho_A } & $\begin{array}{c}\text { Composite } \\
\text { Reliability }\end{array}$ & $\begin{array}{c}\text { Average Variance } \\
\text { Extracted (AVE) }\end{array}$ \\
\hline Competências & 0,862 & 0,862 & 0,916 & 0,784 \\
\hline DESEMPENHO & 0,769 & 0,818 & 0,845 & 0,533 \\
\hline Desenvolvimento & 0,860 & 0,863 & 0,893 & 0,545 \\
\hline Especificações_Técnicas & 0,827 & 0,835 & 0,869 & 0,457 \\
\hline Gestão & 0,803 & 0,826 & 0,860 & 0,511 \\
\hline Organização & 0,881 & 0,882 & 0,918 & 0,737 \\
\hline Portfolio & 0,759 & 0,763 & 0,847 & 0,582 \\
\hline Recursos & 0,809 & 0,821 & 0,862 & 0,513 \\
\hline Requisitos do Projeto & 0,621 & 0,629 & 0,800 & 0,573 \\
\hline Requisitos_Regulatórios & 0,688 & 0,688 & 0,828 & 0,616 \\
\hline
\end{tabular}

Fonte: Dados da pequisa 
APÊNDICE XVI - Validade discriminate (critério de Fornell-Larcker)

\begin{tabular}{|c|c|c|c|c|c|c|c|c|c|c|}
\hline & 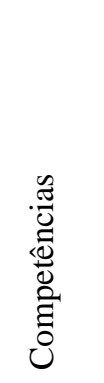 & 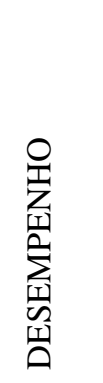 & 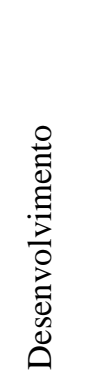 & 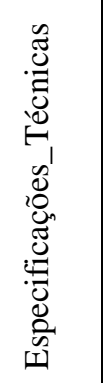 & 氶 & 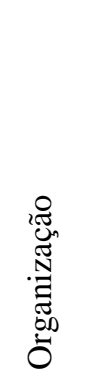 & $\begin{array}{l}\stackrel{9}{0} \\
\stackrel{0}{0} \\
\stackrel{0}{2}\end{array}$ & 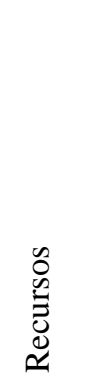 & 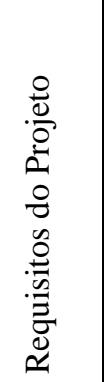 & 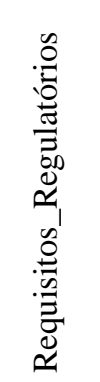 \\
\hline Competências & 0,886 & & & & & & & & & \\
\hline DESEMPENHO & 0,260 & 0,730 & & & & & & & & \\
\hline Desenvolvimento & 0,697 & 0,335 & 0,738 & & & & & & & \\
\hline $\begin{array}{l}\text { Especificações_ } \\
\text { Técnicas }\end{array}$ & 0,589 & 0,296 & 0,736 & 0,676 & & & & & & \\
\hline Gestão & 0,576 & 0,383 & 0,768 & 0,655 & 0,715 & & & & & \\
\hline Organização & 0,635 & 0,286 & 0,639 & 0,504 & 0,683 & 0,859 & & & & \\
\hline Portfolio & 0,603 & 0,360 & 0,726 & 0,629 & 0,817 & 0,663 & 0,763 & & & \\
\hline Recursos & 0,773 & 0,244 & 0,690 & 0,604 & 0,585 & 0,722 & 0,589 & 0,716 & & \\
\hline Requisitos do Projeto & 0,402 & 0,254 & 0,566 & 0,618 & 0,578 & 0,443 & 0,544 & 0,533 & 0,757 & \\
\hline $\begin{array}{l}\text { Requisitos_ } \\
\text { Regulatórios }\end{array}$ & 0,438 & 0,263 & 0,612 & 0,654 & 0,532 & 0,390 & 0,531 & 0,458 & 0,553 & 0,785 \\
\hline
\end{tabular}


APÊNDICE XVII - Validade discriminate (critério de Fornell-Larcker)

\begin{tabular}{|c|c|c|c|c|c|c|c|c|c|c|}
\hline & 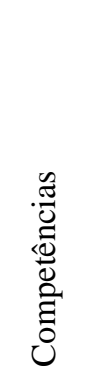 & 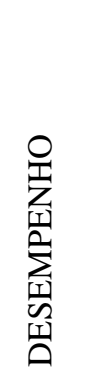 & 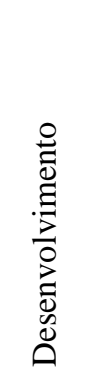 & 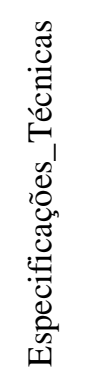 & 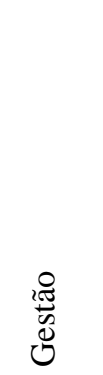 & 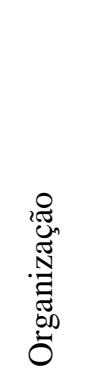 & $\begin{array}{l}\stackrel{0}{\circ} \\
\stackrel{0}{\overparen{D}} \\
\stackrel{0}{2}\end{array}$ & $\begin{array}{l}\mathscr{0} \\
\stackrel{0}{\Xi} \\
\tilde{U} \\
\simeq\end{array}$ & $\begin{array}{l}\frac{0}{0} \\
\frac{0}{0} \\
0 \\
0 \\
0 \\
0 \\
0 \\
0 \\
\frac{0}{0} \\
\frac{0}{0} \\
\simeq\end{array}$ & 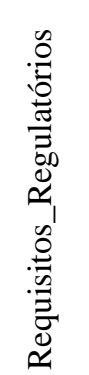 \\
\hline Competências & 0,886 & & & & & & & & & \\
\hline DESEMPENHO & 0,262 & 0,730 & & & & & & & & \\
\hline Desenvolvimento & 0,698 & 0,335 & 0,738 & & & & & & & \\
\hline Especificações_Técnicas & 0,577 & 0,284 & 0,716 & 0,684 & & & & & & \\
\hline Gestão & 0,563 & 0,375 & 0,734 & 0,621 & 0,709 & & & & & \\
\hline Organização & 0,635 & 0,285 & 0,638 & 0,487 & 0,665 & 0,859 & & & & \\
\hline Portfolio & 0,569 & 0,306 & 0,666 & 0,550 & 0,719 & 0,602 & 0,823 & & & \\
\hline Recursos & 0,729 & 0,240 & 0,684 & 0,577 & 0,552 & 0,688 & 0,548 & 0,719 & & \\
\hline Requisitos do Projeto & 0,401 & 0,256 & 0,566 & 0,614 & 0,553 & 0,443 & 0,505 & 0,545 & 0,757 & \\
\hline Requisitos_Regulatórios & 0,438 & 0,265 & 0,613 & 0,633 & 0,518 & 0,390 & 0,510 & 0,455 & 0,553 & 0,785 \\
\hline
\end{tabular}


APÊNDICE XVIII - Confiabilidade e validade do constructo

\begin{tabular}{|l|r|r|r|r|}
\hline & \multicolumn{1}{c|}{$\begin{array}{c}\text { Cronbach's } \\
\text { Alpha }\end{array}$} & rho_A & $\begin{array}{c}\text { Composite } \\
\text { Reliability }\end{array}$ & $\begin{array}{c}\text { Average } \\
\text { Variance } \\
\text { Extracted (AVE) }\end{array}$ \\
\hline Competências & 0,862 & 0,862 & 0,916 & 0,784 \\
\hline DESEMPENHO & 0,769 & 0,816 & 0,846 & 0,533 \\
\hline Desenvolvimento & 0,860 & 0,863 & 0,893 & 0,545 \\
\hline Especificações_Técnicas & 0,807 & 0,817 & 0,859 & 0,468 \\
\hline Gestão & 0,748 & 0,774 & 0,832 & 0,502 \\
\hline Organização & 0,881 & 0,881 & 0,918 & 0,737 \\
\hline Portfolio & 0,762 & 0,768 & 0,863 & 0,678 \\
\hline Recursos & 0,768 & 0,774 & 0,843 & 0,518 \\
\hline Requisitos do Projeto & 0,621 & 0,631 & 0,800 & 0,573 \\
\hline Requisitos_Regulatórios & 0,688 & 0,828 & 0,616 \\
\hline
\end{tabular}

